\title{
Methodology and Calculations for the Assignment of Waste Groups for the Large Underground Waste Storage Tanks at the Hanford Site
}

\author{
R. A. Weber \\ Washington River Protection Solutions LLC \\ Richland, WA 99352 \\ U.S. Department of Energy Contract DE-AC27-08RV14800

$\begin{array}{lll}\text { EDT/ECN: } & \text { ECN 724007-R3 } & \text { UC: N/A } \\ \text { Cost Center: } & 7 \text { T600 } & \text { Charge Code: } 200035 \\ \text { B\&R Code: } & \text { N/A } & \text { Total Pages: } 253\end{array}$

Key Words: Tank farms, gas retention, energy ratio, buoyancy ratio, lower flammability limit, buoyant displacement, gas release event, GRE, LFL, tank classification, flammable gas hazard, HGR

Abstract: This document categorizes each of the large waste storage tanks into one of several categories based on each tank's waste characteristics. These waste group assignments reflect a tank's propensity to retain a significant volume of flammable gases and the potential of the waste to release retained gas by a buoyant displacement event. Revision 8 is the annual update of the calculations of the flammable gas Waste Groups for DSTs and SSTs.

TRADEMARK DISCLAIMER. Reference herein to any specific commercial product, process, or service by trade name, trademark, manufacturer, or otherwise, does not necessarily constitute or imply its endorsement, recommendation, or favoring by the United States Government or any agency thereof or its contractors or subcontractors.
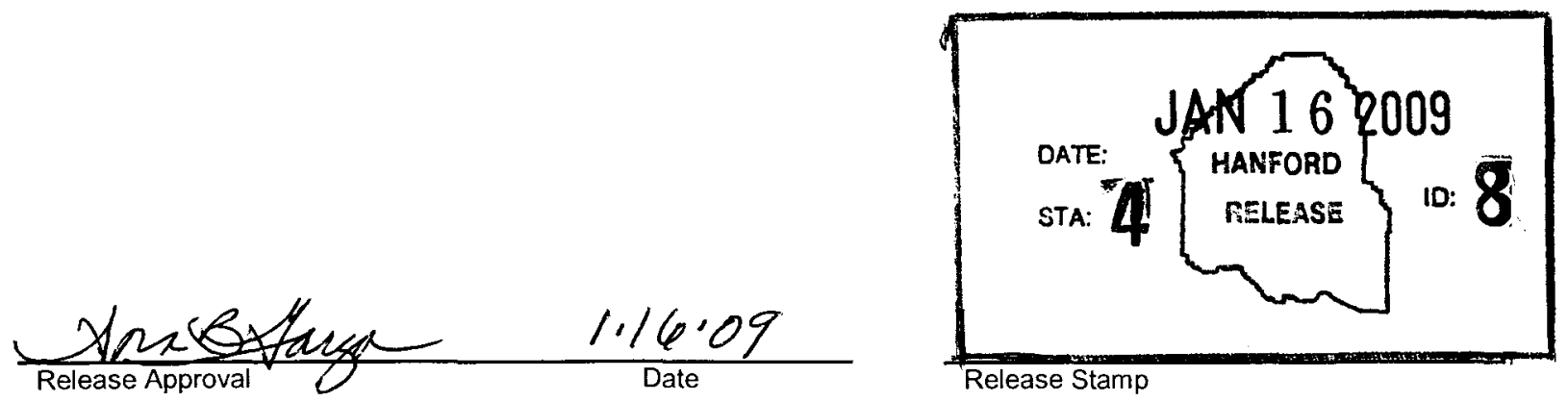

Approved For Public Release 


\begin{tabular}{|c|c|c|c|}
\hline \multicolumn{2}{|r|}{$\begin{array}{l}\text { Tank Farm Contractor (TFC) } \\
\text { RECORD OF REVISION }\end{array}$} & $\begin{array}{l}\text { (1) Document Number: } \\
\text { RPP-10006 }\end{array}$ & Page 1 \\
\hline \multicolumn{4}{|l|}{ (2) Title: } \\
\hline \multicolumn{4}{|c|}{$\begin{array}{l}\text { Methodology and Calculations for the Assignment of Waste Groups for the Large Underground Waste Storage Tanks at the } \\
\text { Hanford Site }\end{array}$} \\
\hline \multicolumn{4}{|c|}{ Change Control Record } \\
\hline \multirow{2}{*}{$\begin{array}{c}(3) \\
\text { Revision }\end{array}$} & \multirow{2}{*}{ (4) Description of Change - Replace, Add, and Delete Pages } & \multicolumn{2}{|c|}{ Authorized for Release } \\
\hline & & (5) Resp. Engr. (print/sign/date) & (6) Resp. Mgr. (print/sign/date) \\
\hline 0 & Original Release via EDT 636634, March 22, 2003 & S. A. Barker & $\begin{array}{l}\text { J. Grigsby } \\
3 / 22 / 03\end{array}$ \\
\hline 1 & $\begin{array}{l}\text { Revision to address comments resulting from review of } \\
\text { the Tank Farms DSA supporting documents }\end{array}$ & S. A. Barker & $\begin{array}{l}\text { R. J. Stevens } \\
8 / 28 / 03\end{array}$ \\
\hline 2 & Complete response to comments & S. A. Barker & $\begin{array}{l}\text { R. J. Stevens } \\
10 / 15 / 03\end{array}$ \\
\hline $2 \mathrm{~A}$ & Modify main document for clarity & S. A. Barker & $\begin{array}{l}\text { R. J. Stevens } \\
10 / 22 / 03\end{array}$ \\
\hline 2B & $\begin{array}{l}\text { Add Appendix } M \text { to discuss inadvertent transfer of } \\
\text { C-200 vacuum retrieval dump to } 241-C-203\end{array}$ & S. A. Barker & $\begin{array}{l}\text { R. J. Stevens } \\
11 / 19 / 03\end{array}$ \\
\hline 3 & $\begin{array}{l}\text { Rewrite main body of document in response to } \\
\text { 03-TED-111 dated 10/24/03 ECN-722103-R0 }\end{array}$ & S. A. Barker & $\begin{array}{l}\text { T. M. Horner } \\
\text { 7/28/04 }\end{array}$ \\
\hline 4 & Complete revision & S. A. Barker & $\begin{array}{l}\text { T. M. Horner } \\
10 / 27 / 04\end{array}$ \\
\hline 5 & ECN 724 R0 - Annual Update - Complete revision & $\begin{array}{l}\text { S. A. Barker } \\
7 / 25 / 06\end{array}$ & $\begin{array}{l}\text { M. A. Knight } \\
7 / 25 / 06\end{array}$ \\
\hline 6 & ECN 724 R1 - Annual Update - Complete revision & T. A. Hu & $\begin{array}{l}\text { N.W. Kirch } \\
12 / 22 / 06\end{array}$ \\
\hline 7 & ECN 724 R2 - Annual Update - Complete Revision & K. D. Fowler & N. W. Kirch \\
\hline 8 & $\begin{array}{c}\text { ECN 724 R3 - Annual Update - Complete Revision } \\
007\end{array}$ & R. Apreber $1 / 13$ log & N.W. Kirch Kenl $1-15-200$ \\
\hline
\end{tabular}




\section{RPP-10006 REV 8}

\section{EXECUTIVE SUMMARY}

The Hanford Site contains 177 large underground radioactive waste storage tanks (28 double-shell tanks and 149 single-shell tanks). These tanks are categorized into one of three waste groups (A, B, and C) based on their waste and tank characteristics. These waste group assignments reflect a tank's propensity to retain a significant volume of flammable gases and the potential of the waste to release retained gas by a buoyant displacement gas release event. Assignments of waste groups to the 177 double-shell tanks and single-shell tanks, as reported in this document, are based on a Monte Carlo analysis of three criteria.

The first criterion is the headspace flammable gas concentration following release of retained gas. This criterion determines whether the tank contains sufficient retained gas such that the well-mixed headspace flammable gas concentration would reach $100 \%$ of the lower flammability limit if the entire tank's retained gas were released. If the volume of retained gas is not sufficient to reach $100 \%$ of the lower flammability limit, then flammable conditions cannot be reached and the tank is classified as a waste group C tank independent of the method the gas is released.

The second criterion is the energy ratio and considers whether there is sufficient supernatant on top of the saturated solids such that gas-bearing solids have the potential energy required to break up the material and release gas. Tanks that are not waste group $\mathrm{C}$ tanks and that have an energy ratio $<3.0$ do not have sufficient potential energy to break up material and release gas and are assigned to waste group B. These tanks are considered to represent a potential induced flammable gas release hazard, but no spontaneous buoyant displacement flammable gas release hazard. Tanks that are not waste group $\mathrm{C}$ tanks and have an energy ratio $\geq 3.0$, but that pass the third criterion (buoyancy ratio $<1.0$, see below) are also assigned to waste group B. Even though the designation as a waste group B (or A) tank identifies the potential for an induced flammable gas release hazard, the hazard only exists for specific operations that can release the retained gas in the tank at a rate and quantity that results in reaching $100 \%$ of the lower flammability limit in the tank headspace. The identification and evaluation of tank farm operations that could cause an induced flammable gas release hazard in a waste group B (or A) tank are included in other documents.

The third criterion is the buoyancy ratio. This criterion addresses tanks that are not waste group $\mathrm{C}$ double-shell tanks and have an energy ratio $\geq 3.0$. For these double-shell tanks, the buoyancy ratio considers whether the saturated solids can retain sufficient gas to exceed neutral buoyancy relative to the supernatant layer and therefore have buoyant displacement gas release events. If the buoyancy ratio is $\geq 1.0$, that double-shell tank is assigned to waste group $\mathrm{A}$. These tanks are considered to have a potential spontaneous buoyant displacement flammable gas release hazard in addition to a potential induced flammable gas release hazard.

In determining the final waste group for a tank, uncertainty in the input data parameters used in the above calculations is accounted for by performing a Monte Carlo analysis. For each tank, 5,000 trial calculations of the waste group are performed using the criteria and method described above. For each trial, the input data for the calculations are randomly selected from pre-determined distributions that span the range of uncertainty in each parameter. 


\section{RPP-10006 REV 8}

The final waste group assigned to a tank is based on a 95\% confidence level of the 5,000 trials. If the tank exhibits category $\mathrm{C}$ behavior at the $95 \%$ confidence level or for $95 \%$ of the trials, the tank is classified as waste group C. If the tank exhibits category $\mathrm{C}$ behavior at less than the $95 \%$ confidence level, but exhibits combined category $\mathrm{C}$ and category B behavior at more than $95 \%$ confidence level, the tank is then classified as a waste group B tank. The remaining tanks, those that exhibit category A behavior for greater than $5 \%$ of the trials, are placed in the waste group A category.

Sensitivity studies of waste group assignments were also performed for the cases of water and caustic additions to the waste tanks.

This document incorporates the following changes and analysis:

- Double-shell tank input data have been updated.

- Single-shell tank input data have been updated to reflect changes from the previous revision of this document.

- Waste group calculations have been performed for all 28 double-shell tanks and for 4 single-shell tanks based on the updated input data.

Based on the existing evaluation methodology and data updates discussed above, the resulting flammable gas waste groups for 177 double-shell tanks and single-shell tanks are given as follows:

- For the double-shell tanks overall, there are 5 waste group A tanks, 7 waste group B tanks, and 16 waste group $\mathrm{C}$ tanks.

- Waste group calculations show that tank 241-AP-105 should be categorized as a waste group $\mathrm{C}$ tank. However historically tank 241-AP-105 has been categorized as a waste group B tank. The tank will conservatively remain as a Waste group B, because it is assumed that future transfers will result in this Waste group designation.

- Tanks 241-C-108, 241-C-109, 241-S-102, and 241-S-112 were re-evaluated because the respective waste volumes changed for this revision.

- For the remaining 145 single-shell tanks, waste group assignments are unchanged. 
RPP-10006 REV 8

\section{CONTENTS}

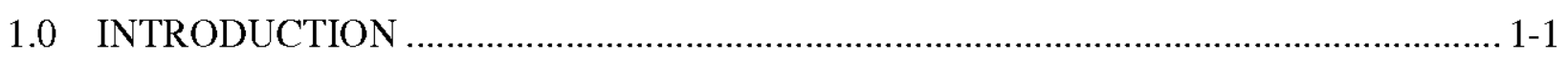

1.1 GAS RETENTION IN SINGLE-SHELL TANKS AND DOUBLE-SHELL TANKS .................................................................... 1-1

1.2 GAS RELEASE EVENTS..................................................................... 1-2

1.3 WASTE GROUPS FOR SINGLE-SHELL TANKS AND
DOUBLE-SHELL TANKS ……………................................................ 1-3

2.0 WASTE GROUP SELECTION CRITERIA ……....................................................... 2-1

2.1 CRITERIA USED TO ASSIGN TANKS TO A WASTE GROUP .....................2-1

2.2 SELECTION OF BUOYANCY RATIO CALIBRATION FACTOR ……..........2-7

2.3 EXPLANATION OF HOW CRITERIA ARE USED ………………................ 2-10

$2.4 \quad$ APPLICATION OF DATA TO SLUDGE TANKS........................................ 2-11

3.0 CALCULATIONAL METHODOLOGY .................................................................

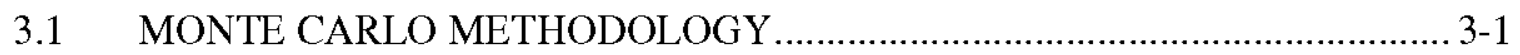

3.2 RANDOM NUMBER SEED SENSITIVITY TEST ..................................... 3-2

3.3 APPLICATION OF CRYSTAL BALL.................................................. 3-4

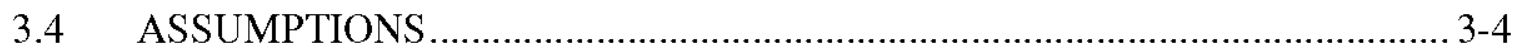

3.5 SOFTWARE USED ......................................................................... $3-5$

4.0 SOURCES OF INPUT DATA AND HIERARCHY ....................................................... 4-1

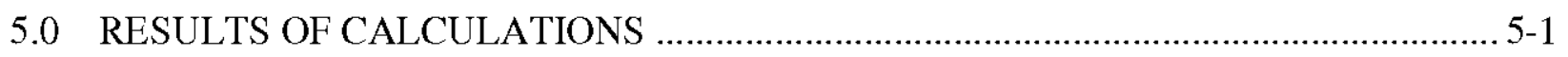

5.1 WASTE GROUP ASSIGNMENTS …………….................................. 5-1

5.1.1 Double-Shell Tanks ....................................................................... 5-8

5.1.2 Single-Shell Tanks ....................................................................... 5-9

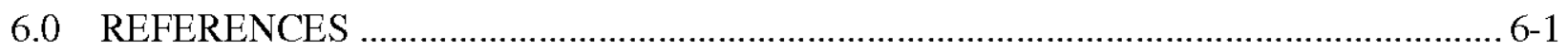

\section{APPENDICES}

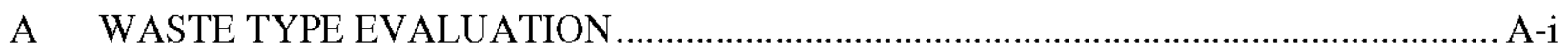

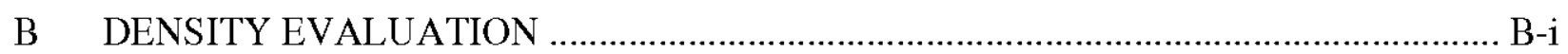

C WASTE LAYER HEIGHT AND UNCERTAINTY DETERMINATION ……................. C-i

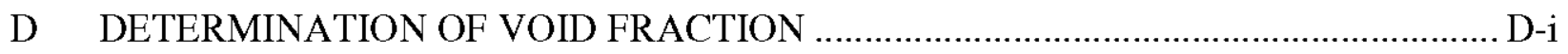

E HYDROGEN GENERATION RATES CALCULATIONS FOR BUOYANT DISPLACEMENT GAS RELEASE EVENT CRITERIA DETERMINATIONS ................E-i

F WELLS, B. E., AND S. A. BARKER, 2003, SUMMARY OF YIELD STRESS IN SHEAR DATA FOR HANFORD WASTE, TWS03.044, PACIFIC NORTHWEST NATIONAL LABORATORY, RICHLAND, WASHINGTON 
RPP-10006 REV 8

G DERIVATION OF RETAINED GAS COMPOSITIONS ........................................... G-i

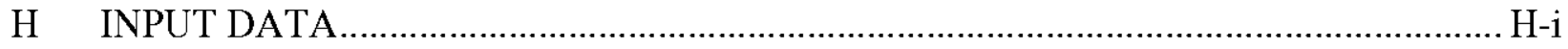

I PEER REVIEW CHECKLIST ….............................................................................

\section{LIST OF FIGURES}

Figure 3-1. RPP-10006, Rev. 5, Spreadsheet and Macro Hierarchy. $3-8$

\section{LIST OF TABLES}

Table 1-1. Total Tank Retained Gas Volumes and Corresponding Release Fractions for Five Double-Shell Tanks.*

Table 2-1. Data Specific to Buoyancy Ratio Calibration. (3 sheets) ...................................2-8

Table 3-1. Stability Test Results (Evaluation Performed for RPP-10006, Rev. 5). ..................3-3

Table 4-1. Data Source Summary Table. (1 sheet) ....................................................... 4-2

Table 4-2. Monte Carlo Model Dynamic Constraints. ................................................ 4-3

Table 5-1. Determination of Waste Group Classification. (6 sheets) ..................................... 5-2

Table 5-2. Indicators of Buoyant Displacement Gas Release Event Behavior..........................5-8

Table 5-3. Waste Group Assignments for Double-Shell Tanks. ............................................ 5-8

Table 5-4. Waste Group Assignments for Single-Shell Tanks. (2 sheets) ........................... 5-10 


\section{LIST OF TERMS}

BBI

BDGRE

BPE

DST

ENRAF

GRE

HGR

LFL

PNNL

RGS

SST

VFI
Best-Basis Inventory

buoyant displacement gas release event

barometric pressure effect

double-shell tank

Enraf-Nonius Series 854 (level gauge)

gas release event

hydrogen generation rate

lower flammability limit

Pacific Northwest National Laboratory

retained gas sampler

single-shell tank

void fraction instrument 
RPP-10006 REV 8

This page intentionally left blank. 


\section{RPP-10006 REV 8}

\subsection{INTRODUCTION}

Waste stored within tank farm double-shell tanks (DST) and single-shell tanks (SST) generates flammable gas (principally hydrogen) to varying degrees depending on the type, amount, and condition of the waste. Waste generates hydrogen through the radiolysis of water and organic compounds, thermolytic decomposition of organic compounds, and corrosion of a tank's carbon steel walls. Radiolysis and thermolytic decomposition also generates ammonia. Nonflammable gases, which act as dilutents (such as nitrous oxide), also are produced. Additional flammable gases (e.g., methane) are generated by chemical reactions between various degradation products of organic chemicals present in the tanks. Volatile and semi-volatile organic chemicals in tanks also produce organic vapors. The generated gases in tank waste are either released continuously to the tank headspace or are retained in the waste matrix. Retained gas may be released in a spontaneous or induced gas release event (GRE) that can significantly increase the flammable gas concentration in the tank headspace as described in RPP-7771, Flammable Gas Safety Issue Resolution.

\subsection{GAS RETENTION IN SINGLE-SHELL TANKS AND DOUBLE-SHELL TANKS}

Studies have shown that some tanks store significant volumes of gas in their waste. Free gas can accumulate in submerged solids, which are saturated. Convective fluid layers of waste do not retain significant amounts of insoluble gases (e.g., hydrogen and methane) because bubbles rise through liquid waste as fast as they are generated. Soluble gases (primarily ammonia) are dissolved in liquid waste; however, ammonia release is significant only when a free liquid surface is freshly exposed or agitated.

Direct measurements of retained gas are not available for most tanks. Estimates of the amount of retained gas stored in each DST and SST were made based on two indirect methods provided in WHC-SD-WM-ER-526, Evaluation of Hanford Tanks for Trapped Gas. Based on WHC-SD-WM-ER-526, only 49 of the 177 SSTs and DSTs were determined by the barometric pressure effect (BPE) method to have trapped gas and, of these, only 15 tanks, including 4 DSTs (241-AN-103, 241-AN-104, 241-AN-105, and 241-AW-104) stored relatively large volumes of gas, greater than $10 \%$ of the solid waste volume. Sixty-eight tanks have so little waste that gas retention is of no concern. Even if all the stored gas were hypothetically released, the relatively large headspace provides significant dilution.

Both of the indirect estimation methods include significant uncertainties, as described in WHC-SD-WM-ER-594, Evaluation of Recommendation for Addition of Tanks to the Flammable Gas Watch List. Uncertainties arise because the models are simplified and approximate the physical condition of the waste in all DSTs and SSTs and because the data used lacks the accuracy necessary to make estimates of the retained gas. Given the uncertainty in the methods and data, a conservative assumption is that all the DSTs and SSTs retain gas in their saturated solid layers. 


\section{RPP-10006 REV 8}

Retained gas estimates used in this document are based on the void fraction in the saturated solids of each tank considered. Void fraction distributions are based on all available void fraction instrument (VFI) data, retained gas sampler (RGS) data, appropriate BPE data, and similarities in waste type for the other tanks as described in Appendix A.

\subsection{GAS RELEASE EVENTS}

Gases released from the waste in a DST or SST in a nearly continuous manner can be managed effectively by ventilation. However, it is more difficult to manage when a significant amount of the gas retained within waste is released relatively rapidly in a buoyant displacement gas release event (BDGRE). BDGREs were observed in six of the DSTs (241-AN-103, 241-AN-104, 241-AN-105, 241-AW-101, 241-SY-101, and 241-SY-103). Data regarding the physics of GRE in the tanks is provided in Pacific Northwest National Laboratory (PNNL) documents PNNL-11296, In Situ Rheology and Gas Volume in Hanford Double-Shell Waste Tanks, and PNNL-11536, Gas Retention and Release Behavior in Double-Shell Waste Tanks. Estimations of released gas volumes are found in RPP-6655, Data Observations on Double-Shell Flammable Gas Watchlist Tank Behavior.

The large GREs that occurred in DST 241-SY-101 before mitigation by the mixer pump, and remediation by transfers and dilution, were unique in size and frequency. The largest release was the December 4, 1991, GRE of 183 to $263 \mathrm{~m}^{3}$ of gas (RPP-6655), or 39 to $56 \%$ of its retained gas inventory. ${ }^{1}$ The observed frequency of GREs in DST 241-SY-101, prior to remediation, was every 80 to 150 days (RPP-6517, Evaluation of Hanford High-Level Waste Tank 241-SY-101). In contrast, the total tank retained gas volumes (including transient and retained gas in the crust and convective layer) and corresponding release fractions for the other five GRE DSTs based on VFI and RGS data for these tanks are given in Table 1-1.

\footnotetext{
${ }^{1}$ DST 241-SY-101 percent gas released is based on the following calculations. The high estimate is calculated using the December 4, 1991, maximum calculated release volume, $263 \mathrm{~m}^{3}$ (RPP-6655), with a retained gas volume based on the post mixer pump retained gas volume at standard conditions, $195 \mathrm{~m}^{3}$ (RPP-6655), corrected for the difference in total waste height at the time of the GRE, 416 in. (height on December 4, 1991, from Personal Computer-Surveillance Analysis Computer System) minus post mixer pump waste height of 399 in. (RPP-6517). The volume of gas released by mixer pump operations is determined to be $177 \mathrm{~m}^{3}([416 \mathrm{in} .-399 \mathrm{in}$. $] \mathrm{x} 2,754 \mathrm{gal} / \mathrm{in}$. $\mathrm{x} 0.003785 \mathrm{~m}^{3} / \mathrm{gal}$ ) corrected for pressure (i.e., 1.53 pressure ratio [RPP-6655]) to $271 \mathrm{~m}^{3}$. The conservative retained gas volume at tank headspace conditions on December 4,1991 , is calculated to be $466 \mathrm{~m}^{3}\left(195 \mathrm{~m}^{3}+\right.$ $\left.271 \mathrm{~m}^{3}\right)$. When the maximum calculated volume of gas released is divided by the calculated retained gas volume, all volumes at headspace conditions, the calculated release volume is $56 \%$ of the retained gas volume $\left(263 \mathrm{~m}^{3} /\right.$ $466 \mathrm{~m}^{3}$ ). Similarly, the calculated volume for the December 4,1991 , release is $183 \mathrm{~m}^{3}$, which corresponds to $39 \%$ $\left(183 \mathrm{~m}^{3} / 466 \mathrm{~m}^{3}\right)$ of the retained gas volume.
} 
Table 1-1. Total Tank Retained Gas Volumes and Corresponding Release Fractions for Five Double-Shell Tanks.*

\begin{tabular}{|l|c|c|}
\hline \multicolumn{1}{|c|}{ Tank } & $\begin{array}{c}\text { Total retained gas volume } \\
\text { (Standard } \mathbf{~ m}^{\mathbf{3}} \text { ) }\end{array}$ & Release fraction \\
\hline $241-\mathrm{AN}-103$ & $393 \pm 64$ & 0.02 \\
\hline $241-\mathrm{AN}-104$ & $259 \pm 48$ & 0.07 \\
\hline $241-\mathrm{AN}-105$ & $202 \pm 68$ & 0.15 \\
\hline $241-\mathrm{AW}-101$ & $153 \pm 38$ & 0.19 \\
\hline 241-SY-103 & $198 \pm 86$ & 0.12 \\
\hline
\end{tabular}

The uncertainties for the total retained gas volumes represent a 95\% confidence bound. The release fractions were calculated by dividing maximum observed hydrogen release by total retained hydrogen volume (RPP-7771). None of the gas releases in the DSTs, other than DST 241-SY-101 prior to remediation, have been large enough to create flammable mixtures after mixing in the tank headspace as described in RPP-6517 and RPP-7771.

A study of gas retention behavior in SST waste has narrowed the number of plausible spontaneous release mechanisms to a few that are capable of only small releases (less than $10 \mathrm{~m}^{3}$ compared with 100 to $200 \mathrm{~m}^{3}$ in DST 241-SY-101). The study is discussed in HNF-SP-1193, Flammable Gas Project Topical Report. Observation of a number of the most active flammable-gas-retaining SSTs indicates that no large BDGREs are occurring and that only a few SSTs experience small spontaneous GREs. The typical spontaneous GRE in an SST has a small release volume of tens of cubic feet of hydrogen and no release in the SSTs has been observed with the "classic" BDGRE properties as described in RPP-7771 and RPP-7249, Data and Observations of Single-Shell Flammable Gas Watch List Tank Behavior. The variation in gas release volumes and fractions within the same tank are a good indication of tank waste inhomogeneity and supports the use of uncertainty distributions for the modeling of this type of behavior.

\subsection{WASTE GROUPS FOR SINGLE-SHELL TANKS AND DOUBLE-SHELL TANKS}

Waste group assignments have been developed for the 177 DSTs and SSTs for application of flammable gas controls. The SST and DST groupings are based on waste tank characteristics and the propensity of the waste to experience a large BDGRE. Waste group selection criteria were developed based on both empirical data and analytical concepts with the objective of identifying and separating waste tanks into groups that posed similar GRE risks.

The SSTs and DSTs are assigned to one of three groups as described below:

- Waste Group C: Tanks with no potential GRE flammable gas hazard. That is, tanks that are conservatively estimated to contain insufficient retained gas to achieve $100 \%$ of 
the lower flammability limit (LFL), even if all of the retained gas is released into the tank headspace.

- Waste Group B: Tanks with a potential induced GRE flammable gas hazard, but no potential spontaneous BDGRE flammable gas hazard. That is, tanks that are conservatively estimated to contain sufficient retained gas to achieve $100 \%$ of the LFL if all of the retained gas is released into the tank headspace, but are not waste group A tanks (see below).

- Waste Group A: Tanks with a potential spontaneous BDGRE flammable gas hazard in addition to a potential induced GRE flammable gas hazard. That is, tanks that are conservatively estimated to achieve a flammable gas concentration of $100 \%$ of the LFL in the tank headspace if all of the retained gas is released from a spontaneous BDGRE.

Potential induced GRE flammable gas hazards exist in waste group A and B tanks only for specific operations that can release the retained gas in the tank at a rate and quantity that results in reaching $100 \%$ of the LFL in the tank headspace. The identification and evaluation of tank farm operations that could cause an induced flammable gas release hazard in a waste group A and B tank are included in other documents. 
RPP-10006 REV 8

\subsection{WASTE GROUP SELECTION CRITERIA}

\subsection{CRITERIA USED TO ASSIGN TANKS TO A WASTE GROUP}

The waste parameters or combinations of waste parameters that are used to assign individual SSTs and DSTs to waste groups are as follows.

Headspace Flammable Gas Concentration Following Release of Retained Gas: This criterion determines whether the tank contains sufficient retained gas such that the well-mixed headspace flammable gas concentration would reach $100 \%$ of the LFL if the entire tank's retained gas were released. If there is not sufficient retained gas to reach $100 \%$ of the LFL, then flammable conditions cannot be reached and the tank is classified as a waste group $\mathrm{C}$ tank independent of the gas release method.

The saturated settled solids depth ${ }^{2}$ and gas volume fraction distribution can be used to determine whether there is sufficient retained gas in the waste to cause the tank headspace to become flammable if the gas were instantaneously released. The sediment gas volume fraction may be determined using void fraction data, assigned conservative bounding values, or conservatively calculated as the neutral buoyancy gas fraction (for tanks with liquid-over-sediment waste configuration). This calculation can be used as a quick screen for determining whether a tank poses a potential GRE hazard and does not model expected tank behavior. Equations 1,2, and 3 are used to make these calculations relating to headspace flammable gas concentration criterion.

In Equation 3, the pressure on the retained gas is determined. The slightly conservative assumption is made that the gas is stored as particle-displacing bubbles (hydro-dendritic bubbles or lithostatic conditions). The depth of the crust, if continuous across the surface, is added to the convective layer depth to determine the pressure contribution from these layers. Because the amount of crust floating above the liquid is not measured, the full crust level is used in the pressure calculation. In addition, it is assumed that the crust has the same density as the convective layer. For tanks with a noncontiguous crust and for which the convective layer surface level is known, there is no need to add the depth of the crust, since the effect of the crust layer would be included in the convective layer surface level.

\footnotetext{
${ }^{2}$ Saturated settled solids depth is considered in the retained gas volume determination versus the depth of solids saturated with liquid. The difference is that the volume of saturated solids in a floating crust layer is not included. This simplification is reasonable for several reasons. First, the existing crusts in the DSTs are less than $1 \mathrm{~m}$ thick (Appendix $\mathrm{H}$ ) and only approximately one half of this depth is saturated with liquid and capable of retaining flammable gas. Second, the retained gas within the crust does not have the same pressure head as the retained gas within the main body of solids, because the liquid layer, which contributes a significant portion of the retained gas pressure head, is below the crust layer. The effective head pressure on the retained gas in the settled solids ranges from 1.7 to 2.3 atmospheres (RPP-6655) when compared to the head pressure on the crust retained gas of about 1 atmosphere. These considerations indicate that the crust's retained gas volume at headspace conditions is small relative to the settled solids retained gas volume. Finally, floating crusts are currently only found in waste group A tanks and would have no impact on the final classification of the tank.
} 


\section{RPP-10006 REV 8}

Retained Gas Flammability at Headspace Criterion \%LFL HS $_{\text {LFL }}>100 \%$

$$
\% \mathrm{LFL}_{\mathrm{HS}}=\left(\frac{\left[\mathrm{H}_{2}\right]_{R G}}{\% \mathrm{LFL}_{\mathrm{H} 2}}+\frac{\left[\mathrm{CH}_{4}\right]_{\mathrm{RG}}}{\% \mathrm{LFL}_{\mathrm{CH} 4}}+\frac{\left[\mathrm{NH}_{3}\right]_{\mathrm{RG}}}{\% \mathrm{LFL}_{\mathrm{NH} 3}}\right) * \frac{\mathrm{VG}_{\mathrm{WNCL}} * \mathrm{~F}_{\text {GasRelease }}}{\mathrm{V}_{\mathrm{HS}}}
$$

Where

$$
\begin{aligned}
& \mathrm{VG}_{\mathrm{WNCL}}=\mathrm{VF}_{\mathrm{WNCL}} * A * \mathrm{H}_{\mathrm{WNCL}} *\left(\frac{\mathrm{P}_{\mathrm{WNCL}}}{\mathrm{P}_{H S}}\right) *\left(\frac{\mathrm{T}_{\mathrm{HS}}}{\mathrm{T}_{\mathrm{WNCL}}}\right) \\
& \mathrm{P}_{\mathrm{WNCL}}=\mathrm{P}_{\mathrm{HS}}+\rho_{\mathrm{CL}} * \mathrm{~g} *\left(\mathrm{H}_{\mathrm{CL}}+\mathrm{H}_{\mathrm{CR}}+0.5 * \mathrm{H}_{\mathrm{WNCL}}\right)
\end{aligned}
$$

$\% \mathrm{LFL}_{\mathrm{CH} 4}=$ methane concentration at $100 \% \mathrm{LFL}(5.0 \mathrm{vol} \%)$

$\% \mathrm{LFL}_{\mathrm{H} 2}=$ hydrogen concentration at $100 \% \mathrm{LFL}(4.0 \mathrm{vol} \%)$

$\% \mathrm{LFL}_{\mathrm{HS}}=$ headspace flammable gas concentration following gas release

$\% \mathrm{LFL}_{\mathrm{NH} 3}=$ ammonia concentration at $100 \% \mathrm{LFL}(15.0$ vol\% $)$

$\left[\mathrm{CH}_{4}\right]_{\mathrm{RG}}=$ methane concentration in the retained gas in nonconvective layer (vol\%)

$\left[\mathrm{H}_{2}\right]_{\mathrm{RG}}=$ hydrogen concentrations in the retained gas in nonconvective layer (vol\%)

$\left[\mathrm{NH}_{3}\right]_{\mathrm{RG}}=$ ammonia concentration in the retained gas in nonconvective layer (vol\%)

A $\quad=$ cross-sectional area of tank $\left(\mathrm{m}^{2}\right)$

$\mathrm{F}_{\text {GasRelease }}=$ fraction of gas released (assumed to be $100 \%$ )

$\mathrm{g} \quad=$ gravity acceleration $9.806 \mathrm{~m} / \mathrm{sec}^{2}$

$\mathrm{H}_{\mathrm{CL}} \quad=$ height of the liquid (convective) layer $(\mathrm{m})$

$\mathrm{H}_{\mathrm{CR}} \quad=$ height of the crust layer $(\mathrm{m})$

$\mathrm{H}_{\mathrm{WNCL}}=$ height of liquid saturated nonconvective layer $(\mathrm{m})$

$\mathrm{P}_{\mathrm{HS}} \quad=$ pressure in tank headspace and assume the pressure is $1 \mathrm{~atm}=101,325 \mathrm{~Pa}$ (or $\mathrm{N} / \mathrm{m}^{2}$ ) 


\section{RPP-10006 REV 8}

$\mathrm{P}_{\mathrm{WNCL}}=$ calculated representative retained gas pressure in saturated settled solids layer in atm or $\mathrm{Pa}\left(\mathrm{N} / \mathrm{m}^{2}\right)$

$\mathrm{T}_{\mathrm{HS}} \quad=$ representative temperature of headspace of waste tank $(\mathrm{K})$

$\mathrm{T}_{\mathrm{WNCL}}=$ representative temperature of saturated settled solids layer $(\mathrm{K})$

$\mathrm{VF}_{\mathrm{WNCL}}=$ representative void fraction in saturated settled solids layer

$\mathrm{VG}_{\mathrm{WNCL}}=$ calculated volume of gas retained in the saturated settled solids layer at headspace conditions $\left(\mathrm{m}^{3}\right)$

$\mathrm{V}_{\mathrm{HS}}=$ volume of headspace of waste tank after gas release $\left(\mathrm{m}^{3}\right)$

$\rho_{\mathrm{CL}} \quad=$ density of convective layer $\left(\mathrm{kg} / \mathrm{m}^{3}\right)$.

Note 1: The dilution of released gases by water vapor is not considered.

Note 2: Uncertainty distributions are utilized to account for the scatter of retained gas volumes in the waste and uncertainty in the solid volumes. Void fraction distributions are based on all available VFI data, RGS data, and appropriate BPE data.

Energy Ratio: The presence of a significant supernatant layer introduces the possibility of BDGREs. The supernatant layer depth can be utilized as a criterion for determining susceptibility to BDGREs by using a term called "energy ratio" as described in PNNL-11296. The waste in tanks with supernatant layers below an energy ratio threshold of about 3 is not expected to contain sufficient energy to release gas during a buoyant displacement event.

If a tank's waste fails the retained gas volume criterion, the energy ratio criterion is applied. The process of gas release from a gob undergoing buoyant displacement requires that sufficient energy be released to disrupt the waste surrounding the bubbles to allow them to escape as the gob reaches the waste surface. The amount of energy available is directly proportional to the depth of the supernatant through which the gob rises.

The energy ratio is the ratio of the buoyant potential energy of the gas-bearing gobs to the energy required to yield the waste and release gas from those gobs participating in buoyant displacements. The depth of the convective layer above a nonconvective layer in a tank's waste determines whether gas retained in gobs from the saturated nonconvective layer can be released.

Equations 4, 5, and 6 are used for energy ratio calculations. If the energy ratio for the waste in a DST or SST is less than 3, for a tank that can reach $100 \%$ of the LFL in the headspace based on the calculation in Equation 1, then that tank is classified as a waste group B tank. The DSTs that fail both the retained gas volume criterion and the energy ratio criterion are examined for tendencies to have spontaneous BDGREs. The criterion comparison value of 3 accounts for the energy needed to overcome the yield stress, plus a factor to account for energy lost through other processes during the gas release. Based on experimental observations and tank behavior, some gas can be released when the energy ratio exceeds 3 , and release of a large fraction of stored gas 
can occur when the energy ratio exceeds 5. Although the effect of the critical void fraction is discussed in PNNL-13782, Analysis of Induced Gas Releases During Retrieval of Hanford Double-Shell Tank Waste, it requires knowledge of the value for the yield stress, which is accurately known only in tanks where the ball rheometer has been used for in-situ determinations of yield stress. In tanks where this value has not been measured, the uncertainty introduced by estimating this value is not justified, and the neutral buoyancy void fraction is used. In addition, for weak waste, the critical void fraction approaches the neutral buoyancy void fraction.

Energy Ratio Criteria ER: ER $<3.0$

$$
\mathrm{ER}=\left(\frac{\alpha_{\mathrm{NB}} * \gamma * \mathrm{P}_{\mathrm{HS}}}{\left(1-\alpha_{\mathrm{NB}}\right) * \tau_{\mathrm{WNCL}} * \varepsilon_{\mathrm{y}}}\right) *\left(\left(1+\frac{1}{\gamma}\right) * \ln (1+\gamma)-1\right)
$$

where

$$
\begin{aligned}
& \gamma=\frac{\rho_{\mathrm{CL}} * g *\left(\mathrm{H}_{\mathrm{CL}}+\mathrm{H}_{\mathrm{CR}}\right)}{\mathrm{P}_{\mathrm{HS}}} \\
& \alpha_{\mathrm{NB}}=1-\frac{\rho_{\mathrm{CL}}}{\rho_{\mathrm{WNCL}}}
\end{aligned}
$$

ER = energy ratio, the ratio of the buoyant potential energy of the gas-bearing gobs to the energy required to yield the waste and release gas from those gobs participating in buoyant displacements

$\mathrm{g}=$ gravity acceleration, $9.806 \mathrm{~m} / \mathrm{sec}^{2}$

$\mathrm{H}_{\mathrm{CL}} \quad=$ height of the liquid (convective) layer (m)

$\mathrm{H}_{\mathrm{CR}} \quad=$ height of the crust layer $(\mathrm{m})$

$\mathrm{P}_{\mathrm{HS}}=$ pressure in tank headspace, assuming the pressure is $1 \mathrm{~atm}=101,325 \mathrm{~Pa}$ (or $\mathrm{N} / \mathrm{m}^{2}$ )

$\alpha_{\mathrm{NB}}=$ calculated or measured neutral buoyancy of saturated settled solids layer relative to the convective layer on top of it (calculated neutral buoyancy is one minus the ratio of convective layer density to saturated non-convective layer density)

$\gamma=$ calculated ratio of pressure head of convective layer in a waste tank to the headspace pressure, which is assumed to be one atmosphere

$\rho_{\mathrm{CL}}=$ density of convective layer $\left(\mathrm{kg} / \mathrm{m}^{3}\right)$

$\rho_{\mathrm{WNCL}}=$ density of saturated non-convective layer $\left(\mathrm{kg} / \mathrm{m}^{3}\right)$ 


\section{RPP-10006 REV 8}

$$
\begin{aligned}
& \tau_{\mathrm{WNCL}}=\text { representative yield stress of saturated non-convective layer (Pa) } \\
& \varepsilon_{\mathrm{y}} \quad=\text { nonconvective layer strain at failure (assumed to be } 1 \text { ). }
\end{aligned}
$$

Only saltcake/salt slurry tanks have exhibited BDGRE behavior. For reasons given in Section 2.4, the energy ratio is considered valid for both saltcake/salt slurry and sludge tanks.

An energy ratio of 3 is the decision criterion specified in PNNL-13781, Effects of Globally Waste-Disturbing Activities on Gas Generation, Retention, and Release in Hanford Waste Tanks.

Buoyancy Ratio: This is a semi-empirical relation presented in PNNL-13337, Preventing Buoyant Displacement Gas Release Events in Hanford Double-Shell Waste Tanks, and updated in PNNL-15238, Predicting Peak Hydrogen Concentrations from Spontaneous Gas Releases in Hanford Waste Tanks, which estimates the average waste gas fraction based on a balance of gas generation and background release. The buoyancy ratio represents the average saturated settled solids (nonconvective) layer gas fraction divided by the neutral buoyancy gas fraction. This physics-based buoyancy model was developed from the theory of bubble transport. This model predicts whether there is sufficient gas build up in the saturated settled solids layer in a DST to make gobs of waste buoyant and produce BDGREs (PNNL-13337). If the average void fraction in the saturated settled solids layer of waste is less than the neutral buoyant void fraction, a BDGRE cannot occur. Conversely, an average void fraction greater than the neutral buoyant void fraction predicts that BDGREs will occur prior to reaching steady state. The ratio of the average steady-state void fraction to the neutral buoyant void fraction for the case of constant nucleation is given by Equation 7. The constant in the numerator of the first factor is adjusted so that the minimum buoyancy ratio for DSTs experiencing BDGREs is 1.00 . In this report, DST 241-AN-103 is used to calculate the constant.

Buoyancy Ratio Criterion BR: $\mathrm{BR}<1$

$$
\mathrm{BR}=\left(\frac{\mathrm{CF}}{\rho_{\mathrm{WNCL}}-\rho_{\mathrm{CL}}}\right) *\left(\frac{\frac{\mathrm{HG}_{\mathrm{WNCL}}}{\left[\mathrm{H}_{2}\right]_{\mathrm{RG}}}}{\mathrm{P}_{\mathrm{WNCL}}} \mathrm{T}_{\mathrm{WNCL}}\right)^{\frac{1}{3}} * \mathrm{H}_{\mathrm{WNCL}}^{2}
$$

\footnotetext{
$\left[\mathrm{H}_{2}\right]_{\mathrm{RG}}=$ hydrogen concentrations in the retained gas in nonconvective layer (vol\%)

BR = buoyancy ratio, the average saturated settled solids layer gas fraction divided by the neutral buoyancy gas fraction. This ratio predicts whether there is sufficient gas buildup in the saturated settled solids layer in a DST to make gobs of waste buoyant and produce BDGREs
} 


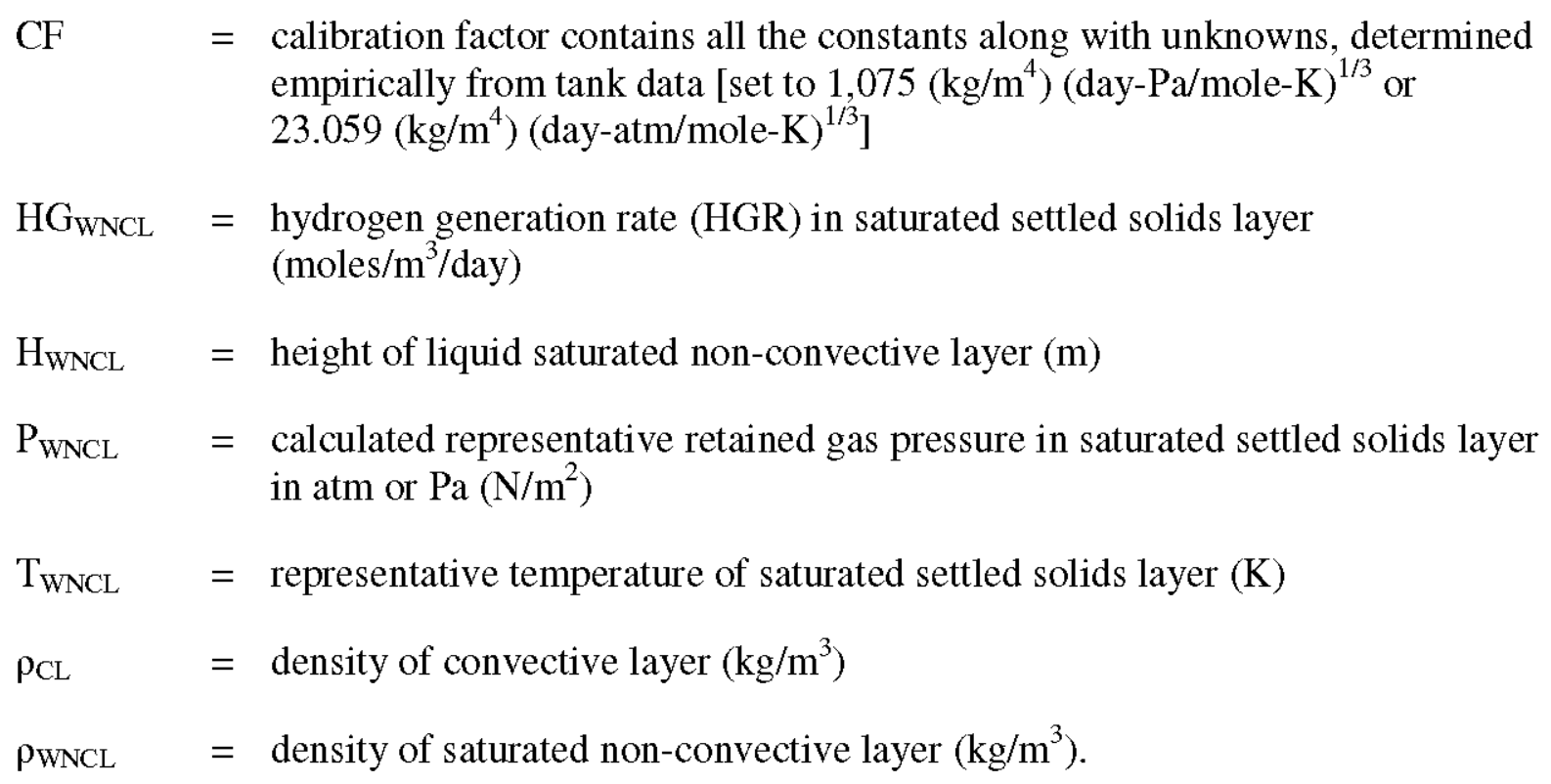

Note 1: Uncertainty distributions are utilized to account for the scatter of retained gas volumes in the waste and uncertainty in the solid volumes. Void fraction distributions are based on all available VFI data, RGS data, and appropriate BPE data.

Note 2: The calibration factor (CF) is $(3 / 16)\left(\mathrm{N}^{2 / 3} \mathrm{R}^{1 / 3} \mathrm{~m}_{\tau} /(\mathrm{SKg})\right)$ and includes the parameters $\mathrm{N}$ (the bubble nucleation rate per unit volume), $\mathrm{R}$ (the gas constant), $\mathrm{m}_{\tau}$ (the slope of the yield stress versus depth curve representing the ball rheometer data), S (the proportionality constant in Stokes flow), K (the unknown proportionality constant between the unknown effective viscosity and the yield stress), and $\mathrm{g}$ (acceleration due to gravity).

Note 3: The total gas generation, $\mathrm{G}$, in buoyancy ratio (Equation 7) is estimated by the HGR divided by the fraction of hydrogen generation. However, the data of hydrogen fraction in retained gas is used because of the lack of data on the hydrogen generation fraction in total gas generation. 


\section{RPP-10006 REV 8}

The buoyancy ratio criterion is not applicable for SSTs since it is a semi-empirical relation based on BDGRE experience in DSTs. Therefore, large water additions $(>10,000$ gal for 100 -series tanks, $>1,000$ gal for 200-series tanks) to SSTs that could lead to failing the first two criteria (i.e., retained gas volume and energy ratio) are prohibited until re-evaluated. This prevents the creation of an SST with an unknown and unanalyzed GRE flammable gas hazard.

The buoyancy ratio model is sensitive at conditions where the convective layer and nonconvective layer densities are close. Layer buoyancy is dependent on the amount of gas required to balance (or overcome the balance of) the densities of the two layers. Physically, as the densities of the two layers invert, the nonconvective layer will become buoyant and will rise to the surface releasing its gas. It should be noted that the nonconvective layer also has to have sufficient potential energy to overcome the yield strength of the solid particles to release as a gob.

\subsection{SELECTION OF BUOYANCY RATIO CALIBRATION FACTOR}

The buoyancy ratio was developed to describe the relationship between DSTs that historically exhibited BDGRE behavior. It was found that tanks exhibiting BDGRE behavior have a relationship between the average saturated settled solids layer gas fraction and the neutral buoyancy gas fraction that is greater than the ratio of these values determined for tanks that never exhibited BDGREs. This buoyancy ratio is used to predict whether there is sufficient gas buildup in the saturated settled solids layer in a DST to make gobs of waste buoyant and produce BDGREs. It was determined that tanks with documented BDGREs would have buoyancy ratios greater than 1 (where the calibration factor was set such that the lowest buoyancy ratio for a tank exhibiting BDGRE behavior would be unity) (PNNL-13337).

The buoyancy ratio calibration factor is set based on the median properties for each DST which exhibits BDGRE behavior. However, whether or not a tank is classified as a waste group A tank is based on the $95 \%$ confidence level for a given set of current tank conditions (the Monte Carlo analysis). The methodology for calculating convective layer densities has changed since the 1990s and has been incorporated in the rebaselined buoyancy ratio calibration factor. In addition, there have been some changes in the method used to determine the convective layer specific gravities due to adjustments when dealing with solids that precipitate upon sample cooling after removal from the tank. The results of this calibration factor determination will be used for all future waste group analyses unless there is a significant change in the buoyancy ratio formula.

Data in Table 2-1 were taken from the following sources: the total waste depth (RPP-6655), the nonconvective layer depth (PNNL-15238), the crust depth (RPP-6655), the convective layer depth (by difference), the layer densities (PNNL-15238), and the HGRs (RPP-5926, Rev. 0). Yield stress data and the percent void information were based on information used in Revision 5 of this document. Data were first used to find the BDGRE tank with the lowest buoyancy ratio and then the calibration factor was adjusted until the buoyancy ratio calibration factor equaled 1 . DST 241-AN-103 was determined to be the BDGRE tank with the lowest buoyancy ratio. The calibration factor was calculated to be $1,075\left(\mathrm{~kg} / \mathrm{m}^{4}\right)\left(\right.$ day- $\mathrm{Pa} /$ mole-K) ${ }^{1 / 3}$, where the buoyancy 
ratio for 241-AN-103 was set to 1 . Buoyancy ratio calculations for all five historical BDGRE tanks are presented in Table 2-1.

Table 2-1. Data Specific to Buoyancy Ratio Calibration. (3 sheets)

\begin{tabular}{|c|c|c|c|c|c|}
\hline Tank & $\begin{array}{c}\text { Median } \\
\text { buoyancy ratio } \\
\text { with calibration } \\
\text { factor }=1075\end{array}$ & $\begin{array}{l}\text { Total waste } \\
\text { depth } \\
(\mathbf{m})^{\mathbf{a}}\end{array}$ & $\begin{array}{c}\text { Total waste } \\
\text { depth } \\
\text { uncertainty } \\
(\mathbf{m})^{\mathrm{b}}\end{array}$ & $\begin{array}{c}\text { Total } \\
\text { nonconvective } \\
\text { waste depth } \\
(\mathbf{m})^{\mathrm{c}}\end{array}$ & $\begin{array}{c}\text { Total } \\
\text { nonconvective } \\
\text { waste depth } \\
\text { uncertainty } \\
(\mathrm{m})^{\mathrm{c}}\end{array}$ \\
\hline 241-AN-103 & 1.00 & 8.84 & 0.080 & 3.79 & 0.290 \\
\hline 241-AN-104 & 1.75 & 9.79 & 0.035 & 3.96 & 0.310 \\
\hline 241-AN-105 & 2.13 & 10.41 & 0.050 & 4.36 & 0.154 \\
\hline 241-AW-101 & 1.46 & 10.40 & 0.100 & 2.89 & 0.287 \\
\hline 241-SY-103 & 1.87 & 6.91 & 0.065 & 3.26 & 0.395 \\
\hline Tank & $\begin{array}{c}\text { Total } \\
\text { nonconvective } \\
\text { waste depth } \\
\text { lower bound } \\
(\mathrm{m})^{\mathbf{d}}\end{array}$ & $\begin{array}{c}\text { Wetted } \\
\text { nonconvective } \\
\text { waste depth } \\
(\mathbf{m})^{\mathrm{e}}\end{array}$ & $\begin{array}{c}\text { Wetted } \\
\text { nonconvective } \\
\text { waste depth } \\
\text { uncertainty } \\
(\mathrm{m})^{\mathrm{e}}\end{array}$ & $\begin{array}{c}\text { Wetted } \\
\text { nonconvective } \\
\text { waste depth } \\
\text { lower bound } \\
(\mathrm{m})^{\mathrm{e}}\end{array}$ & $\begin{array}{c}\text { Convective } \\
\text { waste depth } \\
(\mathrm{m})^{\mathrm{f}}\end{array}$ \\
\hline 241-AN-103 & 0.010 & 3.79 & 0.290 & 0.010 & 4.17 \\
\hline 241-AN-104 & 0.010 & 3.96 & 0.310 & 0.010 & 5.42 \\
\hline 241-AN-105 & 0.010 & 4.36 & 0.154 & 0.010 & 5.60 \\
\hline 241-AW-101 & 0.010 & 2.89 & 0.287 & 0.010 & 6.71 \\
\hline 241-SY-103 & 0.010 & 3.26 & 0.395 & 0.010 & 3.07 \\
\hline Tank & $\begin{array}{c}\text { Convective } \\
\text { waste depth } \\
\text { uncertainty } \\
\text { (m) }\end{array}$ & $\begin{array}{l}\text { Mean crust } \\
\text { depth } \\
(\mathbf{m})^{\mathbf{a}}\end{array}$ & $\begin{array}{c}\text { Convective } \\
\text { waste density } \\
\text { mean } \\
\left(\mathbf{k g} / \mathbf{m}^{3}\right)^{\mathrm{g}}\end{array}$ & $\begin{array}{c}\text { Convective } \\
\text { waste density } \\
\text { std dev } \\
\left(\mathbf{k g} / \mathbf{m}^{3}\right)^{\mathrm{g}} \\
\end{array}$ & $\begin{array}{c}\text { Convective } \\
\text { waste density } \\
\text { min } \\
\left(\mathbf{k g} / \mathbf{m}^{3}\right)^{\mathrm{g}} \\
\end{array}$ \\
\hline 241-AN-103 & $\mathrm{NA}$ & 0.89 & 1,497 & 34 & 1,390 \\
\hline 241-AN-104 & NA & 0.41 & 1,403 & 34 & 1,339 \\
\hline 241-AN-105 & NA & 0.45 & 1,417 & 46 & 1,330 \\
\hline 241-AW-101 & NA & 0.80 & 1,443 & 39 & 1,370 \\
\hline 241-SY-103 & NA & 0.58 & 1,474 & 46 & 1,352 \\
\hline Tank & $\begin{array}{c}\text { Convective } \\
\text { waste density } \\
\max \\
\left(\mathbf{k g} / \mathbf{m}^{3}\right)^{\mathbf{g}} \\
\end{array}$ & $\begin{array}{c}\text { Convective waste } \\
\text { density } \\
\text { dist } \\
\left(\mathbf{k g} / \mathbf{m}^{3}\right)^{\mathbf{h}}\end{array}$ & $\begin{array}{c}\text { Nonconvective } \\
\text { waste density } \\
\text { mean } \\
\left(\mathbf{k g} / \mathbf{m}^{3}\right)^{\mathbf{i}} \\
\end{array}$ & $\begin{array}{c}\text { Nonconvective } \\
\text { waste density } \\
\text { std dev } \\
\left(\mathbf{k g} / \mathbf{m}^{3}\right)^{\mathbf{i}} \\
\end{array}$ & $\begin{array}{c}\text { Nonconvective } \\
\text { waste density } \\
\text { min } \\
\left(\mathbf{k g} / \mathbf{m}^{3}\right)^{\mathbf{i}} \\
\end{array}$ \\
\hline 241-AN-103 & 1,559 & Normal & 1,733 & 106 & 1,590 \\
\hline 241-AN-104 & 1,500 & Normal & 1,578 & 45 & 1,520 \\
\hline 241-AN-105 & 1,534 & Normal & 1,585 & 45 & 1,520 \\
\hline 241-AW-101 & 1,524 & Normal & 1,570 & 27 & 1,540 \\
\hline 241-SY-103 & 1,529 & Normal & 1,592 & 40 & 1,510 \\
\hline
\end{tabular}


Table 2-1. Data Specific to Buoyancy Ratio Calibration. (3 sheets)

\begin{tabular}{|c|c|c|c|c|c|}
\hline Tank & $\begin{array}{c}\text { Nonconvective } \\
\text { waste density } \\
\text { max } \\
\left(\mathbf{k g} / \mathbf{m}^{3}\right)^{\mathbf{i}}\end{array}$ & $\begin{array}{c}\text { Nonconvective } \\
\text { waste density } \\
\text { dist } \\
\left(\mathbf{k g} / \mathbf{m}^{\mathbf{3}}\right)^{\mathbf{h}}\end{array}$ & $\begin{array}{c}\text { Void percent } \\
\text { or maximum } \\
\text { wetted solids } \\
\text { void percent } \\
\text { mean } \\
(\%)^{\mathrm{j}}\end{array}$ & $\begin{array}{c}\text { Void percent } \\
\text { or maximum } \\
\text { wetted solids } \\
\text { void percent } \\
\text { uncertainty } \\
\qquad \%)^{j}\end{array}$ & $\begin{array}{c}\text { Void percent } \\
\text { or maximum } \\
\text { wetted solids } \\
\text { void percent } \\
\text { minimum } \\
\qquad \%)^{j}\end{array}$ \\
\hline 241-AN-103 & 1,930 & Normal & 10.700 & 5.35 & 0.01 \\
\hline 241-AN-104 & 1,710 & Normal & 6.200 & 3.1 & 0.01 \\
\hline 241-AN-105 & 1,660 & Normal & 4.200 & 2.1 & 0.01 \\
\hline 241-AW-101 & 1,600 & Normal & 4.700 & 2.35 & 0.01 \\
\hline 241-SY-103 & 1,634 & Normal & 6.000 & 3.000 & 0.00 \\
\hline Tank & $\begin{array}{l}\text { Void percent or } \\
\text { maximum } \\
\text { wetted solids } \\
\text { void percent } \\
\text { maximum } \\
(\%)^{\mathbf{j}}\end{array}$ & $\begin{array}{c}\text { Void percent or } \\
\text { maximum wetted } \\
\text { solids void } \\
\text { percent dist type } \\
(\%)^{\mathbf{j}}\end{array}$ & $\begin{array}{l}\text { Nonconvective } \\
\text { waste yield } \\
\text { stress mean } \\
(\mathrm{Pa})^{\mathbf{k}}\end{array}$ & $\begin{array}{c}\text { Nonconvective } \\
\text { waste yield } \\
\text { stress std dev } \\
(\mathrm{Pa})^{\mathrm{k}}\end{array}$ & $\begin{array}{l}\text { Nonconvective } \\
\text { waste yield } \\
\text { stress min } \\
(\mathrm{Pa})^{1}\end{array}$ \\
\hline 241-AN-103 & 15.11 & Normal & 144 & 13.87 & 88.52 \\
\hline 241-AN-104 & 15.11 & Normal & 144 & 13.87 & 88.52 \\
\hline 241-AN-105 & 15.11 & Normal & 144 & 13.87 & 88.52 \\
\hline 241-AW-101 & 15.11 & Normal & 144 & 13.87 & 88.52 \\
\hline 241-SY-103 & 15.11 & Normal & 144 & 13.87 & 88.52 \\
\hline Tank & $\begin{array}{c}\text { Nonconvective } \\
\text { waste yield } \\
\text { stress max } \\
(\mathrm{Pa})^{1}\end{array}$ & $\begin{array}{c}\text { Nonconvective } \\
\text { waste yield stress } \\
\text { dist type }(\mathrm{Pa})^{\mathbf{k}}\end{array}$ & $\begin{array}{c}\text { Hydrogen } \\
\text { generation rate } \\
\text { in nonconvective } \\
\text { waste } \\
\left(\mathrm{moles} / \mathrm{m}^{3} / \mathrm{day}\right)^{\mathbf{m}} \\
\end{array}$ & $\begin{array}{c}\text { Hydrogen } \\
\text { generation rate } \\
\text { in nonconvective } \\
\text { waste min } \\
\left(\mathrm{moles} / \mathrm{m}^{3} / \text { day }\right)^{\mathbf{n}} \\
\end{array}$ & $\begin{array}{c}\text { Hydrogen } \\
\text { generation rate } \\
\text { in nonconvective } \\
\text { waste max } \\
\left(\mathbf{m o l e s} / \mathbf{m}^{3} / \text { day }\right)^{\mathbf{0}} \\
\end{array}$ \\
\hline 241-AN-103 & 199.48 & Normal & $1.26 \mathrm{E}-03$ & $6.30 \mathrm{E}-04$ & $2.52 \mathrm{E}-03$ \\
\hline 241-AN-104 & 199.48 & Normal & $1.62 \mathrm{E}-03$ & $8.09 \mathrm{E}-04$ & $3.24 \mathrm{E}-03$ \\
\hline 241-AN-105 & 199.48 & Normal & $2.02 \mathrm{E}-03$ & $1.01 \mathrm{E}-03$ & $4.04 \mathrm{E}-03$ \\
\hline 241-AW-101 & 199.48 & Normal & $1.82 \mathrm{E}-03$ & $9.08 \mathrm{E}-04$ & $3.63 \mathrm{E}-03$ \\
\hline 241-SY-103 & 199.48 & Normal & $1.68 \mathrm{E}-03$ & 8.38E-04 & $3.35 \mathrm{E}-03$ \\
\hline
\end{tabular}


Table 2-1. Data Specific to Buoyancy Ratio Calibration. (3 sheets)

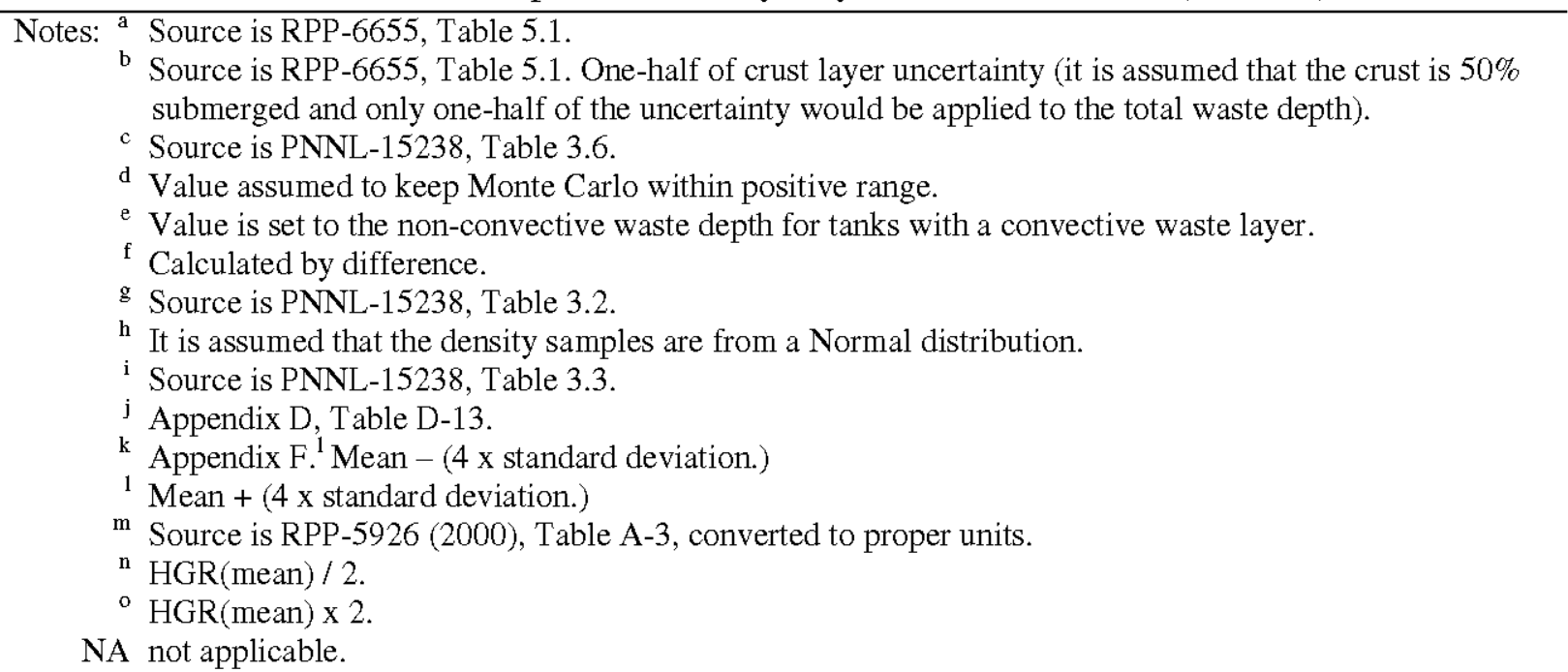

\subsection{EXPLANATION OF HOW CRITERIA ARE USED}

First the retained gas criterion is applied. If there is not enough retained gas in the waste to allow the tank headspace to reach $100 \%$ of the LFL, the tank "passes" and is classified as a waste group C tank. No further calculations are performed. If there is sufficient retained gas in the waste to allow the tank headspace to reach $100 \%$ of the LFL, the tank "fails." The retained gas criterion determines either that a tank is a waste group $\mathrm{C}$ tank (passes criterion) or it is a waste group A or B tank and the next criterion must be applied.

The energy ratio criterion is used next. The energy ratio criterion is the ratio of the buoyant potential energy for gas-bearing gobs to the energy required to yield the waste and release gas from those gobs participating in buoyant displacements. If the ratio is less than 3 , the tank "passes" the criterion, the tank is classified as a waste group B tank, and no further calculations are performed. If the energy ratio is equal to or greater than 3 , the buoyancy ratio criterion is applied. Failing the energy ratio criterion does not make a tank a BDGRE tank. It only says that there is enough buoyant potential energy to support a BDGRE if all the other factors are present. A tank that fails the energy ratio criterion is still a waste group A or waste group B tank and the next criterion is evaluated.

The buoyancy ratio criteria separates the waste group A and waste group B tanks. This criterion predicts whether there is sufficient gas buildup in the saturated settled solids layer in a DST to make gobs of waste buoyant and produce BDGREs. If the answer is yes, the tank "fails" and is classified as a waste group A tank. If the answer is no, the tank passes and is classified as a waste group B tank. 


\subsection{APPLICATION OF DATA TO SLUDGE TANKS}

In 1996, PNNL-11391, Gas Retention and Release Behavior in Hanford Single-Shell Waste Tanks, reported the results of investigations into the gas retention and release behavior of SSTs. It was reported that, given the proper configuration of the materials in the tank, a buoyant displacement was possible in sludge-type materials. In practical experience at the Hanford Site, BDGREs have only been observed in tanks containing saltcake/salt slurry wastes with overlaying supernatant liquid.

The findings (PNNL-11391) were based on bench-scale experiments using Bentonite clay as a simulant for SST sludge materials. The tank used in the experiments was $27 \mathrm{~cm}$ in diameter. In the experiment, gases retained in the solids and driving the BDGREs were generated relatively quickly using the decomposition of hydrogen peroxide. The bench-scale observations were then used in the development of the energy ratio criterion, which was found to be applicable to tanks with a significant supernatant layer. When the energy ratio was applied to Hanford DST waste, it was found to be a good predictor of the energetics of buoyant displacements. 
The only Hanford tanks to exhibit BDGRE behavior as predicted by the buoyancy ratio are tanks containing saltcake/salt slurry wastes. Because the Hanford tanks containing sludge materials have not historically warranted additional investigation into their behavior with respect to flammable gas retention and release, there is very little data pertaining to these tanks. It has not been demonstrated that the BDGRE prediction criteria, the energy ratio and the buoyancy ratio, apply to the sludge tanks. However, because the original experiments from which the theory of buoyant displacements was developed used sludge simulants, it is assumed that applying the energy criteria will provide a conservative estimation of the propensity of the sludge wastes to exhibit BDGRE behavior.

The buoyancy ratio has been developed using the physics of gas retention and release independent of waste type. The use of the buoyancy ratio to evaluate sludge tanks at the Hanford Site has only predicted non-BDGRE behavior in sludge tanks correctly. Since BDGREs are absent in sludge tanks, no method is available to calibrate the buoyancy ratio model to include sludge wastes. The effect of waste type is reflected by the calibration of the model, which is done on the set of saltcake/salt slurry BDGRE tanks at the Hanford Site. 


\subsection{CALCULATION METHODOLOGY}

Tank waste data are available from a variety of sources. Regardless of the source, tank waste information has a degree of uncertainty associated with its value. The size of property or measurement uncertainty is affected by a number of factors, such as the heterogeneous nature of the waste, uncertainties due to the analysis methodology and measuring devices, and incomplete or missing data. In order to account for uncertainty in the data, the values used in this study have been assigned distributions that reflect the uncertainty in the estimation of the various tank waste properties. To perform the calculations necessary to utilize data expressed as distributions, a statistical method known as the Monte Carlo methodology was utilized in this study.

\subsection{MONTE CARLO METHODOLOGY}

The Monte Carlo methodology is a statistical calculation method. In this method, parameters expressed as distributions are sampled repeatedly and the single-point calculation is run many times to produce a result that is a distribution accounting for the ranges of all of the individual data parameters. In the Monte Carlo analysis, the analyst selects the number of simulation runs to perform, 'n'. A random number table is produced, which allows the calculation to select ' $n$ ' discrete values from a given input distribution. These values are then used in 'sampled' order to perform the calculation. This process is repeated for each distribution in the calculation. After this selection is completed, ' $n$ ' values have been selected from each distribution. If ' $n$ ' is sufficiently large, the frequency of the selected values mirrors the frequency of the values in the original distribution. The 'sampled' values are then used in the order of selection (not in numerical order) in the single-point calculation. The results of the 'n' single-point calculations form a distribution that will reflect the combined uncertainties from the original data. One of the advantages of the Monte Carlo simulation is that bounding property data can be used in the evaluation, but the likelihood of bounding data for all properties to be used simultaneously is very small, therefore, physically unrealistic conditions are less likely to be the basis for a decision.

A confidence level of $95 \%$ was chosen for the selection criteria prior to the start of the evaluation in order not to presuppose the result of this analysis. Selecting a confidence level allows bounding property data to be used in the evaluation. While the likelihood of a Monte Carlo simulation result using bounding data for all properties simultaneously is very small, providing a confidence level will limit decisions based on combinations of many physically bounding conditions. On the other hand, the possibility of making a nonconservative waste group assignment is reduced by the conservative assumption that $100 \%$ of the gas is released. Past experience with all tanks indicates that the largest observed gas release is on the order of $56 \%$ of the retained gas (see Section 1.2). Except for releases from DST 241-SY-101 (preremediation), the largest gas release reported in RPP-7771 was 19\% in DST 241-AW-101 (see Section 1.2, Table 1-1). 
RPP-10006 REV 8

\subsection{RANDOM NUMBER SEED SENSITIVITY TEST}

To test the stability or reproducibility of the model, DST 241-SY-103 and SST 241-TX-105 were selected for evaluation. These tanks were the tanks closest to the boundary between waste groups A and B for DSTs and B and C for SSTs, respectively. The stability test checks the operation of the model using different "seed" numbers from the random number generation algorithm for 13 parameters. The study ran the DST 241-SY-103 and SST 241-TX-105 models 50 times each, with 5,000 trials per run. Fifty 5,000-trial runs equates to 250,000 trials using $3,250,000$ data points.

The initial analysis (5,000 trials) for DST 241-SY-103 resulted in 2.38\% of the trials indicating tank 241-SY-103 is a waste group A tank, 5.6\% indicating waste group B, and $92.02 \%$ indicating waste group C. Since less than $95 \%$ of the trials were classified as a waste group C tank, DST 241-SY-103 would not be a waste group C tank but would be either a waste group B or waste group A tank. Since less than 5\% of the trials indicated the tank would be a waste group A tank, DST 241-SY-103 would be classified as a waste group B tank. The stability test gave a mean value of $2.33 \%$ waste group $\mathrm{A}$ and a median value of $2.33 \%$ waste group $\mathrm{A}$. The range of results of $0.76 \%(1.96 \%$ A to $2.72 \% \mathrm{~A})$ for 5,000 trials is adequate for a screening criteria. Based on the stability test, DST 241-SY-103 would be classified as a waste group B tank 50 times; the tank would be classified as a waste group A tank for the "as is" case zero times. As a further stability test, 25 runs, with 50,000 trials per run, were performed. This test gave a mean and median value of $2.33 \%$ and $2.35 \%$ waste group $\mathrm{A}$. The range of results was reduced to $0.24 \%$ (2.18\% A to $2.42 \% \mathrm{~A})$ for the 2550,000 trial runs. Table 3-1 summarizes the stability tests for this tank.

The results for SST 241-TX-105 are shown in Table 3-1. The initial analysis (5,000 trials) for SST 241-TX-105 resulted in $95.04 \%$ of the trials indicating that tank SST 241-TX-105 is a waste group $\mathrm{C}$ tank. The stability test gave a mean value of $94.64 \%$ waste group $\mathrm{C}$ and a median value of $94.65 \%$ in waste group C, thus the conclusion of the stability test is that SST 241-TX-105 is a waste group B tank. The range of the results of the stability test for SST 241-TX-105 is about $1.2 \%(94.00 \% \mathrm{C}$ to $95.20 \% \mathrm{C})$. 
Table 3-1. Stability Test Results (Evaluation Performed for RPP-10006, Rev. 5).

\begin{tabular}{|c|c|c|}
\hline Tank & DST 241-SY-103 & SST 241-TX-105 \\
\hline Value tracked & $\begin{array}{l}\text { Confidence level tank is a waste } \\
\text { group A tank }\end{array}$ & Confidence level tank is a waste group C tank \\
\hline \multirow[t]{2}{*}{ Initial run } & $\begin{array}{l}2.38 \text { (this value is less than the } 5 \\
\text { required to classify this tank as a } \\
\text { waste group A tank) }\end{array}$ & $\begin{array}{l}95.04 \text { (this value is more than the } 95 \text { required to } \\
\text { classify this tank as a waste group } \mathrm{C} \text { tank) }\end{array}$ \\
\hline & "As is" & "As is" \\
\hline $\begin{array}{l}\text { Number of } \\
\text { repetitions }\end{array}$ & 50 & 50 \\
\hline $\begin{array}{l}\text { Number of trials } \\
\text { per repetition }\end{array}$ & 5,000 & 5,000 \\
\hline Mean & 2.33 & 94.64 \\
\hline Median & 2.33 & 94.65 \\
\hline $\begin{array}{l}\text { Standard } \\
\text { deviation }\end{array}$ & 0.18 & 0.27 \\
\hline Minimum & 1.96 & 94.00 \\
\hline Maximum & 2.72 & 95.20 \\
\hline Range of results & 0.76 & 1.20 \\
\hline $\begin{array}{l}\text { Number of } \\
\text { repetitions }\end{array}$ & 25 & \\
\hline $\begin{array}{l}\text { Number of trials } \\
\text { per repetition }\end{array}$ & 50,000 & \\
\hline Mean & 2.33 & \\
\hline Median & 2.35 & NA \\
\hline Minimum & 2.18 & \\
\hline Maximum & 2.42 & \\
\hline Range of results & 0.24 & \\
\hline
\end{tabular}

Notes: The confidence level that DST 241-SY-103 is a waste group A tank is less than 5\%.

$$
\begin{aligned}
& \text { DST = single-shell tank. } \\
& \text { NA = not applicable. } \\
& \text { SST = single-shell tank. }
\end{aligned}
$$

Based on the range of results for both DST 241-SY-103 and SST 241-TX-105, any screening run result that is within 1.5 percentage points of $95 \%$ or within 1.5 percentage points of $5 \%$ if testing for waste group A, should be rerun with 50,000 trials. In the second run of 50,000 trials, any case within 0.5 percentage points of $95 \%$ (or $5 \%$ for waste group A) should be classified as the more conservative waste group.

As a result of these sensitivity studies and the uncertainty of the results, any result testing for waste group B or C, DST or SST, within 1.5 percentage points of $95 \%$ (between 95 to $96.5 \%$ ) should be rerun using 50,000 trials. For the 50,000 trial rerun, any case within 0.5 percentage points of $95 \%$ (between 95 to $95.5 \%$ ) should be classified as the more conservative waste group. 


\section{RPP-10006 REV 8}

\subsection{APPLICATION OF CRYSTAL BALL ${ }^{3}$}

Crystal Ball ${ }^{\mathrm{TM}}$ is an Excel $^{4}$ add-in, which performs data sampling and handling for the Monte Carlo simulation. Appropriate distributions are selected and defined as assumptions in the Crystal Ball analysis. The model-calculated results of interest are determined and defined as forecast values. The number of runs and random number seed value (optional) are also selected to control the selection of random numbers and termination of the program. Crystal Ball ${ }^{\mathrm{TM}}$ will generate a table of random numbers sufficiently large to randomly sample all distributions once for each run. The number of random numbers in the table is the product of the number of distributions and number of runs. Crystal Ball ${ }^{\mathrm{TM}}$ will then sample each distribution based on its random number and perform the model calculation once for each run. The individual run results are kept and a product or forecast distribution is calculated at the completion of the simulation. Crystal Ball ${ }^{\mathrm{TM}}$ can graphically display the forecast distributions as the runs are performed and then produce a report as desired.

\subsection{ASSUMPTIONS}

The following assumptions are used in this methodology.

- Gas releases are rapid with respect to the ventilation rate.

- One hundred percent of the gas is released.

- The BDGRE models apply to sludge-waste tanks.

- An energy ratio of 3 indicates that a BDGRE is capable of releasing retained gas. Experimental data and tank observations indicate that an energy ratio of 5 or greater is required to produce a significant gas release.

- In-situ measurements of yield stress are not readily available. The distribution for yield stress is conservative towards favoring BDGRE behavior as indicated by the energy ratio.

- The gas is retained under hydrostatic conditions (the solids are self-supporting and only the convective layer and interstitial liquid contributes to the retained gas pressure).

- Assuming the headspace gas concentrations are proportional to retained gas concentrations may be a conservative assumption.

- Available void fraction information for sludge tanks with at least $1 \mathrm{~m}$ of supernatant is not sufficient for the creation of a distribution for this tank configuration. The default void fraction derived for saltcake/salt slurry tanks with $1 \mathrm{~m}$ of liquid is used for this tank configuration.

\footnotetext{
${ }^{3}$ Crystal Ball is a trademark of Decisioneering, Inc., Denver, Colorado.

${ }^{4}$ Excel is a trademark of Microsoft Corporation, Redmond, Washington.
} 


\section{RPP-10006 REV 8}

- Void fractions are considered constant in tanks that have been saltwell pumped when compared to the prepumping condition of the tank.

- Retained gas void fractions are bound by the neutral buoyancy void fraction in DSTs only.

- There is no correlation as sumed between $\mathrm{H}_{2}$ and $\mathrm{NH}_{3}$ gas concentrations.

- The volume of waste, when less than the dish height, is assumed to be proportional to the height within the dish. When converting waste height to volume, this is conservative by overestimating the volume of waste and, therefore, overestimating the volume of retained gas when waste is contained only in the dish.

- The volume of waste, when less than the knuckle height, is assumed to be proportional to the height within the knuckle. When converting waste height to volume, this is conservative by overestimating the volume of waste and, therefore, overestimating the volume of retained gas when waste is contained only in the knuckle.

- SSTs contain little or no supernatant, precluding the formation of a waste group A tank. Equations 1, 2, and 3 determine if a tank will be waste group B or C. The solids height shows up twice in the variable $\mathrm{VG}_{\mathrm{WNCL}}$ (Equation 2), and indirectly in the variable $\mathrm{V}_{\mathrm{HS}}$ (Equation 3). Therefore, the headspace flammable gas concentration (\%LFL $\mathrm{HS}_{\mathrm{HS}}$, Equation 1) will be strongly influenced by the height of the tank solids. As can be seen in equations 2 and 3, the convective layer density (or interstitial liquid density) and temperature ratio between the tank headspace plays a much smaller role than that of the solids height. Based on this analysis the re-evaluation of a single-shell tank waste group will only be performed when a change in solids level is indicated by the Best Basis Inventory (BBI).

\subsection{SOFTWARE USED}

Calculations use Microsoft Excel ${ }^{\mathrm{TM}} 2003$ spreadsheets. These spreadsheets compile data, determine uncertainty ranges, establish distributions to represent the uncertainty, and perform the final waste group calculations. The final spreadsheet used to perform the waste group calculations contains the Excel add-in software Crystal Ball ${ }^{\mathrm{TM}}$ described in Section 3.3, which performs the data sampling and handling for the Monte Carlo simulation that is used to determine the confidence level of the waste group assignment. Figure 3-1 illustrates the hierarchy of the spreadsheets and macros. Full details of each spreadsheet used to perform the data manipulation and calculations are provided in the following documents. 


\section{RPP-10006 REV 8}

Spreadsheet Verification Form Number: SVF-1588, Spreadsheet Verification Records for Spreadsheet 'SVF-1588.xls'

Base Software: Microsoft Excel 2003

Spreadsheet Title: SVF-1588.x1s

Document: RPP-36011, Spreadsheet Description Document for SVF-1588, Updated DST

Solids Levels for RPP-10006, Rev 8

Author: J. M. Conner

Purpose: Double-shell tank nonconvective layer depth determination

Spreadsheet Verification Form Number: SVF-1117, Spreadsheet Verification and Release Form for Spreadsheet 'RPP-10006 R5 Tank Physical Data 060208.xls'

Base Software: Microsoft Excel 2003

Spreadsheet Title: RPP-10006 R5 Tank Physical Data 060208.xls.

Document: RPP-29121, Spreadsheet Description Document for RPP-10006 R5 Tank

Physical Data 060208.xls

Author: V. S. Anda

Purpose: Determination and compilation of the tank physical property data

Spreadsheet Verification Form Number: SVF-1118, Spreadsheet Verification and Release Form for Spreadsheet 'RPP-10006 Rev 5 Data Rebuild 060306.xls'

Base Software: Microsoft Excel 2003

Spreadsheet Title: RPP-10006 Rev 5 Data Rebuild 060306.xls.

Document: RPP-29167, Spreadsheet Description Document for RPP-10006 Rev 5 Data

Rebuild 060306.xls

Author: V. S. Anda

Purpose: Compilation of tank property data and source of data for RPP-10006 database

Spreadsheet Verification Form Number: SVF-1123, Spreadsheet Verification and

Release Form for Spreadsheet 'RPP-5926 Rev 5 Update for BDGRE.xls'

Base Software: Microsoft Excel 2003

Spreadsheet Title: RPP-5926 Rev 5 Update for BDGRE.xls

Document: Appendix E, Hydrogen Generation Rates Calculations for Buoyant

Displacement Gas Release Event Criteria Determinations

Author: T. A. Hu

Purpose: Calculates HGR for tank wastes where solids were recently found

Spreadsheet Verification Form Number: SVF-1127, Spreadsheet Verification and Release Form for Spreadsheet '!!RPP-10006R5_Waste_Groups-rev-44-060420 .xls'

Base Software: Microsoft Excel 2003

Spreadsheet Title: !!RPP-10006R5_Waste_Groups-rev-44-060420 .xls

Document: RPP- 29581, Spreadsheet Description Document For

'!'RPP-10006R5_Waste_Groups-rev-44-060420.xls'

Author: S. A. Barker

Purpose: Calculates flammable gas waste group for waste configurations

Spreadsheet Verification Form Number: SVF-1131, Spreadsheet Verification and

Release Form for Spreadsheet 'SVF 1131 BPE to Void Fraction Master R0 060221 .xls' 


\section{RPP-10006 REV 8}

Base Software: Microsoft Excel 2003

Spreadsheet Title: SVF 1131 BPE to Void Fraction Master R0 060221 .xls

Document: RPP-29388, Spreadsheet Description Document For 'SVF 1131 BPE to Void

Fraction Master R0 060221 .xls'

Author: S. A. Barker

Purpose: Converts BPE data to retained gas void fractions

Spreadsheet Verification Form Number: SVF-1132, Spreadsheet Verification and

Release Form for Spreadsheet 'RPP-10006r5 Void fraction revised data by tank 060519.xls'

Base Software: Microsoft Excel 2003

Spreadsheet Title: RPP-10006r5 Void fraction revised data by tank - 060519 .xls

Document: RPP-29389, Spreadsheet Description Document For 'RPP-10006r5 Void

fraction revised data by tank - 060519.xls'

Author: S. A. Barker

Purpose: Compiles void fractions for individual tanks, determines default void fractions

by waste type for tanks with no void fraction data 
Figure 3-1. Spreadsheet and Macro Hierarchy.

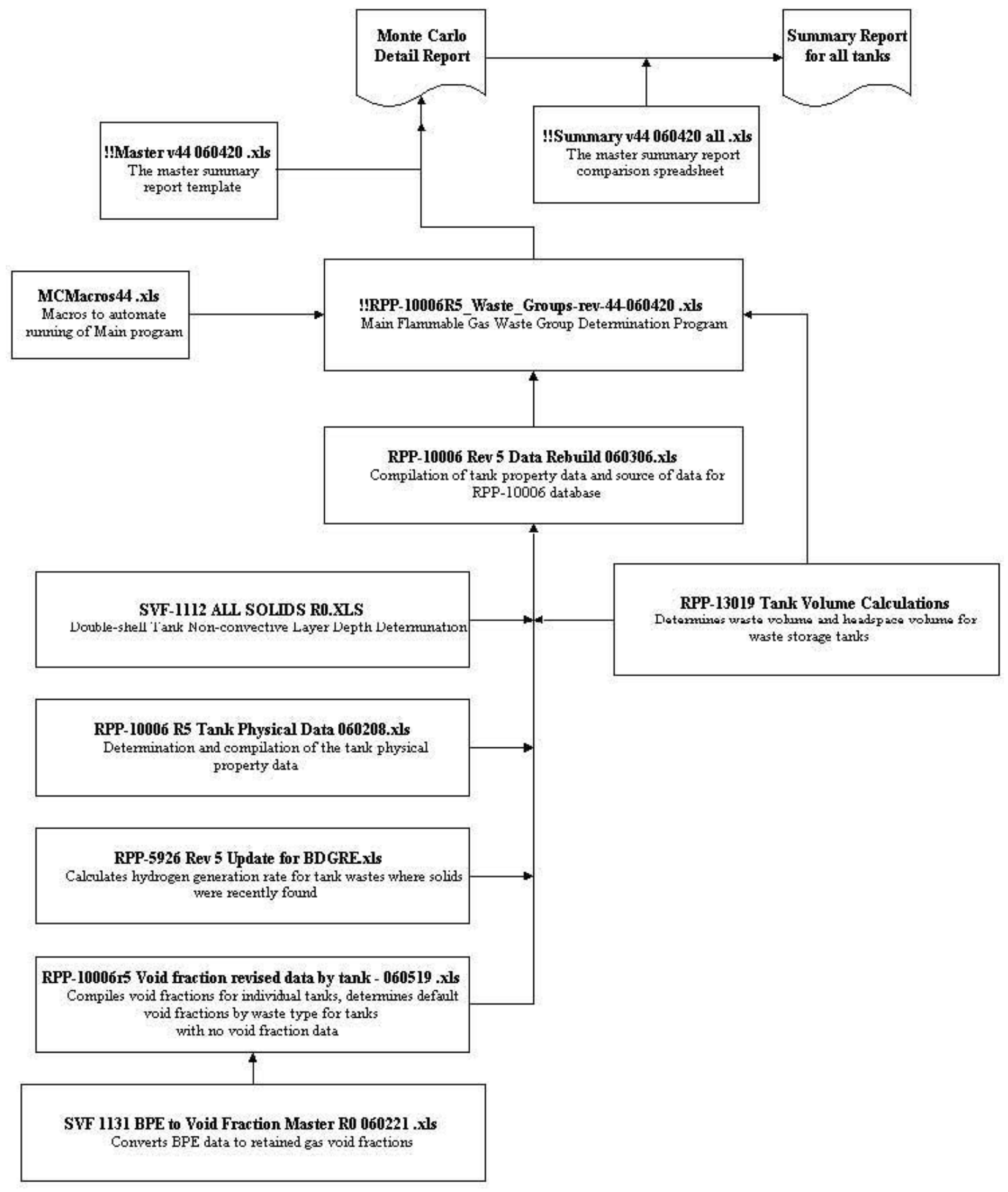


RPP-10006 REV 8

\subsection{SOURCES OF INPUT DATA AND HIERARCHY}

The BBI database is the preferred database for waste characterization information. This database is used whenever possible to maintain consistency between various engineering documents produced by Hanford Site contractors. Data not available in the BBI, such as vapor data, were obtained from other sources as described below.

A summary of the input data required for this evaluation and the primary source for that information is presented in Table 4-1. A table of the specific input data used for this evaluation is provided in Appendix $\mathrm{H}$.

For DSTs, non-convective waste depths and uncertainties are shown in Appendix C. The remaining updated input data are taken from RPP-5926, Rev. 8. These data are based on the BBI database queried on August 4, 2008. In cases where the required input data were not reported in RPP-5926, data were carried over from previous revisions.

RPP-5926, Rev. 8 (August 4, 2008, BBI database), is the default source for input data to update and analyze SST information. In cases where the required input data were not reported in RPP-5926, data were carried over from previous revisions.

For both DSTs and SSTs uncertainty information for the BBI data was obtained from RPP-7625, Best-Basis Inventory Process Requirements. Data pertaining to the tanks that display buoyant displacement behavior were obtained from RPP-6655 and PNNL-15238. Tank dimensions are based on updated tank volume calculations presented in RPP-13019, Determination of Hanford Waste Tank Volumes.

For characterization information that is not included in the BBI database, or for information with values that are uncertain, the information is expressed as distributions. Yield stress data for six tanks (DSTs 241-AN-103, 241-AN-104, 241-AN-105, 241-AW-101, 241-SY-103, and 241-SY-101 [premitigation]) was based on in-situ ball rheometer testing (RPP-6655). The distribution established for this data is shown in Appendix F. 
Table 4-1. Data Source Summary Table. (1 sheet)

\begin{tabular}{|c|c|c|}
\hline Variable & Variable type & $\begin{array}{l}\text { Primary source of } \\
\text { information }\end{array}$ \\
\hline Total nonconvective waste depth & Distribution & Appendix C \\
\hline Saturated nonconvective waste depth & Distribution & Appendix $\mathrm{C}$ \\
\hline Total waste depth & Distribution & Appendix $\mathrm{C}$ \\
\hline Crust depth & Distribution & Appendix C \\
\hline Nonconvective waste density & Distribution & Appendix B \\
\hline Convective waste density & Distribution & Appendix B \\
\hline Nonconvective waste average temperature & Single point value & RPP-5926 \\
\hline Tank headspace average temperature & Single point value & RPP-5926 \\
\hline Tank dimensions & Single point values & RPP-13019 \\
\hline DST OSD design limit & Single point value & OSD-T-151-00007 \\
\hline SST OSD design limit & Single point value & OSD-T-151-00013 \\
\hline Void fraction or maximum saturated solids void fraction & Distribution & Appendix D \\
\hline Nonconvective waste yield stress & Distribution & Appendix F \\
\hline Retained gas ratio $\mathrm{CH}_{4}$ & Distribution & Appendix $G$ \\
\hline Retained gas ratio $\mathrm{N}_{2} \mathrm{O}$ & Distribution & Appendix $G$ \\
\hline Retained gas composition $\mathrm{N}_{2}$ & Distribution & Appendix $G$ \\
\hline Retained gas composition $\mathrm{NH}_{3}$ & Distribution & Appendix $G$ \\
\hline Hydrogen generation rate in nonconvective waste & Distribution & RPP-5926 \\
\hline
\end{tabular}

Notes:

OSD-T-151-00007, 2007, Operating Specifications for the Double-Shell Storage Tanks, Rev. 1. OSD-T-151-00013, 2006, Operating Specifications for Single-Shell Waste Storage Tanks, Rev. 1. RPP-5926, 2008, Steady-State Flammable Gas Release Rate Calculation and Lower Flammability Level Evaluation for Hanford Tank Waste, Rev. 8.

RPP-13019, 2003, Determination of Hanford Waste Tank Volumes, Rev. 0.

DST = double-shell tank.

SST $=$ single-shell tank.

Gas composition and void fraction data are not in the BBI database. Gas composition data distributions are based on RGS results and can be found in Appendix G. BPE model void fractions are based on previously unused data (RPP-15488, Investigation of Tank Void Fraction Using Liquid Level Response to Atmospheric Pressure Changes) for all tanks with Enraf-Nonius Series 854 level gauges (Enraf) surface level measurements (see Appendix D). Information from Appendix D and Appendix $\mathrm{H}$ includes the results of a statistical evaluation that generates a distribution for the void fraction and retained gas composition for tanks where no data is available. For tanks where gas composition data is available, the RGS measured gas compositions are used. For tanks with acceptable void fraction measurements, such as VFI data or good BPE data, the void fraction used in this evaluation is the measured value.

Individual tank HGRs are taken from RPP-5926. The solid phase thermolysis and radiolysis are added together to yield the total non-convective hydrogen generation rate (See Appendix E). 


\section{RPP-10006 REV 8}

Because the data set is limited, it is assumed that a triangular distribution adequately describes the true distribution. Determination of HGR distribution ranges is documented in Appendix E.

Some distributions are constrained to be sure that the sampled properties are in the range of expected values and also so that nonphysical conditions are not selected by the Monte Carlo sampler. There are two types of constraints used in this model: limits on property ranges and dynamically calculated controls on range values or interactions. The limits on property ranges for each distribution are listed in Appendix H. The constraints and dynamic controls are listed in Table 4-2.

Table 4-2. Monte Carlo Model Dynamic Constraints.

\begin{tabular}{|c|c|}
\hline Variable & Constraint \\
\hline Total waste depth & Constrained to tank operating limit \\
\hline Total nonconvective waste depth & Constrained to total waste depth \\
\hline Saturated nonconvective waste depth & $\begin{array}{l}\text { Constrained to always be less than or equal to "total } \\
\text { nonconvective waste depth" }\end{array}$ \\
\hline Convective waste depth & Calculated by difference \\
\hline Crust depth & No dynamic constraint \\
\hline Convective waste density & No dynamic constraint \\
\hline Nonconvective waste density offset & $\begin{array}{l}\text { Set as the difference between the mean convective waste density } \\
\text { and the mean nonconvective waste density with a standard } \\
\text { deviation equal to the nonconvective waste density standard } \\
\text { deviation. }\end{array}$ \\
\hline Nonconvective waste density & $\begin{array}{l}\text { Constrained to be greater than the convective waste density as it } \\
\text { is set equal to the sum of the convective waste density and the } \\
\text { nonconvective waste density offset. }\end{array}$ \\
\hline $\begin{array}{l}\text { Void fraction or maximum saturated solids void } \\
\text { fraction }\end{array}$ & $\begin{array}{l}\text { No dynamic constraint for SSTs. For DSTs the void fraction is } \\
\text { dynamically limited to the } \alpha_{\mathrm{NB}} \text { void fraction. }\end{array}$ \\
\hline Nonconvective waste yield stress & No dynamic constraint \\
\hline Retained gas ratio $\mathrm{CH}_{4}$ & No dynamic constraint \\
\hline Retained gas ratio $\mathrm{N}_{2} \mathrm{O}$ & No dynamic constraint \\
\hline Retained gas composition $\mathrm{N}_{2}$ & No dynamic constraint \\
\hline Retained gas composition $\mathrm{NH}_{3}$ & No dynamic constraint \\
\hline $\begin{array}{l}\text { Hydrogen generation rate in nonconvective } \\
\text { waste }\end{array}$ & No dynamic constraint \\
\hline $\begin{array}{l}\text { Notes: } \\
\begin{array}{rll}\text { DST } & = & \text { double-shell tank. } \\
\text { SST } & = & \text { single-shell tank. }\end{array}\end{array}$ & \\
\hline
\end{tabular}


In order to reflect the inter-dependency between convective and nonconvective waste densities, a nonconvective waste density offset distribution is created. The distribution is determined by setting its mean as the difference between the mean convective waste density and the mean nonconvective waste density with a standard deviation equal to the nonconvective waste density standard deviation. The nonconvective waste density is constrained to be greater than the convective waste density by setting the nonconvective waste density equal to the sum of the convective waste density and the nonconvective waste density offset.

The most complicated distribution is the void fraction distribution. Based on RPP-21336, Flammable Gas Waste Group Assessment FY-2004-ENG-S-0133, the truncation point of the void fraction distribution was changed to a distribution with a dynamic upper limit for DSTs. The buoyant GRE model reports that the retained gas void fraction in the nonconvective layer is limited by the neutral buoyancy void fraction. A simple dynamic distribution was created in Crystal Ball which calculates and then applies the limit to the void fraction distribution for each model iteration. This distribution is truncated on the upper end by the neutral buoyancy void fraction.

As the neutral buoyancy void fraction approaches the mean of the original distribution (is less than $0.1 \%$ greater than the mean when expressed as a percentage), the mean is adjusted to be equal to the neutral buoyancy void fraction (expressed in percent) minus $0.1 \%$. This modification maintains the shape of the original distribution up to the truncation point. The modification of the distribution mean is performed for each trial in which the neutral buoyancy void fraction approaches or is less than the original distribution mean. This modification does not alter the shape of the original distribution and only affects the one trial. 
RPP-10006 REV 8

\subsection{RESULTS OF CALCULATIONS}

An evaluation of the SSTs and DSTs at the Hanford Site has been completed using the methodology presented in Section 3.0, and the input data in Appendix H. Three conditions were evaluated for each tank:

- Base tank condition as of the selected data date ("as is" case)

- "As is" case with an addition of 10,000 gal of water (10,000-gal water addition case) (1,000-gal addition for 200 -series SSTs)

- "As is" case with an addition of 500 gal of $8 \mathrm{M}$ caustic (500-gal caustic addition case) (not performed for SSTs).

The last two cases were performed to determine if any tanks change classification as the result of the addition of modest amounts of water or caustic. These two cases demonstrate what can happen to the tank classification during normal operations as the result of a number of water flushes over time, or if caustic is added to the water flush for water conditioning purposes. An additional constraint was placed on the tanks related to these additions, near-full tanks were not allowed to exceed the tank operating limit for waste volume.

The results of the waste group evaluations are shown in Table 5-1, which gives the breakdown of the results of the 5,000 trials for each tank, and whether the result classifies the tank as a waste group A, B, or C for the "As is" case. The result reported for tank AW-104 is based on the 50,000 trial results since the 5,000 trial results were within the range where the outcome is too close to determine the waste group based on the seed sensitivity test criteria (see Section 3.2).

\subsection{WASTE GROUP ASSIGNMENTS}

The methodology used in this waste classification evaluation indicates that if the tank exhibits category $\mathrm{C}$ behavior at the $95 \%$ confidence level or for $95 \%$ of the trials, the tank is classified as waste group $\mathrm{C}$. If the tank exhibits category $\mathrm{C}$ behavior at less than the $95 \%$ confidence level, but exhibits combined category $\mathrm{C}$ and category $\mathrm{B}$ behavior at more than $95 \%$ confidence level, the tank is then classified as a waste group B tank. The remaining tanks, those that exhibit category A behavior for greater than $5 \%$ of the trials, are placed in the waste group A category. 
RPP-10006 REV 8

Table 5-1. Determination of Waste Group Classification. (6 sheets)

\begin{tabular}{|c|c|c|c|c|c|c|}
\hline Tank & Type & Waste type $\mathrm{e}^{\mathrm{a}}$ & $\begin{array}{c}\text { Category A } \\
(\%)\end{array}$ & $\begin{array}{c}\text { Category B } \\
(\%)\end{array}$ & $\begin{array}{c}\text { Category C } \\
(\%)\end{array}$ & "As is" \\
\hline 241-AN-101* & DST & SC/SS-LIQ & 0.00 & 1.90 & 98.10 & $\mathrm{C}$ \\
\hline 241-AN-102* & DST & SC/SS-LIQ & 1.38 & 27.64 & 70.98 & B \\
\hline 241-AN-103* & DST & SC/SS-LIQ & 33.98 & 5.84 & 60.18 & $\mathrm{~A}$ \\
\hline 241-AN-104* & DST & SC/SS-LIQ & 50.32 & 0.78 & 48.90 & $\mathrm{~A}$ \\
\hline 241-AN-105* & DST & SC/SS-LIQ & 67.10 & 0.16 & 32.74 & $\mathrm{~A}$ \\
\hline 241-AN-106* & DST & SL-LIQ & 0.00 & 2.76 & 97.24 & $\mathrm{C}$ \\
\hline 241-AN-107* & DST & SC/SS-LIQ & 0.00 & 0.00 & 100.00 & $\mathrm{C}$ \\
\hline 241-AP-101* & DST & LIQ & 0.00 & 0.00 & 100.00 & $\mathrm{C}$ \\
\hline 241-AP-102* & DST & SL-LIQ & 0.00 & 1.84 & 98.16 & $\mathrm{C}$ \\
\hline 241-AP-103* & DST & SL-LIQ & 0.00 & 0.00 & 100.00 & $\mathrm{C}$ \\
\hline 241-AP-104* & DST & SC/SS-LIQ & 0.00 & 0.00 & 100.00 & $\mathrm{C}$ \\
\hline 241-AP-105* & DST & SC/SS-LIQ & 0.00 & 0.00 & 100.00 & $\mathrm{~B}^{\mathrm{C}}$ \\
\hline 241-AP-106* & DST & SC/SS-LIQ & 0.00 & 0.80 & 99.20 & $\mathrm{C}$ \\
\hline 241-AP-107* & DST & SC/SS-LIQ & 0.00 & 0.34 & 99.66 & $\mathrm{C}$ \\
\hline 241-AP-108* & DST & SC/SS-LIQ & 0.04 & 41.58 & 58.38 & $\mathrm{~B}$ \\
\hline 241-AW-101* & DST & SC/SS-LIQ & 16.28 & 7.02 & 76.70 & $\mathrm{~A}$ \\
\hline 241-AW-102* & DST & SL-LIQ & 0.00 & 0.32 & 99.68 & $\mathrm{C}$ \\
\hline 241-AW-103* & DST & SL-LIQ & 0.00 & 0.00 & 100.00 & $\mathrm{C}$ \\
\hline $241-\mathrm{AW}-104 * \mathrm{~b}$ & DST & SC/SS-LIQ & 3.44 & 27.99 & 68.57 & B \\
\hline 241-AW-105* & DST & SL-LIQ & 0.00 & 0.00 & 100.00 & $\mathrm{C}$ \\
\hline 241-AW-106* & DST & SC/SS-LIQ & 0.00 & 34.48 & 65.52 & $\mathrm{~B}$ \\
\hline 241-AY-101* & DST & SL-LIQ & 0.00 & 0.02 & 99.98 & $\mathrm{C}$ \\
\hline 241-AY-102* & DST & SL-LIQ & 0.00 & 9.54 & 90.46 & $\mathrm{~B}$ \\
\hline 241-AZ-101* & DST & SL-LIQ & 0.00 & 0.00 & 100.00 & $\mathrm{C}$ \\
\hline 241-AZ-102* & DST & SL-LIQ & 0.00 & 0.22 & 99.78 & $\mathrm{C}$ \\
\hline 241-SY-101* & DST & SC/SS-LIQ & 0.00 & 62.18 & 37.82 & $\mathrm{~B}$ \\
\hline 241-SY-102* & DST & SL-LIQ & 0.00 & 0.00 & 100.00 & $\mathrm{C}$ \\
\hline 241-SY-103* & DST & SC/SS-LIQ & 7.40 & 1.66 & 90.94 & $\mathrm{~A}$ \\
\hline 241-A-101 & SST & SC/SS-NL & 0.00 & 19.18 & 80.82 & $\mathrm{~B}$ \\
\hline 241-A-102 & SST & SC/SS-NL & 0.00 & 0.00 & 100.00 & $\mathrm{C}$ \\
\hline 241-A-103 & SST & SC/SS-NL & 0.00 & 0.00 & 100.00 & $\mathrm{C}$ \\
\hline 241-A-104 & SST & SL-NL & 0.00 & 0.00 & 100.00 & $\mathrm{C}$ \\
\hline 241-A-105 & SST & SL-NL & 0.00 & 0.00 & 100.00 & $\mathrm{C}$ \\
\hline 241-A-106 & SST & MIX-NL & 0.00 & 0.00 & 100.00 & $\mathrm{C}$ \\
\hline 241-AX-101 & SST & SC/SS-NL & 0.00 & 0.16 & 99.84 & $\mathrm{C}$ \\
\hline 241-AX-102 & SST & SC/SS-NL & 0.00 & 0.00 & 100.00 & $\mathrm{C}$ \\
\hline 241-AX-103 & SST & SC/SS-NL & 0.00 & 0.00 & 100.00 & $\mathrm{C}$ \\
\hline
\end{tabular}


RPP-10006 REV 8

Table 5-1. Determination of Waste Group Classification. (6 sheets)

\begin{tabular}{|c|c|c|c|c|c|c|}
\hline Tank & Type & Waste type $^{\mathrm{a}}$ & $\begin{array}{c}\text { Category A } \\
(\%)\end{array}$ & $\begin{array}{c}\text { Category B } \\
(\%)\end{array}$ & $\begin{array}{c}\text { Category C } \\
(\%)\end{array}$ & "As is" \\
\hline 241-AX-104 & SST & SL-NL & 0.00 & 0.00 & 100.00 & $\mathrm{C}$ \\
\hline 241-B-101 & SST & SC/SS-NL & 0.00 & 0.02 & 99.98 & $\mathrm{C}$ \\
\hline 241-B-102 & SST & SC/SS-NL & 0.00 & 0.00 & 100.00 & $\mathrm{C}$ \\
\hline 241-B-103 & SST & SC/SS-NL & 0.00 & 0.00 & 100.00 & $\mathrm{C}$ \\
\hline 241-B-104 & SST & SL-NL & 0.00 & 3.40 & 96.60 & $\mathrm{C}$ \\
\hline 241-B-105 & SST & SC/SS-NL & 0.00 & 0.44 & 99.56 & $\mathrm{C}$ \\
\hline 241-B-106 & SST & SL-NL & 0.00 & 0.00 & 100.00 & $\mathrm{C}$ \\
\hline 241-B-107 & SST & MIX-NL & 0.00 & 1.72 & 98.28 & $\mathrm{C}$ \\
\hline 241-B-108 & SST & SC/SS-NL & 0.00 & 0.00 & 100.00 & $\mathrm{C}$ \\
\hline 241-B-109 & SST & MIX-NL & 0.00 & 0.00 & 100.00 & $\mathrm{C}$ \\
\hline 241-B-110 & SST & SL-NL & 0.00 & 0.44 & 99.56 & $\mathrm{C}$ \\
\hline 241-B-111 & SST & SL-NL & 0.00 & 0.32 & 99.68 & $\mathrm{C}$ \\
\hline 241-B-112 & SST & MIX-NL & 0.00 & 0.00 & 100.00 & $\mathrm{C}$ \\
\hline 241-B-201 & SST & SL-NL & 0.00 & 6.08 & 93.92 & $\mathrm{~B}$ \\
\hline $241-\mathrm{B}-202$ & SST & SL-NL & 0.00 & 4.60 & 95.40 & B \\
\hline $241-B-203$ & SST & SL-NL & 0.00 & 69.00 & 31.00 & $\mathrm{~B}$ \\
\hline 241-B-204 & SST & SL-NL & 0.00 & 67.00 & 33.00 & $\mathrm{~B}$ \\
\hline 241-BX-101 & SST & SL-NL & 0.00 & 0.00 & 100.00 & $\mathrm{C}$ \\
\hline 241-BX-102 & SST & SL-NL & 0.00 & 0.00 & 100.00 & $\mathrm{C}$ \\
\hline 241-BX-103 & SST & SL-NL & 0.00 & 0.00 & 100.00 & $\mathrm{C}$ \\
\hline 241-BX-104 & SST & SL-NL & 0.00 & 0.00 & 100.00 & $\mathrm{C}$ \\
\hline 241-BX-105 & SST & MIX-NL & 0.00 & 0.00 & 100.00 & $\mathrm{C}$ \\
\hline 241-BX-106 & SST & SC/SS-NL & 0.00 & 0.00 & 100.00 & $\mathrm{C}$ \\
\hline 241-BX-107 & SST & SL-NL & 0.00 & 0.02 & 99.98 & $\mathrm{C}$ \\
\hline 241-BX-108 & SST & SL-NL & 0.00 & 0.00 & 100.00 & $\mathrm{C}$ \\
\hline 241-BX-109 & SST & SL-NL & 0.00 & 0.04 & 99.96 & $\mathrm{C}$ \\
\hline 241-BX-110 & SST & MIX-NL & 0.00 & 0.00 & 100.00 & $\mathrm{C}$ \\
\hline 241-BX-111 & SST & SC/SS-NL & 0.00 & 0.00 & 100.00 & $\mathrm{C}$ \\
\hline 241-BX-112 & SST & SL-NL & 0.00 & 0.00 & 100.00 & $\mathrm{C}$ \\
\hline 241-BY-101 & SST & SC/SS-NL & 0.00 & 17.22 & 82.78 & B \\
\hline 241-BY-102 & SST & SC/SS-NL & 0.00 & 1.18 & 98.82 & $\mathrm{C}$ \\
\hline 241-BY-103 & SST & SC/SS-NL & 0.00 & 34.30 & 65.70 & $\mathrm{~B}$ \\
\hline 241-BY-104 & SST & SC/SS-NL & 0.00 & 10.40 & 89.60 & $\mathrm{~B}$ \\
\hline 241-BY-105 & SST & SC/SS-NL & 0.00 & 32.3 & 67.70 & $\mathrm{~B}$ \\
\hline 241-BY-106 & SST & SC/SS-NL & 0.00 & 8.42 & 91.58 & $\mathrm{~B}$ \\
\hline 241-BY-107 & SST & SC/SS-NL & 0.00 & 1.28 & 98.72 & $\mathrm{C}$ \\
\hline 241-BY-108 & SST & SC/SS-NL & 0.00 & 0.54 & 99.46 & $\mathrm{C}$ \\
\hline
\end{tabular}


RPP-10006 REV 8

Table 5-1. Determination of Waste Group Classification. (6 sheets)

\begin{tabular}{|c|c|c|c|c|c|c|}
\hline Tank & Type & Waste type $\mathrm{e}^{\mathrm{a}}$ & $\begin{array}{c}\text { Category A } \\
(\%)\end{array}$ & $\begin{array}{c}\text { Category B } \\
(\%)\end{array}$ & $\begin{array}{c}\text { Category C } \\
(\%)\end{array}$ & "As is" \\
\hline 241-BY-109 & SST & SC/SS-NL & 0.00 & 12.80 & 87.20 & $\mathrm{~B}$ \\
\hline 241-BY-110 & SST & SC/SS-NL & 0.00 & 14.50 & 85.50 & B \\
\hline 241-BY-111 & SST & SC/SS-NL & 0.00 & 4.20 & 95.80 & $\mathrm{C}$ \\
\hline 241-BY-112 & SST & SC/SS-NL & 0.00 & 0.00 & 100.00 & $\mathrm{C}$ \\
\hline 241-C-101 & SST & SL-NL & 0.00 & 0.00 & 100.00 & $\mathrm{C}$ \\
\hline 241-C-102 & SST & SL-NL & 0.00 & 1.22 & 98.78 & $\mathrm{C}$ \\
\hline 241-C-103 & SST & SL-NL & 0.00 & 0.00 & 100.00 & $\mathrm{C}$ \\
\hline 241-C-104 & SST & SL-NL & 0.00 & 0.50 & 99.50 & $\mathrm{C}$ \\
\hline 241-C-105 & SST & SL-NL & 0.00 & 0.00 & 100.00 & $\mathrm{C}$ \\
\hline 241-C-106 & SST & SL-NL & 0.00 & 0.00 & 100.00 & $\mathrm{C}$ \\
\hline 241-C-107 & SST & SL-NL & 0.00 & 0.36 & 99.64 & $\mathrm{C}$ \\
\hline 241-C-108* & SST & SL-NL & 0.00 & 0.00 & 100.00 & $\mathrm{C}$ \\
\hline 241-C-109* & SST & SL-NL & 0.00 & 0.00 & 100.00 & $\mathrm{C}$ \\
\hline 241-C-110 & SST & SL-NL & 0.00 & 0.02 & 99.98 & $\mathrm{C}$ \\
\hline 241-C-111 & SST & SL-NL & 0.00 & 0.00 & 100.00 & $\mathrm{C}$ \\
\hline 241-C-112 & SST & SL-NL & 0.00 & 0.02 & 99.98 & $\mathrm{C}$ \\
\hline 241-C-201 & SST & SL-NL & 0.00 & 0.00 & 100.00 & $\mathrm{C}$ \\
\hline 241-C-202 & SST & SL-NL & 0.00 & 0.00 & 100.00 & $\mathrm{C}$ \\
\hline 241-C-203 & SST & SL-NL & 0.00 & 0.00 & 100.00 & $\mathrm{C}$ \\
\hline 241-C-204 & SST & SL-NL & 0.00 & 0.00 & 100.00 & $\mathrm{C}$ \\
\hline 241-S-101 & SST & MIX-NL & 0.00 & 0.06 & 99.94 & $\mathrm{C}$ \\
\hline 241-S-102* & SST & MIX-NL & 0.00 & 0.00 & 100.00 & $\mathrm{C}$ \\
\hline 241-S-103 & SST & SC/SS-NL & 0.00 & 18.40 & 81.60 & $\mathrm{~B}$ \\
\hline 241-S-104 & SST & MIX-NL & 0.00 & 15.86 & 84.14 & $\mathrm{~B}$ \\
\hline 241-S-105 & SST & SC/SS-NL & 0.00 & 0.88 & 99.12 & $\mathrm{C}$ \\
\hline 241-S-106 & SST & SC/SS-NL & 0.00 & 0.20 & 99.80 & $\mathrm{C}$ \\
\hline 241-S-107 & SST & SL-NL & 0.00 & 0.00 & 100.00 & $\mathrm{C}$ \\
\hline 241-S-108 & \begin{tabular}{|l} 
SST \\
\end{tabular} & SC/SS-NL & 0.00 & 8.68 & 91.32 & $\mathrm{~B}$ \\
\hline 241-S-109 & SST & SC/SS-NL & 0.00 & 12.10 & 87.90 & $\mathrm{~B}$ \\
\hline $241-S-110$ & SST & SC/SS-NL & 0.00 & 33.90 & 66.10 & $\mathrm{~B}$ \\
\hline $241-S-111$ & SST & SC/SS-NL & 0.00 & 38.80 & 61.20 & $\mathrm{~B}$ \\
\hline 241-S-112* & SST & SC/SS-NL & 0.00 & 0.00 & 100.00 & $\mathrm{C}$ \\
\hline 241-SX-101 & SST & MIX-NL & 0.00 & 13.10 & 86.90 & $\bar{B}$ \\
\hline 241-SX-102 & SST & SC/SS-NL & 0.00 & 11.20 & 88.80 & B \\
\hline 241-SX-103 & SST & SC/SS-NL & 0.00 & 7.48 & 92.52 & B \\
\hline 241-SX-104 & SST & MIX-NL & 0.00 & 7.70 & 92.30 & $\mathrm{~B}$ \\
\hline 241-SX-105 & SST & SC/SS-NL & 0.00 & 2.80 & 97.20 & $\mathrm{C}$ \\
\hline
\end{tabular}


RPP-10006 REV 8

Table 5-1. Determination of Waste Group Classification. (6 sheets)

\begin{tabular}{|c|c|c|c|c|c|c|}
\hline Tank & Type & Waste type $^{\mathrm{a}}$ & $\begin{array}{c}\text { Category A } \\
(\%)\end{array}$ & $\begin{array}{c}\text { Category B } \\
(\%)\end{array}$ & $\begin{array}{c}\text { Category C } \\
(\%)\end{array}$ & "As is" \\
\hline 241-SX-106 & SST & SC/SS-NL & 0.00 & 1.84 & 98.16 & $\mathrm{C}$ \\
\hline 241-SX-107 & SST & SL-NL & 0.00 & 0.00 & 100.00 & $\mathrm{C}$ \\
\hline 241-SX-108 & SST & SL-NL & 0.00 & 0.00 & 100.00 & $\mathrm{C}$ \\
\hline 241-SX-109 & SST & SC/SS-NL & 0.00 & 1.44 & 98.56 & $\mathrm{C}$ \\
\hline 241-SX-110 & SST & SL-NL & 0.00 & 0.00 & 100.00 & $\mathrm{C}$ \\
\hline 241-SX-111 & SST & SL-NL & 0.00 & 0.00 & 100.00 & $\mathrm{C}$ \\
\hline 241-SX-112 & SST & SL-NL & 0.00 & 0.00 & 100.00 & $\mathrm{C}$ \\
\hline 241-SX-113 & SST & SL-NL & 0.00 & 0.00 & 100.00 & $\mathrm{C}$ \\
\hline 241-SX-114 & SST & SL-NL & 0.00 & 0.00 & 100.00 & $\mathrm{C}$ \\
\hline 241-SX-115 & SST & SL-NL & 0.00 & 0.00 & 100.00 & $\mathrm{C}$ \\
\hline 241-T-101 & SST & MIX-NL & 0.00 & 0.00 & 100.00 & $\mathrm{C}$ \\
\hline 241-T-102 & SST & SL-NL & 0.00 & 0.00 & 100.00 & $\mathrm{C}$ \\
\hline 241-T-103 & SST & SL-NL & 0.00 & 0.00 & 100.00 & $\mathrm{C}$ \\
\hline 241-T-104 & SST & SL-NL & 0.00 & 1.12 & 98.88 & $\mathrm{C}$ \\
\hline 241-T-105 & SST & SL-NL & 0.00 & 0.00 & 100.00 & $\mathrm{C}$ \\
\hline 241-T-106 & SST & SL-NL & 0.00 & 0.00 & 100.00 & $\mathrm{C}$ \\
\hline 241-T-107 & SST & SL-NL & 0.00 & 0.02 & 99.98 & $\mathrm{C}$ \\
\hline 241-T-108 & SST & MIX-NL & 0.00 & 0.00 & 100.00 & $\mathrm{C}$ \\
\hline 241-T-109 & SST & SC/SS-NL & 0.00 & 0.00 & 100.00 & $\mathrm{C}$ \\
\hline $241-\mathrm{T}-110$ & SST & SL-NL & 0.00 & 3.42 & 96.58 & $\mathrm{C}$ \\
\hline 241-T-111 & SST & SL-NL & 0.00 & 8.82 & 91.18 & $\mathrm{~B}$ \\
\hline 241-T-112 & SST & SL-NL & 0.00 & 0.00 & 100.00 & $\mathrm{C}$ \\
\hline 241-T-201 & SST & SL-NL & 0.00 & 6.82 & 93.18 & $\mathrm{~B}$ \\
\hline 241-T-202 & SST & SL-NL & 0.00 & 1.02 & 98.98 & $\mathrm{C}$ \\
\hline 241-T-203 & SST & SL-NL & 0.00 & 16.40 & 83.60 & B \\
\hline 241-T-204 & SST & SL-NL & 0.00 & 16.30 & 83.70 & B \\
\hline 241-TX-101 & SST & SL-NL & 0.00 & 0.00 & 100.00 & $\mathrm{C}$ \\
\hline 241-TX-102 & SST & SC/SS-NL & 0.00 & 0.26 & 99.74 & $\mathrm{C}$ \\
\hline 241-TX-103 & SST & SC/SS-NL & 0.00 & 0.00 & 100.00 & $\mathrm{C}$ \\
\hline 241-TX-104 & SST & MIX-NL & 0.00 & 0.00 & 100.00 & $\mathrm{C}$ \\
\hline 241-TX-105 & SST & SC/SS-NL & 0.00 & 5.33 & 94.67 & $\mathrm{~B}$ \\
\hline 241-TX-106 & SST & SC/SS-NL & 0.00 & 12.30 & 87.70 & B \\
\hline 241-TX-107 & SST & SC/SS-NL & 0.00 & 0.00 & 100.00 & $\mathrm{C}$ \\
\hline 241-TX-108 & SST & SC/SS-NL & 0.00 & 0.02 & 99.98 & $\mathrm{C}$ \\
\hline 241-TX-109 & SST & SL-NL & 0.00 & 0.72 & 99.28 & $\mathrm{C}$ \\
\hline 241-TX-110 & SST & SC/SS-NL & 0.00 & 2.26 & 97.74 & $\mathrm{C}$ \\
\hline 241-TX-111 & SST & SC/SS-NL & 0.00 & 3.32 & 96.68 & $\mathrm{C}$ \\
\hline
\end{tabular}




\section{RPP-10006 REV 8}

Table 5-1. Determination of Waste Group Classification. (6 sheets)

\begin{tabular}{|c|c|c|c|c|c|c|}
\hline Tank & Type & Waste type $^{\mathrm{a}}$ & $\begin{array}{c}\text { Category A } \\
(\%)\end{array}$ & $\begin{array}{c}\text { Category B } \\
(\%)\end{array}$ & $\begin{array}{c}\text { Category C } \\
(\%)\end{array}$ & "As is" \\
\hline 241-TX-112 & SST & $\mathrm{SC} / \mathrm{SS}-\mathrm{NL}$ & 0.00 & 63.00 & 37.00 & B \\
\hline 241-TX-113 & SST & SC/SS-NL & 0.00 & 26.10 & 73.90 & B \\
\hline 241-TX-114 & SST & SC/SS-NL & 0.00 & 16.70 & 83.30 & B \\
\hline 241-TX-115 & SST & $\mathrm{SC} / \mathrm{SS}-\mathrm{NL}$ & 0.00 & 35.40 & 64.60 & B \\
\hline 241-TX-116 & SST & $\mathrm{SC} / \mathrm{SS}-\mathrm{NL}$ & 0.00 & 6.04 & 93.96 & B \\
\hline 241-TX-117 & SST & SC/SS-NL & 0.00 & 0.46 & 99.54 & $\mathrm{C}$ \\
\hline 241-TX-118 & SST & $\mathrm{SC} / \mathrm{SS}-\mathrm{NL}$ & 0.00 & 2.88 & 97.12 & $\mathrm{C}$ \\
\hline 241-TY-101 & SST & MIX-NL & 0.00 & 0.02 & 99.98 & $\mathrm{C}$ \\
\hline 241-TY-102 & SST & SC/SS-NL & 0.00 & 0.00 & 100.00 & $\mathrm{C}$ \\
\hline 241-TY-103 & SST & MIX-NL & 0.00 & 0.16 & 99.84 & $\mathrm{C}$ \\
\hline 241-TY-104 & SST & SL-NL & 0.00 & 0.00 & 100.00 & $\mathrm{C}$ \\
\hline 241-TY-105 & SST & SL-NL & 0.00 & 0.00 & 100.00 & $\mathrm{C}$ \\
\hline 241-TY-106 & SST & SL-NL & 0.00 & 0.00 & 100.00 & $\mathrm{C}$ \\
\hline 241-U-101 & SST & SL-NL & 0.00 & 0.00 & 100.00 & $\mathrm{C}$ \\
\hline 241-U-102 & SST & SC/SS-NL & 0.00 & 17.70 & 82.30 & $\mathrm{~B}$ \\
\hline 241-U-103 & SST & SC/SS-NL & 0.00 & 0.00 & 100.00 & $\mathrm{C}$ \\
\hline 241-U-104 & SST & SL-NL & 0.00 & 0.00 & 100.00 & $\mathrm{C}$ \\
\hline 241-U-105 & SST & SC/SS-NL & 0.00 & 13.00 & 87.00 & B \\
\hline 241-U-106 & SST & SC/SS-NL & 0.00 & 0.00 & 100.00 & $\mathrm{C}$ \\
\hline 241-U-107 & SST & SC/SS-NL & 0.00 & 1.50 & 98.50 & $\mathrm{C}$ \\
\hline 241-U-108 & SST & SC/SS-NL & 0.00 & 56.50 & 43.50 & B \\
\hline 241-U-109 & SST & SC/SS-NL & 0.00 & 0.00 & 100.00 & $\mathrm{C}$ \\
\hline 241-U-110 & SST & SL-NL & 0.00 & 0.00 & 100.00 & $\mathrm{C}$ \\
\hline 241-U-111 & SST & SC/SS-NL & 0.00 & 5.34 & 94.66 & B \\
\hline 241-U-112 & \begin{tabular}{|l} 
SST \\
\end{tabular} & SL-NL & 0.00 & 0.00 & 100.00 & $\mathrm{C}$ \\
\hline 241-U-201 & SST & SL-NL & 0.00 & 0.00 & 100.00 & $\mathrm{C}$ \\
\hline 241-U-202 & SST & SL-NL & 0.00 & 0.00 & 100.00 & $\mathrm{C}$ \\
\hline
\end{tabular}


Table 5-1. Determination of Waste Group Classification. (6 sheets)

\begin{tabular}{|c|l|l|c|c|c|c|}
\hline Tank & Type & \multicolumn{1}{|c|}{ Waste type $^{\mathbf{a}}$} & $\begin{array}{c}\text { Category A } \\
(\boldsymbol{\%})\end{array}$ & $\begin{array}{c}\text { Category B } \\
(\boldsymbol{\%})\end{array}$ & $\begin{array}{c}\text { Category C } \\
(\boldsymbol{\%})\end{array}$ & “As is" \\
\hline $241-U-203$ & SST & SL-NL & 0.00 & 0.00 & 100.00 & C \\
\hline $241-U-204$ & SST & SL-NL & 0.00 & 0.00 & 100.00 & C \\
\hline
\end{tabular}

Notes: *Tank re-evaluated for this revision

${ }^{\mathrm{a}} \mathrm{See}$ Appendix A

${ }^{\mathrm{b}}$ Based on 50,000 trials.

"Tank 241-AP-105 will remain a Waste Group "B" tank. See the 5.1.1.

DST $=$ double-shell tank.

$\mathrm{LIQ}=$ deep liquid layer above solids, liquid layer is at least $1 \mathrm{~m}$ deep.

MIX $=$ mixed waste, less than 75 vol\% sludge or saltcake.

$\mathrm{NL}=$ no deep liquid layer above solids, liquid layer is less than $1 \mathrm{~m}$ deep.

$\mathrm{SC} / \mathrm{SS}=$ saltcake/salt slurry solids, at least $75 \mathrm{vol} \%$ saltcake/salt slurry solids.

$\mathrm{SL}=$ sludge solids, at least 75 vol\% sludge solids.

$\mathrm{SST}=$ single-shell tank.

Table 5-2 lists the tanks that have a median buoyancy ratio near to or greater than 1 . These tanks include the historic BDGRE tanks plus 241-AN-107, which, to date, has not exhibited BDGRE behavior. DSTs 241-AN-103, 241-AN-104, 241-AN-105, 241-AW-101 and 241-SY-103 exhibit BDGRE behavior and are waste group A tanks.

DST 241-AN-107 has a buoyancy ratio greater than 1 due to the small differences between the convective and nonconvective layer densities. However, it has a very low gas retention rate and has not exhibited any BDGRE behavior to date. The tank does not contain sufficient retained gas to reach $100 \%$ LFL and, therefore, is classified as a waste group C tank. Historically only DSTs 241-AN-103, 241-AN-104, 241-AN-105, 241-AW-101, 241-SY-101 (pre-mitigation), and 241-SY-103 have documented cases of BDGRE behavior (RPP-6655). 


\section{RPP-10006 REV 8}

Table 5-2. Indicators of Buoyant Displacement Gas Release Event Behavior.

\begin{tabular}{|c|c|c|c|c|c|c|}
\hline Tank & {$[\% \mathbf{A}]$} & {$[\% \mathrm{~B}]$} & {$[\% \mathrm{C}]$} & $\begin{array}{c}\underset{\text { Energy ratio }}{\text { (dimensionless })} \\
(95 \% \mathrm{CL})\end{array}$ & $\begin{array}{c}\text { Buoyancy ratio } \\
\text { (dimensionless) } \\
\text { (Median) }\end{array}$ & $\begin{array}{c}\text { Buoyancy ratio } \\
\text { (dimensionless }) \\
(95 \% \mathrm{CL})\end{array}$ \\
\hline 241-AN-103 & 33.98 & 5.84 & 60.18 & 23.26 & 2.45 & 22.18 \\
\hline 241-AN-104 & 50.32 & 0.78 & 48.90 & 29.11 & 3.07 & 22.74 \\
\hline 241-AN-105 & 67.10 & 0.16 & 32.74 & 30.22 & 3.11 & 25.93 \\
\hline 241-AN-107 & 0.00 & 0.00 & 100.00 & 46.19 & 1.49 & 12.22 \\
\hline 241-AW-101 & 16.28 & 7.02 & 76.70 & 41.36 & 2.08 & 20.05 \\
\hline 241-SY-103 & 7.40 & 1.66 & 90.94 & 10.69 & 2.52 & 21.11 \\
\hline \multicolumn{7}{|c|}{$\begin{array}{lll}\text { Notes: } & 95 \% \text { CL } & =95 \% \text { confidence level. } \\
\text { LFL } & =\text { lower flammability limit. } \\
\text { NCL } & =\text { nonconvective layer. } \\
\text { DST } & =\text { double-shell tank. }\end{array}$} \\
\hline
\end{tabular}

\subsubsection{Double-Shell Tanks}

As shown in Table 5-3, 16 of the 28 DSTs are currently classified as waste group C tanks. For these 16 DSTs, even if $100 \%$ of the retained gas is released, the headspace flammable gas concentration will not exceed $100 \%$ LFL at a 95\% confidence level. Six DSTs, 241-AN-102, 241-AP-108, 241-AW-104, 241-AW-106, 241-AY-102, and 241-SY-101 are classified as waste group B tanks based on the model for the "as is" condition. Tank 241-AP-105 will conservatively remain a Waste group B tank even though the Waste group calculation shows it to be a Waste group C tank. Future operations to tank 241-AP-105 may change the "as is" waste group category as waste additions decrease headspace volume. Five DSTs, 241-AN-103, 241-AN-104, 241-AN-105, 241-AW-101 and 241-SY-103, based on this evaluation are classified as waste group A tanks.

In all cases, up to $10,000 \mathrm{gal}$ of water or $500 \mathrm{gal}$ of $8 \mathrm{M}$ caustic, can be added to the DSTs during routine operations without affecting the waste groupings as summarized in Table 5-3.

Table 5-3. Waste Group Assignments for Double-Shell Tanks.

\begin{tabular}{|c|c|c|c|}
\hline Tank & “As is" condition & $\begin{array}{c}\mathbf{1 0 , 0 0 0} \text { gal } \\
\mathbf{H}_{2} \mathbf{O} \text { addition }\end{array}$ & $\begin{array}{c}\mathbf{5 0 0} \text { gal caustic } \\
\text { addition }\end{array}$ \\
\hline $241-\mathrm{AN}-101$ & $\mathrm{C}$ & $\mathrm{C}$ & $\mathrm{C}$ \\
\hline $241-\mathrm{AN}-102$ & $\mathrm{~B}$ & $\mathrm{~B}$ & $\mathrm{~B}$ \\
\hline $241-\mathrm{AN}-103$ & $\mathrm{~A}$ & $\mathrm{~A}$ & $\mathrm{~A}$ \\
\hline $241-\mathrm{AN}-104$ & $\mathrm{~A}$ & $\mathrm{~A}$ & $\mathrm{~A}$ \\
\hline $241-\mathrm{AN}-105$ & $\mathrm{~A}$ & $\mathrm{~A}$ & $\mathrm{~A}$ \\
\hline $241-\mathrm{AN}-106$ & $\mathrm{C}$ & $\mathrm{C}$ & $\mathrm{C}$ \\
\hline
\end{tabular}


Table 5-3. Waste Group Assignments for Double-Shell Tanks.

\begin{tabular}{|c|c|c|c|}
\hline Tank & "As is" condition & $\begin{array}{c}10,000 \text { gal } \\
\mathrm{H}_{2} \mathrm{O} \text { addition }\end{array}$ & $\begin{array}{c}500 \text { gal caustic } \\
\text { addition }\end{array}$ \\
\hline 241-AN-107 & $\mathrm{C}$ & $\mathrm{C}$ & $\mathrm{C}$ \\
\hline 241-AP-101 & $\mathrm{C}$ & $\mathrm{C}$ & $\mathrm{C}$ \\
\hline 241-AP-102 & $\mathrm{C}$ & $\mathrm{C}$ & $\mathrm{C}$ \\
\hline 241-AP-103 & $\mathrm{C}$ & $\mathrm{C}$ & $\mathrm{C}$ \\
\hline 241-AP-104 & $\mathrm{C}$ & $\mathrm{C}$ & $\mathrm{C}$ \\
\hline 241-AP-105* & $\mathrm{C}$ & $\mathrm{C}$ & $\mathrm{C}$ \\
\hline 241-AP-106 & $\mathrm{C}$ & $\mathrm{C}$ & $\mathrm{C}$ \\
\hline 241-AP-107 & $\mathrm{C}$ & $\mathrm{C}$ & $\mathrm{C}$ \\
\hline 241-AP-108 & B & B & B \\
\hline 241-AW-101 & $\mathrm{A}$ & $\mathrm{A}$ & $\mathrm{A}$ \\
\hline 241-AW-102 & $\mathrm{C}$ & $\mathrm{C}$ & $\mathrm{C}$ \\
\hline 241-AW-103 & $\mathrm{C}$ & $\mathrm{C}$ & $\mathrm{C}$ \\
\hline 241-AW-104 & $\mathrm{B}$ & $\mathrm{B}$ & $\mathrm{B}$ \\
\hline 241-AW-105 & $\mathrm{C}$ & $\mathrm{C}$ & $\mathrm{C}$ \\
\hline 241-AW-106 & $\mathrm{B}$ & $\mathrm{B}$ & $\mathrm{B}$ \\
\hline 241-AY-101 & $\mathrm{C}$ & $\mathrm{C}$ & $\mathrm{C}$ \\
\hline $241-\mathrm{AY}-102$ & $\mathrm{~B}$ & $\mathrm{~B}$ & $\mathrm{~B}$ \\
\hline 241-AZ-101 & $\mathrm{C}$ & $\mathrm{C}$ & $\mathrm{C}$ \\
\hline 241-AZ-102 & $\mathrm{C}$ & $\mathrm{C}$ & $\mathrm{C}$ \\
\hline 241-SY-101 & $\mathrm{B}$ & $\mathrm{B}$ & $\mathrm{B}$ \\
\hline 241-SY-102 & $\mathrm{C}$ & $\mathrm{C}$ & $\mathrm{C}$ \\
\hline 241-SY-103 & $\mathrm{A}$ & A & A \\
\hline
\end{tabular}

Notes: * Evaluation of tank 241-AP-105 resulted in a waste group C designation for all three scenarios. However the tank will conservatively remain a waste group B tank

(See section 5.1.1).

\subsubsection{Single-Shell Tanks}

A review of BBI update reports shows that data for most of the SSTs has remained unchanged over the past year. For these tanks, previous results are still valid and remain unchanged. However, waste heights for C-108, C-109, S-102, and S-112 indicate a potentially significant change. These tanks were reevaluated and incorporated into Table 5-4.

Tanks were evaluated based on the "worst case" conditions. For waste group C tanks, even if $100 \%$ of the retained gas is released, the headspace flammable gas concentration will not exceed $100 \% \mathrm{LFL}$ at a $95 \%$ confidence level. For waste group B tanks, the headspace flammable gas concentration can reach $100 \%$ of the LFL if all of the retained gas is released at a $95 \%$ 
RPP-10006 REV 8

confidence level. None of the SSTs that could reach $100 \%$ LFL in the headspace have energy ratios $\geq 3$.

Table 5-4. Waste Group Assignments for Single-Shell Tanks. (2 sheets)

\begin{tabular}{|c|c|c|c|c|c|}
\hline Tank & $\begin{array}{l}\text { "As is" } \\
\text { condition }\end{array}$ & $\begin{array}{c}10,000 \text { gal } \\
\text { water } \\
\text { addition }^{a}\end{array}$ & Tank & $\begin{array}{l}\text { "As is" } \\
\text { condition }\end{array}$ & $\begin{array}{c}10,000 \text { gal } \\
\text { water addition }\end{array}$ \\
\hline $241-\mathrm{A}-101$ & B & B & $241-S-110$ & B & B \\
\hline $241-\mathrm{A}-102$ & $\mathrm{C}$ & $\mathrm{C}$ & $241-S-111$ & B & B \\
\hline $241-\mathrm{A}-103$ & $\mathrm{C}$ & $\mathrm{C}$ & $241-\mathrm{S}-112^{*}$ & $\mathrm{C}$ & $\mathrm{C}$ \\
\hline 241-A-104 & $\mathrm{C}$ & $\mathrm{C}$ & 241-SX-101 & B & $\mathrm{B}$ \\
\hline $241-\mathrm{A}-105$ & $\mathrm{C}$ & $\mathrm{C}$ & $241-\mathrm{SX}-102$ & B & B \\
\hline $241-\mathrm{A}-106$ & $\mathrm{C}$ & $\mathrm{C}$ & $241-\mathrm{SX}-103$ & $\bar{B}$ & B \\
\hline $241-\mathrm{AX}-101$ & $\mathrm{C}$ & $\mathrm{C}$ & 241-SX-104 & B & B \\
\hline $241-\mathrm{AX}-102$ & $\mathrm{C}$ & $\mathrm{C}$ & $241-\mathrm{SX}-105$ & $\mathrm{C}$ & $\mathrm{C}$ \\
\hline $241-\mathrm{AX}-103$ & $\mathrm{C}$ & $\mathrm{C}$ & $241-\mathrm{SX}-106$ & $\mathrm{C}$ & $\bar{B}$ \\
\hline $241-\mathrm{AX}-104$ & $\mathrm{C}$ & $\mathrm{C}$ & 241-SX-107 & $\mathrm{C}$ & $\mathrm{C}$ \\
\hline 241-B-101 & $\mathrm{C}$ & $\mathrm{C}$ & 241-SX-108 & $\mathrm{C}$ & $\mathrm{C}$ \\
\hline $241-B-102$ & $\mathrm{C}$ & $\mathrm{C}$ & 241-SX-109 & $\mathrm{C}$ & $\mathrm{C}$ \\
\hline 241-B-103 & $\mathrm{C}$ & $\mathrm{C}$ & 241-SX-110 & $\mathrm{C}$ & $\mathrm{C}$ \\
\hline 241-B-104 & $\mathrm{C}$ & $\mathrm{C}$ & 241-SX-111 & $\mathrm{C}$ & $\mathrm{C}$ \\
\hline $241-B-105$ & $\mathrm{C}$ & $\mathrm{C}$ & $241-\mathrm{SX}-112$ & $\mathrm{C}$ & $\mathrm{C}$ \\
\hline $241-B-106$ & $\mathrm{C}$ & $\mathrm{C}$ & $241-\mathrm{SX}-113$ & $\mathrm{C}$ & $\mathrm{C}$ \\
\hline 241-B-107 & $\mathrm{C}$ & $\mathrm{C}$ & 241-SX-114 & $\mathrm{C}$ & $\mathrm{C}$ \\
\hline $241-B-108$ & $\mathrm{C}$ & $\mathrm{C}$ & $241-\mathrm{SX}-115$ & $\mathrm{C}$ & $\mathrm{C}$ \\
\hline 241-B-109 & $\mathrm{C}$ & $\mathrm{C}$ & 241-T-101 & $\mathrm{C}$ & $\mathrm{C}$ \\
\hline $241-B-110$ & $\mathrm{C}$ & $\mathrm{C}$ & $241-\mathrm{T}-102$ & $\mathrm{C}$ & $\mathrm{C}$ \\
\hline $241-B-111$ & $\mathrm{C}$ & $\mathrm{C}$ & $241-\mathrm{T}-103$ & $\mathrm{C}$ & $\mathrm{C}$ \\
\hline $241-B-112$ & $\mathrm{C}$ & $\mathrm{C}$ & 241-T-104 & $\mathrm{C}$ & $\mathrm{C}$ \\
\hline $241-B-201$ & B & B & 241-T-105 & $\mathrm{C}$ & $\mathrm{C}$ \\
\hline $241-B-202$ & $\mathrm{C}$ & $\mathrm{B}$ & $241-\mathrm{T}-106$ & $\mathrm{C}$ & $\mathrm{C}$ \\
\hline $241-B-203$ & B & B & 241-T-107 & $\mathrm{C}$ & $\mathrm{C}$ \\
\hline 241-B-204 & B & B & 241-T-108 & $\mathrm{C}$ & $\mathrm{C}$ \\
\hline $241-B X-101$ & $\mathrm{C}$ & $\mathrm{C}$ & 241-T-109 & $\mathrm{C}$ & $\mathrm{C}$ \\
\hline $241-\mathrm{BX}-102$ & $\mathrm{C}$ & $\mathrm{C}$ & $241-\mathrm{T}-110$ & $\mathrm{C}$ & $\mathrm{C}$ \\
\hline $241-B X-103$ & $\mathrm{C}$ & $\mathrm{C}$ & 241-T-111 & B & B \\
\hline $241-B X-104$ & $\mathrm{C}$ & $\mathrm{C}$ & $241-\mathrm{T}-112$ & $\mathrm{C}$ & $\mathrm{C}$ \\
\hline $241-B X-105$ & $\mathrm{C}$ & $\mathrm{C}$ & $241-\mathrm{T}-201$ & B & B \\
\hline 241-BX-106 & $\mathrm{C}$ & $\mathrm{C}$ & $241-\mathrm{T}-202$ & $\mathrm{C}$ & $\mathrm{C}$ \\
\hline $241-B X-107$ & $\mathrm{C}$ & $\mathrm{C}$ & $241-\mathrm{T}-203$ & B & B \\
\hline 241-BX-108 & $\mathrm{C}$ & $\mathrm{C}$ & 241-T-204 & B & B \\
\hline 241-BX-109 & $\mathrm{C}$ & $\mathrm{C}$ & 241-TX-101 & $\mathrm{C}$ & $\mathrm{C}$ \\
\hline $241-B X-110$ & $\mathrm{C}$ & $\mathrm{C}$ & $241-\mathrm{TX}-102$ & $\mathrm{C}$ & $\mathrm{C}$ \\
\hline 241-BX-111 & $\mathrm{C}$ & $\mathrm{C}$ & 241-TX-103 & $\mathrm{C}$ & $\mathrm{C}$ \\
\hline 241-BX-112 & $\mathrm{C}$ & $\mathrm{C}$ & 241-TX-104 & $\mathrm{C}$ & $\mathrm{C}$ \\
\hline 241-BY-101 & $\mathrm{B}$ & $\mathrm{B}$ & 241-TX-105 & $\mathrm{B}$ & $\mathrm{B}$ \\
\hline $241-B Y-102$ & $\mathrm{C}$ & $\mathrm{C}$ & 241-TX-106 & B & B \\
\hline 241-BY-103 & B & B & 241-TX-107 & $\mathrm{C}$ & $\mathrm{C}$ \\
\hline 241-BY-104 & $\mathrm{B}$ & $\mathrm{B}$ & 241-TX-108 & $\mathrm{C}$ & $\mathrm{C}$ \\
\hline $241-B Y-105$ & B & B & 241-TX-109 & $\mathrm{C}$ & $\mathrm{C}$ \\
\hline 241-BY-106 & B & B & 241-TX-110 & $\mathrm{C}$ & $\mathrm{C}$ \\
\hline 241-BY-107 & $\mathrm{C}$ & $\mathrm{C}$ & 241-TX-111 & $\mathrm{C}$ & $\mathrm{B}$ \\
\hline
\end{tabular}


RPP-10006 REV 8

Table 5-4. Waste Group Assignments for Single-Shell Tanks. (2 sheets)

\begin{tabular}{|c|c|c|c|c|c|}
\hline Tank & $\begin{array}{l}\text { "As is" } \\
\text { condition }\end{array}$ & $\begin{array}{c}10,000 \text { gal } \\
\text { water } \\
\text { addition }^{a}\end{array}$ & Tank & $\begin{array}{l}\text { "As is" } \\
\text { condition }\end{array}$ & $\begin{array}{c}10,000 \text { gal } \\
\text { water addition }^{a}\end{array}$ \\
\hline 241-BY-108 & $\mathrm{C}$ & $\mathrm{C}$ & 241-TX-112 & B & B \\
\hline 241-BY-109 & $\mathrm{B}$ & $\mathrm{B}$ & $241-\mathrm{TX}-113$ & $\mathrm{~B}$ & $\mathrm{~B}$ \\
\hline $241-B Y-110$ & B & B & 241-TX-114 & B & B \\
\hline 241-BY-111 & $\mathrm{C}$ & B & $241-\mathrm{TX}-115$ & B & B \\
\hline $241-B Y-112$ & $\mathrm{C}$ & $\mathrm{C}$ & $241-\mathrm{TX}-116$ & B & $\bar{B}$ \\
\hline 241-C-101 & $\mathrm{C}$ & $\mathrm{C}$ & 241-TX-117 & $\mathrm{C}$ & $\mathrm{C}$ \\
\hline $241-\mathrm{C}-102$ & $\mathrm{C}$ & $\mathrm{C}$ & 241-TX-118 & $\mathrm{C}$ & $\mathrm{C}$ \\
\hline $241-C-103$ & $\mathrm{C}$ & $\mathrm{C}$ & 241-TY-101 & $\mathrm{C}$ & $\mathrm{C}$ \\
\hline 241-C-104 & $\mathrm{C}$ & $\mathrm{C}$ & $241-\mathrm{TY}-102$ & $\mathrm{C}$ & $\mathrm{C}$ \\
\hline 241-C-105 & $\mathrm{C}$ & $\mathrm{C}$ & 241-TY-103 & $\mathrm{C}$ & $\mathrm{C}$ \\
\hline $241-\mathrm{C}-106$ & $\mathrm{C}$ & $\mathrm{C}$ & 241-TY-104 & $\mathrm{C}$ & $\mathrm{C}$ \\
\hline 241-C-107 & $\mathrm{C}$ & $\mathrm{C}$ & 241-TY-105 & $\mathrm{C}$ & $\mathrm{C}$ \\
\hline $241-\mathrm{C}-108^{*}$ & $\mathrm{C}$ & $\mathrm{C}$ & 241-TY-106 & $\mathrm{C}$ & $\mathrm{C}$ \\
\hline $241-\mathrm{C}-109^{*}$ & $\mathrm{C}$ & $\mathrm{C}$ & 241-U-101 & $\mathrm{C}$ & $\mathrm{C}$ \\
\hline $241-\mathrm{C}-110$ & $\mathrm{C}$ & $\mathrm{C}$ & 241-U-102 & B & B \\
\hline 241-C-111 & $\mathrm{C}$ & $\mathrm{C}$ & 241-U-103 & $\mathrm{C}$ & $\mathrm{C}$ \\
\hline $241-\mathrm{C}-112$ & $\mathrm{C}$ & $\mathrm{C}$ & 241-U-104 & $\mathrm{C}$ & $\mathrm{C}$ \\
\hline $241-\mathrm{C}-201$ & $\mathrm{C}$ & $\mathrm{C}$ & 241-U-105 & B & B \\
\hline $241-\mathrm{C}-202$ & $\mathrm{C}$ & $\mathrm{C}$ & 241-U-106 & $\mathrm{C}$ & $\mathrm{C}$ \\
\hline $241-\mathrm{C}-203$ & $\mathrm{C}$ & $\mathrm{C}$ & 241-U-107 & $\mathrm{C}$ & $\mathrm{C}$ \\
\hline $241-C-204$ & $\mathrm{C}$ & $\mathrm{C}$ & 241-U-108 & B & B \\
\hline $241-S-101$ & $\mathrm{C}$ & $\mathrm{C}$ & 241-U-109 & $\mathrm{C}$ & $\mathrm{C}$ \\
\hline $241-S-102 *$ & $\mathrm{C}$ & $\mathrm{C}$ & 241-U-110 & $\mathrm{C}$ & $\mathrm{C}$ \\
\hline $241-S-103$ & B & B & 241-U-111 & B & B \\
\hline 241-S-104 & B & B & 241-U-112 & $\mathrm{C}$ & $\mathrm{C}$ \\
\hline $241-S-105$ & $\mathrm{C}$ & $\mathrm{C}$ & 241-U-201 & $\mathrm{C}$ & $\mathrm{C}$ \\
\hline 241-S-106 & $\mathrm{C}$ & $\mathrm{C}$ & $241-\mathrm{U}-202$ & $\mathrm{C}$ & $\mathrm{C}$ \\
\hline $241-S-107$ & $\mathrm{C}$ & $\mathrm{C}$ & 241-U-203 & $\mathrm{C}$ & $\mathrm{C}$ \\
\hline $241-S-108$ & B & B & 241-U-204 & $\mathrm{C}$ & $\mathrm{C}$ \\
\hline 241-S-109 & B & B & & & \\
\hline
\end{tabular}

Notes: *Tank re-evaluated for this revision.

${ }^{a}$ In 200 -series tanks only 1,000 gal of water are added.

$\mathrm{SST}=$ single-shell tank.

There are three tanks that would change classification based on the addition of 10,000 gal (or $1,000 \mathrm{gal}$ for 200 -series tanks) of water to the tanks.

Since the current condition of SSTs precludes the formation of a waste group A tank (i.e., the tanks contain little or no supernatant) and since the tanks are inactive unless subject to retrieval, a routine annual re-evaluation of the SSTs will not occur in the future unless there is a significant change in tank properties, as identified from a review of published Best-Basis Inventory changes. The tanks will be re-evaluated prior to any planned retrieval activity. 
RPP-10006 REV 8

This page intentionally left blank.

$5-12$ 


\section{RPP-10006 REV 8}

\subsection{REFERENCES}

HNF-SP-1193, 1997, Flammable Gas Project Topical Report, Rev. 2, DE\&S Hanford Company, Inc., Richland, Washington.

OSD-T-151-00007, 2007, Operating Specifications for the Double-Shell Storage Tanks, Rev. 1, CH2M HILL Hanford Group, Inc., Richland, Washington.

OSD-T-151-00013, 2006, Operating Specifications for Single-Shell Waste Storage Tanks, Rev. 1, CH2M HILL Hanford Group, Inc., Richland, Washington.

PNNL-11296, 1996, In Situ Rheology and Gas Volume in Hanford Double-Shell Waste Tanks, Pacific Northwest National Laboratory, Richland, Washington.

PNNL-11391, 1996, Gas Retention and Release Behavior in Hanford Single-Shell Waste Tanks, Pacific Northwest National Laboratory, Richland, Washington.

PNNL-11536, 1997, Gas Retention and Release Behavior in Double-Shell Waste Tanks, Rev. 1, Pacific Northwest National Laboratory, Richland, Washington.

PNNL-13337, 2001, Preventing Buoyant Displacement Gas Release Events in Hanford Double-Shell Waste Tanks, Pacific Northwest National Laboratory, Richland, Washington.

PNNL-13781, 2005, Effects of Globally Waste-Disturbing Activities on Gas Generation, Retention, and Release in Hanford Waste Tanks, Rev. 3, Pacific Northwest National Laboratory, Richland, Washington.

PNNL-13782, 2002, Analysis of Induced Gas Releases During Retrieval of Hanford Double-Shell Tank Waste, Rev. 1, Pacific Northwest National Laboratory, Richland, Washington.

PNNL-15238, 2005, Predicting Peak Hydrogen Concentrations from Spontaneous Gas Releases in Hanford Waste Tanks, Rev. 0, Pacific Northwest National Laboratory, Richland, Washington.

RPP-5926, 2000, Steady-State Flammable Gas Release Rate Calculation and Lower Flammability Level Evaluation for Hanford Tank Waste, Rev. 0, CH2M HILL Hanford Group, Inc., Richland, Washington.

RPP-5926, 2008, Steady-State Flammable Gas Release Rate Calculation and Lower Flammability Level Evaluation for Hanford Tank Waste, Rev. 8, Washington River Protection Solutions LLC, Richland, Washington.

RPP-6517, 2000, Evaluation of Hanford High-Level Waste Tank 241-SY-101, Rev. 0, CH2M HILL Hanford Group, Inc., Richland, Washington. 


\section{RPP-10006 REV 8}

RPP-6655, 2000, Data Observations on Double-Shell Flammable Gas Watchlist Tank Behavior, Rev. 0, CH2M HILL Hanford Group, Inc., Richland, Washington.

RPP-7249, 2001, Data and Observations of Single-Shell Flammable Gas Watch List Tank Behavior, Rev. 0, CH2M HILL Hanford Group, Inc., Richland, Washington.

RPP-7625, 2008, Best-Basis Inventory Process Requirements, Rev. 8, CH2M HILL Hanford Group, Inc., Richland, Washington.

RPP-7771, 2001, Flammable Gas Safety Issue Resolution, Rev. 0-A, CH2M HILL Hanford Group, Inc., Richland, Washington.

RPP-10006, 2006, Methodology and Calculations for the Assignment of Waste Groups for the Large Underground Waste Storage Tanks at the Hanford Site, Rev. 5, CH2M HILL Hanford Group, Inc., Richland, Washington.

RPP-13019, 2003, Determination of Hanford Waste Tank Volumes, Rev. 0, CH2M HILL Hanford Group, Inc., Richland, Washington.

RPP-15488, 2004, Investigation of Tank Void Fraction Using Liquid Level Response to Atmospheric Pressure Changes, Rev. 0, CH2M HILL Hanford Group, Inc., Richland, Washington.

RPP-21336, 2004, Flammable Gas Waste Group Assessment FY-2004-ENG-S-0133, Rev. 0, CH2M HILL Hanford Group, Inc., Richland, Washington.

RPP-29121, 2006, Spreadsheet Description Document for RPP-10006 R5 Tank Physical Data 060208.xls, Rev. 0, CH2M HILL Hanford Group, Inc., Richland, Washington.

RPP-29166, 2006, Spreadsheet Description Document For SVF-1112 All Solids RO.XLS, Rev. 0, CH2M HILL Hanford Group, Inc., Richland, Washington.

RPP-29167, 2006, Spreadsheet Description Document for RPP-10006 Rey 5 Data Rebuild 060306.xls, Rev. 0, CH2M HILL Hanford Group, Inc., Richland, Washington.

RPP-29388, 2006, Spreadsheet Description Document For 'SVF 1131 BPE to Void Fraction Master R0 060221 .xls', Rev. 0, CH2M HILL Hanford Group, Inc., Richland, Washington.

RPP-29389, 2006, Spreadsheet Description Document For 'RPP-10006r5 Void fraction revised data by tank - 060519 .xls', Rev. 0, CH2M HILL Hanford Group, Inc., Richland, Washington.

RPP-29581, 2006, Spreadsheet Description Document For '!!RPP-10006R5_Waste_Groups-rev-44-060420.xls', Rev. 0, CH2M HILL Hanford Group, Inc., Richland, Washington. 


\section{RPP-10006 REV 8}

SVF-1112, 2006, Spreadsheet Verification and Release Form for Spreadsheet 'SVF-1112 All Solids R0.xls', Rev. 0, CH2M HILL Hanford Group, Inc., Richland, Washington.

SVF-1117, 2006, Spreadsheet Verification and Release Form for Spreadsheet 'RPP-10006 R5 Tank Physical Data 060208.xls', Rev. 0, CH2M HILL Hanford Group, Inc., Richland, Washington.

SVF-1118, 2006, Spreadsheet Verification and Release Form for Spreadsheet 'RPP-10006 Rev 5 Data Rebuild 060306.xls', Rev. 0, CH2M HILL Hanford Group, Inc., Richland, Washington.

SVF-1123, 2006, Spreadsheet Verification and Release Form for Spreadsheet 'RPP-5926 Rev 5 Update for BDGRE.xls', Rev. 0, CH2M HILL Hanford Group, Inc., Richland, Washington.

SVF-1127, 2006, Spreadsheet Verification and Release Form for Spreadsheet '!!RPP-10006R5_Waste_Groups-rev-44-060420.xls', Rev. 0, CH2M HILL Hanford Group, Inc., Richland, Washington.

SVF-1131, 2006, Spreadsheet Verification and Release Form for Spreadsheet 'SVF 1131 BPE to Void Fraction Master R0 060221 .xls', Rev. 0, CH2M HILL Hanford Group, Inc., Richland, Washington.

SVF-1132, 2006, Spreadsheet Verification and Release Form for Spreadsheet 'RPP-10006r5 Void fraction revised data by tank - 060519.xls', Rev. 0, CH2M HILL Hanford Group, Inc., Richland, Washington.

TFC-ENG-DESIGN-C-32, 2006, Spreadsheet Development and Verification, Rev. B-3, CH2M HILL Hanford Group, Inc., Richland, Washington.

WHC-SD-WM-ER-526, 2001, Evaluation of Hanford Tanks for Trapped Gas, Rev. 1-E, CH2M HILL Hanford Group, Inc., Richland, Washington.

WHC-SD-WM-ER-594, 1996, Evaluation of Recommendation for Addition of Tanks to the Flammable Gas Watch List, Rev. 0, Westinghouse Hanford Company, Richland, Washington.

WHC-SD-WM-TI-755, 1996, An Analysis of Parameters Describing Gas Retention/Release Behavior in Double Shell Tank Waste, Rev. 0, CH2M HILL Hanford Group, Inc., Richland, Washington. 
RPP-10006 REV 8

This page intentionally left blank. 
RPP-10006 REV 8

APPENDIX A

WASTE TYPE ASSIGNMENT METHODOLOGY 
RPP-10006 REV 8

This page intentionally left blank.

A-ii 


\section{RPP-10006 REV 8}

\section{CONTENTS}

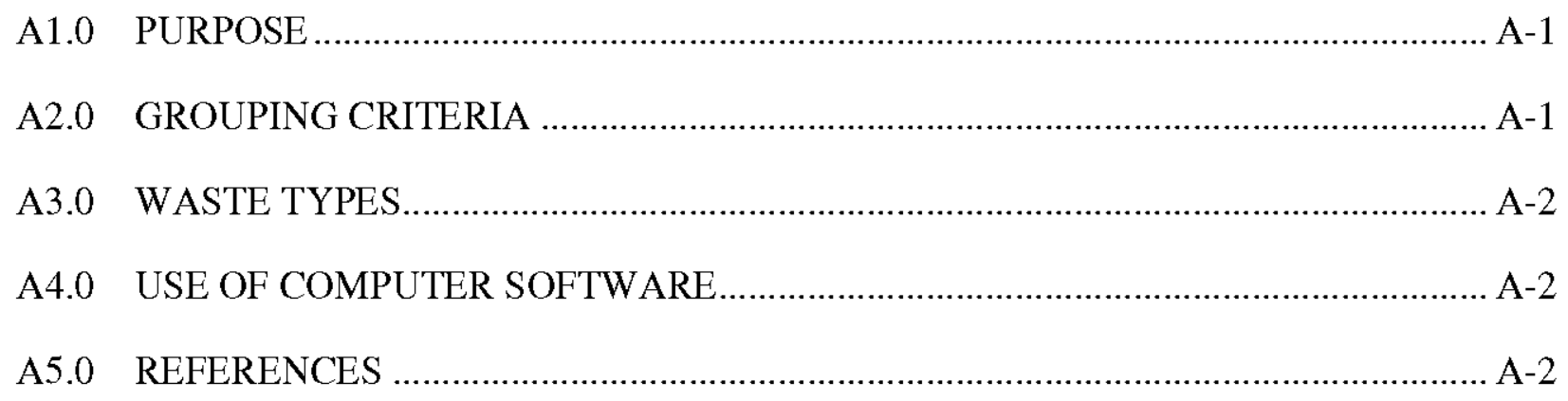

\section{TABLES}

Table A-1. Waste Grouping Criteria, from SNL-000198, Section 2.2.2.............................. A-1 


\section{LIST OF TERMS}

LIQ

MIX-LIQ

MIX-NL

$\mathrm{SC} / \mathrm{SS}$

SC/SS-LIQ

SC/SS-NL

SL

SL-LIQ

SL-NL

vol\% liquid waste form

mixed waste form with $\geq 1 \mathrm{~m}$ liquid over solids

mixed waste form with $<1 \mathrm{~m}$ liquid over solids

saltcake/salt slurry

saltcake/salt slurry waste form with $\geq 1 \mathrm{~m}$ liquid over solids

saltcake/salt slurry waste form with $<1 \mathrm{~m}$ liquid over solids

sludge

sludge waste form with $\geq 1 \mathrm{~m}$ liquid over solids

sludge waste form with $<1 \mathrm{~m}$ liquid over solids

volume percent 
RPP-10006 REV 8

APPENDIX A

WASTE TYPE EVALUATION

A1.0 PURPOSE

This appendix presents the tank waste type assignment methodology, based on the criteria in SNL-000198, Flammable Gas Safety Analysis Data Review. Updated input data for tank waste type assignment is based on the updated Best-Basis Inventory data for the tanks as reported in the most current revision of RPP-5926 unless indication of a solids layer in Appendix C suggests a more conservative waste type (i.e. tanks 241-AP-101, 241-AP-106 and 241-AP-107). The waste types presented are used in assigning variables to complete the flammable gas waste group calculations.

\section{A2.0 GROUPING CRITERIA}

SNL-000198 identifies seven possible waste forms and criteria for waste type assignment. Table A-1 presents the abbreviated waste types and definitions.

Table A-1. Waste Grouping Criteria, from

SNL-000198, Section 2.2.2.

\begin{tabular}{|l|l|}
\hline \multicolumn{1}{|c|}{ Waste Type } & \multicolumn{1}{c|}{ Definition } \\
\hline LIQ & Liquid waste with less than 3 vol\% solids \\
\hline MIX-LIQ & Mixed sludge-saltcake waste with $\geq 1 \mathrm{~m}$ liquid over solids \\
\hline MIX-NL & Mixed sludge-saltcake waste with $<1$ m liquid over solids \\
\hline SC/SS-LIQ & Saltcake/salt slurry waste with $\geq 1 \mathrm{~m}$ liquid over solids \\
\hline SC/SS-NL & Saltcake/salt slurry waste with $<1 \mathrm{~m}$ liquid over solids \\
\hline SL-LIQ & Sludge waste with $\geq 1 \mathrm{~m}$ liquid over solids \\
\hline SL-NL & Sludge waste with $<1 \mathrm{~m}$ liquid over solids \\
\hline \\
Note: \\
$\begin{array}{l}\text { SNL-000198, 1999, Flammable Gas Safety Analysis Data Review, Rev. 0, } \\
\text { Sandia National Laboratory, Albequerque, New Mexico. }\end{array}$
\end{tabular}

Liquid waste tanks have at least 97 vol\% liquids. Mixed waste tanks, with or without liquid, must be more than 3 vol\% solids and the solids composition must be less than $70 \mathrm{vol} \%$ of either type of solids. Saltcake/salt slurry tanks, with or without liquid, have greater than 3 vol\% solids and at least $70 \mathrm{vol} \%$ saltcake and/or salt slurry. Sludge tanks, with or without liquid, have greater than 3 vol\% solids and at least 70 vol\% sludge. 
RPP-10006 REV 8

\section{A3.0 WASTE TYPES}

Appendix $\mathrm{H}$ lists the assigned waste type for each tank.

\section{A4.0 USE OF COMPUTER SOFTWARE}

Waste type assignments for tanks updated in Revision 8 of this document are based on the waste phases reported in RPP-5926, Revision 7, Table A-2. A review of HNF-EP-0182, Rev. 247, Waste Tank Summary Report for Month Ending October 31, 2008, shows that none of the waste type assignments for the double shell tanks has changed. For the remaining tanks input data from the spreadsheet described below remains applicable.

Spreadsheet Verification Form Number: SVF-1117, Spreadsheet Verification \& Release Form for Spreadsheet RPP-10006 R5 Tank Physical Data 060208.xls

Base Software: Microsoft Excel ${ }^{1} 2003$

Spreadsheet Title: RPP-10006 R5 Tank Physical Data 060208.xls.

Document: RPP-29121, Spreadsheet Description Document for RPP-10006 R5 Tank Physical Data 060208.xls

Author: V.S. Anda

Purpose: Determination and compilation of the tank physical property data

\section{A5.0 REFERENCES}

HNF-EP-0182, 2008, Waste Tank Summary Report for Month Ending October 31, 2008, Rev. 247, Washington River Protection Solutions LLC, Richland, Washington

RPP-5926, 2007, Steady-State Flammable Gas Release Rate Calculation and Lower Flammability Level Evaluation for Hanford Tank Waste, Rev. 7, CH2M HILL Hanford Group, Inc., Richland, Washington.

RPP-6171, 2000, Determination Of Waste Groupings For Safety Analyses, Rev. 0, CH2M HILL Hanford Group, Inc., Richland, Washington.

RPP-29121, 2006, Spreadsheet Description Document for RPP-10006 R5 Tank Physical Data 060208.xls, Rev. 0, CH2M HILL Hanford Group, Inc., Richland, Washington.

\footnotetext{
${ }^{1}$ Excel is a registered trademark of Microsoft Corporation, Redmond, Washington.
} 


\section{RPP-10006 REV 8}

SNL-000198, 1999, Flammable Gas Safety Analysis Data Review, Rev. 0, Sandia National Laboratory, Albequerque, New Mexico.

SVF-1117, 2006, Spreadsheet Verification \& Release Form for Spreadsheet RPP-10006 R5 Tank Physical Data 060208.xls, Rev. 0, CH2M HILL Hanford Group, Inc., Richland, Washington. 
RPP-10006 REV 8

APPENDIX B

DENSITY EVALUATION

B-i 
RPP-10006 REV 8

This page intentionally left blank.

B-ii 


\section{RPP-10006 REV 8}

\section{CONTENTS}

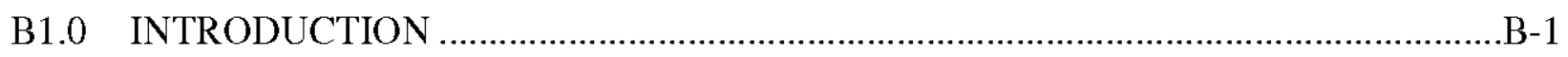

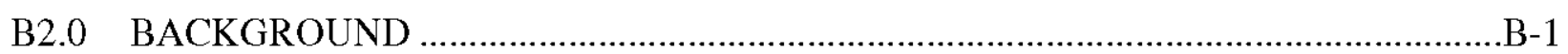

B3.0 DENSITY METHODOLOGY AND INPUT DATA …….............................................

B3.1 MONTE CARLO ANALYSIS APPROACH...............................................

B3.2 APPLIED DENSITY UNCERTAINTY ………..........................................

B3.3 DEVIATIONS IN MEAN DENSITY INPUTS ……………...........................

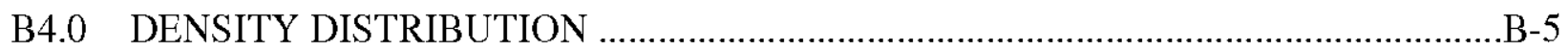

B4.1 RELATIVE STANDARD DEVIATION ………..........................................

B4.2 CONVECTIVE LAYER DENSITY DISTRIBUTION .......................................

B4.3 NONCONVECTIVE LAYER DENSITY DISTRIBUTION ..............................

B5.0 USE OF COMPUTER SOFTWARE ...............................................................................

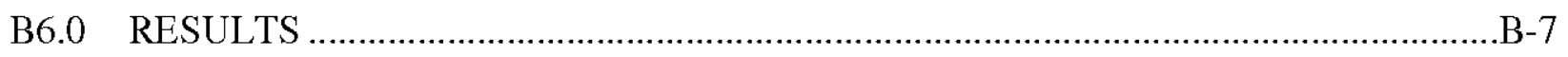

B6.1 DENSITY DISTRIBUTIONS ………………….....................................

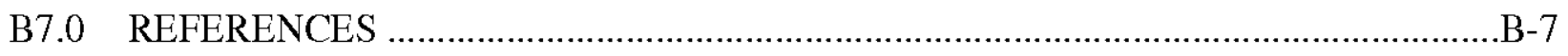

\section{TABLES}

Table B-1. Best-Basis Inventory Relative Standard Deviation (\%)

Versus Relative Error (\%). B-4 


\section{LIST OF TERMS}

BBI

CL

DST

LIQ

LL

Max

Min

MIX-LIQ

MIX-NL

NCL

PNNL

RSD

SC/SS

SC/SS-LIQ

SC/SS-NL

SL

SL-LIQ

SL-NL

SST

TWINS

UL
Best-Basis Inventory

convective layer (liquid)

double-shell tank

liquid waste form

lower limit

95\% upper limit

95\% lower limit

mixed waste form with $\geq 1 \mathrm{~m}$ liquid over solids

mixed waste form with $<1 \mathrm{~m}$ liquid over solids

nonconvective layer (solid)

Pacific Northwest National Laboratory

relative standard deviation

saltcake/salt slurry

saltcake/salt slurry waste form with $\geq 1 \mathrm{~m}$ liquid over solids

saltcake/salt slurry waste form with $<1 \mathrm{~m}$ liquid over solids

sludge

sludge waste form with $\geq 1 \mathrm{~m}$ liquid over solids

sludge waste form with $<1 \mathrm{~m}$ liquid over solids

single-shell tank

Tank Waste Information Network System

upper limit 
RPP-10006 REV 8

APPENDIX B

DENSITY EVALUATION

\section{B1.0 INTRODUCTION}

The purpose of this appendix is to document the methodology for determining the convective layer (CL) and nonconvective layer (NCL) density uncertainties, and distributions for use in the flammable gas waste group calculations. The results are based on evaluation of the data used for RPP-10006, Revision 5. However, the resulting uncertainties and distributions are not expected to change significantly. Therefore, results for calculating the density uncertainty and distribution will be used for subsequent revisions.

\section{B2.0 BACKGROUND}

A specialty assessment of the methodology of RPP-10006, Methodology and Calculations for the Waste Groups for Large Underground Waste Storage Tanks at the Hanford Site, for assigning flammable gas waste groups was undertaken in 2004 and is documented in RPP-21336, Flammable Gas Waste Group Assignment: FY2004-ENG-S-0133.

Observation 2 from RPP-21336 stated that:

Certain physical relationships are not accounted for in the calculation that make the output distribution of the Monte Carlo analysis artificially broad and create physically impossible states.

1. Independent selection of CL and NCL densities from their distributions in the Monte Carlo analysis allows density pairs that are not physically achievable.

2. Liquid and solid densities selected from the distribution may approach each other, artificially indicating an unphysical or improbable waste state.

3. The retained gas volume for screening Waste Group $\mathrm{C}$ tanks is not correctly limited by varying neutral buoyancy void fraction computed from the convective and non-convective layer densities selected during the calculation.

4. Available liquid SpG [specific gravity] data suggest that the default uncertainty (5\%) used in the calculation is larger than necessary. (RPP-21336) 
Items 1 and 2 relate to the calculation methodology and item 4 relates to input data for CL and NCL densities used in the analysis for calculating the flammable gas waste groups. Item 3 relates primarily to the way that void fraction is handled in the Monte Carlo analysis. Changes in methodology and input data for density as documented in Revision 5 of this document are described in this appendix. Void fraction determination is discussed in Appendix D.

\section{B3.0 DENSITY METHODOLOGY AND INPUT DATA}

\section{B3.1 MONTE CARLO ANALYSIS APPROACH}

In order to address items 1 and 2 from Observation 2 of RPP-21336 discussed above, changes were made in the waste group determination spreadsheet program to treat CL and NCL waste densities as correlated rather than treating these properties as completely independent. In order to reflect the inter-dependency between convective and nonconvective waste densities, a nonconvective waste density offset distribution was created. The distribution was determined by setting its mean as the difference between the mean convective waste density and the mean nonconvective waste density with a standard deviation equal to the nonconvective waste density standard deviation. The nonconvective waste density was constrained to be greater than the convective waste density by setting the nonconvective waste density equal to the sum of the convective waste density and the nonconvective waste density offset.

The RPP-10006, Rev. 5 database values were given for the mean, standard deviation, minimum value, and maximum value for the convective and nonconvective layer densities. A density offset distribution was created with a mean equal to the difference between the two density means. The density offset distribution was given the same standard deviation as the nonconvective layer density distribution, if one is given, if not, the convective layer density standard deviation was applied. The minimum of the offset was set to be the mean minus 2 times the standard deviation or $1 \mathrm{~kg} / \mathrm{m}^{3}$, whichever is greater. The maximum of the offset was set to be the mean plus 2 times the standard deviation.

During the simulation, a value is taken from the Monte Carlo distribution for the convective layer density and from the density offset distribution. The two values are added to determine the nonconvective layer density. This relationship guarantees that the nonconvective layer density is always at least $1 \mathrm{~kg} / \mathrm{m}^{3}$ greater than the convective layer density.

The methodology described above considers NCL density and void fraction as independent properties. This simplification is made for ease of calculation and due to lack of adequate data to support a more rigorous correlation of NCL density and void fraction. 


\section{B3.2 APPLIED DENSITY UNCERTAINTY}

In order to address item 4 from Observation 2 of RPP-21336 discussed above, a review of sample analysis data for density from the Tank Waste Information Network System (TWINS) was completed and published as part of RPP-10006, Rev. 4. The data review included sample analysis results for specific gravity, solids density, settled solids density, liquid density, density before centrifuging, density, and bulk density, with specific gravity and density assumed to be interchangeable for the purposes of the evaluation. Many data points were excluded from the data set based on criteria included in RPP-10006, Rev. 4, Appendix M. The evaluation documented in Appendix M of RPP-10006, Rev. 4, identified "...the overall uncertainty for density is about $5 \%$. However, for liquid densities the relative error is $3.3 \%$ and the relative error for the solids densities is 6.8\%." The relative error values generated for the waste types were compared to the Best-Basis Inventory (BBI) published relative standard deviation values in Table B-1.

The statement, "The BBI typically lists relative uncertainties for solid and liquid densities as 5\%," was included in RPP-10006, Rev. 4, Appendix M; however, a source was not referenced. A review of RPP-7625, Best-Basis Inventory Process Requirements, Appendix B, "Uncertainty Estimates for the BBI," identified the density uncertainty by tank and waste phase. Table B-1 contains summarized relative standard deviation (RSD) data from RPP-7625, Table B-8. RPP-7625 references RPP-6924, Statistical Methods for Estimating the Uncertainty in the Best Basis Inventories, which explains the methodology used to generate the density RSDs and discusses the number of data points utilized. 
RPP-10006 REV 8

Table B-1. Best-Basis Inventory Relative Standard Deviation (\%)

Versus Relative Error (\%).

\begin{tabular}{|l|c|c|c|}
\hline \multirow{2}{*}{ Layer } & \multicolumn{2}{|c|}{$\begin{array}{c}\text { Relative standard deviation (\%) } \\
\text { (RPP-7625, Rev. 6, Table B-8) }\end{array}$} & \multirow{2}{*}{$\begin{array}{c}\text { Relative error (\%) } \\
\text { (RPP-10006, Rev. 4) }\end{array}$} \\
\cline { 2 - 3 } & Single-shell tank & Double-shell tank & \\
\hline Convective Layer & 5.90 & 8.16 & 3.3 \\
\hline Nonconvective Layer & 7.55 & 6.50 & 6.8 \\
\hline
\end{tabular}

Notes:

RPP-7625, 2006, Best-Basis Inventory Process Requirements, Rev. 6, CH2M HILL Hanford Group, Inc., Richland, Washington.

RPP-10006, 2004, Methodology and Calculations for the Waste Groups for Large Underground Waste Storage Tanks at the Hanford Site, Rev. 4, CH2M HILL Hanford Group, Inc., Richland, Washington.

The mean CL and NCL densities used to calculate the flammable gas waste group assignments for most of the 177 tanks in this revision of RPP-10006 are taken from RPP-5926, Steady-State Flammable Gas Release Rate Calculation and Lower Flammability Level Evaluation for Hanford Tank Waste. RPP-5926 calculates bulk mean densities for the liquid (CL) and solid (NCL) layers. These bulk liquid and solid densities are based on a volume weighted average of the individual waste phase densities obtained from querying the BBI Tank Density and Percent Water report for the 177 tanks.

\section{B3.3 DEVIATIONS IN MEAN DENSITY INPUTS}

RPP-5926 is the source for the mean density inputs for all the SSTs and the DSTs except for DSTs 241-AP-104, 241-AP-106 and 241-AP-107. Although RPP-5926 identifies these tanks as containing no solids, the evaluation in Appendix $\mathrm{C}$ of this document indicates the tanks do contain solids. As a result the RPP-5926 solids bulk density data $(0 \mathrm{~g} / \mathrm{mL})$ cannot be applied for these tanks.

Tanks that do not have a bulk density reported in RPP-5926 are assigned the RPP-10006, Revision 5 value to enable completion of the calculation. The lack of a mean bulk density value signifies the related phase does not exist in the tank.

- Tank 241-AP-106 does not have a reported solid phase prior to RPP-10006, Revision 7. The assigned density and density distribution for tank 241-AP-106 solids are the same as assumed for tanks 241-AP-104 and 241-AP-107.

- A mean solids phase bulk density of $1.75 \mathrm{~g} / \mathrm{mL}$ is assigned as a default value to tanks that do not have a solid phase (241-AP-101).

- For tanks that have a mean solids bulk density reported to be less than the mean liquid bulk density (i.e., 241-BX-102), the mean solid phase bulk density place holder $(1.75 \mathrm{~g} / \mathrm{mL})$ is assigned. 
RPP-10006 REV 8

\section{B4.0 DENSITY DISTRIBUTION}

\section{B4.1 RELATIVE STANDARD DEVIATION}

The correct BBI RSD is determined based on the tank type, SST or DST, and waste phase, liquid or solid. The RSDs, as shown in Table B-1, are converted into standard deviations using Equations 4-1 and 4-2.
CL standard deviation $=$ CL mean $*$ RSD
Equation 4-1
NCL standard deviation $=$ NCL mean $*$ RSD
Equation 4-2

\section{B4.2 CONVECTIVE LAYER DENSITY DISTRIBUTION}

The convective layer density is assumed to be based on a normal distribution with a known variance. A 95\% confidence interval is applied to obtain the minimum and the maximum values. The $95 \%$ confidence interval equations specified in RPP-6924, Section 2.3, are based on assumption of a mean based on a normal distribution with a known variance.

The minimum or $95 \%$ lower limit is calculated following Equation 4-3 with the maximum or 95\% upper limit calculated following Equation 4-4. The equations are based on Equation 2-6 from RPP-6924, Section 2.3, but do not have the same variable references or multiplier order.

$$
\begin{array}{ll}
95 \% \text { Lower Limit }=\text { Mean }-(\text { Mean } \times \text { RSD x 1.96) } & \text { Equation 4-3 } \\
95 \% \text { Upper Limit }=\text { Mean }+(\text { Mean } \times \text { RSD x 1.96) } & \text { Equation 4-4 }
\end{array}
$$

The distribution generated based on Equations 4-3 and 4-4 is applied unless the lower limit for the liquid density falls below $1 \mathrm{~g} / \mathrm{mL}$. Calculated minimum liquid bulk densities less than $1 \mathrm{~g} / \mathrm{mL}$ are truncated at $1 \mathrm{~g} / \mathrm{mL}$ to maintain a realistic distribution.

\section{B4.3 NONCONVECTIVE LAYER DENSITY DISTRIBUTION}

The nonconvective layer density is calculated as the sum of the convective layer density and a density offset as shown in Equation 4-5.

$$
\text { NCL density = CL density + density offset }
$$

Equation 4-5

The mean density offset is equal to the difference between the convective and nonconvective mean densities as shown in Equation 4-6.

Density offset mean = NCL density mean - CL density mean $\quad$ Equation 4-6 
The calculated density offset is assumed to be represented by a normal distribution with a standard deviation equal to the nonconvective layer standard deviation. Equations 4-7 and 4-8 are used to generate the minimum and maximum for the density offset distribution. The minimum density offset value is truncated at $1 \mathrm{~kg} / \mathrm{m}^{3}$. Truncation of the minimum density offset ensures the convective layer density will be at least $1 \mathrm{~kg} / \mathrm{m}^{3}$ less than the nonconvective layer density.

$$
\begin{array}{ll}
\text { Minimum }=\text { Density offset mean }-(\text { NCL standard deviation } * 2) & \text { Equation 4-7 } \\
\text { Maximum }=\text { Density offset mean }+(\text { NCL standard deviation } * 2) & \text { Equation 4-8 }
\end{array}
$$

The nonconvective density is calculated during performance of the Monte Carlo simulation. The nonconvective layer density for the run is calculated as the sum of the convective layer density selected for the run plus the density offset value selected for the run. Equation 4-9 provides the mathematical formula.

NCL density $=$ CL density (from Monte Carlo) + Density offset (from Monte Carlo) Equation 4-9

\section{B5.0 USE OF COMPUTER SOFTWARE}

The waste types, convective layer density means, standard deviations, minimums and maximums, as well as the nonconvective layer density means and standard deviations reported in Revision 5 of this document were compiled from the spreadsheet described below.

Spreadsheet Verification Form Number: SVF-1117, Spreadsheet Verification \& Release Form for Spreadsheet RPP-10006 R5 Tank Physical Data 060208.xls

Base Software: Microsoft Excel ${ }^{1} 2003$

Spreadsheet Title: RPP-10006 R5 Tank Physical Data 060208.xls.

Document: RPP-29121, Spreadsheet Description Document for RPP-10006 R5 Tank Physical Data 060208.xls

Author: V.S. Anda

Purpose: Determination and compilation of the tank physical property data

\footnotetext{
${ }^{1}$ Excel is a registered trademark of Microsoft Corporation, Redmond, Washington.
} 


\section{RPP-10006 REV 8}

\section{B6.0 RESULTS}

\section{B6.1 DENSITY DISTRIBUTIONS}

Convective layer and non-convective density distributions for the current revision of RPP-10006 are presented in Appendix H.

\section{B7.0 REFERENCES}

PNNL-15238, 2005, Predicting Peak Hydrogen Concentrations from Spontaneous Gas Releases in Hanford Waste Tanks, Rev. 0, Pacific Northwest National Laboratory, Richland, Washington.

RPP-5926, 2007, Steady-State Flammable Gas Release Rate Calculation and Lower Flammability Level Evaluation for Hanford Tank Waste, Rev. 7, CH2M HILL Hanford Group, Inc., Richland, Washington.

RPP-6924, 2000, Statistical Methods for Estimating the Uncertainty in the Best Basis Inventories, Rev. 0, CH2M HILL Hanford Group, Inc., Richland, Washington.

RPP-7625, 2007, Best-Basis Inventory Process Requirements, Rev. 7, CH2M HILL Hanford Group, Inc., Richland, Washington.

RPP-10006, 2006, Methodology and Calculations for the Waste Groups for Large Underground Waste Storage Tanks at the Hanford Site, Rev. 5, CH2M HILL Hanford Group, Inc., Richland, Washington.

RPP-21336, 2004, Flammable Gas Waste Group Assignment: FY2004-ENG-S-0133, Rev. 0, CH2M HILL Hanford Group, Inc., Richland, Washington.

RPP-29121, 2006, Spreadsheet Description Document for RPP-10006 R5 Tank Physical Data 060208.xls, Rev. 0, CH2M HILL Hanford Group, Inc., Richland, Washington.

RPP-29581, 2006, Spreadsheet Description Document for '!!RPP-10006R5_Waste_Groups-Rev44-060420 .xls' and Associated Spreadsheets, Rev. 0, CH2M HILL Hanford Group, Inc., Richland, Washington.

SVF-1117, 2006, Spreadsheet Verification \& Release Form for Spreadsheet RPP-10006 R5 Tank Physical Data 060208.xls, Rev. 0, CH2M HILL Hanford Group, Inc., Richland, Washington. 
RPP-10006 REV 8

This page intentionally left blank.

B-8 
RPP-10006 REV 8

APPENDIX C

\section{WASTE LAYER HEIGHT AND UNCERTAINTY DETERMINATION}

C-i 
RPP-10006 REV 8

This page intentionally left blank.

C-ii 
RPP-10006 REV 8

\section{CONTENTS}

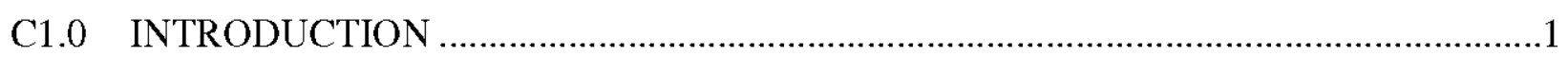

C2.0 TOTAL WASTE HEIGHT (SURFACE LEVEL) AND UNCERTAINTY ........................1

C3.0 DOUBLE-SHELL TANK CRUST LAYER HEIGHT AND UNCERTAINTY ..................2

C4.0 INTERSTITIAL LIQUID LAYER HEIGHT AND UNCERTAINTY .................................

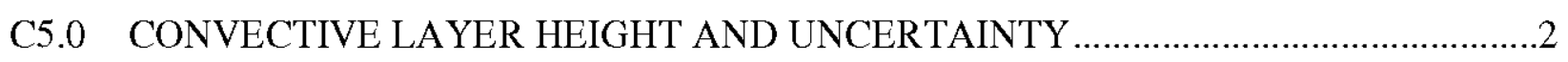

C6.0 NONCONVECTIVE LAYER HEIGHT AND UNCERTAINTY FOR SINGLE-

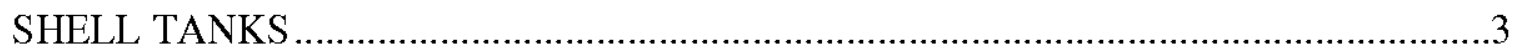

C7.0 NONCONVECTIVE LAYER HEIGHT AND UNCERTAINTY FOR DOUBLE-

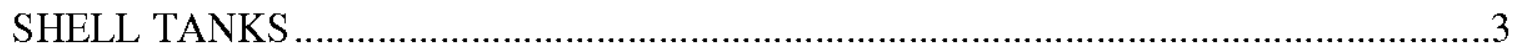

C7.1 DOUBLE-SHELL TANK NONCONVECTIVE LAYER HEIGHT AND

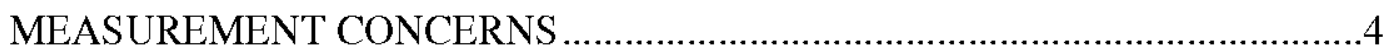

C7.2 NONCONVECTIVE LAYER HEIGHT MEASUREMENT METHODS ..............4

C7.2.1 Description of Measurement Methods ........................................................

C7.2.2 Effect of Waste Consistency on Measurement Uncertainty .......................

C7.2.3 Current Measurement Techniques Compared to Those Used to Develop Waste Group Methodology ........................................................9

C7.3 ACCOUNTING FOR BIAS BETWEEN MEASUREMENT

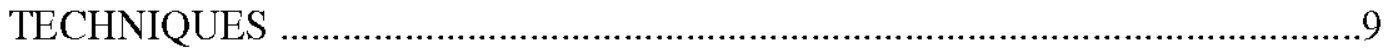

C7.4 UPDATING THE ANALYSIS MEANS AND MEASUREMENT UNCERTAINTIES (STANDARD DEVIATIONS) ……....................................10

C7.5 NONCONVECTIVE LAYER HEIGHTS AND VARIABILITIES FOR

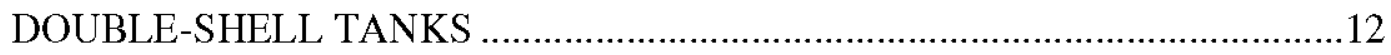

C7.6 OTHER CONSIDERATIONS................................................................13

C7.6.1 Effect of Multiple Riser Locations ........................................................13

C7.6.2 Changes in Solids Levels Over Time........................................................14

C7.7 SUMMARY OF DOUBLE-SHELL TANK NONCONVECTIVE LAYER

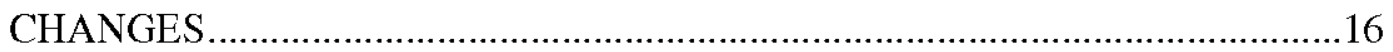

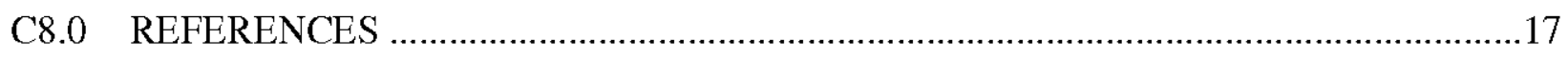

\section{FIGURES}

Figure C-1. Ball Rheometer Data for Nonconvective Layer Interface for Double-Shell Tank 241-AN-105 (Figure 2.5 of PNNL-11296). 


\section{RPP-10006 REV 8}

Figure C-2. Sediment Level History for Selected Risers, Double-Shell Tank 241-SY-102.

Figure C-3. Double-Shell Tank 241-AN-102 Solids History.

\section{TABLES}

Table C-1. Comparison of Densitometer and Sludge Weight Data............................................ 10

Table C-2. Summarized Statistical Data ${ }^{a}$. (2 sheets) …………………………................... 11

Table C-3. Nonconvective Layer Heights and Variances for Double-Shell Tank Waste Group Calculations............................................................................. 12

C-iv 


\section{RPP-10006 REV 8}

\section{LIST OF TERMS}

BBI

BDGRE

DST

Enraf

ILL

MIT

NCL

SACS

SST

TWINS
Best Basis Inventory

buoyant displacement gas release event

double-shell tank

Enraf Series 854 (gauge)

interstitial liquid level

multifunction instrument tree

nonconvective layer

Surveillance Analysis Computer System

single-shell tank

Tank Waste Information Network System 
RPP-10006 REV 8

This page intentionally left blank.

C-vi 
RPP-10006 REV 8

APPENDIX C

WASTE LAYER HEIGHT AND UNCERTAINTY DETERMINATION

\section{C1.0 INTRODUCTION}

The purpose of this appendix is to establish waste layer height estimates and uncertainties that are used in the flammable gas waste group calculations. Because of concerns about potential bias and measurement error in double-shell tank (DST) solids level measurement techniques, an extensive re-evaluation of the DST nonconvective layer (NCL) heights and height uncertainties was performed for Revision 5 of this document. This revision updates that evaluation.

The following sections describe the data used for waste layers, consisting of the total waste height, and the crust, convective layer, and NCL, as applicable. All waste layer data is assumed to be normally distributed, and will be evaluated in Monte Carlo calculations using mean and standard deviation data.

\section{C2.0 TOTAL WASTE HEIGHT (SURFACE LEVEL) AND UNCERTAINTY}

RPP-5926, Steady-State Flammable Gas Release Rate Calculation and Lower Flammability Level Evaluation for Hanford Tank Waste, compiles tank waste layer and total waste volumes from the Best-Basis Inventory (BBI). DST and single-shell tank (SST) total waste heights are calculated from volumes given in this reference. The total waste volumes are converted to height by applying standard tank dimension factors documented in Appendix B of RPP-7625, Best Basis Inventory Process Requirements, Rev. 8 (again, with exceptions noted below).

Total waste height uncertainty is the same as surface level uncertainty. For tanks with free liquid surfaces, the surface level uncertainty is assumed to be $0.25 \mathrm{in}$. This is the uncertainty assumed in Appendix B of RPP-7625 for tanks with an Enraf (Enraf Series 854 [gauge]) surface level measurement. This uncertainty applies to all of the DSTs except those with crusts (241-AN-103, 241-AN-104, 241-AN-105, 241-AW-101, and 241-SY-103). It is also assumed that this applies to all SSTs with free liquid (i.e., supernatant).

For the DST crust tanks, the surface level uncertainty is assumed to be the crust layer uncertainty. The crust layer uncertainty is derived from RPP-6655, Data Observations on Double-Shell Flammable Gas Watch List Tank Behavior, Table 5-1, which gives the crust height mean and range (e.g., $89 \pm 16 \mathrm{~cm}$ for 241-AN-103). Standard deviations are derived from the mean and range values in SVF-1118, Spreadsheet Verification and Release Form for Spreadsheet RPP-10006 Rev 5 Data Rebuild 060306.xls.

SSTs with no free liquid are assumed to have a surface level uncertainty of $11.5 \mathrm{in}$. based on the surface level uncertainty (standard deviation) calculated for saltcake tanks in RPP-7625. The 
reference indicates a smaller uncertainty for sludge tanks, but for this analysis, $11.5 \mathrm{in}$. is assumed regardless of waste type.

\section{C3.0 DOUBLE-SHELL TANK CRUST LAYER HEIGHT AND UNCERTAINTY}

Five DSTs have crust layers: 241-AN-103, 241-AN-104, 241-AN-105, 241-AW-101, and 241-SY-103. As described above, crust layer thicknesses are taken from RPP-6655, Table 5-1, which gives the crust height mean and range (e.g., $89 \pm 16 \mathrm{~cm}$ for 241-AN-103). Uncertainties (standard deviations) are derived from the mean and range values in SVF-1118.

\section{C4.0 INTERSTITIAL LIQUID LAYER HEIGHT AND UNCERTAINTY}

The interstitial liquid level (ILL) marks the top of the saturated (wetted) solids. It is assumed that only saturated solids can retain gas. For tanks that have little or no supernatant, the ILL may be below the average surface level. This configuration is seen in many SSTs due to saltwell pumping. Analyzing only the saturated solids volume rather than the total solids volume provides a more accurate, less conservative Waste Group calculation for tanks with this waste configuration.

ILL heights were taken from SACS (TWINS 2006) and consisted of the latest ILL measurement available for each tank as of November 22, 2005 (prior to the Revision 5 analysis). Relevant data were available for 76 SSTs (the ILL measurements for tanks 241-S-102 and 241-S-112 were not relevant since these tanks were being retrieved). A reevaluation of ILLs is not considered necessary for this revision.

If the ILL is lower than the NCL (see Section C6.0 for discussion of SST NCLs), then the ILL or saturated solids height is used in Waste Group calculations rather than the NCL height.

An uncertainty of $2.36 \mathrm{~cm}$ is applied to the ILL measurements. This is the maximum standard deviation for SST neutron ILL measurements reported in Appendix B of PNNL-11373, Flammable Gas Data Evaluation Report.

Finally, saturated NCL heights are constrained within certain limits to avoid physically impossible conditions in the Monte Carlo analysis. For DSTs, the lower limits are essentially zero $(0.01 \mathrm{~m}$ or less may be used to avoid calculational difficulties that can be encountered with zero values).

\section{C5.0 CONVECTIVE LAYER HEIGHT AND UNCERTAINTY}

Convective layer height is not determined independently. The convective layer height can be determined from the total layer height, the NCL height, and the crust height (if any). Convective 
layer height uncertainty is also considered a dependent variable, and is not calculated nor used in the Waste Group calculations.

\section{C6.0 NONCONVECTIVE LAYER HEIGHT AND UNCERTAINTY FOR SINGLE-SHELL TANKS}

Although uncertainty exists in NCL height for the SSTs, it is of less concern than for the DSTs because the SSTs no longer contain supernatant liquid and solids surfaces in SSTs are typically visible via camera. SST solids volumes in the BBI have typically been established from interim stabilization evaluations (HNF-SD-RE-TI-178, Single-Shell Tank Interim Stabilization Record), which took into account the surface topography of the waste on completion of interim stabilization. The lack of significant supernatant in SSTs also ensures that they cannot display buoyant displacement gas release event (BDGRE) behavior in their current configuration. Hence, a rigorous evaluation of SST NCL height uncertainty was not considered warranted and was not attempted.

For the purposes of this document, mean NCL heights for SSTs have been calculated based on the BBI solids volume and the tank diameter and dish dimensions. The actual NCL heights used as input data for the analysis are provided in Appendix $\mathrm{H}$.

A standard deviation of $11.5 \mathrm{in}$. was used as the uncertainty associated with SST NCL height. This uncertainty was based on the stated BBI surface level uncertainty for saltcake tanks taken from Appendix B of RPP-7625. The documented uncertainty for sludge tanks was less, so using the larger saltcake uncertainty for all SSTs is conservative.

Finally, NCL heights are constrained within certain limits to avoid physically impossible conditions in the Monte Carlo analysis. For DSTs, the lower limits are essentially zero (0.01 m or less may be used to avoid calculational difficulties that can be encountered with zero values).

\section{C7.0 NONCONVECTIVE LAYER HEIGHT AND UNCERTAINTY FOR DOUBLE-SHELL TANKS}

The waste configuration found in certain DSTs consisting of a large volume of concentrated supernatant on top of a large volume of settled solids is the only configuration in which BDGREs have actually occurred. Therefore, it is important to understand the volume of solids in the NCL, as this is a key factor in estimating the amount of gas that can be retained and released in a BDGRE. The DSTs are in active use for both routine transfers and as receiver tanks for solid wastes from SST retrievals and it is important to be able to preclude conditions that would result in BDGRE behavior. However, determining an accurate NCL height in the DSTs is inhibited by the presence of a supernatant liquid layer that prevents direct observation of the underlying solids layer. 
BBI solids volumes for the DSTs are based on solids level measurements from a variety of techniques. The primary techniques used are sludge weight, zip cord, Enraf densitometer, and Enraf surface device (programmed to submerge and detect the solids interface). Core sample extrusions formed the basis for several tanks in Revision 5, several of which have not been updated for this revision. The solids heights in 241-SY-101 and 241-AY-101 are partly based is based on gamma and neutron scans. Other techniques that have been used in the past include ball rheometer and temperature validation profiles.

\section{C7.1 DOUBLE-SHELL TANK NONCONVECTIVE LAYER HEIGHT AND MEASUREMENT CONCERNS}

Revision 5 of this document included a major reevaluation of the DST NCL data and methodology for generating tank mean and standard deviations. The current revision follows the logic established in Revision 5.

Of particular note is that Revision 5 postulated that a bias between measurement methods was present. The bias was determined to be 7 inches for zip cord and sludge weight measurements relative to Enraf densitometer measurements. That is, the sludge weight and zip cord measurements were on average about 7 inches lower than corresponding densitometer solids level measurements in the same location. Although this bias was determined on the basis of only two measurements (for SY-102 and AN-106), it was conservatively applied to all DST NCL measurements made by zip cord or sludge weight (for this BDGRE Waste Group evaluation only). That is, zip cord and sludge weight measurements were adjusted upward by 7 inches prior to generating tank mean and standard deviations. That methodology is continued in this revision, and the tank mean and standard deviation calculations were updated with new data.

\section{C7.2 NONCONVECTIVE LAYER HEIGHT MEASUREMENT METHODS}

\section{C7.2.1 Description of Measurement Methods}

A brief outline of solids (or NCL) measurement techniques follows.

Ball rheometer: The ball rheometer is a tungsten ball (3.6 in. in diameter and $16 \mathrm{lb}$ ) that was deployed in the flammable gas watch list tanks. The ball was raised and lowered through the waste and the wire tension measured via a load cell. PNNL-11296, In Situ Rheology and Gas Volume in Hanford Double-Shell Waste Tanks, states how the interface between the convective and NCLs was detected in each tank:

... we locate the top of the nonconvective layer by slowly dropping the ball from the convective region and observing the apparent weight of the ball. At the boundary the apparent weight begins to drop as the ball becomes increasingly supported by the fluid." (p. 2.2) 


\section{RPP-10006 REV 8}

The ball rheometer locates the liquid level and the top of the nonconvective layer in each riser to within one ball radius $(4.6 \mathrm{~cm})$. Passage of the ball through the liquid is taken to be the midpoint of the decrease in tension due to increasing buoyancy as the ball submerges." (p. 2.6)

Figure C-1. Ball Rheometer Data for Nonconvective Layer Interface for Double-Shell Tank 241-AN-105 (Figure 2.5 of PNNL-11296).

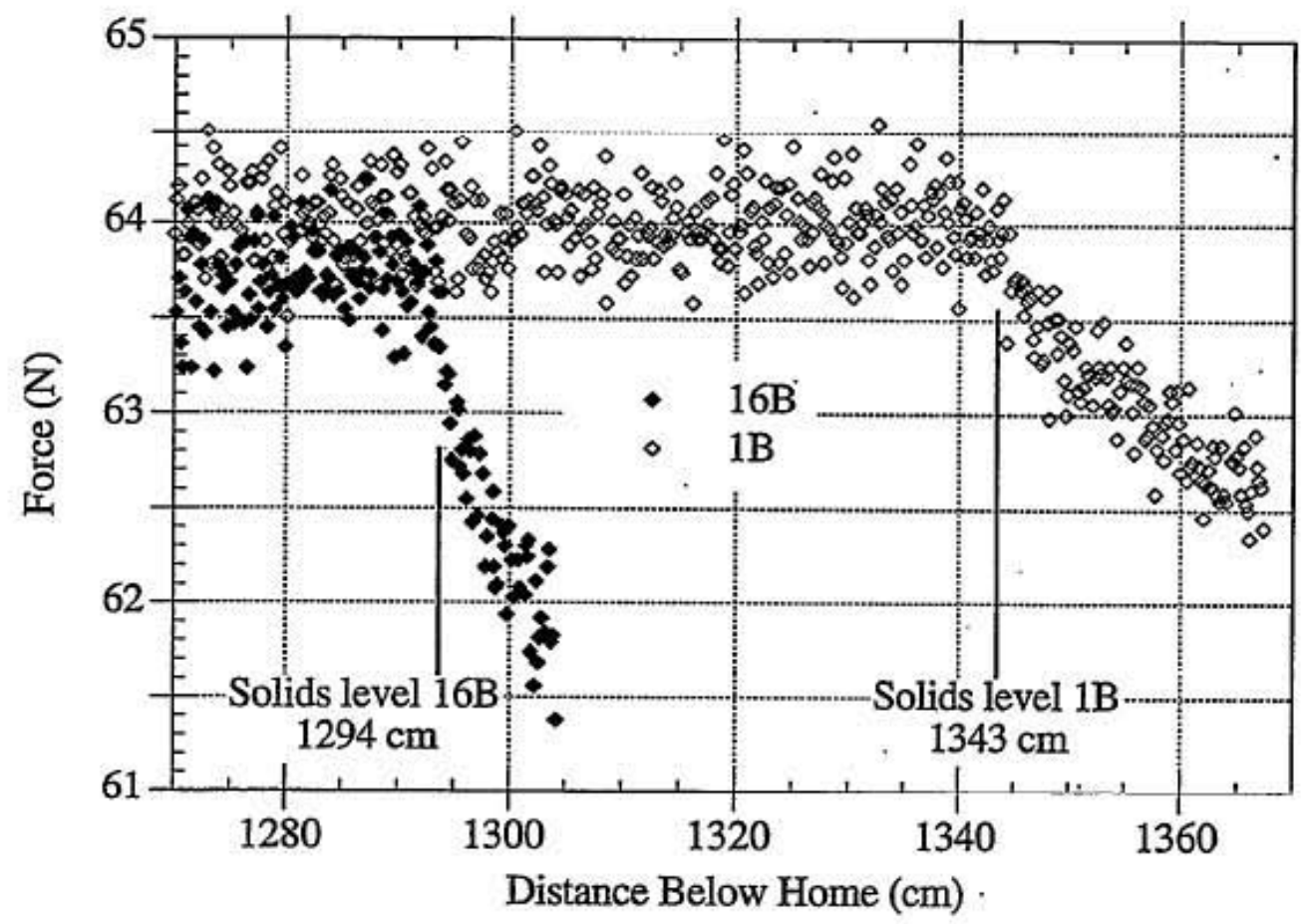

Figure $\mathrm{C}-1$ shows this graphically. As the ball is lowered at a constant rate, the wire tension is constant through the convective layer and then deflects (decreases) as more resistance is detected in the NCL.

Core sample extrusions: Based on lab photos and video, sample recovery data, and field core sampling data, the level of solids can be estimated. This was considered (PNNL-15238, Predicting Peak Hydrogen Concentrations from Spontaneous Gas Releases in Hanford Tank Wastes, Appendix D) to be the least accurate of the three methods typically used in the flammable gas tanks (i.e., ball rheometer, temperature validation probe, or core sample extrusion).

Enraf densitometers: This device consists of a weight (displacer) on a wire, which is lowered into the supernatant. The device detects interfaces and density by measuring the weight or tension of the wire. The solids layer is determined as a decrease in wire tension by a specified amount. For the current DST 241-AN-106 application, the displacer has a mass of $239 \mathrm{~g}$ and the solids level is determined by a decrease in tension equivalent to $25 \mathrm{~g}$. As of January 2009 , 


\section{RPP-10006 REV 8}

densitometers are installed in DSTs 241-SY-102, 241-AN-106, 241-AY-102, and two densitometers are installed in DST 241-AN-107.

Enraf surface level devices: The standard Enraf surface level measurement device installed on many DSTs and SSTs can be reprogrammed to detect a second interface (i.e., the solids level interface). This is not a standard operation and requires a field activity (e.g., reprogramming, flushing). Solids level measurements of this type were performed in DSTs 241-SY-101 and 241-SY-102 in 1999, and in 2007 an effort was begun to upgrade the displacers (increase weight to allow them to submerge) and perform these measurements periodically in most DSTs during maintenance activities or upon request.

Temperature validation scan: The Group A flammable gas tanks (DSTs 241-AN-103, 241-AN-104, 241-AN-105, 241-AW-101, and 241-SY-103) have a multi-function instrument tree (MIT) installed with 22 thermocouples spaced out at 12 to 48 in. intervals. In addition, DST 241-AY-102 has an MIT installed, and DST 241-SY-101 has two MITs. The MIT is a hollow pipe through which other measuring devices can be deployed. A temperature validation probe has been deployed in these tanks consisting of a resistance temperature detector. The probe is in contact with the pipe which conducts heat from the waste. By pausing periodically (approximately every 4 to $6 \mathrm{in}$.) for temperature equilibration, the probe is used to measure the temperature profile. The layer interface is identified by the transition from the isothermal convective layer to the warmer NCL. This technique can only be used in tanks with MITs. Most other tanks have regular thermocouple trees with thermocouples spaced at 24 to 48 in. intervals, which is not close enough for precise determinations of convective and NCLs.

Gamma and neutron scans: Gamma detectors and neutron source/detectors have been deployed in MITs and drywells in DSTs and liquid observation wells in SSTs. The gamma scan is usually considered to be an indication of ${ }^{137} \mathrm{Cs}$ activity, the primary gamma emitter in the waste. Cesium is largely soluble, so counts are usually higher in the liquid. Thus, the solids level is estimated as the point where the gamma counts begin to decrease from the higher levels in the convective layer. If the solids interstitial liquid is higher in ${ }^{137} \mathrm{Cs}$ than the supernatant (because of transfers), or if the solids are high in radioactive ${ }^{90} \mathrm{Sr} /{ }^{90} \mathrm{Y}$, then the counts in the solids layer can be higher than in the liquid layer.

Neutron scans have been more useful for detecting interstitial liquid levels or the presence of trapped gas such as the old crust layer in DST 241-SY-101. This technique measures neutrons reflected by hydrogen (considered an indication of water), and is often not sensitive to differences between liquid and wetted solids.

Sludge weights: Sludge weight readings are described in procedure TO-040-560, Tank Farm Sludge Level Readings, and performed on an as-needed basis. A sludge weight with a known cable length hangs from the riser cap of selected risers. The weight is a short (approximately 2 in.) section of 1.5 or $2 \mathrm{in}$. diameter pipe weighing up to approximately $1.5 \mathrm{lb}$. Sludge weight designs can differ slightly from farm to farm. The operator attaches a measuring tape to the cable and lowers the assembly until a solid interface is detected. The sludge weight is suspended in the waste if the tank is filled, and over time salt solids can build up, resulting in reduced sensitivity. Repeated measurements can cause a localized depression in the solids. This has been observed for surface level measurements in SSTs with exposed solids. 


\section{RPP-10006 REV 8}

Zip cords: A zip cord is an insulated conductive wire attached to a plummet, which is lowered into the riser from the riser flange or a fixed elevation above it (the riser adapter or top hat). "The distance from the riser to the waste surface is required for many jobs such as leak detection, sampling, level gauge installations or repairs, or tank equipment installations" (RPP-10141, Exceptions to Ignition Source Controls). The liquid or surface level is indicated when an electrical signal (continuity) is detected. Zip cords are also used for solids level measurements. The solids level is calculated from the depth at which physical resistance is sensed, or the cable goes slack. Solids level zip cord measurements are typically associated with a core or grab sampling event, and are performed to determine sample points, or at the request of Engineering (e.g., in the Tank Sampling and Analysis Plan). Different plummets are used for different applications. Up until mid-2004, the plummet used for solids level determinations was a 1.5 in. section of 1.5 -in.-diameter, schedule 160 , steel pipe weighing approximately $0.6 \mathrm{lb}$. Since then, the zip cord weights have been the same as the sludge weights (approximately 1 to $1.5 \mathrm{lb}$ ).

Other techniques: Photograph and video evaluation can be used for volume determination when solids are exposed. SST solids volumes are typically estimated in this way (HNF-SD-RE-TI178). One technique used during historical tank sluicing was solids mapping from photographs, used in coordination with pumping and liquid level measurement to allow contour mapping (RHO-ST-30, Hanford Radioactive Tank Cleanout and Sludge Processing). Transfer material balances can also provide useful information on the presence of solids (TFC-ENG-CHEM-D-44, Resolution of Waste Transfer Material Balance Discrepancies).

\section{C7.2.2 Effect of Waste Consistency on Measurement Uncertainty}

Conceptually, it seems evident that the waste consistency will affect the measurement techniques differently. For example, hard layers are difficult to retrieve with core sampling, especially push mode. Core sample recoveries have indicated solids heights could be biased low in these wastes. Measurements in tanks with hard solids layers should exhibit good agreement between physical measurement methods such as sludge weight, zip cord, densitometer, and ball rheometer, as well as indirect methods such as gamma and temperature profiles.

Loosely settled solids (waste with low-yield strength) should be easily recovered in core sampling, and thus core sampling, temperature profiles, and perhaps gamma scans should result in the most conservative measurements. Methods that rely on solids layer resistance to slow or stop a descending weight (zip cord, sludge weight, densitometer) may be biased lower in these types of solids. Automated physical measurements (densitometer and ball rheometer) should provide more consistent measurements than human techniques (sludge weights and zip cords).

Some sludge weight and zip cord data show good consistency among measurements. The 241-SY-102 zip cord measurements have been taken in riser 3 during sampling events for many years. These measurements correlate well with the process history of the tank as noted on Figure C-2. The variability observed from April 2000 to December 2004 is only 3 in., part of which can be explained as actual solids increase from saltwell pumping activities.

Figure C-2. Sediment Level History for Selected Risers, Double-Shell Tank 241-SY-102. 
SY-102 Recent Solids Level History

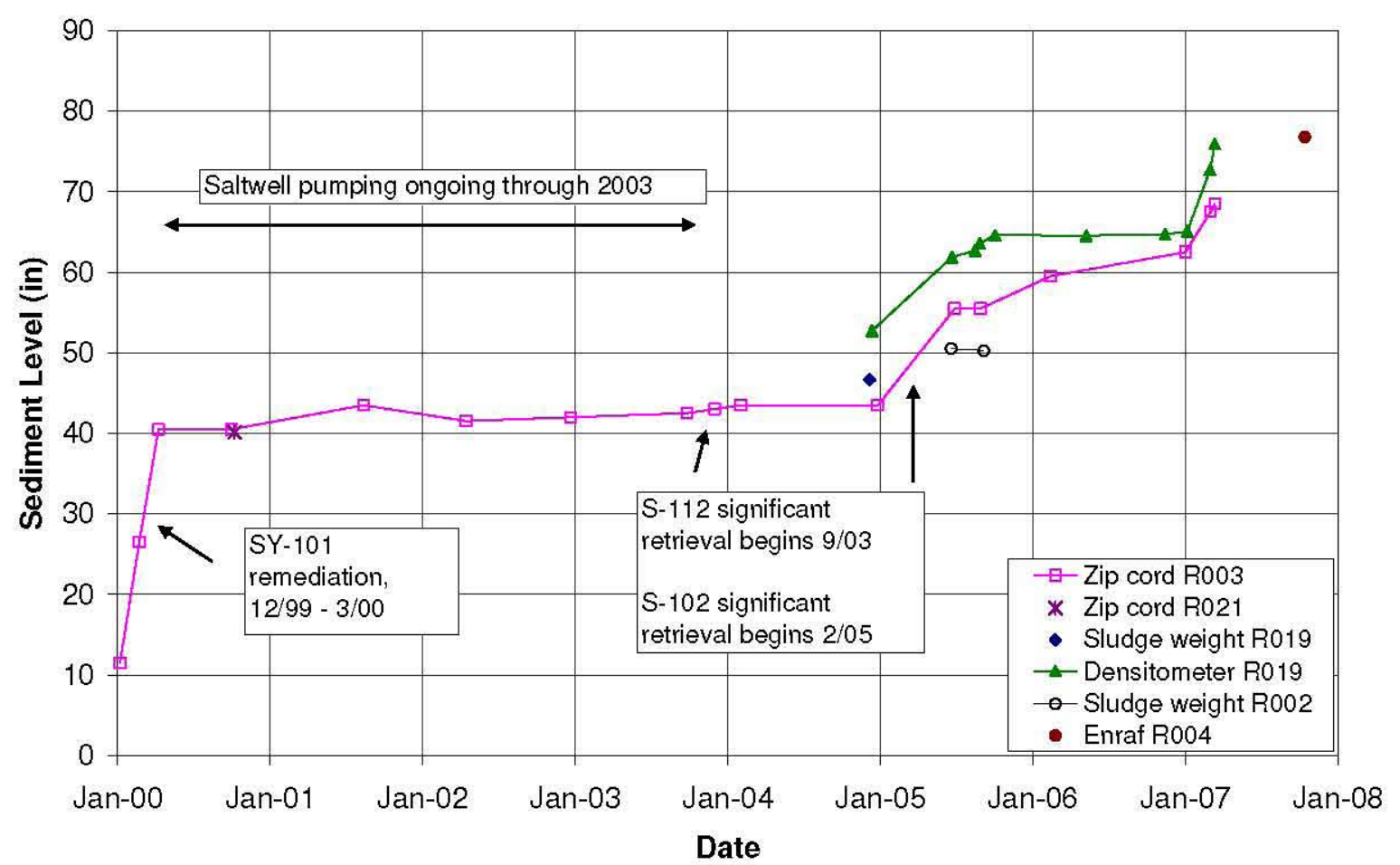

However, other examples of measurements in solids with low-yield stress illustrate the subjectivity inherent in zip cord and sludge weight measurements.

Sludge level measurements taken in DST 241-AN-107 in March 2003 initially indicated 85, 83, and 92 in. (rounded to the nearest inch) in risers 3,18 , and 19, respectively. The work package 2E-03-00339, Perform 241-AN-107 Sludge Level Readings, indicates that a measurement in riser 20 did not detect resistance until the sound of metal on metal was heard when the weight assembly contacted the tank bottom. This sludge weight felt lighter than the other three. The existence of the sludge weight on the cable was confirmed and the measurement was performed again a few days later. The field work supervisor and two operators felt a very slight difference in resistance at a cable depth corresponding to a sludge level of $82 \mathrm{in}$. During readings taken 2 months later in May 2003, the reading in riser 3 was not recorded, because the sludge weight could not be felt (i.e., there was "no restriction in the waste") (2E-03-00794, 241-AN-107 Sludge Weight Readings).

A zip cord measurement was taken in February 1998 in riser 20 of DST 241-AN-102. A solids level measurement of $38 \mathrm{in}$. is calculated based on the first indication of solids (ES-97-00599, 241-AN-102 Obtain Grab Samples). A "slack cable" reading was noted at 26 in. of solids. Several subsequent readings from 2000 to 2004 have indicated 63 to 73 in. of solids at that riser. Solids precipitation from depletion of hydroxide and other mechanisms may account for some of the increase. 
The DST 241-AP-108 sludge weight measurements were taken in September 2005. Results were 63,63 , and 33 in. of solids (rounded to the nearest inch) in risers 18, 19, and 20, respectively. Conversations with the field work supervisor and an operator (personal communication, Chapman 2005) indicated that the lowest measurement (riser 20) was taken first. In taking measurements in the other risers, a slight resistance was detected at cable depths corresponding to the higher measurements. It was conveyed that the same response might have been indicated at the first riser if measurements were retaken.

In summary, the measurement method is expected to make little difference if the solids layer is firm and the interface between solids and liquids is distinct. In weaker solids, differences can be substantial. The human interpretation involved in the zip cord and sludge weight measurements will inevitably lead to much larger variability than mechanical techniques such as densitometers.

\section{C7.2.3 Current Measurement Techniques Compared to Those Used to Develop Waste Group Methodology}

Prior to Revision 5, there was a concern raised that the solids level measurement methods currently used are not the same as the methods originally used in the Waste Group A flammable gas tanks. The buoyancy ratio criterion, which is a critical part of the waste group methodology, was developed by Pacific Northwest National Laboratory (PNNL-13337, Derivation of the Buoyancy Ratio Equation From the Bubble Migration Model) based on an extensive data set collected mostly in the historical flammable gas tanks from approximately 1995 through 2000. This data included measurements of NCL height using a variety of techniques.

The techniques used to measure the NCL height for the historical flammable gas tanks included ball rheometer, MIT temperature validation profile, and core sample extrusion. After the original analysis of NCL heights was completed, measurements were made for 241-SY-101 using MIT gamma scans (since it was remediated in 2000, 241-SY-101 is not a Group A tank). These solids level measurements for the historical flammable gas tanks are presented in PNNL-15238.

Ball rheometer, MIT temperature validation, and gamma scan techniques were not typically and are not normally used in other tanks. The typical techniques currently used for the remaining DSTs are core extrusion, sludge weight, and zip cord, Enraf densitometers, and Enraf surface devices deployed to detect a solids interface, with gamma and neutron scans being performed in 241-SY-101 and 241-AY-101.

If there is a bias between the methods typically used now (almost exclusively sludge weight, zip cord, and densitometer) and the methods originally used to define the Waste Group A flammable gas tanks, then the calculation may not be conservative. Accounting for bias is addressed in Section 7.3.

\section{C7.3 ACCOUNTING FOR BIAS BETWEEN MEASUREMENT TECHNIQUES}

RPP-10006, Revision 5 evaluated the available data by measurement technique, by tank, and by riser location. The bias adjustment recommended in Revision 5 (and implemented in this 
revision as well) is 7 in for zip cord and sludge weight measurements. Other techniques (e.g., Enraf densitometer) are considered equivalent to ball rheometer measurements that were the primary methodology used in the historical flammable gas tanks.

The 7-in adjustment is based on comparisons of sludge weight and densitometer measurements taken in the same riser. These measurements are shown in Table C-1. This adjustment is based on only two sets of measurements. However, the adjustment is an increase, making the calculations more conservative. If additional measurement comparisons are taken in the future, then the 7-in adjustment may be modified.

Table C-1. Comparison of Densitometer and Sludge Weight Data.

\begin{tabular}{|l|c|c|c|c|c|}
\hline Tank & $\begin{array}{c}\text { Sludge } \\
\text { weight } \\
\text { (in.) }\end{array}$ & $\begin{array}{c}\text { Densitometer } \\
\text { (in.) }\end{array}$ & $\begin{array}{c}\text { Offset } \\
\text { (densitometer - } \\
\text { sludge weight) }\end{array}$ & $\begin{array}{c}\text { Ratio, sludge } \\
\text { weight/ } \\
\text { densitometer }\end{array}$ & Comment \\
\hline 241 -SY-102 & 46.6 & 52.7 & 6.1 & $88 \%$ & -- \\
\hline $241-$ AN-106 & 28.125 & 36.81 & 8.7 & $76 \%$ & $\begin{array}{l}\text { Adjusted sludge } \\
\text { weight data based } \\
\text { on data sheet in } \\
\text { work package } \\
\text { 2E-04-01498. }\end{array}$ \\
\hline Average & & & & & -- \\
\hline
\end{tabular}

Note: Data from SVF-1112.

\section{C7.4 UPDATING THE ANALYSIS MEANS AND MEASUREMENT UNCERTAINTIES (STANDARD DEVIATIONS)}

After attempting to account for measurement bias (Section C7.3), measurement variability and solids topography is addressed by applying a standard deviation. This section of the document describes the calculation (or selection) of a mean and standard deviation for the DST NCLs.

In SVF-1588, Updated DST Solids Levels For RPP-10006, Rev. 8, the latest (2003 or later) relevant NCL measurement in each DST riser is presented. Measurements taken prior to significant tank changes (e.g., evaporator slurry transfers or retrieval transfers) are considered not relevant (and not included in the analysis). Data from the RPP-10006, Revision 7 analysis were used, along with updated measurements documented in SVF-1588.

Based on the evaluation in Section C7.3, zip cord and sludge weight data in SVF-1588 were adjusted upward by $7 \mathrm{in}$. to normalize the measurements to the techniques used for the Waste Group A tanks. Statistics (mean and standard deviation) were then calculated on the adjusted data in SVF-1588. Results (for DSTs with available data) are shown in Table C-2. 


\section{RPP-10006 REV 8}

SVF-1588 also calculates a pooled standard deviation of 10.6 in. from tanks with available data. As in Revision 5 and subsequent revisions, the pooled standard deviation will be applied as the variability estimate for many of the DSTs.

Table C-2. Summarized Statistical Data ${ }^{\mathrm{a}}$. (2 sheets)

\begin{tabular}{|c|c|c|c|c|}
\hline Tank & $\begin{array}{c}\text { Adjusted } \\
\text { Mean } \\
\text { (in.) }\end{array}$ & $\begin{array}{l}\text { Standard } \\
\text { deviation } \\
\text { (in.) }\end{array}$ & Count & Comment \\
\hline AN-101 & 18.3 & 5.1 & 3 & No new measurements \\
\hline AN-102 & 73.2 & $\mathrm{n} / \mathrm{a}$ & 1 & $\begin{array}{l}\text { No new measurements. } \\
\text { Older measurements (pre-2003) no longer used. }\end{array}$ \\
\hline AN-106 & 86.8 & 2.4 & 3 & \\
\hline AN-107 & 91.4 & 0.5 & 4 & $\begin{array}{l}\text { No new measurements. } \\
\text { Older measurements (pre-2003) no longer used. }\end{array}$ \\
\hline $\mathrm{AP}-101^{\mathrm{b}}$ & 0.0 & 0.0 & 2 & No new measurements \\
\hline AP-102 & 20.4 & $\mathrm{n} / \mathrm{a}$ & 1 & No new measurements \\
\hline AP-103 & 13.0 & 0.8 & 5 & \\
\hline AP-104 & 13.6 & 0.4 & 4 & \\
\hline AP-105 & 45.0 & 5.9 & 5 & $\begin{array}{l}\text { No new measurements. } \\
\text { Older measurements (pre-2003) no longer used. }\end{array}$ \\
\hline AP-107 & 6.8 & 7.9 & 2 & \\
\hline AP-108 & 38.6 & 18.6 & 6 & No new measurements \\
\hline AW-102 & 22.2 & 3.7 & 3 & \\
\hline AW-103 & 121.7 & 6.8 & 7 & \\
\hline AW-104 & 90.2 & 19.7 & 4 & No new measurements \\
\hline AW-105 & 92.4 & 9.9 & 4 & Older measurements (pre-2003) no longer used. \\
\hline AW-106 & 104.3 & 16.9 & 7 & \\
\hline AY -101 & 35.7 & 6.6 & 3 & Older measurements (pre-2003) no longer used. \\
\hline AY -102 & 60.6 & 5.6 & 6 & Older measurements (pre-2003) no longer used. \\
\hline AZ-101 & 20.7 & $\mathrm{n} / \mathrm{a}$ & 1 & Older measurements (pre-2003) no longer used. \\
\hline AZ-102 & 32.5 & 17.2 & 2 & \\
\hline SY-101 & 90.8 & 12.0 & 6 & No new measurements \\
\hline SY-102 & 76.1 & 0.7 & 3 & No new measurements \\
\hline SY-103 & 144.9 & $\mathrm{n} / \mathrm{a}$ & 1 & No new measurements \\
\hline
\end{tabular}

Notes:

${ }^{\mathrm{a}}$ These data are based on adjusted values from SVF-1588.

${ }^{\mathrm{b}}$ The 7-in adjustment is not applied to AP-101, where both zip cord measurements detected zero solids (assumption documented in SVF-1588).

${ }^{c}$ Tanks with only one measurement are not included in the pooled standard deviation calculation (documented in SVF-1588). 
RPP-10006 REV 8

\section{C7.5 NONCONVECTIVE LAYER HEIGHTS AND VARIABILITIES FOR DOUBLE-SHELL TANKS}

The methodology for estimating DST mean solids levels (NCL) and standard deviations for use in the flammable gas waste group calculations is as follows:

- If the adjusted tank mean is given in Table C-2, then this result is used. The adjusted means include the conservative adjustment ( 7 in.) of zip cord and sludge weight data relative to other measurements. Note that the mean in Table C-2 may be the same as was used in Revision 7 (if no new measurements are available).

- If the tank is not in Table C-2, then the mean from Revision 7 is retained. There is no new information available.

- For variability, if the tank is listed in Table C-2, and there are four or more measurements, then the variability (standard deviation) listed in Table C-2 should be used (again, this may be the same as Revision 7).

- For 241-AN-103, 241-AN-104, 241-AN-105, and 241-SY-103, the variability from Revision 5 is retained. These variabilities are from PNNL-15238 and are generally more conservative than the pooled standard deviation.

- For the remaining tanks, use the pooled standard deviation of $10.6 \mathrm{in}$.

Solids heights and standard deviations for use in the Waste Group calculations, along with comments describing their derivation, are presented in Table C-3.

Table C-3. Nonconvective Layer Heights and Variances for Double-Shell Tank Waste Group Calculations.

\begin{tabular}{|l|l|l|l|l|}
\hline \multicolumn{1}{|c|}{ Tank } & $\begin{array}{c}\text { Adjusted Solids } \\
\text { Level (in) }\end{array}$ & $\begin{array}{c}\text { Standard } \\
\text { Deviation (in) }\end{array}$ & \multicolumn{1}{|c|}{ Adjusted Level Basis } & \multicolumn{1}{|c|}{$\begin{array}{c}\text { Standard } \\
\text { Deviation Basis }\end{array}$} \\
\hline AN-101 & 18.3 & 10.6 & Sample data & Pooled \\
\hline AN-102 & 73.2 & 10.6 & Sample data & Pooled \\
\hline AN-103 & 149 & 11.4 & RPP-10006 Rev 7 & RPP-10006 Rev 5 \\
\hline AN-104 & 163 & 12.2 & RPP-10006 Rev 7 & RPP-10006 Rev 5 \\
\hline AN-105 & 177 & 6.1 & RPP-10006 Rev 7 & RPP-10006 Rev 5 \\
\hline AN-106 & 86.8 & 10.6 & Sample data & Pooled \\
\hline AN-107 & 91.4 & 0.5 & Sample data & Sample-based \\
\hline AP-101 & 0.0 & 10.6 & Sample data & Pooled \\
\hline AP-102 & 20.4 & 10.6 & Sample data & Pooled \\
\hline AP-103 & 13.0 & 0.8 & Sample data & Sample-based \\
\hline AP-104 & 13.6 & 0.4 & Sample data & Sample-based \\
\hline AP-105 & 45.0 & 5.9 & Sample data & Sample-based \\
\hline AP-106 & 9.6 & 10.6 & RPP-10006 Rev 7 & Pooled \\
\hline
\end{tabular}


Table C-3. Nonconvective Layer Heights and Variances for Double-Shell Tank Waste Group Calculations.

\begin{tabular}{|l|l|l|l|l|}
\hline \multicolumn{1}{|c|}{ Tank } & $\begin{array}{c}\text { Adjusted Solids } \\
\text { Level (in) }\end{array}$ & $\begin{array}{c}\text { Standard } \\
\text { Deviation (in) }\end{array}$ & \multicolumn{1}{|c|}{ Adjusted Level Basis } & $\begin{array}{c}\text { Standard } \\
\text { Deviation Basis }\end{array}$ \\
\hline AP-107 & 6.8 & 10.6 & Sample data & Pooled \\
\hline AP-108 & 38.6 & 18.6 & Sample data & Sample-based \\
\hline AW-101 & 112 & 11.3 & RPP-10006 Rev 7 & RPP-10006 Rev 5 \\
\hline AW-102 & 22.2 & 10.6 & Sample data & Pooled \\
\hline AW-103 & 121.7 & 6.8 & Sample data & Sample-based \\
\hline AW-104 & 90.2 & 19.7 & Sample data & Sample-based \\
\hline AW-105 & 92.4 & 9.9 & Sample data & Sample-based \\
\hline AW-106 & 104.3 & 16.9 & Sample data & Sample-based \\
\hline AY-101 & 35.7 & 10.6 & Sample data & Pooled \\
\hline AY-102 & 60.6 & 5.6 & Sample data & Sample-based \\
\hline AZ-101 & 20.7 & 10.6 & Sample data & Pooled \\
\hline AZ-102 & 32.5 & 10.6 & Sample data & Pooled \\
\hline SY-101 & 90.8 & 12.0 & Sample data & Sample-based \\
\hline SY-102 & 76.1 & 10.6 & Sample data & Pooled \\
\hline SY-103 & 144.9 & 15.6 & Sample data & RPP-10006 Rev 5 \\
\hline
\end{tabular}

\section{C7.6 OTHER CONSIDERATIONS}

\section{C7.6.1 Effect of Multiple Riser Locations}

NCL heights can vary widely across the tanks. It is very important to obtain a number of readings over the tank, especially as the NCL height becomes greater and approaches levels that could be of concern for creating Waste Group A conditions (approximately 80 in. and greater). Tanks with NCL levels taken at one or two locations can give a false sense of security due to possible differences in NCL height within a given tank.

A tank that illustrates the effect of location on solids height is DST 241-AW-106. Five sludge weight readings were taken across the tank in 2004. The NCL heights ranged from $69.6 \mathrm{in}$. to $113.3 \mathrm{in}$., a difference of almost $44 \mathrm{in}$. It also appears that tanks with air lift circulators (241-AY and 241-AZ tank farms) have more uniform surfaces. Also, solids that are relatively weak, such as in DST 241-AN-107, may have a self-leveling effect, as this tank shows less variability than many other tanks.

Solids topography in SSTs is evaluated by photograph or video to document stabilization (HNF-SD-RE-TI-178) as discussed in Section C7.0. Large variations, especially from tank wall to center, are common. Reported surface level differences range from an average of $23 \mathrm{in}$. in 
saltcake tanks to 7 in. in sludge tanks (RPP-7625, Appendix B). SST design, wastes, and process histories (e.g., saltwell pumping) may differ substantially from the DSTs. However, there are ample reasons to consider radial variability as a significant issue in the DSTs. Radial variability has been noted in DST 241-AP-105 (HNF-SD-WM-ER-360, Tank Characterization Report for Double-Shell Tank 241-AP-105). Temperature cooling from the annulus is most likely the major reason for radial variability but transfer history will play a part, too. For example, transfer pumps are most often stick pumps located in the central pump pits of a DST. The elevation of the pump suction is typically low in the tank (within $10 \mathrm{in}$. of the bottom). Such configurations are likely to transfer some solids from around the region of the pump suction and leave settled solids further away undisturbed.

Most techniques (except video and photographs) are limited to single point measurements under risers.

Another point to be made about riser locations is that the outermost tank risers in the 241-AN, 241-AW, and 241-SY tank farms are on a $28-\mathrm{ft}$ radius. The tanks are $75 \mathrm{ft}$ in diameter or $37.5 \mathrm{ft}$ in radius. Area (and volume for a cylinder such as the DST waste configuration) is a function of the radius squared. Thus, the waste volume outside of the $28 \mathrm{ft}$ radius is

$$
\frac{(37.5)^{2}-(28)^{2}}{(37.5)^{2}}=44 \% \text {. }
$$

This means that $44 \%$ of the waste is outside of the region that can be sampled or evaluated by single point measurements under risers for tanks in these farms. However, this was also the case for the Group A tanks from which the waste group correlation was developed. The furthest risers in the 241-AP tank farm are on a $30-\mathrm{ft}$ radius, and on a $34.75-\mathrm{ft}$ radius for the $241-\mathrm{AY}$ and 241-AZ tank farms.

\section{C7.6.2 Changes in Solids Levels Over Time}

A number of ongoing processes may change the solids level in a tank over time, especially in tanks with concentrated waste. These include evaporation, absorption of carbon dioxide from air, chemistry $(\mathrm{pH})$ changes, organic degradation reactions, temperature changes, chemical additions, and transfers. A brief description of these processes follows.

- Evaporation removes water and concentrates dissolved species. If a compound is at equilibrium between the precipitated and aqueous phases, it will precipitate and add to the solids layer.

- Absorption of carbon dioxide leads to carbonate saturation and precipitation and caustic (pH) depletion.

- $\mathrm{pH}$ reduction or caustic depletion leads to precipitation of $\mathrm{pH}$ dependent species, especially dissolved aluminum. 


\section{RPP-10006 REV 8}

- Aging of organic causes precipitation of relatively insoluble species such as oxalate, along with caustic depletion.

- Waste temperature changes cause solubility changes. The DSTs are generally cooling as radionuclide concentrations decay, and lower temperatures result in reduced solubility for almost all species.

- Chemical additions may dissolve solids (e.g., aluminum compounds with caustic addition) or may cause precipitation by increasing solution ionic strength.

- Transfers may result in precipitation (e.g., mixing of wastes with differing fluoride and phosphate concentrations may lead to precipitation of the double salt natrophosphate) or could result in dissolution if different caustic concentrations are involved. Transfers may result in inadvertent pumping of solids due to waste and pump configuration. Tanks that have received transfers of evaporator slurry, either directly or from another tank, are often observed to have an increase in solids. Transfers can cause solids with trapped gas to expand or compress as the hydrostatic pressure from the supernatant layer changes.

One example of an increase of solids with time is DST 241-AN-102. The solids history back to 1989 is presented in Figure C-3. The transfer history since 1984 is very limited, consisting of a small waste transfer in 1992 and a caustic addition in 2001. The solids level was about 33 in. in 1989 and has increased to over $60 \mathrm{in}$. based on measurements taken during the last 2 years. All of the mechanisms described above, except waste transfers, have probably contributed to the increased solids. 
Figure C-3. Double-Shell Tank 241-AN-102 Solids History.

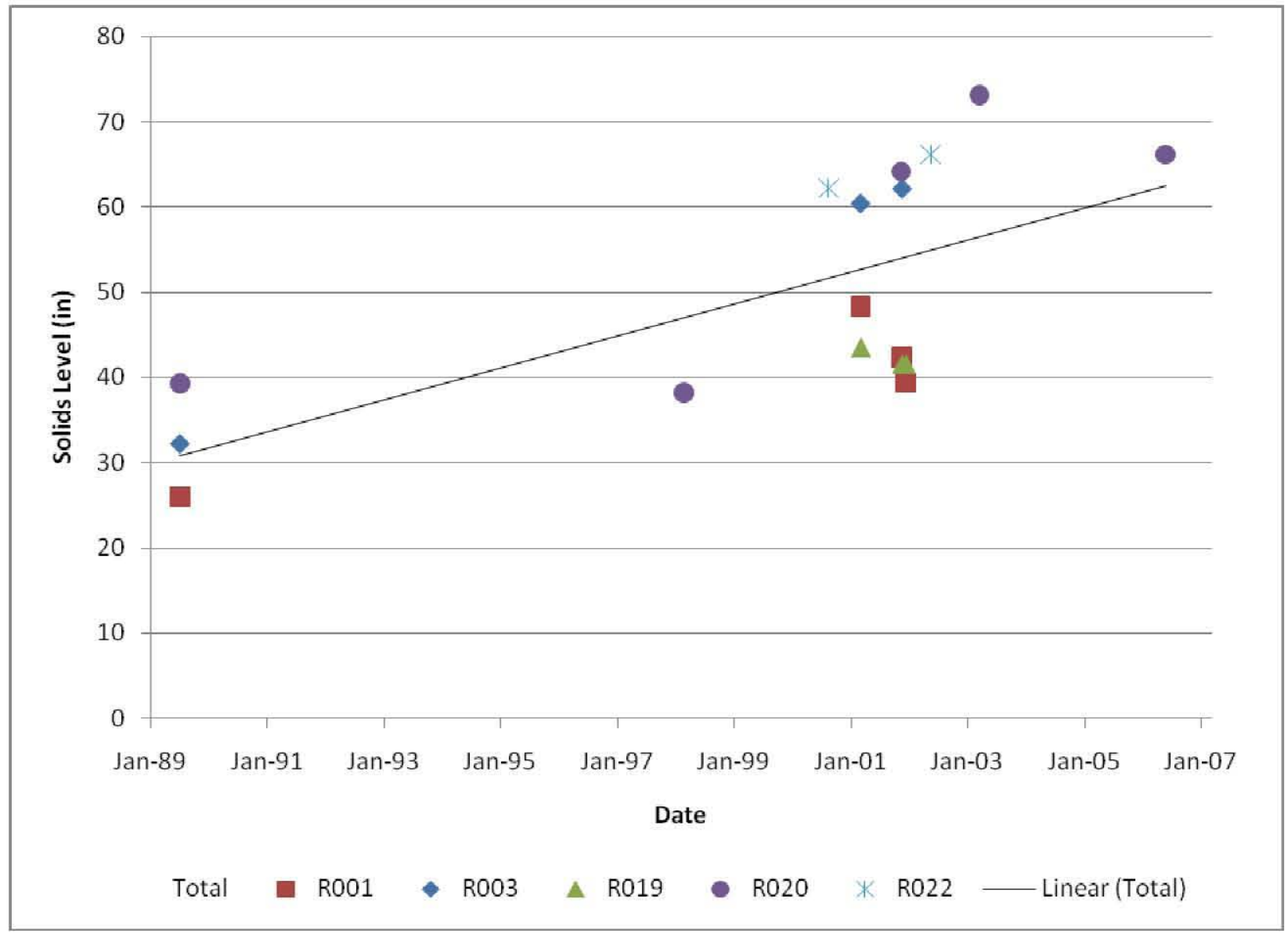

Because of these issues, it is recommended that Waste Group B and C DSTs should have solids level measurements at least every 5 years.

\section{C7.7 SUMMARY OF DOUBLE-SHELL TANK NONCONVECTIVE LAYER CHANGES}

Revision 5 of this document constituted a major reevaluation of the DST solids methodology. There were no changes made for Revision 6 , and Revision 7 and this revision have included updated data, but no changes in methodology. Older data (pre-2003) were dropped from the analysis in this revision. Removing the older measurements results in an increase in the calculated solids level for AN-102.

Because of many factors affecting solids levels over time, it is recommended that solids level measurements be performed in DSTs at least every 5 years. Waste Group A tanks could reasonably be excluded from this recommendation, as the highest level of controls is already being applied to these tanks. 
RPP-10006 REV 8

\section{C8.0 REFERENCES}

2E-03-00339, 2003, Perform 241-AN-107 Sludge Level Readings, CH2M HILL Hanford Group, Inc., Richland, Washington.

2E-03-00794, 2003, 241-AN-107 Sludge Weight Readings, CH2M HILL Hanford Group, Inc., Richland, Washington.

2E-04-01498, 2005, 241-AN-106 Install New Enraf Densitometer, CH2M HILL Hanford Group, Inc., Richland, Washington.

ES-97-00599, 1998, 241-AN-102 Obtain Grab Samples, Lockheed Martin Hanford Corporation, Richland, Washington.

HNF-SD-RE-TI-178, 2005, Single Shell Tank Interim Stabilization Record, Rev. 9, CH2M HILL Hanford Group, Inc., Richland, Washington.

HNF-SD-WM-ER-360, 1998, Tank Characterization Report for Double-Shell Tank 241-AP-105, Rev. 2, Lockheed Martin Hanford Corporation, Richland, Washington.

PNNL-11296, 1996, In Situ Rheology and Gas Volume in Hanford Double-Shell Waste Tanks, Pacific Northwest National Laboratory, Richland, Washington.

PNNL-11373, 1996, Flammable Gas Data Evaluation Report, Pacific Northwest National Laboratory, Richland, Washington.

PNNL-13337, 2005, Derivation of the Buoyancy Ratio Equation From the Bubble Migration Model, Pacific Northwest National Laboratory, Richland, Washington.

PNNL-15238, 2005, Predicting Peak Hydrogen Concentrations from Spontaneous Gas Releases in Hanford Tank Wastes, Pacific Northwest National Laboratory, Richland, Washington.

RHO-ST-30, 1980, Hanford Radioactive Tank Cleanout and Sludge Processing, Rockwell Hanford Operations, Richland, Washington.

RPP-5926, 2005, Steady-State Flammable Gas Release Rate Calculation and Lower Flammability Level Evaluation for Hanford Tank Waste, Rev. 5, CH2M HILL Hanford Group, Inc., Richland, Washington.

RPP-6655, 2000, Data Observations on Double-Shell Flammable Gas Watch List Tank Behavior, Rev. 0, CH2M HILL Hanford Group, Inc., Richland, Washington.

RPP-7625, 2008, Best Basis Inventory Process Requirements, Rev. 8, CH2M HILL Hanford Group, Inc., Richland, Washington. 
RPP-10006, 2006, Methodology and Calculations for Assignment of Waste Groups for Large Underground Storage Tanks at Hanford, Rev. 5, CH2M HILL Hanford Group, Inc., Richland, Washington.

RPP-10006, 2008, Methodology and Calculations for Assignment of Waste Groups for Large Underground Storage Tanks at Hanford, Rev. 7, CH2M HILL Hanford Group, Inc., Richland, Washington.

RPP-10141, 2003, Exceptions to Ignition Source Controls, Rev. 0, CH2M HILL Hanford Group, Inc., Richland, Washington.

S. Chapman, 2005, personal communications, S. Chapman and J. Petty with J. Jo and J. M. Conner, November.

SVF-1112, 2006, Spreadsheet Verification and Release Form for Spreadsheet 'SVF-1112 all solids RO', Rev. 0, CH2M HILL Hanford Group, Inc., Richland, Washington.

SVF-1118, 2006, Spreadsheet Verification and Release Form for Spreadsheet RPP-10006 Rev 5 Data Rebuild 060306.xls, Rev. 0, CH2M HILL Hanford Group, Inc., Richland, Washington.

SVF-1588, 2009, Updated DST Solids Levels For RPP-10006, Rev. 8, Rev. 0, Washington River Protection Solutions, LLC, Richland, Washington.

Tank Waste Information Network System (TWINS), Queried February 3, 2006, [Measurements, SACS, Surface Levels], http://twins.pnl.gov/data/datamenu.htm.

TFC-ENG-CHEM-D-44, 2008, Resolution of Waste Transfer Material Balance Discrepancies, Rev. A-2, CH2M HILL Hanford Group, Inc., Richland, Washington.

TO-040-560, 2008, 200 East/West Tank Farms Sludge Level Readings, Rev. F-8, CH2M HILL Hanford Group, Inc., Richland, Washington. 
RPP-10006 REV 8

APPENDIX D

DETERMINATION OF VOID FRACTION

D-i 
RPP-10006 REV 8

This page intentionally left blank.

D-ii 
RPP-10006 REV 8

\section{CONTENTS}

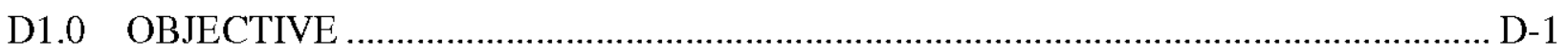

D2.0 BACKGROUND DATA SOURCES FOR VOID FRACTION ……....................... D-1

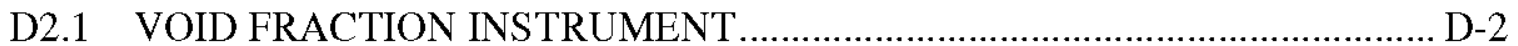

D2.2 RETAINED GAS SAMPLER ………………......................................

D2.3 BAROMETRIC PRESSURE EFFECT METHOD .......................................... D-3

D3.0 INPUT DATA

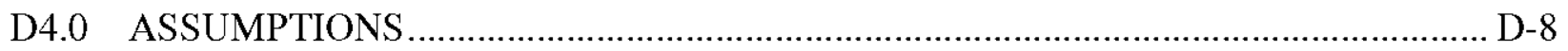

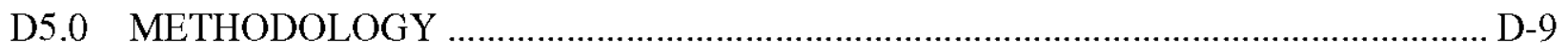

D6.0 COMPUTER SOFTWARE USE AND VERIFICATION ……………..................... D-11

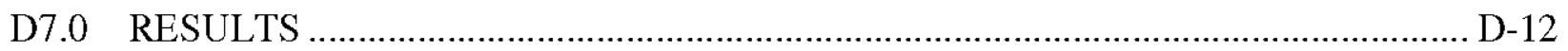

D7.1 VOID FRACTION FOR DOUBLE-SHELL TANKS 241-AN-107 AND

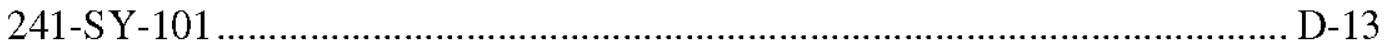

D7.1.1 Determination of Void Fraction for Double-Shell Tank

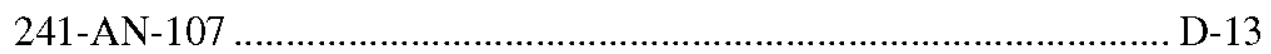

D7.1.2 Determination of Void Fraction for Double-Shell Tank

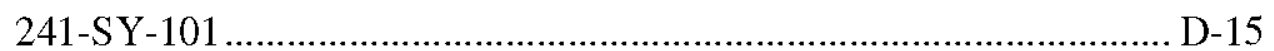

D7.2 BEST VOID FRACTION DATA ............................................................

D7.3 DEFAULT VOID FRACTIONS FOR EACH WASTE TYPE....................... D-20

D7.3.1 SC/SS-NL and MIX-NL Default Void Fraction................................ D-20

D7.3.2 SL-NL Default Void Fraction ........................................................ D-22

D7.3.3 SC/SS-LIQ, SL-LIQ, and MIX-LIQ Default Void Fraction................. D-24

D7.3.4 Liquid Waste Void Fractions ........................................................ D-26

D7.4 VOID FRACTION ASSIGNMENT FOR 177 DOUBLE-SHELL TANKS

AND SINGLE-SHELL TANKS............................................................ D-26

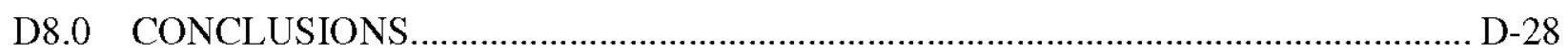

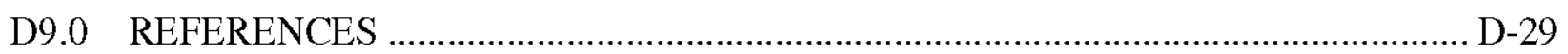


RPP-10006 REV 8

\section{FIGURES}

Figure D-1. Example of the Correlation Between Double-Shell Tank 241-AN-107

Surface Level With the Inverse Barometric Pressure...

Figure D-2. Example of the Correlation Between Double-Shell Tank 241-SY-101

Surface Level With the Inverse Barometric Pressure............................................ D-16

Figure D-3. Void Fraction Regression Results for SC/SS-NL and MIX-NL Wastes. ............ D-22

Figure D-4. Void Fraction Regression Results for SL-NL Wastes. ....................................... D-24

Figure D-5. Void Fraction Regression Results for SC/SS-LIQ, SL-LIQ, and MIX-LIQ Wastes.

D-26

\section{TABLES}

Table D-1. dL/dP Data from Barometric Pressure Effects and Related Data to Calculate Void Fraction. (3 sheets) .......................................................................... D-5

Table D-2. Results of the Barometric Pressure Effect Evaluation for Double-Shell Tank 241-AN-107.

Table D-3. Results of the Void Fraction Determination for Double-Shell Tank 241-AN-107.

Table D-4. Results of the Barometric Pressure Effect Evaluation for Double-Shell Tank 241-SY-101.

Table D-5. Results of the Void Fraction Determination for Double-Shell Tank 241-SY-101.

Table D-6. Void Fraction Data from Barometric Pressure Effect and Related Data to Calculate Void Fraction. (4 sheets)

Table D-7. Summary of Mean Void Fraction Data for SC/SS-NL and MIX-NL Tanks With Measured Values. (2 sheets).

Table D-8. Default Void Fraction for SC/SS-NL and MIX-NL Waste with Truncated Normal Distribution.

Table D-9. Summary of Average Void Fraction Data for SL-NL Tanks With Measured Values.

Table D-10. The Default Void Fraction for SL-NL Waste with Truncated LogNormal Distribution.

Table D-11. Summary of Average Void Fraction Data for SC/SS-LIQ Tanks With Measured Values.

Table D-12. Default Void Fraction for SC/SS-LIQ, SL-LIQ, and MIX-LIQ Waste with Truncated Normal Distribution. D-25

Table D-13. Void Percent Distributions for Non-Default Tanks. (2 sheets) D-27 


\section{LIST OF TERMS}

acf

BPE

BPE1

BPE2

$\mathrm{dL} / \mathrm{dP}$

DST

Enraf

MIX-LIQ

MIX-NL

PCSACS

PNNL

RGS

SC/SS

SC/SS-LIQ

SC/SS-NL

SL-LIQ

SL-NL

SST

VFI actual cubic feet (gas conditions at depth at mid-point of nonconvective layer layer)

barometric pressure effect

original BPE model

steep slope form of the BPE model

change in tank level divided by corresponding change in pressure

double-shell tank

Enraf Series 854 (gauge)

mixed waste form with $\geq 1 \mathrm{~m}$ liquid over solids

mixed waste form with $<1 \mathrm{~m}$ liquid over solids

personal computer Surveillance Analysis Computer System

Pacific Northwest National Laboratory

Retained Gas Sampler

saltcake/salt slurry

saltcake/salt slurry waste form with $\geq 1 \mathrm{~m}$ liquid over solids

saltcake/salt slurry waste form with $<1 \mathrm{~m}$ liquid over solids

sludge waste form with $\geq 1 \mathrm{~m}$ liquid over solids

sludge waste form with $<1 \mathrm{~m}$ liquid over solids

single-shell tank

Void Fraction Instrument 
RPP-10006 REV 8

This page intentionally left blank.

D-vi 
RPP-10006 REV 8

\section{APPENDIX D \\ DETERMINATION OF VOID FRACTION}

D1.0 OBJECTIVE

When analyzing tank hazards relating to flammable gas accidents it is important understand the ability of solid wastes to retain gas and then release it due to change in tank characteristics or due to outside influence or waste disturbing activities. This appendix documents the methodology used in RPP-10006, Revision 5, to develop void fraction estimates for the Hanford waste tanks. No new or revised void fraction analysis was performed for RPP-10006, Revision 8.

\section{D2.0 BACKGROUND DATA SOURCES FOR VOID FRACTION}

Void fraction data can be obtained or derived from the following available field measured data sources:

- Void Fraction Instrument (VFI): An average gas volume fraction may be estimated from direct measurements of the local gas volume fraction with the VFI.

- Retained Gas Sampler (RGS): A localized average gas volume fraction may be estimated from direct measurements of the local gas volume fraction with the RGS.

- Barometric pressure effect (BPE) method: An average void fraction can be computed from the correlation of the changes in waste surface level in response to barometric pressure fluctuations.

- Surface level rise: An increase in global average void fraction may be indicated by a rise in waste surface level such as 241-SY-101 prior to remediation (not used in this report).

- Core sample X-ray: Voids or gaps shown in X-rays of core samples may indicate stored gas. However, these observations are only qualitative and cannot be used to derive an average void fraction value (not used in this report).

In this report, only the data from VFI, RGS and BPE are used to obtain or derive the void fraction for waste tanks at Hanford. Void fraction is available directly from the data sources of VFI and RGS, while it requires extra data such as waste level, waste density, etc., and calculations to convert the BPE data to a void fraction. Once the void fraction data are obtained, a value is assigned to each individual tank based on the data quality preference given in Section 4.0. For those tanks that do not have field measured data, a default value is assigned based on the tank waste type (as defined in SNL-000198 and listed in Appendix H). The default values for each waste type are developed statistically based on the available measured field data. Details of VFI, RGS and BPE data measurements are given below. 


\section{RPP-10006 REV 8}

\section{D2.1 VOID FRACTION INSTRUMENT}

A VFI deployment produces a relatively large number of data points in the vertical direction, but only from two risers. Each measurement is based on sampling a $367 \mathrm{~mL}$ waste volume (roughly a cylinder 3 in. in diameter and 3 in. long). A basic assumption made in computing the average void fraction is that data from two risers represent the entire tank. In five of the six double-shell tanks (DST) sampled with the VFI, RGS samples from two additional risers and BPE results have provided independent corroboration that this assumption is valid. Uncertainties in the average void fraction derived from VFI data range from 10 to $30 \%$ standard deviation due mainly to variability in the data (PNNL-11536, Gas Retention and Release Behavior in Hanford Double-Shell Waste Tanks). For these reasons the Analyst Team concluded that VFI data, with or without additional data from RGS samples, are sufficiently representative to characterize the average void fraction for a specific tank.

\section{D2.2 RETAINED GAS SAMPLER}

A single RGS gas fraction measurement is made on a 19-in. core sample segment. The void value from an RGS segment is generally as accurate as a single VFI data point, but there are far fewer RGS data. There are usually only 3 to 6 RGS measurements per tank, 1 to 3 per riser, compared to 20 to 40 VFI data points. Therefore, it is much more difficult to show that the RGS measurements are representative of the entire tank. In comparing the results for DSTs, the RGS differed from the VFI by about 50\% for two tanks (DSTs 241-AN-103 and 241-AW-101) where the sparse RGS data missed the bulk of the stored gas (PNNL-11450, Composition and Quantities of Retained Gas Measured in Hanford Waste Tanks 241-AW-101, A-101, AN-105, $A N-104$, and $A N-103$ ). VFI data for single-shell tank (SST) waste are not available. For SSTs, the average gas fraction measurements with the RGS are compared with results from BPE and surface level rise analyses. Where the latter two support each other, the RGS value may differ by 50\% (PNNL-11450, PNNL-11777, Composition and Quantities of Retained Gas Measured in Hanford Waste Tanks 241-U-103, S-106, BY-101, and BY-109). Based on these comparisons, where only RGS data are available, Pacific Northwest National Laboratory (PNNL) assigns an uncertainty of $\pm 50 \%$ to the RGS value. For these reasons, the Analyst Team concluded that RGS data alone are not sufficiently representative to characterize the average void fraction in the tank waste, but can be used in determining void fraction distributions for the respective waste forms. 


\section{RPP-10006 REV 8}

\section{D2.3 BAROMETRIC PRESSURE EFFECT METHOD}

The BPE method is the only means available to directly measure the total gas volume in the tank waste independent of its past history. A correlation between waste level change and barometric pressure indicates the presence of gas. However, the waste and surface level measurement system must meet the following criteria before the correlation can be used as a measurement (PNNL-11536):

- The waste must be wet. The free liquid level must be above or within a few inches of the top of the gas-retaining solids, or the solids must contain sufficient gas to float on the liquid, or both.

- The tank must contain minimal suspended hardware items (that could support the waste and interfere with level change measurements).

- The waste must not be disturbed by mixing (such as was done in DST 241-SY-101) that suspends solids and gas bubbles during the period of the BPE measurement.

- The effective pressure on the stored gas must not change significantly during the BPE measurement (e.g., by transfers).

- The precision of the waste surface level instrument must be within $0.1 \mathrm{in}$. and the level must be recorded at least daily. Because of an amplification effect that is not fully understood, the BPE method cannot be applied to interstitial liquid level data obtained with the neutron probe.

Ideally, the pressure-level correlation should be developed using data obtained from November through February when barometric pressure fluctuations are greatest. The "steep slope" BPE model, abbreviated here as the BPE2 model, uses only data obtained during these months to correlate barometric pressure and waste level. The BPE2 model also accounts for the effect of waste strength (PNNL-11693, Estimating Retained Gas Volumes in the Hanford Tanks using Waste Level Measurements), unlike the original, more simplified BPE model (which will be abbreviated here as the BPE1 model). In cases where only BPE1 data are available, they will be included in the development of an average void fraction value on a case-by-case basis.

The overall uncertainty in the void fraction value determined with a BPE model is driven by the uncertainty in determining both the effective pressure of the stored gas and the correlation of waste height change with barometric pressure change (the $\mathrm{dL} / \mathrm{dP}$ value). The computed uncertainty varies from 20 to $50 \%$, and void fractions determined with a BPE model can differ from RGS and VFI average void values by about the same amount. 


\section{D3.0 INPUT DATA}

The void fraction assigned to each waste tank is either a field-measured value or statistically determined default value corresponding to the tank waste type. To derive the default void fraction distributions the input data of field observed void fraction data and waste property data are required. The field observed VFI and RGS void fraction data are used to assign individual tank void fractions as well as to determine the default void fraction distributions statistically. The VFI and RGS void fraction data along with the waste type data are listed in Section D7.3. The VFI and VFI with RGS results are presented in PNNL-11536, and RGS results are reported in PNNL-11373, Flammable Gas Data Evaluation Progress Report.

The other type of input data is $\mathrm{dL} / \mathrm{dP}$ data from the BPE method along with other data such as density and waste level, which are used to derive the void fraction. Once the void fraction is derived from BPE then the void fraction values are assigned to individual data and also join the field measured void fraction data from VFI and RGS to determine the default value statistically for each waste type. Table D-1 lists the $\mathrm{dL} / \mathrm{dP}$ data from BPE together with other data required to derive the void fraction. RPP-15488, Investigation of Tank Void Fraction Using Liquid Level to Atmospheric Pressure Changes, calculated the BPEs over the period from 1997 through 1999 using the BPE2 model for tanks with Enraf-Nonius Series 854 (ENRAF) gauges and meeting BPE requirements, and the results were reported at the Data Review Workshops in 1999.

The additional data, including density and waste level to determine the void fraction, are taken from RPP-5926, Steady-State Flammable Gas Release Rate Calculation or Lower Flammability Evaluation for Hanford Tank Waste, Rev. 0, which provides data from the corresponding time period as the BPE data. RPP-10006, Rev. 5, Appendix A, is used to update waste types of selected tanks based on improved tank content analysis.

In addition, the $\mathrm{dL} / \mathrm{dP}$ data of tanks 241-AN-107 and 241-SY-101 has been developed using waste level and pressure data, which were queried from personal computer Surveillance Analysis Computer System (PCSACS) for various time periods from October 1, 2004, through November 1, 2005, as listed in the Section D7.1. 
Table D-1. dL/dP Data from Barometric Pressure Effects and Related Data to Calculate Void Fraction. (3 sheets)

\begin{tabular}{|c|c|c|c|c|c|c|c|}
\hline Tank name & Waste type & $\begin{array}{c}\text { NCL } \\
\text { volume } \\
\left(\mathrm{m}^{3}\right)\end{array}$ & $\begin{array}{c}\mathrm{CL} \\
\text { volume } \\
\left(\mathrm{m}^{3}\right)\end{array}$ & $\begin{array}{c}\text { NCL } \\
\text { depth } \\
\text { (in) }\end{array}$ & $\begin{array}{c}\text { CL } \\
\text { depth } \\
\text { (in) }\end{array}$ & $\begin{array}{c}\text { CL } \\
\text { density } \\
(\mathrm{g} / \mathrm{mL})\end{array}$ & $\begin{array}{l}\text { BPE slope } \\
\text { (in/in Hg) }\end{array}$ \\
\hline References & $\begin{array}{l}\text { RPP-10006, Rev. 5, } \\
\text { Appendix A }\end{array}$ & \multicolumn{5}{|c|}{ RPP-5926, Rev. 0, 2000} & RPP-15488 \\
\hline $241-\mathrm{A}-101^{\mathrm{a}}$ & SC/SS-NL & 1,685 & 1,923 & 161.8 & 184.7 & 1.40 & -0.364 \\
\hline 241-A-103 & SC/SS-NL & 1,385 & 19 & 133.1 & 1.8 & 1.48 & -0.013 \\
\hline $241-\mathrm{A}-106$ & MIX-NL & 473 & 0 & 45.5 & 0.0 & 1.17 & 0.005 \\
\hline 241-AN-101 & SC/SS-LIQ & 125 & 481 & 12.0 & 46.2 & 1.16 & 0.000 \\
\hline 241-AN-103 & SC/SS-LIQ & 1,552 & 2,074 & 149.1 & 199.3 & 1.49 & -0.535 \\
\hline 241-AN-104 & SC/SS-LIQ & 1,700 & 2,286 & 163.3 & 219.6 & 1.40 & -0.226 \\
\hline 241-AN-105 & SC/SS-LIQ & 1,851 & 2,411 & 177.8 & 231.6 & 1.42 & -0.180 \\
\hline 241-AW-101 & SC/SS-LIQ & 1,158 & 3,104 & 111.3 & 298.2 & 1.4 & -0.255 \\
\hline 241-AW-103 & SL-LIQ & 1,317 & 613 & 126.6 & 58.9 & 1.02 & -0.029 \\
\hline 241-AW-104 & $\begin{array}{l}\text { SC/SS-LIQ } \\
\text { STS }\end{array}$ & 874 & 3,361 & 84.0 & 322.9 & 1.25 & -0.076 \\
\hline 241-AW-105 & SL-LIQ & 1,060 & 564 & 101.8 & 54.2 & 1.02 & 0.001 \\
\hline 241-AW-106 & SC/SS-LIQ & 863 & 927 & 82.9 & 89.1 & 1.38 & -0.062 \\
\hline $241-A X-101^{\mathrm{a}}$ & SC/SS-NL & 1,370 & 1,461 & 131.6 & 140.4 & 1.48 & -0.003 \\
\hline 241-AX-102 & SC/SS-NL & 114 & 0 & 10.9 & 0.0 & 1.39 & 0.005 \\
\hline 241-AX-103 & SC/SS-NL & 424 & 0 & 40.7 & 0.0 & 1.39 & -0.002 \\
\hline 241-AX-104 & SL-NL & 30 & 0 & 2.9 & 0.0 & 1.17 & 0.000 \\
\hline 241-AY-101 & SL-NL & 409 & 174 & 39.3 & 16.7 & 1.08 & -0.050 \\
\hline 241-AY-102 & SL-LIQ & 799 & 1,556 & 76.7 & 149.5 & 1.09 & -0.018 \\
\hline 241-AZ-101 & SL-LIQ & 178 & 3,021 & 17.1 & 290.2 & 1.19 & 0.093 \\
\hline $241-B-102$ & SC/SS-NL & 106 & 15 & 17.6 & 1.5 & 1.39 & -0.001 \\
\hline $241-B-112$ & MIX-NL & 114 & 11 & 18.4 & 1.1 & 1.27 & -0.002 \\
\hline 241-BX-101 & SL-NL & 159 & 4 & 22.7 & 0.4 & 1.28 & -0.010 \\
\hline $241-B X-102$ & $\begin{array}{l}\text { SL-NL } \\
\end{array}$ & 363 & 0 & 42.4 & 0.0 & 1.17 & -0.003 \\
\hline 241-BX-103 & SL-NL & 235 & 34 & 30.0 & 3.3 & 1.28 & -0.003 \\
\hline 241-BX-104 & SL-NL & 363 & 11 & 42.4 & 1.1 & 1.29 & -0.082 \\
\hline 241-BX-105 & MIX-NL & 174 & 19 & 24.2 & 1.8 & 1.29 & -0.002 \\
\hline 241-BX-106 & SC/SS-NL & 144 & 0 & 21.3 & 0.0 & 1.17 & 0.001 \\
\hline 241-BX-107 & SL-NL & 1,302 & 4 & 132.6 & 0.4 & 1.17 & -0.088 \\
\hline 241-BX-108 & SL-NL & 98 & 0 & 16.9 & 0.0 & 1.17 & 0.001 \\
\hline 241-BX-109 & SL-NL & 731 & 0 & 77.6 & 0.0 & 1.17 & -0.007 \\
\hline 241-BX-110 & MIX-NL & 772 & 11 & 81.6 & 1.1 & 1.40 & -0.086 \\
\hline 241-BX-111 & SC/SS-NL & 609 & 4 & 66.0 & 0.4 & 1.39 & -0.002 \\
\hline
\end{tabular}




\section{RPP-10006 REV 8}

Table D-1. dL/dP Data from Barometric Pressure Effects and Related Data to Calculate Void Fraction. (3 sheets)

\begin{tabular}{|c|c|c|c|c|c|c|c|}
\hline Tank name & Waste type & $\begin{array}{c}\text { NCL } \\
\text { volume } \\
\left(\mathrm{m}^{3}\right)\end{array}$ & $\begin{array}{c}\mathrm{CL} \\
\text { volume } \\
\left(\mathrm{m}^{3}\right)\end{array}$ & $\begin{array}{c}\text { NCL } \\
\text { depth } \\
\text { (in) }\end{array}$ & $\begin{array}{c}\text { CL } \\
\text { depth } \\
\text { (in) }\end{array}$ & $\begin{array}{c}\mathrm{CL} \\
\text { density } \\
(\mathrm{g} / \mathrm{mL})\end{array}$ & $\begin{array}{l}\text { BPE slope } \\
\text { (in/in Hg) }\end{array}$ \\
\hline References & $\begin{array}{l}\text { RPP-10006, Rev. 5, } \\
\text { Appendix A }\end{array}$ & \multicolumn{5}{|c|}{ RPP-5926, Rev. 0, 2000} & RPP-15488 \\
\hline 241-BX-112 & SL-NL & 621 & 4 & 67.1 & 0.4 & 1.18 & -0.009 \\
\hline 241-C-103 & SL-NL & 450 & 299 & 50.7 & 28.7 & 1.08 & -0.001 \\
\hline 241-C-106 & SL-NL & 30 & 159 & 10.4 & 15.3 & 1.09 & 0.009 \\
\hline 241-C-107 & SL-NL & 973 & 0 & 100.9 & 0.0 & 1.17 & -0.004 \\
\hline 241-S-101 & MIX-NL & 1,571 & 45 & 158.4 & 4.4 & 1.36 & -0.171 \\
\hline $241-S-102$ & SC/SS-NL & 1,946 & 0 & 194.4 & 0.0 & 1.39 & -0.518 \\
\hline $241-\mathrm{S}-103^{\mathrm{b}}$ & SC/SS-NL & 874 & 0 & 91.5 & 6.2 & 1.39 & -0.349 \\
\hline $241-\mathrm{S}-106^{\mathrm{b}}$ & SC/SS-NL & 1,613 & 0 & 162.4 & 19.3 & 1.39 & -0.316 \\
\hline $241-S-107$ & SL-NL & 1,370 & 53 & 139.1 & 5.1 & 1.17 & -0.087 \\
\hline 241-S-108 & SC/SS-NL & 1,703 & 0 & 171.1 & 0.0 & 1.39 & -0.001 \\
\hline $241-\mathrm{S}-110$ & SC/SS-NL & 1,476 & 0 & 149.3 & 0.0 & 1.43 & 0.026 \\
\hline 241-S-111 & SC/SS-NL & 1,624 & 420 & 163.5 & 40.4 & 1.39 & -0.437 \\
\hline 241-SX-101 & MIX-NL & 1,696 & 0 & 171.1 & 0.0 & 1.50 & -1.513 \\
\hline 241-SX-103 & SC/SS-NL & 2,400 & 0 & 238.7 & 0.0 & 1.47 & -3.103 \\
\hline 241-SX-104 & MIX-NL & 1,768 & 0 & 178.0 & 0.0 & 1.39 & -0.056 \\
\hline 241-SX-105 & SC/SS-NL & 2,411 & 0 & 239.8 & 0.0 & 1.47 & -3.181 \\
\hline 241-SX-106 & SC/SS-NL & 1,223 & 379 & 125.6 & 36.4 & 1.42 & -0.407 \\
\hline 241-SY-102 & SL-LIQ & 333 & 1,984 & 32.0 & 190.6 & 1.18 & -0.006 \\
\hline 241-SY-103 & SC/SS-LIQ & 1,370 & 1,446 & 131.6 & 138.9 & 1.47 & -0.196 \\
\hline 241-T-101 & MIX-NL & 382 & 4 & 44.2 & 0.4 & 1.40 & -0.001 \\
\hline 241-T-102 & SL-NL & 72 & 49 & 14.4 & 4.7 & 1.14 & 0.000 \\
\hline 241-T-107 & SL-NL & 655 & 0 & 70.4 & 0.0 & 1.17 & -0.024 \\
\hline 241-T-108 & MIX-NL & 167 & 0 & 23.5 & 0.0 & 1.40 & -0.013 \\
\hline 241-T-109 & SC/SS-NL & 220 & 0 & 28.6 & 0.0 & 1.39 & -0.003 \\
\hline 241-TX-101 & SL-NL & 318 & 11 & 38.0 & 1.1 & 1.17 & -0.002 \\
\hline 241-TX-102 & SC/SS-NL & 821 & 0 & 86.4 & 0.0 & 1.39 & -1.570 \\
\hline 241-TX-103 & SC/SS-NL & 594 & 0 & 64.6 & 0.0 & 1.39 & -0.100 \\
\hline 241-TX-104 & MIX-NL & 227 & 19 & 29.3 & 1.8 & 1.45 & -0.002 \\
\hline 241-TX-105 & SC/SS-NL & 2,305 & 0 & 228.9 & 0.0 & 1.39 & -0.001 \\
\hline 241-TX-106 & SC/SS-NL & 1,291 & 0 & 131.5 & 0.0 & 1.39 & -0.002 \\
\hline 241-TX-107 & SC/SS-NL & 132 & 4 & 20.2 & 0.4 & 1.39 & -0.003 \\
\hline 241-TX-108 & SC/SS-NL & 507 & 0 & 56.2 & 0.0 & 1.39 & 0.004 \\
\hline 241-TX-109 & SL-NL & 1454 & 0 & 147.1 & 0.0 & 1.17 & -0.002 \\
\hline 241-TX-110 & SC/SS-NL & 1,749 & 0 & 175.5 & 0.0 & 1.39 & -0.004 \\
\hline
\end{tabular}




\section{RPP-10006 REV 8}

Table D-1. dL/dP Data from Barometric Pressure Effects and Related Data to Calculate Void Fraction. (3 sheets)

\begin{tabular}{|c|c|c|c|c|c|c|c|}
\hline Tank name & Waste type & $\begin{array}{c}\text { NCL } \\
\text { volume } \\
\left(\mathrm{m}^{3}\right)\end{array}$ & $\begin{array}{c}\mathrm{CL} \\
\text { volume } \\
\left(\mathrm{m}^{3}\right)\end{array}$ & $\begin{array}{c}\text { NCL } \\
\text { depth } \\
\text { (in) }\end{array}$ & $\begin{array}{c}\text { CL } \\
\text { depth } \\
\text { (in) }\end{array}$ & $\begin{array}{c}\mathrm{CL} \\
\text { density } \\
(\mathrm{g} / \mathrm{mL})\end{array}$ & $\begin{array}{l}\text { BPE slope } \\
\text { (in/in } \mathrm{Hg} \text { ) }\end{array}$ \\
\hline References & $\begin{array}{l}\text { RPP-10006, Rev. 5, } \\
\text { Appendix A }\end{array}$ & \multicolumn{5}{|c|}{ RPP-5926, Rev. 0, 2000} & RPP-15488 \\
\hline 241-TX-111 & SC/SS-NL & 1,401 & 0 & 142.0 & 0.0 & 1.39 & 0.001 \\
\hline 241-TX-112 & SC/SS-NL & 2,457 & 0 & 243.5 & 0.0 & 1.39 & -0.002 \\
\hline 241-TX-113 & SC/SS-NL & 2,298 & 0 & 228.2 & 0.0 & 1.40 & 0.000 \\
\hline 241-TX-114 & SC/SS-NL & 2,025 & 0 & 202.0 & 0.0 & 1.39 & 0.000 \\
\hline 241-TX-115 & SC/SS-NL & 2,150 & 0 & 214.0 & 0.0 & 1.39 & -0.004 \\
\hline 241-TX-116 & SC/SS-NL & 2,389 & 0 & 236.9 & 0.0 & 1.39 & -0.002 \\
\hline 241-TX-117 & SC/SS-NL & 2,370 & 0 & 235.1 & 0.0 & 1.39 & 0.001 \\
\hline 241-TX-118 & SC/SS-NL & 1,136 & 0 & 116.6 & 0.0 & 1.39 & 0.003 \\
\hline 241-TY-101 & MIX-NL & 447 & 0 & 50.4 & 0.0 & 1.40 & -0.004 \\
\hline 241-TY-102 & SC/SS-NL & 242 & 0 & 30.7 & 0.0 & 1.39 & -0.008 \\
\hline 241-TY-103 & MIX-NL & 613 & 0 & 66.4 & 0.0 & 1.23 & -0.014 \\
\hline 241-TY-104 & SL-NL & 163 & 11 & 23.1 & 1.1 & 1.17 & -0.002 \\
\hline 241-TY-105 & SL-NL & 874 & 0 & 91.5 & 0.0 & 1.17 & -0.009 \\
\hline 241-TY-106 & SL-NL & 79 & 0 & 15.1 & 0.0 & 1.17 & -0.003 \\
\hline 241-U-103 & SC/SS-NL & 1,722 & 49 & 172.9 & 4.7 & 1.41 & -0.334 \\
\hline 241-U-105 & SC/SS-NL & 1,442 & 140 & 146.0 & 13.5 & 1.46 & -0.257 \\
\hline 241-U-106 & SC/SS-NL & 799 & 57 & 84.2 & 5.5 & 1.35 & -0.034 \\
\hline 241-U-107 & SC/SS-NL & 1,420 & 125 & 143.8 & 12.0 & 1.41 & -0.267 \\
\hline 241-U-109 & SC/SS-NL & 1,688 & 72 & 169.6 & 6.9 & 1.47 & -0.165 \\
\hline 241-U-110 & SL-NL & 704 & 0 & 75.1 & 0.0 & 1.17 & 0.004 \\
\hline
\end{tabular}

Notes:

${ }^{\mathrm{a}} \mathrm{CL}$ depth is 0 for calculation purposes - waste layers were inverted prior to saltwell pumping.

${ }^{\mathrm{b}} \mathrm{CL}$ Depth is based on information from HNF-EP-0182-130, 1999, Waste Tank Summary Report for Month

Ending 01/31/1999, Lockheed Martin Hanford Company, Richland, Washington.

RPP-5926, 2000, Steady-State Flammable Gas Release Rate Calculation and Lower Flammability Level

Evaluation for Hanford Tank Waste, Rev. 0, CH2M HILL Hanford Group, Inc., Richland, Washington.

RPP-15488, 2004, Investigation of Tank Void Fraction Using Liquid Level to Atmospheric Pressure Changes,

Rev. 0, CH2M HILL Hanford Group, Inc., Richland, Washington.

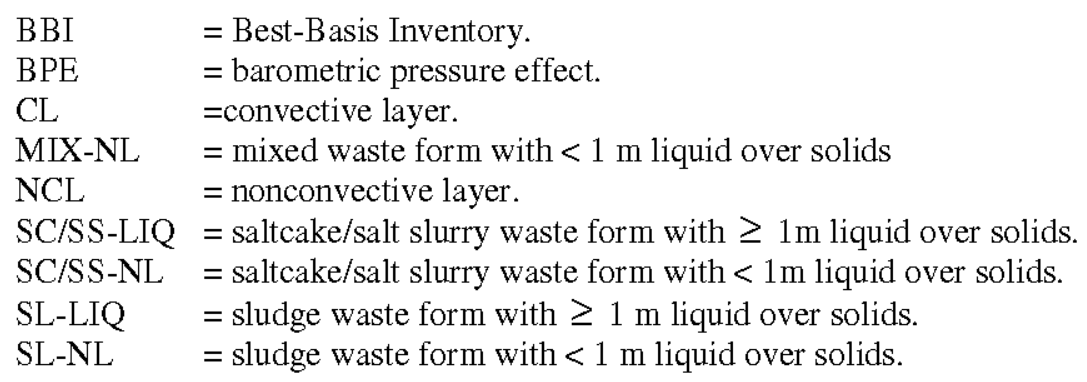




\section{D4.0 ASSUMPTIONS}

The following assumptions pertain to the void fraction development using the $\mathrm{dL} / \mathrm{dP}$ data of BPE which is calculated in the spreadsheet "SVF 1131 BPE to Void Fraction Master R0 060221 .xls" (see Section D6.0).

1. BPE sample data is normally distributed.

2. The waste surface is not fixed by waste intrusion such as risers, liquid observation wells, etc.

3. The surface of the waste was at least a small depth of liquid supernatant at the time of the level readings. The liquid pool should cover a majority of the waste surface.

4. The retained gas is subject to the pressure due to the liquid head only. The solids are self-supporting and do not contribute to the pressure on the retained gas.

5. Minimum retained gas volume is $100 \mathrm{ft}^{3}$

The following assumptions pertain to the default void fraction development for each waste type using all available field measured void fractions, which is calculated in the spreadsheet "RPP-10006r5 Void fraction revised data by tank - 060519 .xls" (see Section D6.0.)

1. Individual tank void fractions are normally distributed.

2. The default void fractions for the various waste types are fit to specific continuous distributions based on the results of a regression performed using Crystal Ball. ${ }^{1}$

3. The distributions selected for analysis are:

- Normal

- LogNormal

- Uniform

- Triangular

- Gamma.

\footnotetext{
${ }^{1}$ Crystal Ball is a trademark of Decisioneering, Inc., Denver, Colorado.
} 


\section{RPP-10006 REV 8}

4. The following waste types have insufficient data to be regressed by themselves. It is assumed that the following values will provide conservative default distributions for these waste types.

- $\quad$ SL-LIQ (sludge waste form with $\geq 1 \mathrm{~m}$ liquid over solids) tanks - Use SC/SS-LIQ (saltcake/salt slurry waste form with $\geq 1 \mathrm{~m}$ liquid over solids) distribution results bounded by the void fraction at neutral buoyancy.

- Liquid waste tanks - Set the void fraction to 0 .

- MIX-NL (mixed waste form with $<1 \mathrm{~m}$ liquid over solids) tanks - Use SC/SS-NL (saltcake/salt slurry waste form with $<1 \mathrm{~m}$ liquid over solids) distribution results.

- $\quad$ MIX-LIQ (mixed waste form with $\geq 1 \mathrm{~m}$ liquid over solids) tanks - Use SC/SS-LIQ distribution results bounded by the void fraction at neutral buoyancy.

5. The following list gives the order of void fraction data preference, the most preferred data source is given first:

- $\quad \mathrm{VFI}+\mathrm{RGS}$

- VFI

- BPE

- Derived default distribution based on waste type

- $\quad$ RGS (not to be used as a basis for individual tank mean void fraction).

\section{D5.0 METHODOLOGY}

The void fraction assigned to all 177 tanks is either field-measured data or statistically determined default value of each waste type. The void fractions of several tanks (Table D-7) have been reported based on the field-measured void fraction data from the VFI or RGS project. These data can be assigned to individual tanks and can also be used to determine the default value for each waste type.

The other field measured $\mathrm{dL} / \mathrm{dP}$ data is taken from the BPE method, which is the change in level corresponding to a unit change in pressure, can be used to derive the void fraction. The relationship between $\mathrm{dL} / \mathrm{dP}$ and the average in-situ void fraction, (PNNL-11693) based on the ideal gas law, is given as follows: 


$$
\alpha=\frac{P}{L} \times\left(-\frac{d L}{d P}\right)
$$

where $\mathrm{P}$ is the effective pressure at which the gas is stored, $\mathrm{L}$ is the total depth of the wetted waste.

In the calculation, the effective pressure can be calculated as follows:

$$
\mathrm{P}=\mathrm{P}_{\mathrm{HS}}+\rho_{\mathrm{CL}} * \mathrm{~g} *\left(\mathrm{H}_{\mathrm{CL}}+\mathrm{H}_{\mathrm{CR}}+0.5 * \mathrm{H}_{\mathrm{WNCL}}\right)
$$

where $\mathrm{P}_{\mathrm{HS}}$ is the pressure in the tank headspace (assumed to be 1 atmosphere), $\mathrm{g}$ is the gravity acceleration $\left(9.806 \mathrm{~m} / \mathrm{sec}^{2}\right), \mathrm{H}_{\mathrm{CL}}$ is the height of the liquid (convective) layer (m), $\mathrm{H}_{\mathrm{CR}}$ is the height of the crust layer (m), and $\mathrm{H}_{\mathrm{WNCL}}$ is the height of liquid saturated nonconvective layer $(\mathrm{m})$.

The total in-situ gas volume $V_{\text {gas }}$ is obtained by multiplying Equation D- 1 by the total waste volume

$$
V_{g a s}=A P \times\left(-\frac{d L}{d P}\right)
$$

where $\mathrm{A}$ is the tank cross-sectional area and $\mathrm{P}$ is the effective pressure of the gas stored.

As mentioned in Section D2.0, even though the $\mathrm{dL} / \mathrm{dP}$ are developed for all tanks that currently had ENRAF data, there are additional criteria for discarding the BPE data. Tanks that have a $\mathrm{BPE}$ response that is positive or equal to zero are not used. Tanks that do not have a liquid surface (greater than 0.3 in. of liquid) are also not used. In addition, if the calculated retained gas volume is less than $100 \mathrm{ft}^{3}$, the retained gas volume is increased to $100 \mathrm{ft}^{3}$. This is a conservative assumption which allows the use of BPE data from low volume tanks. Details of individual tank data are discussed in Section D7.0.

For DSTs 241-AN-107 and 241-SY-101, the dL/dP data are determined based on the waste level and pressure. The void fraction of DST 241-AN-107 has been evaluated using PCSACS data over 12 months, from October 1, 2004, through November 1, 2005. Using the spreadsheet "BP Correlation with DB Connect .xls" template, the ENRAF and meteorological data was retrieved from PCSACS and regressed to determine the BPE correlation for the time period selected. The methodology used in the spreadsheet is a simplified version of the methodology used in RPP-15488 and verified in Software Verification Form 1002. The spreadsheet "BP Correlation with DB Connect .xls" performs the evaluation of the surface level (ENRAF data from PCSACS) response to atmospheric pressure. The user estimates an approximate slope to the surface level response, then the program uses the Excel ${ }^{2}$ solver function to minimize the error to produce a statistical fit to the observed data, which returns the negative of the BPE slope.

\footnotetext{
${ }^{2}$ Excel is a registered trademark of Microsoft Corporation, Redmond, Washington.
} 


\section{RPP-10006 REV 8}

Once all the available void fraction data are collected or derived from the field-measurements, data are assigned to the specific tank and are used to determine the default void fraction distributions based on waste type. The individual tank void fractions are selected based on the priority of data as listed in the assumptions, Section D4.0. The tank specific void fractions for those with VFI or BPE data use an uncertainty of one half of the mean void fraction.

For tanks with no void fraction measurements, a default void fraction distribution is used. The default void fraction distributions are developed based on tanks with similar waste types. All void fraction data for a specific waste type is grouped together, no matter the source. There may be multiple void fractions for selected tanks, such as a collection of BPE, RGS, and VFI data. The collected data is ordered in increasing magnitude, and fit by Crystal Ball. The distributions evaluated -- normal, lognormal, uniform and gamma -- are listed in Section D4.0. When the regression data is returned, the best fit results are used to describe the default distribution for the evaluated waste type. Waste types with sparse data, less than seven samples, are assigned a conservative default distribution from the waste types that have been successfully evaluated. Similar waste types may also be grouped together for the creation of a default distribution. For example, SC/SS-NL and MIX-NL data are grouped together. Currently, for all waste types, SC/SS-LIQ is the conservative waste type.

\section{D6.0 COMPUTER SOFTWARE USE AND VERIFICATION}

The spreadsheets used in the calculations are as follows.

Spreadsheet: "BP Correlation with DB Connect .xls"

Spreadsheet Verification Form Number: SVF-1002, Spreadsheet Verification and Release Form for Spreadsheet 'BP Correlation with DB Connect .xls '

Author: Barnes, D. A.

Revision: Rev. 0, released 6/27/2005

Purpose: Identify if there is a statistically significant correlation between tank level changes and atmospheric barometric pressure and quantify the effects.

Spreadsheet Name: "SVF 1131 BPE to Void Fraction Master R0 060221 .xls"

Spreadsheet Verification Form Number: SVF-1131, Spreadsheet Verification and Release Form for Spreadsheet 'SVF 1131 BPE to Void Fraction Master R0 060221 .xls'

Author: Barker, S. A.

Spreadsheet Description Document: RPP-29388, Spreadsheet Description Document For 'SVF 1131 BPE to Void Fraction Master R0 060221 .xls'

Purpose: Converts raw BPE data to void fraction. 
RPP-10006 REV 8

Spreadsheet Name: "RPP-10006r5 Void fraction revised data by tank - 060519 .xls" Spreadsheet Verification Form Number: SVF-1132, Spreadsheet Verification and Release Form for Spreadsheet 'RPP-10006r 5 Void fraction revised data by tank 060519.xls'

Author: Barker, S. A.

Spreadsheet Description Document: RPP-29389, Spreadsheet Description Document For 'RPP-10006r5 Void fraction revised data by tank - 060519.xls'

Purpose: Calculates the various default distributions based on waste type.

\section{D7.0 RESULTS}

The results for the calculations documented in this appendix are given as follows.

- The $\mathrm{dL} / \mathrm{dP}$ data development and related void fraction calculations are performed for DSTs 241-AN-107 and 241-SY-101 based on the waste level and pressure with results in Section D7.1.

- There are $86 \mathrm{dL} / \mathrm{dP}$ data points available from the BPE study (RPP-15488). Void fractions are derived from the $\mathrm{dL} / \mathrm{dP}$ data using the density, waste level, and waste type data. Only 39 void fractions are validated and adopted for use (excluding 241-AN-107 and 241-SY-101) (see Section D7.2).

- With all the available void fraction data from VFI, RGS, and BPE methods, the default value for the waste types given below are listed in Section D7.3. Default void fraction assignments are made for the waste types below using available VFI, RGS, and BPE void fraction data.

- SC/SS-NL, and MIX-NL wastes using SC/SS-NL data

- SL-NL wastes

- SC/SS-LIQ, SL-LIQ, and MIX-LIQ wastes using SC/SS-LIQ data.

In addition, liquid waste is assigned a zero void fraction.

- Appendix H contains the void fraction value assigned to all 177 DSTs and SSTs. 


\section{D7.1 VOID FRACTION FOR DOUBLE-SHELL TANKS 241-AN-107 AND 241-SY-101}

Void fractions are determined using waste level, pressure, and dL/dP data for DSTs 241-AN-107 and 241-SY-101. Section D.7.1.1 summarizes the evaluation for DST 241-AN-107. Section D.7.1.2 summarizes the void fraction determination for DST 241-SY-101.

\section{D7.1.1 Determination of Void Fraction for Double-Shell Tank 241-AN-107}

Figure D-1 illustrates the relationship between the surface level in DST 241-AN-107 and the inverse barometric pressure for the time period between March 14, 2005, and May 16, 2005. The R-squared value of 0.93 indicates the fit of inverse barometric pressure to surface level is significant. Note that the sign convention for this procedure is opposite the sign convention used by PNL-10821, Screening the Hanford Tanks for Trapped Gas. Positive slopes for the BPE correlation are valid responses to the BPE test in spreadsheet "BP Correlation with DB Connect .xls," whereas negative slopes are valid responses to the BPE test in the PNL-10821 analyses.

In the analysis of DST 241-AN-107, it was found that six of the seven periods of time met the criteria required for a good fit to BPE data. Table D-2 presents the statistics and results for this analysis. The BPE results were then entered into the spreadsheet template "SVF 1131 BPE to Void Fraction Master R0 060221 .xls" to convert the results into void fraction (see Table D-3). After data analysis, an average void fraction of 0.011 was found and used to generate the void fraction distribution. The standard deviation of the good BPE data from all six periods with good fit is 0.003 and the observed void fractions ranged from 0.007 to 0.017 .

Table D-2. Results of the Barometric Pressure Effect Evaluation for Double-Shell Tank 241-AN-107.

\begin{tabular}{|c|l|l|c|c|c|c|c|c|c|}
\hline No. & Start date & End date & $\begin{array}{c}\text { Barometric } \\
\text { pressure } \\
\text { effect } \\
\text { (in./in._Hg)* }\end{array}$ & Gain & Offset & Slope & r 2 & Error & $\begin{array}{c}\text { Max } \\
\text { baro } \\
\text { press } \\
\text { change } \\
\text { (in._Hg) }\end{array}$ \\
\hline 1 & $10 / 1 / 2004$ & $12 / 10 / 2004$ & 0.012 & 9.97 & 400.100 & -1.289 & 0.981 & 0.007 & 1.37 \\
\hline 2 & $12 / 10 / 2004$ & $1 / 9 / 2005$ & 0.009 & 7.44 & 400.099 & 0.819 & 0.925 & 0.001 & 1.46 \\
\hline 3 & $3 / 14 / 2005$ & $5 / 16 / 2005$ & 0.015 & 12.79 & 400.019 & 0.619 & 0.930 & 0.004 & 1.03 \\
\hline 4 & $5 / 16 / 2005$ & $6 / 2 / 2005$ & 0.012 & 10.00 & 400.152 & -1.402 & 0.936 & 0.000 & 0.81 \\
\hline 5 & $6 / 3 / 2005$ & $7 / 17 / 2005$ & -0.011 & -9.19 & 400.873 & -1.005 & 0.972 & 0.001 & 0.62 \\
\hline 6 & $7 / 18 / 2005$ & $9 / 3 / 2005$ & 0.014 & 12.01 & 400.152 & 1.234 & 0.987 & 0.001 & 0.71 \\
\hline 7 & $9 / 9 / 2005$ & $11 / 1 / 2005$ & 0.022 & 18.68 & 399.866 & -2.137 & 0.990 & 0.006 & 0.85 \\
\hline
\end{tabular}

Note:

*For the analysis using "BP Correlation with DB Connect .xls," a positive barometric pressure effect indicates the data is valid. 
Figure D-1. Example of the Correlation Between Double-Shell Tank 241-AN-107 Surface Level With the Inverse Barometric Pressure.

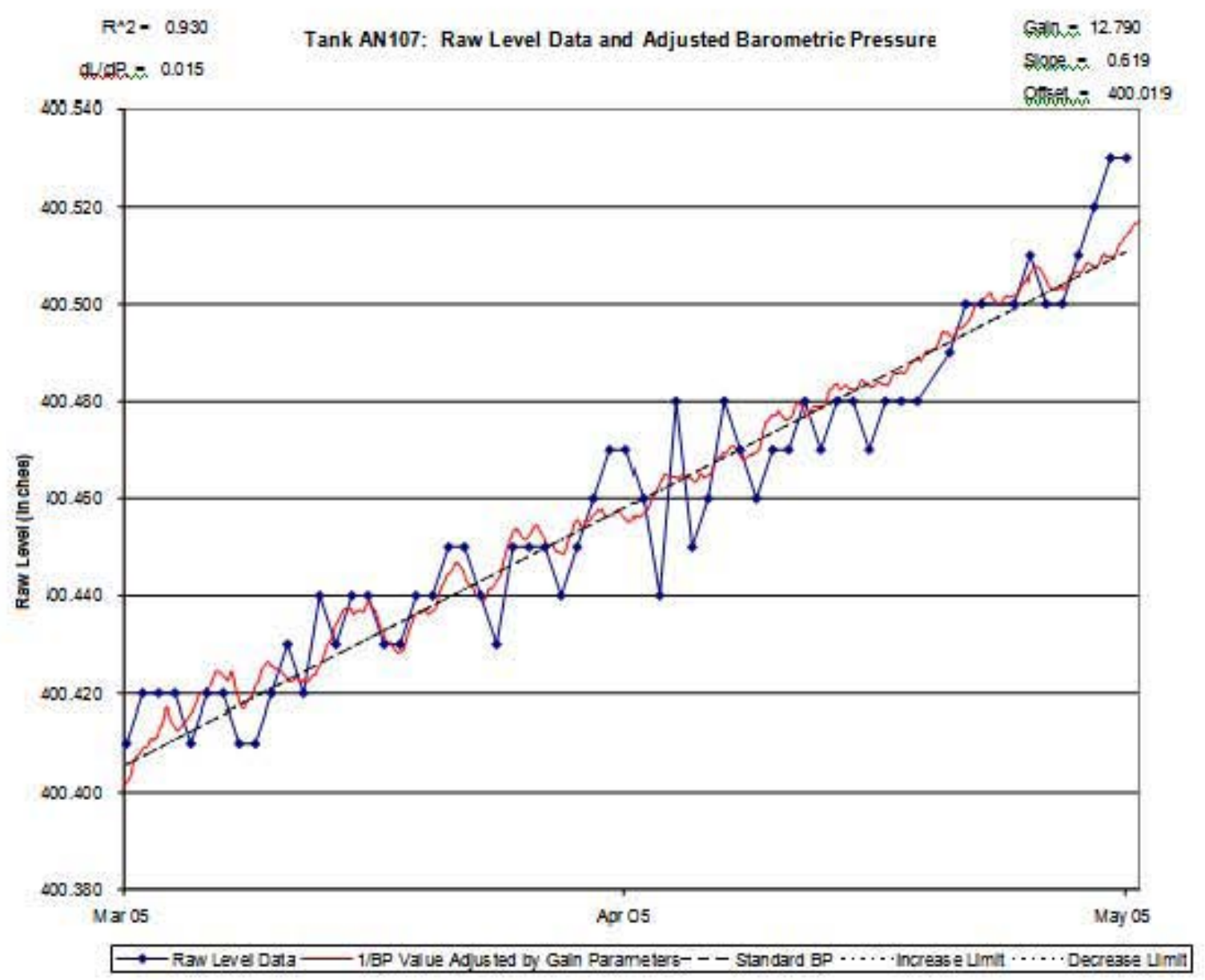

Table D-3. Results of the Yoid Fraction Determination for Double-Shell Tank 241-AN-107.

\begin{tabular}{|c|c|c|c|c|c|c|c|c|c|}
\hline No. & $\begin{array}{c}\text { PCSACs } \\
\text { waste level } \\
\text { (in.) }\end{array}$ & $\begin{array}{c}\text { Liquid } \\
\text { layer depth } \\
\text { (in.) }\end{array}$ & $\left|\begin{array}{l}\text { Solid layer } \\
\text { depth (in.) }\end{array}\right|$ & $\begin{array}{l}\text { Liquid } \\
\text { density } \\
\text { (gimL) }\end{array}$ & $\begin{array}{c}\text { Head } \\
\text { pressure } \\
\text { on gas (psi) }\end{array}$ & $\begin{array}{l}\text { BPE slope } \\
\text { (in/in. Hg) }\end{array}$ & $\begin{array}{c}\text { Volume of } \\
\text { retained } \\
\text { gas } \\
\text { (acf) }\end{array}$ & $\mid \begin{array}{c}\text { Volume of } \\
\text { solids } \\
\left(\mathrm{ft}^{2}\right)\end{array}$ & $\begin{array}{c}\text { Void } \\
\text { fraction }\end{array}$ \\
\hline 1 & 400.4 & 310.58 & 89.82 & 1.43 & 33.06 & -0.012 & 297 & 33,019 & 0.009 \\
\hline 2 & 400.4 & 310.58 & 89.82 & 1.43 & 33.06 & -0.009 & 223 & 33,019 & 0.007 \\
\hline 3 & 400.5 & 310.68 & 89.82 & 1.43 & 33.06 & -0.015 & 372 & 33,019 & 0.011 \\
\hline 4 & 400.5 & 310.68 & 89.82 & 1.43 & 33.06 & -0.012 & 297 & 33,019 & 0.009 \\
\hline 5 & 400.6 & 310.78 & 89.82 & 1.43 & 33.07 & 0.011 & NA & 33,019 & NA \\
\hline 6 & 400.6 & 310.78 & 89.82 & 1.43 & 33.07 & -0.014 & 347 & 33,019 & 0.011 \\
\hline 7 & 400.5 & 310.68 & 89.82 & 1.43 & 33.06 & -0.022 & 545 & 33,019 & 0.017 \\
\hline
\end{tabular}

Notes: BPE = barometric pressure ef fect.

PCSACS = per sonal computer Surveillance Analysis Computer System. 


\section{D7.1.2 Determination of Void Fraction for Double-Shell Tank 241-SY-101}

Figure D-2 illustrates the relationship between the surface level in DST 241-SY-101 and the inverse barometric pressure for the time period between March 14, 2005, and May 16, 2005. The R-squared value of 0.785 indicates that the fit of inverse barometric pressure to surface level is adequate. Figure D-2 shows much more movement in the hourly barometric pressure readings than can be explained by the number of surface readings stored in PCSACS (one surface level reading per day).

In the analysis of DST 241-SY-101, it was found that 11 periods of time met the criteria required for a good fit to BPE data. Table D-4 presents the statistics and results for this analysis.

Between October 2004 and September 2005, about 270 in. of liquid were added to the tank. The transfer into DST 241-SY-101 was completed on June 30, 2005. As expected, a slight decrease in void fraction was noted as the result of the increased head pressure on the retained gas due to this additional liquid.

The BPE results were then entered into the spreadsheet template "SVF 1131 BPE to Void Fraction Master R0 060221 .xls" to convert the results into void fraction. In all cases, the retained gas volume was found to be greater than $1,000 \mathrm{ft}^{3}$. The mean void fraction for DST 241-SY-101 is 0.085 with a standard deviation of 0.024 and a range from 0.041 to 0.125 . Table D-5 presents the summary of retained gas volumes and void fraction.

Table D-4. Results of the Barometric Pressure Effect Evaluation for Double-Shell Tank 241-SY-101.

\begin{tabular}{|c|l|l|c|c|c|c|c|c|c|}
\hline No. & Start date & End date & $\begin{array}{c}\text { Barometric } \\
\text { pressure } \\
\text { effect } \\
\text { (in./in._hg)* }\end{array}$ & Gain & Offset & Slope & $\mathbf{r}^{2}$ & Error & $\begin{array}{c}\text { Baro } \\
\text { press } \\
\text { change } \\
\text { (in._Hg) }\end{array}$ \\
\hline 1 & $9 / 13 / 2005$ & $9 / 29 / 2005$ & 0.063 & 53.38 & 409.612 & 0.901 & 0.71 & 0.001 & 0.56 \\
\hline 2 & $8 / 25 / 2005$ & $9 / 13 / 2005$ & 0.112 & 95.33 & 408.193 & 0.019 & 0.71 & 0.002 & 0.56 \\
\hline 3 & $7 / 14 / 2005$ & $8 / 13 / 2005$ & 0.093 & 79.06 & 407.846 & 0.576 & 0.785 & 0.002 & 0.69 \\
\hline 4 & $5 / 13 / 2005$ & $5 / 29 / 2005$ & 0.24 & 205.1 & 138.591 & 0.992 & 0.799 & 0.013 & 0.81 \\
\hline 5 & $4 / 13 / 2005$ & $5 / 12 / 2005$ & 0.24 & 205.1 & 140.58 & 2.396 & 0.886 & 0.026 & 0.66 \\
\hline 6 & $3 / 31 / 2005$ & $4 / 12 / 2005$ & 0.227 & 193.83 & 140.58 & 0.496 & 0.694 & 0.017 & 0.9 \\
\hline 7 & $3 / 7 / 2005$ & $3 / 30 / 2005$ & 0.278 & 237.01 & 137.432 & 0.496 & 0.831 & 0.017 & 0.9 \\
\hline 8 & $3 / 7 / 2005$ & $3 / 4 / 2005$ & 0.25 & 212.90 & 138.338 & -0.72 & 0.904 & 0.000 & 0.38 \\
\hline 9 & $1 / 21 / 2005$ & $3 / 4 / 2005$ & 0.25 & 210.63 & 131.157 & -0.72 & 0.722 & 0.024 & 0.66 \\
\hline 10 & $1 / 21 / 2005$ & $1 / 18 / 2005$ & 0.325 & 277.41 & 128.989 & -2.093 & 0.917 & 0.041 & 1.57 \\
\hline 11 & $10 / 17 / 2004$ & $1 / 18 / 2004$ & 0.231 & 196.78 & 131.746 & -2.191 & 0.914 & 0.131 & 1.48 \\
\hline
\end{tabular}

Note:

*For the analysis using "BP Correlation with DB Connect .xls," a positive barometric pressure effect indicates the data is valid. 


\section{RPP-10006 REV 8}

Figure D-2. Example of the Correlation Between Double-Shell Tank 241-SY-101 Surface Level With the Inverse Barometric Pressure.

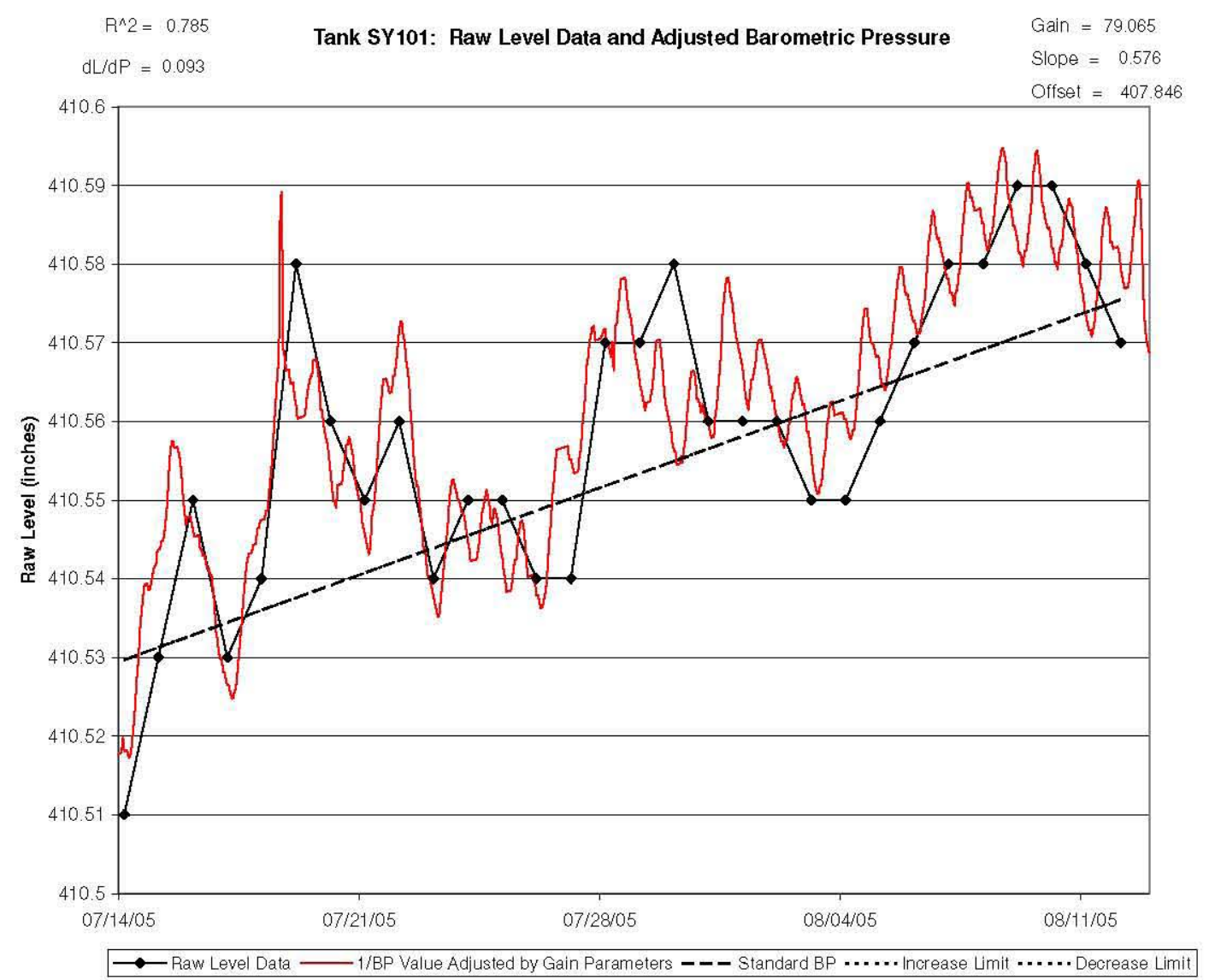

Table D-5. Results of the Void Fraction Determination for Double-Shell Tank 241-SY-101.

\begin{tabular}{|c|c|c|c|c|c|c|c|c|c|}
\hline No. & $\begin{array}{c}\text { PCSACS } \\
\text { waste } \\
\text { level } \\
\text { (in) }\end{array}$ & $\begin{array}{c}\text { Liquid } \\
\text { layer } \\
\text { depth } \\
\text { (in) }\end{array}$ & $\begin{array}{c}\text { Solid } \\
\text { layer } \\
\text { depth } \\
\text { (in) }\end{array}$ & $\begin{array}{c}\text { Liquid } \\
\text { density } \\
\text { (g/mL) }\end{array}$ & $\begin{array}{c}\text { Head } \\
\text { pressure } \\
\text { on gas } \\
\text { (psi) }\end{array}$ & $\begin{array}{c}\text { BPE } \\
\text { slope } \\
\text { (in/in Hg) }\end{array}$ & $\begin{array}{c}\text { Retained } \\
\text { gas } \\
\text { volume } \\
\text { (acf) }\end{array}$ & $\begin{array}{c}\text { Volume } \\
\text { of solids } \\
\left.\text { (ft } \mathbf{3}^{3}\right)\end{array}$ & $\begin{array}{c}\text { Void } \\
\text { fraction }\end{array}$ \\
\hline 1 & 411.4 & 311.4 & 100 & 1.30 & 31.66 & 0.063 & NA & 36,833 & NA \\
\hline 2 & 411.5 & 311.5 & 100 & 1.30 & 31.67 & -0.112 & 2,659 & 36,833 & 0.072 \\
\hline 3 & 410.6 & 310.6 & 100 & 1.30 & 31.63 & -0.093 & 2,205 & 36,833 & 0.060 \\
\hline 4 & 145.6 & 45.6 & 100 & 1.30 & 19.18 & -0.24 & 3,450 & 36,833 & 0.094 \\
\hline 5 & 145.6 & 45.6 & 100 & 1.30 & 19.18 & -0.24 & 2,473 & 36,833 & 0.067 \\
\hline 6 & 145.5 & 46 & 100 & 1.30 & 19.18 & -0.227 & 3,264 & 36,833 & 0.089 \\
\hline 7 & 145.6 & 46 & 100 & 1.30 & 19.18 & -0.278 & 3,997 & 36,833 & 0.109 \\
\hline 8 & 145.6 & 45.6 & 100 & 1.30 & 19.18 & -0.25 & 3,594 & 36,833 & 0.098 \\
\hline 9 & 138.3 & 38.3 & 100 & 1.30 & 18 & -0.25 & 3,488 & 36,833 & 0.095 \\
\hline 10 & 138.5 & 38.5 & 100 & 1.30 & 18.85 & -0.325 & 4,592 & 36,833 & 0.125 \\
\hline 11 & 138.5 & 38.5 & 100 & 1.30 & 18.85 & -0.231 & 3,264 & 36,833 & 0.089 \\
\hline
\end{tabular}

Notes: $\mathrm{BPE}=$ barometric pressure effect.

PCSACS $=$ personal computer Surveillance Analysis Computer System. 


\section{D7.2 BEST VOID FRACTION DATA}

The distribution of all available tank average void fraction values determined from VFI data (with or without RGS data added) or RGS and BPE data are used to derive an average void fraction distribution for a waste form. When available for a specific tank, RGS and VFI data are combined into a single average. A distribution of individual RGS segment voids is not appropriate to characterize a tank average void since, at present, there are very few data points per tank (e.g., three to six) and they represent local effects. Therefore, in the cases where RGS data are available, it is only appropriate to use them to develop an average void fraction distribution for each waste form.

Table D-6 summarizes the BPE evaluation final results. The actual values used for the tank void fraction means or the default distribution regression are identified in the "Validated void fraction from $\mathrm{dL} / \mathrm{dP}$ data" column.

The average void fraction distribution determined for a specific tank from VFI data (with or without RGS data added) or BPE should be used in preference to the default void fraction distribution for the tank waste form.

Table D-6. Void Fraction Data from Barometric Pressure Effect and Related Data to Calculate

Void Fraction. (4 sheets)

\begin{tabular}{|c|c|c|c|c|c|}
\hline Tank name & Waste type & $\begin{array}{l}\text { Effective } \\
\text { Pressure } \\
\quad \text { (psi) }\end{array}$ & $\begin{array}{l}\text { Calculated } \\
\text { void fraction } \\
\text { (unitless) }\end{array}$ & $\begin{array}{l}\text { Calculated } \\
\text { retained gas } \\
\text { volume } \\
\quad \text { (acf) }\end{array}$ & $\begin{array}{l}\text { Validated void fraction } \\
\text { from dL/dP data }\end{array}$ \\
\hline 241-A-101 & SC/SS-NL & 18.78 & 0.086 & 5,124 & Adopted value 0.086 \\
\hline 241-A-103 & SC/SS-NL & 18.35 & 0.004 & 179 & Adopted value 0.004 \\
\hline 241-A-106 & MIX-NL & 15.65 & NA & -59 & Dropped due to zero or positive $\mathrm{dL} / \mathrm{dP}$ \\
\hline 241-AN-101 & SC/SS-LIQ & 16.88 & NA & 0 & Dropped due to zero or positive $\mathrm{dL} / \mathrm{dP}$ \\
\hline 241-AN-103 & SC/SS-LIQ & 29.43 & 0.215 & 11,802 & Adopted value 0.215 \\
\hline 241-AN-104 & SC/SS-LIQ & 29.93 & 0.084 & 5,070 & Adopted value 0.084 \\
\hline $241-\mathrm{AN}-105$ & SC/SS-LIQ & 31.13 & 0.064 & 4,200 & Adopted value 0.064 \\
\hline 241-AW-101 & SC/SS-LIQ & 32.59 & 0.152 & 6,229 & Adopted value 0.152 \\
\hline 241-AW-103 & SL-LIQ & 19.19 & 0.009 & 417 & Adopted value 0.009 \\
\hline 241-AW-104 & SC/SS-LIQ & 31.17 & 0.058 & 1,776 & Adopted value 0.058 \\
\hline 241-AW-105 & SL-LIQ & 18.56 & NA & -14 & Dropped due to zero or positive $\mathrm{dL} / \mathrm{dP}$ \\
\hline 241-AW-106 & SC/SS-LIQ & 21.2 & 0.032 & 985 & Adopted value 0.032 \\
\hline 241-AX-101 & SC/SS-NL & 18.21 & 0.002 & 41 & $\begin{array}{l}\text { Updated value } \mathrm{w} / 100 \mathrm{ft}^{3} \mathrm{RG} \quad 0.002 \\
\text { Not used - too far from RGS sample } \\
0.170\end{array}$ \\
\hline 241-AX-102 & SC/SS-NL & 14.96 & NA & -56 & Dropped due to zero or positive $\mathrm{dL} / \mathrm{dP}$ \\
\hline
\end{tabular}


RPP-10006 REV 8

Table D-6. Void Fraction Data from Barometric Pressure Effect and Related Data to Calculate Void Fraction. (4 sheets)

\begin{tabular}{|c|c|c|c|c|c|}
\hline Tank name & Waste type & $\begin{array}{l}\text { Effective } \\
\text { Pressure } \\
\text { (psi) }\end{array}$ & $\begin{array}{l}\text { Calculated } \\
\text { void fraction } \\
\text { (unitless) }\end{array}$ & $\begin{array}{l}\text { Calculated } \\
\text { retained gas } \\
\text { volume } \\
\text { (acf) }\end{array}$ & $\begin{array}{l}\text { Validated void fraction } \\
\text { from } \mathrm{dL} / \mathrm{dP} \text { data }\end{array}$ \\
\hline 241-AX-103 & SC/SS-NL & 15.71 & NA & 24 & Dropped due to no liquid layer \\
\hline 241-AX-104 & SL-NL & 14.75 & NA & 0 & Dropped due to zero or positive $\mathrm{dL} / \mathrm{dP}$ \\
\hline 241-AY-101 & SL-NL & 16.11 & 0.042 & 604 & Adopted value 0.042 \\
\hline 241-AY-102 & SL-LIQ & 22.09 & 0.011 & 298 & Dropped due to waste transfer interrupt \\
\hline 241-AZ-101 & SL-LIQ & 27.53 & NA & $-1,919$ & Dropped due to zero or positive $\mathrm{dL} / \mathrm{dP}$ \\
\hline 241-B-102 & SC/SS-NL & 15.2 & 0.027 & 11 & Updated value $\mathrm{w} / 100 \mathrm{ft}^{3} \mathrm{RG} \quad 0.027$ \\
\hline 241-B-112 & MIX-NL & 15.16 & 0.025 & 23 & Updated value $w / 100 \mathrm{ft}^{3} \mathrm{RG} \quad 0.025$ \\
\hline 241-BX-101 & SL-NL & 15.23 & 0.020 & 114 & Adopted value 0.02 \\
\hline 241-BX-102 & SL-NL & 15.59 & NA & 35 & Dropped due to no liquid layer \\
\hline $241-B X-103$ & SL-NL & 15.53 & 0.012 & 35 & Updated value $\mathrm{w} / 100 \mathrm{ft}^{3} \mathrm{RG} \quad 0.012$ \\
\hline 241-BX-104 & SL-NL & 15.73 & 0.075 & 967 & Adopted value 0.075 \\
\hline 241-BX-105 & MIX-NL & 15.34 & 0.016 & 23 & Updated value $\mathrm{w} / 100 \mathrm{ft}^{3} \mathrm{RG} \quad 0.016$ \\
\hline 241-BX-106 & SC/SS-NL & 15.14 & NA & -11 & Dropped due to zero or positive $\mathrm{dL} / \mathrm{dP}$ \\
\hline 241-BX-107 & SL-NL & 17.51 & 0.025 & 1,155 & Adopted value 0.025 \\
\hline 241-BX-108 & SL-NL & 15.05 & NA & -11 & Dropped due to zero or positive $\mathrm{dL} / \mathrm{dP}$ \\
\hline 241-BX-109 & SL-NL & 16.33 & NA & 86 & Dropped due to no liquid layer \\
\hline $241-B X-110$ & MIX-NL & 16.81 & 0.040 & 1,084 & Adopted value 0.040 \\
\hline 241-BX-111 & SC/SS-NL & 16.37 & 0.005 & 25 & Updated value $w / 100 \mathrm{ft}^{3} \mathrm{RG} \quad 0.005$ \\
\hline 241-BX-112 & SL-NL & 16.14 & 0.005 & 109 & Adopted value 0.005 \\
\hline 241-C-103 & SL-NL & 16.8 & 0.006 & 13 & Updated value $\mathrm{w} / 100 \mathrm{ft}^{3} \mathrm{RG} \quad 0.006$ \\
\hline 241-C-106 & SL-NL & 15.5 & NA & -105 & Dropped due to zero or positive $\mathrm{dL} / \mathrm{dP}$ \\
\hline 241-C-107 & SL-NL & 16.82 & NA & 50 & Dropped due to no liquid layer \\
\hline 241-S-101 & MIX-NL & 18.8 & 0.043 & 2,410 & Adopted value 0.043 \\
\hline 241-S-102 & SC/SS-NL & 19.57 & NA & 7,599 & Dropped due to no liquid layer \\
\hline 241-S-103 & SC/SS-NL & 17.3 & 0.147 & 4,526 & Adopted value 0.147 \\
\hline 241-S-106 & SC/SS-NL & 19.74 & 0.082 & 4,676 & Adopted value 0.082 \\
\hline 241-S-107 & SL-NL & 17.84 & 0.024 & 1,163 & Adopted value 0.024 \\
\hline $241-\mathrm{S}-108$ & SC/SS-NL & 18.99 & NA & 14 & Dropped due to no liquid layer \\
\hline $241-\mathrm{S}-110$ & SC/SS-NL & 18.55 & NA & -362 & Dropped due to zero or positive dL/dP \\
\hline 241-S-111 & SC/SS-NL & 20.82 & 0.119 & 6,820 & Adopted value 0.119 \\
\hline 241-SX-101 & MIX-NL & 19.33 & NA & 21,922 & Dropped due to no liquid layer \\
\hline 241-SX-103 & SC/SS-NL & 21.03 & NA & 48,914 & Dropped due to no liquid layer \\
\hline 241-SX-104 & MIX-NL & 19.16 & NA & 804 & Dropped due to no liquid layer \\
\hline 241-SX-105 & SC/SS-NL & 21.06 & NA & 50,215 & Dropped due to no liquid layer \\
\hline
\end{tabular}


RPP-10006 REV 8

Table D-6. Void Fraction Data from Barometric Pressure Effect and Related Data to Calculate Void Fraction. (4 sheets)

\begin{tabular}{|c|c|c|c|c|c|}
\hline Tank name & Waste type & $\begin{array}{l}\text { Effective } \\
\text { Pressure } \\
\text { (psi) }\end{array}$ & $\begin{array}{l}\text { Calculated } \\
\text { void fraction } \\
\text { (unitless) }\end{array}$ & $\begin{array}{l}\text { Calculated } \\
\text { retained gas } \\
\text { volume } \\
\text { (acf) }\end{array}$ & $\begin{array}{l}\text { Validated void fraction } \\
\text { from } \mathrm{dL} / \mathrm{dP} \text { data }\end{array}$ \\
\hline 241-SX-106 & SC/SS-NL & 19.78 & 0.140 & 6,034 & Adopted value 0.140 \\
\hline 241-SY-102 & SL-LIQ & 23.5 & 0.009 & 106 & Adopted value 0.009 \\
\hline 241-SY-103 & SC/SS-LIQ & 25.56 & 0.078 & 3,755 & Adopted value 0.078 \\
\hline 241-T-101 & MIX-NL & 15.83 & 0.007 & 12 & Updated value $\mathrm{w} / 100 \mathrm{ft}^{3} \mathrm{RG} \quad 0.007$ \\
\hline $241-\mathrm{T}-102$ & SL-NL & 15.18 & NA & 0 & Dropped due to zero or positive $\mathrm{dL} / \mathrm{dP}$ \\
\hline 241-T-107 & SL-NL & 16.18 & NA & 291 & Dropped due to no liquid layer \\
\hline 241-T-108 & MIX-NL & 15.28 & NA & 149 & Dropped due to no liquid layer \\
\hline 241-T-109 & SC/SS-NL & 15.41 & NA & 35 & Dropped due to no liquid layer \\
\hline 241-TX-101 & SL-NL & 15.54 & 0.009 & 23 & Updated value $w / 100 \mathrm{ft}^{3} \mathrm{RG} \quad 0.009$ \\
\hline 241-TX-102 & SC/SS-NL & 16.86 & NA & 19,841 & Dropped due to no liquid layer \\
\hline 241-TX-103 & SC/SS-NL & 16.31 & NA & 1,223 & Dropped due to no liquid layer \\
\hline 241-TX-104 & MIX-NL & 15.55 & 0.012 & 23 & Updated value $\mathrm{w} / 100 \mathrm{ft}^{3} \mathrm{RG} \quad 0.012$ \\
\hline 241-TX-105 & SC/SS-NL & 20.44 & NA & 15 & Dropped due to no liquid layer \\
\hline 241-TX-106 & SC/SS-NL & 17.99 & NA & 27 & Dropped due to no liquid layer \\
\hline 241-TX-107 & SC/SS-NL & 15.22 & 0.021 & 34 & Updated value w/ $100 \mathrm{ft}^{3} \mathrm{RG} \quad 0.021$ \\
\hline 241-TX-108 & SC/SS-NL & 16.1 & NA & -48 & Dropped due to zero or positive $\mathrm{dL} / \mathrm{dP}$ \\
\hline 241-TX-109 & SL-NL & 17.8 & NA & 27 & Dropped due to no liquid layer \\
\hline 241-TX-110 & SC/SS-NL & 19.1 & NA & 57 & Dropped due to no liquid layer \\
\hline 241-TX-111 & SC/SS-NL & 18.26 & NA & -14 & Dropped due to zero or positive $\mathrm{dL} / \mathrm{dP}$ \\
\hline 241-TX-112 & SC/SS-NL & 20.8 & NA & 31 & Dropped due to no liquid layer \\
\hline 241-TX-113 & SC/SS-NL & 20.46 & NA & 0 & Dropped due to zero or positive $\mathrm{dL} / \mathrm{dP}$ \\
\hline 241-TX-114 & SC/SS-NL & 19.76 & NA & 0 & Dropped due to zero or positive $\mathrm{dL} / \mathrm{dP}$ \\
\hline 241-TX-115 & SC/SS-NL & 20.06 & NA & 60 & Dropped due to no liquid layer \\
\hline 241-TX-116 & SC/SS-NL & 20.64 & NA & 31 & Dropped due to no liquid layer \\
\hline 241-TX-117 & SC/SS-NL & 20.59 & NA & -15 & Dropped due to zero or positive $\mathrm{dL} / \mathrm{dP}$ \\
\hline 241-TX-118 & SC/SS-NL & 17.62 & NA & -33 & Dropped due to zero or positive $\mathrm{dL} / \mathrm{dP}$ \\
\hline 241-TY-101 & MIX-NL & 15.96 & NA & 48 & Dropped due to no liquid layer \\
\hline 241-TY-102 & SC/SS-NL & 15.46 & NA & 93 & Dropped due to no liquid layer \\
\hline 241-TY-103 & MIX-NL & 16.17 & NA & 170 & Dropped due to no liquid layer \\
\hline 241-TY-104 & SL-NL & 15.22 & 0.017 & 23 & Updated value w/ $100 \mathrm{ft}^{3} \mathrm{RG} \quad 0.017$ \\
\hline 241-TY-105 & SL-NL & 16.62 & NA & 112 & Dropped due to no liquid layer \\
\hline 241-TY-106 & SL-NL & 15.01 & NA & 34 & Dropped due to no liquid layer \\
\hline 241-U-103 & SC/SS-NL & 19.33 & 0.080 & 4,839 & Adopted value 0.080 \\
\hline 241-U-105 & SC/SS-NL & 19.25 & 0.073 & 3,708 & Adopted value $\quad 0.073$ \\
\hline
\end{tabular}


Table D-6. Void Fraction Data from Barometric Pressure Effect and Related Data to Calculate Void Fraction. (4 sheets)

\begin{tabular}{|l|l|c|c|c|l|}
\hline Tank name & Waste type & $\begin{array}{c}\text { Effective } \\
\text { Pressure } \\
\text { (psi) }\end{array}$ & $\begin{array}{c}\text { Calculated } \\
\text { void fraction } \\
\text { (unitless) }\end{array}$ & $\begin{array}{c}\text { Calculated } \\
\text { retained gas } \\
\text { volume } \\
\text { (acf) }\end{array}$ & $\begin{array}{c}\text { Validated void fraction } \\
\text { from dL/dP data }\end{array}$ \\
\hline 241-U-106 & SC/SS-NL & 17.01 & 0.015 & 434 & Adopted value 0.015 \\
\hline $241-U-107$ & SC/SS-NL & 18.96 & 0.076 & 3,795 & Adopted value 0.076 \\
\hline $241-U-109$ & SC/SS-NL & 19.56 & 0.041 & 2,419 & Adopted value 0.041 \\
\hline 241-U-110 & SL-NL & 16.28 & NA & -49 & Dropped due to zero or positive $\mathrm{dL} / \mathrm{dP}$ \\
\hline
\end{tabular}

Notes:

MIX-NL = mixed waste form with $<1 \mathrm{~m}$ liquid over solids

NA $\quad=$ not applicable.

SC/SS-LIQ $=$ saltcake/salt slurry waste form with $\geq 1 \mathrm{~m}$ liquid over solids.

$\mathrm{SC} / \mathrm{SS}-\mathrm{NL}=$ saltcake/salt slurry waste form with $<1 \mathrm{~m}$ liquid over solids.

SL-LIQ = sludge waste form with $\geq 1 \mathrm{~m}$ liquid over solids.

SL-NL = sludge waste form with $<1 \mathrm{~m}$ liquid over solids.

\section{D7.3 DEFAULT VOID FRACTIONS FOR EACH WASTE TYPE}

The void fraction analysis was performed based on the type of waste found in the tanks. A full discussion of the waste type classification can be found in SNL-000198 and RPP-6171. Default distributions are generated for the following waste categories: saltcake/salt slurry waste without at least $1 \mathrm{~m}$ of supernatant liquid (SC/SS-NL), sludge waste without at least $1 \mathrm{~m}$ of supernatant liquid (SL-NL), saltcake/salt slurry waste with at least $1 \mathrm{~m}$ of supernatant liquid (SC/SS-LIQ), sludge waste with at least $1 \mathrm{~m}$ of supernatant liquid (SL-LIQ), liquid waste (LIQUID), mixed waste without at least $1 \mathrm{~m}$ of supernatant liquid (MIX-NL), and mixed waste with at least $1 \mathrm{~m}$ of supernatant liquid (MIX-LIQ). The void fraction results are grouped together to conservatively estimate void fractions for waste types, which do not have sufficient void fraction data to perform a valid statistical analysis. A complete listing of the tanks and their waste types can be found in Appendix $\mathrm{H}$.

\section{D7.3.1 SC/SS-NL and MIX-NL Default Void Fraction}

The data for SC/SS-NL and MIX-NL wastes (Table D-7) have been regressed using Crystal Ball to fit a normal distribution which is then truncated to bound the values to those expected for the void fraction for the given waste type as shown in Figure D-3. The original boundary recommendations are presented in SNL-000198. The graph represents a truncated normal distribution with a mean and standard deviation as shown below. The default void fraction of 8.84 and its statistical distribution for SC/SS-NL and MIX-NL waste is given in Table D-8. 
Table D-7. Summary of Mean Void Fraction Data for SC/SS-NL and MIX-NL Tanks With Measured Values. (2 sheets)

\begin{tabular}{|c|c|c|c|c|c|c|c|c|}
\hline Tank ID & $\begin{array}{l}\text { BPE } \\
\text { data }^{a}\end{array}$ & $\begin{array}{c}\text { BPE } \\
\text { method } \\
\text { calc'd } \\
\text { retained } \\
\text { gas volume } \\
\text { (acf) }\end{array}$ & $\begin{array}{l}\text { VFI } \\
\text { only } \\
\text { data }\end{array}$ & $\begin{array}{c}\text { VFI+RGS } \\
\text { data }^{b}\end{array}$ & $\begin{array}{l}\text { Mahoney } \\
\text { RGS void } \\
\text { fraction }^{\mathrm{c}}\end{array}$ & $\begin{array}{l}\text { Huckaby/ } \\
\text { Whitney } \\
\text { BPE data } \\
10 / 01 / 03^{d}\end{array}$ & $\begin{array}{c}\text { Barker- } \\
\text { Barnes } \\
\text { 2/8/2006 }\end{array}$ & Waste type \\
\hline 241-B-112 & 0.025 & 23 & -- & -- & -- & -- & & MIX-NL \\
\hline 241-BX-105 & 0.016 & 23 & -- & -- & -- & -- & -- & MIX-NL \\
\hline 241-BX-110 & 0.04 & 1,084 & -- & -- & -- & -- & -- & MIX-NL \\
\hline 241-S-101 & 0.043 & 2,410 & -- & -- & -- & -- & -- & MIX-NL \\
\hline 241-T-101 & 0.007 & 12 & -- & -- & -- & -- & -- & MIX-NL \\
\hline 241-TX-104 & 0.012 & 23 & -- & -- & -- & -- & -- & MIX-NL \\
\hline 241-A-101 & 0.086 & 5,124 & -- & -- & 0.18 & -- & -- & SC/SS-NL \\
\hline 241-A-103 & 0.004 & 179 & -- & -- & -- & -- & -- & SC/SS-NL \\
\hline 241-AX-101 & -- & 41 & -- & -- & 0.17 & -- & -- & $\mathrm{SC} / \mathrm{SS}-\mathrm{NL}$ \\
\hline 241-B-102 & 0.027 & 11 & -- & -- & -- & -- & -- & SC/SS-NL \\
\hline 241-BX-111 & 0.005 & 25 & -- & -- & -- & -- & -- & SC/SS-NL \\
\hline 241-BY-109 & -- & 86 & - & -- & 0.094 & - & - & $\mathrm{SC} / \mathrm{SS}-\mathrm{NL}$ \\
\hline $241-\mathrm{S}-102$ & -- & 7,599 & -- & -- & 0.26 & -- & -- & SC/SS-NL \\
\hline $241-\mathrm{S}-103$ & 0.147 & 4,526 & -- & -- & -- & -- & -- & SC/SS-NL \\
\hline $241-S-106$ & 0.082 & 4,676 & -- & -- & 0.1 & -- & -- & $\mathrm{SC} / \mathrm{SS}-\mathrm{NL}$ \\
\hline $241-\mathrm{S}-111$ & 0.119 & 6,820 & -- & -- & 0.15 & -- & -- & $\mathrm{SC} / \mathrm{SS}-\mathrm{NL}$ \\
\hline 241-SX-106 & 0.14 & 6,034 & -- & -- & 0.14 & -- & -- & $\mathrm{SC} / \mathrm{SS}-\mathrm{NL}$ \\
\hline 241-TX-107 & 0.021 & 34 & -- & -- & -- & -- & -- & SC/SS-NL \\
\hline 241-U-103 & 0.08 & 4,839 & -- & -- & 0.19 & -- & -- & $\mathrm{SC} / \mathrm{SS}-\mathrm{NL}$ \\
\hline 241-U-105 & 0.073 & 3,708 & -- & -- & -- & -- & -- & SC/SS-NL \\
\hline 241-U-106 & 0.015 & 434 & -- & -- & -- & -- & -- & $\mathrm{SC} / \mathrm{SS}-\mathrm{NL}$ \\
\hline 241-U-107 & 0.076 & 3,795 & -- & -- & -- & -- & -- & $\mathrm{SC} / \mathrm{SS}-\mathrm{NL}$ \\
\hline 241-U-109 & 0.041 & 2,419 & -- & -- & 0.22 & -- & -- & SC/SS-NL \\
\hline
\end{tabular}

Notes:

References:

${ }^{\mathrm{a}} \mathrm{B}$ ased on BPE data from RPP-15488, 2004.

bPNL-11536, 1997.

'PNNL-13317, 2000.

${ }^{\mathrm{d}} \mathrm{RPP}-10006,2004$.

$\mathrm{BPE}=$ barometric pressure effect.

MIX-NL = mixed waste from with $<1 \mathrm{~m}$ liquid over solids.

NA $\quad=$ not applicable.

RGS = retained gas sampler.

SC/SS-NL = saltcake/salt slurry waste form with $<1 \mathrm{~m}$ liquid over solids .

VFI = void fraction instrument. 
Table D-8. Default Void Fraction for

SC/SS-NL and MIX-NL Waste with

Truncated Normal Distribution.

\begin{tabular}{|l|c|}
\hline Mean & 8.84 \\
\hline Standard deviation & 7.13 \\
\hline Truncate low & 0.01 \\
\hline Truncate high & 40 \\
\hline
\end{tabular}

Figure D-3. Void Fraction Regression Results for SC/SS-NL and MIX-NL Wastes.

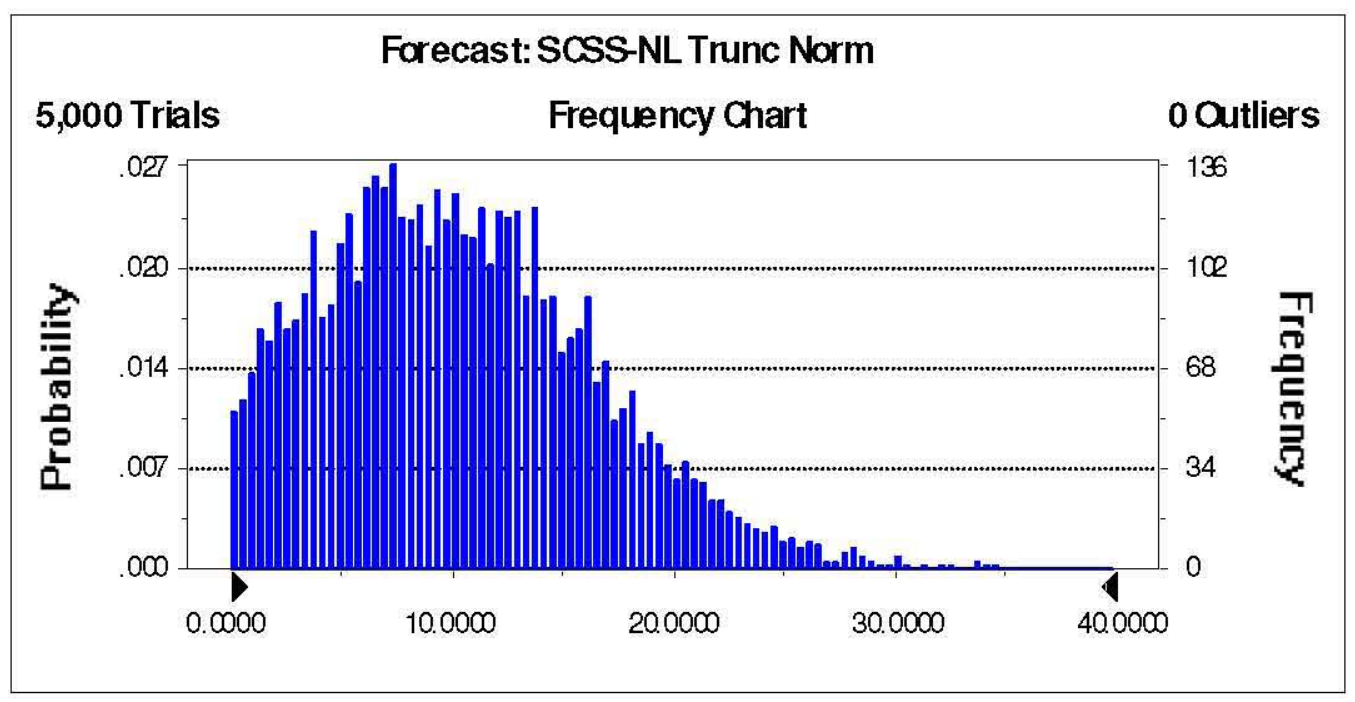

\section{D7.3.2 SL-NL Default Void Fraction}

The data for SL-NL wastes (Table D-9) have been regressed using Crystal Ball to fit a normal distribution which is then truncated to bound the values to those expected for the given waste type void fraction, as shown in Figure D-4. The original boundary recommendations are presented in SNL-000198. Figure D-4 represents a truncated normal distribution with a mean and standard deviation as shown below. The default void fraction of 2.44 and the statistical distribution for SL-NL waste is given in Table D-10. 
Table D-9. Summary of Average Void Fraction Data for SL-NL Tanks With Measured Values.

\begin{tabular}{|c|c|c|c|c|c|c|c|c|}
\hline Tank ID & $\begin{array}{l}\text { BPE } \\
\text { data }^{a}\end{array}$ & $\begin{array}{l}\text { BPE method } \\
\text { calc'd } \\
\text { retained gas } \\
\text { volume (acf) }\end{array}$ & $\begin{array}{l}\text { VFI } \\
\text { only } \\
\text { data }\end{array}$ & $\begin{array}{c}\text { VFI+RGS } \\
\text { data }^{b}\end{array}$ & $\begin{array}{l}\text { Mahoney } \\
\text { RGS void } \\
\text { fraction }^{\mathrm{c}}\end{array}$ & $\begin{array}{l}\text { Huckaby/ } \\
\text { Whitney } \\
\text { BPE data } \\
10 / 01 / 03^{d}\end{array}$ & $\begin{array}{c}\text { Barker- } \\
\text { Barnes } \\
\text { 2/8/2006 }\end{array}$ & Waste type \\
\hline 241-AY-101 & 0.042 & 604 & - & -- & -- & -- & -- & SL-NL \\
\hline 241-BX-101 & 0.02 & 114 & -- & -- & -- & -- & -- & SL-NL \\
\hline 241-BX-103 & 0.012 & 35 & -- & -- & -- & -- & -- & SL-NL \\
\hline 241-BX-104 & 0.075 & 967 & -- & -- & -- & -- & -- & SL-NL \\
\hline 241-BX-107 & 0.025 & 1,155 & -- & -- & -- & -- & -- & SL-NL \\
\hline 241-BX-112 & 0.005 & 109 & -- & -- & -- & -- & -- & SL-NL \\
\hline 241-C-103 & 0.006 & 13 & -- & -- & -- & -- & -- & SL-NL \\
\hline 241-S-107 & 0.024 & 1,163 & -- & -- & -- & -- & -- & SL-NL \\
\hline 241-TX-101 & 0.009 & 23 & -- & -- & -- & -- & -- & SL-NL \\
\hline 241-TY-104 & 0.017 & 23 & -- & -- & -- & -- & -- & SL-NL \\
\hline
\end{tabular}

Notes:

References:

${ }^{\mathrm{a}} \mathrm{B}$ ased on BPE data from RPP-15488, 2004.

${ }^{\mathrm{b}} \mathrm{PNNL}-11536,1997$.

${ }^{c}$ PNNL-13317, 2000.

${ }^{\mathrm{d}} \mathrm{RPP}-10006,2004$.

$\mathrm{BPE}=$ barometric pressure effect.

RGS = retained gas sampler.

SL-NL = sludge waste form with $<1 \mathrm{~m}$ liquid over solids.

VFI = void fraction instrument.

Table D-10. The Default Void Fraction for SL-NL Waste with Truncated LogNormal Distribution.

\begin{tabular}{|l|c|}
\hline Mean & 2.44 \\
\hline Standard deviation & 2.49 \\
\hline Truncate low & 0.01 \\
\hline Truncate high & 26.5 \\
\hline
\end{tabular}


RPP-10006 REV 8

Figure D-4. Void Fraction Regression Results for SL-NL Wastes.

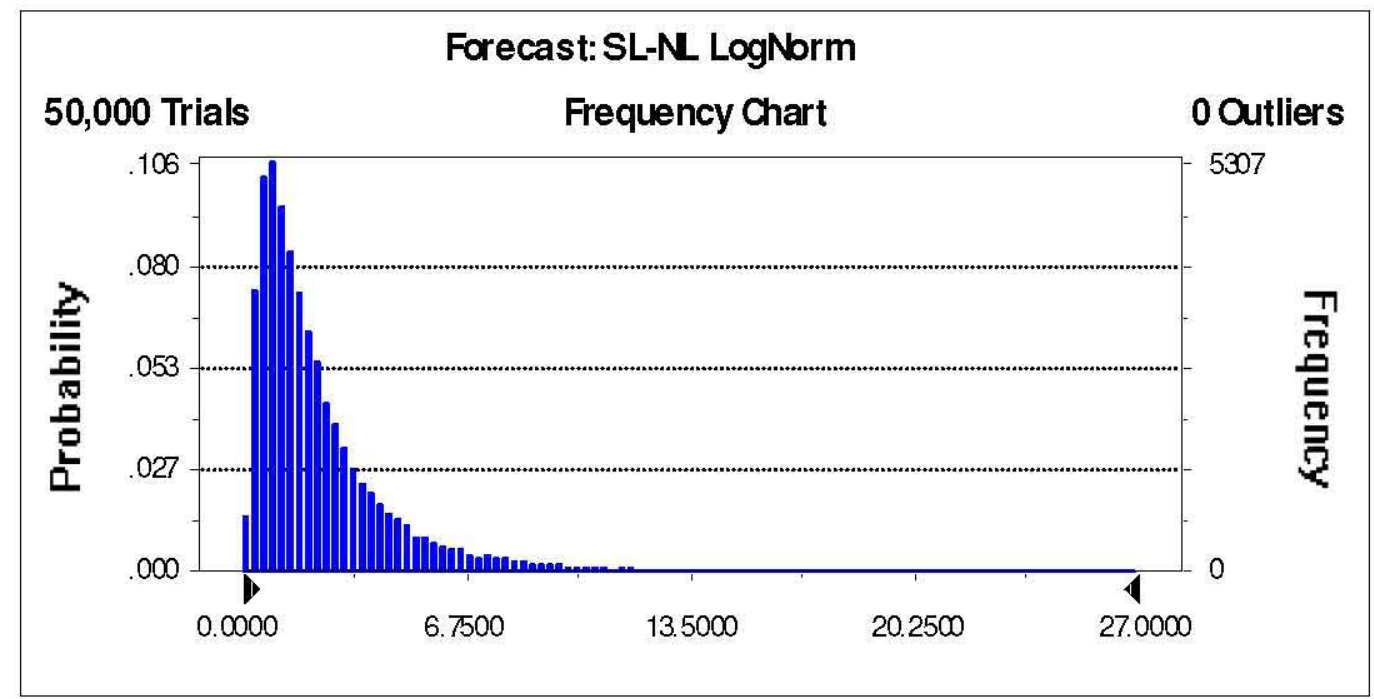

\section{D7.3.3 SC/SS-LIQ, SL-LIQ, and MIX-LIQ Default Void Fraction}

The data for SC/SS-LIQ wastes (Table D-11) have been regressed to fit a truncated normal distribution as shown in Figure D-5. Figure D-5 represents a truncated normal distribution with a mean and standard deviation as shown below. In addition, wastes with significant supernatant (greater than $1 \mathrm{~m}$ depth) have an upper bound at the neutral buoyancy void fraction for the waste. The modification of the upper limit of the void fraction to account for the neutral buoyancy void fraction within a given tank is done within the model at execution time and is not reflected here. The default void fraction of 6.37 and its statistical distribution for SC/SS-LIQ waste is given in Table D-12.

Although no SL-LIQ or MIX-LIQ waste type tanks are used in the regression of this default distribution, the SC/SS-LIQ default distribution will be applied to SL-LIQ and MIX-LIQ tanks. 
Table D-11. Summary of Average Void Fraction Data for SC/SS-LIQ Tanks With Measured Values.

\begin{tabular}{|l|c|c|c|c|c|c|c|c|}
\hline Tank ID & $\begin{array}{c}\text { BPE } \\
\text { data }^{\mathbf{a}}\end{array}$ & $\begin{array}{c}\text { BPE } \\
\text { method } \\
\text { calc'd } \\
\text { retained } \\
\text { gas } \\
\text { volume } \\
\text { (acf) }\end{array}$ & $\begin{array}{c}\text { VFI } \\
\text { only } \\
\text { data }\end{array}$ & $\begin{array}{c}\text { VFI+RGS } \\
\text { datab }^{\mathbf{b}}\end{array}$ & $\begin{array}{c}\text { Mahoney } \\
\text { RGS void } \\
\text { fraction }^{\mathbf{c}}\end{array}$ & $\begin{array}{c}\text { Huckaby } \\
\text { /Whitney } \\
\text { BPE } \\
\text { data } \\
\mathbf{1 0 / 0 1 / 0 3}\end{array}$ & $\begin{array}{c}\text { Barker- } \\
\text { Barnes } \\
\mathbf{2 / 8 / 2 0 0 6}\end{array}$ & $\begin{array}{c}\text { Waste } \\
\text { type }\end{array}$ \\
\hline 241-AN-103 & $0.215^{\text {e }}$ & 11,802 & 0.122 & 0.107 & 0.092 & -- & -- & SC/SS-LIQ \\
\hline 241-AN-104 & 0.084 & 5,070 & 0.059 & 0.062 & 0.08 & -- & -- & SC/SS-LIQ \\
\hline 241-AN-105 & 0.064 & 4,200 & 0.038 & 0.042 & 0.051 & -- & -- & SC/SS-LIQ \\
\hline 241-AN-107 & -- & -- & -- & -- & -- & -- & 0.011 & SC/SS-LIQ \\
\hline 241-AW-101 & $0.152^{\text {e }}$ & 6,229 & 0.047 & 0.038 & 0.037 & -- & -- & SC/SS-LIQ \\
\hline 241-AW-104 & 0.058 & 1,776 & -- & -- & -- & -- & -- & SC/SS-LIQ \\
\hline 241-AW-106 & 0.032 & 985 & -- & -- & -- & -- & -- & SC/SS-LIQ \\
\hline 241-SY-101 & -- & -- & -- & -- & -- & 0.091 & 0.085 & SC/SS-LIQ \\
\hline 241-SY-103 & 0.078 & 3,755 & 0.06 & -- & -- & -- & -- & SC/SS-LIQ \\
\hline
\end{tabular}

Notes:

References:

${ }^{a}$ Based on BPE data from RPP-15488, 2004.

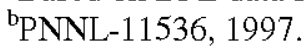

${ }^{c}$ PNNL-13317, 2000.

${ }^{\mathrm{d}} \mathrm{RPP}-10006,2004$.

${ }^{\mathrm{e}}$ Data not used since it appears to be inconsistent with higher quality data.

$\mathrm{BPE} \quad=$ barometric pressure effect.

RGS = retained gas sampler.

SC/SS-LIQ $=$ saltcake/salt slurry waste form with $\geq 1 \mathrm{~m}$ liquid over solids.

VFI $\quad=$ void fraction instrument.

Table D-12. Default Void Fraction for

SC/SS-LIQ, SL-LIQ, and MIX-LIQ

Waste with Truncated Normal

Distribution.

\begin{tabular}{|l|c|}
\hline Mean & 6.37 \\
\hline Standard deviation & 2.73 \\
\hline Truncate low & 0.01 \\
\hline Truncate high & 15.11 \\
\hline
\end{tabular}


Figure D-5. Void Fraction Regression Results for SC/SS-LIQ, SL-LIQ, and MIX-LIQ Wastes.

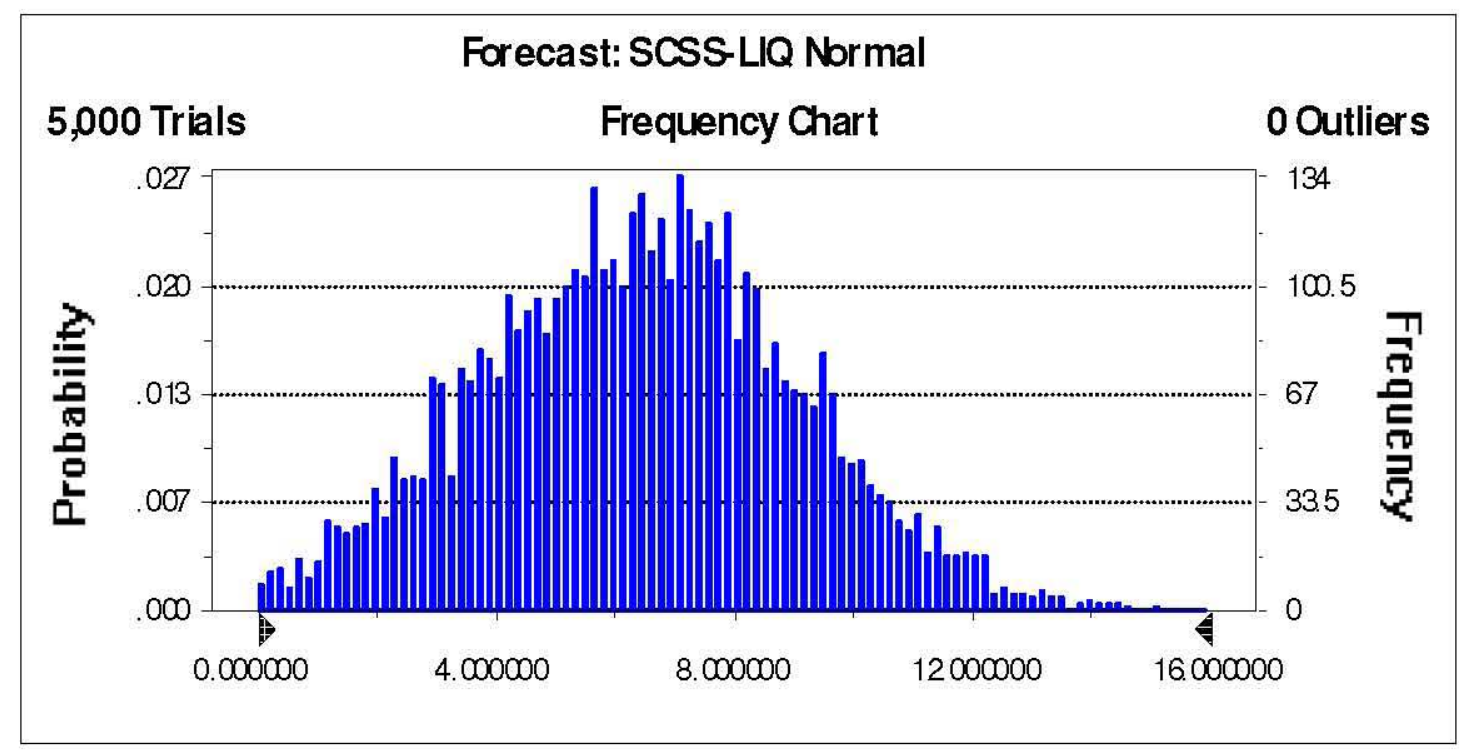

\section{D7.3.4 Liquid Waste Void Fractions}

Liquid wastes do not retain gas. Any gas found in the liquid wastes is considered transient and is not considered as trapped or retained gas. Therefore, the void fraction for liquid waste is set to 0.0. In order to comply with Crystal Ball run-time requirements, the mean of the liquid distribution will be set to $0.15 \mathrm{vol} \%$ gas, otherwise simulations with liquid wastes will fail.

\section{D7.4 VOID FRACTION ASSIGNMENT FOR 177 DOUBLE-SHELL TANKS AND SINGLE-SHELL TANKS}

Table D-13 presents the void fraction distributions and their source for tanks with void fraction measurements. All other tanks use default distributions based on waste type. 
Table D-13. Void Percent Distributions for Non-Default Tanks. (2 sheets)

\begin{tabular}{|c|c|c|c|c|c|c|c|}
\hline \multirow[b]{2}{*}{ Tank } & \multicolumn{5}{|c|}{ Void Percent or Maximum Wetted Solids Void Percent } & \multirow[b]{2}{*}{$\begin{array}{l}\text { Data } \\
\text { source }\end{array}$} & \multirow[b]{2}{*}{ Waste type } \\
\hline & $\begin{array}{c}\text { Mean } \\
(\%)\end{array}$ & $\begin{array}{c}\text { Uncertainty } \\
(\%)\end{array}$ & $\begin{array}{c}\text { Minimum } \\
(\%)\end{array}$ & $\begin{array}{c}\text { Maximum } \\
(\%)\end{array}$ & $\begin{array}{c}\text { Distri- } \\
\text { bution } \\
(\%)\end{array}$ & & \\
\hline 241-A-103 & 0.40 & 0.20 & 0.01 & 40.00 & Normal & $\mathrm{BPE}$ & SC/SS-NL \\
\hline 241-AN-103 & 10.70 & 5.35 & 0.01 & 15.11 & Normal & RGS/VFI & SC/SS-LIQ \\
\hline 241-AN-104 & 6.20 & 3.10 & 0.01 & 15.11 & Normal & RGS/VFI & SC/SS-LIQ \\
\hline 241-AN-105 & 4.20 & 2.10 & 0.01 & 15.11 & Normal & RGS/VFI & SC/SS-LIQ \\
\hline 241-AN-107 & 1.10 & 0.55 & 0.01 & 15.11 & Normal & $\mathrm{BPE}$ & SC/SS-LIQ \\
\hline 241-AW-101 & 4.70 & 2.35 & 0.01 & 15.11 & Normal & RGS/VFI & SC/SS-LIQ \\
\hline 241-AW-103 & 0.90 & 0.45 & 0.01 & 15.11 & Normal & $\mathrm{BPE}$ & SL-LIQ \\
\hline 241-AW-104 & 5.80 & 2.90 & 0.00 & 15.11 & Normal & $\mathrm{BPE}$ & SC/SS-LIQ \\
\hline 241-AW-106 & 3.20 & 1.60 & 0.01 & 15.11 & Normal & $\mathrm{BPE}$ & SC/SS-LIQ \\
\hline 241-AY-101 & 4.20 & 2.10 & 0.00 & 26.50 & Normal & $\mathrm{BPE}$ & SL-NL \\
\hline 241-B-102 & 2.70 & 1.35 & 0.01 & 40.00 & Normal & $\mathrm{BPE}$ & SC/SS-NL \\
\hline 241-B-112 & 2.50 & 1.25 & 0.01 & 40.00 & Normal & $\mathrm{BPE}$ & MIX-NL \\
\hline 241-BX-101 & 2.00 & 1.00 & 0.00 & 26.50 & Normal & BPE & SL-NL \\
\hline 241-BX-103 & 1.20 & 0.60 & 0.00 & 26.50 & Normal & $\mathrm{BPE}$ & SL-NL \\
\hline 241-BX-104 & 7.50 & 3.75 & 0.00 & 26.50 & Normal & BPE & SL-NL \\
\hline 241-BX-105 & 1.60 & 0.80 & 0.01 & 40.00 & Normal & BPE & MIX-NL \\
\hline 241-BX-107 & 2.50 & 1.25 & 0.00 & 26.50 & Normal & $\mathrm{BPE}$ & SL-NL \\
\hline 241-BX-110 & 4.00 & 2.00 & 0.01 & 40.00 & Normal & BPE & MIX-NL \\
\hline 241-BX-111 & 0.50 & 0.25 & 0.01 & 40.00 & Normal & $\mathrm{BPE}$ & SC/SS-NL \\
\hline 241-BX-112 & 0.50 & 0.25 & 0.00 & 26.50 & Normal & BPE & SL-NL \\
\hline 241-C-103 & 0.60 & 0.30 & 0.00 & 26.50 & Normal & BPE & SL-NL \\
\hline 241-S-101 & 4.30 & 2.15 & 0.01 & 40.00 & Normal & BPE & MIX-NL \\
\hline $241-S-103$ & 14.70 & 7.35 & 0.01 & 40.00 & Normal & BPE & SC/SS-NL \\
\hline $241-S-106$ & 8.20 & 4.10 & 0.01 & 40.00 & Normal & BPE & SC/SS-NL \\
\hline 241-S-107 & 2.40 & 1.20 & 0.01 & 26.50 & Normal & BPE & SL-NL \\
\hline 241-S-111 & 11.90 & 5.95 & 0.01 & 40.00 & Normal & BPE & SC/SS-NL \\
\hline 241-SX-106 & 14.00 & 7.00 & 0.01 & 40.00 & Normal & BPE & SC/SS-NL \\
\hline 241-SY-101 & 8.50 & 4.25 & 0.00 & 15.11 & Normal & BPE & SC/SS-LIQ \\
\hline 241-SY-102 & 0.90 & 0.45 & 0.01 & 15.11 & Normal & $\mathrm{BPE}$ & SL-LIQ \\
\hline 241-SY-103 & 6.00 & 3.00 & 0.00 & 15.11 & Normal & VFI & SC/SS-LIQ \\
\hline 241-T-101 & 0.70 & 0.35 & 0.01 & 40.00 & Normal & BPE & MIX-NL \\
\hline 241-TX-101 & 0.90 & 0.45 & 0.01 & 26.50 & Normal & $\mathrm{BPE}$ & SL-NL \\
\hline 241-TX-104 & 1.20 & 0.60 & 0.01 & 40.00 & Normal & $\mathrm{BPE}$ & MIX-NL \\
\hline 241-TX-107 & 2.10 & 1.05 & 0.01 & 40.00 & Normal & $\mathrm{BPE}$ & SC/SS-NL \\
\hline
\end{tabular}


RPP-10006 REV 8

Table D-13. Void Percent Distributions for Non-Default Tanks. (2 sheets)

\begin{tabular}{|c|c|c|c|c|c|c|c|}
\hline \multirow[b]{2}{*}{ Tank } & \multicolumn{5}{|c|}{ Void Percent or Maximum Wetted Solids Void Percent } & \multirow[b]{2}{*}{$\begin{array}{l}\text { Data } \\
\text { source }\end{array}$} & \multirow[b]{2}{*}{ Waste type } \\
\hline & $\begin{array}{c}\text { Mean } \\
(\%)\end{array}$ & $\begin{array}{c}\text { Uncertainty } \\
(\%)\end{array}$ & $\begin{array}{c}\text { Minimum } \\
(\%)\end{array}$ & $\begin{array}{c}\text { Maximum } \\
(\%)\end{array}$ & $\begin{array}{c}\text { Distri- } \\
\text { bution } \\
(\%)\end{array}$ & & \\
\hline 241-TY-104 & 1.70 & 0.85 & 0.01 & 26.50 & Normal & $\mathrm{BPE}$ & SL-NL \\
\hline 241-U-103 & 8.00 & 4.00 & 0.01 & 40.00 & Normal & $\mathrm{BPE}$ & SC/SS-NL \\
\hline 241-U-105 & 7.30 & 3.65 & 0.01 & 40.00 & Normal & $\mathrm{BPE}$ & SC/SS-NL \\
\hline 241-U-106 & 1.50 & 0.75 & 0.01 & 40.00 & Normal & $\mathrm{BPE}$ & SC/SS-NL \\
\hline 241-U-107 & 7.60 & 3.80 & 0.01 & 40.00 & Normal & $\mathrm{BPE}$ & SC/SS-NL \\
\hline 241-U-109 & 4.10 & 2.05 & 0.01 & 40.00 & Normal & BPE & SC/SS-NL \\
\hline
\end{tabular}

Notes:

$\mathrm{BPE}=$ barometric pressure effect.

LIQ = liquid

MIX-LIQ $=$ mixed waste form with $\geq 1 \mathrm{~m}$ liquid over solids.

MIX-NL = mixed waste form with $<1 \mathrm{~m}$ liquid over solids.

RGS = retained gas sampler.

SC/SS-LIQ $=$ saltcake/salt slurry waste form with $\geq 1 \mathrm{~m}$ liquid over solids .

$\mathrm{SC} / \mathrm{SS}-\mathrm{NL}=$ saltcake/salt slurry waste form with $<1 \mathrm{~m}$ liquid over solids.

SL-LIQ = sludge waste form with $\geq 1 \mathrm{~m}$ liquid over solids.

SL-NL = sludge waste form with $<1 \mathrm{~m}$ liquid over solids.

VFI $\quad=$ void fraction instrument.

\section{D8.0 CONCLUSIONS}

The field measured data from VFI, RGS, and BPE have been thoroughly examined to determine, calculate, and develop the void fractions for the 177 DSTs and SSTs. The void fraction is being validated, adopted, and calculated using 39 of the $86 \mathrm{dL} / \mathrm{dP}$ data points from RPP-15884. In addition, dL/dP data have been developed for DSTs 241-AN-107 and 241-SY-101, and the void fractions were calculated. The dL/dP data from Huckaby (RPP-10006, Methodology and Calculations for the Assignment of Waste for the Large Underground Storage Tanks at Hanford Site, Rev. 3) and the void fraction data reported using VFI and RGS have been used to develop three default void fractions for SC/SS-NL and MIX-NL waste types, for SL-NL waste type, and for SC/SS-LIQ, SL-LIQ and MIX-LIQ waste types. 
RPP-10006 REV 8

\section{D9.0 REFERENCES}

HNF-EP-0182-130, 1999, Waste Tank Summary Report for Month Ending 01/31/1999, Lockheed Martin Hanford Corporation, Richland, Washington.

PNL-10821, 1995, Screening the Hanford Tanks for Trapped Gas, Pacific Northwest National Laboratory, Richland, Washington.

PNNL-11373, 1996, Flammable Gas Data Evaluation Progress Report, Pacific Northwest National Laboratory, Richland Washington.

PNNL-11450, 1997, Composition and Quantities of Retained Gas Measured in Hanford Waste Tanks 241-AW-101, A-101, AN-105, AN-104, and AN-103, Rev. 1, Pacific Northwest National Laboratory, Richland, Washington.

PNNL-11536, 1997, Gas Retention and Release Behavior in Hanford Double-Shell Waste Tanks, Rev. 1, Pacific Northwest National Laboratory, Richland, Washington.

PNNL-11693, 1997, Estimating Retained Gas Volumes in the Hanford Tanks using Waste Level Measurements, Pacific Northwest National Laboratory, Richland, Washington.

PNNL-11777, 1997, Composition and Quantities of Retained Gas Measured in Hanford Waste Tanks 241-U-103, S-106, BY-101, and BY-109, Rev. 1, Pacific Northwest National Laboratory, Richland, Washington.

PNNL-13317, 2000, Ammonia Results Review for Retained Gas Sampling, Pacific Northwest National Laboratory, Richland, Washington.

RPP-5926, 2000, Steady-State Flammable Gas Release Rate Calculation and Lower Flammability Level Evaluation for Hanford Tank Waste, Rev. 0, CH2M HILL Hanford Group, Inc., Richland, Washington.

RPP-5926, 2005, Steady-State Flammable Gas Release Rate Calculation or Lower Flammability Evaluation Level for Hanford Tank Waste, Rev. 5, CH2M HILL Hanford Group, Inc., Richland, Washington.

RPP-6171, 2000, Determination of Waste Groupings for Safety Analyses, Rev. 0, CH2M HILL Hanford Group, Inc., Richland, Washington.

RPP-10006, 2004, Methodology and Calculations for the Assignment of Waste for the Large Underground Storage Tanks at Hanford Site, Rev. 3, CH2M HILL Hanford Group, Inc., Richland, Washington.

RPP-15488, 2004, Investigation of Tank Void Fraction Using Liquid Level to Atmospheric Pressure Changes, Rev. 0, CH2M HILL Hanford Group, Inc., Richland, Washington. 


\section{RPP-10006 REV 8}

RPP-29388, 2006, Spreadsheet Description Document For 'SVF 1131 BPE to Void Fraction Master R0 060221 .xls', Rev. 0, CH2M HILL Hanford Group, Inc., Richland, Washington.

RPP-29389, 2006, Spreadsheet Description Document For 'RPP-10006r5 Void fraction revised data by tank - 060519 .xls', Rev. 0, CH2M HILL Hanford Group, Inc., Richland, Washington.

SNL-000198, 1999, Flammable Gas Safety Analysis Data Review, Sandia National Laboratory, Albuquerque, New Mexico.

SVF-1002, 2006, Spreadsheet Verification and Release Form for Spreadsheet 'BP Correlation with DB Connect .xls ', Rev. 0, CH2M HILL Hanford Group, Inc., Richland, Washington.

SVF-1131, 2006, Spreadsheet Verification and Release Form for Spreadsheet 'SVF 1131 BPE to Void Fraction Master R0 060221 .xls', Rev. 0, CH2M HILL Hanford Group, Inc., Richland, Washington.

SVF-1132, 2006, Spreadsheet Verification and Release Form for Spreadsheet 'RPP-10006r5 Void fraction revised data by tank - 060519.xls', Rev. 0, CH2M HILL Hanford Group, Inc., Richland, Washington. 
RPP-10006 REV 8

APPENDIX E

DETERMINATION OF HYDROGEN GENERATION RATE DISTRIBUTION RANGES 
RPP-10006 REV 8

This page intentionally left blank.

E-ii 


\section{CONTENTS}

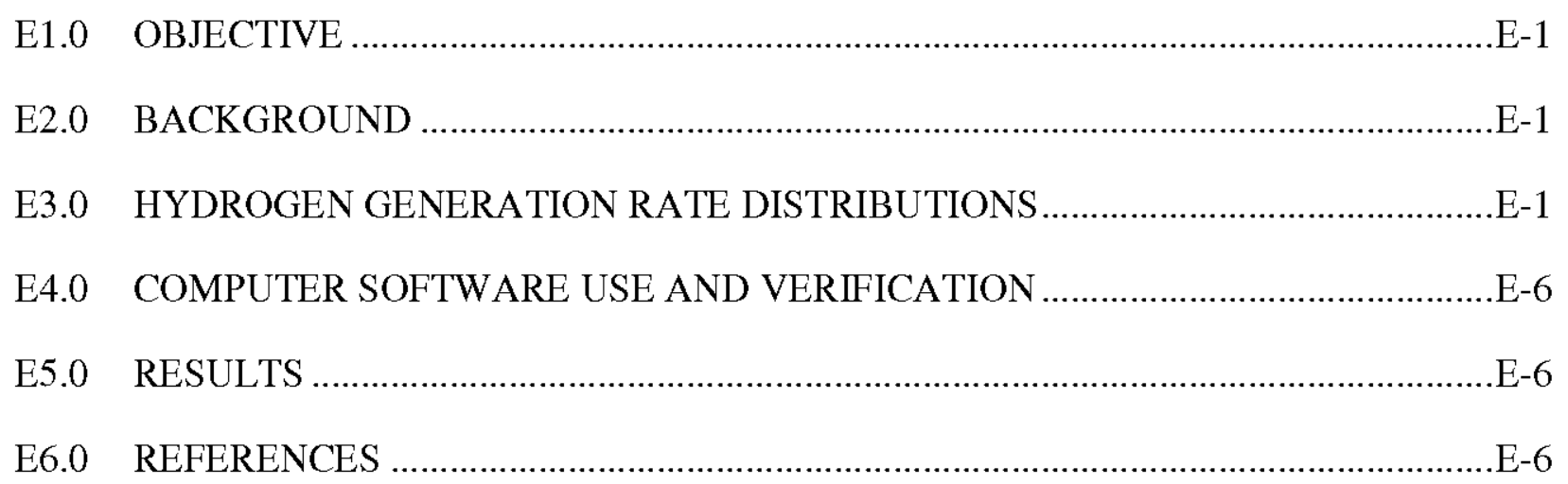

\section{TABLES}

Table E-1. Comparison of Model-Calculated and Field-Observed Hydrogen Generation

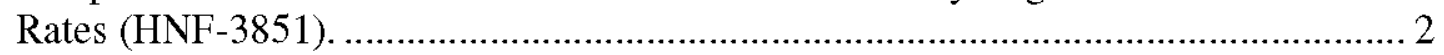

Table E-3. Hydrogen Generation Rate Distribution for Tanks with $1.5 \mathrm{E}-03 \mathrm{ft}^{3} / \mathrm{min}>$

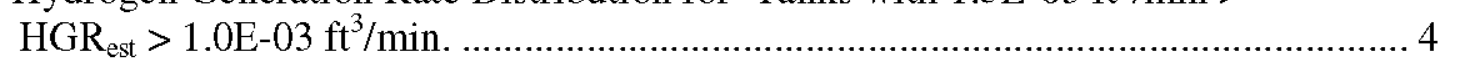

Table E-4. Hydrogen Generation Rate Distribution for Tanks with $1.0 \mathrm{E}-03 \mathrm{ft}^{3} / \mathrm{min} \geq$ $\mathrm{HGR}_{\mathrm{est}}$. 5 


\section{RPP-10006 REV 8}

\section{LIST OF TERMS}

BBI

BDGRE

CL

DST

HGR

NA

NCL

RGS

TOC
Best-Basis Inventory

buoyant displacement gas release event convective layer

double-shell tank

hydrogen generation rate

not applicable

nonconvective layer

retained gas solids

total organic carbon 


\section{APPENDIX E \\ DETERMINATION OF HYDROGEN GENERATION RATE DISTRIBUTION RANGES \\ E1.0 OBJECTIVE}

The purpose of this appendix is to document the methodology used to determine the distribution ranges for the hydrogen generation rates (HGR) based on a comparison between calculated and observed HGRs as presented in HNF-3851, Empirical Rate Equation Model and Rate Calculations of Hydrogen Generation for Hanford Tank Waste.

\section{E2.0 BACKGROUND}

RPP-5926 R8 does not directly calculate the solid phase HGR for the tanks. However it does give both the solid layer radiolysis, and the solid layer thermolysis for all the tanks. To calculate a value for the solid phase HGR both the solid layer thermolysis, and radiolysis from RPP-5926 R8 were added together. In addition, corresponding maxima, minima and distribution types are not included in RPP-5926. The methodology for deriving these values was established in RPP10006, Revision 5 and is used in subsequent revisions.

Tanks 241-AP-101, 241-AP-106 and 241-AP-107 do not have solid phase HGRs reported in RPP-5926. Therefore, the values from RPP-10006, Revision 5, and RPP-10006 Revision 7, will continue to be used for the previously identified solids in tanks 241-AP-101, 241-AP-106 and 241-AP-107.

\section{E3.0 HYDROGEN GENERATION RATE DISTRIBUTIONS}

The HGR distributions are based on the evaluation of model-calculated and field-observed rates from HNF-3851, as presented in Table E-1. In Table E-1, positive "Relative Differences" indicate overestimation of the HGR; negative "Relative Differences" indicate model underestimation of the HGR. 
Table E-1. Comparison of Model-Calculated and Field-Observed Hydrogen Generation Rates (HNF-3851).

\begin{tabular}{|c|c|c|c|c|c|}
\hline Tanks & $\begin{array}{c}\mathbf{G}_{\bmod } \\
\left(\mathrm{ft}^{3} / \mathrm{min}\right) \\
\text { total HGR } \\
\text { from model }\end{array}$ & 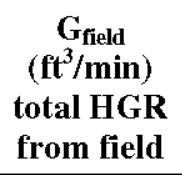 & $\begin{array}{c}\mathbf{G}_{\text {mod }} \\
\text { (L/day) total } \\
\text { HGR from } \\
\text { model }\end{array}$ & $\begin{array}{c}\mathbf{G}_{\text {field }} \\
(\mathrm{L} / \text { day }) \\
\text { total HGR } \\
\text { from field }\end{array}$ & $\begin{array}{c}\text { Relative } \\
\text { differences } \\
\text { [model vs. field } \\
\text { data] }\end{array}$ \\
\hline 241-AN-101 & $1.73 \mathrm{E}-04$ & $2.50 \mathrm{E}-04$ & 7 & 10 & $-31 \%$ \\
\hline 241-U-107 & $4.71 \mathrm{E}-04$ & 8.27E-04 & 19 & 34 & $-43 \%$ \\
\hline 241-U-109 & 5.44E-04 & 7.11E-04 & 22 & 29 & $-23 \%$ \\
\hline 241-SX-101 & $6.64 \mathrm{E}-04$ & $4.20 \mathrm{E}-04$ & 27 & 17 & $58 \%$ \\
\hline 241-U-108 & $9.42 \mathrm{E}-04$ & $1.41 \mathrm{E}-03$ & 39 & 57 & $-33 \%$ \\
\hline 241-SY-102 & $9.66 \mathrm{E}-04$ & $7.26 \mathrm{E}-04$ & 40 & 30 & $33 \%$ \\
\hline $241-\mathrm{U}-102$ & $1.05 \mathrm{E}-03$ & $1.10 \mathrm{E}-03$ & 43 & 45 & $-4 \%$ \\
\hline 241-U-106 & $1.12 \mathrm{E}-03$ & $6.62 \mathrm{E}-04$ & 46 & 27 & $69 \%$ \\
\hline 241-S-102 & $1.25 \mathrm{E}-03$ & $1.64 \mathrm{E}-03$ & 51 & 67 & $-24 \%$ \\
\hline 241-SX-104 & $1.31 \mathrm{E}-03$ & $2.51 \mathrm{E}-04$ & 53 & 10 & $420 \%$ \\
\hline 241-U-105 & $1.37 \mathrm{E}-03$ & $1.61 \mathrm{E}-03$ & 56 & 65 & $-15 \%$ \\
\hline 241-U-103 & $1.46 \mathrm{E}-03$ & $1.48 \mathrm{E}-03$ & 60 & 60 & $-1 \%$ \\
\hline 241-SX-106 & $1.53 \mathrm{E}-03$ & $1.24 \mathrm{E}-03$ & 63 & 50 & $24 \%$ \\
\hline 241-C-104 & $2.56 \mathrm{E}-03$ & $2.21 \mathrm{E}-03$ & 105 & 90 & $16 \%$ \\
\hline \begin{tabular}{|l|}
$241-S X-103$ \\
\end{tabular} & $3.03 \mathrm{E}-03$ & $1.27 \mathrm{E}-03$ & 124 & 52 & $139 \%$ \\
\hline 241-AW-101 & $3.55 \mathrm{E}-03$ & $3.17 \mathrm{E}-03$ & 146 & 129 & $12 \%$ \\
\hline \begin{tabular}{|l|}
$241-S Y-103$ \\
\end{tabular} & $3.63 \mathrm{E}-03$ & $3.54 \mathrm{E}-03$ & 149 & 145 & $2 \%$ \\
\hline 241-AN-103 & $4.54 \mathrm{E}-03$ & $4.76 \mathrm{E}-03$ & 186 & 195 & $-5 \%$ \\
\hline $241-\mathrm{AN}-105$ & $5.14 \mathrm{E}-03$ & $3.06 \mathrm{E}-03$ & 211 & 125 & $68 \%$ \\
\hline 241-AN-104 & $5.53 \mathrm{E}-03$ & $2.55 \mathrm{E}-03$ & 227 & 104 & $117 \%$ \\
\hline 241-A-101 & $5.76 \mathrm{E}-03$ & $2.14 \mathrm{E}-03$ & 236 & 87 & $169 \%$ \\
\hline 241-SX-105 & $5.77 \mathrm{E}-03$ & $4.82 \mathrm{E}-03$ & 236 & 197 & $20 \%$ \\
\hline 241-AN-107 & $1.09 \mathrm{E}-02$ & $5.25 \mathrm{E}-03$ & 447 & 214 & $108 \%$ \\
\hline 241-C-106 & $1.62 \mathrm{E}-02$ & $9.03 \mathrm{E}-03$ & 664 & 368 & $79 \%$ \\
\hline 241-AY-102 & $2.10 \mathrm{E}-02$ & $1.70 \mathrm{E}-02$ & 859 & 691 & $24 \%$ \\
\hline \begin{tabular}{|l|}
$241-A Z-101$ \\
\end{tabular} & $2.79 \mathrm{E}-02$ & $9.44 \mathrm{E}-03$ & 1144 & 385 & $196 \%$ \\
\hline 241-AZ-102 & $2.90 \mathrm{E}-02$ & $1.90 \mathrm{E}-02$ & 1190 & 775 & $53 \%$ \\
\hline 241-SY-101 & $5.96 \mathrm{E}-02$ & $2.44 \mathrm{E}-02$ & 2441 & 993 & $145 \%$ \\
\hline
\end{tabular}

Notes:

HNF-3851, 2004, Empirical Rate Equation Model and Rate Calculations of Hydrogen Generation for Hanford Tank Waste, Rev. 1, CH2M HILL Hanford Group, Inc., Richland Washington.

HGR = hydrogen generation rate. 


\section{RPP-10006 REV 8}

Based on the evaluations given below the HGR distributions are described by a triangular distribution with the upper and lower bounds defined as listed below.

\author{
$\underline{\text { Model Estimated HGR }}$ \\ $\mathrm{HGR}_{\text {est }} \geq 1.5 \mathrm{E}-03\left(\mathrm{ft}^{3} / \mathrm{min}\right)$ \\ $1.5 \mathrm{E}-03>\mathrm{HGR}_{\mathrm{est}} \geq 1.0 \mathrm{E}-03\left(\mathrm{ft}^{3} / \mathrm{min}\right)$ \\ $1.0 \mathrm{E}-03\left(\mathrm{ft}^{3} / \mathrm{min}\right)>\mathrm{HGR}_{\text {est }}$ \\ Notes $\quad$ HGR $_{\text {est }}=$ estimated HGR \\ The model estimated HGR is the total HGR for the tank. It is assumed that the \\ nonconvective layer HGR has the same upper and lower bound relationships as used for the specific \\ tank's total HGR.
}

Previously, the distribution maxima and minima for the HGRs were defined loosely as the "HGR mean +2 times $\mathrm{HGR}_{\text {mean " and "HGR }} \mathrm{Hean}_{-} \mathrm{HGR}_{\text {mean }} / 2$," respectively. When tanks are arranged in order from smallest to largest HGR it was found that the larger model HGRs consistently overestimated the observed HGRs and the smaller HGRs typically underestimated the observed HGRs. As a result, it was decided to divide the range of model-generated HGR values such that the ranges of the observed HGRs were underestimated, overestimated, or mixed (overestimated and underestimated).

The range of HGRs was arbitrarily divided in to the following three groups:

- $\mathrm{HGR}_{\mathrm{est}} \geq 1.5 \mathrm{E}-03 \mathrm{ft}^{3} / \mathrm{min}$

- $1.5 \mathrm{E}-03 \mathrm{ft}^{3} / \mathrm{min} \geq \mathrm{HGR}_{\text {est }} \geq 1.0 \mathrm{E}-03 \mathrm{ft}^{3} / \mathrm{min}$

- $1.0 \mathrm{E}-03 \mathrm{ft}^{3} / \mathrm{min} \geq \mathrm{HGR}_{\text {est }}$.

For tanks with $\mathrm{HGR}_{\text {est }}>1.5 \mathrm{E}-03 \mathrm{ft}^{3} / \mathrm{min}$, the data ranges from underestimating the observed value by $5 \%$ (only 1 value underestimated the observed value) to overestimating the observed HGR by a factor of 3 ( 15 values overestimated the observed HGR). The distribution ranges were set to encompass the range of observations in this bin. To cover the underestimated values, the upper bound for the range was set to " $110 \%$ of the mean" (100\% plus twice "the relative difference for 241-AN-103"), and the lower bound was set to the "mean /3" (the mean divided by " $100 \%$ plus the relative difference for $241-\mathrm{AZ}-101 ")$. The resulting distributions for this range of data are presented in Table E-2.

Six tanks fell into the tanks with $1.5 \mathrm{E}-03 \mathrm{ft}^{3} / \mathrm{min}>\mathrm{HGR}_{\mathrm{est}}>1.0 \mathrm{E}-03 \mathrm{ft}^{3} / \mathrm{min}$ bin. Of these, four tanks underestimated the HGR by up to $25 \%$, and two tanks overestimated the HGR by up to $420 \%$. To account for this range, the underestimated values the upper bound for the range was set to " $150 \%$ of the mean" ( $100 \%$ plus twice "the relative difference for $241-\mathrm{S}-102$ "), and the lower bound was set to the "mean $/ 2$ " (the mean divided by " $100 \%$ plus $1 / 4$ of the relative difference for 241-SX-104." This is a conservative assumption). The resulting distributions for this range of data are presented in Table E-3. 
Table E- 2. Hydrogen Generation Rate Distribution for Tanks with $\mathrm{HGR}_{\text {est }}>1.5 \mathrm{E}-03 \mathrm{ft}^{3} / \mathrm{min}$.

\begin{tabular}{|c|c|c|c|c|c|c|c|c|}
\hline \multirow[b]{2}{*}{ Tanks } & \multirow{2}{*}{$\begin{array}{c}\mathbf{G}_{\bmod } \\
\left(\mathrm{ft}^{3} / \mathbf{m i n}\right) \\
\text { total HGR } \\
\text { from } \\
\text { model }\end{array}$} & \multirow{2}{*}{$\begin{array}{c}\mathbf{G}_{\text {field }} \\
\left(\mathbf{f t}^{3} / \mathbf{m i n}\right) \\
\text { total } \\
\text { HGR } \\
\text { from } \\
\text { field }\end{array}$} & \multirow{2}{*}{$\begin{array}{c}\mathbf{G}_{\mathrm{mod}} \\
\text { (L/day) } \\
\text { total } \\
\text { HGR } \\
\text { from } \\
\text { model }\end{array}$} & \multirow{2}{*}{$\begin{array}{c}\mathbf{G}_{\text {field }} \\
\text { (L/day) } \\
\text { total } \\
\text { HGR } \\
\text { from } \\
\text { field }\end{array}$} & \multirow{2}{*}{$\begin{array}{c}\text { Relative } \\
\text { differences } \\
\text { (model vs. } \\
\text { field data) }\end{array}$} & \multicolumn{3}{|c|}{$\begin{array}{c}\text { Resulting distribution using } \\
\mathbf{H G R}_{\text {est }} / \mathbf{3} \leq \mathbf{H G R} \mathbf{R s t}_{\text {est }} \leq 1.10 * \mathbf{H G R}_{\text {est }}\end{array}$} \\
\hline & & & & & & $\begin{array}{l}\text { Lower } \\
\text { bound } \\
\text { (L/day) }\end{array}$ & $\begin{array}{c}\text { Mean } \\
\text { (L/day) }\end{array}$ & $\begin{array}{l}\text { Upper } \\
\text { bound } \\
(\mathrm{L} / \text { day })\end{array}$ \\
\hline 241-AN-103 & $4.54 \mathrm{E}-03$ & $4.76 \mathrm{E}-03$ & 186 & 195 & $-5 \%$ & 62 & 186 & 204 \\
\hline 241-SY-103 & $3.63 \mathrm{E}-03$ & $3.54 \mathrm{E}-03$ & 149 & 145 & $2 \%$ & 50 & 149 & 163 \\
\hline 241-AW-101 & $3.55 \mathrm{E}-03$ & 3.17E-03 & 146 & 129 & $12 \%$ & 49 & 146 & 160 \\
\hline 241-C-104 & $2.56 \mathrm{E}-03$ & $2.21 \mathrm{E}-03$ & 105 & 90 & $16 \%$ & 35 & 105 & 115 \\
\hline 241-SX-105 & 5.77E-03 & $4.82 \mathrm{E}-03$ & 236 & 197 & $20 \%$ & 79 & 236 & 260 \\
\hline 241-AY-102 & $2.10 \mathrm{E}-02$ & $1.70 \mathrm{E}-02$ & 859 & 691 & $24 \%$ & 286 & 859 & 945 \\
\hline 241-SX-106 & $1.53 \mathrm{E}-03$ & $1.24 \mathrm{E}-03$ & 63 & 50 & $24 \%$ & 21 & 63 & 69 \\
\hline 241-AZ-102 & $2.90 \mathrm{E}-02$ & $1.90 \mathrm{E}-02$ & 1,190 & 775 & $53 \%$ & 397 & 1,190 & 1,309 \\
\hline 241-AN-105 & 5.14E-03 & $3.06 \mathrm{E}-03$ & 211 & 125 & $68 \%$ & 70 & 211 & 232 \\
\hline 241-C-106 & $1.62 \mathrm{E}-02$ & $9.03 \mathrm{E}-03$ & 664 & 368 & $79 \%$ & 221 & 664 & 730 \\
\hline 241-AN-107 & $1.09 \mathrm{E}-02$ & $5.25 \mathrm{E}-03$ & 447 & 214 & $108 \%$ & 149 & 447 & 492 \\
\hline 241-AN-104 & $5.53 \mathrm{E}-03$ & $2.55 \mathrm{E}-03$ & 227 & 104 & $117 \%$ & 76 & 227 & 249 \\
\hline 241-SX-103 & 3.03E-03 & $1.27 \mathrm{E}-03$ & 124 & 52 & $139 \%$ & 41 & 124 & 137 \\
\hline 241-SY-101 & $5.96 \mathrm{E}-02$ & 2.44E-02 & 2,441 & 993 & $145 \%$ & 814 & 2,441 & 2,685 \\
\hline 241-A-101 & 5.64E-03 & 2.14E-03 & 231 & 87 & $164 \%$ & 77 & 231 & 254 \\
\hline 241-AZ-101 & $2.79 \mathrm{E}-02$ & $9.44 \mathrm{E}-03$ & 1,144 & 385 & $196 \%$ & 381 & 1,144 & 1,258 \\
\hline
\end{tabular}

Note: HGR = hydrogen generation rate.

Table E-3. Hydrogen Generation Rate Distribution for

Tanks with $1.5 \mathrm{E}-03 \mathrm{ft}^{3} / \mathrm{min}>\mathrm{HGR}_{\text {est }}>1.0 \mathrm{E}-03 \mathrm{ft}^{3} / \mathrm{min}$.

\begin{tabular}{|c|c|c|c|c|c|c|c|c|}
\hline \multirow{2}{*}{ Tanks } & \multirow{2}{*}{$\begin{array}{c}\mathbf{G}_{\bmod } \\
\left(\mathbf{f t}^{3} / \mathbf{m i n}\right) \\
\text { total HGR } \\
\text { from } \\
\text { model }\end{array}$} & \multirow{2}{*}{$\begin{array}{c}\mathbf{G}_{\text {field }} \\
\left(\mathrm{ft}^{3} / \mathrm{min}\right) \\
\text { total } \\
\text { HGR } \\
\text { from field }\end{array}$} & \multirow{2}{*}{$\begin{array}{c}\mathbf{G}_{\bmod } \\
(\mathrm{L} / \mathrm{day}) \\
\text { total } \\
\text { HGR } \\
\text { from } \\
\text { model }\end{array}$} & \multirow{2}{*}{$\begin{array}{c}\mathbf{G}_{\text {field }} \\
\text { (L/day) } \\
\text { total } \\
\text { HGR } \\
\text { from } \\
\text { field }\end{array}$} & \multirow{2}{*}{$\begin{array}{c}\text { Relative } \\
\text { differences } \\
\text { (model vs. } \\
\text { field data) }\end{array}$} & \multicolumn{3}{|c|}{$\begin{array}{c}\text { Resulting distribution using } \\
\mathrm{HGR}_{\text {est }} / 2 \leq \mathrm{HGR}_{\text {est }} \leq 1.5 * \mathrm{HGR}_{\text {est }}\end{array}$} \\
\hline & & & & & & $\begin{array}{c}\text { Lower } \\
\text { bound } \\
\text { (L/day) }\end{array}$ & $\begin{array}{c}\text { Mean } \\
\text { (L/day) }\end{array}$ & $\begin{array}{l}\text { Upper } \\
\text { bound } \\
(\mathrm{L} / \text { day })\end{array}$ \\
\hline 241-S-102 & $1.25 \mathrm{E}-03$ & $1.64 \mathrm{E}-03$ & 51 & 67 & $-24 \%$ & 26 & 51 & 77 \\
\hline 241-U-105 & $1.37 \mathrm{E}-03$ & $1.61 \mathrm{E}-03$ & 56 & 65 & $-15 \%$ & 28 & 56 & 84 \\
\hline 241-U-102 & $1.05 \mathrm{E}-03$ & $1.10 \mathrm{E}-03$ & 43 & 45 & $-4 \%$ & 22 & 43 & 65 \\
\hline 241-U-103 & $1.46 \mathrm{E}-03$ & $1.48 \mathrm{E}-03$ & 60 & 60 & $-1 \%$ & 30 & 60 & 90 \\
\hline 241-U-106 & $1.12 \mathrm{E}-03$ & $6.62 \mathrm{E}-04$ & 46 & 27 & $69 \%$ & 23 & 46 & 69 \\
\hline 241-SX-104 & $1.31 \mathrm{E}-03$ & $2.51 \mathrm{E}-04$ & 53 & 10 & $420 \%$ & 27 & 53 & 80 \\
\hline
\end{tabular}

Note: HGR = hydrogen generation rate. 
Six tanks fell into the $1.0 \mathrm{E}-03 \mathrm{ft}^{3} / \mathrm{min} \geq \mathrm{HGR}_{\text {est }}$ bin. Of these, tanks four tanks underestimated the HGR by up to $43 \%$, and two tanks overestimated the HGR by up to $60 \%$. To account for this range, the underestimated values the upper bound for the range was set to "190\% of the mean" (100\% plus twice "the relative difference for 241-U-107"), and the lower bound was set to the "mean $/ 2$ " (the mean divided by " $100 \%$ plus $\sim 2$ times of the relative difference for 241-SX-101"). The resulting distributions for this range of data are presented in Table E-4.

Table E-4. Hydrogen Generation Rate Distribution for Tanks with $1.0 \mathrm{E}-03 \mathrm{ft}^{3} / \mathrm{min} \geq \mathrm{HGR}_{\text {est }}$.

\begin{tabular}{|c|c|c|c|c|c|c|c|c|}
\hline \multirow{2}{*}{ Tanks } & \multirow{2}{*}{$\begin{array}{c}\mathbf{G}_{\text {mod }} \\
\left(\mathrm{ft}^{3} / \mathrm{min}\right) \\
\text { total HGR } \\
\text { from } \\
\text { model }\end{array}$} & \multirow{2}{*}{$\begin{array}{c}\mathbf{G}_{\text {field }} \\
\left(\mathrm{ft}^{3} / \mathrm{min}\right) \\
\text { total } \\
\text { HGR } \\
\text { from feld }\end{array}$} & \multirow{2}{*}{$\begin{array}{c}\mathbf{G}_{\text {mod }} \\
(\mathrm{L} / \text { day }) \\
\text { total } \\
\text { HGR } \\
\text { from } \\
\text { model }\end{array}$} & \multirow{2}{*}{$\begin{array}{c}\mathbf{G}_{\text {field }} \\
\text { (L/day) } \\
\text { total } \\
\text { HGR } \\
\text { from } \\
\text { field }\end{array}$} & \multirow{2}{*}{$\begin{array}{c}\text { Relative } \\
\text { differences } \\
\text { (model vs. } \\
\text { field data) }\end{array}$} & \multicolumn{3}{|c|}{$\begin{array}{c}\text { Resulting distribution using } \\
\mathbf{H G R}_{\text {est }} / 2 \leq \mathbf{H G R}_{\text {est }} \leq 1.9 * \mathrm{HGR}_{\text {est }}\end{array}$} \\
\hline & & & & & & $\begin{array}{c}\text { Lower } \\
\text { bound } \\
\text { (L/day) }\end{array}$ & $\begin{array}{c}\text { Mean } \\
\text { (L/day) }\end{array}$ & $\begin{array}{l}\text { Upper } \\
\text { bound } \\
(\mathrm{L} / \text { day })\end{array}$ \\
\hline 241-U-107 & $4.71 \mathrm{E}-04$ & $8.27 \mathrm{E}-04$ & 19 & 34 & $-43 \%$ & 10 & 19 & 37 \\
\hline 241-U-108 & $9.42 \mathrm{E}-04$ & $1.41 \mathrm{E}-03$ & 39 & 57 & $-33 \%$ & 19 & 39 & 73 \\
\hline 241-AN-101 & $1.73 \mathrm{E}-04$ & $2.50 \mathrm{E}-04$ & 7 & 10 & $-31 \%$ & 4 & 7 & 13 \\
\hline 241-U-109 & $5.44 \mathrm{E}-04$ & $7.11 \mathrm{E}-04$ & 22 & 29 & $-23 \%$ & 11 & 22 & 42 \\
\hline 241-SY-102 & $9.66 \mathrm{E}-04$ & $7.26 \mathrm{E}-04$ & 40 & 30 & $33 \%$ & 20 & 40 & 75 \\
\hline 241-SX-101 & 6.64E-04 & $4.20 \mathrm{E}-04$ & 27 & 17 & $58 \%$ & 14 & 27 & 52 \\
\hline \multicolumn{9}{|c|}{ GR } \\
\hline
\end{tabular}


RPP-10006 REV 8

\section{E4.0 COMPUTER SOFTWARE USE AND VERIFICATION}

The spreadsheet used to determine the HGR distribution limits is described below:

- Microsoft Excel ${ }^{1} 2003$ was used to create the spreadsheet

- Spreadsheet owner: S. A. Barker

- Spreadsheet file name: RPP-10006r4 HGR Dists 041014 .xls

- File location²: \\AP003\BarolSteveBLRPP-10006r4\DatabaseBuild

- The spreadsheet is verified and documented in Spreadsheet Verification and Release Form SVF-269 Spreadsheet Verification and Release Form for RPP-10006r4 HGR Dists 041014 .xls, Rev. 0.

\section{E5.0 RESULTS}

Appendix $\mathrm{H}$ lists the solid phase HGRs along with associated maximum and minimum values.

\section{E6.0 REFERENCES}

HNF-3851, 2004, Empirical Rate Equation Model and Rate Calculations of Hydrogen Generation for Hanford Tank Waste, Rev 1, CH2M HILL Hanford Group, Inc., Richland, Washington.

Personal Computer-Surveillance Analysis Computer System (PCSACS), Queried on 2/14/2006, [DST 241-AP-103 and 241-AP-108 temperatures for 2/1/2005 through 2/14/2006], HISI ID No. 242.

RPP-5926, 2005, Steady-State Flammable Gas Release Rate Calculation and Lower Flammability Level Evaluation for Hanford Tank Waste, Rev. 5, CH2M HILL Hanford Group, Inc, Richland, Washington.

RPP-10006, 2006, Methodology and Calculations for the Assignment of Waste Groups for the Large Underground Waste Storage Tanks at the Hanford Site, Rev. 5, CH2M HILL Hanford Group, Inc., Richland, Washington.

RPP-10006, 2007, Methodology and Calculations for the Assignment of Waste Groups for the Large Underground Waste Storage Tanks at the Hanford Site, Rev. 7, CH2M HILL Hanford Group, Inc., Richland, Washington.

\footnotetext{
${ }^{1}$ Microsoft Excel is a registered trademark of Microsoft Corporation, Redmond, Washington.

${ }^{2}$ The content of network share $\ \mathrm{AP} 003 \mathrm{BB}$ aro has been transitioned to network share $\mid \mathrm{H}$ anfordldatalsitedata $\mathrm{B}$ aro.
} 


\section{RPP-10006 REV 8}

SVF-269, Spreadsheet Verification and Release Form for RPP-10006r4 HGR Dists 041014 .xls, CH2M HILL Hanford Group, Inc., Richland, Washington. 
RPP-10006 REV 8

\title{
APPENDIX F
}

\author{
WELLS, B. E., AND S. A. BARKER, \\ 2003, \\ SUMMARY OF YIELD STRESS IN SHEAR DATA FOR HANFORD WASTE, \\ TWS03.044, \\ PACIFIC NORTHWEST NATIONAL LABORATORY, \\ RICHLAND, WASHINGTON
}


RPP-10006 REV 8

This page intentionally left blank 


\section{Pacific Northwest \\ National Laboratory \\ Operated by Battelle for the \\ U.S. Department of Energy}

September 15, 2003

Bill Cowley, Manager

Flammable Gas Project

CH2M HILL Hanford Group, Inc.

MSIN S4-44

Richland, WA 99352

Dear Bill:

\section{SUMMARY OF YIELD STRESS IN SHEAR DATA FOR HANFORD WASTE}

Enclosed is PNNL letter report TWS03.044, Summary of Yield Stress in Shear Data for Hanford Waste, by BE Wells and SA Barker.

If you have any questions, please call me at 375-6671. Changes to distribution can be made by e-mail or phone.

Sincerely,
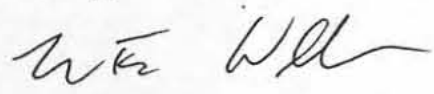

Beric E. Wells, Manager

PNNL Flammable Gas Project

\section{BEW:ekm}

cc: $\quad$ File T1.3.1/LB

SA Barker $\quad$ S7-90

WL Cowley $\quad$ S4-44

JM Grigsby $\quad$ S7-90

DCHedengren R1-44

LJ Kripps $\quad$ S7-90

CHG Correspondence Control H6-08

TCSRC R1-10 
RPP-10006 REV 8

This page intentionally left blank.

F-2 
RPP-10006 REV 8

TWS03.044

\section{Summary of Yield Stress in Shear Data for Hanford Waste}

BE Wells

Pacific Northwest National Laboratory

SA Barker

CH2MHILL Hanford Group, Inc.

September 2003

Pacific Northwest National Laboratory

Richland, Washington

\section{LIMITED DISTRIBUTION NOTICE}

This document is made available to the CH2M Hill Hanford Group, Inc. in confidence solely for use in performance of work under contracts with the U.S. Department of Energy. This document is not to be published or referenced in another publication, nor its contents otherwise disseminated or revealed or used for purposes other than specified above, without determination of final review authority. If the information contained herein is incorporated in a Hanford document, such document shall receive appropriate clearance. 


\section{RPP-10006 REV 8}

\subsection{Introduction}

The Hanford waste tanks are categorized into waste groups based on the tank's retention of flammable gas and the potential for that gas to be released by a buoyant displacement gas release event (BDGRE). In support of this categorization, data pertaining to the yield stress in shear of the waste sediments are herein reviewed.

Waste management and retrieval issues such as flammable gas retention and release and waste mixing are dependent on the yield stress in shear of the waste sediment. The waste sediment is a solid, liquid, and gas matrix that varies in composition from tank to tank. Yield stress in shear, or shear strength as it is commonly referred to in Hanford literature, may be defined as the point at which the sediment material ceases to deform like a solid under applied stress but instead flows like a truly viscous material with a finite viscosity.

Limitations of available instrumentation, the varied sediment conditions and compositions, and the influence of the sediment history for a given tank or waste sample render the determination of in situ sediment shear strength a challenging task. In this document, sediments are grouped into categories similar to those of Barker and Lechelt (2000), and representative shear strength data pertaining to these waste types are reviewed.

In Section 2, an overview of shear strength measurement techniques used on the Hanford sediment is presented. Data is presented in Section 3, and general trends related with waste type are discussed. Cited references are listed in Section 4. 
RPP-10006 REV 8

\subsection{Shear Strength Measurement Techniques}

Ex-tank (laboratory measurements performed on samples removed from the waste tank) and in situ shear strength measurements have been conducted on Hanford sediment. The ex-tank measurement techniques are discussed in Section 2.1, and the in situ measurements are discussed in Section 2.2.

\subsection{Ex-tank Shear Strength Measurements}

Numerous techniques to determine a material's shear strength have been developed. A review of both direct (direct assessment of the point at which the material yields or starts to flow) and indirect (extrapolation of shear stress-shear rate data to zero shear rate) techniques is presented by Nguyen and Boger (1992). Typical ex-tank measurements at Hanford are made with a shear vane (direct) or Couette type viscometers (indirect). Shear strength estimates have also been made based on horizontal waste core extrusion behavior.

\subsubsection{Couette Viscometer}

As discussed in the literature (Nguyen and Boger 1983 and 1992, Barnes 1999), Couette viscometer data at low shear rates suffers due to the sensitivity of the instrument and additional shearing and slip caused by the configuration of the instrument. The model assumed (i.e. Bingham, Casson, etc.) for the data can also affect the results (Nguyen and Boger 1992, Chhabra 1992). The data presented in Tingey et al. (2003) demonstrates that, at least for those wastes they considered, the waste has overshoot behavior, resulting in under-prediction of the yield point if the traditional models are applied.

Additionally, as has been noted in the referenced literature and with Hanford sediment (Onishi et al. 2003), sample disturbance history can have a direct impact on the measured shear stress. Aside from sample history prior to introduction into the viscometer, the configuration of the Couette viscometer itself may therefore also preclude the applicability of shear strength estimates from this devise to in situ conditions.

\subsubsection{Shear Vane}

Issues with the Coutte type viscometers such as slip and the sensitivity at low rotational speeds may be resolved by the use of a rotating vane device. However, although the instrument sample configuration is more representative of in situ conditions than that of the Couette viscometer, the sample history may still have significant impact on the results. Results of shear vane measurements are typically significantly larger than the in situ shear strength (Gauglitz and Aikin 1997, Heath 1987, Onishi et al. 2003). 


\section{RPP-10006 REV 8}

\subsubsection{Waste Core Extrusion Behavior}

Gauglitz and Aikin (1997) developed a methodology to determine the shear stress of waste sediment based on a visual comparison of horizontal waste core extrusion behavior for simulants with known shear strength to that of Hanford Waste. In this document, estimates based on this methodology are termed "visual observations." Their results generally agreed within a factor of two with the in situ ball rheometer data (see Section 2.2 for a discussion of the ball rheometer).

An "extrusion length" methodology based on the simulant extrusion data of Gauglitz and Aikin (1997) for estimating the yield stress in shear of Hanford Waste was developed in Rassat et al. (2003). This methodology relies on measuring the initial extrusion length of the waste core at plastic failure and produces shear strength values similar in magnitude and with similar trends as the ball rheometer results. It was concluded that, in the absence of definitive in situ measurements, or in support of them, this methodology is expected to produce representative results for the waste shear strength.

Note that although both of the waste core extrusion estimates rely on ex-tank core extrusion behavior, they are as representative of in situ conditions as is available ex-tank. Further, all applicable core segments from a given tank are evaluated, which, given that differences in shear strength have been observed with depth, may provide a more complete data set.

\subsection{In Situ Shear Strength Measurements}

The ball rheometer was developed to meet the need for measurement of the in situ rheological properties in Hanford double-shell tanks. The rheology of the waste material can be estimated in situ directly from the drag force on a ball as it moves through the waste at various speeds. The ball rheometer results are typically accepted as being more representative of in situ waste conditions than laboratory measurements (Hedengren et al. 2000). 


\section{RPP-10006 REV 8}

\subsection{Hanford Shear Strength Data}

Sediments with shear strength measurements considered in this review are grouped into categories similar to those of Barker and Lechelt (2000). These categories include:

- Saltcake waste with $>=1 \mathrm{~m}$ liquid over solids (SC-LIQ)

- Saltcake waste with $<1 \mathrm{~m}$ liquid over solids (SC-NL)

- Sludge waste with $>=1 \mathrm{~m}$ liquid over solids (SL-LIQ)

- Sludge waste with $<1 \mathrm{~m}$ liquid over solids (SL-NL)

Data comparing the various ex-tank and in situ measurements are presented in Table 1. For this general analysis, measurements given are typically average or median values. In some instances, multiple measurements are available throughout the depth and/or at different radial locations in the tank. In others, single measurements are reported. No attempt is made to reconcile these differences, and the average values reported are simple arithmetic averages of the data and do not take into account measurement location, etc. Sample results are chosen as close to in situ waste conditions (i.e. solid volume fraction and temperature) as possible.

As expected (see Section 2), for all waste types with both Couette viscometer and shear vane data, the viscometer results are significantly lower than the shear vane results. For SC-LIQ tanks, the waste core extrusion methodologies compare well with the ball rheometer results, are larger that the viscometer results, and are significantly lower than the shear vane results. In SLLIQ tanks, where the ball rheometer has not been deployed, the extrusion length results compare favorably with the shear vane results. The extrusion length results are also similar in magnitude to the shear vane values in SL-NL wastes. It is postulated that the shear vane and extrusion results are more similar in sludge than saltcake waste due to solids precipitation in the saltcake samples. 


\section{RPP-10006 REV 8}

Table 1. Hanford Sediment Measured Shear Strength (Pa), [Reference]

\begin{tabular}{|c|c|c|c|c|c|c|}
\hline \multirow[b]{2}{*}{ Tank } & \multirow[b]{2}{*}{ Waste Type } & \multicolumn{5}{|c|}{ Measurement Technique } \\
\hline & & $\begin{array}{c}\text { Couette } \\
\text { Viscometer }\end{array}$ & Shear Vane & $\begin{array}{c}\text { Visual } \\
\text { Observation }\end{array}$ & $\begin{array}{l}\text { Extrusion } \\
\text { Length }\end{array}$ & $\begin{array}{c}\text { Ball } \\
\text { Rheometer }\end{array}$ \\
\hline AN-103 & SC-LIQ & & $8,000[2]$ & $225[2]^{1}$ & $990[3]$ & $160[1]^{T}$ \\
\hline AN-104 & SC-LIQ & $0.5[5]$ & & & $130[3]$ & $125[1]$ \\
\hline AN-105 & SC-LIQ & $0.75[14]$ & & & & $135[1]$ \\
\hline AW-101 & SC-LIQ & & 900 [2] & $100[2]$ & $150[3]$ & $150[1]$ \\
\hline SY $-101^{3}$ & SC-LIQ & 60 [15] & $\begin{array}{l}290[15] \\
730[8]\end{array}$ & & & \\
\hline SY-103 & SC-LIQ & 4 [4] & $1,500[2,4]$ & $195[2]$ & $160[3]$ & $150[1]$ \\
\hline A-101 & SC-NL & & & $525[11]$ & & \\
\hline S-102 & SC-NL & & & $800[2]$ & & \\
\hline U-103 & SC-NL & & & $885[11]$ & & \\
\hline U-107 & SC-NL & & $50[8]$ & 315 [11] & & \\
\hline AW-103 & SL-LIQ & & $590[6]$ & & & \\
\hline AY-102 & SL-LIQ & & $510[6]$ & & $1,090[7]$ & \\
\hline AZ-101 & SL-LIQ & $4.7[12]$ & $\begin{array}{l}1,770[6] \\
1,500[13]\end{array}$ & & 740 [7] & \\
\hline AZ-102 & SL-LIQ & & $870[6]$ & & & \\
\hline AY-101 & SL-NL & & $2,020[6]$ & & & \\
\hline B-201 & SL-NL & & $1,270[8]$ & & & \\
\hline B-203 & SL-NL & $12.3[9]^{2}$ & $\begin{array}{l}2,280[9] \\
60[9]^{2} \\
\end{array}$ & & $1,140[10]$ & \\
\hline B-204 & SL-NL & & & & $860[10]$ & \\
\hline C-104 & SL-NL & & $850[6]$ & & & \\
\hline C-107 & SL-NL & & $1,050[8]$ & & & \\
\hline $\mathrm{T}-110$ & SL-NL & & & & $1,150[10]$ & \\
\hline $\mathrm{T}-201$ & SL-NL & & & & $1,770[10]$ & \\
\hline T-202 & SL-NL & & & & $950[10]$ & \\
\hline $\mathrm{T}-203$ & SL-NL & $40[9]^{2}$ & $\begin{array}{l}3,770[9] \\
310[9]^{2} \\
\end{array}$ & & $1,030[10]$ & \\
\hline $\mathrm{T}-204$ & SL-NL & & 1,520 [9] & & $1,090[10]$ & \\
\hline
\end{tabular}

Table References:

[1] Hedengren et al. 2000

[2] Gauglitz and Aikin 1997

[3] Rassat et al. 2003

[4] Bredt PR, JD Hudson, and JM Tingey. 1995. Effects of Dilution on the Physical, Rheological, and Chemical Properties of Tank 241-SY-103. Letter Report PNL MIT 092995, Pacific Northwest National Laboratory, Richland, WA.

[5] Herting 1998

[6] Memorandum from DB Bechtold to KE Bell, RA Esch, and FH Steen. Correction of Shear Strength Measurements Reported by 222-S Laboratory. March 28, 2001, 8D500-DBB-01-018. Fluor Hanford, Richland, WA. [7] Analysis performed for $\mathrm{W}-211$ project. 


\section{RPP-10006 REV 8}

[8] TWINS, Tank Waste Information System, http://twins.pnl.gov/

[9] Tingey et al. 2003

[10] Rassat et al. 2003

[11] Hedengren et al. 2001

[12] Urie et al. 2002

[13] Gray et al. 1993

[14] Herting 1997

[15] Tingey et al. 1994

${ }^{1}$ Upper portion of sediment layer only

${ }^{2}$ Diluted sample; results included to illustrate difference in viscometer and shear vane results.

${ }^{3}$ SY-101 prior to mixer pump and mitigation.

The most representative shear strength values for in situ waste conditions are obtained with the ball rheometer. For waste processing conditions, other methods may be more appropriate. The accuracy of the extrusion length waste core extrusion methodology in reproducing the ball rheometer results indicates that, in the absence of in situ measurements, this methodology is expected to produce representative results for the waste shear strength. The similarity between the extrusion length and shear vane results in sludge suggest that the shear vane results in sludge waste may be representative of in situ conditions. Therefore, using these guidelines, the following methodology to assign shear strength based on waste type is proposed:

- SC-LIQ, Figure 1, Normal distribution with mean 144 and standard deviation 13.87; data from AN-103, AN-104, AN-105, AW-101, and SY-103, ball rheometer

- SC-NL, Figure 2, Normal distribution with mean 631.25, standard deviation 260.88 , and minimum truncated at two standard deviations; data from A-101, S$102, \mathrm{U}-103$, and U-107, visual observation

- SL-LIQ, Figure 3, Log-normal distribution with mean 829.55 and standard deviation 218.64; data from AW-103 and AZ-102, shear vane; AY-102 and AZ101 , extrusion length

- SL-NL, Figure 4, Log-normal distribution with mean 1,143.27 and standard deviation 272.08; data from AY-101, B-201, C-104, and C-107, shear vane; B203, B-204, T-110, T-201, T-202, T-203, and T-204, extrusion length

The distributions were determined from the data sources specified. The shear strength values listed in Table 1 have varying degrees of uncertainty. Although the uncertainty in the data is not specifically accounted for, by fitting a distribution to the data, some uncertainty is allowed for. A series of goodness-of-fit tests were conducted using Crystal Ball ${ }^{\mathrm{TM}}$ to determine the distribution that best fits the data. Normal and log-normal distributions were preferentially chosen. With the limited amount of data points and their varied pedigree, these distributions should not be interpreted as the true distribution; they are representations of the above listed data.

Differences in shear strength in a given waste type exist, and location in the waste, history, etc. may potentially affect shear strength values. As such, the results presented here should only be used as representative values, and should not be used as substitute for specific analysis of a given waste. 
RPP-10006 REV 8

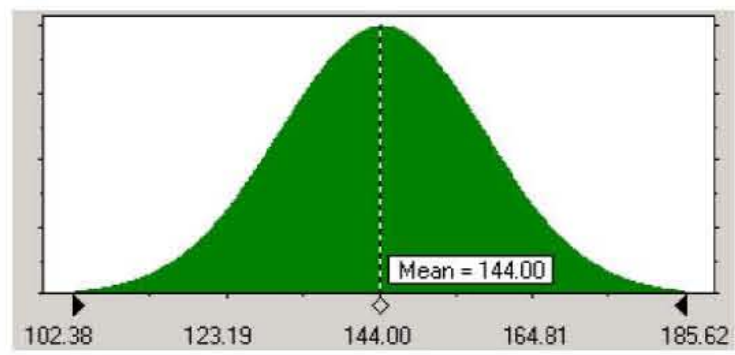

Figure 1. SC-LIQ Shear Strength Distribution (horizontal axis is shear strength $(\mathrm{Pa})$, vertical axis is probability of occurrence)

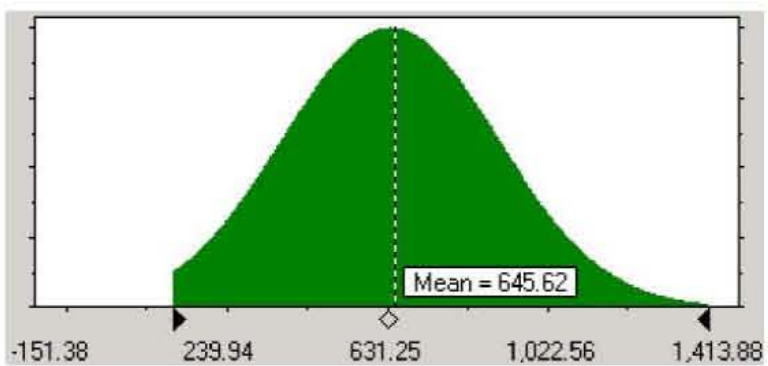

Figure 2. SC-NL Shear Strength Distribution (horizontal axis is shear strength (Pa), vertical axis is probability of occurrence)

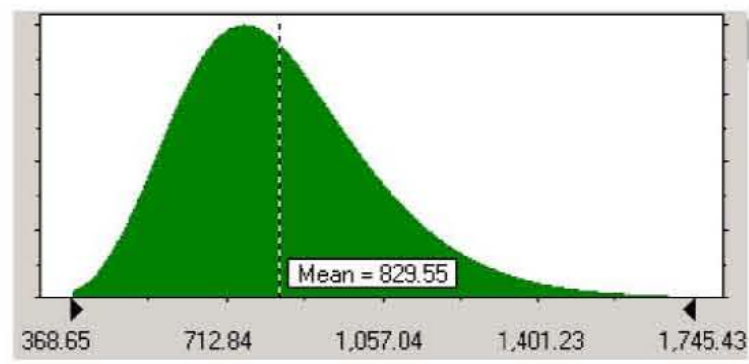

Figure 3. SL-LIQ Shear Strength Distribution (horizontal axis is shear strength (Pa), vertical axis is probability of occurrence) 


\section{RPP-10006 REV 8}

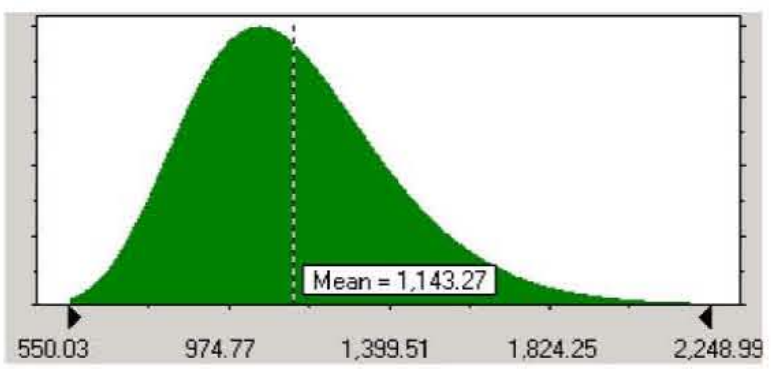

Figure 4. SL-NL Shear Strength Distribution (horizontal axis is shear strength (Pa), vertical axis is probability of occurrence) 


\section{RPP-10006 REV 8}

\subsection{References}

Barker SA and AR Lechelt. 2000. Determination of Waste Groupings for Safety Analyses. RPP6171. Rev. 0. CH2M HILL Hanford Group, Inc., Richland, Washington.

Barnes HA. 1999. The Yield Stress - A Review or ' $\pi \alpha v \tau \alpha \rho \varepsilon l$ ' Everything Flows? Journal of Non-Newtonian Fluid Mechanics. 81: 133-178.

Chhabra RP. 1992. Bubbles, Drops, and Particles in Non-Newtonian Fluids. CRC Press, Inc. Boca Raton, FL.

Gauglitz PA, and JT Aikin. 1997. Waste Behavior During Horizontal Extrusion: Effect of Waste Strength for Bentonite and Kaolin/Ludox Simulants and Strength Estimates for Wastes from Hanford Waste Tanks 241-SY-103, AW-101, AN-103, and S-102. PNNL-11706. Pacific Northwest National Laboratory, Richland, WA.

Gray WJ, ME Peterson, RD Scheele, and JM Tingey. Characterization of the Second Core Sample of Neutralized Current Acid Waste from Double-Shell Tank 101-AZ. PNNL-13027. Pacific Northwest National Laboratory, Richland, WA.

Heath WO. 1987. Development of an In-Situ Method to Define the Rheological Properties of Slurries and Sludges Stored in Underground Tanks. PNL-6083. Pacific Northwest Laboratory, Richland, WA.

Hedengren DC, TA Hu, MA Kufahl, DJ McCain, CW Stewart, JL Huckaby, LA Mahoney, and KG Rappe. 2001. Data and Observations of Single-Shell Flammable Gas Watch List Tank Behavior. RPP-7249, Rev. 0. CH2M HILL Hanford Group, Inc., Richland, Washington.

Hedengren DC, KM Hodgson, WB Barton, CW Stewart, JM Cuta, and BE Wells. 2000. Data Observations on Double-Shell Flammable Gas Watch List Tank Behavior. RPP-6655. Rev. 0. CH2M HILL Hanford Group, Inc., Richland, Washington.

Herting DA. 1998. Results of Dilution Studies with Waste from Tank 241-AN-104. HNF-3352, Rev. 0. Fluor Daniel Hanford Inc., Richland, WA.

Herting DA. 1997. Results of Dilution Studies with Waste from Tank 241-AN-105. HNF-SDWM-DTR-046, Rev. 0. Numatec Hanford Corporation, Richland, WA.

Nquyen QD, and DV Boger. 1992. Measuring the Flow Properties of Yield Stress Fluids. Annual Review of Fluid Mechanics. 24: 47-88.

Nquyen QD, and DV Boger. 1983. Yield Stress Measurement for Concentrated Suspensions. Journal of Rheology. 27 (4): 321-349. 


\section{RPP-10006 REV 8}

Onishi Y, BE Wells, ST Yokuda, and GT Terrones. 2003. Feasibility Study on Using a Single Mixer Pump for Tank 241-AN-101 Waste Retrieval. PNNL-14105. Pacific Northwest National Laboratory, Richland, WA.

Rassat SD, LA Mahoney, BE Wells, DP Mendoza, and DD Caldwell. 2003. Assessment of Physical Properties of Transuranic Waste in Hanford Single-Shell Tanks. PNNL-14221. Pacific Northwest National Laboratory, Richland, WA.

Tingey JM, J Gao, CH Delegrad, LM Bagaason, and BE Wells. 2003. Physical Property and Rheological Testing of Actual Transuranic Waste from Hanford Single-Shell Tanks. PNNL14365. Pacific Northwest National Laboratory, Richland, WA.

Tingey JM, PR Bredt, and EH Shade. 1993. The Effects of Heating and Dilution on the Rheological and Physical Properties of Tank 241-SY-101 Waste. PNL-10198. Pacific Northwest Laboratory, Richland, WA.

Urie MW, PR BRedt, JA Campbell, OT Farmer, SK Fiskum, LR Greenwood, EW Hoppe, LK Jagoda, GM Mong, AP Poloski, RD Scheele, CZ Soderquist, RG Swoboda, MP Thomas, and JJ Wagner. 2002. Chemical Analysis and Physical Property Testing of 241-AZ-101 Tank Waste Supernatant and Centrifuged Solids. PNWD-3215. Battelle, Richland, WA. 
RPP-10006 REV 8

This page intentionally left blank. 
RPP-10006 REV 8

APPENDIX G

DERIVATION OF RETAINED GAS COMPOSITIONS

G-i 
RPP-10006 REV 8

This page intentionally left blank

G-ii 


\section{RPP-10006 REV 8}

\section{CONTENTS}

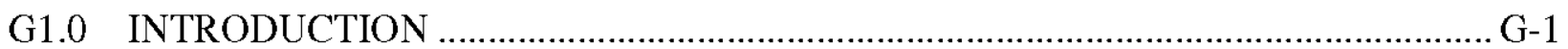

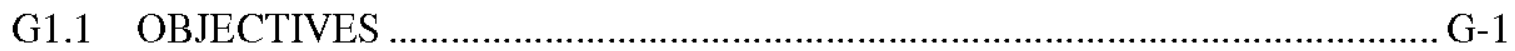

G1.2 DISTRIBUTIONS REQUIRED TO DETERMINE THE RETAINED GAS

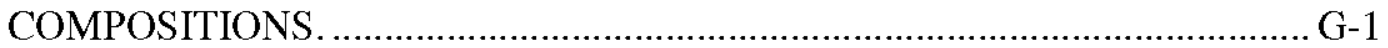

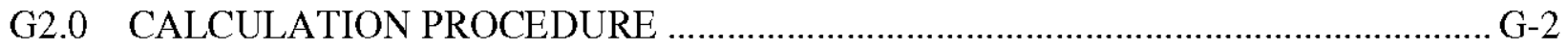

G2.1 SCAN IN RGS DATA TABLES ................................................................

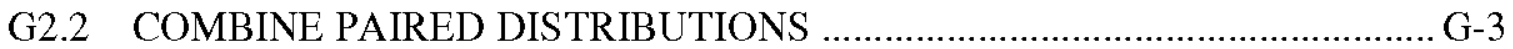

G2.3 CREATE DISTRIBUTIONS FOR RGS TANKS ……................................ G-28

G2.4 CREATE DISTRIBUTIONS FOR NON-RGS TANKS ………..................... G-49

G2.5 REFORMAT RESULTS TO FIT DATABASE ............................................. G-52

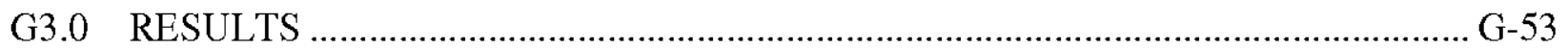

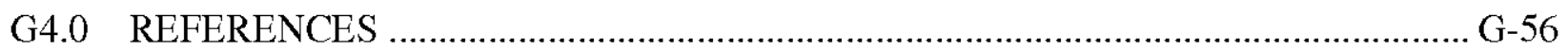

\section{FIGURES}

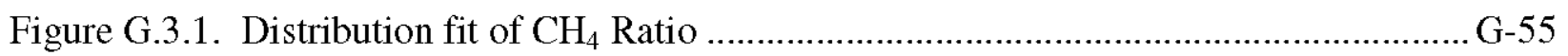

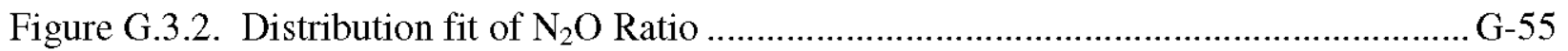

Figure G.3.3. Distribution fit of $\mathrm{N}_{2}$ Concentration ............................................................ 55

\section{TABLES}

Table G.3.1. Retained Gas Concentration Distribution Results ............................................. G-53 


\section{RPP-10006 REV 8}

Calculation Reviewed: Appendix J -- Derivation Of Retained Gas Compositions, RPP-10006 Rev 4, Methodology and Calculations for the Assignment of Waste Groups for the Large Underground Waste Storage Tanks at the Hanford Site

Scope of Review: _Appendix J_(See also Spreadsheet Verification 271) (e.g., document section or portion of calculation)

\begin{tabular}{|c|c|c|c|c|}
\hline Engineer/Analyst: & S. A. Barker & & Date: & $10 / 27 / 2004$ \\
\hline Organizational Mgr: & T. M. Horner & T.ul. & Date: & $10 / 27 / 2004$ \\
\hline
\end{tabular}

This document consists of $\underline{60}$ pages and the following attachments (if applicable):

Yes No NA*

[X [ ] [ ] 1. Analytical and technical approaches and results are reasonable and appropriate.

(x [ ] [ ] 2. Necessary assumptions are reasonable, explicitly stated, and supported.

[X [ ] [ ] 3. Ensure calculations that use software include a paper printout, microfiche, $C D$ ROM, or other electronic file of the input data and identification to the computer codes and versions used, or provide alternate documentation to uniquely and clearly identify the exact coding and execution process.

[X [] [ ] 4. Input data were checked for consistency with original source information.

[X] [ ] [ 5. For both qualitative and quantitative data, uncertainties are recognized and discussed.

[X [ ] [ ] 6. Mathematical derivations were checked including dimensional consistency of results.

X [ ] [ ] 7. Calculations are sufficiently detailed such that a technically qualified person can understand the analysis without requiring outside information.

[X [ ] [ ] 8. Software verification and validation are addressed adequately.

[X [ ] [ ] 9. Limits/criteria/guidelines applied to the analysis results are appropriate and referenced. Limits/criteria/guidelines were checked against references.

[X [ ] [ ] 10. Conclusions are consistent with analytical results and applicable limits.

[X] [ ] [ ] 11. Results and conclusions address all points in the purpose.

[ [ ] [ ] 12. Referenced documents are retrievable or otherwise available.

[x] [ ] [ ] 13. The version or revision of each reference is cited.

[x [] [] 14. The document was prepared in accordance with Attachment A, "Calculation Format and Preparation Instructions."

(X [] [ ] 15. Impacts on requirements have been assessed and change documentation initiated to incorporate revisions to affected documents as appropriate.

[X [ ] [ ] 16. All checker comments have been dispositioned and the design media matches the calculations.

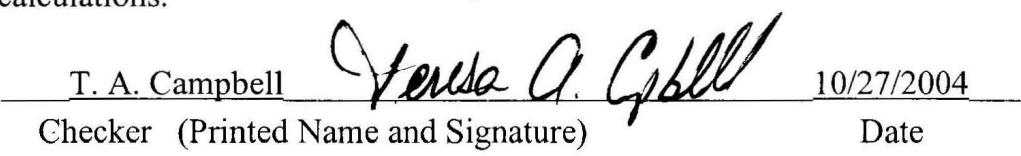

* If No or NA is chosen, an explanation must be provided on or attached to this form. 
RPP-10006 REV 8

\section{APPENDIX G \\ DERIVATION OF RETAINED GAS COMPOSITIONS}

\section{G1.0 INTRODUCTION}

This report provides the documentation for the derivation of the retained gas composition parameters. The major components for of the flammable gases generated within the Hanford wastes are hydrogen $\left(\mathrm{H}_{2}\right)$, nitrogen $\left(\mathrm{N}_{2}\right)$, methane $\left(\mathrm{CH}_{4}\right)$, ammonia $\left(\mathrm{NH}_{3}\right)$, and nitrous oxide $\left(\mathrm{N}_{2} \mathrm{O}\right)$. The values for these compositions within a tank are quite variable and are best expressed as a distribution. In order to constrain the compositions in the gas phase during the Monte Carlo simulation, the concentration of $\mathrm{N}_{2} \mathrm{O}$ and $\mathrm{CH}_{4}$ are expressed as ratios with $\mathrm{H}_{2}$, and the $\mathrm{H}_{2}$ concentration is determined by difference. The retained gas composition is required in the determination of the waste groupings described in the document. This gas composition determined the flammability of the headspace following a release of retained gas.

\section{G1.1 OBJECTIVES}

The objective of this appendix is to use the available Retained Gas Sampler (RGS) data for 16 tanks to derive the distributions required to predict the gas composition for the 16 sampled tanks and to prepare default retained gas composition distributions for tanks that have not been sampled.

\section{G1.2 DISTRIBUTIONS REQUIRED TO DETERMINE THE RETAINED GAS COMPOSITIONS.}

In order to determine the total retained gas composition, the concentration of the five gases, which make up the retained gas must be estimated. These gases are $\mathrm{H}_{2}, \mathrm{~N}_{2}, \mathrm{CH}_{4}, \mathrm{NH}_{3}$, and $\mathrm{N}_{2} \mathrm{O}$. A Monte Carlo simulation picking random values from the individual gas compositions without constrains will rarely pick a set of five concentrations that would add up to exactly $100 \%$. In order to constrain the Monte Carlo, the following method for determining the retained gas composition has bee developed. The concentrations of $\mathrm{N}_{2}$ and $\mathrm{NH}_{3}$ are determined directly. The compositions for the $\mathrm{CH}_{4}$ and $\mathrm{N}_{2} \mathrm{O}$ gases are described as ratios to the hydrogen concentrations. Equations 1 through 7 describe these ratios and an example solution to the retained gas concentrations is presented.

\section{Given:}

Retained gas

concentration of

$\mathrm{N}_{2} \quad=\quad\left[\mathrm{N}_{2}\right]=29.2 \%$

Retained gas

concentration of

$\mathrm{NH}_{3}$

$$
=\left[\mathrm{NH}_{3}\right]=0.079 \%
$$


$\mathrm{CH}_{4}$ gas ratio $=\left[\mathrm{CH}_{4}\right] /\left\{\left[\mathrm{CH}_{4}\right]+\left[\mathrm{H}_{2}\right]\right\}$

$$
\mathrm{CH}_{4 \text { ratio_rg }}=0.114
$$

$\mathrm{N}_{2} \mathrm{O}$ gas ratio $=\left[\mathrm{N}_{2} \mathrm{O}\right] /\left\{\left[\mathrm{CH}_{4}\right]+\left[\mathrm{H}_{2}\right]+\left[\mathrm{N}_{2} \mathrm{O}\right]\right\}$

$$
\mathrm{N}_{2} \mathrm{O}_{\text {ratio_rg }}=0.271
$$

The $\mathrm{CH}_{4}$ term is defined as

$$
\begin{aligned}
\mathrm{t}_{\mathrm{CH} 4} & =\frac{\mathrm{CH}_{4 \text { ratio_rg }}}{1-\mathrm{CH}_{4 \text { ratio_rg }}} \\
\mathrm{t}_{\mathrm{CH} 4} & =0.1287
\end{aligned}
$$

The $\mathrm{N}_{2} \mathrm{O}$ term is defined as

$$
\begin{aligned}
\mathrm{t}_{\mathrm{N} 2 \mathrm{O}} & =\frac{\mathrm{N}^{2} \mathrm{O} \text { ratio_rg }}{1-\mathrm{N} 2 \mathrm{O} \text { ratio_rg }} \\
\mathrm{t}_{\mathrm{N} 2 \mathrm{O}} & =0.3717
\end{aligned}
$$

The $\mathrm{H}_{2}$ concentration is calculated from the equation

$$
\begin{aligned}
& {\left[\mathrm{H}_{2}\right]=\frac{1-\left(\left[\mathrm{NH}_{3}\right]+\left[\mathrm{N}_{2}\right]\right)}{1+\mathrm{t}_{\mathrm{CH} 4}{ }^{+\mathrm{t}} \mathrm{CH} 4{ }^{*}{ }^{\mathrm{t}} 2 \mathrm{O}{ }^{+\mathrm{t}} \mathrm{N} 2 \mathrm{O}}} \\
& {\left[\mathrm{H}_{2}\right]=45.68 \%}
\end{aligned}
$$

The $\mathrm{CH}_{4}$ concentration is calculated from the equation

$$
\begin{aligned}
& {\left[\mathrm{CH}_{4}\right]=\left[\mathrm{H}_{2}\right] * \mathrm{t}_{\mathrm{ch} 4}} \\
& {\left[\mathrm{CH}_{4}\right]=5.88 \%}
\end{aligned}
$$

And finally the $\mathrm{N}_{2} \mathrm{O}$ concentration is calculated from the equation

$$
\begin{aligned}
& {\left[\mathrm{N}_{2} \mathrm{O}\right]=\left(\left[\mathrm{H}_{2}\right]+\left[\mathrm{CH}_{4}\right]\right) * \mathrm{t}_{\mathrm{N} 2 \mathrm{O}}} \\
& {\left[\mathrm{N}_{2} \mathrm{O}\right]=19.17 \%}
\end{aligned}
$$

\section{G2.0 CALCULATION PROCEDURE}

The process for calculating the retained gas compositions is outlined in the following procedure. The retained gas composition is based on the RGS results published in PNNL-13317, "Ammonia Results Review for Retained Gas Sampling". This procedure begins with scanned in images of Table 2.3 of PNNL-13317. 


\section{RPP-10006 REV 8}

All calculations are done in EXCEL ${ }^{1}$ with the Crystal Ball ${ }^{2}$ Monte Carlo add-in.

\section{G2.1 SCAN IN RGS DATA TABLES}

Spreadsheet "rgs FinalSumTable Rev 1 Tab_6MC 030823 .xls", Tab "1-Major Components"

1. Scan Data into digital format from document and proofread.

Tab "2-Minor comps"

Scan unpublished data on minor component compositions and proofread. The minor components are often listed in the tables as "other". This breakdown allows the approximately $3 \%$ of the gases listed as other to be broken down and assigned to the appropriate gas. In this case $\mathrm{CH}_{\mathrm{x}}$ hydrocarbons are assigned to methane $\left(\mathrm{CH}_{4}\right)$ and nitrous oxides $\left(\mathrm{NO}_{\mathrm{x}}\right)$ are assigned to nitrogen $\left(\mathrm{N}_{2}\right)$.

\section{G2.2 COMBINE PAIRED DISTRIBUTIONS}

Combine Paired Distributions for High and Low Salt Conditions to Make a Single Distribution

Assume that a combined stepwise distribution adequately describes combination of high and low salt compositions.

Tab "3-revised comps"

1. Copy values from Tabs 1 and 2 and paste and transpose into appropriate column "C" cells.

Combine Distributions for All Tanks Except for SY-101

2. Create Crystal Ball assumption for components listed below with mean and standard deviation data in Columns "D" and "H."

$\mathrm{H} 2, \mathrm{~N} 2, \mathrm{~N} 2 \mathrm{O}, \mathrm{CH} 4, \mathrm{NH} 3, \mathrm{C} 2 \mathrm{Hx}, \mathrm{C} 3 \mathrm{Hx}$, Other $\mathrm{HC}$, Other $\mathrm{NOx}$

${ }^{1}$ EXCEL is a trademark of Microsoft Corporation, Redmond, Washington.

${ }^{2}$ Crystal Ball is a trademark of Decisioneering, Inc, Denver, Colorado. 
"rgs FinalSumTable Rev 1 Tab_6MC 030823 .xls", Tab "1-Major Components"

\begin{tabular}{|c|c|c|c|c|c|c|c|c|}
\hline \multirow{2}{*}{ Tank and Sample (or Layer) } & \multicolumn{6}{|c|}{ Mole Prercent of Constituent in Butboles } & \multirow{2}{*}{ Gas Volume Percent } & \multirow{2}{*}{$\begin{array}{l}\text { Elevation } \\
\text { (cm. in.) }\end{array}$} \\
\hline & $\mathrm{H}_{2}$ & N2 & N2O & $\mathrm{CH} 4$ & WNH3 & Tother & & \\
\hline$A W-101-24 \mathrm{~A}-\mathrm{B}$ & $26 \pm 9.4$ to $24 \pm 8.8$ & $68 \pm 32$ to 70434 & $1.8 \pm 0.7$ to $0.5 \pm 0.2$ & $1.0 \pm 0.4$ & 0.440 .2 & $3.0 \pm 1.4$ to $3.6 \pm 1.6$ & $0.8 \pm 0.1$ to $0.7 \pm 0.1$ & \\
\hline AW-101-24A-17 & $29 \pm 3.9$ & $59 \pm 8.9$ to $62 \pm 9.3$ & $5.5 \pm 0.91$ to 2.910 .4 & $1.8 \pm 0.3$ & $0.6 \pm 0.3$ & $3.4 \pm 0.6$ to $3.6 \pm 0.6$ & $2.7 \pm 0.3$ to $2.5 \pm 0.3$ & $265,104.5$ \\
\hline AW-101-24B-18 & $19 \pm 3.1$ & $68+1.4$ to $71+14$ & $6.7 \pm 1.2$ to $3.2 \pm 0.6$ & $2.0 \pm 0.4$ & $0.3+0.1$ & $4.2+0.7$ to $4.6 \pm 0.8$ & $2.1 \pm 0.4$ to $1.9+0.4$ & $217,86.5$ \\
\hline AW-101-24A-19 & $43 \pm 3.5$ to $44 \pm 3.6$ & $47 \pm 4.1$ to $48 \pm 4.1$ & $5.7 \pm 0.5$ to $3.9 \pm 0.3$ & $1,4 \pm 0.1$ & $0.8+0.4$ & $1.9+0.2$ to $2.0 \pm 0.2$ & $5.2+0.5$ to $5.0+0.5$ & $169,66.5$ \\
\hline$A \mathrm{~W}-101-24 \mathrm{~A}-21$ & $30 \pm 2.5$ to $31 \pm 2.6$ & $57 \pm 4,8$ to $59 \pm 5.0$ & $8.0 \pm 0.7$ to $5.3 \pm 0.5$ & $1.8 \pm 0.3$ & $0.7 \pm 0.3$ & $2.5 \pm 0.3$ to $2.6 \pm 0.3$ & $5,1 \pm 0.5$ to $48 \pm 0.5$ & $723,36.5$ \\
\hline$A W-101-24 B-Z 2$ & $13 \pm 2.1$ to $14 \pm 2.1$ & $67 \pm 11$ to $72 \pm 12$ & $12 \pm 2.0$ to $5.2 \pm 0.9$ & $2.2 \pm 0.4$ to $23+0.5$ & $0.3+0,1$ & $5.3 \pm 1,3$ to $6.0 \pm 1,4$ & $2.0 \pm 0.4$ to $1.8 \pm 0.4$ & $24.1,9.5$ \\
\hline$A W-101-C(b)$ & $26 \pm 9.4$ to $24 \pm 8.8$ & $68+32$ to $70+34$ & 1.840 .7 to 0.540 .2 & $1.0 \pm 0.4$ & 0.440 .2 & $30 \pm 1.4 \pm 0.3 .8 \pm 1.8$ & $0.8 \pm 0.3$ to $0.7 \pm 0.3$ & 673,265 \\
\hline$A W=101=N C(b)$ & $32 \pm 3.2$ to $33 \pm 3.2$ & $56 \pm 6.2$ to $58.8 \pm 6.4$ & $7.2 \pm 0.8$ to $4.4 \pm 0.5$ & $1.7 \pm 0.2$ & $0.6 \pm 0.3$ & $3.0 \pm 0.5$ to $3.2 \pm 0.5$ & $3.7 \pm 1.8$ to $3.5 \pm 1.8$ & $131,51.6$ \\
\hline & & & & & & & & \\
\hline$A-101-24-2$ & $63 \pm 5.5$ to $64 \pm 5.6$ & $26 \pm 4.9$ to $27 \pm 4.9$ & $7.4 \pm 0.7$ to $6.5: 5 \pm 0.6$ & $0.4 \pm 0.1$ & $\frac{2.1 \pm 1.0}{3.54 .7}$ & $0.5 \pm 0.07$ & $16 \pm 1.4$ & 845,3325 \\
\hline A-101-15-5 & $75 \pm 8.1$ & $15 \pm 4.8$ & $5.7 \pm 0.6 .105 .2 \pm 0.6$ & $0.7 \pm 0.1$ & $3.5+1.2$ & $0.3 \pm 0.06$ & $18 \pm 2.1$ & $700,275.5$ \\
\hline A-101-15-8 & $76 \pm 7.8$ & $16+5.4$ & $5.3+0.6$ to $5.0+0.5$ & $0.7 \pm 0.08$ & $2.0+0.6$ & $0.3+0.04$ & $20+2.1$ & $555,2+18.5$ \\
\hline A-101-24-9 & $70 \pm 6.1$ & $23 \pm 4.6$ & $4.9 \pm 0.4$ to $4.5+0.4$ & $0.8 \pm 0.09$ & $1.7 \pm 0.3$ & $0.2+0.03$ & $22 \pm 2.1$ to $21+2.1$ & $507,199.5$ \\
\hline A-101-15-12 & $12 \pm 44$ & $63 \pm 29$ to $73 \pm 34$ & 1616.7 to $4.9+22$ & $3,1 \pm 1,7$ to $3.2 \pm 1,8$ & $37 \pm 1,9$ & $2.6 \pm 1.4$ to $3.6 \pm 1.9$ & $0.7 \pm 0.3$ to $0.5 \pm 0.3$ & $302,142.5$ \\
\hline A-101-24-16 & $15 \pm 4.2$ to $14 \pm 4.0$ & $64 \pm 20$ to $74 \pm 24$ & $14 \pm 4.4$ to $4.1 \pm 1.3$ & $0.9 \pm 0.3$ & $3.7 \pm 1.8$ & $2.2 \pm 0.9$ to $3.0 \pm 1.3$ & $0.6 \pm 0.3$ to $0.5+0.3$ & $\pi 69,66.5$ \\
\hline A-101-24-19 & $18 \pm 4.5$ & $65 \pm 20$ to $72 \pm 23$ & $12 \pm 3.4$ to $4.2 \pm 1.2$ & $0.7 \pm 0.2$ & $3.3 \pm 1.6$ & 1.340 .5 to $1.6 \pm 0.7$ & $1.0 \pm 0.3$ to $0.8 \pm 0.3$ & $24.1,9.5$ \\
\hline$A-1 O A=N C$ & $72 \pm 7.1$ & $19 \pm 4.9$ & $5.8 \pm 0.6$ to $5.3 \pm 0.5$ & $0.7 \pm 0.1$ & $2.5 \pm 0.9$ & 0.340 .05 & 1849.0 & 641,252 \\
\hline$A-101-C$ & $15 \pm 4.5$ & $64 \pm 24$ to $73 \pm 27$ & $14 \pm 4.9$ to $4.4 \pm 1.6$ & $1.7 \pm 0.8$ & $3.5 \pm 1.8$ & $2.1 \pm 0.9$ to $2.8 \pm 1.3$ & $0.7 \pm 0.3$ to 0.640 .3 & 186,73 \\
\hline & & & & & & & & \\
\hline AN-105-7B-4 & $25 \pm 12$ to $24 \pm 12$ & $58 \pm 42$ to $66 \pm 49$ & $11 \pm 5.6$ to $3.4 \pm 1.8$ & $1.4 \pm 0.9$ & $0.6 \pm 0.4$ & $3.2 \pm 1.4104 .3 \pm 2.0$ & $0.7 \pm 0.3$ to $0.5 \pm 0.3$ & $893,351.5$ \\
\hline AN-105-12A-15 & $20 \pm 14$ to $18 \pm 14$ & $64+64$ to $73+73$ & $11 \pm 8.1$ to $3.1 \pm 2.4$ & $1,4 \pm 1.1$ & $0.4+0.4$ & $3.0 \pm 1.7$ to $4.4+2.7$ & $0.5+0.2$ to $0.3+0.2$ & $362,142.5$ \\
\hline AN-105-78-16 & $19 \pm 5.9$ to $17 \pm 5.6$ & $71 \pm 28$ to $77 \pm 31$ & $7.1 \pm 2.6$ to $2.1 \pm 0.8$ & $0.8 \pm 0.4$ & $0.3+0.2$ & $2.1 \pm 0.9$ to $2.7 \pm 1.1$ & $0.7 \pm 0.2$ to $0.5+0.2$ & $314,123.5$ \\
\hline AN-105-12A-17 & $65 \pm 5.2$ to $67 \pm 5.3$ & $22 \pm 2.0$ to $23 \pm 2.1$ & $11 \pm 1.0$ to $7.9 \pm 0.7$ & $0.6 \pm 0.1$ & 0.640 .3 & $0.7 \pm 0.1$ & $6.9 \pm 0.7$ to $6.5 \pm 0.7$ & $265,104.5$ \\
\hline$A=105-7 B=18$ & $55 \pm 7.8$ to $57 \pm 8.1$ & $31 \pm 5.0$ to $33 \pm 5.3$ & $11 \pm 1.9$ to $6.3 \pm 1.1$ & $0.8 \pm 0.2$ & $0.5+0.2$ & $1.7 \pm 0.5$ to $1.8 \pm 0.6$ & $2.7 \pm 0.4$ to 2.440 .4 & $217,85.5$ \\
\hline AN-105-12A-19 & $65 \pm 4.9$ to $66 \pm 5.0$ & $21 \pm 3.4$ to $22 \pm 3.5$ & $12 \pm 1.0$ to $10 \pm 0.8$ & $0.6 \pm 0.08$ & $0.5 \pm 0.2$ & $0.4 \pm 0.1$ & 1240.8 & $169,66.5$ \\
\hline AN-105-12A-21 & $57 \pm 4.0$ to $60 \pm 4.2$ & $22 \pm 1.6$ to $24 \pm 1.7$ & $19 \pm 1.5$ to $14 \pm 1.2$ & $0.8 \pm 0.08$ & $0.3 \pm 0.2$ & $0.5 \pm 0.1$ & $7.4 \pm 0.7$ to $6.9 \pm 0.7$ & $72.4,28.5$ \\
\hline AN-105-C & $25 \pm 12$ 10 $24 \pm 12$ & $58 \pm 42$ to $68 \pm 49$ & $11 \pm 5.6$ to $3.4 \pm 1.8$ & $1.4 \pm 0.8$ & $0.6 \pm 0.4$ & $3.2 \pm 1.4$ to $4.3 \pm 2.0$ & $0.5 \pm 0.2$ to $0.4 \pm 0.2$ & 608,239 \\
\hline$A N-105-N C$ & $60 \pm 5.4$ to $62 \pm 5.5$ & $24 \pm 4.0$ to $25 \pm 3.9$ & $14 \pm 1.5$ to $11 \pm 1.1$ & $0.7 \pm 0.09$ & $0.5 \pm 0.2$ & $0.6 \pm 0.1$ & $5.1 \pm 2.6$ to $4.8 \pm 2.4$ & 136,53 \\
\hline \multicolumn{9}{|c|}{ 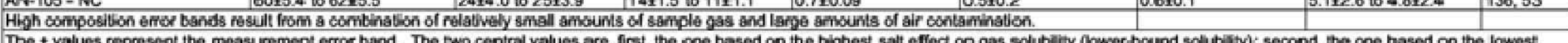 } \\
\hline \multicolumn{9}{|c|}{ 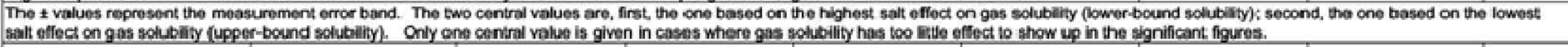 } \\
\hline & & & & & & & & \\
\hline & & & & & & & & \\
\hline Tank and Sample & & & & & & & & \\
\hline (or Layor) & Mole Percent of Constituer & rGas Volum- Percent & Elevation $(\mathrm{cm}, \mathrm{in})$ & & & & & \\
\hline & H2 & N2 & $\mathrm{N} 2 \mathrm{O}$ & $\mathrm{CH} 4$ & NAH3 & Other & & \\
\hline$A N=104-10 A-3$ & $25 \pm 13$ & $56+49$ to $65+58$ & $14 \pm 7.6$ to $4.0 \pm 2.4$ & $1.9 \pm 1.3$ & $0.8 \pm 0.5$ & $2.8 \pm 1.4$ to $3.5 \pm 1.9$ & $0.9+0.3$ to $0.7+0.3$ & $8903,351.5$ \\
\hline$A N=104-10 A=13$ & $41 \pm 8.2$ to $44 \pm 8.6$ & $41 \pm 9.7$ to $45 \pm 11$ & $14 \pm 3.7$ to $6.7 \pm 1.8$ & $1.3 \pm 0.5$ to $1.4 \pm 0.5$ & $0.4 \pm 0.2$ & $1.9 \pm 0.7$ to $2.2 \pm 0.8$ & $2.2 \pm 0.4$ to $1.9 \pm 0.4$ & $410,161.5$ \\
\hline AN-104-10A-15 & $50 \pm 8.1$ to $52 \pm 8.4$ & $32 \pm 5.7$ to $34 \pm 6.0$ & $13 \pm 2.5$ to $8.8 \pm 1.6$ & $1.1 \pm 0.3$ to $1.2 \pm 0.3$ & 1.940 .9 & 1.340 .4 to $1.4 \pm 0.5$ & $4.7 \pm 0.8$ to 4.440 .8 & $314,123.5$ \\
\hline$A N=104=10 A-17$ & $29 \pm 6.0$ to 3016.3 & $53 \pm 13$ to $55 \pm 14$ & $14 \pm 3.1$ to $10 \pm 2.2$ & 1.510 .3 to 1.640 .4 & $0.7 \pm 0.3$ & 1.610.4 to $1.7 \pm 0.4$ & 5.740 .8 to 5.340 .8 & 217.85 .5 \\
\hline$A N-104-12 A-1 B$ & $45 \pm 3.6 \div$ to $47 \pm 3.8$ & $37 \pm 3.01038 \pm 3.2$ & $15 \pm 1.5$ to $12 \pm 1.1$ & $1.1 \pm 0.2$ & $0.5 \pm 0.2$ & $1.4 \pm 0.4$ to $1.5 \pm 0.4$ & $7.1 \pm 0.7$ to $6.7 \pm 0.7$ & $169,68.5$ \\
\hline AN-104-10A-21 & $47 \pm 7.8$ to $49 \pm 8.1$ & $21 \pm 3.5$ to $22 \pm 3.6$ & $30 \pm 5.110 .27 \pm 4.6$ & $0.6 \pm 0.1$ & $0.9+0.4$ & $0.3+0.07$ & $17 \pm 1.9$ to $16 \pm 1.9$ & $24.1,9.5$ \\
\hline$A N-104-C$ & $25 \pm 13$ & $56 \pm 49$ to $65 \pm 58$ & $14 \pm 7.6$ to $4.0 \pm 2.4$ & $1.9 \pm 1.3$ & $0.8 \pm 0.5$ & $2.6 \pm 1.4$ to $3.5 \pm 1.9$ & $0.5+0.2$ to $0.4 \pm 0.2$ & 695,274 \\
\hline$A N-104-N C$ & $45 \pm 6.9$ to $47 \pm 7.1$ & $29 \pm 4.8$ to $31 \pm 5.1$ & $23 \pm 3.7$ to $20 \pm 3.2$ & $0.9 \pm 0.2$ & $0.9 \pm 0.4$ & $0.8 \pm 0.2100 .9 \pm 0.2$ & $8.0 \pm 4.0$ to $7.5+3.8$ & 7115,45 \\
\hline & & & & & & & & \\
\hline$\frac{A N-103-12 A-2}{A N=103-12 A-5}$ & $\frac{62 \pm 6.4 \text { to } 63 \pm 6.4}{19+18018+10}$ & $\frac{29 \pm 3.2}{69+5.4 \text { to } 75+60}$ & $\begin{array}{l}6.9+0.7 \text { to } 6.0 * 0.6 \\
7.94 .7 \text { to } 2.3 * 1.4\end{array}$ & $\frac{0.6 \pm 0.07}{1.7 \pm 1.3}$ & $\frac{1.440 .6}{1.040 .7}$ & $\frac{0.25+0.04}{1.440 .74017 \pm 0.8}$ & $\frac{16+1.4}{0.8+0.3 \text { to } 0.840 .3}$ & $\frac{845,332.5}{700.275}$ \\
\hline$\frac{A N=103-12 A-5}{A N-103-21 A-10}$ & $\begin{array}{l}79 \pm 10 \text { to } 18 \pm 10 \\
20 \pm 13 \text { to } 18 \pm 13\end{array}$ & $\begin{array}{l}69 \pm 54 \text { to } 75 \pm 60 \\
70 \pm 70 \text { to } 76 \pm 76\end{array}$ & $\begin{array}{l}7.94 .7 \text { to } 2.341 .4 \\
7.044 .8 \text { to } 1.8: 41.3\end{array}$ & $\frac{1.7 \pm 1.3}{1.2 \pm 0.9 \text { to } 1.1 \pm 0.9}$ & $\begin{array}{l}10.0 \pm 0.7 \\
0.840 .8\end{array}$ & $\frac{1.4 \pm 0.7 \text { to } 1.7 \pm 0.8}{1.4 \pm 0.7 \text { to } 1.8 \pm 0.9}$ & $\frac{0.8 \pm 0.3 \text { to } 0.6 \pm 0.3}{0.6 \pm 0.3 \text { to } 0.5 \pm 0.3}$ & $\frac{700,275.5}{458,180.5}$ \\
\hline AN-103-12A-14 & $55 \pm 8.8$ & $38 \pm 6.5$ to $39 \pm 6.6$ & $4.9 \pm 0.8$ to $3.8 * 0.6$ & $0.7 \pm 0.2$ & $0.7 \pm 0.3$ & 0.440 .1 & $6.7 \pm 1.2$ to $6.5 \pm 1.2$ & $265,104.5$ \\
\hline AN-103-21A-16 & $64 \pm 7.2$ & $30 \pm 3.5$ to $3.1 \pm 3.5$ & $3.8 \pm 0.4$ to $3.3 \pm 0.4$ & $0.6 \pm 0.1$ & $0.6 \pm 0.2$ & 0.440 .08 & $12 \pm 1.5$ & $469,66.5$ \\
\hline AN-103 crust & $62 \pm 6.4$ to $63 \pm 6.4$ & $29 \pm 3.2$ & $6.9+0.7$ to $6.0+0.6$ & $0.6 \pm 0.07$ & 1.440 .6 & $0.2+0.03$ & $16 \pm 7.9$ & 838,330 \\
\hline
\end{tabular}


"rgs FinalSumTable Rev 1 Tab_6MC 030823 .xls", Tab "1-Major Components"

\begin{tabular}{|c|c|c|c|c|c|c|c|c|}
\hline \multirow{3}{*}{\begin{tabular}{|l|l|} 
Tank and Sample (or Layer) \\
AN-103-C
\end{tabular}} & \multicolumn{6}{|c|}{ Mole Prercent of Constituent in Bubbles } & \multirow{2}{*}{ Gas Volume Percent } & \multirow{2}{*}{$\begin{array}{l}\text { Elevation } \\
\text { (cm. in.) }\end{array}$} \\
\hline & $\mathrm{H}_{2}$ & N2 & N2O & CH4 & NHH3 & other & & \\
\hline & $19 \pm 12$ to $18 \pm 12$ & $70 \pm 62$ to $76 \pm 69$ & $7.5 \pm 4.8:$ to $2.1 \pm 1.4$ & $1.4 \pm 1.1$ & $0.9 \pm 0.6$ & $1.4 \pm 0.6$ to $1.7 \pm 0.8$ & $0.7 \pm 0.3$ to $0.6 \pm 0.3$ & \\
\hline$A N-103-N C$ & 6147.7 to 62.7 .7 & $33 \pm 4.3$ & $4.1 \pm 0.6 \cdot$ to $3.4 \pm 0.5$ & 0.610 .1 & 0.610 .2 & 0.410 .09 & $9.2 \pm 4.6$ to $9.0 \pm 4.5$ & 160.63 \\
\hline U-103-7-2 & $23 \pm 1.3$ & $36 \pm 2.1$ to $37 \pm 2.1$ & $40 \pm 2,1$ to $39+2.1$ & $0,4 \pm 0.03$ & $0.13+0.04$ to $0.07 \pm 0.02$ & $20.5+0.05$ & $42 \pm 2.6$ to $41 \pm 2.6$ & $362,142.5$ \\
\hline$U-103-7-5$ & $74 \pm 0.9$ to $16 \pm 1.0$ & $32 \pm 2.0$ to $36 \pm 2.2$ & $5.1 \pm 3.1$ to $46 \pm 2.8$ & $0.26 \pm 0.06$ & $1.6 \pm 0.6$ & $0.4 \pm 0.1$ & $9.6 \pm 0.8$ to $8.5 \pm 0.8$ & 217.85 .5 \\
\hline $\mathrm{U}-103-7-7$ & $24 \pm 1.5$ to $25 \pm 1.6$ & $41 \pm 2.6$ to $44 \pm 2.8$ & $32 \pm 1.9$ to $28 \pm 1,7$ & $0.6 \pm 0.1$ & $1.1 \pm 0.3$ & $1,0 \pm 0,1$ to $1,1 \pm 0.1$ & $11 \pm 1.21010 \pm 1.2$ & $121,47.5$ \\
\hline $\mathrm{U}-103.7-8$ & $34 \pm 3.1$ to $33 \pm 3.3$ & $36 \pm 3.6$ to $39 \pm 3.9$ & 2942.9102442 .4 & $0.8 \pm 0.1$ & $1.1 \pm 0.8$ & 1.740 .2 to $9.8 \pm 0.2$ & $7.8 \pm 1.0$ to $7.1 \pm 1.0$ & 72.28 .5 \\
\hline $\mathrm{U}-103$ - NC & $23 \pm 1.4$ to $24 \pm 1.5$ & $36 \pm 2.3$ to 38.2 .4 & $39 \pm 2.4$ to $37 \pm 2.2$ & $0.4 \pm 0.05$ & $0.6 \pm 0.3$ to $0.5 \pm 0.2$ & $0.7 \pm 0.08$ & $19 \pm 9.5$ to $18 \pm 9.0$ & 277,109 \\
\hline & & & & & & & & \\
\hline S-106-7-3 & $59 \pm 5.0$ to $60 \pm 5.1$ & $32 \pm 3.1$ to $33 \pm 3.2$ & $7.8 \pm 0.7$ to $5.9 \pm 0.5$ & $0.4 \pm 0.2$ & $0.3 \pm 0.2$ & $0.2+0.1$ & $8.6 \pm 0.9$ to $9.3 \pm 0.9$ & $362,142.5$ \\
\hline $5-106-7-5$ & $62+5.5$ to $65 \pm 5.7$ & $23 \pm 3.6$ & $14+1.2$ to $11 \pm 1.0$ & $0.01 \pm 0.01$ & $0.3+0.1$ & $0.5+0.2$ to $0.6 \pm 0.2$ & $10+1.0$ & $285,104.5$ \\
\hline $5-106-8-6$ & $63 \pm 8.6$ to $65 \pm 8.8$ & $25 \pm 3.6$ to $26 \pm 3.7$ & $9.9 \pm 1.5$ to $7.2 \pm 1.1$ & $0.5 \pm 0.2$ & $0.5 \pm 0.3$ & $0.9 \pm 0.5$ to $1.0 \pm 0.5$ & $7.6 \pm 0.8$ to 7.340 .8 & 217.85 .5 \\
\hline S-106-8-10 & $655+4.91$ to $66+5,1$ & $23 \pm 4,2$ to $24 \pm 4.3$ & $11+0.8$ to $9.0 \pm 0.7$ & $0.2+0.02$ & $0.2 \pm 0.1$ & $0.4 \pm 0.2$ & $14 \pm 1.2$ & $24,9.5$ \\
\hline S-106-NC & $63 \pm 5.7$ to $65 \pm 5.9$ & $25+3.7$ to $26 \pm 3.8$ & $11 \pm 1.0$ to $8.4 \pm 0.8$ & $0.3 \pm 0.08$ & $0.3 \pm 0.2$ & $0.5+0.2$ & $10 \pm 5.0$ & $151,59.5$ \\
\hline High composition error bands mo & sult from a combination of $r$ & rolatively small amounts & sof samplo gass and & arge amounts of air cont & tamination. & & & \\
\hline $\begin{array}{l}\text { The } \pm \text { values represent the mea } \\
\text { saitt effect on gas solubitity (upp }\end{array}$ & 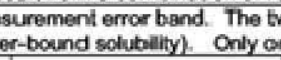 & $\begin{array}{l}\text { Ewo central values are, } \\
\text { gne central value is give }\end{array}$ & $\begin{array}{l}\text { first, the wone based o } \\
\text { on in cases where gas }\end{array}$ & $\begin{array}{l}\text { ithe highest salt elfiect } \\
\text { solubulity hes too little }\end{array}$ & $\begin{array}{l}\text { on ges soli } \\
\text { eftect to she }\end{array}$ & $\begin{array}{l}\text { ound s } \\
\text { gnifice }\end{array}$ & nd, the one based o & at \\
\hline & & & & & & & & \\
\hline & & & & & & & & \\
\hline Tank and Sample & & & & & & & & \\
\hline (or Layer) & Mole Percent of Constituer & Gas Volumes Perceent & Elevasion (cm, in.) & & & & & \\
\hline Non & H2 & N2 & N.2O & CH4 & NH3 & Ocher & & \\
\hline BY-109-12C-4 & $35 \pm 3.6$ to $36 \pm 3.8$ & $40 \pm 7.91042 \pm 8.3$ & $21 \pm 2.21018 \pm 1.9$ & $1.0 \pm 0.2$ & $0.3+0.2$ & $2.2+0.3$ to $2.3+10.3$ & $6.3 \pm 0.4$ to $6.1 \pm 0.4$ & $121,47,5$ \\
\hline$B Y-109-10 B-5$ & $52 \pm 5.5$ to $53 \pm 5.6$ & $20 \pm 5.0$ & $16 \pm 1.7$ to $15 \pm 1.6$ & $0.7 \pm 0.1$ & $0.2 \pm 0.1$ & $1.8 \pm 0.3$ & $8.7 \pm 0.8$ to $8.4 \pm 0.8$ & $121,47.5$ \\
\hline$B Y-109-10 B-6$ & $56 \pm 6.4$ to $57 \pm 0.5$ & $23 \pm 3.8$ & $17 \pm 3.3$ to $16 \pm 3.1$ & $0.9 \pm 0.1$ & $0.2 \pm 0.1$ & $2.8 \pm 0.4$ to $2.7 \pm 0.4$ & $12 \pm 1.0$ & 72.28 .5 \\
\hline BY-109 bolow ILL & $50 \pm 5.5$ to $51 \pm 5.6$ & $29 \pm 5.1$ & $18+2.5$ to $16 \pm 2.3$ & $0.9 \pm 0.1$ & $0.2 \pm 0,1$ & 2.340 .3 & $9.4 \pm 4.7$ to $9.2 \pm 4.6$ & 120,47 \\
\hline & & & & & & & & \\
\hline $5 \times-106-3-2$ & $22 \pm 2.91$ to $15 \pm 24$ & $63 \pm 11$ to $74 \pm 14$ & $11 \pm 1.5$ to $1.7 \pm 0.3$ & $1.4 \pm 0.5$ to $1.0 \pm 0.4$ & 1.040 .2 to $0.4 \pm 0.1$ & 1.940 .7 to $7.7 \pm 2.9$ & $0.1 \pm 0.04$ to $0.03 \pm 0.03$ & $458,180.5$ \\
\hline $5 \times-106-3-4$ & $19 \pm 6.1$ to $16 \pm 5.1$ & $65 \pm 28$ to $78 \pm 34$ & $13 \pm 4.8$ to $2.2 \pm 0.8$ & $0.9 \pm 0.4$ to $0.7 \pm 0.3$ & $0.840 .3100 .4 \pm 0.1$ & $1.0 \pm 0.4$ to $2.5 \pm 0.9$ & $0.2 \pm 0.07$ to $0.07 \pm 0.07$ & $362,142.5$ \\
\hline $5 \times-106-6-6$ & $50 \pm 5.01$ to $53 \pm 5.4$ & $23 \pm 3.3$ to $25 \pm 3.5$ & $18 \pm 1.9$ to $16 \pm 1.7$ & $1.9 \pm 0.3$ to $20 \pm 0.3$ & $6.7 \pm 0.8$ to $3.0 \pm 0.4$ & $1.0 \pm 0.3$ to $1.1 \pm 0.3$ & Q.11 1.0 to $8.4 \pm 1.0$ & $265,104.5$ \\
\hline $5 \times-106-6-6 \mathrm{~A}$ & $51 \pm 5.6$. to $56 \pm 6.2$ & $19 \pm 3.3$ to $21 \pm 3.7$ & $22 \pm 2.9$ to $17 \pm 2.2$ & $2.7 \pm 0.9103 .0 \pm 1.0$ & $4.0 \pm 0.5$ to $1.8 \pm 0.2$ & $1.4 \pm 0.4$ to $1.6 \pm 0.4$ & $4.1 \pm 0.6$ to $3.6 \pm 0.6$ & $265,104.5$ \\
\hline $5 X-106-3-7$ & $48 \pm 8.5$ to $50+8.5$ & $19+8.6$ to $20+9.0$ & $27 \pm 7.4$ & $0.5 \pm 0.09$ & $5.7 \pm 2.7$ to $2.5 \pm 1.2$ & $0.3+0.08$ & $30+11$ to $29+11$ & 217.85 .5 \\
\hline $5 x-106-6-9$ & $60 \pm 3.6 \pm$ to $62 \pm 3.6$ & $17 \pm 2.0$ to $18+2.0$ & $17 \pm 1,1$ & $0.4 \pm 0.1$ & $4.9 \pm 0.8$ to $2.2 \pm 0.3$ & $0.3 \pm 0.09$ & $36 \pm 2.2$ to $34+2.2$ & $121,47.5$ \\
\hline$\$ x-106-7-19$ & $44 \pm 2,8.21047 \pm 2,7$ & $21 \pm 2.41022 \pm 2.5$ & $28+1,8$ & $0,6 \pm 0,05$ & $5.540,8402,4 \pm 0.4$ & $0,3+0,098$ & $32+2.01931+2.0$ & $72,28,5$ \\
\hline SX-10B-C & $21 \pm 4.99$ to $16 \pm 4.0$ & $64 \pm 21$ to $77 \pm 26$ & $12 \pm 3.4$ to $2.1 \pm 0.6$ & $1.1 \pm 0.4$ to $0.8 \pm 0.4$ & $0.9 \pm 0.2$ to $0.4 \pm 0.1$ & $1.4 \pm 0.5$ to $3.9 \pm 1.4$ & $0.2+0.1$ to $0.05 \pm 0.05$ & 418,164 \\
\hline SX: $106=\mathrm{NC}$ & $50 \pm 4.5$ to $52 \pm 4.5$ & $20 \pm 3.8$ to $21 \pm 4.0$ & $24 \pm 2.8$ to $24 \pm 2.7$ & $0.6 \pm 0.1$ & $5.5 \pm 1.2$ to $2.4 \pm 0.5$ & $0.3 \pm 0.08$ & $26 \pm 13$ to $25 \pm 13$ & 136,53 \\
\hline$A \times-101-9 D-8$ & $61 \pm 5.5$ to $64 \pm 5.5$ & $17 \pm 2.6$ to $1.8 \pm 2.7$ & $11 \pm 1.0$ & $2.4 \pm 0.2$ to $2.5 \pm 0.2$ & $8.4 * 1.9104 .3 \pm 1.0$ & $0.7 \pm 0.2$ & $17 \pm 1.3$ to $16 \pm 1.3$ & 362,1425 \\
\hline & & & & & & & & \\
\hline S-102-16-2 & $36 \pm 2.5 ;$ to $37 \pm 2.5$ & $37 \pm 4.4$ to $38 \pm 4.4$ & $28 \pm 1.8$ lo $24 \pm 1.7$ & $0.4 \pm 0.05$ & $0.6 \pm 0.410 .0 .4 \pm 0.2$ & $0.1 \pm 0.02$ & $39 \pm 4.31032 \pm 4.3$ & $458,180.5$ \\
\hline S-102-16 AR & $33 \pm 2.91$ to $37 \pm 3.2$ & $31 t 4.1$ to $36 t 4.7$ & $3.4 \pm 3.4$ to $26 \pm 2.5$ & $0.2+0.07$ to $0.3+0.08$ & $1.3 \pm 0.9$ to $0.7 \pm 0.5$ & $0.3+0.09$ & $7.4 \pm 0.7$ to $6.4 \pm 0.7$ & $362,142.5$ \\
\hline S-102-16-7 & $27 \pm 3.1$ to $28 \pm 3.2$ & $20 \pm 4.2$ to $30 \pm 4.4$ & $42 \pm 4.8$ to $41 \pm 4.6$ & $0.4 \pm 0.06$ & $1.5 \pm 0.4$ to $0.8 \pm 0.2$ & $0.07 \pm 0.03$ & $30 \pm 1.9$ to $20 \pm 1.9$ & 217.85 .5 \\
\hline s-102-16-10 & $43 \pm 3.8$ to $46 \pm 4,1$ & $20 \pm 4,3$ to $3.1 \pm 4.6$ & $25+2.2$ to $21 \pm 1.9$ & $0.7 \pm 0.08$ to 0.840 .08 & $1.2 \pm 0.3$ to $0.6 \pm 0.2$ & $0.8 \pm 0.1$ & $12 \pm 1.1$ to $11 \pm 1.1$ & $72,28.5$ \\
\hline S-102 tank avg. & $33 \pm 3.0$ to $35 \pm 3.1$ & $32 \pm 4.3$ to $33 \pm 4.5$ & $33 \pm 3.1$ to $31 \pm 2.9$ & $0.4 \pm 0.08$ to 0.540 .06 & 1.140 .4 to $0.6 \pm 0.2$ & 0.240 .04 & $20 \pm 13$ to $25 \pm 13$ & 292,115 \\
\hline & & & & & & & & \\
\hline S-111-6-2 & $6.3 \pm 3.4605 .8 \pm 3.2$ & $90 \pm 68$ to $92 \pm 70$ & $1.7 \pm 1.0$ to $0.7 \pm 0.4$ & $0.3 \pm 0.2$ & $0.2 \pm 0.2$ to $0.1 \pm 0.1$ & $1.0 \pm 0.8$ to $1.2 \pm 0.9$ & $0.8 \pm 0.2$ to $0.7 \pm 0.2$ & $458,180.5$ \\
\hline S-111 & $48 \pm 24$ to $51 \pm 25$ & $36 \pm 22$ to $38 \pm 223$ & $14 \pm 5.5$ to $9.8 \pm 4.0$ & $0.6 \pm 0.2$ & $0.9 \pm 0.4100 .5 \pm 0.2$ & 0.340 .08 & 6.9 $9 \pm 2.1$ to $6.5 \pm 2.1$ & $362,142.5$ \\
\hline$S-111-6-6$ & $58 \pm 5.1$ to 60.5 .2 & $26 \pm 3.4$ to $27 \pm 3.5$ & $14 \pm 1.3$ to $11 \pm 1.1$ & $0.8 \pm 0.1$ & $1.2 \pm 0.4100 .7 \pm 0.2$ & $0.5 \pm 0.2$ & $15 \pm 5$ & $265,104.5$ \\
\hline $9-111-8-8$ & $67 \pm 7.1$ w 68.7 .2 & $20 \pm 2.8$ & $12 \pm 1.3$ to $11 \pm 1.2$ & $0.6 \pm 0.08$ & $0.7 \pm 0.2160 .4 \pm 0.1$ & $0.2+0.07$ & $20+2.81620+2.9$ & $169,68.5$ \\
\hline $5-111-6-10$ & $73 \pm 5.6=$ to $74 \pm 5.7$ & $16 \pm 2.0$ to $16 \pm 2.0$ & $9.2+0.8$ to $8.5+0.7$ & $0.3 \pm 0.04$ & $1.6 \pm 0.4$ to $0.9 \pm 0.3$ & 0.0010 .04 & $23 \pm 3.2$ to $22 \pm 3.2$ & $72,28.5$ \\
\hline
\end{tabular}


"rgs FinalSumTable Rev 1 Tab_6MC 030823 .xls", Tab "1-Major Components"

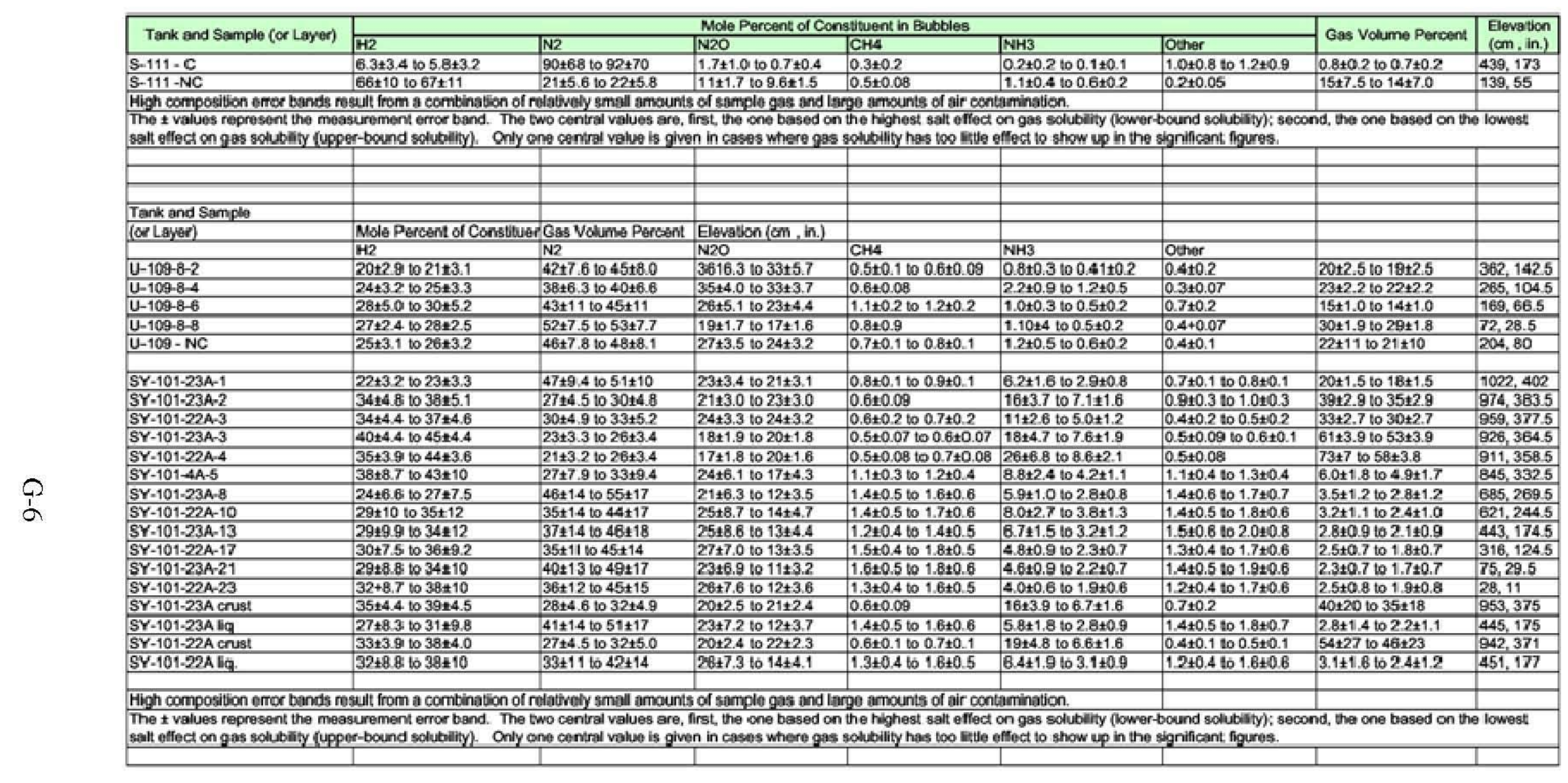


"rgs FinalSumTable Rev 1 Tab_6MC 030823 .xls",Tab "2-Minor comps"

Step 2 of 7 - Original Tables for breakdown of "Other" components

Source: "rgs FinalSumTable.doc" Personal Communication from Lenna Mahonioy. Not previously published.

\begin{tabular}{|c|c|c|c|c|c|c|}
\hline \multirow{3}{*}{ Tank and Samplo (or Layer) } & \multicolumn{6}{|c|}{ Mole Percent of Constitueent In Bubbies } \\
\hline & & & & ther & & \\
\hline & $\mathrm{CH} 4$ & $\mathrm{C}_{2} \mathrm{Hx}$ & C3HEx & Other HC & Other NOx & Total "Other" \\
\hline AW-101 solids & $1.7 \pm 0.2$ & $1.1 \pm 0.2$ to $1.2 \pm 0.2$ & $0.26 \pm 0.160 .27 \pm 0.1$ & $1.3 \pm 0.3$ to $1.4 \pm 0.3$ & $0.12 \pm 0.06000 .12 \pm 0.07$ & $2.8 \pm 0.5$ to $2.9 \pm 0.6$ \\
\hline A-101 upper & $0.7 \pm 0.1$ & $0,12+0.02$ & $0.07 \pm 0.03$ & $0.11 \pm 0.03$ & $0.07 \pm 0.02$ & $0.3 * 0.06$ \\
\hline AN-105 solids & $0.7 \pm 0.07$ & $0.11 \pm 0.04$ to $0.12 \pm 0.05$ & $0.05 \pm 0.02$ & $0.19 \pm 0.06$ to 0.2040 .07 & $0.18 \pm 0.04$ to $0.21 \pm 0.04$ & $0.6 \pm 0.1$ \\
\hline AN-104 solids & $0.9 \pm 0.2$ & $0.30+0.10$ to 0.3110 .11 & $0.08 \div 0.03$ & $0.44 \div 0.18$ to $0.46 \div 0.19$ & $0.03 * 0.02$ & $0.8 \pm 0.3$ to $0.9 \pm 0.3$ \\
\hline AN-103 crust & $0.6 \pm 0.07$ & $0.13+0.02$ & $0.04 \pm 0.01$ & $0.05 \pm 0.01$ & $0.02 \pm 0.01$ & $0.2 \pm 0.05$ \\
\hline AN-103 bolids & $0.8 \pm 0.1$ & $0.15 \pm 0.05$ to $0.16 \pm 0.05$ & $0.07 \pm 0.02$ to $3.6 \pm 0.5$ & $0.15+0.06$ & $0.02 \pm 0.02100 .03 \pm 0.02$ & $0.4 \pm 0.1$ \\
\hline U-103 slumy & $0.4 \pm 0.03$ & $0,41 \pm 0.04$ & $0 \pm 0,02$ & $0.04 \pm 0.01$ & $0.01 \pm 0.01$ & $0.5 \div 0.05$ \\
\hline U. -100 solids & $0.4 \pm 0.08$ to $0.5 \pm 0.09$ & $0.59 \pm 0.10$ to $0.64 \pm 0.10$ & $0.02 \pm 0.02$ & $0.09+0.02$ & $0.14 \pm 0.04 \pm 00.16 \pm 0.05$ & $0.8 \pm 0.2$ to $0.9 \pm 0.2$ \\
\hline S-106 solids & $0.2+0.07$ & $0.24 \pm 0.19 t 00.25 \pm 0.19$ & $0.13 * 0.07$ & $0.06+0.03$ & $0.05 \div 0.0460 .0640 .04$ & $0.5+0.3$ \\
\hline Br- 109 benlow $14 L$ & $0.8 \pm 0.1$ & $1.0 \pm 0.2$ to $1.1 \pm 0.2$ & $0.15 \pm 0.07$ & $1.1 \pm 0.2$ & $0.01 \pm 0.01$ to $0.02+0.01$ & $2.3 \pm 0.4$ \\
\hline SX-106 solids & $0.6 \pm 0.1$ & $0.20 \pm 0.07$ to 0.2110 .07 & $0.06 \pm 0.01$ & $0.06 \pm 0.03$ to & $0.01 \pm 0.01600 .01 \pm 0.01$ & 0.410 .1 \\
\hline S. 102 tank avg. & $0.4 \pm 0.07$ & $0.10 \pm 0.03$ & & $0.06 \pm 0.03$ to 0.0740 .03 & & $0.2 \pm 0.06$ \\
\hline S-111 golds & $0.4 \pm 0.07$ to $0.5 * 0.07$ & $0.08 \div 0.03$ & & $0.07 \pm 0.04$ & & $0.2+0.07$ \\
\hline $\mathrm{U}-409$ tank avg. & $0.7 \pm 0.1$ & $0.28+0.08$ to $0.29 \geq 0.08$ & & $0.13 \pm 0.07$ to & & $0.4 \pm 0.2$ \\
\hline SY-101-022 crust & $0.6 \pm 0.08$ to $0.7 \pm 0.09$ & $0.56 \pm 0.15$ to $0.67 \pm 0.17$ & & $0.06 \pm 0.03$ to $0.07 \pm 0.04$ & & $0.6 \pm 0.2$ to $0.7 \pm 0.2$ \\
\hline SY-101-021 cnst & $0.5 \pm 0.1 \% 0.7 \pm 0.1$ & $0.38+0.08$ to $0.47 \pm 0.10$ & & $0.05+0.02$ to 0.0640 .03 & & $0,4 \pm 0.1$ to $0.5 \pm 0.1$ \\
\hline $5 Y-101-0221 / 4$ & $1.3 \pm 0.5$ to $1.8 \pm 0.6$ & $0.70 \pm 0.32$ to $0.87 \pm 0.40$ & & $0.67 \pm 0.41$ to 0.8340 .51 & & $1.4 \pm 0.7$ to $1.7=0.9$ \\
\hline 3Y-101-021 liq. & $1.3 \pm 0.4601 .640 .5$ & $0.66 \div 0.27$ to $0.83 \div 0.34$ & & $0.54 \pm 0.31$ to $0.67 \pm 0.39$ & & $1.2+0.6$ to $1.5 \pm 0.7$ \\
\hline
\end{tabular}


"rgs FinalSumTable Rev 1 Tab_6MC 030823 .xls",Tab "3-Revised comps"

\section{Step 3 of 7 - Combine Original and "Other" Component Tables}

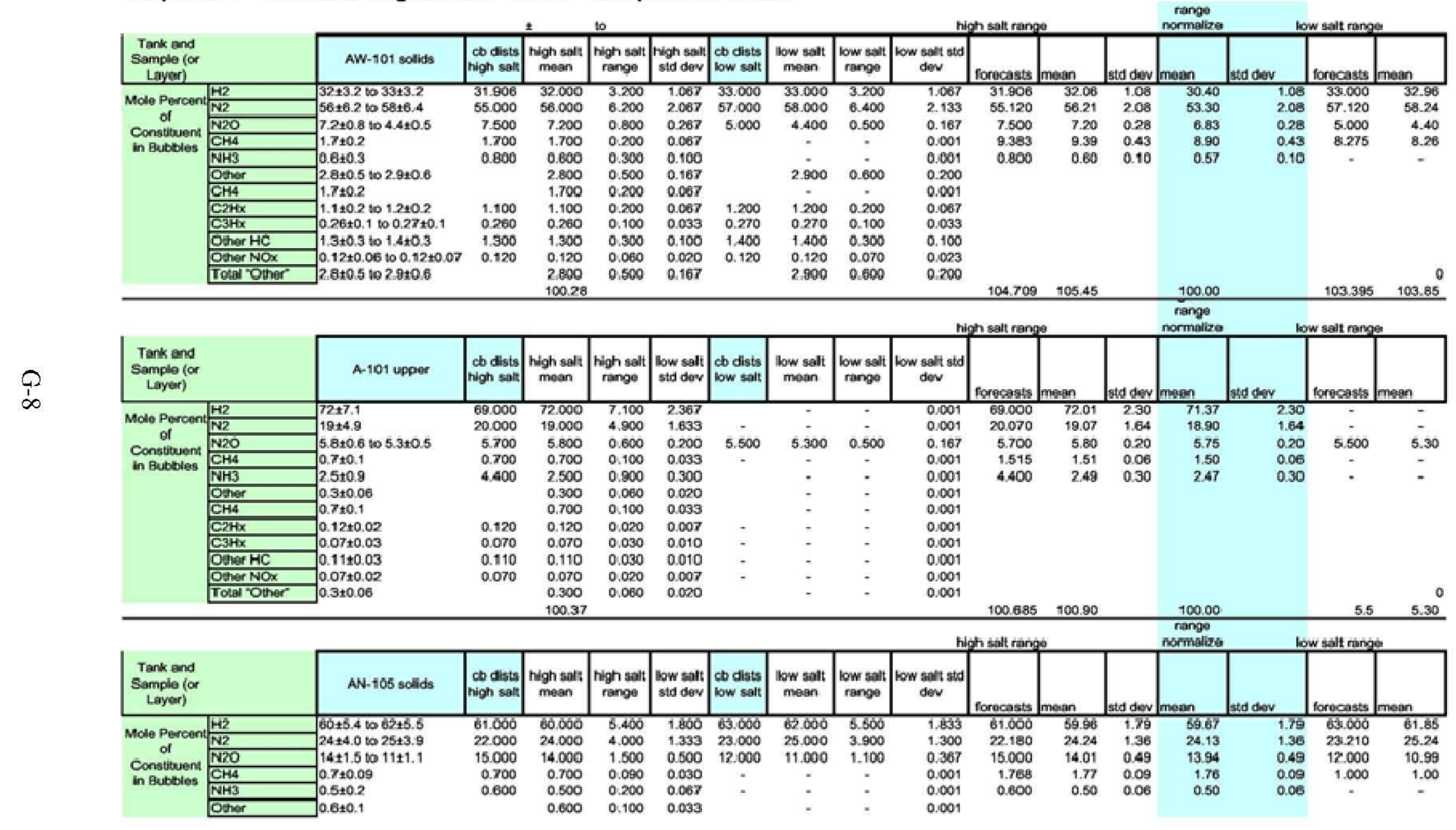


“rgs FinalSumTable Rev 1 Tab_6MC 030823 .xls",Tab “3-Revised comps"

Step 3 of 7 - Combine Original and "Other" Component Tables
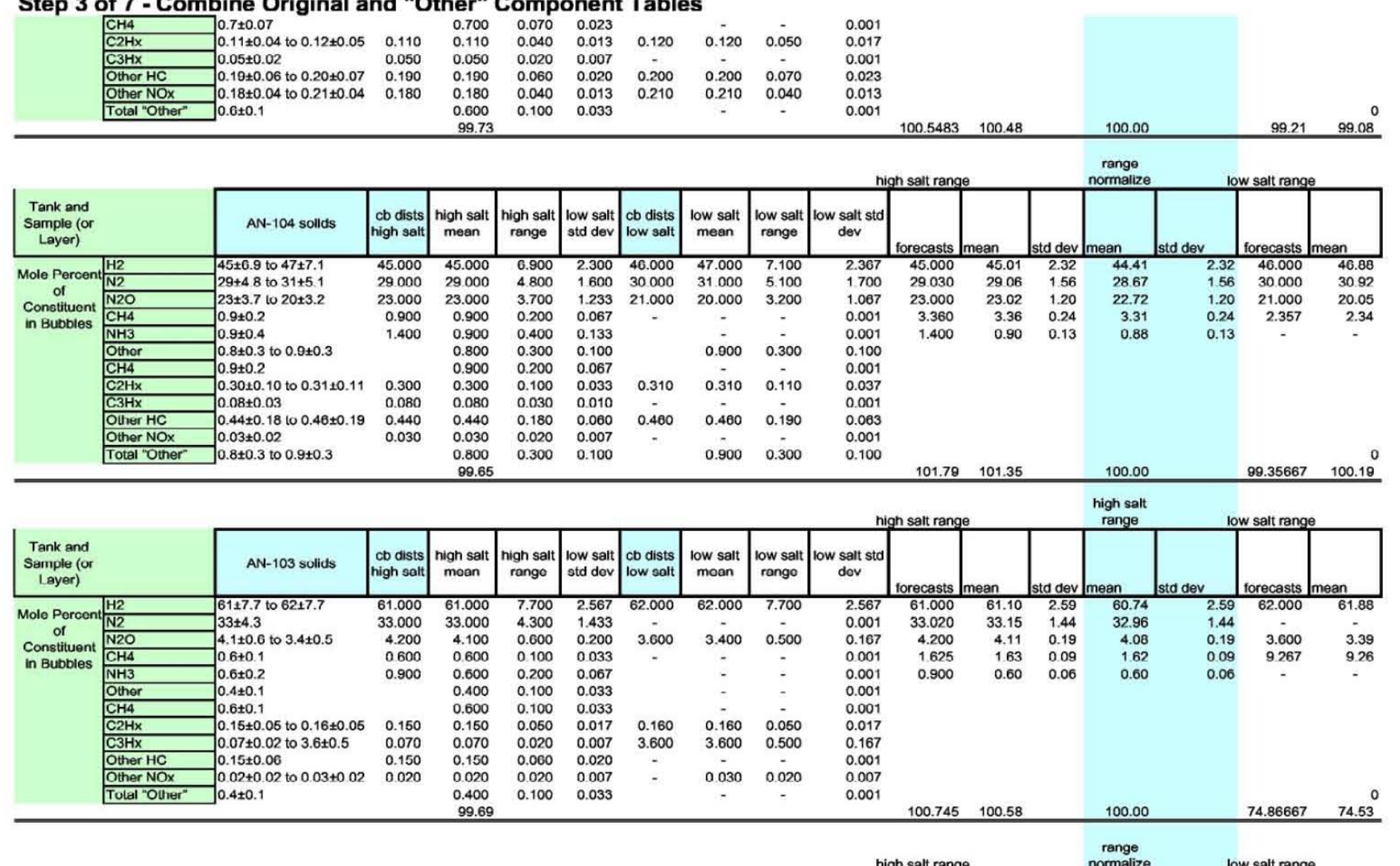

high salt range

range
normalize 
"rgs FinalSumTable Rev 1 Tab_6MC 030823 .xls",Tab "3-Revised comps"

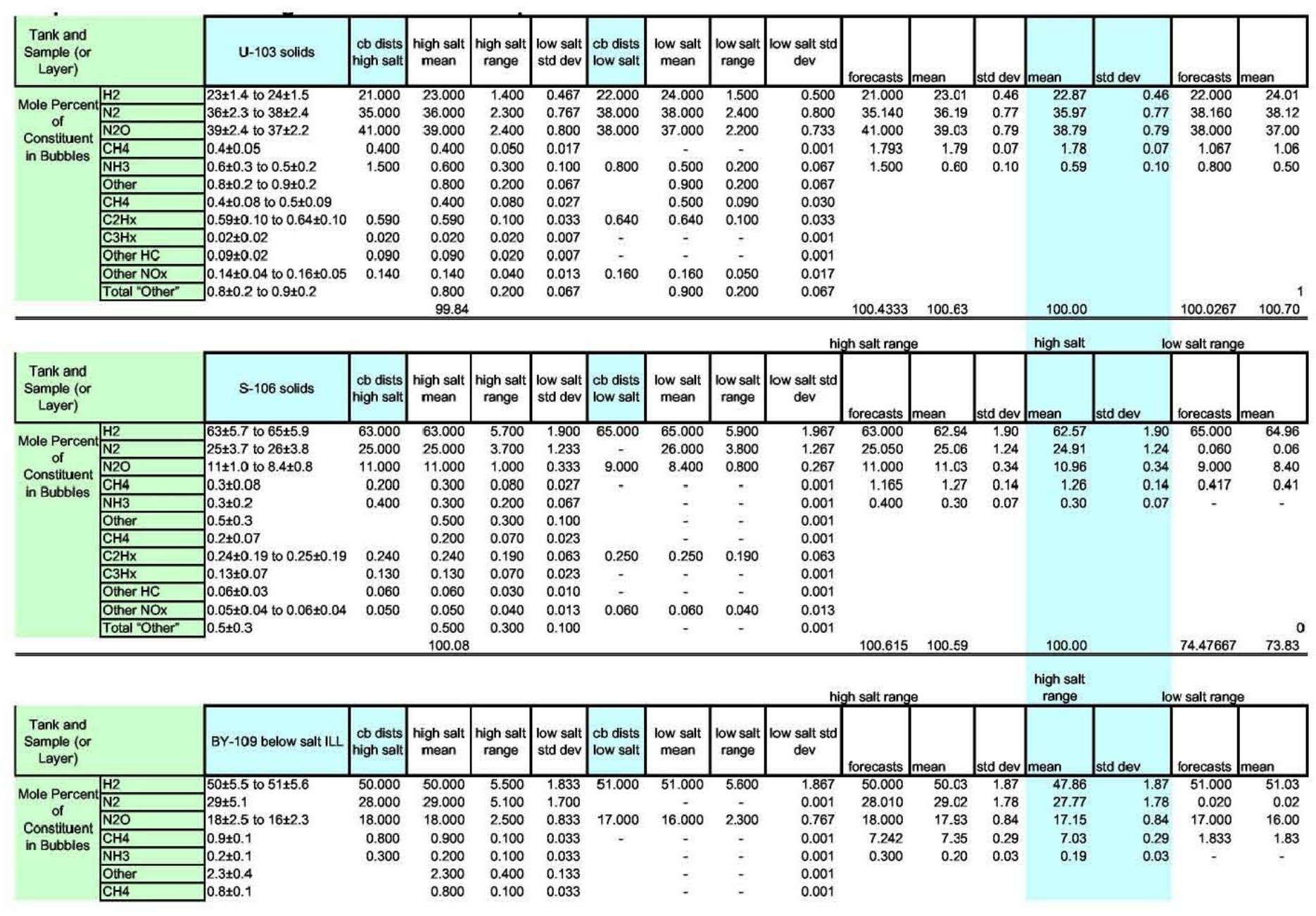


"rgs FinalSumTable Rev 1 Tab_6MC 030823 .xls",Tab “3-Revised comps"

Step 3 of 7 - Combine Original and "Other" Component Tables

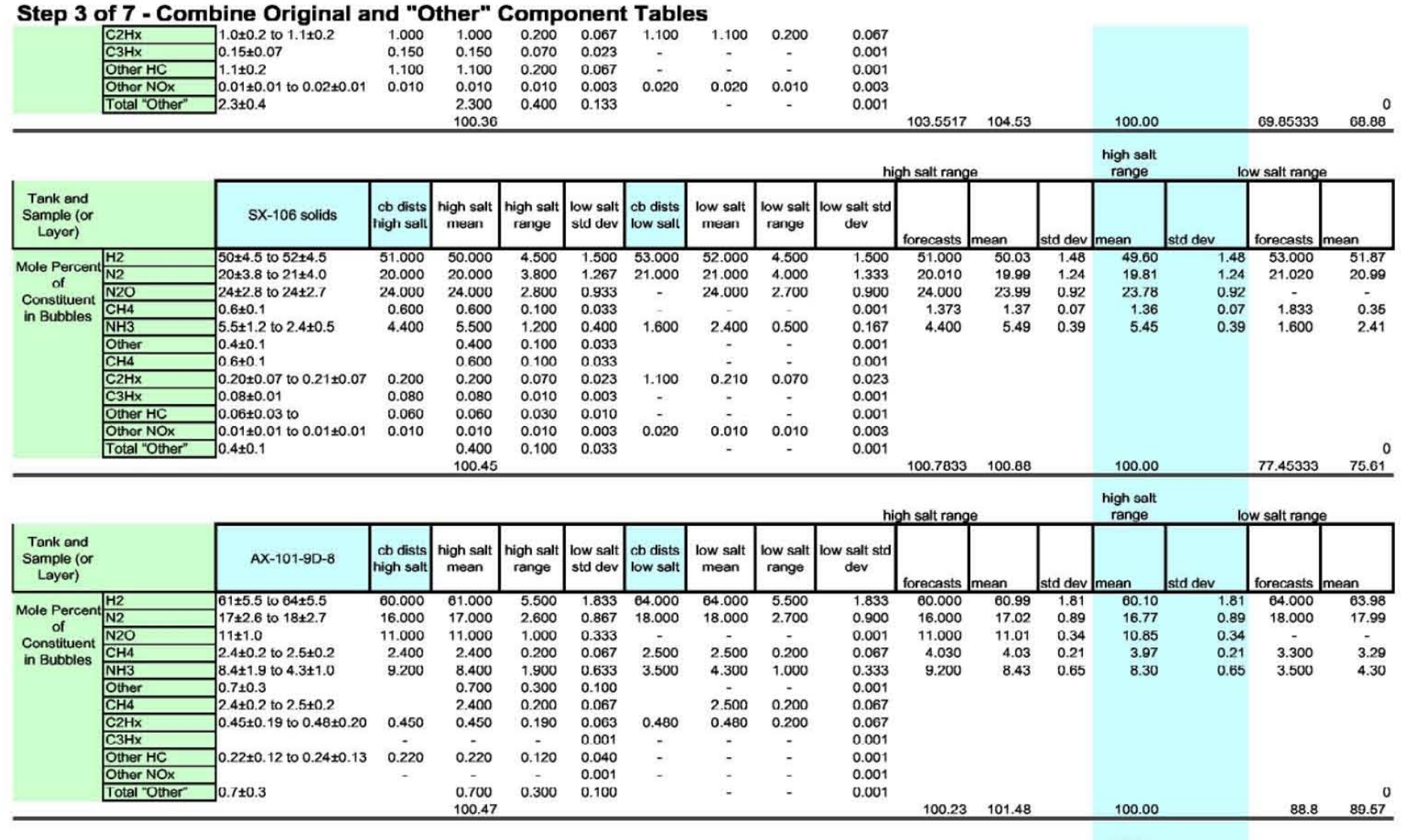


“rgs FinalSumTable Rev 1 Tab_6MC 030823 .xls",Tab “3-Revised comps"

Step 3 of 7 - Combine Original and "Other" Component Tables

\begin{tabular}{|c|c|c|c|c|c|c|c|c|c|c|c|c|c|c|c|c|c|}
\hline \multicolumn{2}{|l|}{$\begin{array}{l}\text { Tank and } \\
\text { Sample (or } \\
\text { Layer) }\end{array}$} & S-102 tank avg. & $\left|\begin{array}{c}\text { cb dists } \\
\text { high satt }\end{array}\right|$ & $\begin{array}{c}\text { high salt } \\
\text { mean }\end{array}$ & $\begin{array}{l}\text { high salt } \\
\text { range }\end{array}$ & $\begin{array}{l}\text { low salt } \\
\text { std dev }\end{array}$ & $\begin{array}{c}\text { cb dists } \\
\text { low salt }\end{array}$ & $\begin{array}{l}\text { low salt } \\
\text { mean }\end{array}$ & $\begin{array}{l}\text { low salt } \\
\text { range }\end{array}$ & $\left|\begin{array}{c}\text { low salt std } \\
\text { dev }\end{array}\right|$ & forecasts & mean & std dev & mean & \multirow{2}{*}{ sttd dev } & forecasts & mean \\
\hline & H2 & $33 \pm 3.0$ to $35 \pm 3.1$ & 32.000 & 33.000 & 3.000 & 1.000 & 34.000 & 35.000 & 3.100 & 1.033 & 32.000 & 33.05 & 1.05 & 33.08 & & 34.000 & 35.01 \\
\hline 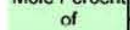 & N2 & $32 \pm 4.3$ to $33 \pm 4.5$ & 31.000 & 32.000 & & & 32.000 & 33.000 & 4.500 & & 31.000 & 31.97 & 1.41 & 31.99 & 1.41 & 32.000 & 33.06 \\
\hline Constituent & $\frac{\mathrm{N} 2 \mathrm{O}}{\mathrm{CH} 4}$ & $33 \pm 3.1$ to $31 \pm 2.9$ & 33.000 & 33.000 & 3.100 & 1.033 & $\begin{array}{r}32.000 \\
0.500\end{array}$ & $\begin{array}{l}31.000 \\
0.500\end{array}$ & 2.900 & & & 33.00 & 1.04 & 33.03 & 1.04 & 32.000 & 31.02 \\
\hline in Rubbles & $\frac{\mathrm{CH} 4}{\mathrm{NH3}}$ & {$\left[\begin{array}{l}0.410 .06 \\
\text { to } 0.5 \pm 0.06\end{array}\right.$} & 0.400 & 0.400 & 0.060 & 0.020 & 0.500 & 0.500 & 0.060 & & 0.807 & 0.81 & 0.05 & 0.81 & 0.05 & 0.500 & 0.50 \\
\hline & $\frac{\mathrm{NAH}}{\text { OUther }}$ & $\mid \begin{array}{l}1,1.1 \pm 0.4 \text { to } \\
0.2 \pm 0.00\end{array}$ & & $\begin{array}{l}1.100 \\
0.200\end{array}$ & $\begin{array}{l}0.400 \\
0.080\end{array}$ & $\begin{array}{l}0.133 \\
0.020\end{array}$ & 1.300 & 0.600 & 0.200 & $\begin{array}{l}0.067 \\
0.001\end{array}$ & 3.200 & & 0.14 & 1.10 & 0.14 & 1.300 & 0.60 \\
\hline & $\mathrm{CH} 4$ & $0.4 \pm 0$ & & 0.400 & 0.070 & 0.023 & & - & - & 0.001 & & & & & & & \\
\hline & $\mathrm{C} 2 \mathrm{Hx}$ & $0.10 \pm 0.03$ & 0.100 & 0.100 & 0.030 & 0.010 & - & - & - & 0.001 & & & & & & & \\
\hline & $\mathrm{C} 3 \mathrm{Hx}$ & & & & & 0.001 & - & - & - & 0.0 & & & & & & & \\
\hline & Othe & $0.06 \pm 0.03$ to $0.07 \pm 0.03$ & 0.060 & 0.060 & 0.030 & 0.010 & - & - & - & 0.001 & & & & & & & \\
\hline & \begin{tabular}{|l} 
Other NOx \\
Total "Other"'
\end{tabular} & $0.2+0.06$ & & 0.200 & 0.060 & $\begin{array}{l}0.001 \\
0.020\end{array}$ & & : & : & $\begin{array}{l}0.001 \\
0.001\end{array}$ & & & & & & & \\
\hline
\end{tabular}

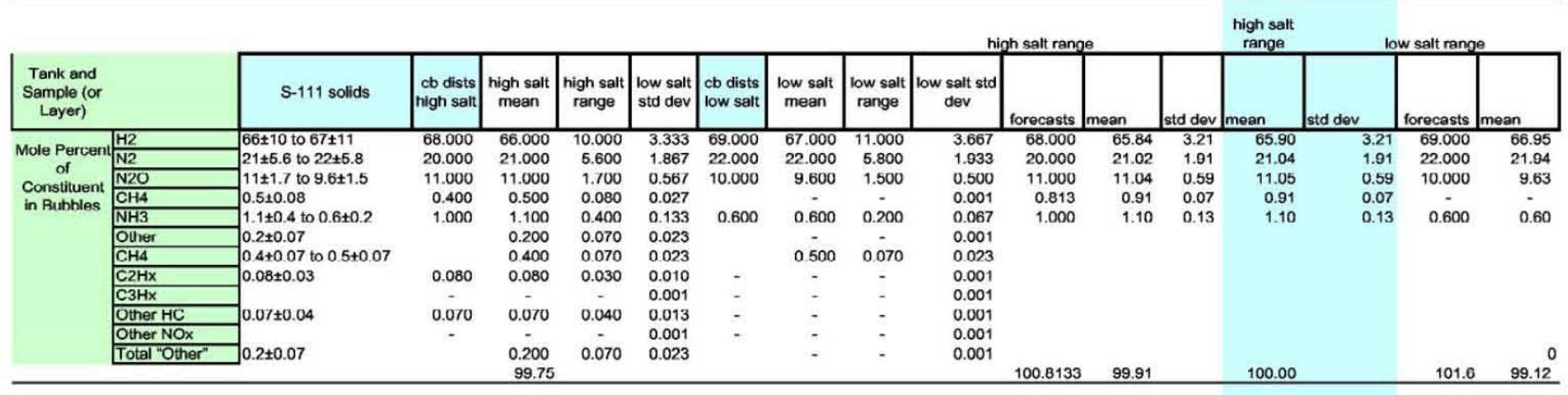

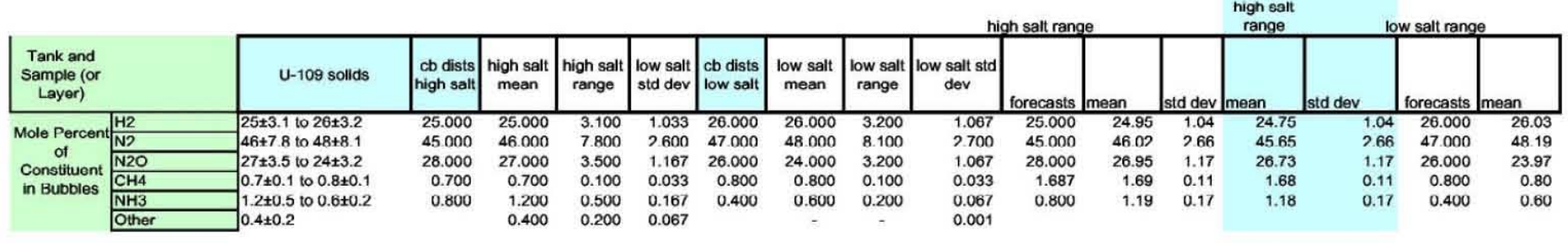


"rgs FinalSumTable Rev 1 Tab_6MC 030823 .xls",Tab “3-Revised comps"

Step 3 of 7 - Combine Original and "Other" Component Tables

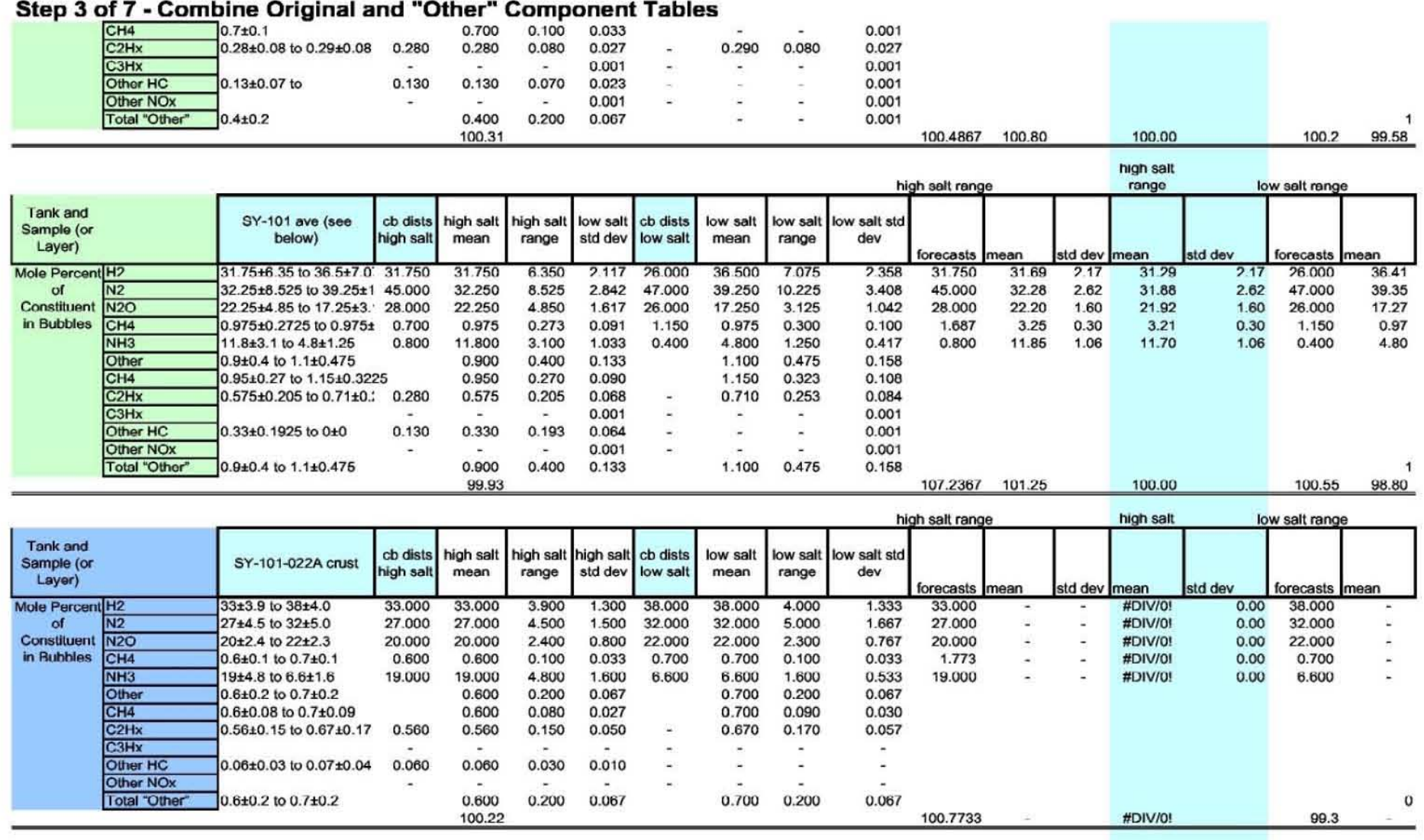


“rgs FinalSumTable Rev 1 Tab_6MC 030823 .xls",Tab “3-Revised comps"

Step 3 of 7 - Combine Original and "Other" Component Tables

\begin{tabular}{|c|c|c|c|c|c|c|c|c|c|c|}
\hline \multicolumn{2}{|l|}{$\begin{array}{l}\text { Tank and } \\
\text { Sample (or } \\
\text { Layer) }\end{array}$} & SY-101-023A crust & \begin{tabular}{|l} 
cb dists \\
high salt
\end{tabular} & $\begin{array}{c}\text { high salt } \\
\text { mean }\end{array}$ & $\begin{array}{c}\text { high salt } \\
\text { range }\end{array}$ & $\begin{array}{l}\text { high sat } \\
\text { std dev }\end{array}$ & \begin{tabular}{|l} 
co dists \\
low salt
\end{tabular} & $\begin{array}{c}\text { low salt } \\
\text { mean }\end{array}$ & $\begin{array}{l}\text { low salt } \\
\text { range }\end{array}$ & $\begin{array}{c}\text { low salt std } \\
\text { dev }\end{array}$ \\
\hline $\begin{array}{l}\text { Mole Percent } \\
\text { of }\end{array}$ & & $\begin{array}{l}35 \pm 4 \\
28 \pm 4\end{array}$ & $\begin{array}{l}25 \\
45\end{array}$ & $\overline{0}$ & $\overline{00}$ & $\begin{array}{l}1.467 \\
1.633\end{array}$ & 26.000 & $\overline{00}$ & 4.500 & 3 \\
\hline co & $\frac{\mathrm{N2}}{\mathrm{N2O}}$ & 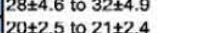 & & & & & 47.000 & & & \\
\hline Bubbles & $\mathrm{CH} 4$ & 0. & 0.700 & & & & 26.000 & 00 & 0 & $800^{\circ}$ \\
\hline & $\mathrm{NH3}$ & $16 \pm 3.9$ to 6. & 0.800 & & & 1.300 & 0.400 & & & \\
\hline & & $0.4 \pm 0$. & & & & & & & & \\
\hline & $\mathrm{Cr}$ & & & & & 0.033 & & & & 033 \\
\hline & $\mathrm{C} 2 \mathrm{P}$ & $0.38 \pm 0.08$ to $0.47 \pm 0.10$ & 0.280 & 0.380 & 0.080 & 0.027 & - & 0.470 & 0.100 & 0.033 \\
\hline & $\mathrm{C}_{3 \mathrm{H}}$ & & & & & & & & & \\
\hline & Othe & $0.05 \pm 0.02$ to $0.06 \pm 0.03$ & 0.130 & 0.050 & 0.020 & 0.007 & - & - & - & - \\
\hline & 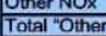 & $0.4 \pm 0.1$ to $0.5 \pm 0.1$ & & 0.400 & 0.100 & 0.033 & & 0.500 & 0.100 & 0.033 \\
\hline
\end{tabular}

\begin{tabular}{|c|c|c|c|c|c|c|c|c|c|c|}
\hline \multicolumn{2}{|l|}{$\begin{array}{l}\text { Tank and } \\
\text { Sample (or } \\
\text { Layer) }\end{array}$} & SY-101-022A liq. & $\begin{array}{l}\text { cb dists } \\
\text { high salt }\end{array}$ & $\begin{array}{c}\text { high salt } \\
\text { mean }\end{array}$ & $\begin{array}{l}\text { high salt } \\
\text { range }\end{array}$ & $\begin{array}{l}\text { high salt } \\
\text { etdd dev }\end{array}$ & $\begin{array}{l}\text { cb dists } \\
\text { low salt }\end{array}$ & $\begin{array}{l}\text { low salt } \\
\text { mean }\end{array}$ & $\begin{array}{l}\text { low salt } \\
\text { range }\end{array}$ & $\begin{array}{c}\text { low salt std } \\
\text { dev }\end{array}$ \\
\hline \multicolumn{2}{|c|}{ Mole Percent $1 \mathrm{H} 2$} & $32 \pm 8.8$ to $38 \pm 10$ & 25.000 & 32.000 & 8.800 & 2.933 & 26.000 & 38.000 & 10.000 & 3.333 \\
\hline \multirow{11}{*}{$\begin{array}{l}\text { Constivent } \\
\text { in Bubobles }\end{array}$} & N2 & $33 \pm 11$ & 45.000 & 33.000 & & 3.667 & 47.000 & 42.000 & 14.000 & 4.667 \\
\hline & $\mathrm{N2O}$ & $26 \pm 7.3$ & 28.000 & 20.000 & 7.300 & 2.433 & 20.000 & 14.000 & 4.100 & 1.367 \\
\hline & $\mathrm{CH} 4$ & $1.3 \pm 0.4$ & 0.700 & 1.300 & 0.400 & 0.133 & 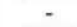 & 1.600 & 0.500 & 0.167 \\
\hline & $\mathrm{NH3}$ & $0.4 \pm 1$ & 0.800 & 8.400 & 1.900 & 0.833 & 0.400 & 3.100 & 0.900 & 0.300 \\
\hline & Other & $1.4 \pm 0.7$ to & & 1.400 & 0.700 & 0.233 & & 1.700 & 0.900 & 0.300 \\
\hline & CH4 & $1.3 \pm 0.5$ & & 1.300 & 0.500 & 0.167 & & 1.600 & 0.600 & 0.200 \\
\hline & $\mathrm{C} 2 \mathrm{Hx}$ & $0.70 \pm 0.32$ to $0.87 \pm 0.40$ & 0.280 & 0.700 & 0.320 & 0.107 & - & 0.870 & 0.400 & 0.133 \\
\hline & $\mathrm{C} 3 \mathrm{HX}$ & & & & & & - & - & 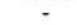 & - \\
\hline & Othert & $0.67 \pm 0.41$ to $0.83 \pm 0.51$ & 0.130 & 0.670 & 0.410 & 0.137 & - & - & - & - \\
\hline & Other $\mathrm{N}$ & & & & & & - & & & \\
\hline & Total "Other" & $14+07$ b & & $\begin{array}{c}1.400 \\
100.07\end{array}$ & 0.700 & 0.233 & & 1.700 & 0.900 & 0.300 \\
\hline
\end{tabular}

\begin{tabular}{|c|c|c|c|c|c|c|c|c|c|c|}
\hline $\begin{array}{l}\text { Tank and } \\
\text { Sample (or } \\
\text { Layer) }\end{array}$ & & SY-101-021 liq & $\left|\begin{array}{c}c b \text { dists } \\
\text { high salt }\end{array}\right|$ & $\begin{array}{l}\text { high salt } \\
\text { mean }\end{array}$ & \begin{tabular}{|} 
high salt \\
range
\end{tabular} & $\begin{array}{l}\text { high salt } \\
\text { sta dev }\end{array}$ & \begin{tabular}{|l} 
cb dists \\
low salt
\end{tabular} & $\begin{array}{c}\text { low salt } \\
\text { mean }\end{array}$ & $\begin{array}{c}\text { low salt } \\
\text { range }\end{array}$ & $\begin{array}{c}\text { low salt std } \\
\text { dev }\end{array}$ \\
\hline \multirow{8}{*}{$\begin{array}{l}\text { Mole Percen } \\
\text { of } \\
\text { Constituent } \\
\text { in Bubbles }\end{array}$} & $\mathrm{H} 2$ & $27 \pm 8.3$ to $31 \pm 9.8$ & 25.000 & 27.000 & 8.300 & 2.767 & 26.000 & 31.000 & 9.800 & 3.26 \\
\hline & $\mathrm{N} 2$ & $41 \pm 14$ to & 45.000 & 41.000 & 14.000 & 4.667 & 47.000 & 51.000 & 17.000 & 5.667 \\
\hline & $\mathrm{N} 2 \mathrm{O}$ & $23+7$ 2 to $12+3.7$ & 28.000 & 23.000 & 7200 & 2.400 & 26.000 & 12000 & 3.700 & 1.233 \\
\hline & $\mathrm{CH}_{4}$ & $1.4 \pm 0.5$ to $1.6 \pm 0.6$ & 0.700 & 1.400 & 0.500 & 0.167 & & 1.600 & 0.600 & 0.200 \\
\hline & $\mathrm{NH} 3$ & 5.8ะ1.8 to $2.8 \pm 0.9$ & 0.800 & & & 0.600 & 0.400 & & 0.900 & \\
\hline & Other & $1.2 \pm 0.6$ to $1.5 \pm 0.7$ & & 1.200 & 0.600 & 0.200 & & 1.500 & 0.700 & 0.233 \\
\hline & $\mathrm{CH} 4$ & $1.3 \pm 0.4$ to $1.6 \pm 0.5$ & & & 0 & 0.133 & & 00 & 0.500 & \\
\hline & $\mathrm{C} 2 \mathrm{Hx}$ & ] $0.66 \pm 0.27$ to $0.83 \pm 0.34$ & 0.280 & 0.660 & 0.270 & 0.090 & - & 0.830 & 0.340 & 0.113 \\
\hline
\end{tabular}


"rgs FinalSumTable Rev 1 Tab_6MC 030823 .xls",Tab “3-Revised comps"

Step 3 of 7 - Combine Original and "Other" Component Tables

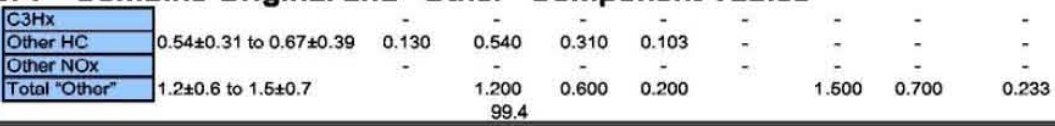

\begin{tabular}{|c|c|c|c|c|c|c|c|c|c|c|}
\hline \multicolumn{2}{|l|}{$\begin{array}{l}\text { Tank and } \\
\text { Sample (or } \\
\text { Layer) }\end{array}$} & SY-101 ave. & $\mid \begin{array}{c}\text { cb dists } \\
\text { high salt }\end{array}$ & $\begin{array}{c}\text { high salt } \\
\text { mean }\end{array}$ & \begin{tabular}{|c} 
high salt \\
range
\end{tabular} & $\begin{array}{l}\text { high salt } \\
\text { std dev }\end{array}$ & $\begin{array}{l}\text { cb dists } \\
\text { low salt }\end{array}$ & $\begin{array}{c}\text { low salt } \\
\text { mean }\end{array}$ & \begin{tabular}{|c|} 
low salt \\
range
\end{tabular} & $\begin{array}{c}\text { low salt std } \\
\text { dev }\end{array}$ \\
\hline \multirow{11}{*}{$\begin{array}{l}\text { Mole Percen } \\
\text { of } \\
\text { Consutuent } \\
\text { in Bubbles }\end{array}$} & & $31.75 \pm 6.35$ to 36.547 & & 31.8 & $\overline{6.4}$ & & & 36.5 & & \\
\hline & $\mathrm{N} 2$ & $32.25 \pm 8.525$ to 39.25 & 10.225 & 32.3 & 8.5 & & & 39.3 & 10.2 & \\
\hline & N20 & $22.25 \pm 4.85$ to $17.25 \pm$ & & 22.3 & 4.9 & & & 17.3 & & \\
\hline & $\mathrm{CH} 4$ & $0.975+0.2725$ to 0.97 & & 1.0 & 0.3 & & & & & \\
\hline & & 11. $8 \pm 3.1$ to $4.8 \pm 1.25$ & & 11.8 & 3.1 & & & 4.8 & & \\
\hline & Other & $0.9 \pm 0.4$ to $1.1 \pm 0.475$ & & 0.9 & 0.4 & & & 1.1 & & \\
\hline & $\mathrm{CH} 4$ & $0.95+0.27$ to $1.15+0.3$ & & 10 & 0.3 & & & 12 & 0.3 & \\
\hline & $\mathrm{C}_{2 \mathrm{Hx}}$ & $0.575 \pm 0.205$ to $0.71 \pm$ & & 0.6 & 0.2 & & & 0.7 & 0.3 & \\
\hline & $\begin{array}{l}\text { C3Hx } \\
\text { Other } H C \\
\end{array}$ & $0.33 \pm 0.1925$ to $0 \pm 0$ & & 0.3 & 0.2 & & & - & - & \\
\hline & Othor NOx & $0.9+0.4$ to $1,1+0.475$ & & & 0.4 & & & 111 & 0.5 & \\
\hline & & & & 99.93 & & & & & & \\
\hline
\end{tabular}


“rgs FinalSumTable Rev 1 Tab_6MC 030823.xls”,Tab “3-Revised comps"

Step 3 of 7 - Comt
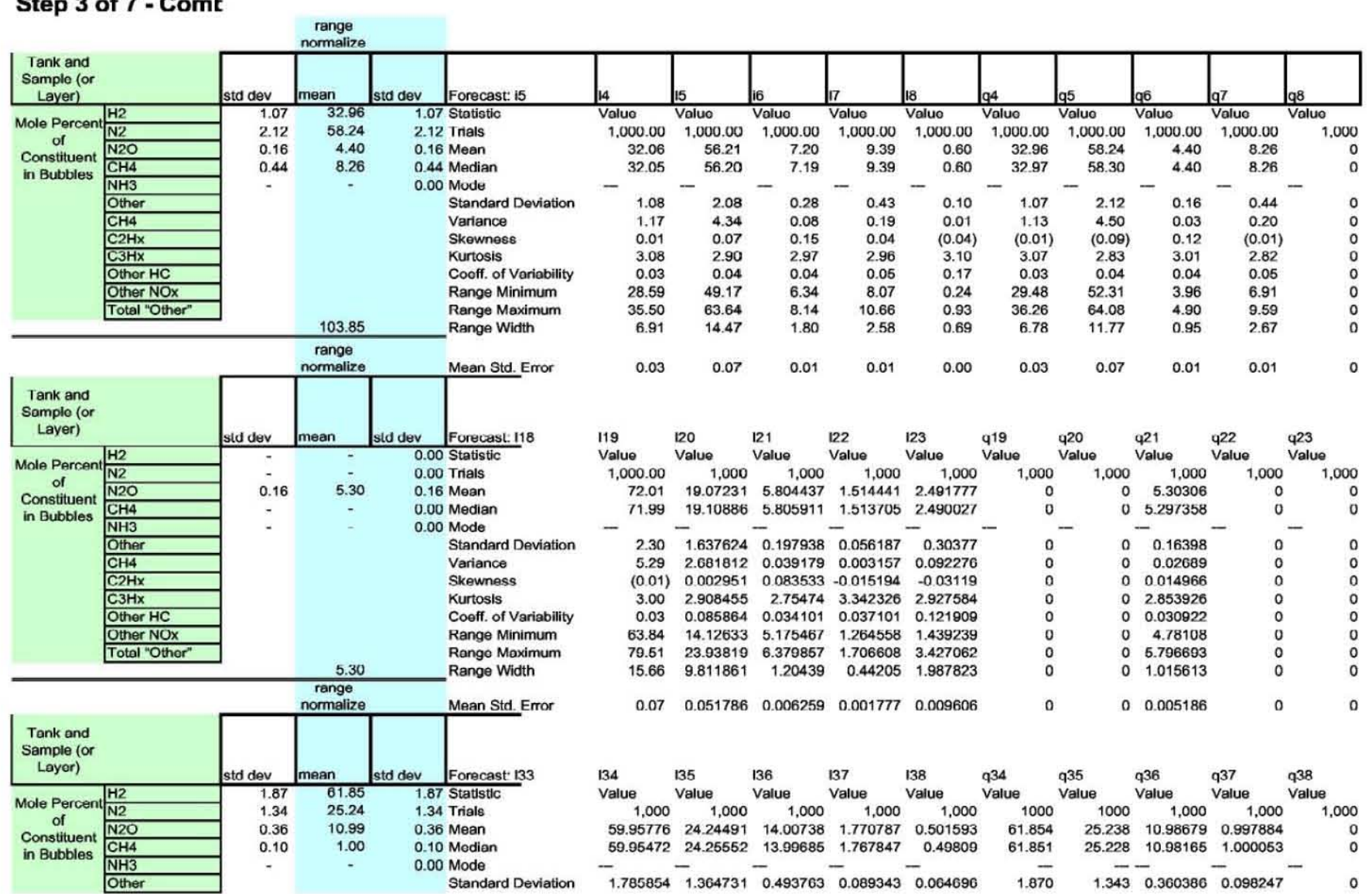

$\begin{array}{llllllllll}119 & 120 & 121 & 122 & 123 & \mathbf{1 1 9} & \mathbf{4 2 0} & \mathbf{q 2 1} & \mathbf{q 2 2} & \mathbf{q 2 3} \\ \text { Value } & \text { Value } & \text { Value } & \text { Value } & \text { Value } & \text { Value } & \text { Value } & \text { Value } & \text { Value } & \text { Value }\end{array}$

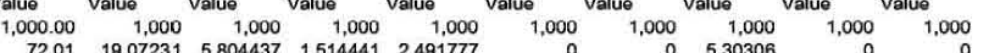
$\begin{array}{lllllll}71.99 & 19.10886 & 5.805911 & 1.513705 & 2.490027\end{array}$ $2.30 \overline{-}_{1.637624} \overline{0}_{0.197938} \overline{0}_{0.056187}{ }^{-} 0.30377-$ $\begin{array}{llllll}5.29 & 2.681812 & 0.039179 & 0.003157 & 0.092276\end{array}$ $\begin{array}{lllllll}3.00 & 2908455 & 275474 & 3.342326 & 2927584\end{array}$ $\begin{array}{lllllll}0.03 & 0.085864 & 0.034101 & 0.037101 & 0.121909\end{array}$ $\begin{array}{llllll}63.84 & 14.12633 & 5.175467 & 1.264558 & 1.439239\end{array}$

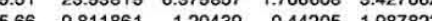
$\begin{array}{lllllll}0.07 & 0.051786 & 0.006259 & 0.001777 & 0.009606\end{array}$ $\begin{array}{lr}1 & 5.30306 \\ 0 & 5.297358\end{array}$ $0.16398-$ $\begin{array}{rrr}0 & 0.16398 \\ 0 & 0.02689 \\ 0 & 0.014966\end{array}$ $\begin{array}{lll}0 & 0.014966 \\ 0 & 2853926 \\ 0 & 0 & 0.030022\end{array}$ $0 \quad 0.030922$ $0 \quad 4.78108$ 0 5.796693

0.005186 $\begin{array}{llllllllll}134 & 135 & 136 & 137 & 138 & 934 & 935 & 936 & 937 & 938 \\ \text { Value } & \text { Value } & \text { Value } & \text { Value } & \text { Value } & \text { Value } & \text { Value } & \text { Value } & \text { Value } & \text { Value }\end{array}$ $\begin{array}{llllllllll}1,1,000 & 1,000 & 1,000 & 1,000 & 1,000 & 1000 & 1000 & 1,000 & 1,000 & 1,000\end{array}$ $\begin{array}{rrrrrrrrrrr}59.95776 & 24.24491 & 14.00738 & 1.770787 & 0.501593 & 61.854 & 25.238 & 10.98679 & 0.997884 & 0 \\ 59.95472 & 24.25552 & 13.99685 & 1.767847 & 0.49809 & 61.851 & 25.228 & 10.98165 & 1.000053 & 0\end{array}$ 
“rgs FinalSumTable Rev 1 Tab_6MC 030823.xls”,Tab “3-Revised comps"

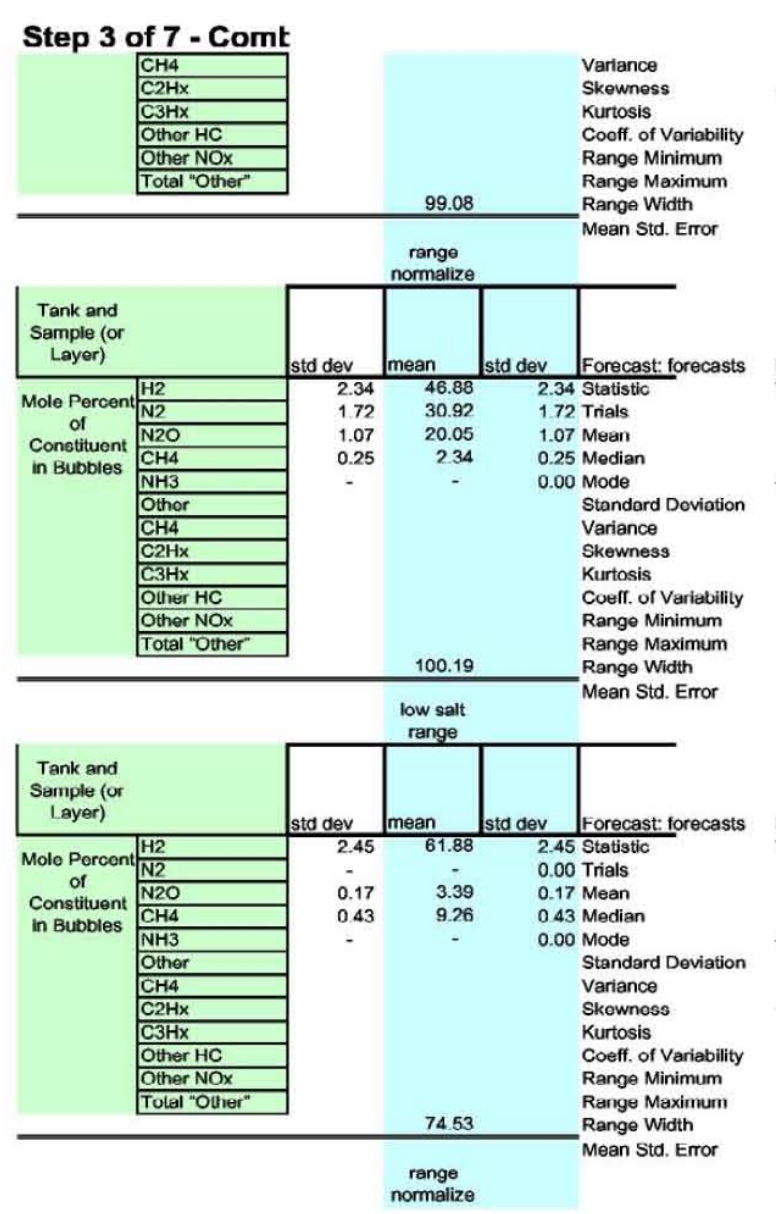
$\begin{array}{rrrrrrrrr}3.189274 & 1.86249 & 0.243802 & 0.007982 & 0.004186 & 3.496 & 1.804 & 0.129878 & 0.009652 \\ -0.005243 & -0.174528 & -0.017678 & 0.134001 & 0.142467 & -0.01 & 0.02 & 0.049127 & -0.091965 \\ 3.040792 & 3.195469 & 2.923574 & 2.7839 & 2.962868 & 2.70 & 2.70 & 3.126106 & 3.213292 \\ 0.029785 & 0.056289 & 0.03625 & 0.050454 & 0.12898 & 0.03 & 0.05 & 0.032802 & 0.098456 \\ 54.04147 & 19.02917 & 12.41771 & 1.516606 & 0.305079 & 56.699 & 21.203 & 9.886958 & 0.673734 \\ 65.61884 & 28.23635 & 15.42897 & 2.071723 & 0.702529 & 66.932 & 29.468 & 12.31259 & 1.305372 \\ 11.57736 & 9.207179 & 3.011265 & 0.555117 & 0.39745 & 10.233 & 8.265 & 2.425627 & 0.631638\end{array}$ $\begin{array}{lllllllll}0.056474 & 0.043157 & 0.015614 & 0.002825 & 0.002046 & 0.059 & 0.042 & 0.011396 & 0.003107\end{array}$

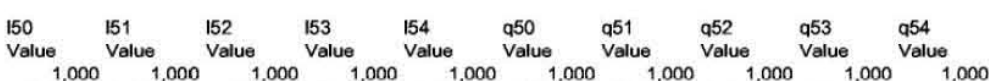
$\begin{array}{llllllllll}45.01309 & 29.06324 & 23.0237 & 3.358001 & 0.896019 & 46.88424 & 30.91883 & 20.05001 & 2.337788 \\ 44.99726 & 29.04332 & 23.05964 & 3.357393 & 0.891358 & 46.97183 & 30.8813 & 20.05277 & 2.339867\end{array}$ (324619 $\begin{array}{rrrrrrrrr}2.324619 & 1.560725 & 1.199418 & 0.238141 & 0.131958 & 2.342188 & 1.72249 & 1.069311 & 0.254816 \\ 5.403855 & 2.435863 & 1.438603 & 0.056711 & 0.017413 & 5.485845 & 2.966971 & 1.143425 & 0.064931\end{array}$ $\begin{array}{lllllllllll}0.064836 & 0.03668 & 0.072719 & 0.026606 & 0.075635 & -0.08027 & -0.044557 & 0.035086 & 0.011753\end{array}$ $\begin{array}{llllllllllll}2.949772 & 2.884611 & 2.665125 & 2.888823 & 2.734561 & 3.213638 & 3.078716 & 2.842746 & 3.001134\end{array}$ $\begin{array}{llllllllll}0.051643 & 0.053701 & 0.052095 & 0.070917 & 0.147271 & 0.049957 & 0.05571 & 0.053331 & 0.108999\end{array}$

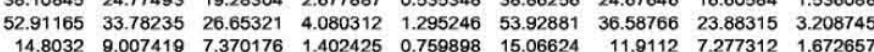
$\begin{array}{llllllllll}0.073511 & 0.049354 & 0.037929 & 0.007531 & 0.004173 & 0.074066 & 0.05447 & 0.033815 & 0.008058\end{array}$

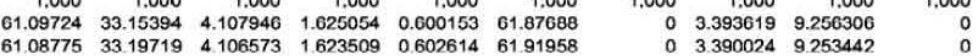

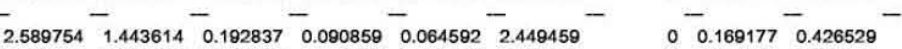

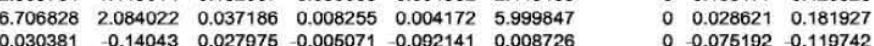

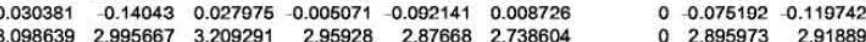
$\begin{array}{lllllllllll}0.042387 & 0.043543 & 0.046943 & 0.055912 & 0.107625 & 0.039586 & 0 & 0.049851 & 0.04600\end{array}$ $\begin{array}{llllllllll}51.37039 & 2811163 & 3.337206 & 1.335281 & 0.406588 & 5524226 & 0 & 289077 & 7.875715\end{array}$

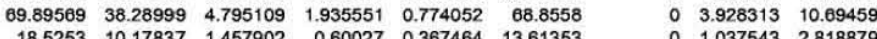

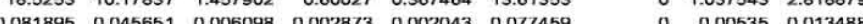

range
nomalize 
“rgs FinalSumTable Rev 1 Tab_6MC 030823.xls”,Tab “3-Revised comps"

\begin{tabular}{|c|c|c|c|c|c|c|c|c|c|c|c|c|c|c|c|}
\hline \multicolumn{16}{|c|}{ Step 3 of 7 - Comt } \\
\hline \multicolumn{2}{|c|}{\begin{tabular}{|l|} 
Tank and \\
Sample (or \\
Layer)
\end{tabular}} & \multirow{2}{*}{$\frac{\text { std dev }}{0.51}$} & \multirow{3}{*}{$\frac{\text { mean }}{23.84}$} & \multirow{2}{*}{ std dev } & \multirow{2}{*}{ Forecast: forecasts } & \multirow{2}{*}{$\begin{array}{l}182 \\
\text { Value }\end{array}$} & \multirow{2}{*}{$\begin{array}{l}183 \\
\text { Value }\end{array}$} & \multirow{2}{*}{184} & \multirow{2}{*}{185} & \multirow{2}{*}{186} & \multirow{2}{*}{982} & \multirow{2}{*}{$\begin{array}{l}\text { q83 } \\
\text { Value }\end{array}$} & \multirow{2}{*}{$\begin{array}{l}\text { q84 } \\
\text { Value }\end{array}$} & \multirow{2}{*}{$\begin{array}{l}\text { q85 } \\
\text { Value }\end{array}$} & \multirow{2}{*}{ q86 } \\
\hline & & & & & & & & & & & & & & & \\
\hline Mole Percent & $\frac{118}{N 2}$ & 0.85 & & 0.8 & 5 Trials & 1,000 & 1000 & 1000 & 1000 & 1000 & 1,000 & 1000 & 1000 & 1000 & \\
\hline of & N2O & 0.73 & 36.75 & & $3 \mathrm{Mes}$ & 23.01222 & 36.191 & & 1.793 & 0.598 & & 38.123 & & 1.065 & 0.498 \\
\hline $\begin{array}{l}\text { Constutuent } \\
\text { in Bubbles }\end{array}$ & $\mathrm{CH} 4$ & 0.06 & 1.06 & 0.0 & & 22.99235 & 36.218 & 39.028 & 1.793 & 0.599 & 24.00625 & 38.129 & 37.009 & 1.067 & 0.497 \\
\hline & $\mathrm{NH3}$ & 0.07 & 0.49 & 0.0 & & - & & & & & & & & & \\
\hline & \begin{tabular}{|l|l|l|l} 
\\
\end{tabular} & & & & $\mathrm{su}$ & 0.4 & 0.7 & 3 & 0.0 & & & & & & \\
\hline & $\mathrm{CH} 4$ & & & & & & 0.5 & 0.628 & 0.005 & 0.010 & & 0.719 & 7 & 003 & 0.004 \\
\hline & $\mathrm{C} 2 \mathrm{Hx}$ & & & & & & -0.04 & 0.00 & 0.02 & -0.01 & & & & 0.03 & 0.00 \\
\hline & $\mathrm{C} 3 \mathrm{Hx}$ & & & & & 2.86 & & 0 & & 3.07 & & & & 2.76 & 2.90 \\
\hline & Other H & & & & ity & 0.020148 & 0.02 & 0.02 & 4 & & & & & 0.05 & 0.13 \\
\hline & Other $N$ & & & & & 21.47335 & 33.822 & 6.456 & 1.551 & & & & 4 & 0.906 & 0.295 \\
\hline & Total "Other" & & & & & 24.6611 & 38.750 & 41.607 & 2.0 & 0.965 & & 40.818 & 39.371 & 1.233 & 0.684 \\
\hline & & & 100.00 & & & 3.187744 & 4.928 & 5.151 & 0.483 & 0.760 & 6 & 5.534 & 5.047 & 0.327 & 0.389 \\
\hline
\end{tabular}


“rgs FinalSumTable Rev 1 Tab_6MC 030823 .xls",Tab “3-Revised comps"

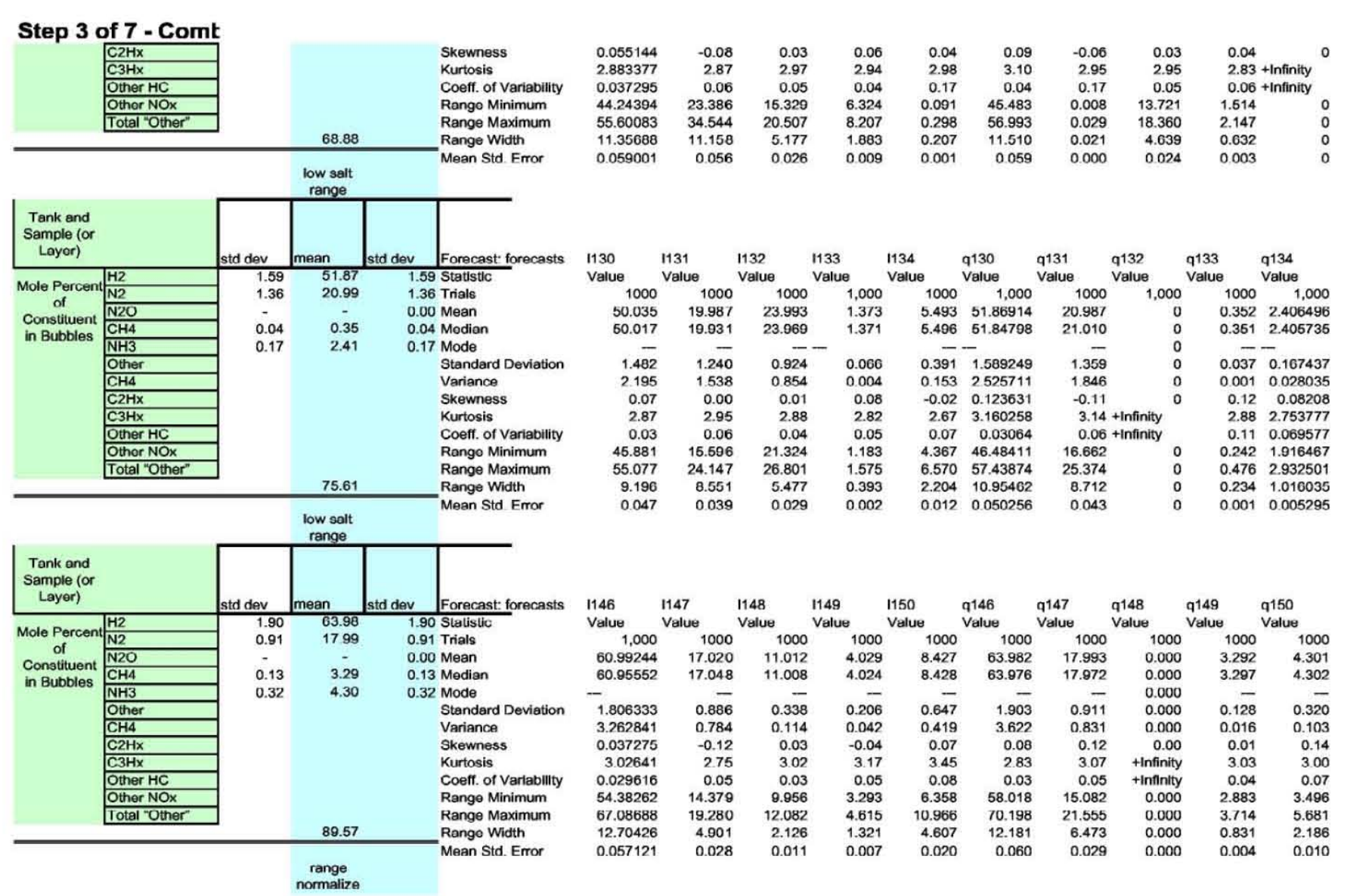


“rgs FinalSumTable Rev 1 Tab_6MC 030823 .xls",Tab “3-Revised comps"

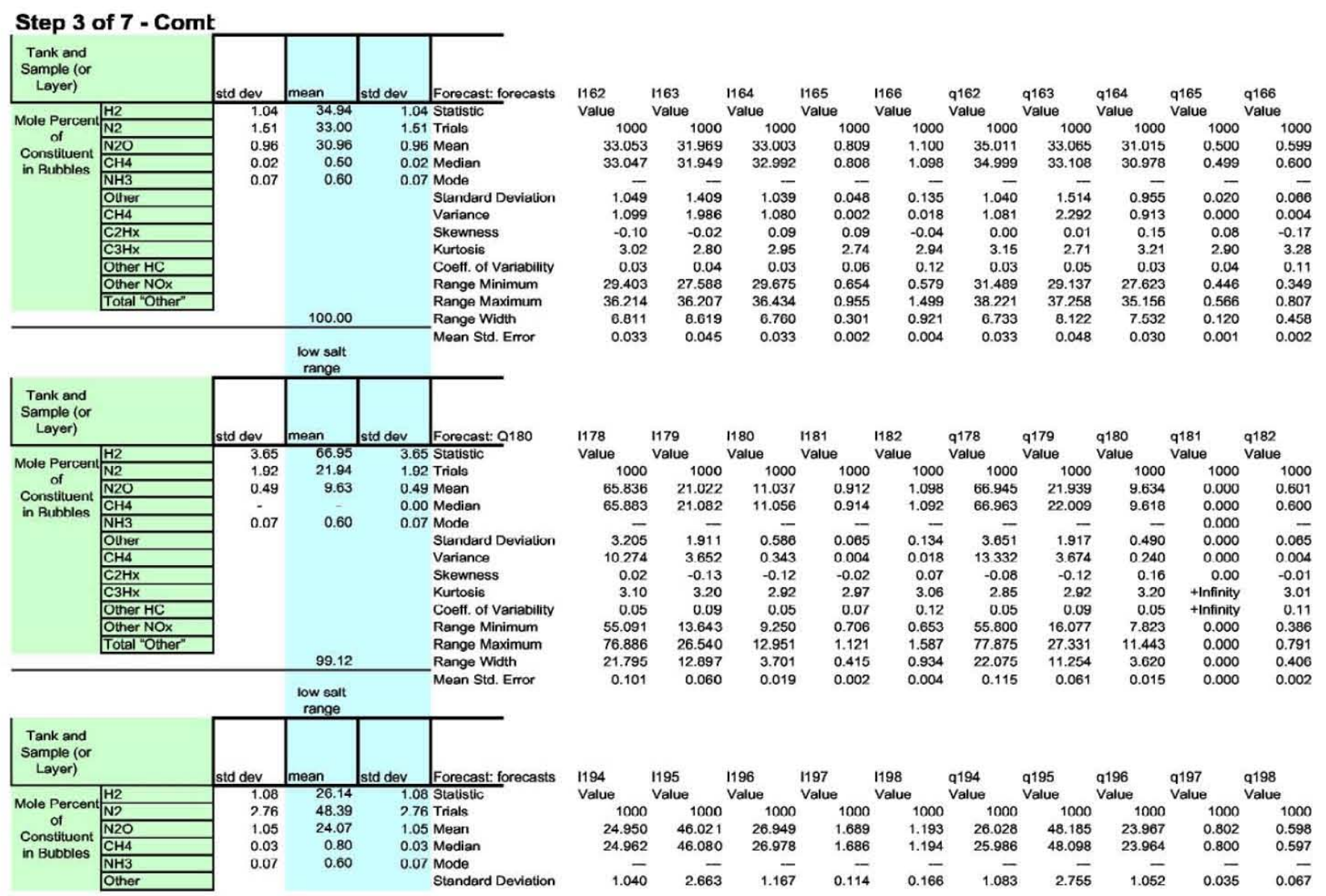


"rgs FinalSumTable Rev 1 Tab_6MC 030823 .xls",Tab “3-Revised comps"

\begin{tabular}{cllrrrrrrrr} 
Step 3 of 7 - Comb & & & & & & & \\
\hline
\end{tabular}

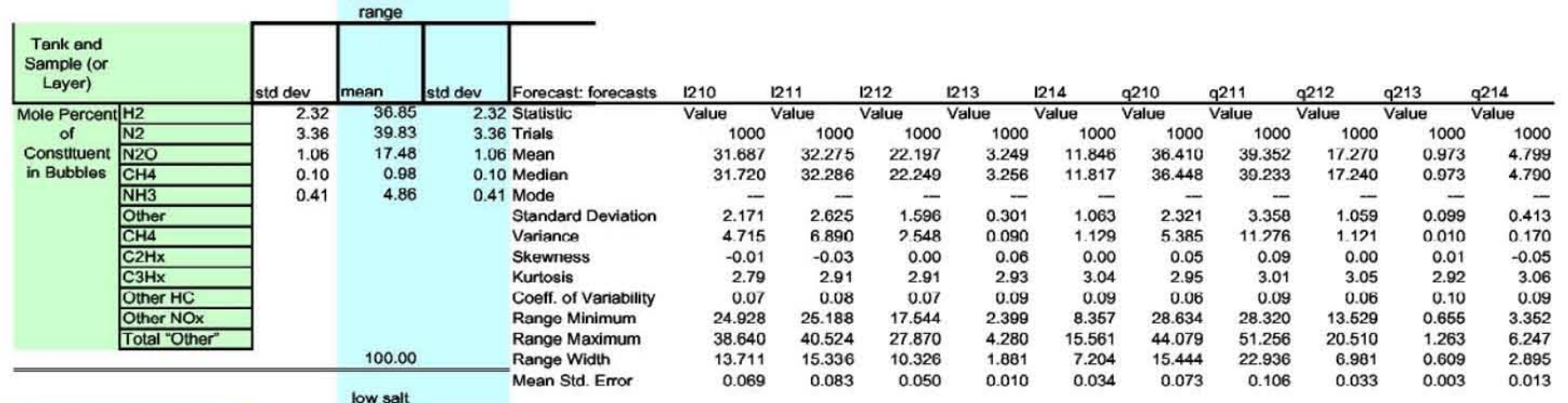

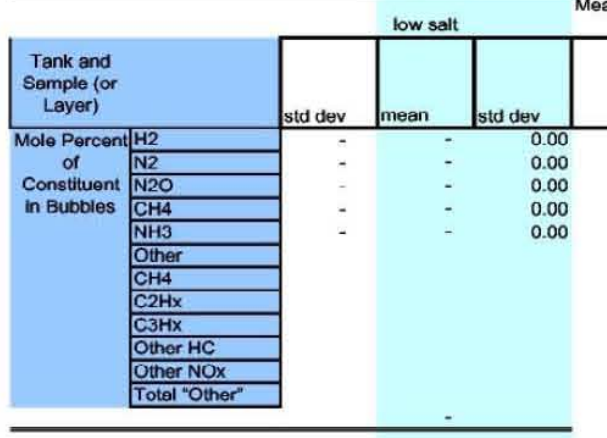




\section{RPP-10006 REV 8}

"rgs FinalSumTable Rev 1 Tab_6MC 030823 .xls",Tab “3-Revised comps" Cell Equations

\begin{tabular}{|c|c|c|}
\hline Cell & Value & Formula \\
\hline$c 4$ & $32 \pm 3.2$ to $33 \pm 3.2$ & $32 \pm 3.2$ to $33 \pm 3.2$ \\
\hline c5 & $56 \pm 6.2$ to $58 \pm 6.4$ & $56 \pm 6.2$ to $58 \pm 6.4$ \\
\hline$c 6$ & $7.2 \pm 0.8$ to $4.4 \pm 0.5$ & $7.2 \pm 0.8$ to $4.4 \pm 0.5$ \\
\hline c7 & $1.7 \pm 0.2$ & $1.7 \pm 0.2$ \\
\hline$c 8$ & $0.6 \pm 0.3$ & $0.6 \pm 0.3$ \\
\hline c9 & $2.8 \pm 0.5$ to $2.9 \pm 0.6$ & $2.8 \pm 0.5$ to $2.9 \pm 0.6$ \\
\hline $\mathrm{c} 10$ & $1.7 \pm 0.2$ & $1.7 \pm 0.2$ \\
\hline c11 & $1.1 \pm 0.2$ to $1.2 \pm 0.2$ & $1.1 \pm 0.2$ to $1.2 \pm 0.2$ \\
\hline c12 & $0.26 \pm 0.1$ to $0.27 \pm 0.1$ & $0.26 \pm 0.1$ to $0.27 \pm 0.1$ \\
\hline $\mathrm{c} 13$ & $1.3 \pm 0.3$ to $1.4 \pm 0.3$ & $1.3 \pm 0.3$ to $1.4 \pm 0.3$ \\
\hline c14 & $0.12 \pm 0.06$ to $0.12 \pm 0.07$ & $0.12 \pm 0.06$ to $0.12 \pm 0.07$ \\
\hline c15 & $2.8 \pm 0.5$ to $2.9 \pm 0.6$ & $2.8 \pm 0.5$ to $2.9 \pm 0.6$ \\
\hline \multicolumn{3}{|l|}{ c16 } \\
\hline $\mathrm{d} 4$ & 31.90562462 & 31.90562462 \\
\hline d5 & 55 & 55 \\
\hline d6 & 7.5 & 7.5 \\
\hline d7 & 1.7 & 1.7 \\
\hline $\mathrm{d} 8$ & 0.8 & 0.8 \\
\hline \multicolumn{3}{|l|}{ d9 } \\
\hline \multicolumn{3}{|l|}{ d10 } \\
\hline d11 & 1.1 & 1.1 \\
\hline$d 12$ & 0.26 & 0.26 \\
\hline d13 & 1.3 & 1.3 \\
\hline d14 & 0.12 & 0.12 \\
\hline \multicolumn{3}{|l|}{ d15 } \\
\hline \multicolumn{3}{|l|}{ d16 } \\
\hline$\theta 4$ & 32 & $=$ "=IF (ISERR (FIND $(\$ E \$ 2$, C307, 1)) , 0, VALUE (LEFT (C307, FIND $(\$ E \$ 2$, C307, 1) - 1) \\
\hline e5 & 56 & 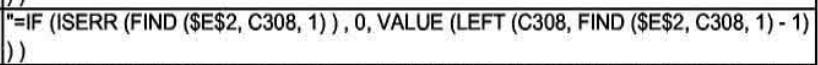 \\
\hline e6 & 7.2 & $\begin{array}{l}\text { "=IF (ISERR (FIND }(\$ E \$ 2, \text { C309, 1)) , 0, VALUE (LEFT }(C 309, \text { FIND }(\$ E \$ 2, C 309,1)-1) \\
\text { )) }\end{array}$ \\
\hline e7 & 1.7 & $\begin{array}{l}\text { "=IF (ISERR (FIND }(\$ E \$ 2, \text { C310, 1) ) , 0, VALUE (LEFT }(C 310, \text { FIND }(\$ E \$ 2, C 310,1)-1) \\
\text { )) }\end{array}$ \\
\hline e8 & 0.6 & $\begin{array}{l}\text { "=IF (ISERR (FIND (\$E\$2, C311, 1)) , 0, VALUE (LEFT (C311, FIND (\$E\$2, C311, 1) - 1) } \\
\text { )) }\end{array}$ \\
\hline e9 & 2.8 & $\begin{array}{l}\text { "=IF (ISERR (FIND }(\$ E \$ 2, \text { C312, 1)) , 0, VALUE (LEFT }(C 312, \text { FIND }(\$ E \$ 2, C 312,1)-1) \\
\text { )) }\end{array}$ \\
\hline e10 & 1.7 & $\begin{array}{l}\text { "=IF (ISERR (FIND }(\$ E \$ 2, \text { C } 313,1)), 0 \text {, VALUE (LEFT }(C 313, \text { FIND }(\$ E \$ 2, C 313,1)-1) \\
\text { )) }\end{array}$ \\
\hline e11 & 1.1 & $\begin{array}{l}\text { "=IF (ISERR (FIND }(\$ E \$ 2, \text { C } 314,1)), 0 \text {, VALUE (LEFT }(C 314, \text { FIND }(\$ E \$ 2, C 314,1)-1) \\
\text { )) }\end{array}$ \\
\hline e12 & 0.26 & "=IF (ISERR (FIND (\$E\$2, C315, 1)) , 0, VALUE (LEFT (C315, FIND (\$E\$2, C315, 1) - 1) \\
\hline e13 & 1.3 & $\begin{array}{l}\text { "=IF (ISERR (FIND (\$E\$2, C316, 1)) , 0, VALUE (LEFT (C316, FIND (\$E\$2, C316, 1) - 1) } \\
\text { )) }\end{array}$ \\
\hline e14 & 0.12 & $\begin{array}{l}\text { "=IF (ISERR (FIND }(\$ E \$ 2, \text { C } 317,1)), 0 \text {, VALUE (LEFT }(C 317, \text { FIND }(\$ E \$ 2, C 317,1)-1) \\
\text { ) }\end{array}$ \\
\hline e15 & 2.8 & $\begin{array}{l}\text { "=IF (ISERR (FIND }(\$ E \$ 2, \text { C318, 1) ) , 0, VALUE (LEFT }(C 318, \text { FIND }(\$ E \$ 2, C 318,1)-1) \\
\text { ) }\end{array}$ \\
\hline e16 & 100.28 & "=SUM (E307:E318) - E312 - E313 - E31E \\
\hline f4 & 3.2 & 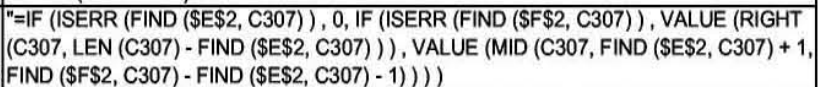 \\
\hline f5 & 6.2 & $\begin{array}{l}=\text { IF (ISERR (FIND (\$E\$2, C308)) , 0, IF (ISERR (FIND (\$F\$2, C308)), VALUE (RIGHT } \\
(C 308, \text { LEN }(C 308)-\text { FIND }(\$ E \$ 2, C 308))), \text { VALUE (MID }(C 308, \text { FIND }(\$ E \$ 2, C 308)+1, \\
\text { FIND }(\$ F \$ 2, C 308)-\text { FIND }(\$ E \$ 2, C 308)-1))))\end{array}$ \\
\hline f6 & 0.8 & $\begin{array}{l}=\text { IF (ISERR (FIND (\$E\$2, C309)), 0, IF (ISERR (FIND (\$F\$2, C309)), VALUE (RIGHT } \\
(C 309, \text { LEN }(C 309)-\text { FIND }(\$ E \$ 2, \text { C309) ) ), VALUE (MID }(C 309, \text { FIND }(\$ E \$ 2, C 309)+1, \\
\text { FIND }(\$ F \$ 2, C 309)-\text { FIND }(\$ E \$ 2, C 309)-1))))\end{array}$ \\
\hline f7 & 0.2 & $\begin{array}{l}\text { "=IF (ISERR (FIND (\$E\$2, C310)), 0, IF (ISERR (FIND (\$F\$2, C310)), VALUE (RIGHT } \\
(C 310, \text { LEN }(C 310)-\text { FIND }(\$ E \$ 2, C 310))), \text { VALUE (MID }(C 310, \text { FIND }(\$ E \$ 2, C 310)+1, \\
\text { FIND }(\$ F \$ 2, C 310)-\text { FIND }(\$ E \$ 2, C 310)-1))))\end{array}$ \\
\hline
\end{tabular}




\section{RPP-10006 REV 8}

“rgs FinalSumTable Rev 1 Tab_6MC 030823 .xls",Tab “3-Revised comps" Cell Equations

\begin{tabular}{|c|c|c|}
\hline Cell & Value & Formula \\
\hline f8 & 0.3 & 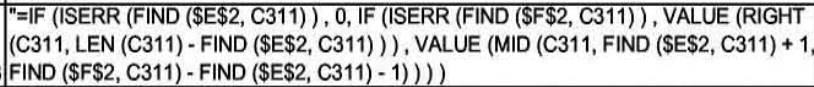 \\
\hline f9 & 0.5 & 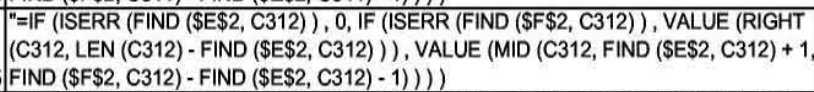 \\
\hline $\mathrm{f} 10$ & 0.2 & 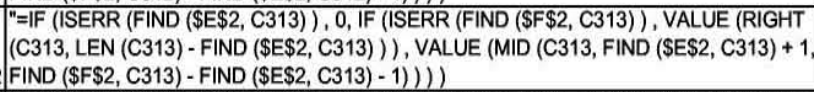 \\
\hline $\mathrm{f} 11$ & 0.2 & 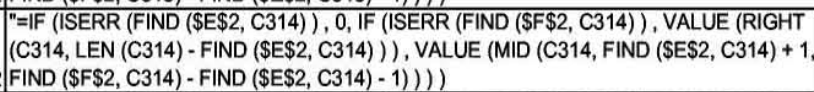 \\
\hline $\mathrm{f} 12$ & 0.1 & 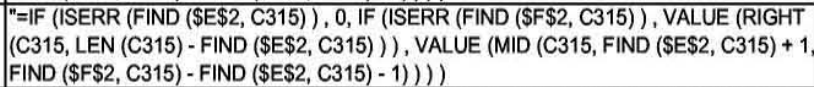 \\
\hline $\mathrm{f} 13$ & 0.3 & 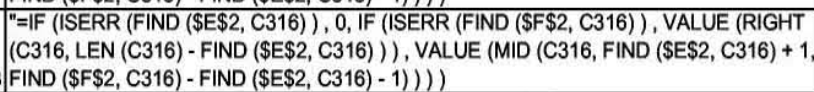 \\
\hline $\mathrm{f} 14$ & 0.06 & 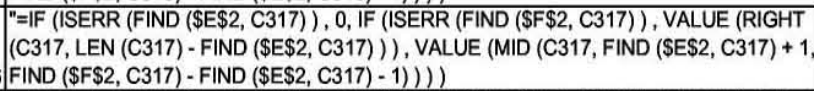 \\
\hline $\mathrm{f} 15$ & 0.5 & $\begin{array}{l}\text { "=IF (ISERR (FIND (\$E\$2, C318)) , 0, IF (ISERR (FIND (\$F\$2, C318)), VALUE (RIGHT } \\
(\text { C318, LEN }(C 318)-\text { FIND }(\$ E \$ 2, \text { C318) )), VALUE (MID }(C 318, \text { FIND }(\$ E \$ 2, C 318)+1 \\
\text { FIND }(\$ F \$ 2, C 318)-\text { FIND }(\$ E \$ 2, C 318)-1))))\end{array}$ \\
\hline f16 & & \\
\hline 94 & 2.366666667 & "=IF (ISERR (F307/3), 0.001, MAX (+F307/3, 0.001)) \\
\hline g5 & 1.633333333 & "=IF $($ ISERR $(F 308 / 3), 0.001, \operatorname{MAX}(+F 308 / 3,0.001))$ \\
\hline$\frac{g v}{g 6}$ & 0.2 & $==\mid F($ ISERR $(F 309 / 3), 0.001, \operatorname{MAX}(+F 309 / 3,0.001))$ \\
\hline g7 & 0.033333333 & $=I F($ ISERR $(F 310 / 3), 0.001, \operatorname{MAX}(+F 310 / 3,0.001))$ \\
\hline 98 & 0.3 & $"=I F(\operatorname{ISERR}(F 311 / 3), 0.001, \operatorname{MAX}(+F 311 / 3,0.001))$ \\
\hline g9 & 0.02 & $"=I F($ ISERR $(F 312 / 3), 0.001, \operatorname{MAX}(+F 312 / 3,0.001))$ \\
\hline $\mathrm{g} 10$ & 0.033333333 & $=\mid F($ ISERR $(F 313 / 3), 0.001$, MAX $(+F 313 / 3,0.001))$ \\
\hline$g 11$ & 0.006666667 & $"=I F($ ISERR $(F 314 / 3), 0.001$, MAX $(+F 314 / 3,0.001))$ \\
\hline$g 12$ & 0.01 & $=$ IF $($ ISERR $(F 315 / 3), 0.001$, MAX $(+F 315 / 3,0.001))$ \\
\hline$g 13$ & 0.01 & $"=I F($ ISERR $(F 316 / 3), 0.001$, MAX $(+F 316 / 3,0.001))$ \\
\hline g14 & 0.006666667 & "=IF (ISERR $(F 317 / 3), 0.001, \operatorname{MAX}(+\mathrm{F} 317 / 3,0.001))$ \\
\hline$g 15$ & 0.02 & "=IF $($ ISERR $(F 318 / 3), 0.001, \operatorname{MAX}(+F 318 / 3,0.001))$ \\
\hline g16 & & \\
\hline h4 & 33 & 33 \\
\hline h5 & 57 & 57 \\
\hline h6 & 5 & 5 \\
\hline h7 & & \\
\hline h8 & & \\
\hline h9 & & \\
\hline $\mathrm{h} 10$ & & \\
\hline h11 & 1.2 & $\overline{1.2}$ \\
\hline h12 & 0.27 & 0.27 \\
\hline h13 & 1.4 & 1.4 \\
\hline h14 & 0.12 & 0.12 \\
\hline h15 & & \\
\hline h16 & & \\
\hline 14 & 33 & $\begin{array}{l}\text { "=IF (ISERR (FIND (\$F\$2, C307)) , 0, VALUE (MID (C307, FIND (\$F\$2, C307) + LEN } \\
\text { (\$F\$2), FIND (\$E\$2, C307, FIND (\$F\$2, C307) + 1) - (FIND (\$F\$2, C307) + LEN (\$F\$2)) } \\
\text { ))) }\end{array}$ \\
\hline 15 & 58 & $\begin{array}{l}\text { "=IF (ISERR (FIND (\$F\$2, C308) ), 0, VALUE (MID (C308, FIND (\$F\$2, C308) + LEN } \\
\text { (\$F\$2), FIND (\$E\$2, C308, FIND (\$F\$2, C308) + 1) - (FIND (\$F\$2, C308) + LEN (\$F\$2)) } \\
\text { ))) }\end{array}$ \\
\hline 16 & 4.4 & $\begin{array}{l}\text { "=IF (ISERR (FIND (\$F\$2, C309)) , 0, VALUE (MID (C309, FIND (\$F\$2, C309) + LEN } \\
\text { (\$F\$2), FIND (\$E\$2, C309, FIND (\$F\$2, C309) + 1) - (FIND (\$F\$2, C309) + LEN (\$F\$2) ) } \\
\text { ))) }\end{array}$ \\
\hline 17 & & $\begin{array}{l}\text { "=IF (ISERR (FIND (\$F\$2, C310) ), 0, VALUE (MID (C310, FIND (\$F\$2, C310) + LEN } \\
(\$ F \$ 2), \text { FIND (\$E\$2, C310, FIND (\$F\$2, C310) + 1) - (FIND (\$F\$2, C310) + LEN (\$F\$2)) } \\
\text { )) }\end{array}$ \\
\hline
\end{tabular}


"rgs FinalSumTable Rev 1 Tab_6MC 030823 .xls",Tab “3-Revised comps" Cell Equations

\begin{tabular}{|c|c|c|}
\hline Cell & Value & Formula \\
\hline 18 & & $\begin{array}{l}\text { "=IF (ISERR (FIND (\$F\$2, C311)), 0, VALUE (MID (C311, FIND (\$F\$2, C311) + LEN } \\
(\$ F \$ 2), \text { FIND (\$E\$2, C311, FIND (\$F\$2, C311) + 1) - (FIND (\$F\$2, C311) + LEN (\$F\$2)) } \\
\text { ))) }\end{array}$ \\
\hline 19 & 2.9 & $\begin{array}{l}\text { "=IF (ISERR (FIND (\$F\$2, C312)) , 0, VALUE (MID (C312, FIND (\$F\$2, C312) + LEN } \\
(\$ F \$ 2), \text { FIND (\$E\$2, C312, FIND (\$F\$2, C312) + 1) - (FIND (\$F\$2, C312) + LEN (\$F\$2)) } \\
\text { )) ) }\end{array}$ \\
\hline 110 & & $\begin{array}{l}\text { "=IF (ISERR (FIND (\$F\$2, C313)) , 0, VALUE (MID (C313, FIND (\$F\$2, C313) + LEN } \\
(\$ F \$ 2), \text { FIND (\$E\$2, C313, FIND (\$F\$2, C313) + 1) - (FIND (\$F\$2, C313) + LEN (\$F\$2)) } \\
\text { ))) }\end{array}$ \\
\hline I11 & 1.2 & $\begin{array}{l}\text { "=IF (ISERR (FIND (\$F\$2, C314)), 0, VALUE (MID (C314, FIND (\$F\$2, C314) + LEN } \\
(\$ F \$ 2), \text { FIND (\$E\$2, C314, FIND (\$F\$2, C314) + 1) - (FIND (\$F\$2, C314) + LEN (\$F\$2)) } \\
\text { ))) }\end{array}$ \\
\hline $\mid 12$ & 0.27 & $\begin{array}{l}\text { =IF (ISERR (FIND (\$F\$2, C315)), 0, VALUE (MID (C315, FIND (\$F\$2, C315) + LEN } \\
(\$ F \$ 2), \text { FIND (\$E\$2, C315, FIND (\$F\$2, C315) + 1) - (FIND (\$F\$2, C315) + LEN (\$F\$2)) } \\
\text { )) ) }\end{array}$ \\
\hline $\mid 13$ & & $\begin{array}{l}\text { "=IF (ISERR (FIND (\$F\$2, C316)) , 0, VALUE (MID (C316, FIND (\$F\$2, C316) + LEN } \\
(\$ F \$ 2), \text { FIND (\$E\$2, C316, FIND (\$F\$2, C316) + 1) - (FIND (\$F\$2, C316) + LEN (\$F\$2)) } \\
\text { )) ) }\end{array}$ \\
\hline I14 & & $\begin{array}{l}\text { "=IF (ISERR (FIND (\$F\$2, C317)) , 0, VALUE (MID (C317, FIND (\$F\$2, C317) + LEN } \\
(\$ F \$ 2), \text { FIND (\$E\$2, C317, FIND (\$F\$2, C317) + 1) - (FIND (\$F\$2, C317) + LEN (\$F\$2)) } \\
\text { ))) }\end{array}$ \\
\hline 115 & 2.9 & $\begin{array}{l}\text { "=IF (ISERR (FIND (\$F\$2, C318)), 0, VALUE (MID (C318, FIND (\$F\$2, C318) + LEN } \\
(\$ F \$ 2), \text { FIND (\$E\$2, C318, FIND (\$F\$2, C318) + 1) - (FIND (\$F\$2, C318) + LEN (\$F\$2)) } \\
\text { ))) }\end{array}$ \\
\hline 116 & & \\
\hline j4 & 3.2 & $\begin{array}{l}\text { "=IF (ISERR (FIND (\$F\$2, C307)) , 0, VALUE (RIGHT (C307, LEN (C307) - FIND (\$E\$2, } \\
\text { C307, FIND (\$F\$2, C307) + 1) - (LEN (\$E\$2) - 1)) ) ) }\end{array}$ \\
\hline j5 & 6.4 & $\begin{array}{l}"=I F(\text { ISERR (FIND }(\$ F \$ 2, \text { C308) ) , 0, VALUE (RIGHT (C308, LEN (C308) - FIND (\$E\$2, } \\
\text { C308, FIND }(\$ F \$ 2, C 308)+1)-(\text { LEN }(\$ E \$ 2)-1))))\end{array}$ \\
\hline j6 & 0.5 & $\begin{array}{l}\text { "=IF (ISERR (FIND (\$F\$2, C309)) , 0, VALUE (RIGHT (C309, LEN (C309) - FIND (\$E\$2, } \\
\text { C309, FIND (\$F\$2, C309) + 1) - (LEN (\$E\$2) - 1)) )) }\end{array}$ \\
\hline j7 & 0 & $\begin{array}{l}\text { "=IF (ISERR (FIND (\$F\$2, C310)) , 0, VALUE (RIGHT (C310, LEN (C310) - FIND (\$E\$2, } \\
\mathrm{C} 310, \text { FIND }(\$ F \$ 2, \mathrm{C} 310)+1)-(\text { LEN (\$E\$2) - 1) ) ) ) }\end{array}$ \\
\hline j8 & 0 & $\begin{array}{l}"=I F(\text { ISERR (FIND (\$F\$2, C311)) , 0, VALUE (RIGHT (C311, LEN (C311) - FIND (\$E\$2, } \\
\text { C311, FIND }(\$ F \$ 2, \text { C311) + 1) - (LEN (\$E\$2) - 1)) )) }\end{array}$ \\
\hline j9 & 0.6 & $\begin{array}{l}\text { "=IF (ISERR (FIND (\$F\$2, C312)) , 0, VALUE (RIGHT (C312, LEN (C312) - FIND (\$E\$2, } \\
\mathrm{C} 312, \text { FIND }(\$ F \$ 2, \mathrm{C} 312)+1)-(\text { LEN }(\$ E \$ 2)-1))))\end{array}$ \\
\hline j10 & 0 & $\begin{array}{l}\text { "=IF (ISERR (FIND (\$F\$2, C313)), 0, VALUE (RIGHT (C313, LEN (C313) - FIND (\$E\$2, } \\
\mathrm{C} 313, \text { FIND }(\$ F \$ 2, \mathrm{C} 313)+1)-(\text { LEN }(\text { (SE\$2) - 1)) )) }\end{array}$ \\
\hline j11 & 0.2 & $\begin{array}{l}\text { "=IF (ISERR (FIND (\$F\$2, C314)) , 0, VALUE (RIGHT (C314, LEN (C314) - FIND (\$E\$2, } \\
\text { C314, FIND (\$F\$2, C314) + 1) - (LEN (\$E\$2) - 1)))) }\end{array}$ \\
\hline j12 & 0.1 & $\begin{array}{l}\text { "=IF (ISERR (FIND (\$F\$2, C315)) , 0, VALUE (RIGHT (C315, LEN (C315) - FIND (\$E\$2, } \\
\text { C315, FIND (\$F\$2, C315) + 1) - (LEN (\$E\$2) - 1) ) )) }\end{array}$ \\
\hline j13 & 0.3 & $\begin{array}{l}\text { "=IF (ISERR (FIND (\$F\$2, C316)) , 0, VALUE (RIGHT (C316, LEN (C316) - FIND (\$E\$2, } \\
\text { C316, FIND }(\$ F \$ 2, C 316)+1)-(\text { LEN }(\text { (SE } 2)-1))))\end{array}$ \\
\hline j14 & 0.07 & $\begin{array}{l}"=I F(\text { ISERR (FIND (\$F\$2, C317)) , 0, VALUE (RIGHT (C317, LEN (C317) - FIND (\$E\$2, } \\
\text { C317, FIND }(\$ F \$ 2, C 317)+1)-(\text { LEN }(\$ E \$ 2)-1))))\end{array}$ \\
\hline j15 & 0.6 & $\begin{array}{l}\text { "=IF (ISERR (FIND (\$F\$2, C318)), 0, VALUE (RIGHT (C318, LEN (C318) - FIND (\$E\$2, } \\
\text { C318, FIND (\$F\$2, C318) + 1) - (LEN (\$E\$2) - 1)) )) }\end{array}$ \\
\hline j16 & & \\
\hline k4 & 1.066666667 & $"=$ IF (ISERR $(\mathrm{J} 4 / 3), 0.001, \operatorname{MAX}(+\mathrm{J} 4 / 3,0.001))$ \\
\hline $\mathrm{k} 5$ & 2.133333333 & $"=\operatorname{IF}($ ISERR $(J 5 / 3), 0.001, \operatorname{MAX}(+\mathrm{J} 5 / 3,0.001))$ \\
\hline $\mathrm{k} 6$ & 0.166666667 & $"=\operatorname{IF}($ ISERR $(\mathrm{J} 6 / 3), 0.001, \mathrm{MAX}(+\mathrm{J} 6 / 3,0.001))$ \\
\hline k7 & 0.001 & $"=\operatorname{IF}(\operatorname{ISERR}(\mathrm{J} 7 / 3), 0.001, \mathrm{MAX}(+\mathrm{J} 7 / 3,0.001))$ \\
\hline k8 & 0.001 & "=IF $($ ISERR $(J 8 / 3), 0.001, \operatorname{MAX}(+\mathrm{J} 8 / 3,0.001))$ \\
\hline $\mathrm{k9}$ & 0.2 & $"=\operatorname{IF}($ ISERR $(\mathrm{J} 9 / 3), 0.001, \operatorname{MAX}(+\mathrm{J} 9 / 3,0.001))$ \\
\hline k10 & 0.001 & $"=I F($ ISERR $(J 10 / 3), 0.001, \operatorname{MAX}(+J 10 / 3,0.001))$ \\
\hline k11 & 0.066666667 & $"=\operatorname{IF}($ ISERR $(\mathrm{J} 11 / 3), 0.001, \operatorname{MAX}(+\mathrm{J} 11 / 3,0.001))$ \\
\hline k12 & 0.033333333 & $"=\mid \mathrm{F}(\operatorname{ISERR}(\mathrm{J} 12 / 3), 0.001, \operatorname{MAX}(+\mathrm{J} 12 / 3,0.001))$ \\
\hline k13 & 0.1 & $=I F(\operatorname{ISERR}(\mathrm{J} 13 / 3), 0.001, \operatorname{MAX}(+\mathrm{J} 13 / 3,0.001))$ \\
\hline k14 & 0.023333333 & $"=I F($ ISERR $(J 14 / 3), 0.001, \operatorname{MAX}(+J 14 / 3,0.001))$ \\
\hline k15 & 0.2 & $"=I F($ ISERR $(J 15 / 3), 0.001, \operatorname{MAX}(+J 15 / 3,0.001))$ \\
\hline k16 & & \\
\hline
\end{tabular}


RPP-10006 REV 8

"rgs FinalSumTable Rev 1 Tab_6MC 030823 .xls",Tab “3-Revised comps"

\section{Cell Equations}

\begin{tabular}{|c|c|c|}
\hline Cell & Value & Formula \\
\hline 14 & 31.90562462 & $=+$ + D307 \\
\hline 15 & 55.12 & $"=+\mathrm{D} 308$ + D317 \\
\hline 16 & 7.5 & $"=+$ D309 \\
\hline 17 & 9.383333333 & $"=+\mathrm{D} 310+\mathrm{D} 314^{*} 5 / 3+\mathrm{D} 315^{*} 5 / 2+\mathrm{D} 316^{*} 4$ \\
\hline 18 & 0.8 & $"=+D 311$ \\
\hline \multicolumn{3}{|c|}{$x_{1}$} \\
\hline \multicolumn{3}{|l|}{110} \\
\hline \multicolumn{3}{|l|}{111} \\
\hline \multicolumn{3}{|l|}{112} \\
\hline \multicolumn{3}{|l|}{113} \\
\hline \multicolumn{3}{|l|}{114} \\
\hline \multicolumn{3}{|l|}{115} \\
\hline 116 & 104.708958 & "=SUM (L307:L318) \\
\hline $\mathrm{m} 4$ & 32.05737627 & $"=+\times 309$ \\
\hline m5 & 56.20912925 & $"=+Y 309$ \\
\hline $\mathrm{m} 6$ & 7.199081032 & $"=+Z 309$ \\
\hline $\mathrm{m} 7$ & 9.38931521 & $"=+$ AA309 \\
\hline $\mathrm{m} 8$ & 0.599613297 & "=AB309 \\
\hline \multicolumn{3}{|l|}{$\mathrm{m} 9$} \\
\hline \multicolumn{3}{|l|}{$\mathrm{m} 10$} \\
\hline \multicolumn{3}{|l|}{$\mathrm{m} 11$} \\
\hline \multicolumn{3}{|l|}{$\mathrm{m} 12$} \\
\hline \multicolumn{3}{|l|}{$\mathrm{m} 13$} \\
\hline \multicolumn{3}{|l|}{$\mathrm{m} 14$} \\
\hline \multicolumn{3}{|l|}{ m15 } \\
\hline $\mathrm{m} 16$ & 105.4545151 & "=SUM (M307:M318) \\
\hline $\mathrm{n} 4$ & 1.081848013 & $"=+X 312$ \\
\hline n5 & 2.08239897 & $"=+Y 312$ \\
\hline n6 & 0.278946023 & $"=+Z 312$ \\
\hline n7 & 0.431529823 & $"=+\mathrm{AA} 312$ \\
\hline n8 & 0.101245517 & $"=+A B 312$ \\
\hline \multicolumn{3}{|l|}{ n9 } \\
\hline \multicolumn{3}{|l|}{$\mathrm{n} 10$} \\
\hline $\mathrm{n} 11$ & & \\
\hline $\mathrm{n} 12$ & & \\
\hline $\mathrm{n} 13$ & & \\
\hline $\mathrm{n} 14$ & & \\
\hline n15 & & \\
\hline $\mathrm{n} 16$ & & \\
\hline 04 & 30.39924488 & $"=+M 307 / M 319^{*} 100$ \\
\hline 05 & 53.30177586 & $"=+M 308 / M 319 * 100$ \\
\hline 06 & 6.826716739 & $"=+M 309 / M 319^{*} 100$ \\
\hline 07 & 8.903663541 & $"=+M 310 / M 319^{*} 100$ \\
\hline 08 & 0.56859898 & $"=+M 311 / M 319 * 100$ \\
\hline 09 & & \\
\hline 010 & & \\
\hline 011 & & \\
\hline 012 & & \\
\hline 013 & & \\
\hline 014 & & \\
\hline 015 & & \\
\hline 016 & 100 & "=SUM (0307:0318) \\
\hline p4 & 1.081848013 & $"=+\mathrm{N} 307$ \\
\hline p5 & 2.08239897 & $"=+\mathrm{N} 308$ \\
\hline p6 & 0.278946023 & $"=+$ N309 \\
\hline$p 7$ & 0.431529823 & $"=+N 310$ \\
\hline $\mathrm{p8}$ & 0.101245517 & $"=+\mathrm{N} 311$ \\
\hline p9 & & \\
\hline p10 & & \\
\hline p11 & & \\
\hline p12 & & \\
\hline p13 & & \\
\hline p14 & & \\
\hline
\end{tabular}


"rgs FinalSumTable Rev 1 Tab_6MC 030823 .xls",Tab “3-Revised comps"

\section{Cell Equations}

\begin{tabular}{|c|c|c|}
\hline Cell & Value & Formula \\
\hline \multicolumn{3}{|l|}{ p15 } \\
\hline \multicolumn{3}{|l|}{ p16 } \\
\hline 94 & 33 & $"=+\mathrm{H} 307$ \\
\hline q5 & 57.12 & $"=+\mathrm{H} 308+\mathrm{H} 317$ \\
\hline 96 & 5 & $"=+\mathrm{H} 309$ \\
\hline 97 & 8.275 & $"=+\mathrm{H} 310+\mathrm{H} 314^{*} 5 / 3+\mathrm{H} 315^{*} 5 / 2+\mathrm{H} 316^{*} 4$ \\
\hline 98 & 07 & $"=+\mathrm{H} 311$ \\
\hline \multicolumn{3}{|l|}{ q9 } \\
\hline \multicolumn{3}{|l|}{$\mathrm{q} 10$} \\
\hline \multicolumn{3}{|l|}{$q 11$} \\
\hline \multicolumn{3}{|l|}{$q 12$} \\
\hline \multicolumn{3}{|l|}{$q 13$} \\
\hline \multicolumn{3}{|l|}{ q14 } \\
\hline \multicolumn{3}{|l|}{ q15 } \\
\hline$q 16$ & 103.395 & "=SUM (Q307:Q318) \\
\hline $\mathrm{r} 4$ & 32.95593137 & $"=+$ AC309 \\
\hline r5 & 58.23768653 & $"=+$ AD309 \\
\hline r6 & $4.40194146 \mid "$ & $"=+$ AE309 \\
\hline$r 7$ & 8.256572689 & $"=+$ AF309 \\
\hline r8 & 0 " & $"=A G 309$ \\
\hline \multicolumn{3}{|l|}{ r9 } \\
\hline \multicolumn{3}{|l|}{$\mathrm{r} 10$} \\
\hline \multicolumn{3}{|l|}{$\mathrm{r} 11$} \\
\hline \multicolumn{3}{|l|}{$\mathrm{r} 12$} \\
\hline \multicolumn{3}{|l|}{$\mathrm{r} 13$} \\
\hline \multicolumn{3}{|l|}{$\mathrm{r} 14$} \\
\hline $\mathrm{r} 15$ & 0 " & $"=\operatorname{IF}\left(\mathrm{OR}\left(\mathrm{R} 307^{\prime \prime}=0, \mathrm{R} 308^{n}=0, \mathrm{R} 309^{\prime}=0, \mathrm{R} 310^{\prime \prime}=0, \mathrm{R} 311 "=0\right), 0,1\right)$ \\
\hline $\mathrm{r} 16$ & 103.852132 & "=SUM (R307:R312) \\
\hline s4 & 1.065328453 & $"=+\mathrm{AC} 312$ \\
\hline s5 & 2.122268326 & $"=+$ AD312 \\
\hline s6 & 0.164811503 & $"=+\mathrm{AE} 312$ \\
\hline s7 & 0.442054928 & $"=+$ AF312 \\
\hline s8 & 00 & $"=+$ AG312 \\
\hline \multicolumn{3}{|r|}{ ( } \\
\hline s10 & & \\
\hline s11 & & \\
\hline s12 & & \\
\hline s13 & & \\
\hline s14 & & \\
\hline s15 & & \\
\hline s16 & & \\
\hline 14 & 32.95593137 & "=IF (R318"=0, + R307, + R307/R319*100) \\
\hline 15 & 58.23768653 & "=IF (R318"=0, +R308, + R308/R319*100) \\
\hline 16 & 4.40194146 & $"=I F(R 318 "=0,+R 309,+R 309 / R 319 * 100)$ \\
\hline t7 & 8.256572689 & $"=I F(R 318 "=0,+R 310,+R 310 / R 319 * 100)$ \\
\hline 18 & 0 & $"=\mid F(R 318 "=0,+R 311,+R 311 / R 319 * 100)$ \\
\hline t9 & & \\
\hline $\mathrm{t} 10$ & & \\
\hline $\mathrm{t} 11$ & & \\
\hline $\mathrm{t} 12$ & & \\
\hline$t 13$ & & \\
\hline $\mathrm{t} 14$ & & \\
\hline $\mathrm{t} 15$ & & \\
\hline $\mathrm{t} 16$ & 103.852132 & "=SUM (T307:T318) \\
\hline $\mathrm{u4}$ & 1.065328453 & $"=+S 307$ \\
\hline 45 & 2.122268326 & $"=+S 308$ \\
\hline 46 & 0.164811503 & $"=+S 309$ \\
\hline u7 & 0.442054928 & $"=+S 310$ \\
\hline 48 & $0=$ & $"=+S 311$ \\
\hline u9 & & \\
\hline u10 & & \\
\hline u11 & & \\
\hline $\mathrm{u12}$ & & \\
\hline
\end{tabular}




\section{RPP-10006 REV 8}

"rgs FinalSumTable Rev 1 Tab_6MC 030823 .xls",Tab “3-Revised comps" Cell Equations

\begin{tabular}{|c|l|l|}
\hline Cell & Value & Formula \\
\hline u13 & & \\
\hline u14 & & \\
\hline u15 & & \\
\hline u16 & & \\
\hline
\end{tabular}


3. Create forecasts in columns " $\mathrm{L}$ " and "Q" for the major components. Minor components are added to major components (NOx add to $\mathrm{N} 2$ and fuels are added to $\mathrm{CH} 4)$.

4. Run Crystal Ball for 1,000 trials.

5. Prepare Crystal Ball report.

6. Copy summary statistics to Columns "X" through "AG."

Combine Distributions for SY-101

7. Copy combined SY-101 values from range "C290 to C301" to "C210 to C221."

8. Repeat Step 2 for SY-101.

9. Repeat Step 3 for SY-101.

10. Repeat Step 4 for SY-101.

11. Repeat Step 5 for SY-101.

12. Repeat Step 6 for SY-101.

13. Clear all forecasts and assumptions from spreadsheet.

\section{G2.3 CREATE DISTRIBUTIONS FOR RGS TANKS}

Create the Four Distributions Required to Specify the Retained Gas Distributions for Each of the RGS Tanks

Tab "4-Gas comp by tanks"

1. Recalculate spreadsheet.

2. Set up "Step-wise Continuous" assumptions in cells in rows $8,20,32,45,58,71,84$, 97, 110, 123, 136, 149, 162, 175 and columns "O", "S", "W", "AA."

a. Clear any existing assumptions.

b. Select custom distribution.

c. Select data, then enter the range of cells listed below the cell where the assumption cells.

d. Rescale to 1.00 .

e. Save assumption.

f. If there are not four values to choose from use the original normal distribution. 
"rgs FinalSumTable Rev 1 Tab_6MC 030823 .xls",Tab "4-Gas comp by tanks"

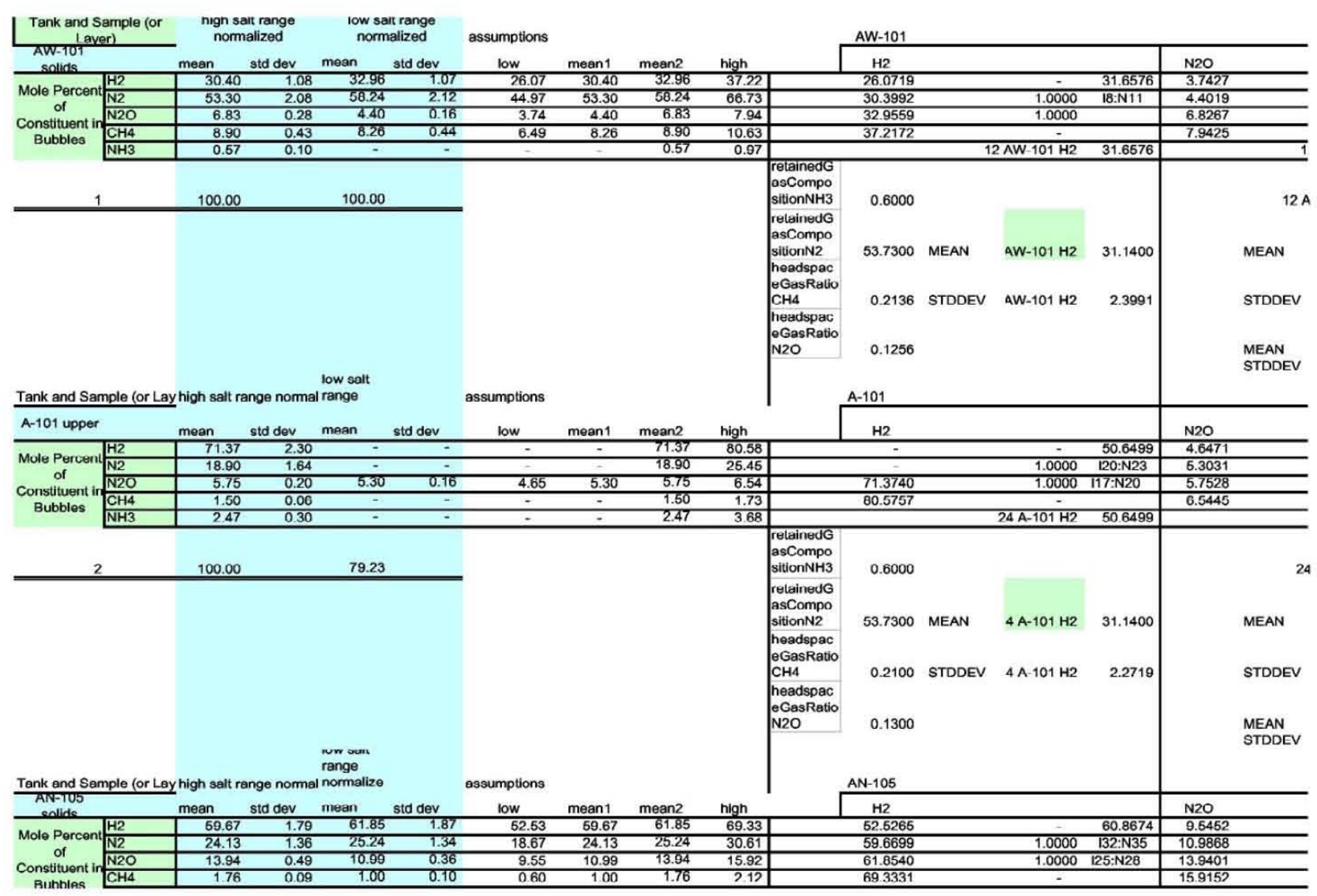


“rgs FinalSumTable Rev 1 Tab_6MC 030823 .xls",Tab “4-Gas comp by tanks"

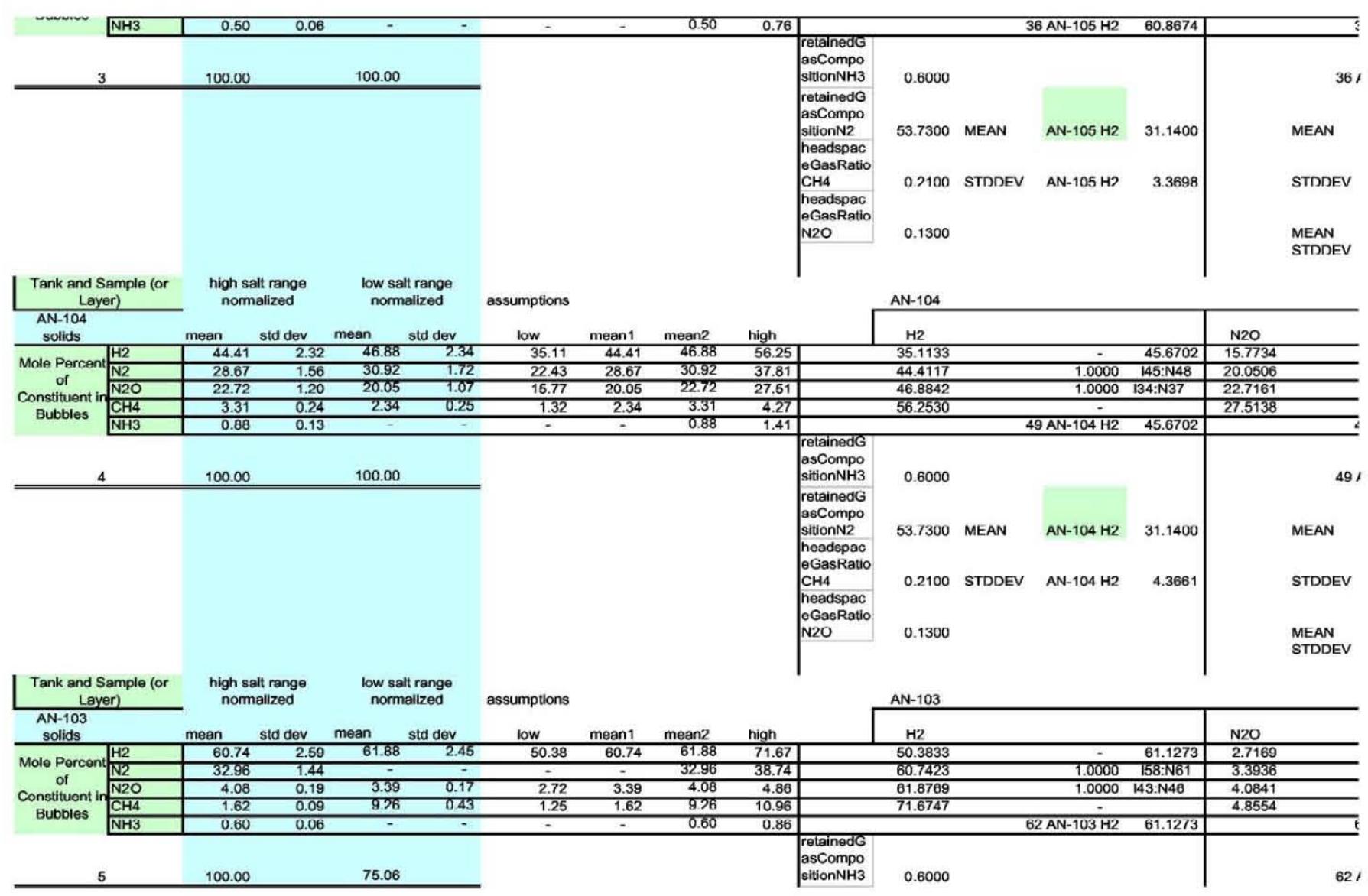


“rgs FinalSumTable Rev 1 Tab_6MC 030823 .xls",Tab “4-Gas comp by tanks"

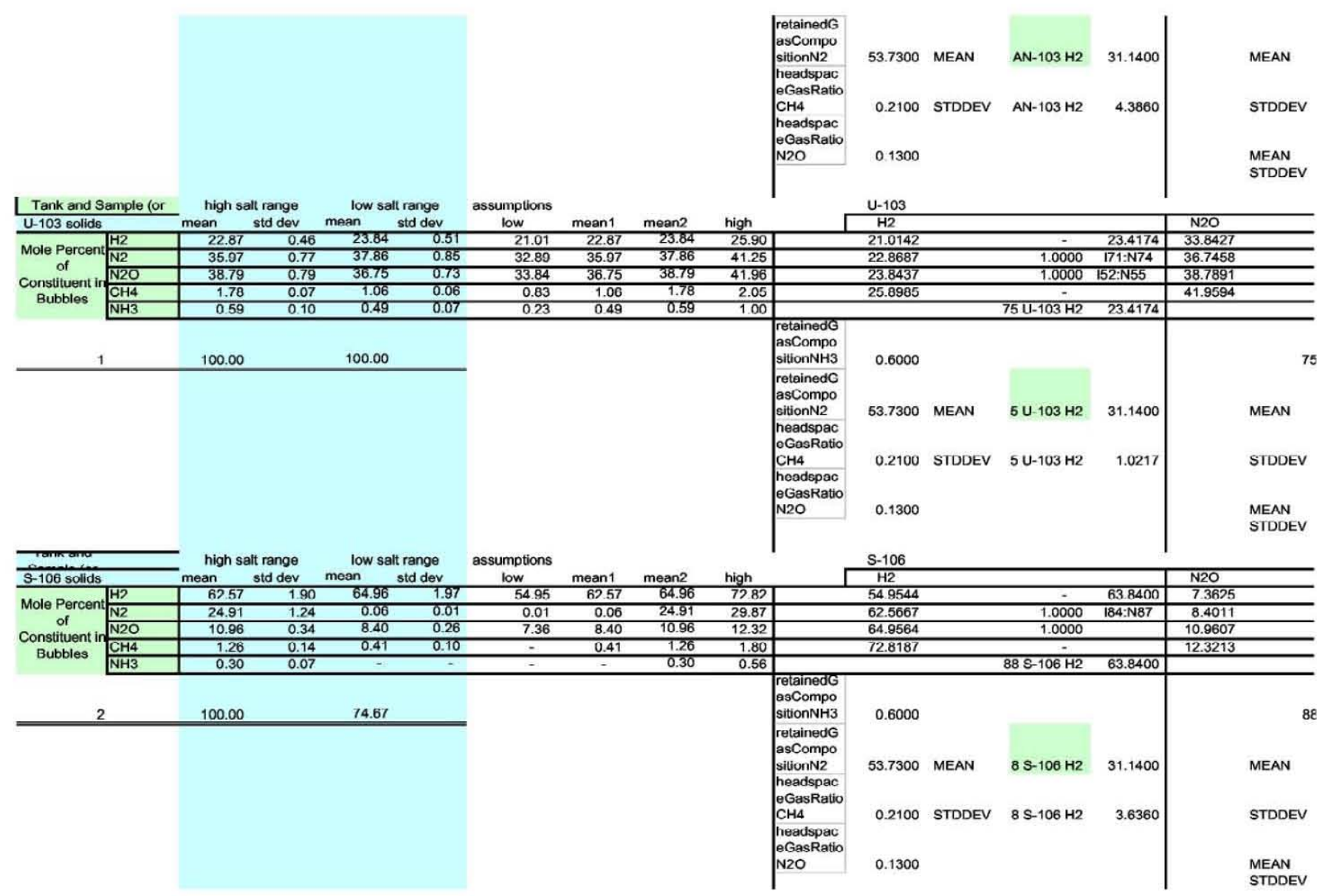


"rgs FinalSumTable Rev 1 Tab_6MC 030823 .xls",Tab “4-Gas comp by tanks"

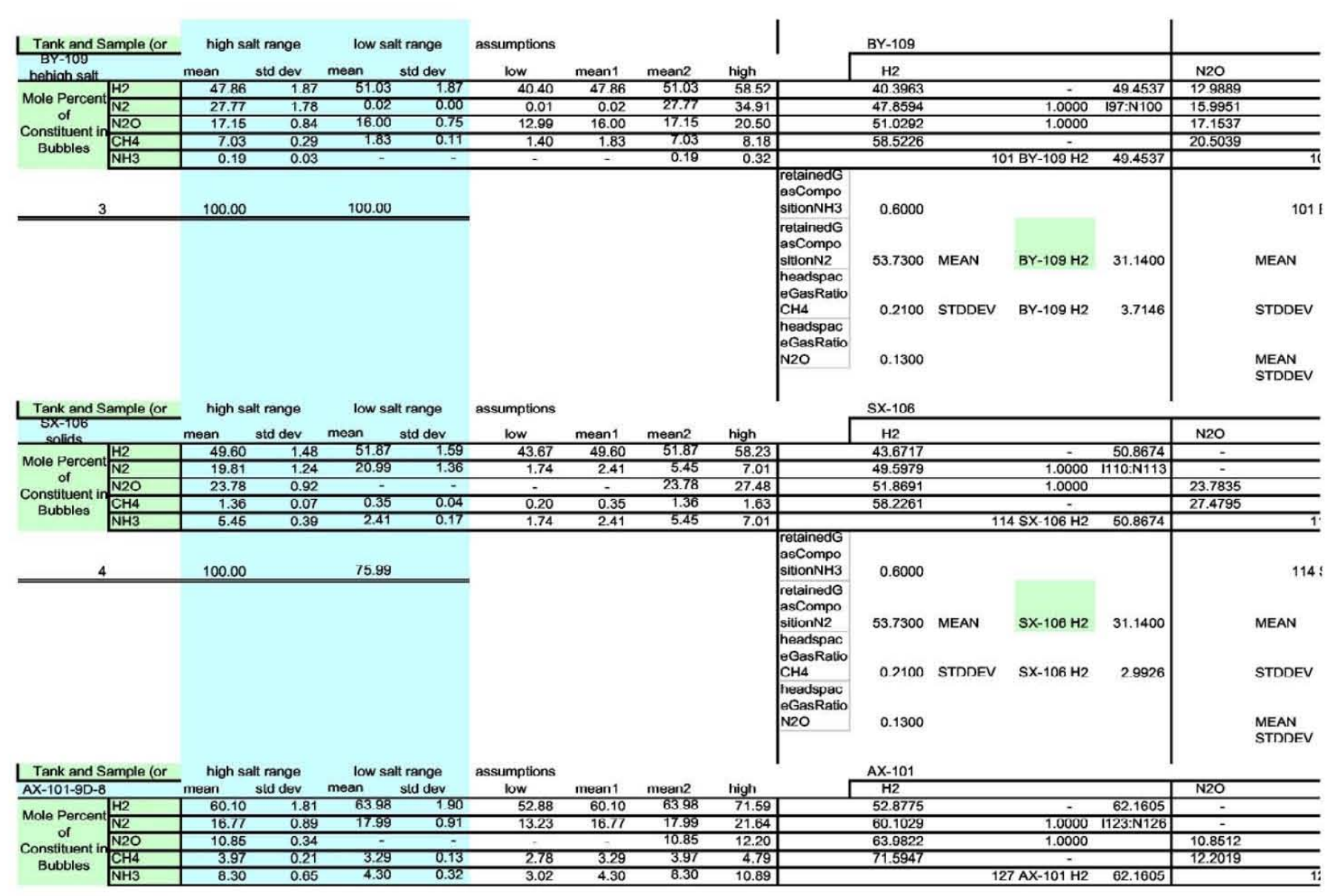


"rgs FinalSumTable Rev 1 Tab_6MC 030823 .xls",Tab “4-Gas comp by tanks"

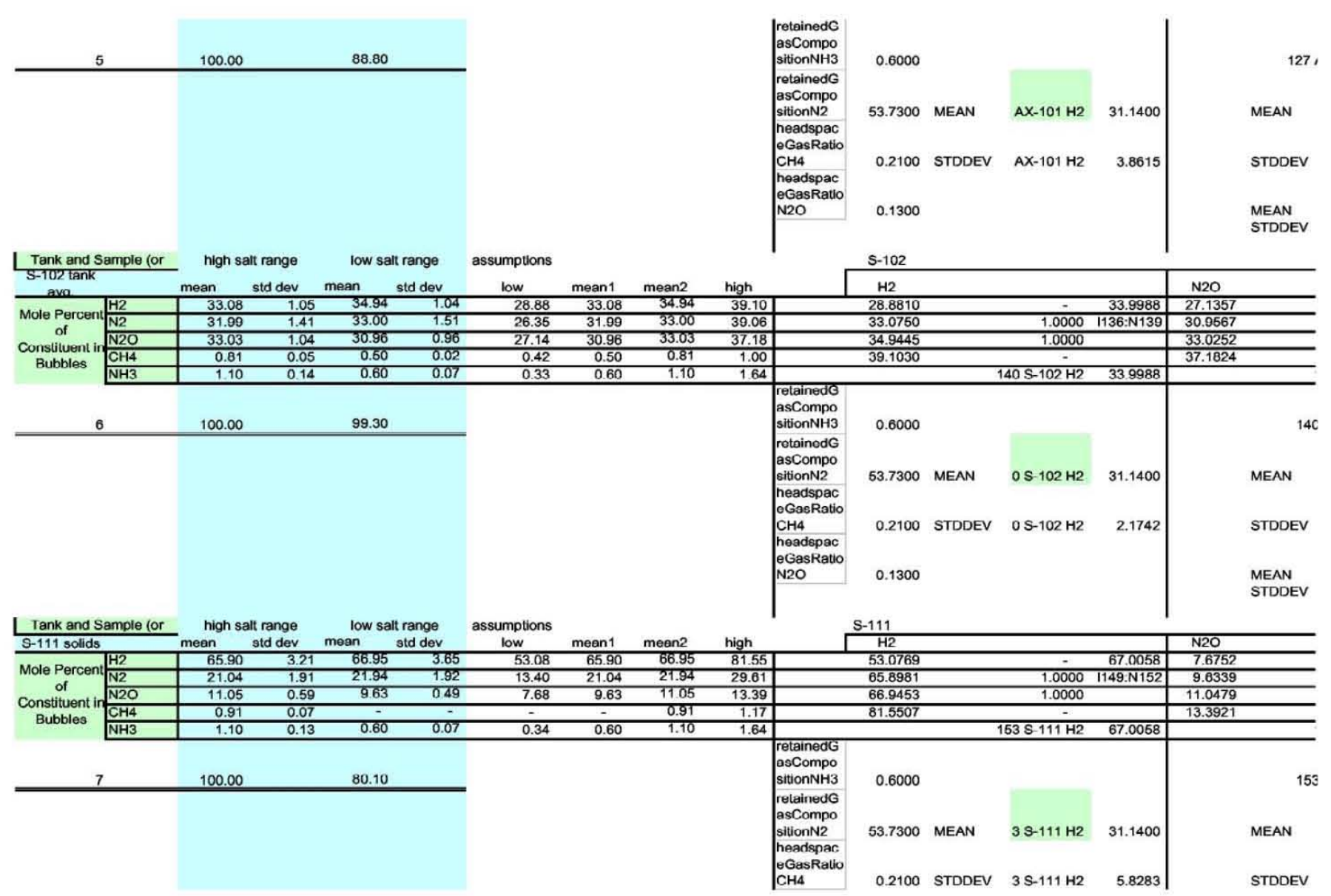


"rgs FinalSumTable Rev 1 Tab_6MC 030823 .xls",Tab “4-Gas comp by tanks"

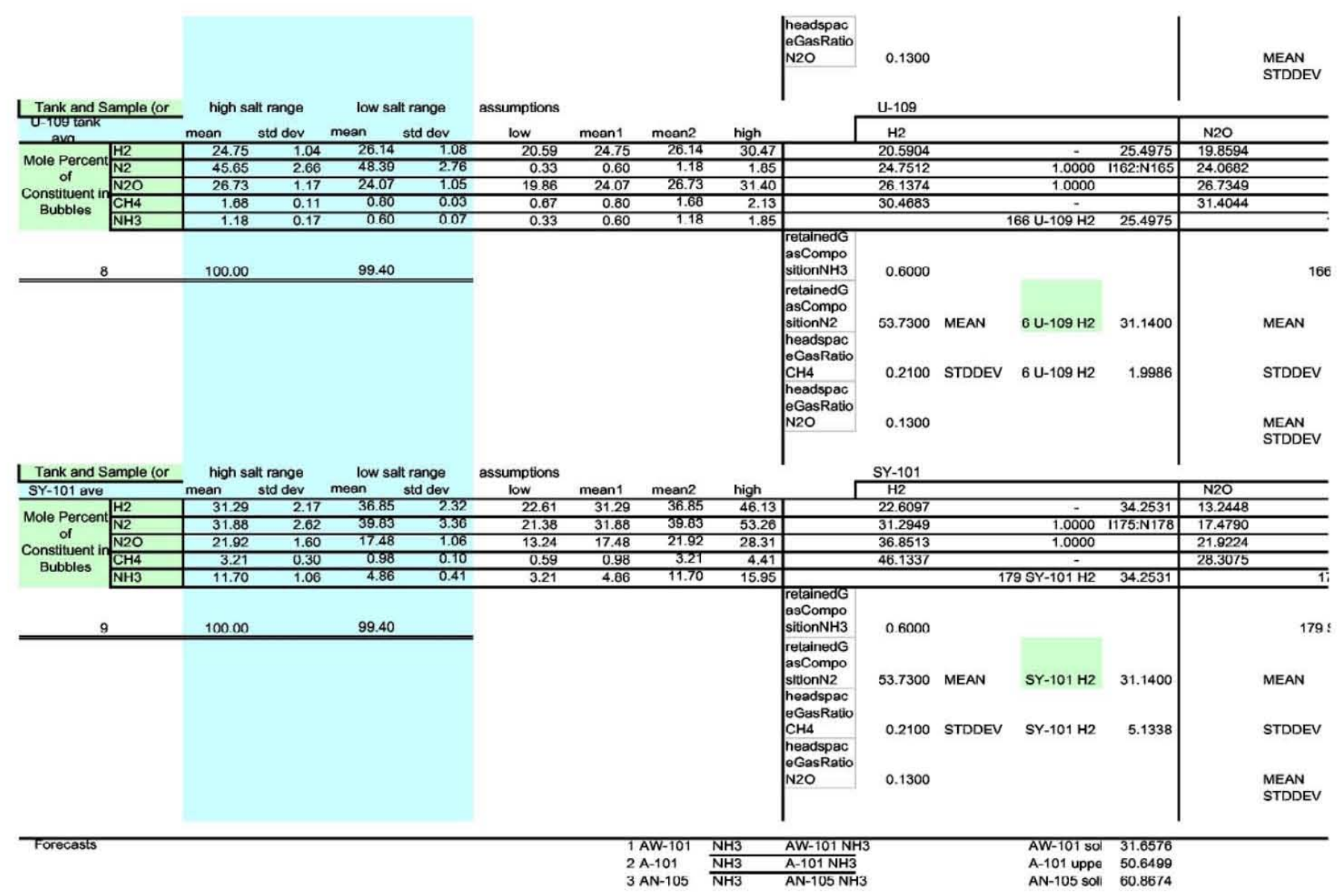


"rgs FinalSumTable Rev 1 Tab_6MC 030823 .xls",Tab “4-Gas comp by tanks"

Mole Percont of Constituent in Bubbles

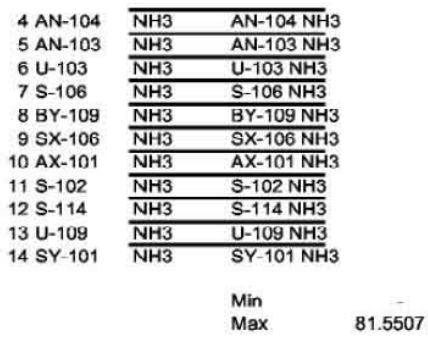

AN-104 soli 45.6702 AN-103 soli 61.1273

$\begin{array}{ll}U-103 \text { solld } & 23.4174 \\ \text { S-106 solid } & 63.8400\end{array}$

BY-109 bet 49.4537

SX-106 soli 50.8674
AX-101-9D

$\begin{array}{ll}\text { S-102 lank } & 33.9988 \\ \text { S-114 solid } & 67.0058\end{array}$

\begin{tabular}{ll} 
U-109 tank & 25.4975 \\
\hline
\end{tabular}

$\begin{array}{lll} & \operatorname{Min} & \\ & \operatorname{Max}_{\operatorname{Min}} & 41.9594 \\ \operatorname{Max} & 67.4174 & \\ & & \end{array}$ 
"rgs FinalSumTable Rev 1 Tab_6MC 030823 .xls",Tab “4-Gas comp by tanks"

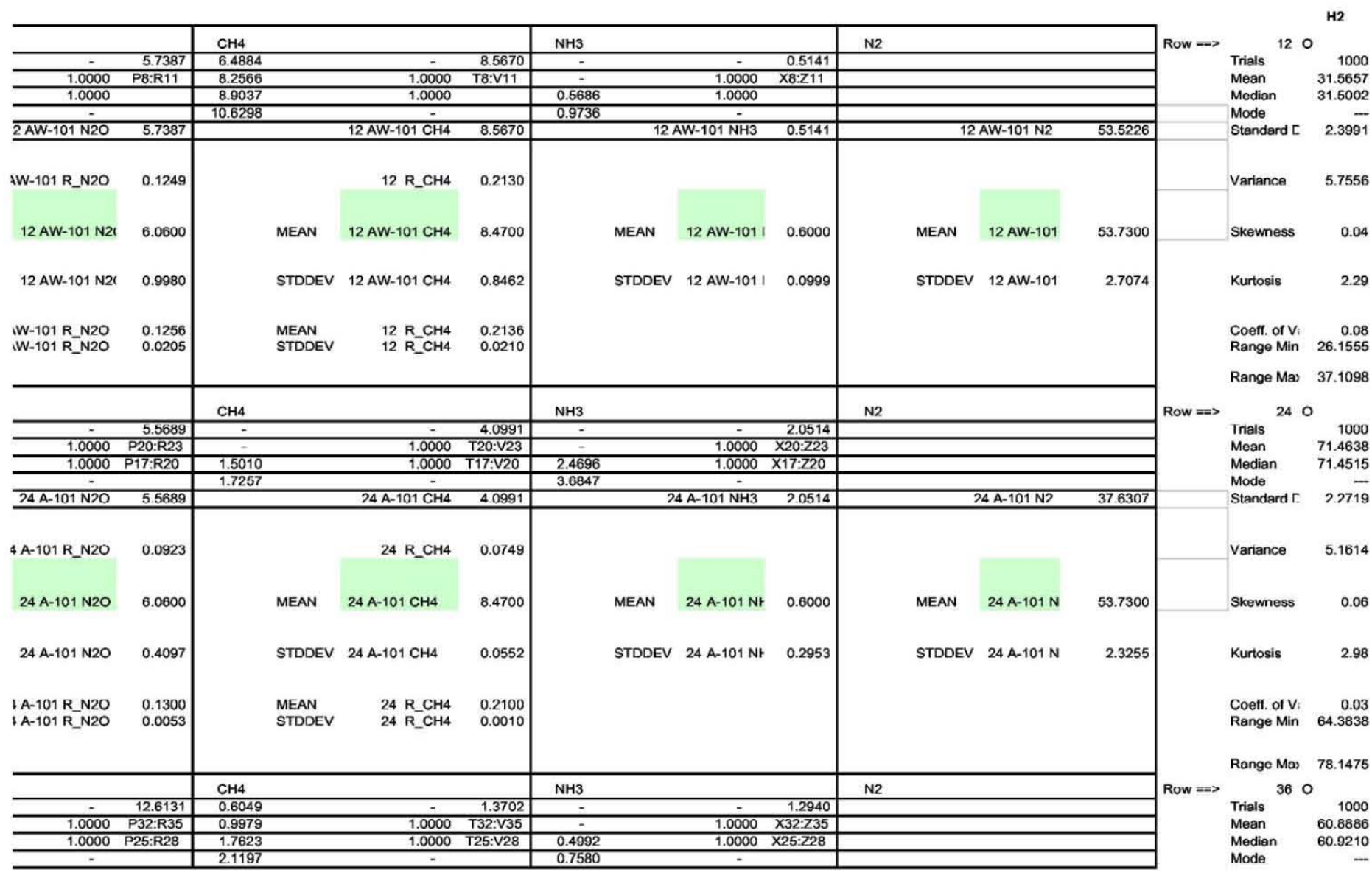


“rgs FinalSumTable Rev 1 Tab_6MC 030823 .xls",Tab “4-Gas comp by tanks"

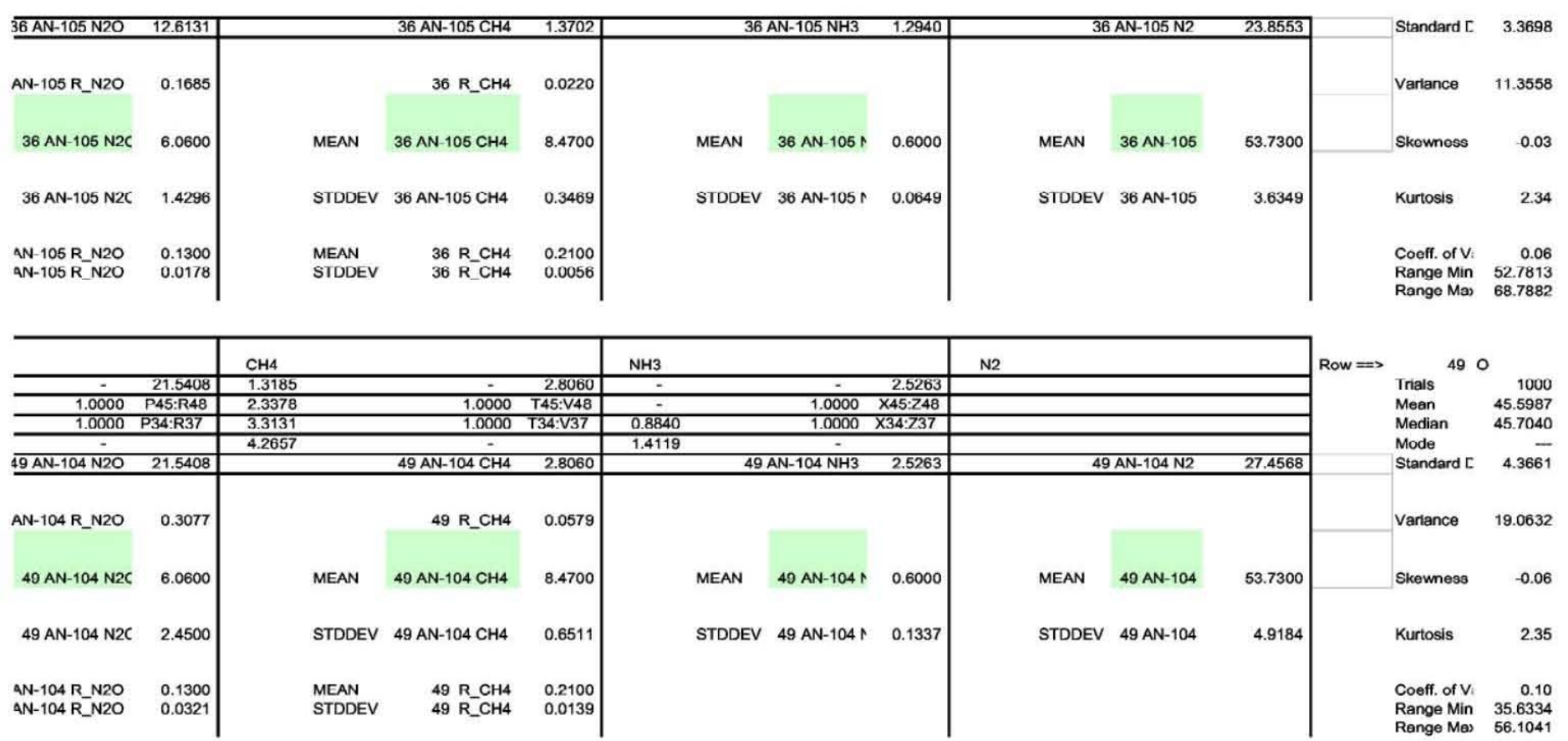

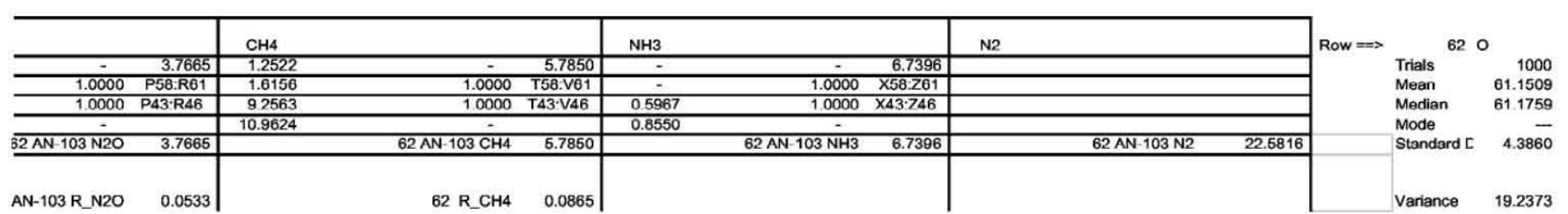


"rgs FinalSumTable Rev 1 Tab_6MC 030823 .xls",Tab “4-Gas comp by tanks"

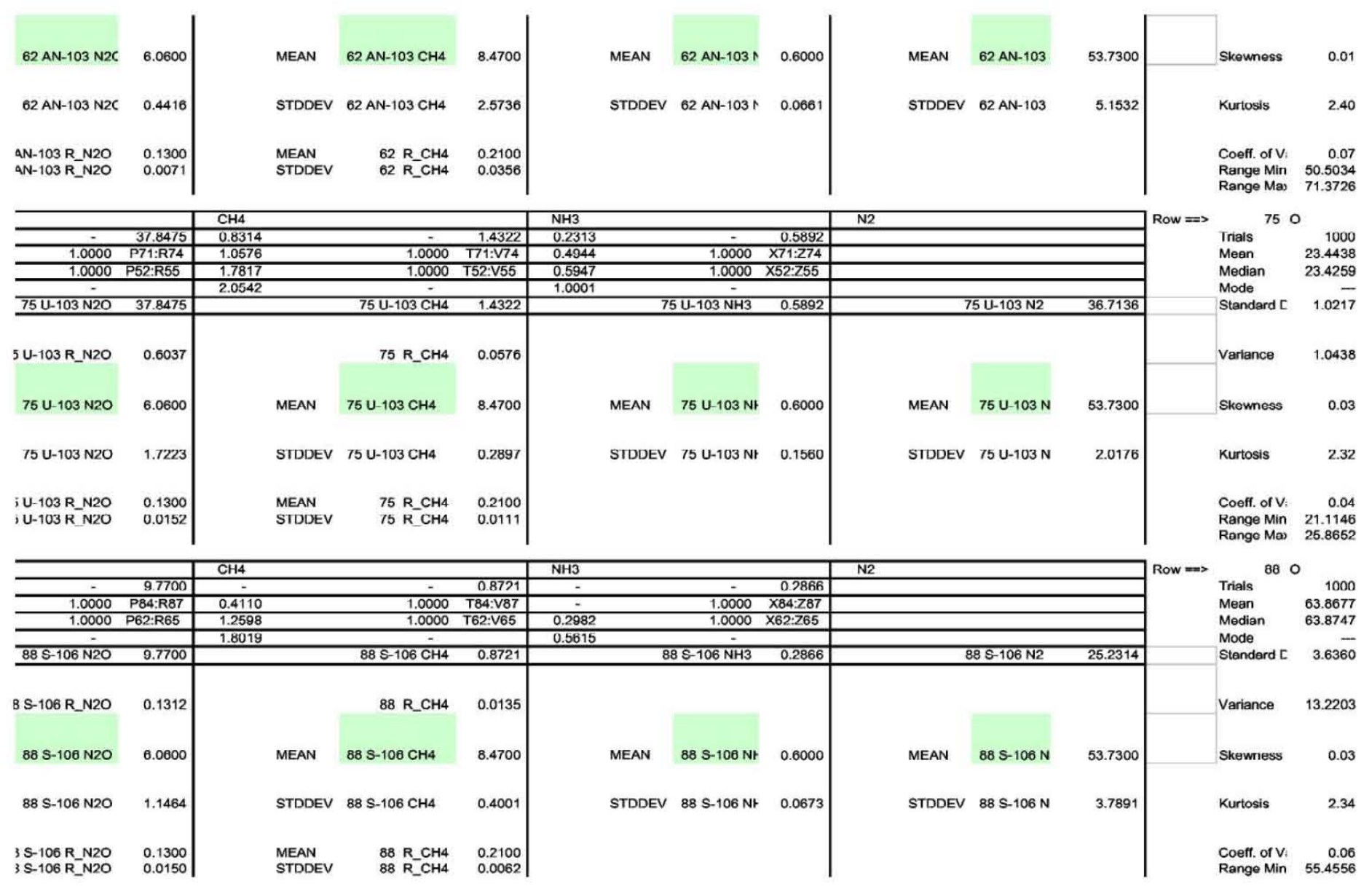


“rgs FinalSumTable Rev 1 Tab_6MC 030823 .xls",Tab “4-Gas comp by tanks"

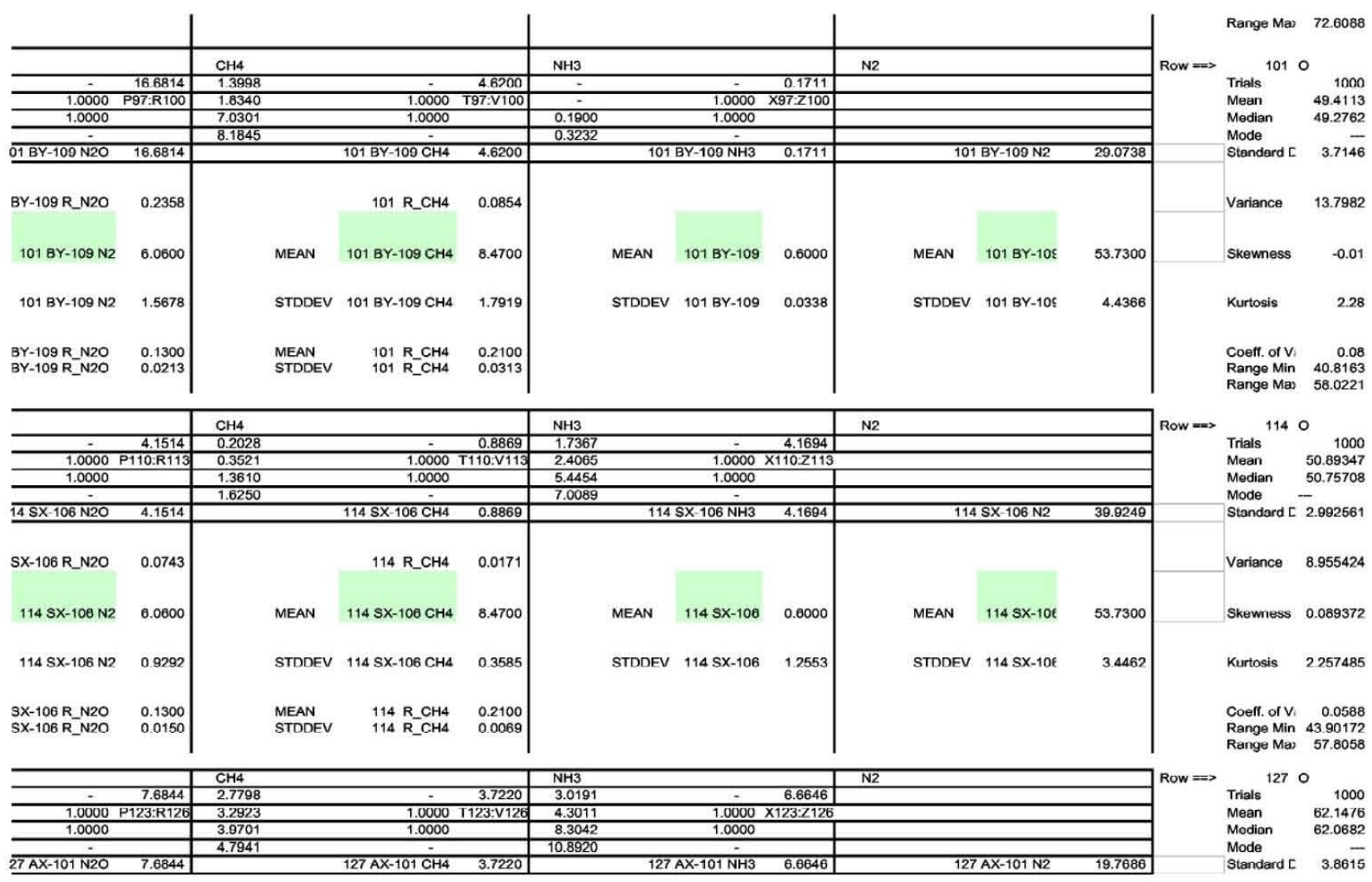


“rgs FinalSumTable Rev 1 Tab_6MC 030823 .xls",Tab “4-Gas comp by tanks"

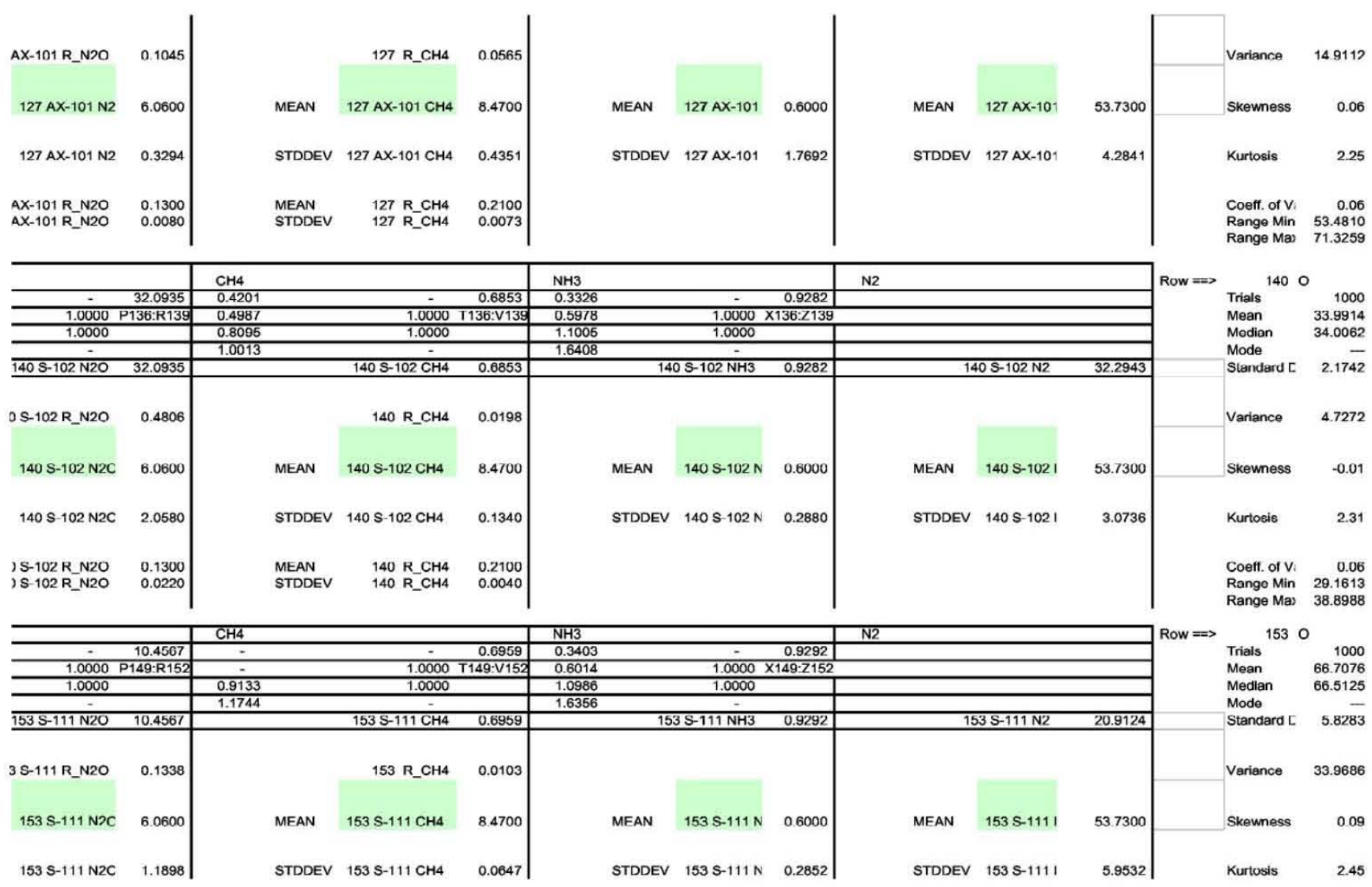


“rgs FinalSumTable Rev 1 Tab_6MC 030823 .xls",Tab “4-Gas comp by tanks"

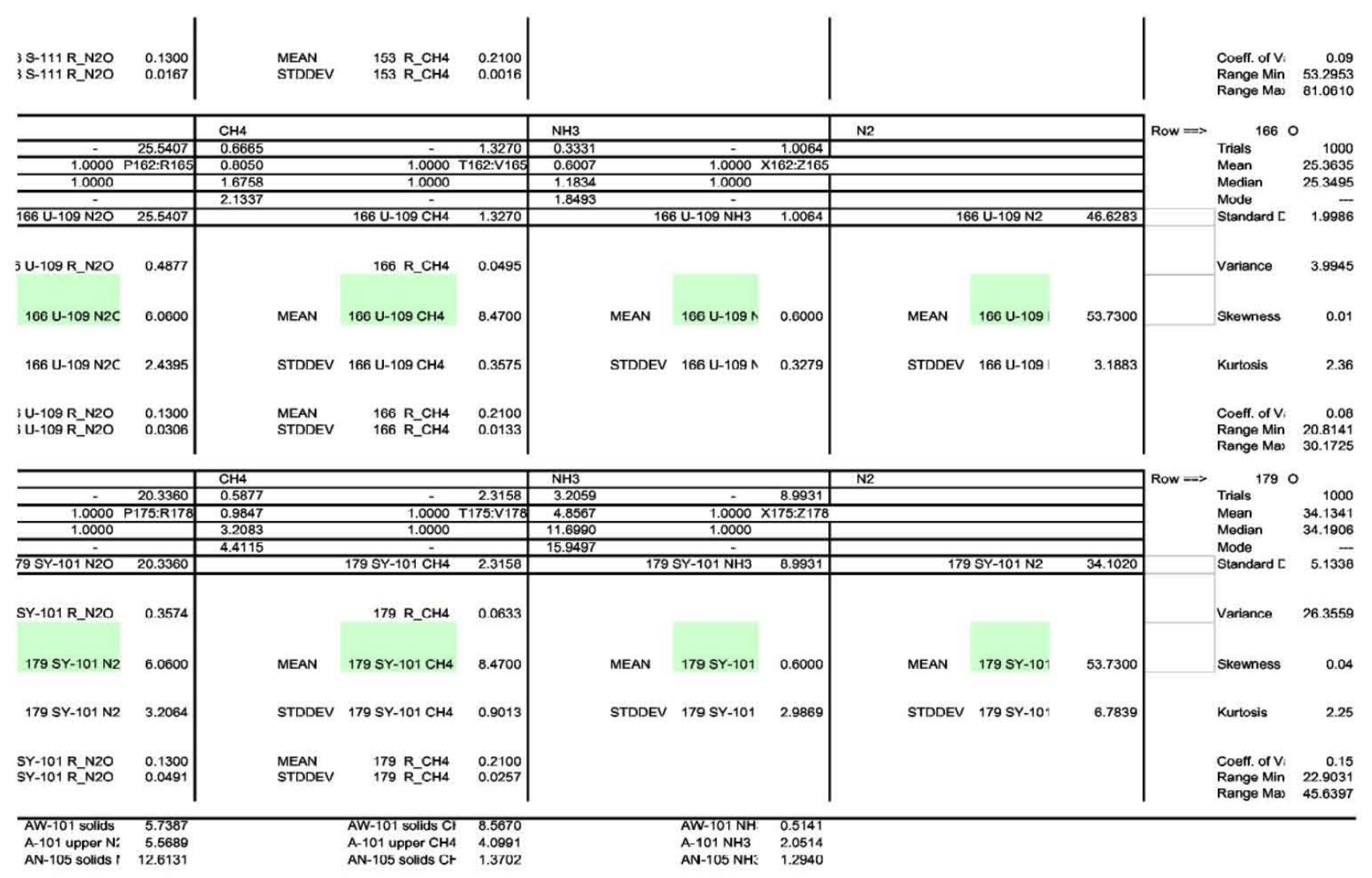


“rgs FinalSumTable Rev 1 Tab_6MC 030823 .xls”,Tab “4-Gas comp by tanks"

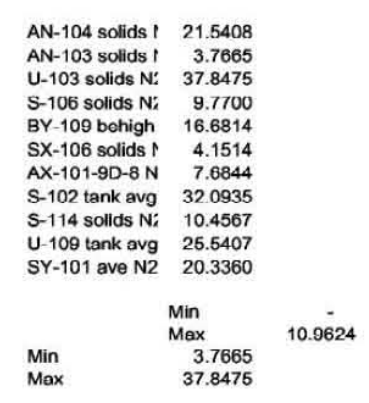

\begin{tabular}{|c|c|}
\hline AN-104 solids $\mathrm{Cr}$ & 2.8060 \\
\hline AN-103 solids $\mathrm{Cr}$ & 5.7850 \\
\hline $\begin{array}{l}U-103 \text { solids } \mathrm{CH}_{4} \\
\mathrm{~S}-106 \text { solids } \mathrm{CH}\end{array}$ & $\begin{array}{l}1.4322 \\
0.8721\end{array}$ \\
\hline BY-109 bohigh se & 4.6200 \\
\hline SX-106 solids Cr & 0.8869 \\
\hline AX-101-9D-8 CH. & 3.7220 \\
\hline S-102 tank avg $C$ & 0.6853 \\
\hline S-114 sollds $\mathrm{CH} 4$ & 0.6959 \\
\hline$U-100$ tank avg. C & 1.3270 \\
\hline \multirow[t]{2}{*}{ SY-101 ave CH4 } & 2.3158 \\
\hline & $\begin{array}{l}\text { Min } \\
\text { Max }\end{array}$ \\
\hline & 0.6853 \\
\hline Max & 8.5670 \\
\hline
\end{tabular}

AN-104 NH: 2.5263

$\begin{array}{lll}\mathrm{AN}-103 \mathrm{NH}: & 6.7396 \\ \mathrm{U}-103 \mathrm{NH3} & 0.5892\end{array}$

S-106 NH3 $\quad 0.2866$

$\begin{array}{ll}\text { BY-109 NHE } & 0.1711 \\ \text { SX-106 NHE } & 4.1694\end{array}$

AX-101 NHE $\quad 6.664$

S-102 NH3 0.928

$\mathrm{U}-109 \mathrm{NH3} \quad 1.0064$

SY-101 NHE 8.9931

Max

3.7665
37.8475

Min
Max

$\begin{array}{ll}\text { Min } & 0.1711 \\ \operatorname{Max} & 8.9931\end{array}$ 
“rgs FinalSumTable Rev 1 Tab_6MC 030823 .xls",Tab “4-Gas comp by tanks"

\begin{tabular}{|c|c|c|c|}
\hline N2) & $\mathrm{CH}_{4}$ & NH3 & N2 \\
\hline v & 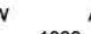 & A & IE \\
\hline 577006 & 8.5528 & 0.5706 & 53.5503 \\
\hline 5.8013 & 8.5615 & 0.5753 & 53.6713 \\
\hline 0.9980 & 0.8462 & 0.0999 & 2.7074 \\
\hline 0.9960 & 0.7160 & 0.0100 & 7.3298 \\
\hline-0.01 & -0.01 & 0.01 & 0.00 \\
\hline 1.90 & 2.37 & 3.07 & 2.59 \\
\hline & 0.10 & 0.18 & 0.05 \\
\hline 7.9000 & 10.5557 & 0.9587 & 62.0123 \\
\hline s & 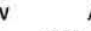 & A & E \\
\hline 1000 & 1000 & 1000 & 1000 \\
\hline 5.5857 & 1.5047 & 2.4429 & 19.0320 \\
\hline 04097 & 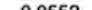 & ๑ & \\
\hline 0.1678 & 0.0030 & 0.0872 & 5.4081 \\
\hline-0.02 & -0.08 & 0.03 & -0.05 \\
\hline 2.27 & 2.84 & 3.28 & 3.06 \\
\hline .07 & 0.04 & & \\
\hline 4.6557 & 1.3021 & 1.2415 & 11.3516 \\
\hline 6.5122 & 1.6906 & 3.3466 & 26.5940 \\
\hline$s \quad v$ & 100 & & 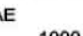 \\
\hline 126560 & 1000 & 1000 & 1000 \\
\hline 12.6099 & 1.4046 & 0.5001 & $\begin{array}{l}24.5713 \\
24715\end{array}$ \\
\hline 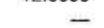 & 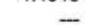 & 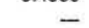 & \\
\hline
\end{tabular}

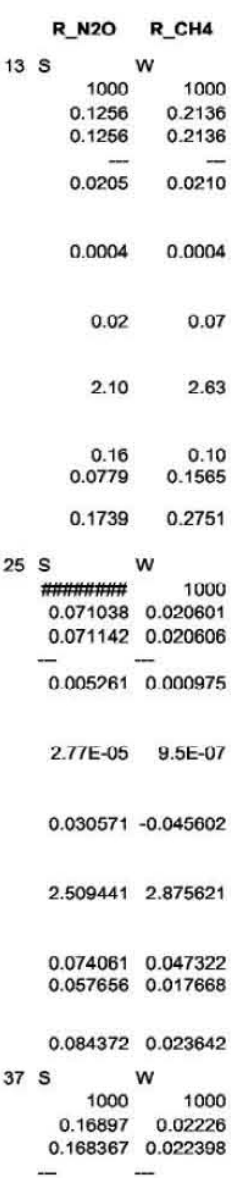

$\begin{array}{lllllll}\text { Tank } & \text { Gas } & \text { Mean } & \text { Sld Dev } & \text { Min } & \text { Max } & \text { Type } \\ \text { AW-101 } & \text { N2 } & 53.5503 & 27074 & 45.4532 & 62.0123 & \text { Nomal }\end{array}$ $\begin{array}{llllrrr}\text { AW-101 } & \text { NH3 } & 0.5706 & 0.0999 & 0.2715 & 0.9587 & \text { Nomal } \\ \text { AW-101 } & \text { N20 Ratio } & 0.1256 & 0.0205 & 0.0779 & 0.1739 & \text { Nomal }\end{array}$ $\begin{array}{lllllll}\text { AW-101 } & \text { N2O Ratio } & 0.1256 & 0.0205 & 0.0779 & 0.1739 & \text { Nomal } \\ \text { AW-101 } & \text { CH4 Ratio } & 0.2136 & 0.0210 & 0.1565 & 0.2751 & \text { Normal }\end{array}$

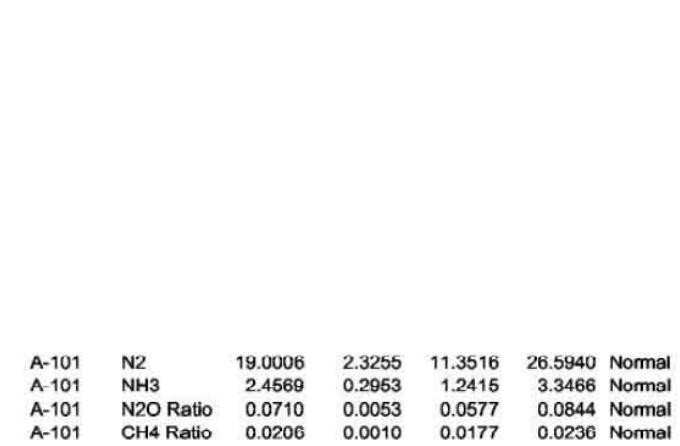

$\begin{array}{lllllll}A N-105 & N 2 & 24.5713 & 3.6349 & 14.1664 & 34.3390 & \text { Nomal }\end{array}$ $\begin{array}{lllllll}\text { AN-105 } & \text { NH3 } & 0.5001 & 0.0649 & 0.3029 & 0.7618 & \text { Nomal } \\ \text { AN-105 } & \text { N2O Ratio } & 0.1690 & 0.0178 & 0.1246 & 0.2198 & \text { Nomal }\end{array}$ $\begin{array}{lllllll}\text { AN-105 } & \text { N2O Ratio } & 0.1690 & 0.0178 & 0.1246 & 0.2198 & \text { Normal } \\ \text { AN-105 } & \text { CH4 Ratio } & 0.0223 & 0.0056 & 0.0108 & 0.0359 & \text { Nomal }\end{array}$ 
“rgs FinalSumTable Rev 1 Tab_6MC 030823 .xls",Tab “4-Gas comp by tanks"

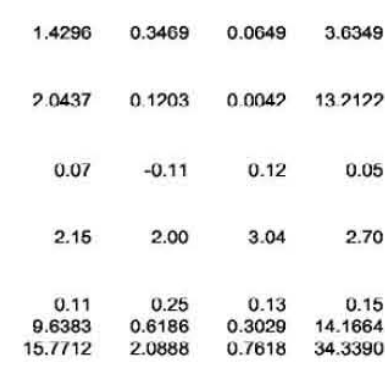

0.0178010 .005617

$0.000317 \quad 3.16 \mathrm{E}-05$

$0.062049-0.052725$

2.4259532 .070183

$\begin{array}{ll}0.105352 & 0.252341 \\ 0.124604 & 0.010841\end{array}$

$\begin{array}{ll}0.124604 & 0.010841 \\ 0.219849 & 0.035899\end{array}$

$50 \mathrm{~s} \quad \mathrm{w}$ $\begin{array}{rr}1000 & 1000 \\ 0.308064 & 0.058752\end{array}$ $\begin{array}{ll}0.308064 & 0.058752 \\ 0.307330 & 0.059095\end{array}$

$\overline{0.032057}^{-}-.013932$

0.0010280 .000194

0.1307190 .017435

$2.709504 \quad 2.34522$

$0.10406 \quad 0.237128$

0.2231490 .026568

$63 \mathrm{~S} \quad \mathrm{w}$ $\begin{array}{rr} & \text { W } \\ 1000 & 1000 \\ 0.053411 & 0.086029 \\ 0.053069 & 0.087424\end{array}$ $\overline{0.007096} \overline{0}_{0.035624}$

5.04E-05 0.001269 $\begin{array}{lllllll}\text { AN-104 } & \text { N2 } & 29.1727 & 4.9184 & 14.3337 & 41.4358 & \text { Normal }\end{array}$

$\begin{array}{lllllll}\text { AN-104 } & \mathrm{NH} 3 & 0.8820 & 0.1337 & 0.3767 & 1.2932 & \text { Nomal }\end{array}$

$\begin{array}{lllllll}\text { AN-104 } & \text { N2O Ratio } & 0.3081 & 0.0321 & 0.2231 & 0.4011 & \text { Nomal } \\ \text { AN-104 } & \text { CH4 Ratio } & 0.0588 & 0.0139 & 0.0266 & 0.0987 & \text { Nomal }\end{array}$

$\begin{array}{lllllll}\text { AN-103 } & \text { N2 } & 28.6602 & 5.1532 & 14.9119 & 42.8042 & \text { Normal } \\ \text { AN-103 } & \text { NH3 } & 05966 & 0.061 & 04003 & 07819 & \text { Nomal }\end{array}$

$\begin{array}{llllllll}\text { AN-103 N2O Ratio } & 0.0534 & 0.0071 & 0.0374 & 0.0768 & \text { Normal }\end{array}$

$\begin{array}{lllllll}\text { AN-103 } & \text { N2O Rato } & 0.0534 & 0.0071 & 0.0374 & 0.0768 & \text { Normal } \\ \text { AN-103 } & \text { CH4 Ratio } & 0.0860 & 0.0356 & 0.0215 & 0.1639 & \text { Nomal }\end{array}$ 
"rgs FinalSumTable Rev 1 Tab_6MC 030823 .xls",Tab “4-Gas comp by tanks"

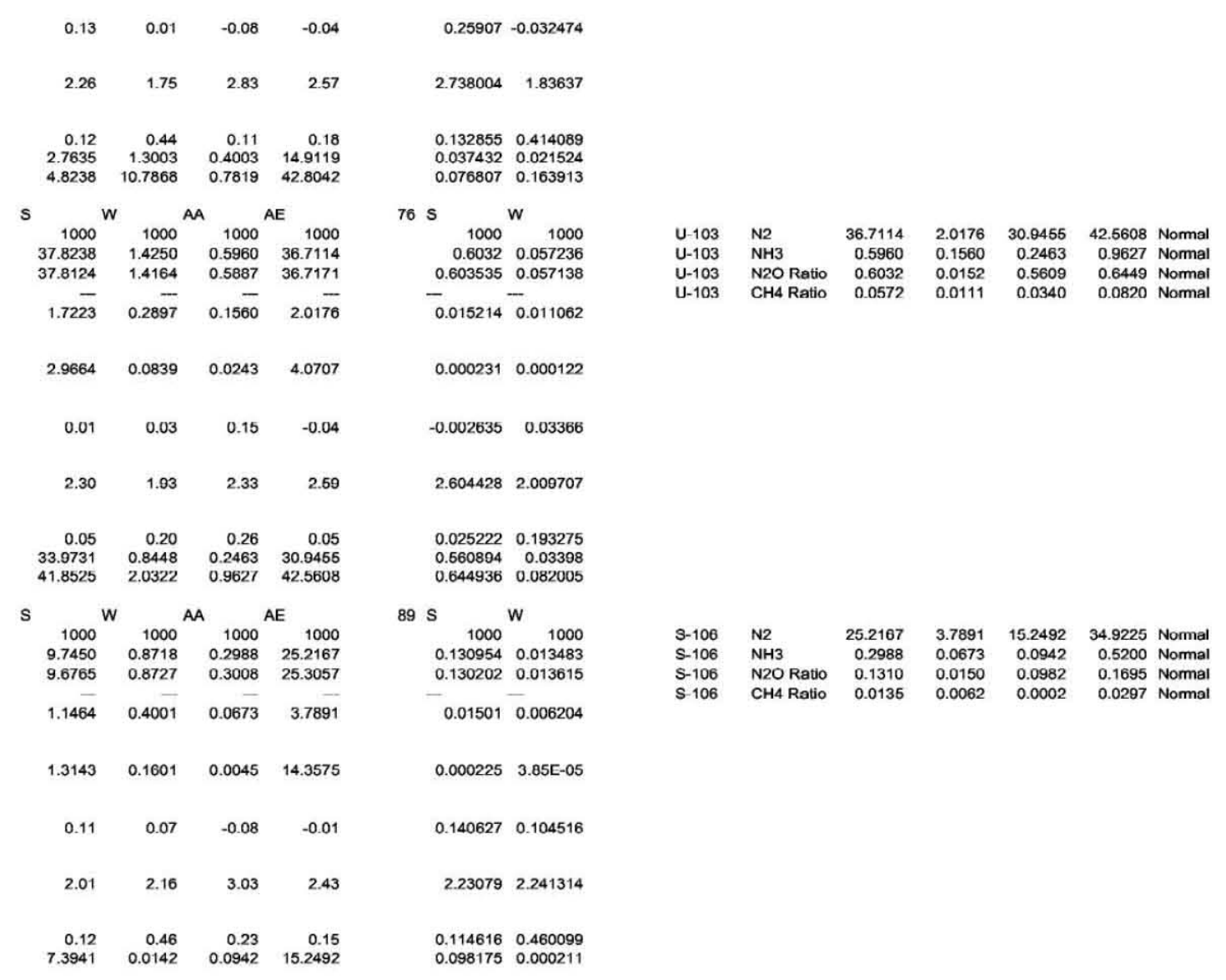


“rgs FinalSumTable Rev 1 Tab_6MC 030823.xls”,Tab “4-Gas comp by tanks"

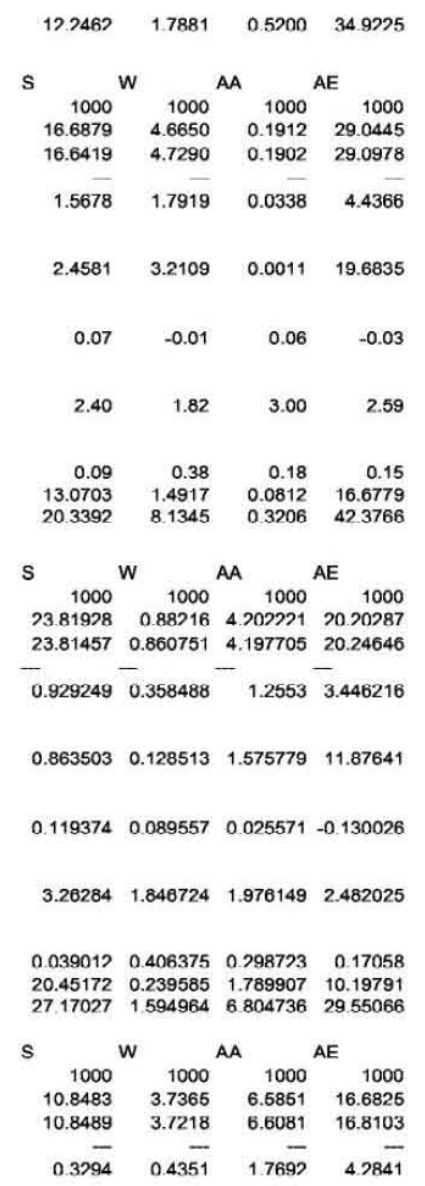

0.1694990 .029665 102 S 1000 W 1000 $0.236007 \quad 0.08591$ $0.021337 \overline{0} 0.031271$

$0.000455 \quad 0.000978$

$0.047369-0.00373$

$2.740707 \quad 1.925684$

0.0903310 .364864 $\begin{array}{rr}0.178078 & 0.027751 \\ 0.30508 & 0.160899\end{array}$

$115 \mathrm{~S}$ \begin{tabular}{rrr}
1000 & \multicolumn{1}{c}{1000} \\
0.31589 & 0.017059 \\
0.315041 & 0.016474
\end{tabular}

$0.015031-0.00695$

$0.000226 \quad 4.83 E-05$

$0.1494 \quad 0.140778$

$2.607714 \quad 1.939413$

$0.047643 \quad 0.407385$ $\begin{array}{ll}0.275284 & 0.004601 \\ 0.360009 & 0.033974\end{array}$

$128 \mathrm{~S}$

\begin{tabular}{rr} 
& W \\
1000 & 1000 \\
0.14172 & 0.056888 \\
0.141378 & 0.056377 \\
- & \multicolumn{2}{c}{-}
\end{tabular} $\begin{array}{llrrrrl}\text { BY-109 } & \text { N2 } & 29.0445 & 4.4366 & 16.6779 & 42.3766 & \text { Nomal } \\ \text { BY-109 } & \text { NH3 } & 0.1912 & 0.0338 & 0.0812 & 0.3206 & \text { Nomal }\end{array}$

$\begin{array}{lllllll}\text { BY-109 } & \text { N2O Ratio } & 0.2362 & 0.0213 & 0.1781 & 0.3051 & \text { Nomal } \\ \text { BY-109 } & \text { CH4 Ratio } & 0.0857 & 0.0313 & 0.0278 & 0.1609 & \text { Normal }\end{array}$

$\begin{array}{lllllll} & & & & & & \\ S X-106 & N 2 & 20.2029 & 3.4462 & 10.1979 & 29.5507 & \text { Normal }\end{array}$

$\begin{array}{lllllll}\text { SX-106 } & \text { NH3 } & 4.132 & 1.535 & 1.7899 & 6.8047 & \text { Nomal } \\ \text { SX-106 } & \text { N2O Ratlo } & 0.3155 & 0.0150 & 0.2753 & 0.3600 & \text { Nomal } \\ \text { SX-106 } & \text { CH4 Ratio } & 0.0171 & 0.0069 & 0.0046 & 0.0340 & \text { Nomal }\end{array}$

$\begin{array}{llrllll}\text { AX-101 } & \text { N2 } & 16.6825 & 4.2841 & 4.6480 & 27.3917 & \text { Nomal } \\ \text { NX-101 } & \text { NH3 } & 6.6851 & 1.7692 & 3.0943 & 10.7840 & \text { Nomal }\end{array}$

$\begin{array}{llllll}\text { AX-101 } & \text { NH3 } & 6.5851 & 1.7692 & 3.0943 & 10.7840 \\ \text { AX-101 } & \text { N2O Ratio } & 0.1417 & 0.0080 & 0.1219 & 0.1633 \\ \text { AX-101 } & \text { CH4 Ral }\end{array}$ 
"rgs FinalSumTable Rev 1 Tab_6MC 030823 .xls",Tab “4-Gas comp by tanks"

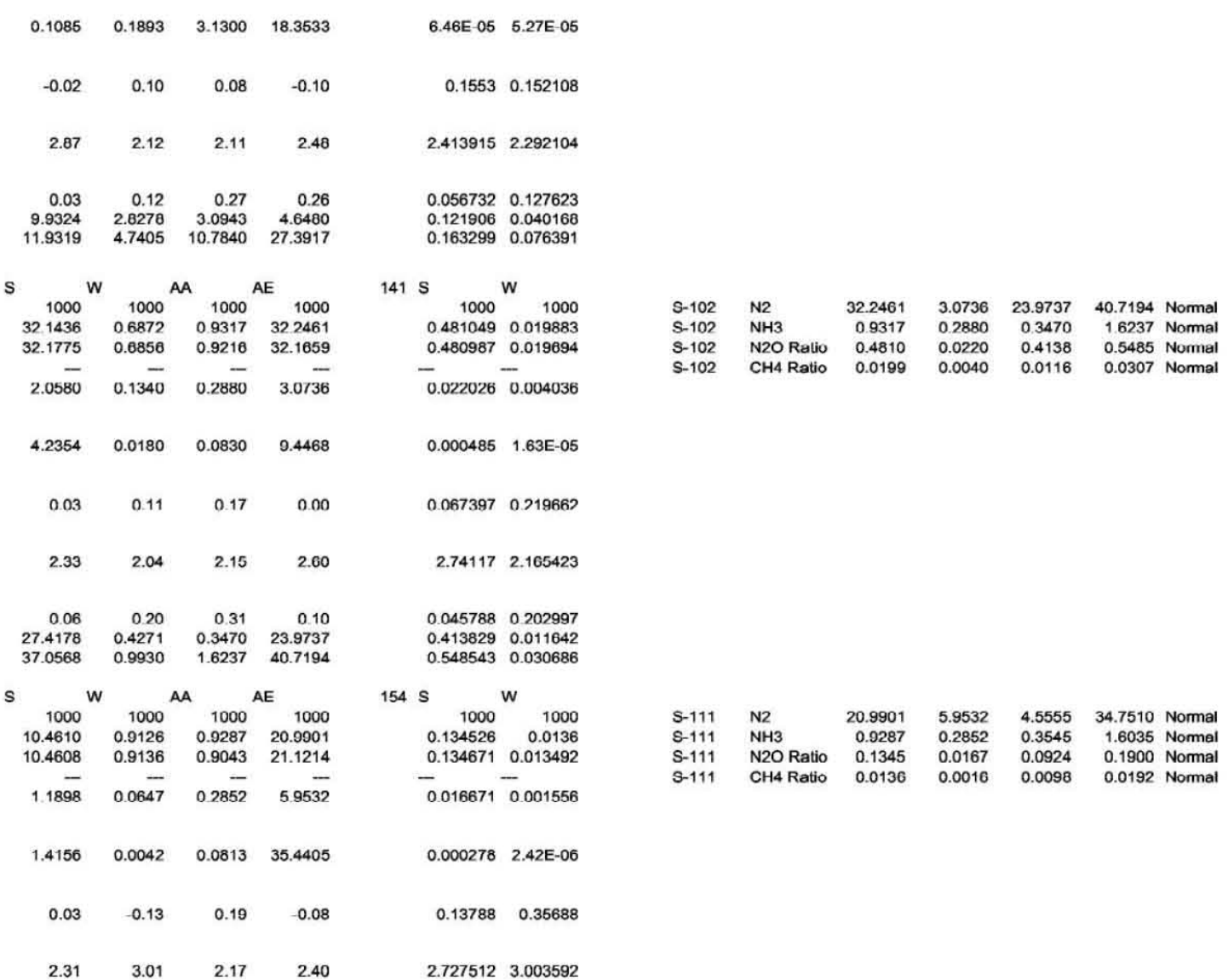


“rgs FinalSumTable Rev 1 Tab_6MC 030823 .xls",Tab “4-Gas comp by tanks"

\begin{tabular}{|c|c|c|c|c|c|c|c|c|c|c|c|}
\hline $\begin{array}{r}0.11 \\
7.1737 \\
13.1623\end{array}$ & $\begin{array}{r}0.07 \\
0.7009 \\
1.1045\end{array}$ & $\begin{array}{r}0.31 \\
0.3545 \\
1.6035\end{array}$ & $\begin{array}{r}0.28 \\
4.4555 \\
34.7510\end{array}$ & $\begin{array}{l}0.123923 \\
0.092432 \\
0.190021\end{array}$ & $\begin{array}{l}0.1114375 \\
0.009973 \\
0.019236\end{array}$ & & & & & & \\
\hline S $\quad{ }_{1000}$ & ${ }^{A}$ & & & $167 \mathrm{~S}$ & & \multirow{4}{*}{ 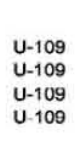 } & \multirow{4}{*}{$\begin{array}{l}\text { N2 } \\
\text { NH3 } \\
\text { N2O Ratio } \\
\text { CH4 Ratio }\end{array}$} & \multirow{4}{*}{$\begin{array}{r}46.7771 \\
1.0071 \\
0.4889 \\
0.0489\end{array}$} & \multirow{4}{*}{$\begin{array}{l}3.1883 \\
0.3279 \\
0.0306 \\
0.0133\end{array}$} & \multirow{4}{*}{$\begin{array}{r}36.8539 \\
0.3542 \\
0.4021 \\
0.0239\end{array}$} & \multirow{4}{*}{$\begin{array}{r}56.6181 \\
1.8118 \text { Nomal } \\
0.5769 \text { Nomal } \\
0.0874 \text { Normal } \\
\end{array}$} \\
\hline $\begin{array}{r}1000 \\
25.5498 \\
25.52228\end{array}$ & $\begin{array}{r}1.000 \\
1.3026\end{array}$ & $\begin{array}{r}1.000 \\
1.0071\end{array}$ & $\begin{array}{l}10000 \\
46.7771\end{array}$ & $\begin{array}{l}0.488936 \\
0.48036\end{array}$ & $\begin{array}{l}0.0489047 \\
0.0490\end{array}$ & & & & & & \\
\hline & 1.2787 & 0.9995 & 46.8855 & 0.489142 & 0.048328 & & & & & & \\
\hline 2.4395 & 0.3575 & 0.3279 & 3.1883 & 0.03062 & 0.013326 & & & & & & \\
\hline 5.9511 & 0.1278 & 0.1075 & 10.1655 & 0.000938 & 0.000178 & & & & & & \\
\hline 0.04 & 0.18 & 0.15 & -0.09 & -0.014956 & 0.251231 & & & & & & \\
\hline 2.23 & 1.94 & 2.18 & 2.70 & 2.546964 & 2.172118 & & & & & & \\
\hline $\begin{array}{r}0.10 \\
20.0417 \\
31.3397\end{array}$ & $\begin{array}{r}0.27 \\
0.6707\end{array}$ & $\begin{array}{r}0.33 \\
0.3542\end{array}$ & $\begin{array}{r}0.07 \\
36.8539\end{array}$ & $\begin{array}{l}0.062625 \\
0.402124\end{array}$ & $\begin{array}{l}0.272249 \\
0.023892\end{array}$ & & & & & & \\
\hline$=\quad n$ & & & & $180 \mathrm{~s}$ & & & & & & & \\
\hline $\begin{array}{r}1000 \\
20.4748\end{array}$ & $\begin{array}{r}1000 \\
2.443\end{array}$ & $\begin{array}{r}1000 \\
9\end{array}$ & 1000 & $\begin{array}{r}1000 \\
0365051\end{array}$ & $\begin{array}{r}1000 \\
00559\end{array}$ & $\begin{array}{l}\text { SY-101 } \\
\text { sY-101 }\end{array}$ & & $\begin{array}{l}33.8747 \\
0.721\end{array}$ & $\begin{array}{l}6.7839 \\
.3989\end{array}$ & $\begin{array}{r}13.3597 \\
{ }_{3}^{3} 3737\end{array}$ & 53.3132 Normal \\
\hline & & 9.2867 & 33.8499 & 0.360514 & 0.063944 & SY-101 & N2O Ratio & 0.3605 & 0.0491 & 0.2261 & 0.5013 Nomal \\
\hline 3.2064 & $0.901 \overline{1}$ & 2.9869 & 6.7839 & $\overline{0} .049085$ & 0.025704 & & & 0.0651 & & & 0.1498 Nomral \\
\hline 10.2810 & 0.8124 & 8.9215 & 46.0215 & 0.002409 & $\mid 0.000661$ & & & & & & \\
\hline 0.11 & 0.03 & 0.00 & 0.00 & 0.072111 & 0.260286 & & & & & & \\
\hline 2.23 & 2.00 & 2.00 & 2.61 & 2.700979 & 2.463738 & & & & & & \\
\hline $\begin{array}{r}0.16 \\
13.3765 \\
280281\end{array}$ & $\begin{array}{r}0.38 \\
0.0343 \\
4.3441\end{array}$ & $\begin{array}{r}0.33 \\
3.2737 \\
1.7673\end{array}$ & $\begin{array}{r}0.20 \\
13.3597 \\
533132\end{array}$ & $\begin{array}{l}0.136158 \\
0.262125 \\
0.5012725\end{array}$ & $\begin{array}{l}0.395124 \\
0.014589 \\
0.14984\end{array}$ & & & & & & \\
\hline
\end{tabular}


3. Setup forecasts in cells in rows $12,13,24,25,36,37,49,50,62,63,75,76,88,89$, $101,102,114,115,127,128,140,141,153,154,166,167,179,180$, and columns "O", "S", "W", "AA."

a. Clear any existing forecasts.

4. Run Crystal Ball for 1,000 trials.

5. Prepare Crystal Ball report.

6. Copy summary statistics from Crystal Ball report to columns "AH" through "AO." a. Save assumption.

7. Final database distributions for the RGS tanks are given in rows "AQ" through "AW."

\section{G2.4 CREATE DISTRIBUTIONS FOR NON-RGS TANKS}

Create the Four Distributions Required to Specify the Retained Gas Distributions for Non-RGS Tanks

- Capture 1,000 data points from each RGS distribution, then reduce data down to 420 points for each gas including 30 points from each RGS tank.

- Determine the default N2 distribution for non-RGS tanks.

- Assume that the first 30 data points from the 1,000 are random and represent the overall distribution for the tank.

Tab "5 - 'CB05all Tab_5mc RGS Forecast Values 030823 .xls" (Note this tab is in separate spreadsheet)

Note: This spreadsheet is set up for 1,000 trials with the same variables as given in 'CB05all Tab_5mc RGS Forecast Values 030823.xls'

1. Extract forecast data from Crystal Ball using the menu items "RUN" "EXTRACT DATA."

2. Open spreadsheet 'CB05all Tab_5mc RGS Forecast Values 030823 .xls' or a copy.

3. Copy all extracted data to tab "All Tab_5mc RGS Forecast Values."

4. On the following tab copy range 'Q5:Q424' to 'R5:R424' and 'S5:S424' using "Paste Special" "values."

a. Use tabs "H2", "N2O", "CH4", "NH3" and "N2."

5. On Tab "N2" regress all 420 combined data points for $\mathrm{N} 2$ to produce a combined distribution using Crystal Ball.

a. Create a distribution using Crystal Ball to fit the data by:

1.) Create assumption.

2.) Select fit data. 


\section{RPP-10006 REV 8}

3.) Enter range of data, S5:S424.

4.) Allow Crystal Ball to fit the data to the regression curves.

- Reduce the 420 data points for "H2", "N2O", "CH4", "NH3" and the minimum and maximum values from all 16,000 data points for each gas to produce continuous linear distribution made up of 55 data pairs.

- Use every eighth data point from the 420 combined points, following numerical sorting of the values, to define 53 of the data pairs.

- Use the minimum and maximum data points as the bounding values for the continuous linear distributions

Tab "6- Gas Forecast Data"

1. Copy from the spreadsheet 'CB05all Tab_5mc RGS Forecast Values 030823 .xls' to this spreadsheet, tab "6- Gas Forecast Data."

a. For H2 - from range 'S5:S424 in tab "H2" to 'b5:b424' using "Paste Special" "values."

b. For N2O - from range 'S5:S424 in tab "N2O" to 'k5:k424' using "Paste Special" "values."

c. For CH4 - from range 'S5:S424 in tab "CH4" to 't5:t424' using "Paste Special" "values."

d. For NH3 - from range 'S5:S424 in tab "NH3" to 'ac5:ac424' using "Paste Special" "values."

2. Sort the raw data as given below.

a. For H2 - sort range a5:c424 with sort keys: 1 -- column C descending; 2 column A ascending; 3 -- NONE.

b. For N2O - sort range J5:L424 with sort keys: 1 -- column J descending; 2 -column $\mathrm{L}$ ascending; 3 -- NONE.

c. For CH4 - sort range S5:U424 with sort keys: 1 -- column U descending; 2 -column $\mathrm{S}$ ascending; 3 -- NONE.

d. For NH3 - sort range AB5:AD424 with sort keys: 1 -- column AD descending; 2 -- column $\mathrm{AB}$ ascending; 3 -- NONE.

3. Sort columns based on mask in columns to the right of the original data

a. For $\mathrm{H} 2$ -

1.) Copy range $\mathrm{B} 5: \mathrm{B} 57$ to range $\mathrm{D} 7: \mathrm{D} 59$.

2.) Copy $\mathrm{H} 2$ minimum from the spreadsheet 'CB05all Tab_5mc RGS Forecast Values 030823 .xls' cell 'O39' in tab H2 to this spreadsheet in tab "6- Gas Forecast Data" cell 'D6.' 


\section{RPP-10006 REV 8}

3.) Copy $\mathrm{H} 2$ maximum from the spreadsheet 'CB05all Tab_5mc RGS Forecast Values 030823 .xls' cell 'O40' in tab H2 to this spreadsheet in tab "6- Gas Forecast Data" cell 'D60.'

b. For $\mathrm{N} 2 \mathrm{O}-$

1.) Copy range $\mathrm{K} 5: \mathrm{K} 57$ to range $\mathrm{M} 7: \mathrm{M} 59$.

2.) Copy $\mathrm{N} 2 \mathrm{O}$ minimum from the spreadsheet 'CB05all Tab_5mc RGS Forecast Values 030823 .xls' cell 'O39' in tab N2O to this spreadsheet in tab "6- Gas Forecast Data" cell 'M6.'

3.) Copy $\mathrm{N} 2 \mathrm{O}$ maximum from the spreadsheet 'CB05all Tab_5mc RGS Forecast Values 030823 .xls' cell 'O40' in tab N2O to this spreadsheet in tab "6- Gas Forecast Data" cell 'M60.'

c. For $\mathrm{CH} 4$ -

1.) Copy range $\mathrm{T} 5: \mathrm{T} 57$ to range $\mathrm{V7:V59}$.

2.) Copy $\mathrm{CH} 4$ minimum from the spreadsheet 'CB05all Tab_5mc RGS Forecast Values 030823 .xls' cell 'O39' in tab CH4 to this spreadsheet in tab "6- Gas Forecast Data" cell 'V6.'

3.) Copy $\mathrm{CH} 4$ maximum from the spreadsheet 'CB05all Tab_5mc RGS Forecast Values 030823 .xls' cell 'O40' in tab CH4 to this spreadsheet in tab "6- Gas Forecast Data" cell 'V60.'

a. For NH3 -

1.) Copy range AC5:AC57 to range AE7:AE59.

2.) Copy NH3 minimum from the spreadsheet 'CB05all Tab_5mc RGS Forecast Values 030823 .xls' cell 'O39' in tab NH3 to this spreadsheet in tab "6- Gas Forecast Data" cell 'AE6.'

3.) Copy NH3 maximum from the spreadsheet 'CB05all Tab_5mc RGS Forecast Values 030823 .xls' cell 'O40' in tab NH3 to this spreadsheet in tab "6- Gas Forecast Data" cell 'AE60.'

4. Sort the raw data as given below

a. For H2 - sort range a5:c424 with sort keys: 1 -- column A ascending; 2 -- NONE; 3 -- NONE.

b. For N2O - sort range J5:L424 with sort keys: 1 -- column L ascending; 2 -NONE; 3 -- NONE.

c. For CH4 - sort range S5:U424 with sort keys: 1 -- column $\mathrm{S}$ ascending; 2 -NONE; 3 -- NONE.

d. For NH3 - sort range AB5:AD424 with sort keys: 1 -- column AB ascending; 2 -NONE; 3 -- NONE.

Calculate the "CH4 Ratio" and "N2O Ratio" distributions

5. Calculate distributions for "CH4 Ratio" and "N2O Ratio." 
a. Create Assumption Distributions for H2, N2O, CH4, and NH3 in cells H6, Q6, Z6, and AI6.

1.) Use the Continuous Linear function.

a). Select Create Assumption.

b.) Select Custom Distribution.

c.) Select Data.

d.) Enter range of data I.e., d6:e60 for $\mathrm{H} 2$ and make sure the "cumulative data" selection is selected.

e). Select "OK" to create the distribution.

b. Create forecasts for "N2", "CH4 Ratio" and "N2O Ratio" values.

1.) The formulas behind the forecasts are:

a.) For $\mathrm{N} 2: 100-[\mathrm{H} 2]-\{\mathrm{N} 2 \mathrm{O}]-[\mathrm{CH} 4]-[\mathrm{NH} 3]$.

b.) For "CH4 Ratio": [CH4] / ( [CH4] + [H2] ).

c.) For "N2O Ratio": $[\mathrm{N} 2 \mathrm{O}] /($ ( $\mathrm{N} 2 \mathrm{O}]+[\mathrm{CH} 4]+[\mathrm{H} 2])$.

2.) Extract data for "CH4 Ratio" and "N2O Ratio" and copy to TAB "7OverallDistributions."

TAB "7-OverallDistributions"

1. Use Crystal Ball to fit 1,000 trails of data into distribution for "CH4 Ratio" and "N2O Ratio."

a. Create a distribution using Crystal Ball to fit the data by:

1.) Create Assumption.

2.) Select fit Data.

3.) Enter range of data.

a.) For "CH4 Ratio" use the range $\mathrm{B} 8: \mathrm{B} 1007$.

b.) For "N2O Ratio" use the range $\mathrm{C} 8: \mathrm{C} 1007$.

4.) Allow Crystal Ball to fit the data to the regression curves.

\section{G2.5 REFORMAT RESULTS TO FIT DATABASE}

Tab "8-RPP-10006 DB values"

1. For RGS Tanks copy data values from tab "4-Gas comp by tanks" range AQ7:AW178 to tab "8-RPP-10006 DB values" cell A4.

2. Remove blank lines and sort by tank name.

3. When positioned as given in tab "8-RPP-10006 DB values" the numbers will automatically be rearranged to fit the database format by the embedded formulas. 


\section{RPP-10006 REV 8}

4. The same procedure is used for the values for the default gas composition specifications.

\section{G3.0 RESULTS}

Table G.3.1 presents the distributions obtained by the methodology explained in Section G2.0. Included in the results are the gas concentration distributions for all 16 RGS tanks as well as the gas concentration distributions for non-RGS tanks, which are labeled "DEFAULT". Following Table G.3.1 are three figures illustrating the distributions overlaying the frequency bins for the DEFAULT distributions, demonstrating the closeness of fit achieved Crystal Ball by its regression algorithm.

Table G.3.1. Retained Gas Concentration Distribution Results. (2 sheets)

\begin{tabular}{|l|l|r|r|r|r|l|}
\hline \multicolumn{1}{|c|}{ Tank } & \multicolumn{1}{|c|}{ Gas } & \multicolumn{1}{c|}{ Mean } & Std Dev & \multicolumn{1}{c|}{ Min } & \multicolumn{1}{c|}{ Max } & $\begin{array}{c}\text { Distribution } \\
\text { Type }\end{array}$ \\
\hline A-101 & CH4 Ratio & 0.0206 & 0.0010 & 0.0177 & 0.0236 & Normal \\
\hline A-101 & N2 & 19.0006 & 2.3255 & 11.3516 & 26.5940 & Normal \\
\hline A-101 & N2O Ratio & 0.0710 & 0.0053 & 0.0577 & 0.0844 & Normal \\
\hline A-101 & NH3 & 2.4569 & 0.2953 & 1.2415 & 3.3466 & Normal \\
\hline AN-103 & CH4 Ratio & 0.0860 & 0.0356 & 0.0215 & 0.1639 & Normal \\
\hline AN-103 & N2 & 28.6602 & 5.1532 & 14.9119 & 42.8042 & Normal \\
\hline AN-103 & N2O Ratio & 0.0534 & 0.0071 & 0.0374 & 0.0768 & Normal \\
\hline AN-103 & NH3 & 0.5966 & 0.0661 & 0.4003 & 0.7819 & Normal \\
\hline AN-104 & CH4 Ratio & 0.0588 & 0.0139 & 0.0266 & 0.0987 & Normal \\
\hline AN-104 & N2 & 29.1727 & 4.9184 & 14.3337 & 41.4358 & Normal \\
\hline AN-104 & N2O Ratio & 0.3081 & 0.0321 & 0.2231 & 0.4011 & Normal \\
\hline AN-104 & NH3 & 0.8820 & 0.1337 & 0.3767 & 1.2932 & Normal \\
\hline AN-105 & CH4 Ratio & 0.0223 & 0.0056 & 0.0108 & 0.0359 & Normal \\
\hline AN-105 & N2 & 24.5713 & 3.6349 & 14.1664 & 34.3390 & Normal \\
\hline AN-105 & N2O Ratio & 0.1690 & 0.0178 & 0.1246 & 0.2198 & Normal \\
\hline AN-105 & NH3 & 0.5001 & 0.0649 & 0.3029 & 0.7618 & Normal \\
\hline AW-101 & CH4 Ratio & 0.2136 & 0.0210 & 0.1565 & 0.2751 & Normal \\
\hline AW-101 & N2 & 53.5503 & 2.7074 & 45.4532 & 62.0123 & Normal \\
\hline AW-101 & N2O Ratio & 0.1256 & 0.0205 & 0.0779 & 0.1739 & Normal \\
\hline AW-101 & NH3 & 0.5706 & 0.0999 & 0.2715 & 0.9587 & Normal \\
\hline AX-101 & CH4 Ratio & 0.0568883 & 0.0072603 & 0.040168 & 0.0763907 & Normal \\
\hline AX-101 & N2 & 16.682515 & 4.2840712 & 4.6480254 & 27.391705 & Normal \\
\hline AX-101 & N2O Ratio & 0.1417203 & 0.0080401 & 0.1219057 & 0.1632994 & Normal \\
\hline AX-101 & NH3 & 6.5851237 & 1.769175 & 3.094251 & 10.784005 & Normal \\
\hline
\end{tabular}




\section{RPP-10006 REV 8}

Table G.3.1. Retained Gas Concentration Distribution Results. (2 sheets)

\begin{tabular}{|c|c|c|c|c|c|c|}
\hline Tank & Gas & Mean & Std Dev & Min & Max & $\begin{array}{c}\text { Distribution } \\
\text { Type }\end{array}$ \\
\hline 09 & $\mathrm{CH} 4$ & 7066 & 712 & 7509 & 8994 & ormal \\
\hline BY-109 & $\mathrm{N} 2$ & 29.044525 & 4.4366125 & 16.677941 & 42.376593 & Normal \\
\hline BY-109 & N2O Ratio & 0.2362124 & 0.0213373 & 0.1780785 & 0.3050799 & Normal \\
\hline BY-109 & $\mathrm{NH} 3$ & 0.1912388 & 0.0337871 & 0.081167 & 0.3206144 & Normal \\
\hline S-102 & CH4 Ratio & 0.0198833 & 0.0040362 & 0.0116416 & 0.0306858 & Normal \\
\hline S-102 & $\mathrm{N} 2$ & 32.246089 & 3.0735677 & 23.973682 & 40.719438 & Normal \\
\hline S-102 & $\mathrm{N} 2 \mathrm{O}$ & 0.4810489 & 0.0220261 & 0.4138286 & 0.5485435 & Normal \\
\hline $\mathrm{S}-102$ & $\mathrm{NH} 3$ & 0.9317253 & 0.28 & 0.3470069 & 1.6237296 & Normal \\
\hline S-106 & CH4 Ratio & 833 & 0.0062037 & 0.000211 & 0.0296648 & Normal \\
\hline S-106 & $\mathrm{N} 2$ & 25.216722 & 3.7891284 & 15.249227 & 34.922471 & Normal \\
\hline S-106 & N2O Ratio & 0.1309545 & 0.0150095 & 0.0981745 & 0.1694995 & Normal \\
\hline S-106 & NH3 & 0.2988262 & 0.0672631 & 0.0941543 & 0.5200336 & Normal \\
\hline S-111 & $\mathrm{CH} 4$ Ratio & 0.0136002 & 0.0015555 & 0.0097731 & 0.0192358 & Normal \\
\hline S-111 & $\mathrm{N} 2$ & 20.990104 & 5.9531917 & 4.5555037 & 34.751033 & Normal \\
\hline S-111 & N2O Ratio & 0.1345261 & 0.0166708 & 0.0924325 & 0.1900213 & Normal \\
\hline S-111 & $\mathrm{NH} 3$ & 0.9286594 & 0.2851553 & 0.354503 & 1.6034667 & Normal \\
\hline SX-106 & $\mathrm{CH} 4$ & 0.0170592 & 0.0069497 & 0.00 & 737 & Normal \\
\hline SX-106 & $\mathrm{N} 2$ & 2874 & 3.44 & 10.197908 & 656 & Normal \\
\hline SX-106 & $\mathrm{N} 2 \mathrm{O}$ & 0.3154821 & 0.0150306 & 0.2752638 & 0.3600094 & Normal \\
\hline SX-106 & $\mathrm{NH} 3$ & 4.2022214 & 1.2553005 & 1.7899067 & 6.8047356 & Normal \\
\hline SY-101 & $\mathrm{CH} 4$ Ratio & 0.0650518 & 0.0257035 & 0.0145888 & 0.1498403 & Normal \\
\hline SY-101 & $\mathrm{N} 2$ & 33.874694 & 6.7839154 & 13.359652 & 53.313162 & Normal \\
\hline SY-101 & N2O Ratio & 0.360501 & 0.0490851 & 0.226125 & 0.5012775 & Normal \\
\hline SY-101 & $\mathrm{NH} 3$ & 9.1721 & 2.9868881 & 3.2737398 & 15.767285 & Normal \\
\hline U-103 & $\mathrm{CH} 4$ Ratio & 0.0572362 & 0.0110623 & 0.0339797 & 0.0820054 & Normal \\
\hline U-103 & $\mathrm{N} 2$ & 36.711397 & 2.0175933 & 30.945456 & 42.560795 & Normal \\
\hline U-103 & N2O Ratio & 0.6032003 & 0.015214 & 0.5608941 & 0.64 & Normal \\
\hline U-103 & $\mathrm{NH} 3$ & 0.59 & 0.15 & 87 & 055 & al \\
\hline U-109 & CH4 Ratio & 0.0489471 & 0.0133258 & 0.0238921 & 0.0873525 & Normal \\
\hline U-109 & $\mathrm{N} 2$ & 46.777093 & 3.1883437 & 36.853937 & 56.618098 & Normal \\
\hline U-109 & N2O Ratio & 0.4889364 & 0.0306199 & 0.4021244 & 0.5769073 & Normal \\
\hline U-109 & NH3 & 1.0070756 & 0.3279163 & 0.3542088 & 1.8118107 & Normal \\
\hline DEFAULT & CH4 Ratio & 0.0529 & 0.0563 & 0.0010 & 0.3178 & LogNorm \\
\hline DEFAULT & $\mathrm{N} 2$ & 29.84 & 12.01 & 4.5000 & 80.0000 & LogNorm \\
\hline DEFAULT & N2O Ratio & 0.2533 & 0.1758 & 0.0010 & 0.6189 & LogNorm \\
\hline
\end{tabular}


Figure G.3.1. Distribution fit of $\mathrm{CH}_{4}$ Ratio
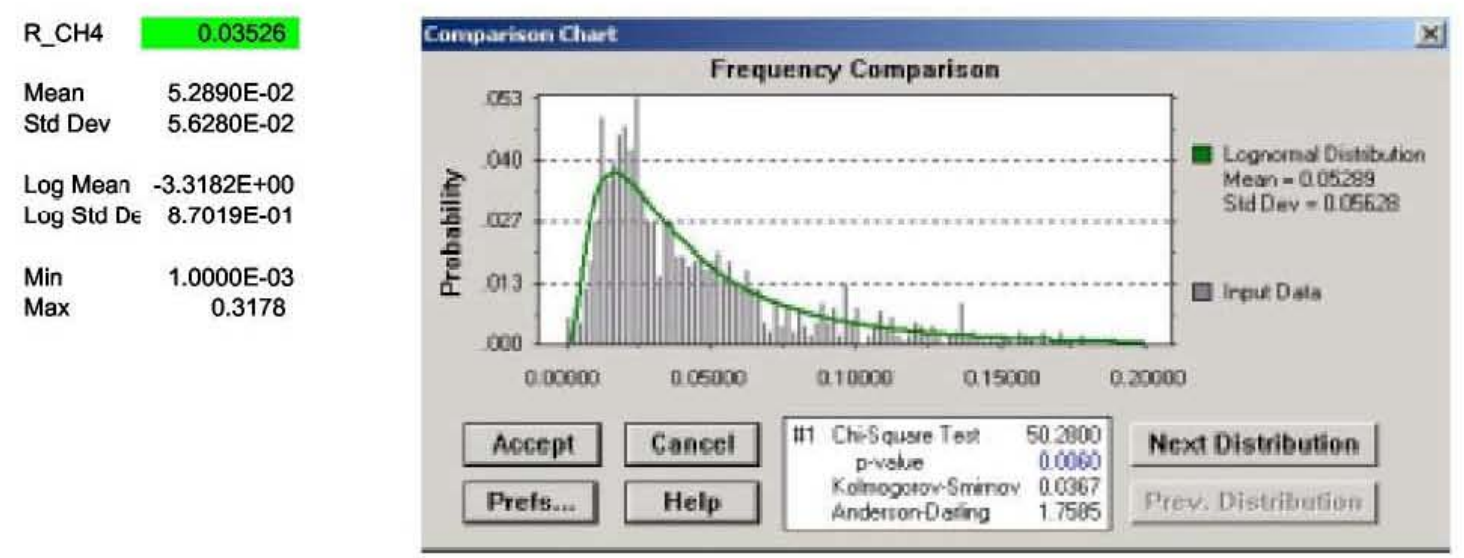

Figure G.3.2. Distribution fit of $\mathrm{N}_{2} \mathrm{O}$ Ratio

$\begin{array}{lr}\text { R_N2O } & 2.3960 E-01 \\ \text { Mean } & 2.53 E-01 \\ \text { Std Dev } & 1.76 E-01 \\ \text { Log Mean } & -1.57 E+00 \\ \text { Log Std D } \epsilon & 6.27 E-01 \\ \text { Min } & 1.0000 E-03 \\ \text { Max } & 0.6189\end{array}$

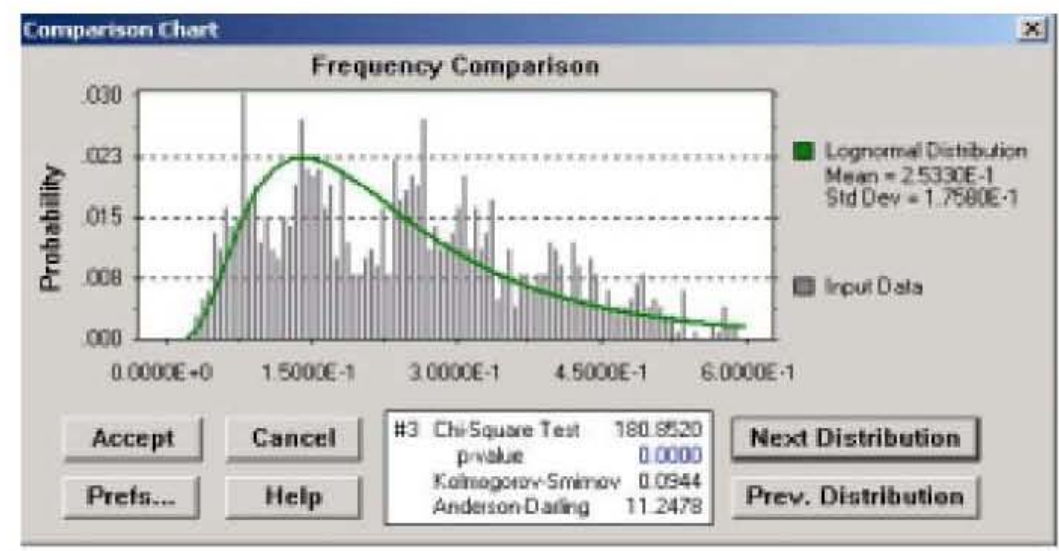

Figure G.3.3. Distribution fit of $\mathrm{N}_{2}$ Concentration

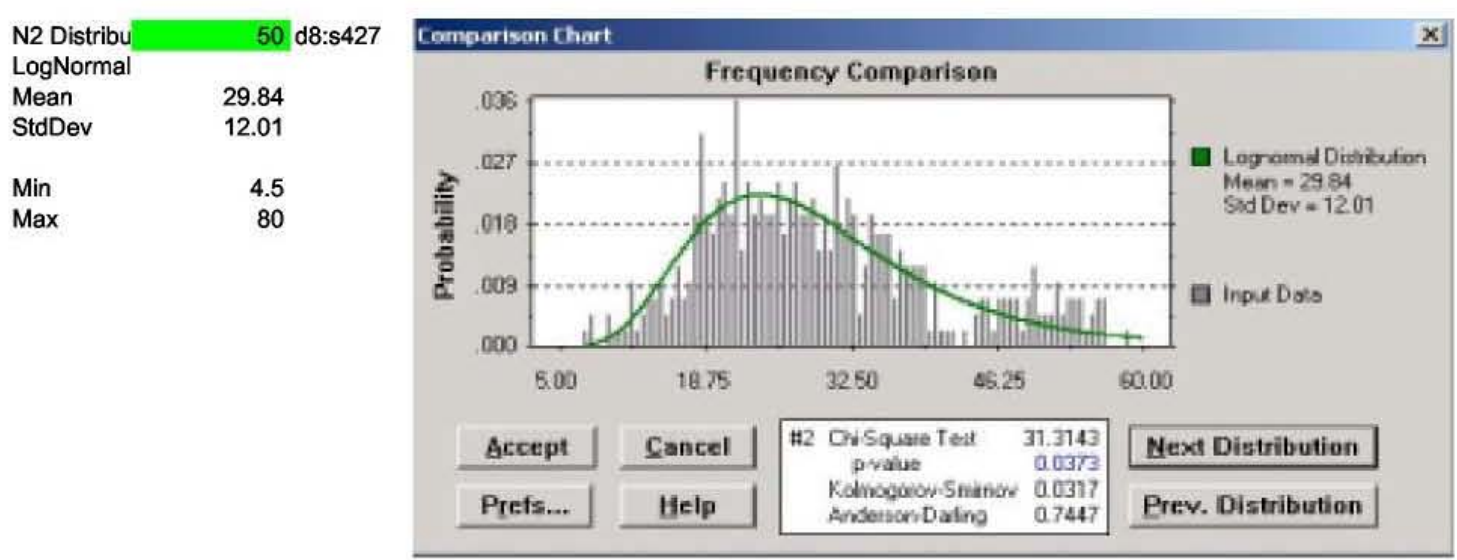




\section{RPP-10006 REV 8}

\section{G4.0 REFERENCES}

PNNL-13317, 2000, “Ammonia Results Review for Retained Gas Sampling", Pacific Northwest National Laboratory, Richland, Washington. 
RPP-10006 REV 8

APPENDIX H

INPUT DATA 
RPP-10006 REV 8

This page intentionally left blank.

H-ii 


\section{RPP-10006 REV 8}

\section{CONTENTS}

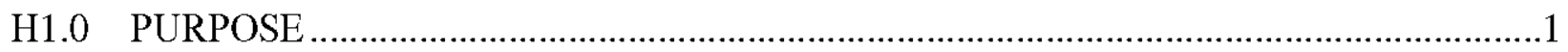

H2.0 INPUT DATA

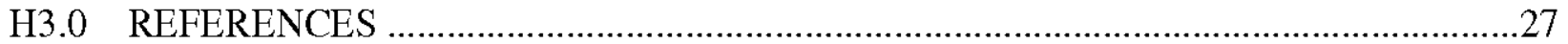

H-iii 


\section{LIST OF TERMS}

DST

LIQ

MIX-LIQ

MIX-NL

$\mathrm{n} / \mathrm{a}$

OSD

PCSACS ILL

SC/SS

SC/SS-LIQ

SC/SS-NL

$\mathrm{SL}$

SL-LIQ

SL-NL

SST

vol\% double-shell tank

liquid waste form

mixed waste form with $\geq 1 \mathrm{~m}$ liquid over solids

mixed waste form with $<1 \mathrm{~m}$ liquid over solids

not applicable

operating specifications documents

Personal Computer Surveillance Analysis Computer System Interstitial Liquid Level

saltcake/salt slurry

saltcake/salt slurry waste form with $\geq 1 \mathrm{~m}$ liquid over solids

saltcake/salt slurry waste form with $<1 \mathrm{~m}$ liquid over solids

sludge

sludge waste form with $\geq 1 \mathrm{~m}$ liquid over solids

sludge waste form with $<1 \mathrm{~m}$ liquid over solids

single shell tank

volume percent 
RPP-10006 REV 8

\section{APPENDIX H}

INPUT DATA

\section{H1.0 PURPOSE}

This appendix presents the input data used to perform the flammable gas waste group assignment calculations. Updated input data for evaluation of all double-shell tanks and single-shell tanks has been incorporated into the input data table.

\section{H2.0 INPUT DATA}

Input data are presented in this appendix. Input data sources are shown in the "Reference" row. Data are taken from RPP-5926 or carried over from the previous revision of this document. DST non-convective waste levels and uncertainties are from Appendix C.

The BBI lists double-shell tanks 241-AP-101, 241-AP-106, and 241-AP-107 as having no solids; therefore, RPP-5926 R8 does not contain input data for the solids layers in these tanks. However tanks 241-AP-106, and 241-AP-107 are now assumed to contain solids. This assumption is based on new information (see Appendix C). Input data for the solids in these tanks were carried through from the previous revisions which assumed tanks 241-AP-106 and 241-AP-107 contain some solids.

Convective waste average temperature for tanks 241-AP-101, 241-AP-106, and 241-AP-107 was used in place of the non-convective waste average temperature. RPP-5926 R8 reports no solids for these tanks and therefore no solid phase temperature. It is assumed that the convective layer average temperature is reasonable for the solid phase average temperature.

Although tank 241-AP-101 is assumed to contain no solids, a nominal solid phase HGR was assigned to the tank to allow evaluation with the waste group model. This HGR value has been carried over from the previous revision.

The HGRs for the remaining tanks were calculated using values from RPP-5926 R8. RPP-5926 R8 does not directly calculate non-convective solid phase HGR. However it does give the solid layer radiolysis, and thermolysis which were used to calculate the non-convective HGR. Under the "HGRsum" tab in the spreadsheet titled DST_SST_TTLFL_v1.xls, columns E "Solid-Layer Radiolysis" and G "Solid-Layer Thermolysis" were added together to get the total Nonconvective HGR. 


\begin{tabular}{|c|c|c|c|c|c|c|c|c|c|c|c|c|c|c|c|c|c|}
\hline Data Source & & $\begin{array}{l}\text { RPP-5926 R8 } \\
\text { RPP-10006 R7 }\end{array}$ & $\begin{array}{c}\text { RPP-10006 R7 } \\
\text { Data }\end{array}$ & $\begin{array}{c}\text { RPP-5926 R8, } \\
\text { Appendix C }\end{array}$ & $\begin{array}{c}\text { RPP-10006 R7 } \\
\text { Data }\end{array}$ & $\begin{array}{c}\text { RPP-10006 R7 } \\
\text { Data }\end{array}$ & $\begin{array}{c}\text { RPP-5926 R8, } \\
\text { Appendix C }\end{array}$ & $\begin{array}{c}\text { RPP-10006 R7 } \\
\text { Data }\end{array}$ & $\begin{array}{c}\text { RPP-10006 R7 } \\
\text { Data }\end{array}$ & $\begin{array}{c}\text { RPP-10006 R7 } \\
\text { Data }\end{array}$ & $\begin{array}{l}\text { RPP-5926 R8, } \\
\text { RPP-10006 R7 }\end{array}$ & \begin{tabular}{|c|} 
Calculated value \\
(see RPP-10006, \\
Appendix B), \\
RPP-10006 R7
\end{tabular} & \begin{tabular}{|} 
Calculated value \\
(see RPP-10006, \\
Appendix B), \\
RPP-10006 R7
\end{tabular} & $\begin{array}{c}\text { Calculated value } \\
\text { (see RPP-10006, } \\
\text { Appendix B), } \\
\text { RPP-10006 R7 }\end{array}$ & $\begin{array}{l}\text { RPP-10006, } \\
\text { Appendix B }\end{array}$ & $\begin{array}{l}\text { RPP-5926 R8, } \\
\text { RPP-10006 R7 }\end{array}$ & $\begin{array}{l}\text { Calculated value } \\
\text { (see RPP-10006, } \\
\text { Appendix B), } \\
\text { RPP-10006 R7 }\end{array}$ \\
\hline Tank \# & Tank Type & $\begin{array}{c}\text { Total waste } \\
\text { depth } \\
\text { (m) }\end{array}$ & \begin{tabular}{|c} 
Total waste \\
depth \\
uncertainty \\
(m)
\end{tabular} & \begin{tabular}{|c|}
$\begin{array}{c}\text { Total non- } \\
\text { convective } \\
\text { waste depth } \\
(\mathbf{m})\end{array}$ \\
\end{tabular} & \begin{tabular}{|c|}
$\begin{array}{c}\text { Total non- } \\
\text { convective } \\
\text { waste depth } \\
\text { uncertainty } \\
(m)\end{array}$ \\
\end{tabular} & \begin{tabular}{|c|} 
Total non- \\
convective \\
waste depth \\
lower bound \\
$(\mathrm{m})$
\end{tabular} & $\begin{array}{c}\text { Wetted non- } \\
\text { convective } \\
\text { waste depth } \\
(\mathbf{m})\end{array}$ & $\begin{array}{c}\text { Wetted non- } \\
\text { convective } \\
\text { waste depth } \\
\text { uncertainty } \\
(m)\end{array}$ & $\begin{array}{c}\text { Wetted non- } \\
\text { convective } \\
\text { waste depth } \\
\text { lower bound } \\
(m)\end{array}$ & \begin{tabular}{|c} 
Mean Crust \\
depth \\
(m)
\end{tabular} & $\begin{array}{c}\text { Convective } \\
\text { Waste } \\
\text { Density } \\
\text { Mean } \\
\text { (kg/m3) } \\
\end{array}$ & \begin{tabular}{|c} 
Convective \\
Waste \\
Density \\
Std Dev \\
$(\mathrm{kg} / \mathrm{m} 3)$
\end{tabular} & \begin{tabular}{|c|} 
Convective \\
Waste \\
Density \\
Min \\
$(\mathrm{kg} / \mathrm{m} 3)$ \\
\end{tabular} & \begin{tabular}{|c|} 
Convective \\
Waste \\
Density \\
Max \\
$(\mathbf{k g} / \mathbf{m} 3)$
\end{tabular} & $\begin{array}{c}\text { Convective } \\
\text { Waste } \\
\text { Density } \\
\text { Dist } \\
(\mathbf{k g} / \mathbf{m} 3)\end{array}$ & $\begin{array}{c}\text { Non- } \\
\text { Convective } \\
\text { Waste } \\
\text { Density } \\
\text { Mean } \\
(\mathrm{kg} / \mathrm{m} 3)\end{array}$ & $\begin{array}{c}\text { Non- } \\
\text { Convective } \\
\text { Waste } \\
\text { Density Std } \\
\text { Dev }(\mathrm{kg} / \mathrm{m} 3)\end{array}$ \\
\hline A-101 & SST & 2.95 & 0.292 & 2.95 & 0.292 & 0.010 & 2.95 & 0.292 & 0.010 & 0.00 & 1490 & 88 & 1318 & 1662 & normal & 1,458 & 128 \\
\hline $\mathrm{A}-102$ & $\begin{array}{l}\text { SST } \\
\end{array}$ & 0.37 & 0.006 & 0.34 & 0.292 & 0.010 & 0.34 & 0.292 & 0.010 & 0.00 & 1570 & 93 & 1388 & 1752 & normal & 1,669 & 126 \\
\hline $\mathrm{A}-103$ & SST & 3.50 & 0.006 & 3.46 & 0.292 & 0.010 & 3.46 & 0.292 & 0.010 & 0.00 & 1510 & 89 & 1335 & 1685 & normal & 1,365 & 132 \\
\hline A-104 & SST & 0.26 & 0.292 & 0.26 & 0.292 & 0.010 & 0.26 & 0.292 & 0.000 & 0.00 & 1640 & 97 & 1450 & 1830 & normal & 950 & 132 \\
\hline $\mathrm{A}-105$ & SST & 0.34 & 0.292 & 0.34 & 0.292 & 0.000 & 0.34 & 0.292 & 0.000 & 0.00 & 1100 & 65 & 1000 & 1227 & normal & 1,540 & 116 \\
\hline A-106 & SST & 0.73 & 0.292 & 0.73 & 0.292 & 0.010 & 0.49 & 0.024 & 0.010 & 0.00 & 1100 & 65 & 1000 & 1227 & normal & 1,700 & 128 \\
\hline AN-101* & DST & 10.56 & 0.006 & 0.47 & 0.27 & 0.01 & 0.47 & 0.25 & 0.01 & 0.00 & 1400 & 114 & 1176 & 1624 & normal & 1549 & 101 \\
\hline AN-102* & DST & 9.83 & 0.006 & 1.86 & 0.27 & 0.01 & 1.86 & 0.34 & 0.01 & 0.00 & 1410 & 115 & 1184 & 1636 & normal & 1530 & 99 \\
\hline AN-103* & DST & 8.85 & 0.080 & 3.78 & 0.29 & 0.01 & 3.78 & 0.29 & 0.01 & 0.89 & 1480 & 121 & 1243 & 1717 & normal & 1516 & 112 \\
\hline AN-104* & DST & 9.72 & 0.035 & 4.14 & 0.31 & 0.01 & 4.14 & 0.31 & 0.01 & 0.41 & 1400 & 114 & 1176 & 1624 & normal & 1478 & 103 \\
\hline AN-105* & DST & 10.40 & 0.050 & 4.50 & 0.15 & 0.01 & 4.50 & 0.15 & 0.01 & 0.45 & 1420 & 116 & 1193 & 1647 & normal & 1486 & 102 \\
\hline AN-106* & DST & 7.00 & 0.006 & 2.20 & 0.27 & 0.01 & 2.20 & 0.25 & 0.01 & 0.00 & 1150 & 91 & 1000 & 1288 & normal & 1481 & 96 \\
\hline AN-107* & $\begin{array}{l}\text { DST } \\
\end{array}$ & 10.17 & 0.006 & 2.32 & 0.01 & 0.01 & 2.32 & 0.10 & 0.01 & 0.00 & 1430 & 117 & 1201 & 1659 & normal & 1480 & 96 \\
\hline AP-101* & DST & 10.65 & 0.006 & 0.00 & 0.27 & 0.00 & 0.00 & 0.25 & 0.00 & 0.00 & 1240 & 100 & 1025 & 1415 & normal & 1750 & 114 \\
\hline AP-102* & DST & 10.03 & 0.006 & 0.52 & 0.27 & 0.01 & 0.52 & 0.25 & 0.01 & 0.00 & 1370 & 113 & 1168 & 1612 & normal & 1730 & 114 \\
\hline AP-103* & DST & 10.49 & 0.006 & 0.33 & 0.02 & 0.01 & 0.33 & 0.02 & 0.01 & 0.00 & 1390 & 112 & 1151 & 1589 & normal & 1680 & 109 \\
\hline AP-104* & DST & 4.53 & 0.006 & 0.34 & 0.01 & 0.01 & 0.34 & 0.25 & 0.01 & 0.00 & 1410 & 104 & 1075 & 1485 & normal & 1610 & 105 \\
\hline AP-105* & DST & 2.34 & 0.006 & 1.14 & 0.15 & 0.01 & 1.14 & 0.14 & 0.01 & 0.00 & 1270 & 104 & 1067 & 1473 & normal & 1610 & 105 \\
\hline AP-106* & DST & 10.49 & 0.006 & 0.24 & 0.27 & 0.01 & 0.24 & 0.25 & 0.01 & 0.00 & 1210 & 99 & 1016 & 1404 & normal & 1610 & 105 \\
\hline AP-107* & DST & 10.43 & 0.006 & 0.17 & 0.27 & 0.01 & 0.17 & 0.25 & 0.01 & 0.00 & 1280 & 104 & 1075 & 1485 & normal & 1610 & 105 \\
\hline AP-108* & DST & 11.52 & 0.006 & 0.98 & 0.47 & 0.01 & 0.98 & 0.47 & 0.01 & 0.00 & 1410 & 115 & 1184 & 1636 & normal & 1550 & 101 \\
\hline AW-101* & DST & 10.41 & 0.100 & 2.84 & 0.29 & 0.01 & 2.84 & 0.29 & 0.01 & 0.80 & 1470 & 120 & 1235 & 1705 & normal & 1489 & 103 \\
\hline AW-102* & DST & 9.24 & 0.006 & 0.56 & 0.27 & 0.01 & 0.56 & 0.25 & 0.01 & 0.00 & 1240 & 87 & 1000 & 1241 & normal & 1600 & 104 \\
\hline AW-103* & DST & 10.10 & 0.006 & 3.09 & 0.17 & 0.01 & 3.09 & 0.16 & 0.01 & 0.00 & 1240 & 101 & 1042 & 1438 & normal & 1489 & 97 \\
\hline AW-104* & DST & 9.84 & 0.006 & 2.29 & 0.50 & 0.01 & 2.29 & 0.50 & 0.01 & 0.00 & 1360 & 110 & 1134 & 1566 & normal & 1461 & 96 \\
\hline AW-105* & DST & 3.83 & 0.006 & 2.35 & 0.25 & 0.01 & 2.35 & 0.31 & 0.01 & 0.00 & 1060 & 85 & 1000 & 1206 & normal & 1332 & 87 \\
\hline AW-106* & DST & 10.46 & 0.006 & 2.65 & 0.43 & 0.01 & 2.65 & 0.36 & 0.01 & 0.00 & 1220 & 100 & 1025 & 1415 & normal & 1770 & 115 \\
\hline AX-101 & SST & 3.30 & 0.292 & 3.30 & 0.292 & 0.010 & 1.71 & 0.024 & 0.000 & 0.00 & 1100 & 65 & 1000 & 1227 & normal & 1,702 & 128 \\
\hline $\mathrm{AX}-102$ & SST & 0.28 & 0.292 & 0.28 & 0.292 & 0.010 & 0.28 & 0.292 & 0.000 & 0.00 & 1100 & 65 & 1000 & 1227 & normal & 1,578 & 119 \\
\hline $\mathrm{AX}-103$ & SST & 0.98 & 0.292 & 0.98 & 0.292 & 0.010 & 0.84 & 0.024 & 0.010 & 0.00 & 1100 & 65 & 1000 & 1227 & normal & 1,580 & 119 \\
\hline AX-104 & SST & 0.07 & 0.292 & 0.07 & 0.292 & 0.010 & 0.07 & 0.292 & 0.000 & 0.00 & 1170 & 69 & 1035 & 1305 & normal & 1,800 & 136 \\
\hline AY-101* & DST & 8.34 & 0.006 & 0.91 & 0.27 & 0.01 & 0.91 & 0.08 & 0.01 & 0.00 & 1120 & 92 & 1000 & 1311 & normal & 1782 & 109 \\
\hline AY-102* & DST & 8.99 & 0.006 & 1.54 & 0.14 & 0.01 & 1.54 & 0.12 & 0.01 & 0.00 & 1300 & 105 & 1084 & 1496 & normal & 1592 & 104 \\
\hline AZ-101* & DST & 7.74 & 0.006 & 0.53 & 0.27 & 0.01 & 0.53 & 0.15 & 0.01 & 0.00 & 1240 & 101 & 1042 & 1438 & normal & 1610 & 105 \\
\hline AZ-102* & DST & 8.68 & 0.006 & 0.83 & 0.27 & 0.01 & 0.83 & 0.25 & 0.01 & 0.00 & 1140 & 92 & 1000 & 1311 & normal & 1410 & 92 \\
\hline B-101 & SST & 1.00 & 0.292 & 1.00 & 0.292 & 0.010 & 1.19 & 0.292 & 0.010 & 0.00 & 1100 & 65 & 1000 & 1227 & normal & 1,513 & 112 \\
\hline B-102 & SST & 0.30 & 0.006 & 0.26 & 0.292 & 0.010 & 0.45 & 0.292 & 0.010 & 0.00 & 1260 & 74 & 1114 & 1406 & normal & 1,612 & 122 \\
\hline
\end{tabular}




\begin{tabular}{|c|c|c|c|c|c|c|c|c|c|c|c|c|c|c|c|c|c|}
\hline Data Source & & $\begin{array}{l}\text { RPP-5926 R8 } \\
\text { RPP-10006 R7 }\end{array}$ & $\begin{array}{c}\text { RPP-10006 R7 } \\
\text { Data }\end{array}$ & $\begin{array}{c}\text { RPP-5926 R8, } \\
\text { Appendix C }\end{array}$ & $\begin{array}{c}\text { RPP-10006 R7 } \\
\text { Data }\end{array}$ & $\begin{array}{c}\text { RPP-10006 R7 } \\
\text { Data }\end{array}$ & $\begin{array}{l}\text { RPP-5926 R8, } \\
\text { Appendix C }\end{array}$ & $\begin{array}{c}\text { RPP-10006 R7 } \\
\text { Data }\end{array}$ & $\begin{array}{c}\text { RPP-10006 R7 } \\
\text { Data }\end{array}$ & $\begin{array}{c}\text { RPP-10006 R7 } \\
\text { Data }\end{array}$ & $\begin{array}{l}\text { RPP-5926 R8, } \\
\text { RPP-10006 R7 }\end{array}$ & \begin{tabular}{|c|} 
Calculated value \\
(see RPP-10006, \\
Appendix B), \\
RPP-10006 R7
\end{tabular} & \begin{tabular}{|} 
Calculated value \\
(see RPP-10006, \\
Appendix B), \\
RPP-10006 R7
\end{tabular} & $\begin{array}{c}\text { Calculated value } \\
\text { (see RPP-10006, } \\
\text { Appendix B), } \\
\text { RPP-10006 R7 }\end{array}$ & $\begin{array}{l}\text { RPP-10006, } \\
\text { Appendix B }\end{array}$ & \begin{tabular}{|l|} 
RPP-5926 R8 \\
RPP-10006 R7
\end{tabular} & \begin{tabular}{|c|} 
Calculated value \\
(see RPP-10006, \\
Appendix B), \\
RPP-10006 R7
\end{tabular} \\
\hline Tank \# & Tank Type & $\begin{array}{c}\text { Total waste } \\
\text { depth } \\
\text { (m) }\end{array}$ & \begin{tabular}{|c} 
Total waste \\
depth \\
uncertainty \\
(m)
\end{tabular} & $\begin{array}{c}\begin{array}{c}\text { Total non- } \\
\text { convective } \\
\text { waste depth } \\
\text { (m) }\end{array} \\
\end{array}$ & \begin{tabular}{|c|}
$\begin{array}{c}\text { Total non- } \\
\text { convective } \\
\text { waste depth } \\
\text { uncertainty } \\
(m)\end{array}$ \\
\end{tabular} & \begin{tabular}{|c|} 
Total non- \\
convective \\
waste depth \\
lower bound \\
$(\mathrm{m})$
\end{tabular} & \begin{tabular}{|c} 
Wetted non- \\
convective \\
waste depth \\
$(\mathrm{m})$
\end{tabular} & $\begin{array}{c}\text { Wetted non- } \\
\text { convective } \\
\text { waste depth } \\
\text { uncertainty } \\
(m)\end{array}$ & \begin{tabular}{|c|} 
Wetted non- \\
convective \\
waste depth \\
lower bound \\
$(\mathrm{m})$
\end{tabular} & $\begin{array}{c}\text { Mean Crust } \\
\text { depth } \\
\text { (m) }\end{array}$ & $\begin{array}{c}\text { Convective } \\
\text { Waste } \\
\text { Density } \\
\text { Mean } \\
\text { (kg/m3) } \\
\end{array}$ & \begin{tabular}{|c|}
$\begin{array}{c}\text { Convective } \\
\text { Waste } \\
\text { Density } \\
\text { Std Dev } \\
(\mathrm{kg} / \mathbf{m} 3)\end{array}$ \\
\end{tabular} & \begin{tabular}{|c|} 
Convective \\
Waste \\
Density \\
Min \\
$(\mathrm{kg} / \mathrm{m} 3)$ \\
\end{tabular} & \begin{tabular}{|c|} 
Convective \\
Waste \\
Density \\
Max \\
$(\mathbf{k g} / \mathbf{m} 3)$ \\
\end{tabular} & $\begin{array}{c}\text { Convective } \\
\text { Waste } \\
\text { Density } \\
\text { Dist } \\
(\mathrm{kg} / \mathrm{m} 3) \\
\end{array}$ & \begin{tabular}{|c|} 
Non- \\
Convective \\
Waste \\
Density \\
Mean \\
$(\mathrm{kg} / \mathrm{m} 3)$ \\
\end{tabular} & $\begin{array}{c}\text { Non- } \\
\text { Convective } \\
\text { Waste } \\
\text { Density Std } \\
\text { Dev }(\mathrm{kg} / \mathrm{m} 3) \\
\end{array}$ \\
\hline B-103 & SST & 0.51 & 0.292 & 0.51 & 0.292 & 0.010 & 0.70 & 0.292 & 0.000 & 0.00 & 1100 & 65 & 1000 & 1227 & normal & 1,613 & 122 \\
\hline B-104 & SST & 3.46 & 0.292 & 3.46 & 0.292 & 0.010 & 3.60 & 0.024 & 0.010 & 0.00 & 1100 & 65 & 1000 & 1227 & normal & 1,385 & 105 \\
\hline B-105 & SST & 2.68 & 0.292 & 2.68 & 0.292 & 0.010 & 1.19 & 0.024 & 0.010 & 0.00 & 1100 & 65 & 1000 & 1227 & normal & 1,653 & 125 \\
\hline B-106 & SST & 1.13 & 0.006 & 1.12 & 0.292 & 0.010 & 1.31 & 0.292 & 0.010 & 0.00 & 1260 & 74 & 1114 & 1406 & normal & 1,381 & 104 \\
\hline B-107 & SST & 1.49 & 0.292 & 1.49 & 0.292 & 0.010 & 1.65 & 0.024 & 0.010 & 0.00 & 1100 & 65 & 1000 & 1227 & normal & 1,626 & 123 \\
\hline B-108 & SST & 0.85 & 0.292 & 0.85 & 0.292 & 0.010 & 0.89 & 0.024 & 0.010 & 0.00 & 1100 & 65 & 1000 & 1227 & normal & 1,703 & 127 \\
\hline B-109 & $\begin{array}{l}\text { SST } \\
\end{array}$ & 1.16 & 0.292 & 1.16 & 0.292 & 0.010 & 1.07 & 0.024 & 0.010 & 0.00 & 1100 & 65 & 1000 & 1227 & normal & 1,820 & 135 \\
\hline B-110 & $\begin{array}{l}\text { SST } \\
\end{array}$ & 2.27 & 0.006 & 2.26 & 0.292 & 0.010 & 2.41 & 0.024 & 0.010 & 0.00 & 1190 & 70 & 1052 & 1328 & normal & 1,360 & 103 \\
\hline B-111 & SST & 2.23 & 0.006 & 2.22 & 0.292 & 0.010 & 2.22 & 0.024 & 0.010 & 0.00 & 1190 & 70 & 1052 & 1328 & normal & 1,270 & 96 \\
\hline B-112 & SST & 0.32 & 0.006 & 0.30 & 0.292 & 0.010 & 0.48 & 0.292 & 0.010 & 0.00 & 1510 & 89 & 1335 & 1685 & normal & 1,493 & 132 \\
\hline B-201 & SST & 0.27 & 0.292 & 0.27 & 0.292 & 0.010 & 4.02 & 0.292 & 0.000 & 0.00 & 1100 & 65 & 1000 & 1227 & normal & 1,260 & 95 \\
\hline B-202 & SST & 0.26 & 0.292 & 0.26 & 0.292 & 0.010 & 3.77 & 0.292 & 0.000 & 0.00 & 1170 & 69 & 1035 & 1305 & normal & 1,220 & 92 \\
\hline B-203 & $\begin{array}{l}\text { SST } \\
\end{array}$ & 0.46 & 0.006 & 0.46 & 0.292 & 0.010 & 6.66 & 0.292 & 0.010 & 0.00 & 1050 & 62 & 1000 & 1171 & normal & 1,190 & 90 \\
\hline B-204 & $\begin{array}{l}\text { SST } \\
\end{array}$ & 0.46 & 0.006 & 0.45 & 0.292 & 0.010 & 6.52 & 0.292 & 0.010 & 0.00 & 1050 & 62 & 1000 & 1171 & normal & 1,190 & 90 \\
\hline BX-101 & SST & 0.44 & 0.292 & 0.44 & 0.292 & 0.010 & 0.63 & 0.292 & 0.000 & 0.00 & 1100 & 65 & 1000 & 1227 & normal & 1,680 & 127 \\
\hline BX-102 & SST & 0.73 & 0.292 & 0.73 & 0.292 & 0.010 & 0.92 & 0.292 & 0.000 & 0.00 & 1170 & 69 & 1035 & 1305 & normal & 1,123 & 114 \\
\hline BX-103 & SST & 0.70 & 0.006 & 0.57 & 0.292 & 0.010 & 0.76 & 0.292 & 0.010 & 0.00 & 1070 & 63 & 1000 & 1194 & normal & 1,661 & 125 \\
\hline BX-104 & SST & 0.93 & 0.006 & 0.90 & 0.292 & 0.010 & 1.09 & 0.292 & 0.010 & 0.00 & 1280 & 76 & 1132 & 1428 & normal & 1,680 & 127 \\
\hline BX-105 & SST & 0.66 & 0.006 & 0.62 & 0.292 & 0.010 & 0.81 & 0.292 & 0.010 & 0.00 & 1290 & 76 & 1141 & 1439 & normal & 1,694 & 128 \\
\hline BX-106 & SST & 0.35 & 0.292 & 0.35 & 0.292 & 0.010 & 0.54 & 0.292 & 0.000 & 0.00 & 1170 & 69 & 1035 & 1305 & normal & 1,617 & 122 \\
\hline BX-107 & SST & 3.20 & 0.292 & 3.20 & 0.292 & 0.010 & 3.39 & 0.292 & 0.000 & 0.00 & 1100 & 65 & 1000 & 1227 & normal & 1,440 & 109 \\
\hline BX-108 & $\begin{array}{l}\text { SST } \\
\end{array}$ & 0.29 & 0.292 & 0.29 & 0.292 & 0.010 & 0.48 & 0.292 & 0.000 & 0.00 & 1100 & 65 & 1000 & 1227 & normal & 1,457 & 110 \\
\hline BX-109 & $\begin{array}{l}\text { SST } \\
\end{array}$ & 1.78 & 0.292 & 1.78 & 0.292 & 0.010 & 1.97 & 0.292 & 0.010 & 0.00 & 1100 & 65 & 1000 & 1227 & normal & 1,520 & 115 \\
\hline BX-110 & SST & 1.98 & 0.006 & 1.97 & 0.292 & 0.010 & 2.16 & 0.292 & 0.010 & 0.00 & 1440 & 85 & 1273 & 1607 & normal & 1,667 & 126 \\
\hline BX-111 & SST & 1.74 & 0.292 & 1.74 & 0.292 & 0.010 & 1.11 & $\begin{array}{c}0.024 \\
\end{array}$ & 0.010 & 0.00 & 1100 & 65 & 1000 & 1227 & normal & 1,447 & 109 \\
\hline BX-112 & SST & 1.52 & 0.006 & 1.51 & 0.292 & 0.010 & 1.69 & 0.292 & 0.010 & 0.00 & 1180 & 70 & 1044 & 1316 & normal & 1,310 & 99 \\
\hline BY-101 & SST & 3.42 & 0.292 & 3.42 & 0.292 & 0.010 & 2.44 & 0.024 & 0.010 & 0.00 & 1510 & 89 & 1335 & 1685 & normal & 1,838 & 139 \\
\hline BY-102 & SST & 2.57 & 0.292 & 2.57 & 0.292 & 0.010 & 1.73 & 0.024 & 0.010 & 0.00 & 1100 & 65 & 1000 & 1227 & normal & 1,571 & 119 \\
\hline BY-103 & SST & 3.82 & 0.292 & 3.82 & 0.292 & 0.010 & 3.14 & 0.024 & 0.010 & 0.00 & 1100 & 65 & 1000 & 1227 & normal & 1,660 & 125 \\
\hline BY-104 & SST & 3.74 & 0.292 & 3.74 & 0.292 & 0.010 & 2.25 & 0.024 & 0.010 & 0.00 & 1100 & 65 & 1000 & 1227 & normal & 1,714 & 129 \\
\hline BY-105 & SST & 4.44 & 0.292 & 4.44 & 0.292 & 0.010 & 2.79 & 0.024 & 0.010 & 0.00 & 1100 & 65 & 1000 & 1227 & normal & 1,801 & 136 \\
\hline BY-106 & SST & 3.96 & 0.292 & 3.96 & 0.292 & 0.010 & 1.90 & 0.024 & 0.010 & 0.00 & 1100 & 65 & 1000 & 1227 & normal & 1,649 & 126 \\
\hline BY-107 & SST & 2.51 & 0.292 & 2.51 & 0.292 & 0.010 & 1.79 & 0.024 & 0.010 & 0.00 & 1100 & 65 & 1000 & 1227 & normal & 1,689 & 127 \\
\hline BY-108 & $\begin{array}{l}\text { SST } \\
\end{array}$ & 2.05 & 0.292 & 2.05 & 0.292 & 0.010 & 1.70 & 0.024 & 0.010 & 0.00 & 1100 & 65 & 1000 & 1227 & normal & 1,485 & 112 \\
\hline BY-109 & SST & 2.65 & 0.292 & 2.65 & 0.292 & 0.010 & 2.73 & 0.024 & 0.010 & 0.00 & 1100 & 65 & 1000 & 1227 & normal & 1,706 & 129 \\
\hline BY-110 & SST & 3.38 & 0.292 & 3.38 & 0.292 & 0.010 & 2.52 & 0.024 & 0.010 & 0.00 & 1100 & 65 & 1000 & 1227 & normal & 1,566 & 118 \\
\hline BY-111 & SST & 3.72 & 0.292 & 3.72 & 0.292 & 0.010 & 1.81 & 0.024 & 0.010 & 0.00 & 1100 & 65 & 1000 & 1227 & normal & 1,673 & 126 \\
\hline
\end{tabular}




\begin{tabular}{|c|c|c|c|c|c|c|c|c|c|c|c|c|c|c|c|c|c|}
\hline Data Source & & $\begin{array}{l}\text { RPP-5926 R8 } \\
\text { RPP-10006 R7 }\end{array}$ & $\begin{array}{c}\text { RPP-10006 R7 } \\
\text { Data }\end{array}$ & $\begin{array}{l}\text { RPP-5926 R8, } \\
\text { Appendix C }\end{array}$ & $\begin{array}{c}\text { RPP-10006 R7 } \\
\text { Data }\end{array}$ & $\begin{array}{c}\text { RPP-10006 R7 } \\
\text { Data }\end{array}$ & $\begin{array}{c}\text { RPP-5926 R8, } \\
\text { Appendix C }\end{array}$ & $\begin{array}{c}\text { RPP-10006 R7 } \\
\text { Data }\end{array}$ & $\begin{array}{c}\text { RPP-10006 R7 } \\
\text { Data }\end{array}$ & $\begin{array}{c}\text { RPP-10006 R7 } \\
\text { Data }\end{array}$ & $\begin{array}{l}\text { RPP-5926 R8, } \\
\text { RPP-10006 R7 }\end{array}$ & \begin{tabular}{|c|} 
Calculated value \\
(see RPP-10006, \\
Appendix B), \\
RPP-10006 R7
\end{tabular} & \begin{tabular}{|} 
Calculated value \\
(see RPP-10006, \\
Appendix B), \\
RPP-10006 R7
\end{tabular} & $\begin{array}{c}\text { Calculated value } \\
\text { (see RPP-10006, } \\
\text { Appendix B), } \\
\text { RPP-10006 R7 }\end{array}$ & $\begin{array}{l}\text { RPP-10006, } \\
\text { Appendix B }\end{array}$ & $\begin{array}{l}\text { RPP-5926 R8, } \\
\text { RPP-10006 R7 }\end{array}$ & $\begin{array}{l}\text { Calculated value } \\
\text { (see RPP-10006, } \\
\text { Appendix B), } \\
\text { RPP-10006 R7 }\end{array}$ \\
\hline Tank \# & Tank Type & $\begin{array}{c}\text { Total waste } \\
\text { depth } \\
\text { (m) }\end{array}$ & \begin{tabular}{|c} 
Total waste \\
depth \\
uncertainty \\
(m)
\end{tabular} & $\begin{array}{c}\text { Total non- } \\
\text { convective } \\
\text { waste depth } \\
(\mathbf{m}) \\
\end{array}$ & \begin{tabular}{|c|} 
Total non- \\
convective \\
waste depth \\
uncertainty \\
$(m)$
\end{tabular} & \begin{tabular}{|c|} 
Total non- \\
convective \\
waste depth \\
lower bound \\
$(\mathrm{m})$
\end{tabular} & $\begin{array}{c}\text { Wetted non- } \\
\text { convective } \\
\text { waste depth } \\
(\mathbf{m})\end{array}$ & $\begin{array}{c}\text { Wetted non- } \\
\text { convective } \\
\text { waste depth } \\
\text { uncertainty } \\
(m)\end{array}$ & $\begin{array}{c}\text { Wetted non- } \\
\text { convective } \\
\text { waste depth } \\
\text { lower bound } \\
(\mathrm{m})\end{array}$ & \begin{tabular}{|c} 
Mean Crust \\
depth \\
(m)
\end{tabular} & $\begin{array}{c}\text { Convective } \\
\text { Waste } \\
\text { Density } \\
\text { Mean } \\
\text { (kg/m3) } \\
\end{array}$ & \begin{tabular}{|c} 
Convective \\
Waste \\
Density \\
Std Dev \\
$(\mathrm{kg} / \mathrm{m} 3)$
\end{tabular} & \begin{tabular}{|c|} 
Convective \\
Waste \\
Density \\
Min \\
$(\mathrm{kg} / \mathrm{m} 3)$ \\
\end{tabular} & \begin{tabular}{|c|} 
Convective \\
Waste \\
Density \\
Max \\
$(\mathbf{k g} / \mathbf{m} 3)$
\end{tabular} & $\begin{array}{c}\text { Convective } \\
\text { Waste } \\
\text { Density } \\
\text { Dist } \\
(\mathbf{k g} / \mathbf{m} 3)\end{array}$ & $\begin{array}{c}\text { Non- } \\
\text { Convective } \\
\text { Waste } \\
\text { Density } \\
\text { Mean } \\
(\mathrm{kg} / \mathrm{m} 3)\end{array}$ & $\begin{array}{c}\text { Non- } \\
\text { Convective } \\
\text { Waste } \\
\text { Density Std } \\
\text { Dev }(\mathrm{kg} / \mathrm{m} 3)\end{array}$ \\
\hline$\overline{B Y-112}$ & SST & 2.64 & 0.292 & 2.64 & 0.292 & 0.010 & 0.74 & 0.024 & 0.010 & 0.00 & 1100 & 65 & 1000 & 1227 & normal & 1,740 & 131 \\
\hline C-101 & $\begin{array}{l}\text { SST } \\
\end{array}$ & 0.81 & 0.292 & 0.81 & 0.292 & 0.010 & 1.00 & 0.292 & 0.000 & 0.00 & 1100 & 65 & 1000 & 1227 & normal & 1,780 & 134 \\
\hline $\begin{array}{l}\mathrm{C}-102 \\
\end{array}$ & $\begin{array}{l}\text { SST } \\
\end{array}$ & 2.92 & 0.292 & 2.92 & 0.292 & 0.010 & 3.11 & 0.292 & 0.000 & 0.00 & 1170 & 69 & 1035 & 1305 & normal & 1,681 & 127 \\
\hline $\mathrm{C}-103$ & SST & 0.02 & 0.006 & 0.02 & 0.292 & 0.010 & 0.21 & 0.292 & 0.010 & 0.00 & 980 & 65 & 1000 & 1238 & normal & 1,610 & 122 \\
\hline C-104 & SST & 2.39 & 0.292 & 2.39 & 0.292 & 0.010 & 2.58 & 0.292 & 0.000 & 0.00 & 1100 & 65 & 1000 & 1227 & normal & 1,680 & 127 \\
\hline $\mathrm{C}-105$ & SST & 1.22 & 0.292 & 1.22 & 0.292 & 0.010 & 1.41 & 0.292 & 0.000 & 0.00 & 1100 & 65 & 1000 & 1227 & normal & 1,550 & 117 \\
\hline $\begin{array}{l}\mathrm{C}-106 \\
\end{array}$ & $\begin{array}{l}\text { SST } \\
\end{array}$ & 0.03 & 0.006 & 0.02 & 0.292 & 0.010 & 0.21 & 0.292 & 0.010 & 0.00 & 1020 & 60 & 1000 & 1138 & normal & 1,560 & 118 \\
\hline $\mathrm{C}-107$ & SST & 2.28 & 0.292 & 2.28 & 0.292 & 0.010 & 2.47 & 0.292 & 0.000 & 0.00 & 1100 & 65 & 1000 & 1227 & normal & 1,550 & 117 \\
\hline C-108* & SST & 0.07 & 0.292 & 0.07 & 0.292 & 0.010 & 0.42 & 0.292 & 0.000 & 0.00 & 1120 & 69 & 1035 & 1305 & normal & 1,480 & 112 \\
\hline $\mathrm{C}-109^{*}$ & SST & 0.09 & 0.292 & 0.09 & 0.292 & 0.010 & 0.77 & 0.292 & 0.000 & 0.00 & 1100 & 65 & 1000 & 1227 & normal & 1,430 & 117 \\
\hline $\mathrm{C}-110$ & SST & 1.64 & 0.006 & 1.63 & 0.292 & 0.010 & 1.82 & 0.292 & 0.010 & 0.00 & 1100 & 65 & 1000 & 1227 & normal & 1,440 & 101 \\
\hline $\mathrm{C}-111$ & SST & 0.53 & 0.292 & 0.53 & 0.292 & 0.010 & 0.72 & 0.292 & 0.000 & 0.00 & 1100 & 65 & 1000 & 1227 & normal & 1,546 & 117 \\
\hline $\mathrm{C}-112$ & $\begin{array}{l}\text { SST } \\
\end{array}$ & 0.96 & 0.292 & 0.96 & 0.292 & 0.010 & 1.15 & 0.292 & 0.000 & 0.00 & 1170 & 69 & 1035 & 1305 & normal & 1,575 & 119 \\
\hline $\mathrm{C}-201$ & $\begin{array}{l}\text { SST } \\
\end{array}$ & 0.00 & 0.292 & 0.00 & 0.292 & 0.010 & 0.26 & 0.292 & 0.000 & 0.00 & 1000 & 65 & 1000 & 1227 & normal & 1,750 & 109 \\
\hline $\mathrm{C}-202$ & SST & 0.00 & 0.006 & 0.00 & 0.292 & 0.010 & 0.10 & 0.292 & 0.000 & 0.00 & 1000 & 65 & 1000 & 1227 & normal & 1,750 & 109 \\
\hline $\mathrm{C}-203$ & SST & 0.00 & 0.006 & 0.00 & 0.292 & 0.010 & 0.09 & 0.292 & 0.000 & 0.00 & 1000 & 59 & 1000 & 1116 & normal & 1,930 & 122 \\
\hline $\mathrm{C}-204$ & SST & 0.00 & 0.292 & 0.00 & 0.292 & 0.010 & 0.09 & 0.292 & 0.000 & 0.00 & 1000 & 59 & 1000 & 1116 & normal & 1,770 & 134 \\
\hline S-101 & SST & 3.25 & 0.292 & 3.25 & 0.292 & 0.010 & 3.20 & 0.024 & 0.010 & 0.00 & 1100 & 65 & 1000 & 1227 & normal & 1,652 & 125 \\
\hline $\mathrm{S}-102^{*}$ & SST & 0.28 & 0.292 & 0.28 & 0.292 & 0.010 & 0.00 & 0.292 & 0.010 & 0.00 & 1460 & 86 & 1291 & 1629 & normal & 1,527 & 136 \\
\hline S-103 & SST & 2.19 & 0.006 & 2.18 & 0.292 & 0.010 & 2.34 & 0.024 & 0.010 & 0.00 & 1450 & 86 & 1282 & 1618 & normal & 1,617 & 122 \\
\hline S-104 & SST & 2.66 & 0.292 & 2.66 & 0.292 & 0.010 & 2.83 & 0.024 & 0.010 & 0.00 & 1370 & 81 & 1212 & 1528 & normal & 1,668 & 126 \\
\hline S-105 & SST & 3.75 & 0.292 & 3.75 & 0.292 & 0.010 & 1.40 & 0.024 & 0.010 & 0.00 & 1100 & 65 & 1000 & 1227 & normal & 1,657 & 125 \\
\hline S-106 & SST & 4.20 & 0.292 & 4.20 & 0.292 & 0.010 & 1.48 & 0.024 & 0.010 & 0.00 & 1100 & 65 & 1000 & 1227 & normal & 1,722 & 130 \\
\hline S-107 & SST & 3.31 & 0.292 & 3.31 & 0.292 & 0.010 & 3.10 & 0.024 & 0.010 & 0.00 & 1310 & 77 & 1159 & 1461 & normal & 1,775 & 134 \\
\hline S-108 & SST & 5.08 & 0.292 & 5.08 & 0.292 & 0.010 & 1.67 & $\begin{array}{c}0.024 \\
\end{array}$ & 0.010 & 0.00 & 1100 & 65 & 1000 & 1227 & normal & 1,677 & 127 \\
\hline S-109 & $\begin{array}{l}\text { SST } \\
\end{array}$ & 4.92 & 0.292 & 4.92 & 0.292 & 0.010 & 1.85 & 0.024 & 0.010 & 0.00 & 1100 & 65 & 1000 & 1227 & normal & 1,657 & 125 \\
\hline S-110 & SST & 3.59 & 0.292 & 3.59 & 0.292 & 0.010 & 3.32 & 0.024 & 0.010 & 0.00 & 1100 & 65 & 1000 & 1227 & normal & 1,662 & 126 \\
\hline S-111 & SST & 3.70 & 0.292 & 3.70 & 0.292 & 0.010 & 2.25 & 0.024 & 0.010 & 0.00 & 1450 & 86 & 1282 & 1618 & normal & 1,425 & 117 \\
\hline S-112* & SST & 0.02 & 0.292 & 0.02 & 0.292 & 0.010 & 0.00 & 0.292 & 0.010 & 0.00 & 1270 & 86 & 1282 & 1618 & normal & 1,900 & 129 \\
\hline SX-101 & SST & 3.86 & 0.292 & 3.86 & 0.292 & 0.010 & 3.05 & 0.024 & 0.010 & 0.00 & 1100 & 65 & 1000 & 1227 & normal & 1,679 & 127 \\
\hline SX-102 & SST & 3.15 & 0.292 & 3.15 & 0.292 & 0.010 & 3.36 & 0.292 & 0.000 & 0.00 & 1100 & 65 & 1000 & 1227 & normal & 1,697 & 128 \\
\hline SX-103 & SST & 4.70 & 0.292 & 4.70 & 0.292 & 0.010 & 2.46 & 0.024 & 0.010 & 0.00 & 1470 & 87 & 1300 & 1640 & normal & 1,729 & 131 \\
\hline SX-104 & SST & 4.12 & 0.292 & 4.12 & 0.292 & 0.010 & 2.40 & 0.024 & 0.010 & 0.00 & 1470 & 87 & 1300 & 1640 & normal & 1,695 & 128 \\
\hline SX-105 & $\begin{array}{l}\text { SST } \\
\end{array}$ & 3.47 & 0.292 & 3.47 & 0.292 & 0.010 & 2.46 & 0.024 & 0.010 & 0.00 & 1100 & 65 & 1000 & 1227 & normal & 1,630 & 123 \\
\hline SX-106 & SST & 3.66 & 0.292 & 3.66 & 0.292 & 0.010 & 2.02 & 0.024 & 0.010 & 0.00 & 1100 & 65 & 1000 & 1227 & normal & 1,578 & 119 \\
\hline SX-107 & SST & 0.87 & 0.292 & 0.87 & 0.292 & 0.010 & 1.08 & 0.292 & 0.000 & 0.00 & 1100 & 65 & 1000 & 1227 & normal & 1,770 & 134 \\
\hline SX-108 & SST & 0.68 & 0.292 & 0.68 & 0.292 & 0.010 & 0.89 & 0.292 & 0.000 & 0.00 & 1100 & 65 & 1000 & 1227 & normal & 1,770 & 134 \\
\hline
\end{tabular}




\begin{tabular}{|c|c|c|c|c|c|c|c|c|c|c|c|c|c|c|c|c|c|}
\hline Data Source & & $\begin{array}{l}\text { RPP-5926 R8 } \\
\text { RPP-10006 R7 }\end{array}$ & $\begin{array}{c}\text { RPP-10006 R7 } \\
\text { Data }\end{array}$ & $\begin{array}{c}\text { RPP-5926 R8, } \\
\text { Appendix C }\end{array}$ & $\begin{array}{c}\text { RPP-10006 R7 } \\
\text { Data }\end{array}$ & $\begin{array}{c}\text { RPP-10006 R7 } \\
\text { Data }\end{array}$ & $\begin{array}{l}\text { RPP-5926 R8, } \\
\text { Appendix C }\end{array}$ & $\begin{array}{c}\text { RPP-10006 R7 } \\
\text { Data }\end{array}$ & $\begin{array}{c}\text { RPP-10006 R7 } \\
\text { Data }\end{array}$ & $\begin{array}{c}\text { RPP-10006 R7 } \\
\text { Data }\end{array}$ & $\begin{array}{l}\text { RPP-5926 R8, } \\
\text { RPP-10006 R7 }\end{array}$ & \begin{tabular}{|c|} 
Calculated value \\
(see RPP-10006, \\
Appendix B), \\
RPP-10006 R7
\end{tabular} & \begin{tabular}{|} 
Calculated value \\
(see RPP-10006, \\
Appendix B), \\
RPP-10006 R7
\end{tabular} & $\begin{array}{c}\text { Calculated value } \\
\text { (see RPP-10006, } \\
\text { Appendix B), } \\
\text { RPP-10006 R7 }\end{array}$ & $\begin{array}{l}\text { RPP-10006, } \\
\text { Appendix B }\end{array}$ & \begin{tabular}{|l|} 
RPP-5926 R8 \\
RPP-10006 R7
\end{tabular} & \begin{tabular}{|c|} 
Calculated value \\
(see RPP-10006, \\
Appendix B), \\
RPP-10006 R7
\end{tabular} \\
\hline Tank \# & Tank Type & $\begin{array}{c}\text { Total waste } \\
\text { depth } \\
\text { (m) }\end{array}$ & \begin{tabular}{|c} 
Total waste \\
depth \\
uncertainty \\
(m)
\end{tabular} & \begin{tabular}{|c|}
$\begin{array}{c}\text { Total non- } \\
\text { convective } \\
\text { waste depth } \\
(\mathbf{m})\end{array}$ \\
\end{tabular} & \begin{tabular}{|c|}
$\begin{array}{c}\text { Total non- } \\
\text { convective } \\
\text { waste depth } \\
\text { uncertainty } \\
(m)\end{array}$ \\
\end{tabular} & \begin{tabular}{|c|} 
Total non- \\
convective \\
waste depth \\
lower bound \\
$(\mathrm{m})$
\end{tabular} & \begin{tabular}{|c} 
Wetted non- \\
convective \\
waste depth \\
$(\mathbf{m})$
\end{tabular} & $\begin{array}{c}\text { Wetted non- } \\
\text { convective } \\
\text { waste depth } \\
\text { uncertainty } \\
(m)\end{array}$ & \begin{tabular}{|c|} 
Wetted non- \\
convective \\
waste depth \\
lower bound \\
$(\mathrm{m})$
\end{tabular} & $\begin{array}{c}\text { Mean Crust } \\
\text { depth } \\
\text { (m) }\end{array}$ & $\begin{array}{c}\text { Convective } \\
\text { Waste } \\
\text { Density } \\
\text { Mean } \\
\text { (kg/m3) } \\
\end{array}$ & \begin{tabular}{|c|}
$\begin{array}{c}\text { Convective } \\
\text { Waste } \\
\text { Density } \\
\text { Std Dev } \\
(\mathrm{kg} / \mathbf{m} 3)\end{array}$ \\
\end{tabular} & \begin{tabular}{|c|} 
Convective \\
Waste \\
Density \\
Min \\
$(\mathrm{kg} / \mathrm{m} 3)$ \\
\end{tabular} & \begin{tabular}{|c|} 
Convective \\
Waste \\
Density \\
Max \\
$(\mathbf{k g} / \mathbf{m} 3)$
\end{tabular} & $\begin{array}{c}\text { Convective } \\
\text { Waste } \\
\text { Density } \\
\text { Dist } \\
(\mathrm{kg} / \mathrm{m} 3)\end{array}$ & \begin{tabular}{|c|} 
Non- \\
Convective \\
Waste \\
Density \\
Mean \\
$(\mathrm{kg} / \mathrm{m} 3)$ \\
\end{tabular} & $\begin{array}{c}\text { Non- } \\
\text { Convective } \\
\text { Waste } \\
\text { Density Std } \\
\text { Dev }(\mathrm{kg} / \mathrm{m} 3)\end{array}$ \\
\hline SX-109 & SST & 2.23 & 0.292 & 2.23 & 0.292 & 0.010 & 2.44 & 0.292 & 0.000 & 0.00 & 1100 & 65 & 1000 & 1227 & normal & 1,734 & 131 \\
\hline SX-110 & SST & 0.52 & 0.292 & 0.52 & 0.292 & 0.010 & 0.72 & 0.292 & 0.000 & 0.00 & 1100 & 65 & 1000 & 1227 & normal & 1,763 & 133 \\
\hline SX-111 & SST & 1.06 & 0.292 & 1.06 & 0.292 & 0.010 & 0.34 & 0.024 & 0.010 & 0.00 & 1100 & 65 & 1000 & 1227 & normal & 1,762 & 133 \\
\hline SX-112 & SST & 0.69 & 0.292 & 0.69 & 0.292 & 0.010 & 0.51 & 0.024 & 0.000 & 0.00 & 1100 & 65 & 1000 & 1227 & normal & 1,770 & 134 \\
\hline SX-113 & SST & 0.18 & 0.292 & 0.18 & 0.292 & 0.010 & 0.38 & 0.292 & 0.000 & 0.00 & 1100 & 65 & 1000 & 1227 & normal & 1,430 & 132 \\
\hline SX-114 & SST & 1.43 & 0.292 & 1.43 & 0.292 & 0.010 & 1.64 & 0.292 & 0.000 & 0.00 & 1100 & 65 & 1000 & 1227 & normal & 1,751 & 132 \\
\hline SX-115 & $\begin{array}{l}\text { SST } \\
\end{array}$ & 0.04 & 0.292 & 0.04 & 0.292 & 0.010 & 0.17 & 0.292 & 0.000 & 0.00 & 1100 & 65 & 1000 & 1227 & normal & 1,770 & 134 \\
\hline SY-101* & DST & 10.22 & 0.006 & 2.31 & 0.30 & 0.01 & 2.31 & 0.30 & 0.01 & 0.00 & 1130 & 92 & 1000 & 1311 & normal & 1512 & 99 \\
\hline SY-102* & DST & 5.25 & 0.006 & 1.93 & 0.27 & 0.01 & 1.93 & 0.25 & 0.01 & 0.00 & 1120 & 92 & 1000 & 1311 & normal & 1552 & 100 \\
\hline SY-103* & DST & 6.82 & 0.065 & 3.68 & 0.40 & 0.01 & 3.68 & 0.40 & 0.01 & 0.58 & 1490 & 120 & 1235 & 1705 & normal & 1553 & 105 \\
\hline T-101 & SST & 0.92 & 0.292 & 0.92 & 0.292 & 0.010 & 1.09 & 0.024 & 0.000 & 0.00 & 1100 & 65 & 1000 & 1227 & normal & 1,544 & 117 \\
\hline T-102 & SST & 0.29 & 0.006 & 0.18 & 0.292 & 0.010 & 0.37 & 0.292 & 0.010 & 0.00 & 1140 & 67 & 1008 & 1272 & normal & 1,797 & 136 \\
\hline T-103 & $\begin{array}{l}\text { SST } \\
\end{array}$ & 0.25 & 0.006 & 0.21 & 0.292 & 0.010 & 0.40 & 0.292 & 0.010 & 0.00 & 1190 & 70 & 1052 & 1328 & normal & 1,714 & 129 \\
\hline T-104 & SST & 2.93 & 0.292 & 2.93 & 0.292 & 0.010 & 2.73 & 0.024 & 0.010 & 0.00 & 1100 & 65 & 1000 & 1227 & normal & 1,290 & 97 \\
\hline T-105 & SST & 0.91 & 0.292 & 0.91 & 0.292 & 0.010 & 1.09 & 0.292 & 0.000 & 0.00 & 1100 & 65 & 1000 & 1227 & normal & 1,460 & 110 \\
\hline T-106 & $\begin{array}{l}\text { SST } \\
\end{array}$ & 0.20 & 0.292 & 0.20 & 0.292 & 0.010 & 0.39 & 0.292 & 0.000 & 0.00 & 1100 & 65 & 1000 & 1227 & normal & 1,587 & 120 \\
\hline T-107 & SST & 1.60 & 0.292 & 1.60 & 0.292 & 0.010 & 1.79 & 0.292 & 0.000 & 0.00 & 1100 & 65 & 1000 & 1227 & normal & 1,560 & 118 \\
\hline T-108 & SST & 0.15 & 0.292 & 0.15 & 0.292 & 0.010 & 0.34 & 0.292 & 0.000 & 0.00 & 1100 & 65 & 1000 & 1227 & normal & 1,547 & 117 \\
\hline T-109 & SST & 0.57 & 0.292 & 0.57 & 0.292 & 0.010 & 0.57 & 0.024 & 0.010 & 0.00 & 1100 & 65 & 1000 & 1227 & normal & 1,646 & 124 \\
\hline T-110 & SST & 3.42 & 0.006 & 3.41 & 0.292 & 0.010 & 3.60 & 0.292 & 0.010 & 0.00 & 1050 & 62 & 1000 & 1171 & normal & 1,250 & 94 \\
\hline T-111 & SST & 4.13 & 0.292 & 4.13 & 0.292 & 0.010 & 4.24 & 0.024 & 0.010 & 0.00 & 1100 & 65 & 1000 & 1227 & normal & 1,240 & 94 \\
\hline T-112 & $\begin{array}{l}\text { SST } \\
\end{array}$ & 0.61 & 0.006 & 0.55 & 0.292 & 0.010 & 0.74 & 0.292 & 0.010 & 0.00 & 1100 & 65 & 1000 & 1227 & normal & 1,280 & 97 \\
\hline T-201 & $\begin{array}{l}\text { SST } \\
\end{array}$ & 0.28 & 0.006 & 0.26 & 0.292 & 0.010 & 3.88 & 0.292 & 0.010 & 0.00 & 1060 & 63 & 1000 & 1183 & normal & 1,310 & 99 \\
\hline T-202 & $\begin{array}{l}\text { SST } \\
\end{array}$ & 0.19 & 0.292 & 0.19 & 0.292 & 0.010 & 2.85 & 0.292 & 0.000 & 0.00 & 1100 & 65 & 1000 & 1227 & normal & 1,180 & 89 \\
\hline $\mathrm{T}-203$ & SST & 0.33 & 0.292 & 0.33 & 0.292 & 0.010 & 4.88 & 0.292 & 0.000 & 0.00 & 1100 & 65 & 1000 & 1227 & normal & 1,220 & 92 \\
\hline T-204 & SST & 0.33 & 0.292 & 0.33 & 0.292 & 0.010 & 4.88 & 0.292 & 0.000 & 0.00 & 1100 & 65 & 1000 & 1227 & normal & 1,180 & 89 \\
\hline TX-101 & SST & 0.84 & 0.292 & 0.84 & 0.292 & 0.010 & 1.03 & 0.292 & 0.000 & 0.00 & 1100 & 65 & 1000 & 1227 & normal & 1,740 & 131 \\
\hline TX-102 & SST & 2.00 & 0.292 & 2.00 & 0.292 & 0.010 & 1.52 & 0.024 & 0.010 & 0.00 & 1100 & 65 & 1000 & 1227 & normal & 1,614 & 122 \\
\hline TX-103 & SST & 1.34 & 0.292 & 1.34 & 0.292 & 0.010 & 1.17 & 0.024 & 0.000 & 0.00 & 1100 & 65 & 1000 & 1227 & normal & 1,611 & 122 \\
\hline TX-104 & SST & 0.64 & 0.006 & 0.62 & 0.292 & 0.010 & 0.81 & 0.292 & 0.010 & 0.00 & 1440 & 85 & 1273 & 1607 & normal & 1,737 & 131 \\
\hline TX-105 & SST & 5.32 & 0.292 & 5.32 & 0.292 & 0.010 & 1.44 & 0.024 & 0.010 & 0.00 & 1100 & 65 & 1000 & 1227 & normal & 1,634 & 123 \\
\hline TX-106 & SST & 3.22 & 0.292 & 3.22 & 0.292 & 0.010 & 2.42 & 0.024 & 0.010 & 0.00 & 1100 & 65 & 1000 & 1227 & normal & 1,620 & 122 \\
\hline TX-107 & SST & 0.27 & 0.292 & 0.27 & 0.292 & 0.010 & 0.46 & 0.292 & 0.000 & 0.00 & 1100 & 65 & 1000 & 1227 & normal & 1,782 & 135 \\
\hline TX-108 & $\begin{array}{l}\text { SST } \\
\end{array}$ & 1.17 & 0.292 & 1.17 & 0.292 & 0.010 & 1.36 & 0.292 & 0.000 & 0.00 & 1100 & 65 & 1000 & 1227 & normal & 1,622 & 122 \\
\hline TX-109 & $\begin{array}{l}\text { SST } \\
\end{array}$ & 3.35 & 0.292 & 3.35 & 0.292 & 0.010 & 3.21 & 0.024 & 0.010 & 0.00 & 1100 & 65 & 1000 & 1227 & normal & 1,430 & 108 \\
\hline TX-110 & SST & 4.32 & 0.292 & 4.32 & 0.292 & 0.010 & 1.48 & 0.024 & 0.010 & 0.00 & 1100 & 65 & 1000 & 1227 & normal & 1,618 & 122 \\
\hline TX-111 & SST & 3.37 & 0.292 & 3.37 & 0.292 & 0.010 & 1.83 & 0.024 & 0.010 & 0.00 & 1100 & 65 & 1000 & 1227 & normal & 1,612 & 122 \\
\hline
\end{tabular}




\begin{tabular}{|c|c|c|c|c|c|c|c|c|c|c|c|c|c|c|c|c|c|}
\hline Data Source & & $\begin{array}{l}\text { RPP-5926 R8 } \\
\text { RPP-10006 R7 }\end{array}$ & $\begin{array}{c}\text { RPP-10006 R7 } \\
\text { Data }\end{array}$ & $\begin{array}{l}\text { RPP-5926 R8, } \\
\text { Appendix C }\end{array}$ & $\begin{array}{c}\text { RPP-10006 R7 } \\
\text { Data }\end{array}$ & $\begin{array}{c}\text { RPP-10006 R7 } \\
\text { Data }\end{array}$ & $\begin{array}{l}\text { RPP-5926 R8, } \\
\text { Appendix C }\end{array}$ & $\begin{array}{c}\text { RPP-10006 R7 } \\
\text { Data }\end{array}$ & $\begin{array}{c}\text { RPP-10006 R7 } \\
\text { Data }\end{array}$ & $\begin{array}{c}\text { RPP-10006 R7 } \\
\text { Data }\end{array}$ & $\begin{array}{l}\text { RPP-5926 R8, } \\
\text { RPP-10006 R7 }\end{array}$ & \begin{tabular}{|c|} 
Calculated value \\
(see RPP-10006, \\
Appendix B), \\
RPP-10006 R7
\end{tabular} & $\begin{array}{l}\text { Calculated value } \\
\text { (see RPP-10006, } \\
\text { Appendix B), } \\
\text { RPP-10006 R7 }\end{array}$ & \begin{tabular}{|} 
Calculated value \\
(see RPP-10006, \\
Appendix B), \\
RPP-10006 R7
\end{tabular} & $\begin{array}{l}\text { RPP-10006, } \\
\text { Appendix B }\end{array}$ & $\begin{array}{l}\text { RPP-5926 R8, } \\
\text { RPP-10006 R7 }\end{array}$ & $\begin{array}{l}\text { Calculated value } \\
\text { (see RPP-10006, } \\
\text { Appendix B), } \\
\text { RPP-10006 R7 }\end{array}$ \\
\hline Tank \# & Tank Type & $\begin{array}{c}\text { Total waste } \\
\text { depth } \\
\text { (m) }\end{array}$ & $\begin{array}{c}\text { Total waste } \\
\text { depth } \\
\text { uncertainty } \\
\text { (m) }\end{array}$ & $\begin{array}{c}\text { Total non- } \\
\text { convective } \\
\text { waste depth } \\
(\mathbf{m})\end{array}$ & $\begin{array}{c}\text { Total non- } \\
\text { convective } \\
\text { waste depth } \\
\text { uncertainty } \\
\text { (m) }\end{array}$ & \begin{tabular}{|c|} 
Total non- \\
convective \\
waste depth \\
lower bound \\
$(\mathbf{m})$
\end{tabular} & $\begin{array}{c}\text { Wetted non- } \\
\text { convective } \\
\text { waste depth } \\
\text { (m) }\end{array}$ & $\begin{array}{c}\text { Wetted non- } \\
\text { convective } \\
\text { waste depth } \\
\text { uncertainty } \\
(m)\end{array}$ & $\begin{array}{c}\text { Wetted non- } \\
\text { convective } \\
\text { waste depth } \\
\text { lower bound } \\
\text { (m) }\end{array}$ & $\begin{array}{c}\text { Mean Crust } \\
\text { depth } \\
\text { (m) }\end{array}$ & $\begin{array}{c}\text { Convective } \\
\text { Waste } \\
\text { Density } \\
\text { Mean } \\
(\mathbf{k g} / \mathbf{m} 3)\end{array}$ & $\begin{array}{c}\text { Convective } \\
\text { Waste } \\
\text { Density } \\
\text { Std Dev } \\
(\mathbf{k g} / \mathbf{m} 3)\end{array}$ & \begin{tabular}{|c} 
Convective \\
Waste \\
Density \\
Min \\
$(\mathrm{kg} / \mathrm{m} 3)$
\end{tabular} & \begin{tabular}{|c|} 
Convective \\
Waste \\
Density \\
Max \\
$(\mathrm{kg} / \mathrm{m} 3)$
\end{tabular} & $\begin{array}{c}\text { Convective } \\
\text { Waste } \\
\text { Density } \\
\text { Dist } \\
(\mathbf{k g} / \mathbf{m} 3)\end{array}$ & \begin{tabular}{|} 
Non- \\
Convective \\
Waste \\
Density \\
Mean \\
$(\mathrm{kg} / \mathrm{m} 3)$
\end{tabular} & $\begin{array}{c}\text { Non- } \\
\text { Convective } \\
\text { Waste } \\
\text { Density } S t d \\
\text { Dev }(\mathrm{kg} / \mathrm{m} 3)\end{array}$ \\
\hline TX-112 & SST & 5.85 & 0.292 & 5.85 & 0.292 & 0.010 & 3.42 & 0.024 & 0.010 & 0.00 & 1100 & 65 & 1000 & 1227 & normal & 1,633 & 123 \\
\hline TX-113 & SST & 5.90 & 0.292 & 5.90 & 0.292 & 0.010 & 1.90 & 0.024 & 0.010 & 0.00 & 1100 & 65 & 1000 & 1227 & normal & 1,608 & 121 \\
\hline TX-114 & SST & 4.91 & 0.292 & 4.91 & 0.292 & 0.010 & 2.00 & 0.024 & 0.010 & 0.00 & 1100 & 65 & 1000 & 1227 & normal & 1,634 & 123 \\
\hline TX-115 & SST & 5.11 & 0.292 & 5.11 & 0.292 & 0.010 & 2.56 & 0.024 & 0.010 & 0.00 & 1100 & 65 & 1000 & 1227 & normal & 1,628 & 123 \\
\hline TX-116 & SST & 5.52 & 0.292 & 5.52 & 0.292 & 0.010 & 1.39 & 0.024 & 0.000 & 0.00 & 1100 & 65 & 1000 & 1227 & normal & 1,658 & 125 \\
\hline TX-117 & SST & 4.43 & 0.292 & 4.43 & 0.292 & 0.010 & 1.13 & 0.024 & 0.010 & 0.00 & 1100 & 65 & 1000 & 1227 & normal & 1,581 & 119 \\
\hline TX-118 & SST & 2.28 & 0.292 & 2.28 & 0.292 & 0.010 & 2.08 & 0.024 & 0.010 & 0.00 & 1100 & 65 & 1000 & 1227 & normal & 1,692 & 128 \\
\hline TY-101 & SST & 1.09 & 0.292 & 1.09 & 0.292 & 0.010 & 1.28 & 0.292 & 0.000 & 0.00 & 1100 & 65 & 1000 & 1227 & normal & 1,627 & 123 \\
\hline TY-102 & SST & 0.64 & 0.292 & 0.64 & 0.292 & 0.010 & 0.83 & 0.292 & 0.000 & 0.00 & 1100 & 65 & 1000 & 1227 & normal & 1,756 & 133 \\
\hline TY-103 & SST & 1.43 & 0.292 & 1.43 & 0.292 & 0.010 & 1.60 & 0.024 & 0.010 & 0.00 & 1100 & 65 & 1000 & 1227 & normal & 1,681 & 127 \\
\hline TY-104 & SST & $\overline{0.41}$ & 0.006 & 0.40 & 0.292 & 0.010 & 0.59 & 0.292 & 0.010 & 0.00 & 1180 & 70 & 1044 & 1316 & normal & 1,650 & 125 \\
\hline TY-105 & SST & 2.13 & 0.292 & 2.13 & 0.292 & 0.010 & 1.65 & 0.024 & 0.010 & 0.00 & 1100 & 65 & 1000 & 1227 & normal & 1,530 & 116 \\
\hline TY-106 & SST & 0.15 & 0.292 & 0.15 & 0.292 & 0.010 & 0.34 & 0.292 & 0.000 & 0.00 & 1100 & 65 & 1000 & 1227 & normal & 1,400 & 106 \\
\hline U-101 & SST & 0.21 & 0.292 & 0.21 & 0.292 & 0.010 & 0.40 & 0.292 & 0.000 & 0.00 & 1100 & 65 & 1000 & 1227 & normal & 1,770 & 134 \\
\hline U-102 & $\begin{array}{l}\text { SST } \\
\end{array}$ & 3.02 & 0.292 & 3.01 & 0.292 & 0.010 & 2.01 & 0.024 & 0.010 & 0.00 & 1480 & 87 & 1309 & 1651 & normal & 1,673 & 126 \\
\hline $\mathrm{U}-103$ & SST & 3.85 & 0.292 & 3.85 & 0.292 & 0.010 & 1.53 & 0.024 & 0.010 & 0.00 & 1440 & 85 & 1273 & 1607 & normal & 1,520 & 128 \\
\hline$\overline{\mathrm{U}-104}$ & $\begin{array}{l}\text { SST } \\
\end{array}$ & 0.50 & 0.292 & 0.50 & 0.292 & 0.010 & 1.32 & 0.292 & 0.000 & 0.00 & 1100 & 65 & 1000 & 1227 & normal & 1,124 & 108 \\
\hline U-105 & SST & 3.26 & 0.292 & 3.26 & 0.292 & 0.010 & 2.58 & 0.024 & 0.010 & 0.00 & 1100 & 65 & 1000 & 1227 & normal & 1,670 & 126 \\
\hline $\mathrm{U}-106$ & SST & $\begin{array}{l}.207 \\
\end{array}$ & 0.006 & 1.56 & 0.292 & 0.010 & 1.75 & 0.292 & 0.010 & 0.00 & 1340 & 79 & 1185 & 1495 & normal & 1,552 & 117 \\
\hline U-107 & SST & 2.72 & 0.292 & 2.72 & 0.292 & 0.010 & 1.92 & 0.024 & 0.010 & 0.00 & 1390 & 82 & 1229 & 1551 & normal & 1,738 & 131 \\
\hline U-108 & $\begin{array}{ll}\text { SST } \\
\end{array}$ & 4.00 & 0.292 & 4.00 & 0.292 & 0.010 & 2.96 & 0.024 & 0.010 & 0.00 & 1400 & 83 & 1238 & 1562 & normal & 1,681 & 127 \\
\hline U-109 & SST & 3.70 & 0.292 & 3.70 & 0.292 & 0.010 & 2.00 & 0.024 & 0.010 & 0.00 & 1100 & 65 & 1000 & 1227 & normal & 1,472 & 125 \\
\hline U-110 & $\begin{array}{ll}\text { SST } \\
\end{array}$ & 1.62 & 0.292 & 1.62 & 0.292 & 0.010 & 0.81 & 0.024 & 0.010 & 0.00 & 1100 & 65 & 1000 & 1227 & normal & 1,715 & 130 \\
\hline U-111 & SST & 2.05 & 0.292 & 2.05 & 0.292 & 0.010 & 1.84 & 0.024 & 0.010 & 0.00 & 1100 & 65 & 1000 & 1227 & normal & 1,633 & 121 \\
\hline U-112 & $\begin{array}{ll}\text { SST } \\
\end{array}$ & 0.42 & 0.292 & 0.42 & 0.292 & 0.010 & 0.61 & 0.292 & 0.000 & 0.00 & 1100 & 65 & 1000 & 1227 & normal & 1,743 & 132 \\
\hline $\mathrm{U}-201$ & SST & 0.04 & 0.006 & 0.03 & 0.292 & 0.010 & 0.58 & 0.292 & 0.010 & 0.00 & 1260 & 74 & 1114 & 1406 & normal & 1,630 & 123 \\
\hline $\mathrm{U}-202$ & $\begin{array}{l}\text { SST } \\
\end{array}$ & 0.03 & 0.006 & 0.02 & 0.292 & 0.010 & 0.54 & 0.292 & 0.010 & 0.00 & 1280 & 76 & 1132 & 1428 & normal & 1,510 & 114 \\
\hline U-203 & SST & 0.03 & 0.006 & 0.02 & 0.292 & 0.010 & 0.50 & 0.292 & 0.010 & 0.00 & 1280 & 76 & 1132 & 1428 & normal & 1,590 & 120 \\
\hline$\overline{\mathrm{U}-204}$ & SST & 0.03 & 0.006 & 0.02 & 0.292 & 0.010 & 0.42 & 0.292 & $\overline{0.010}$ & 0.00 & 1110 & 65 & 1000 & 1238 & normal & 1,470 & 111 \\
\hline
\end{tabular}




\begin{tabular}{|c|c|c|c|c|c|c|c|c|c|c|c|c|c|c|c|c|c|}
\hline Data Source & & $\begin{array}{c}\text { Calculated value } \\
\text { (see RPP-10006, } \\
\text { Appendix B), } \\
\text { RPP-10006 R7 }\end{array}$ & $\begin{array}{l}\text { Calculated value } \\
\text { (see RPP-10006, } \\
\text { Appendix B), } \\
\text { RPP-10006 R7 }\end{array}$ & $\begin{array}{l}\text { RPP-10006, } \\
\text { Appendix B }\end{array}$ & \begin{tabular}{|l|} 
RPP-5926 R8, \\
RPP-10006 R7
\end{tabular} & $\begin{array}{l}\text { RPP-5926 R8, } \\
\text { RPP-10006 R7 }\end{array}$ & $\begin{array}{c}\text { RPP-10006 R7 } \\
\text { Data }\end{array}$ & $\begin{array}{c}\text { RPP-10006 R7 } \\
\text { Data }\end{array}$ & $\begin{array}{c}\text { RPP-10006 R7, } \\
\text { OSD-T-151- } \\
\text { 00007, R1 }\end{array}$ & $\begin{array}{c}\text { RPP-10006 R7 } \\
\text { Data }\end{array}$ & $\begin{array}{c}\text { RPP-10006 R7 } \\
\text { Data }\end{array}$ & $\begin{array}{c}\text { RPP-10006 R7 } \\
\text { Data }\end{array}$ & $\begin{array}{c}\text { RPP-10006 R7 } \\
\text { Data }\end{array}$ & $\begin{array}{c}\text { RPP-10006 R7 } \\
\text { Data }\end{array}$ & $\begin{array}{c}\text { RPP-10006 R7 } \\
\text { Data }\end{array}$ & $\begin{array}{c}\text { RPP-10006 R7 } \\
\text { Data }\end{array}$ & $\begin{array}{c}\text { RPP-10006 R7 } \\
\text { Data }\end{array}$ \\
\hline Tank \# & Tank Type & \begin{tabular}{|c} 
Non- \\
Convective \\
Waste \\
Density \\
Min \\
$(\mathrm{kg} / \mathrm{m} 3)$ \\
\end{tabular} & \begin{tabular}{|c|} 
Non- \\
Convective \\
Waste \\
Density \\
Max \\
$(\mathbf{k g} / \mathbf{m} 3)$ \\
\end{tabular} & $\begin{array}{c}\text { Non- } \\
\text { Convective } \\
\text { Waste } \\
\text { Density } \\
\text { Dist } \\
(\mathrm{kg} / \mathrm{m} 3) \\
\end{array}$ & \begin{tabular}{|c|} 
Non- \\
Convective \\
Waste \\
Average \\
Temperatur \\
$\mathbf{e}(\mathbf{K})$ \\
\end{tabular} & $\begin{array}{c}\text { Tank Vapor } \\
\text { Space } \\
\text { Average } \\
\text { Temperatur } \\
\text { e (K) } \\
\end{array}$ & $\begin{array}{c}\text { Tank type } \\
\text { group }\end{array}$ & $\begin{array}{c}\text { Total tank } \\
\text { volume } \\
(\mathrm{m} 3)\end{array}$ & $\begin{array}{c}\text { OSD } \\
\text { Maximum } \\
\text { Operating } \\
\text { Limit (m) } \\
\end{array}$ & Dish type & \begin{tabular}{|c|} 
Dish height \\
$(\mathbf{m})$
\end{tabular} & $\begin{array}{c}\text { Dish volume } \\
(\mathrm{kL})\end{array}$ & \begin{tabular}{|c|} 
Dish Radius \\
$(\mathbf{m})$
\end{tabular} & $\begin{array}{c}\text { Knuckle } \\
\text { height } \\
\text { (m) }\end{array}$ & $\begin{array}{c}\text { Knuckle } \\
\text { volume } \\
\text { (M3) }\end{array}$ & $\begin{array}{l}\text { Knuckle } \\
\text { Radius } \\
\text { (m) }\end{array}$ & $\begin{array}{c}\text { Body height } \\
\text { (m) }\end{array}$ \\
\hline $\mathrm{A}-101$ & SST & 1,449 & 1,952 & normal & 317 & 307 & $\mathrm{a}$ & 4,988 & 9.27 & flat & 0.0008 & 0.0000 & 0.0000 & 0.0000 & 0.0000 & 0.0003 & 9.855 \\
\hline $\mathrm{A}-102$ & $\begin{array}{l}\text { SST } \\
\end{array}$ & 1,422 & 1,916 & normal & 309 & 308 & $\mathrm{a}$ & 4,988 & 9.27 & flat & 0.0008 & 0.0000 & 0.0000 & 0.0000 & 0.0000 & 0.0003 & 9.855 \\
\hline A-103 & SST & 1,491 & 2,009 & normal & 314 & 307 & $\mathrm{a}$ & 4,988 & 9.27 & flat & 0.0008 & 0.0000 & 0.0000 & 0.0000 & 0.0000 & 0.0003 & 9.855 \\
\hline A-104 & SST & 1,491 & 2,009 & normal & 347 & 307 & $\mathrm{a}$ & 4,988 & 9.27 & flat & 0.0008 & 0.0000 & 0.0000 & 0.0000 & 0.0000 & 0.0003 & 9.855 \\
\hline $\mathrm{A}-105$ & SST & 1,312 & 1,768 & normal & 332 & 332 & $\mathrm{a}$ & 4,988 & 9.27 & flat & 0.0008 & 0.0000 & 0.0000 & 0.0000 & 0.0000 & 0.0003 & 9.855 \\
\hline A-106 & SST & 1,448 & 1,952 & normal & 323 & 323 & $\mathrm{a}$ & 4,988 & 9.27 & flat & 0.0008 & 0.0000 & 0.0000 & 0.0000 & 0.0000 & 0.0003 & 9.855 \\
\hline AN-101* & DST & 1352 & 1747 & normal & 298 & 298 & an & 5,324 & 10.72 & flat & 0.0095 & 3.12 & 0.00 & 0.30 & 123.44 & 0.30 & 10.42 \\
\hline AN-102* & DST & 1335 & 1725 & normal & 307 & 307 & an & 5,324 & 10.72 & flat & 0.0095 & 3.12 & 0.00 & 0.30 & 123.44 & 0.30 & 10.42 \\
\hline AN-103* & DST & 1501 & 1939 & normal & 313 & 304 & an & 5,324 & 10.72 & flat & 0.0095 & 3.12 & 0.00 & 0.30 & 123.44 & 0.30 & 10.42 \\
\hline AN-104* & DST & 1387 & 1793 & normal & 314 & 304 & an & 5,324 & 10.72 & flat & 0.0095 & 3.12 & 0.00 & 0.30 & 123.44 & 0.30 & 10.42 \\
\hline AN-105* & DST & 1370 & 1770 & normal & 310 & 304 & an & 5,324 & 10.72 & flat & 0.0095 & 3.12 & 0.00 & 0.30 & 123.44 & 0.30 & 10.42 \\
\hline AN-106* & DST & 1295 & 1673 & normal & 311 & 304 & an & 5,324 & 10.72 & flat & 0.0095 & 3.12 & 0.00 & 0.30 & 123.44 & 0.30 & 10.42 \\
\hline AN-107* & $\begin{array}{l}\text { DST } \\
\end{array}$ & 1291 & 1669 & normal & 310 & 306 & an & 5,324 & 10.72 & flat & 0.0095 & 3.12 & 0.00 & 0.30 & 123.44 & 0.30 & 10.42 \\
\hline AP-101* & DST & 1527 & 1973 & normal & 297 & 299 & ap & 5,324 & 11.53 & flat & 0.0095 & 3.12 & 0.00 & 0.30 & 123.44 & 0.30 & 10.42 \\
\hline AP-102* & DST & 1527 & 1973 & normal & 300 & 300 & ap & 5,324 & 11.53 & flat & 0.0095 & 3.12 & 0.00 & 0.30 & 123.44 & 0.30 & 10.42 \\
\hline AP-103* & DST & 1466 & 1894 & normal & 304 & 309 & ap & 5,324 & 11.53 & flat & 0.0095 & 3.12 & 0.00 & 0.30 & 123.44 & 0.30 & 10.42 \\
\hline AP-104* & DST & 1405 & 1815 & normal & 310 & 311 & ap & 5,324 & 11.53 & flat & 0.0095 & 3.12 & 0.00 & 0.30 & 123.44 & 0.30 & 10.42 \\
\hline AP-105* & DST & 1405 & 1815 & normal & 298 & 297 & ap & 5,324 & 11.53 & flat & 0.0095 & 3.12 & 0.00 & 0.30 & 123.44 & 0.30 & 10.42 \\
\hline AP-106* & DST & 1405 & 1815 & normal & 297 & 297 & ap & 5,324 & 11.53 & flat & 0.0095 & 3.12 & 0.00 & 0.30 & 123.44 & 0.30 & 10.42 \\
\hline AP-107* & DST & 1405 & 1815 & normal & 296 & 295 & ap & 5,324 & 11.53 & flat & 0.0095 & 3.12 & 0.00 & 0.30 & 123.44 & 0.30 & 10.42 \\
\hline AP-108* & DST & 1353 & 1747 & normal & 297 & 300 & ap & 5,324 & 11.53 & flat & 0.0095 & 3.12 & 0.00 & 0.30 & 123.44 & 0.30 & 10.42 \\
\hline AW-101* & DST & 1387 & 1793 & normal & 313 & 304 & aw & 5,324 & 10.72 & flat & 0.0095 & 3.12 & 0.00 & 0.30 & 123.44 & 0.30 & 10.42 \\
\hline AW-102* & $\begin{array}{l}\text { DST } \\
\end{array}$ & 1396 & 1804 & normal & 299 & 298 & $\mathrm{aw}$ & 5,324 & 10.39 & flat & 0.0095 & 3.12 & 0.00 & 0.30 & 123.44 & 0.30 & 10.42 \\
\hline AW-103* & DST & 1299 & 1678 & normal & 299 & 298 & $\mathrm{aw}$ & 5,324 & 10.72 & flat & 0.0095 & 3.12 & 0.00 & 0.30 & 123.44 & 0.30 & 10.42 \\
\hline AW-104* & DST & 1295 & 1674 & normal & 304 & 302 & aw & 5,324 & 10.72 & flat & 0.0095 & 3.12 & 0.00 & 0.30 & 123.44 & 0.30 & 10.42 \\
\hline AW-105* & DST & 1162 & 1502 & normal & 296 & 298 & $\mathrm{aw}$ & 5,324 & 10.72 & flat & 0.0095 & 3.12 & 0.00 & 0.30 & 123.44 & 0.30 & 10.42 \\
\hline AW-106* & DST & 1545 & 1995 & normal & 311 & 300 & aw & 5,324 & 10.72 & flat & 0.0095 & 3.12 & 0.00 & 0.30 & 123.44 & 0.30 & 10.42 \\
\hline AX-101 & SST & 1,450 & 1,954 & normal & 308 & 300 & $\mathrm{ax}$ & 5,046 & 9.27 & flat & 0.0008 & 0.0000 & 0.0000 & 0.1524 & 62.2477 & 0.1524 & 9.754 \\
\hline $\mathrm{AX}-102$ & SST & 1,344 & 1,811 & normal & 297 & 297 & ax & 5,046 & 9.27 & flat & 0.0008 & 0.0000 & 0.0000 & 0.1524 & 62.2477 & 0.1524 & 9.754 \\
\hline AX-103 & SST & 1,346 & 1,814 & normal & 312 & 306 & ax & 5,046 & 9.27 & flat & 0.0008 & 0.0000 & 0.0000 & 0.1524 & 62.2477 & 0.1524 & 9.754 \\
\hline AX-104 & SST & 1,534 & 2,066 & normal & 305 & 305 & ax & 5,046 & 9.27 & flat & 0.0008 & 0.0000 & 0.0000 & 0.1524 & 62.2477 & 0.1524 & 9.754 \\
\hline AY-101* & DST & 1469 & 1898 & normal & 312 & 301 & ay & 5,325 & 9.42 & flat & 0.0127 & 4.16 & 0.00 & 0.30 & 123.44 & 0.30 & 10.42 \\
\hline AY-102* & DST & 1389 & 1795 & normal & 331 & 316 & ay & 5,325 & 9.42 & flat & 0.0127 & 4.16 & 0.00 & 0.30 & 123.44 & 0.30 & 10.42 \\
\hline AZ-101* & DST & 1405 & 1815 & normal & 336 & 324 & $\mathrm{az}$ & 5,324 & 9.42 & flat & 0.0095 & 3.12 & 0.00 & 0.30 & 123.44 & 0.30 & 10.42 \\
\hline AZ-102* & DST & 1230 & 1590 & normal & 345 & 333 & az & 5,324 & 9.42 & flat & 0.0095 & 3.12 & 0.00 & 0.30 & 123.44 & 0.30 & 10.42 \\
\hline B-101 & SST & 1,269 & 1,709 & normal & 312 & 306 & $\mathrm{~b}$ & 3,215 & 4.80 & dished & 0.3048 & 50.6778 & 173.7360 & 1.2171 & 477.6507 & 1.2192 & 4.269 \\
\hline B-102 & SST & 1,373 & 1,850 & normal & 291 & 294 & $\mathrm{~b}$ & 3,215 & 4.80 & dished & 0.3048 & 50.6778 & 173.7360 & 1.2171 & 477.6507 & 1.2192 & 4.269 \\
\hline
\end{tabular}




\begin{tabular}{|c|c|c|c|c|c|c|c|c|c|c|c|c|c|c|c|c|c|}
\hline Data Source & & \begin{tabular}{|c|} 
Calculated value \\
(see RPP-10006, \\
Appendix B), \\
RPP-10006 R7
\end{tabular} & $\begin{array}{l}\text { Calculated value } \\
\text { (see RPP-10006, } \\
\text { Appendix), } \\
\text { RPP-10006 R7 }\end{array}$ & $\begin{array}{l}\text { RPP-10006, } \\
\text { Appendix B }\end{array}$ & $\begin{array}{l}\text { RPP. } 5926 \mathrm{R}, \\
\text { RPP } 10006 \text { R }\end{array}$ & $\begin{array}{l}\text { RPP-5926 R, } \\
\text { RPP- } 10006 \text { R7 }\end{array}$ & $\begin{array}{c}\text { RPP-10006 R7 } 7 \\
\text { Data }\end{array}$ & $\begin{array}{c}\text { RPP- } 100006 \mathrm{R} 7 \\
\text { Data }\end{array}$ & \begin{tabular}{|c|} 
RPP-10006 R7, \\
OSDD-T-151- \\
00007, R1
\end{tabular} & $\begin{array}{c}\text { RPP-10006 R7 } 7 \\
\text { Data }\end{array}$ & $\begin{array}{c}\text { RPP-10006 R7 } 7 \\
\text { Data }\end{array}$ & $\begin{array}{l}\text { RPP-10006 R7 } 7 \\
\text { Data }\end{array}$ & $\begin{array}{c}\text { RPP-10006 R7 } 7 \\
\text { Data }\end{array}$ & $\begin{array}{c}\text { RPP-10006 R7 } \\
\text { Data }\end{array}$ & $\begin{array}{c}\text { RPP-10006 R7 } 7 \\
\text { Data }\end{array}$ & $\begin{array}{c}\text { RPP-10006 R7 } 7 \\
\text { Data }\end{array}$ & $\begin{array}{c}\text { RPP-10006 R7 } 7 \\
\text { Data }\end{array}$ \\
\hline Tank \# & Tank Type & \begin{tabular}{|c|} 
Non- \\
Convective \\
Waste \\
Density \\
Min \\
(kg/m3)
\end{tabular} & $\begin{array}{c}\text { Non- } \\
\text { Convective } \\
\text { Waste } \\
\text { Density } \\
\text { Max } \\
\text { (kg/m3) }\end{array}$ & $\begin{array}{c}\text { Non- } \\
\text { Convective } \\
\text { Waste } \\
\text { Density } \\
\text { Dist } \\
(\mathbf{k g} / \mathbf{m} 3)\end{array}$ & $\begin{array}{c}\text { Non- } \\
\text { Convective } \\
\text { Waste } \\
\text { Average } \\
\text { Temperatur } \\
\mathbf{e}(\mathbf{K})\end{array}$ & $\begin{array}{c}\text { Tank Vapor } \\
\text { Space } \\
\text { Average } \\
\text { Temperatur } \\
\mathbf{e}(\mathbf{K})\end{array}$ & $\begin{array}{l}\text { Tank type } \\
\text { group }\end{array}$ & $\begin{array}{c}\text { Total tank } \\
\text { volume } \\
\text { (m3) }\end{array}$ & \begin{tabular}{|c|} 
OSD \\
Maximum \\
Operating \\
Limit (m)
\end{tabular} & Dish type & $\begin{array}{l}\text { Dish height } \\
\text { (m) }\end{array}$ & $\begin{array}{c}\text { Dish volume } \\
\text { (kL) }\end{array}$ & \begin{tabular}{|} 
Dish Radius \\
$(\mathbf{m})$
\end{tabular} & $\begin{array}{c}\text { Knuckle } \\
\text { height } \\
\text { (m) }\end{array}$ & 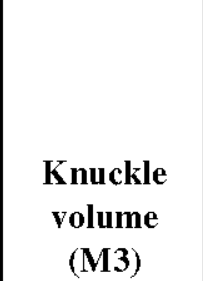 & $\begin{array}{l}\text { Knuckle } \\
\text { Radius } \\
\text { (m) }\end{array}$ & $\begin{array}{l}\text { Body height } \\
\text { (m) }\end{array}$ \\
\hline B-103 & $\begin{array}{l}\text { SST } \\
\text { SSm }\end{array}$ & $\begin{array}{l}1,374 \\
1,10\end{array}$ & 1,851 & normal & 290 & $\begin{array}{l}294 \\
05\end{array}$ & $\mathrm{~b}$ & $\begin{array}{l}, 215 \\
3215\end{array}$ & $\begin{array}{l}4.80 \\
.80\end{array}$ & \begin{tabular}{|l|l|} 
dishhed \\
dishod
\end{tabular} & \begin{tabular}{|l}
0.3048 \\
0300
\end{tabular} & \begin{tabular}{|l|l|}
50.6778 \\
5.670
\end{tabular} & \begin{tabular}{|l|l}
173.7360 \\
\end{tabular} & 1.2171 & 4777.6507 & 1.2192 & $\begin{array}{l}4.269 \\
.1200\end{array}$ \\
\hline$\frac{B-104}{B-105}$ & $\begin{array}{l}\text { SST } \\
\text { SST }\end{array}$ & $\frac{1,1,10}{1,408}$ & $\begin{array}{l}1,590 \\
1,898\end{array}$ & $\begin{array}{c}\text { normal } \\
\text { normal }\end{array}$ & $\frac{295}{292}$ & $\frac{295}{291}$ & $\frac{b}{b}$ & $\frac{3,215}{3,215}$ & $\frac{4.80}{4.80}$ & 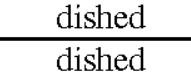 & \begin{tabular}{|l}
0.3048 \\
0.3048
\end{tabular} & $\frac{50.6778}{50.678}$ & $\frac{173.7360}{177.7360}$ & $\frac{1.2171}{1.2171}$ & \begin{tabular}{|l|}
477.6507 \\
47.6507
\end{tabular} & $\frac{1.2192}{1.2192}$ & $\begin{array}{l}4.269 \\
4.269\end{array}$ \\
\hline B-106 & SST & 1,177 & 1,586 & normal & 296 & 293 & $\mathrm{~b}$ & 3,215 & 4.80 & dished & 0.3048 & 50.6778 & 173.7360 & 1.2171 & 477.6507 & 1.2192 & 4.269 \\
\hline B-107 & $\begin{array}{l}\text { SST } \\
\end{array}$ & 1,385 & 1,867 & normal & 289 & 304 & $\mathrm{~b}$ & 3,215 & 4.80 & dished & 0.3048 & 50.6778 & 173.7360 & 1.2171 & 477.6507 & 1.2192 & 4.269 \\
\hline B-108 & $\begin{array}{l}\text { SST } \\
\end{array}$ & 1,428 & 1,924 & normal & 294 & 293 & $\mathrm{~b}$ & 3,215 & 4.80 & dished & 0.3048 & 50.6778 & 173.7360 & 1.2171 & 477.6507 & 1.2192 & 4.269 \\
\hline B-109 & $\begin{array}{l}\text { SST } \\
\end{array}$ & 1,520 & 2,047 & normal & 293 & 293 & $\mathrm{~b}$ & 3,215 & 4.80 & dished & 0.3048 & 50.6778 & $\begin{array}{l}173.7360 \\
\end{array}$ & 1.2171 & \begin{tabular}{|l|l}
47.6507 \\
\end{tabular} & 1.2192 & 4.269 \\
\hline B-110 & $\begin{array}{l}\text { SST } \\
\end{array}$ & 1,159 & 1,561 & normal & 295 & 295 & $\mathrm{~b}$ & 3,215 & 4.80 & $\begin{array}{l}\text { dished } \\
\text { dished }\end{array}$ & 0.3048 & 50.6778 & 173.7360 & 1.2171 & 477.6507 & 1.2192 & 4.269 \\
\hline B-111 & $\begin{array}{l}\text { SST } \\
\end{array}$ & 1,082 & 1,458 & $\begin{array}{l}\text { normal } \\
\end{array}$ & 297 & 298 & $\mathrm{~b}$ & 3,215 & 4.80 & dished & 0.3048 & 78 & 173. & 1.2171 & \begin{tabular}{|l|l|}
477.6507 \\
\end{tabular} & 1.2192 & 4.269 \\
\hline B-112 & SST & $\begin{array}{l}1,491 \\
\end{array}$ & 2,009 & normal & 298 & 293 & $\mathrm{~b}$ & 3,215 & 4.80 & dished & 0.3048 & $\begin{array}{l}50.6778 \\
\end{array}$ & $\begin{array}{l}173.7360 \\
\end{array}$ & 1.2171 & \begin{tabular}{|l|l|}
477.6507 \\
\end{tabular} & 1.2192 & 4.269 \\
\hline $\begin{array}{l}\text { B-201 } \\
\text { B-202 }\end{array}$ & $\begin{array}{l}\text { SST } \\
\text { SCT }\end{array}$ & 1,074 & 1,446 & normal & 291 & 293 & $\mathrm{~b} 2$ & 225 & 7.24 & dished & 0.1524 & 1.2214 & 16.7894 & & 23.3622 & 0.9144 & 6.866 \\
\hline $\begin{array}{l}\text { B-202 } \\
\text { B-2033 }\end{array}$ & $\begin{array}{l}\text { SST } \\
\text { SST }\end{array}$ & $\frac{1,039}{10,014}$ & $\begin{array}{l}1,401 \\
1,366\end{array}$ & $\begin{array}{l}\text { normal } \\
\text { normal }\end{array}$ & $\frac{289}{200}$ & $\frac{292}{204}$ & $\frac{62}{b 2}$ & $\frac{225}{205}$ & $\frac{7.24}{774}$ & $\begin{array}{l}\text { dished } \\
\text { dishedd }\end{array}$ & 0.1524 & $\frac{1.2214}{12214}$ & $\begin{array}{l}16.7894 \\
167894\end{array}$ & 0.9065 & $\begin{array}{l}23.3622 \\
23262 \\
\end{array}$ & $\begin{array}{l}0.9144 \\
0.114\end{array}$ & 6.866 \\
\hline B-204 & $\frac{S O 1}{S S T}$ & $\frac{1,014}{1,014}$ & $\begin{array}{l}1,366 \\
1,366\end{array}$ & normal & $\frac{290}{290}$ & $\frac{2944}{294}$ & $\frac{\mathrm{b} 2}{\mathrm{~b} 2}$ & $\frac{225}{225}$ & $\frac{7.24}{7.24}$ & $\begin{array}{l}\text { dished } \\
\text { dished }\end{array}$ & $\frac{0.1524}{0.1524}$ & $\frac{1.2214}{1.2214}$ & $\frac{16 .}{16 .}$ & $\frac{0.9}{0.9}$ & $\begin{array}{l}23.3622 \\
23.3622 \\
\end{array}$ & $\frac{0.9144}{0.9144}$ & $\frac{6.866}{6.866}$ \\
\hline BX-101 & SST & 1,431 & 1,929 & normal & 295 & 295 & $\mathrm{bx}$ & 3,215 & 4.80 & dished & 0.3048 & 50.6413 & 173.6110 & 1.2171 & 477.3316 & 1.2192 & 4.276 \\
\hline BX-102 & SST & 1,527 & 1,286 & normal & 293 & 295 & $b x$ & 3,215 & 4.80 & dished & 0.3048 & 50.6413 & 173.6110 & 1.2171 & 477.3316 & 1.2192 & 4.276 \\
\hline BX-103 & SST & 1,415 & 1,907 & normal & 294 & 295 & $\mathrm{bx}$ & 3,215 & 4.80 & dished & 0.3048 & 50.6413 & 173.6110 & 1.2171 & 477.3316 & 1.2192 & 4.276 \\
\hline BX-104 & SST & 1,431 & 1,929 & normal & 303 & 298 & $\mathrm{bx}$ & 3,215 & 4.80 & dished & 0.3048 & 50.6413 & 173.6110 & 1.2171 & 4777.3316 & 1.2192 & 4.276 \\
\hline BX-105 & SST & 1,443 & 1,945 & normal & 293 & 293 & $b x$ & 3,215 & 4.80 & dished & 0.3048 & 50.6 & 173 & 1.2171 & 4777 & 1.2192 & 4.276 \\
\hline BX-106 & $\begin{array}{l}\text { SST } \\
\end{array}$ & 1,378 & 1,857 & $\begin{array}{l}\text { normal } \\
\end{array}$ & 294 & 293 & $b x$ & 3, & -1 & dis & & & & & & 1.2192 & 4.276 \\
\hline BX-107 & $\begin{array}{l}\text { SST } \\
\end{array}$ & 1,227 & 1,653 & normal & 295 & 293 & $\mathrm{bx}$ & 3,2 & 4.8 & dished & & & 173. & 1.2 & & 1.2192 & 4.276 \\
\hline BX-108 & SST & 1,242 & 1,673 & normal & 293 & 293 & $\mathrm{bx}$ & 3,2 & & & & & 173. & 1.2 & & 1.2192 & 4.276 \\
\hline $\begin{array}{l}\text { BX-109 } \\
\text { DY } 110\end{array}$ & $\begin{array}{l}\text { SST } \\
\text { SCT }\end{array}$ & 1,295 & 1,745 & normal & 294 & 294 & $\mathrm{bx}$ & $\frac{3,2}{2,2}$ & 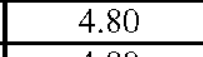 & & & & 173. & 4.2 & \begin{tabular}{|l|l|} 
\\
\end{tabular} & 1.2192 & 4.276 \\
\hline$\frac{B X-110}{\text { By }}$ & $\begin{array}{l}\text { SST } \\
\end{array}$ & $\frac{1,420}{1222}$ & $\frac{1,913}{1,661}$ & normal & 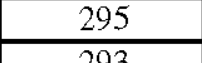 & $\frac{295}{204}$ & $\frac{b x}{b x}$ & 3,2 & 4. & dish & 0.3 & $\frac{50.6}{50.6}$ & 173.6 & 1.2 & & 1.2192 & 4.276 \\
\hline$\frac{B X-111}{B X X 112}$ & $\frac{\text { SST }}{\text { SST }}$ & $\frac{1,233}{1,116}$ & $\begin{array}{l}1,651 \\
1,504\end{array}$ & normal & $\frac{293}{294}$ & $\begin{array}{l}294 \\
292\end{array}$ & $\frac{b x}{b x}$ & $\frac{3,215}{3,215}$ & $\frac{4.80}{4.80}$ & $\begin{array}{l}\text { dishedd } \\
\text { dishhed }\end{array}$ & $\begin{array}{l}0.3048 \\
0.3048\end{array}$ & $\frac{50.6413}{50.613}$ & $\frac{177.6110}{173.6110}$ & $\frac{1.2171}{1.2171}$ & \begin{tabular}{|l|}
4777.31616 \\
47.3316 \\
\end{tabular} & $\frac{1.2192}{1.2192}$ & $\frac{4.2766}{4.276}$ \\
\hline BY-101 & SST & 1,566 & 2,110 & normal & 300 & 298 & by & $\frac{3,411}{3,967}$ & $\frac{4.00}{7.14}$ & dished & 0.3048 & 50.6413 & 173.6110 & $\frac{1.2111}{1.2171}$ & \begin{tabular}{|l}
477.3316 \\
\end{tabular} & $\begin{array}{l}1.2192 \\
.2192\end{array}$ & 6.079 \\
\hline BY-102 & SST & 1,338 & 1,803 & normal & 295 & 295 & by & 3,967 & 7.14 & dished & 0.3048 & 50.6 & 173.6 & 1.2171 & 477.3316 & 1.2192 & 6.079 \\
\hline BY-103 & SST & 1,415 & 1,906 & normal & 297 & 296 & by & 3,967 & 7.14 & dis & 0.3 & & & 1.2 & 477 & 1.2192 & 6.079 \\
\hline BY-104 & $\begin{array}{l}\text { SST } \\
\end{array}$ & 1,460 & 1,96 & $\begin{array}{l}\text { normal } \\
\text { nof }\end{array}$ & 312 & 297 & by & 3,9 & 7.14 & dis & 0. & & 173 & 1.2 & & 1.2192 & 6.079 \\
\hline & SST & 1, & 2,067 & nor & 308 & 294 & by & 3, & 7. & di & & & & & & 2 & 79 \\
\hline $51+2$ & $\begin{array}{l}\text { SST } \\
\end{array}$ & 1,426 & 1,921 & $\begin{array}{l}\text { normal } \\
\end{array}$ & 305 & 310 & by & 3,967 & 7.14 & dist & 0.3048 & & 173 & 1.2 & 477. & 1.2192 & 6.079 \\
\hline BY-107 & $\begin{array}{l}\text { SST } \\
\end{array}$ & 1,438 & $\begin{array}{l}1,937 \\
\end{array}$ & normal & 303 & 298 & by & 3,967 & 7.14 & $\begin{array}{l}\text { dishe } \\
\end{array}$ & 0.3048 & 50.6 & $\begin{array}{l}173.6110 \\
\end{array}$ & 1.2 & \begin{tabular}{|l|l|}
477.3316 \\
\end{tabular} & $\begin{array}{l}1.2192 \\
\end{array}$ & 6.079 \\
\hline BY-108 & SST & 1,265 & 1,704 & normal & 308 & 301 & by & 3,967 & 7.14 & dished & 0.3048 & 50.6 & 173.6110 & 1.2171 & \begin{tabular}{|l|l}
477.3316 \\
\end{tabular} & 1.2192 & 6.079 \\
\hline $\begin{array}{l}\text { BY-109 } \\
\end{array}$ & $\begin{array}{l}\text { SST } \\
\end{array}$ & 1,453 & 1,958 & normal & 292 & 290 & by & 3,967 & 7.14 & dished & 0.3048 & 50.6413 & 173.6 & 1.2171 & 477.3316 & 1.2192 & 6.079 \\
\hline$\frac{Y-110}{Y-111}$ & $\begin{array}{l}\text { SST } \\
\text { SST }\end{array}$ & $\frac{1,334}{1.426}$ & $\begin{array}{l}1,797 \\
1,921\end{array}$ & normal & $\begin{array}{l}306 \\
298\end{array}$ & $\begin{array}{l}293 \\
292\end{array}$ & $\frac{\text { by }}{\text { by }}$ & $\begin{array}{l}3,967 \\
3,667\end{array}$ & $\begin{array}{l}7.14 \\
7.14\end{array}$ & $\begin{array}{l}\text { dished } \\
\text { dished }\end{array}$ & $\begin{array}{l}0.3048 \\
0.3048\end{array}$ & $\frac{50.6413}{50.613}$ & \begin{tabular}{|l|l|}
173.6110 \\
173.6110
\end{tabular} & $\frac{1.2171}{1.2171}$ & \begin{tabular}{|l|}
477.331616 \\
4773316 \\
\end{tabular} & $\begin{array}{l}1.2192 \\
1.2192\end{array}$ & $\frac{6.079}{6.079}$ \\
\hline
\end{tabular}




\begin{tabular}{|c|c|c|c|c|c|c|c|c|c|c|c|c|c|c|c|c|c|}
\hline Data Source & & 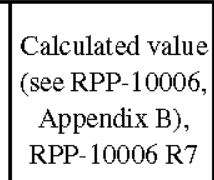 & \begin{tabular}{|l} 
Calculated value \\
(se RPP-1006, \\
Appendix B), \\
RPP-10006 R7
\end{tabular} & $\begin{array}{l}\text { RPP-10006, } \\
\text { Appendix B }\end{array}$ & \begin{tabular}{|l} 
RPP-5926R, \\
RPP-10006 R7
\end{tabular} & \begin{tabular}{|l} 
RPP $5926 \mathrm{RS}$ \\
RPP-1000 RT
\end{tabular} & $\begin{array}{l}\text { RPP-10006 R7 } 7 \\
\text { Data }\end{array}$ & \begin{tabular}{|l} 
RPP-10006 R7 7 \\
Data
\end{tabular} & \begin{tabular}{|c} 
RPP. $100006 \mathrm{RT}$, \\
OSD- T-1-1- \\
$00007, \mathrm{R1}$
\end{tabular} & $\begin{array}{l}\text { RPP-10006 R7 } \\
\text { Data }\end{array}$ & $\begin{array}{c}\text { RPP-10006 R7 } \\
\text { Data }\end{array}$ & $\begin{array}{l}\text { RPP-10006 R7 } 7 \\
\text { Data }\end{array}$ & $\begin{array}{c}\text { RPP-10006 R7 } 7 \\
\text { Data }\end{array}$ & $\begin{array}{l}\text { RPP-10006 R7 } \\
\text { Data }\end{array}$ & $\begin{array}{l}\text { RPP-10006 R7 } 7 \\
\text { Data }\end{array}$ & \begin{tabular}{|l} 
RPP-10006 R7 7 \\
Data
\end{tabular} & \begin{tabular}{|l} 
RPP-10006 R7 \\
Data
\end{tabular} \\
\hline Tank \# & Tank Type & \begin{tabular}{|c|c} 
Non- \\
Convective \\
Waste \\
Density \\
Min \\
(kg $/ \mathbf{m} 3 \mathbf{3})$
\end{tabular} & \begin{tabular}{|c} 
Non- \\
Convective \\
Waste \\
Density \\
Max \\
(kg/m3)
\end{tabular} & $\begin{array}{c}\text { Non- } \\
\text { Convective } \\
\text { Waste } \\
\text { Density } \\
\text { Dist } \\
\text { (kg/m3) }\end{array}$ & \begin{tabular}{|c} 
Non- \\
Convective \\
Waste \\
Average \\
Temperatur \\
$\mathbf{e}(\mathbf{K})$
\end{tabular} & $\mid \begin{array}{c}\text { Tank Vapor } \\
\text { Space } \\
\text { Average } \\
\text { Temperatur } \\
\mathbf{e}(\mathbf{K})\end{array}$ & $\begin{array}{c}\text { Tank type } \\
\text { group }\end{array}$ & \begin{tabular}{|c} 
Total tank \\
volume \\
(m3)
\end{tabular} & \begin{tabular}{|c} 
OSD \\
Maximum \\
Operating \\
Limit (m)
\end{tabular} & Dish type & $\begin{array}{l}\text { Dish height } \\
\text { (m) }\end{array}$ & $\begin{array}{c}\text { Dish volume } \\
\text { (kL) }\end{array}$ & $\begin{array}{l}\text { Dish Radius } \\
(\mathbf{m})\end{array}$ & $\begin{array}{c}\text { Knuckle } \\
\text { height } \\
(\mathbf{m})\end{array}$ & $\begin{array}{l}\text { Knuckle } \\
\text { volume } \\
\text { (M) }\end{array}$ & $\begin{array}{l}\text { Knuckle } \\
\text { Radius }\end{array}$ & \begin{tabular}{|l} 
Body height \\
(m)
\end{tabular} \\
\hline$\frac{\mathrm{BY}-112}{\mathrm{C}-101}$ & SST & 1,482 & 1,997 & normal & \begin{tabular}{|l|}
301 \\
\end{tabular} & 295 & by & 3,967 & 7.14 & dished & 0.3048 & \begin{tabular}{|l}
50.6413 \\
\end{tabular} & \begin{tabular}{|l}
173.6110 \\
\end{tabular} & 1.2171 & 477.3316 & 1.2192 & 6.079 \\
\hline$\frac{C-101}{C-102}$ & $\begin{array}{l}\text { SST } \\
\text { SST }\end{array}$ & $\begin{array}{l}1,517 \\
1432\end{array}$ & $\begin{array}{l}2,043 \\
1930\end{array}$ & $\begin{array}{l}\text { normal } \\
\text { normal }\end{array}$ & 306 & 305 & $\frac{c}{c}$ & $\frac{3,215}{3215}$ & $\begin{array}{l}4.80 \\
480\end{array}$ & $\begin{array}{l}\text { dished } \\
\text { dishod }\end{array}$ & 0.03048 & $\frac{50.6778}{50.678}$ & 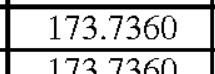 & $\begin{array}{l}.2171 \\
1.171\end{array}$ & \begin{tabular}{|l|l}
477.6507 \\
476501
\end{tabular} & $\frac{1.2192}{1.2190}$ & $\begin{array}{l}4.2699 \\
44269\end{array}$ \\
\hline C-103 & SST & 1,372 & 1,848 & normal & 316 & 296 & $\mathrm{c}$ & 3,215 & $\frac{4.80}{4.80}$ & $\begin{array}{l}\text { disnhed } \\
\text { dished }\end{array}$ & $\frac{0.3048}{0.3048}$ & $\begin{array}{l}50.67 / 8 \\
50.6778\end{array}$ & \begin{tabular}{|c|}
173.1500 \\
173.7360
\end{tabular} & $\begin{array}{l}1.2111 \\
1.2171\end{array}$ & $\begin{array}{l}4 / 1 / .6501 \\
477.6507\end{array}$ & $\begin{array}{l}1.2192 \\
1.2192\end{array}$ & $\begin{array}{l}4.269 \\
4.269\end{array}$ \\
\hline $\bar{C}-104$ & $\begin{array}{ll}\text { SST } \\
\end{array}$ & 1,431 & 1,929 & normal & 311 & 307 & c & 3,215 & 4.80 & dished & 0.3048 & 50.6778 & 173.7360 & 1.2171 & 477.6507 & 1.2192 & 4.269 \\
\hline $\mathrm{C}-105$ & SST & 1,321 & 1,779 & normal & 322 & 316 & $\mathrm{c}$ & 3,215 & 4.80 & dished & 0.3048 & 50.6778 & 173.7360 & 1.2171 & 477.6507 & 1.2192 & 4.269 \\
\hline $\mathrm{C}-106$ & $\begin{array}{l}\text { SST } \\
\end{array}$ & 1,329 & 1,791 & normal & 303 & 299 & $\mathrm{c}$ & 3,215 & 4.80 & dished & 0.3048 & & & 1.2171 & & 1.2192 & 4.269 \\
\hline$\frac{\mathrm{C}-107}{\mathrm{C}}$ & $\begin{array}{l}\text { SST } \\
\end{array}$ & 1,321 & 1,779 & normal & 316 & 313 & $\mathrm{c}$ & 3,215 & 4.80 & dished & 0.3048 & & & 1.2171 & 477.6507 & 1.2192 & 4.269 \\
\hline$\frac{\bar{C}-108^{*}}{C 10^{2 * *}}$ & $\begin{array}{l}\text { SST } \\
\end{array}$ & 1,261 & 1,699 & normal & 298 & 297 & $\mathrm{c}$ & 3,215 & 4.80 & dished & 0.3048 & & $\begin{array}{l}173.7360 \\
\end{array}$ & $\begin{array}{l}1.2171 \\
\end{array}$ & \begin{tabular}{|l|l|}
477.6507 \\
\end{tabular} & 1.2192 & 4.269 \\
\hline$\frac{C-109 *}{C-110}$ & $\begin{array}{l}\text { SST } \\
\text { SCT }\end{array}$ & 1,319 & 1,777 & normal & 298 & 299 & $\mathrm{c}$ & $\begin{array}{l}3,215 \\
201\end{array}$ & 4.80 & dished & 0.3048 & \begin{tabular}{|l|l|}
50.6778 \\
50770
\end{tabular} & \begin{tabular}{lll|l}
173.7360 \\
\end{tabular} & $\begin{array}{l}1.2171 \\
\end{array}$ & 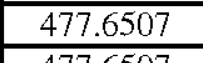 & 1.2192 & 4.269 \\
\hline$\frac{C-110}{C-1111}$ & $\begin{array}{l}\text { SST } \\
\text { SST }\end{array}$ & $\frac{1,142}{1322}$ & $\begin{array}{l}1,538 \\
1781\end{array}$ & $\begin{array}{l}\text { normal } \\
\text { normal }\end{array}$ & 297 & 297 & c & $\frac{3,215}{3215}$ & $\begin{array}{l}4.80 \\
480\end{array}$ & $\begin{array}{l}\text { dished } \\
\text { didhed. }\end{array}$ & $\frac{0.3048}{0.3048}$ & $\frac{50.6778}{50.678}$ & $\begin{array}{l}173.7360 \\
1737726\end{array}$ & \begin{tabular}{|l|}
1.2171 \\
12117 \\
\end{tabular} & $\begin{array}{l}477.6507 \\
1476501\end{array}$ & $\frac{1.2192}{1.0102}$ & 4.269 \\
\hline$\frac{C-112}{C}$ & SST & $\frac{1,322}{1,342}$ & $\frac{1,1 / 81}{1,808}$ & $\begin{array}{l}\text { normal } \\
\text { normal }\end{array}$ & 301 & 300 & $\frac{c}{c}$ & $\frac{3,215}{3,215}$ & $\frac{4.80}{4.80}$ & $\frac{\text { aisned }}{\text { dished }}$ & $\frac{0.3048}{0.3048}$ & $\frac{50.67778}{50.6778}$ & $\begin{array}{l}173.7360 \\
173.7360\end{array}$ & $\frac{1.2171}{1.2171}$ & $\frac{477.6507}{477.6507}$ & $\frac{1.2192}{1.2192}$ & $\frac{4.269}{4.269}$ \\
\hline$\frac{1-201}{\mathrm{C}}$ & SST & 1,227 & $\begin{array}{l}1,653 \\
\end{array}$ & normal & 289 & 293 & $c^{2}$ & $\frac{j, 215}{225}$ & $\frac{7.006}{7.24}$ & $\begin{array}{l}\text { dished } \\
\end{array}$ & 0.1524 & $\frac{1.2214}{1.214}$ & $\begin{array}{l}16.7894 \\
\end{array}$ & $\frac{1.4111}{0.9065}$ & 23.3622 & $\frac{1.212}{0.9144}$ & 6.866 \\
\hline$\overline{\mathrm{C}-202}$ & SST & $\begin{array}{ll}1,227 \\
\end{array}$ & $\begin{array}{ll}1,653 \\
\end{array}$ & normal & 289 & 292 & $\mathrm{c} 2$ & 225 & 7.24 & dished & 0.1524 & 1.2214 & 16.7894 & 0.9065 & 23.3622 & 0.9144 & 6.866 \\
\hline $\mathrm{C}-203$ & SST & $\frac{1,380}{1,380}$ & 1,860 & normal & 288 & 292 & $\mathrm{c} 2$ & 225 & 7.24 & dished & 0.1524 & 1.2214 & 16.7894 & 0.9065 & 23.3622 & 0.9144 & 6.866 \\
\hline$\frac{1-204}{C-204}$ & SST & 1,508 & 2,032 & normal & 291 & 289 & $c^{2} 2$ & 225 & 7.24 & dished & 0.1524 & 1.2214 & 16.7894 & 0.9065 & 23.3622 & 0.9144 & 6.866 \\
\hline S-101 & SST & 1,407 & 1,896 & normal & 311 & 303 & $\mathrm{~s}$ & 3,975 & 7.14 & dished & 0.3048 & 50.6 & 173 & 1.2171 & \begin{tabular}{|l|}
477 \\
\end{tabular} & 1.2192 & 6.098 \\
\hline$\frac{S-102^{*}}{-}$ & $\begin{array}{l}\text { SST } \\
\end{array}$ & 1,531 & 2,06 & norl & 0.02 & 298 & $s$ & 3,6 & & & 0.3 & & & 1.2111 & & & 6.098 \\
\hline S-103 & $\begin{array}{l}\text { SST } \\
\end{array}$ & 1,374 & 1,85 & normal & 302 & 297 & $\mathrm{~s}$ & 3,5 & 7.1. & dit & & & & $\begin{array}{l}1.2171 \\
\end{array}$ & & 1.2192 & 6.098 \\
\hline S-104 & SST & 1,421 & 1,914 & normal & 312 & 304 & $\mathrm{~s}$ & & 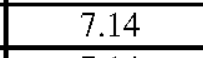 & dishe & $\frac{0.3}{0.3}$ & & 173 & $\begin{array}{l}1.2171 \\
\end{array}$ & 477.3316 & 1.2192 & 6.098 \\
\hline $\begin{array}{l}\text { S- }-105 \\
\text { S.106 }\end{array}$ & $\begin{array}{l}\text { SST } \\
\end{array}$ & 1,412 & 1,902 & normal & 27 & 296 & $\mathrm{~s}$ & 3,975 & 7.14 & dished & 0.30 & 50.6413 & \begin{tabular}{ll|l}
173.6110 \\
\end{tabular} & 1.2171 & \begin{tabular}{|l|l|}
477.3316 \\
\end{tabular} & 1.2192 & 6.098 \\
\hline $\begin{array}{l}\text { S-1066 } \\
\text { S.107 }\end{array}$ & $\begin{array}{l}\text { SST } \\
\text { SST }\end{array}$ & $\begin{array}{l}1,467 \\
1513\end{array}$ & $\begin{array}{r}1,977 \\
2038\end{array}$ & $\begin{array}{l}\text { normal } \\
\text { normal }\end{array}$ & 298 & 294 & s & $\begin{array}{l}3,975 \\
2075\end{array}$ & $\begin{array}{l}7.14 \\
7.14\end{array}$ & dishn & 0.3048 & 50.6413 & 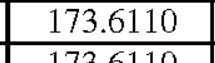 & $\begin{array}{l}1.2171 \\
1.171\end{array}$ & 477.3316 & $\frac{1.2192}{1.190}$ & 6.098 \\
\hline S-108 & $\begin{array}{l}\mathrm{SSS} 1 \\
\mathrm{SST}\end{array}$ & $\frac{1,193}{1,429}$ & \begin{tabular}{|l}
2,038 \\
1,926
\end{tabular} & $\begin{array}{c}\text { normal } \\
\text { normal }\end{array}$ & $\frac{306}{301}$ & $\frac{300}{297}$ & $\frac{\mathrm{s}}{\mathrm{s}}$ & $\begin{array}{l}\frac{3,995}{3,975} \\
\end{array}$ & $\frac{7.14}{7.14}$ & $\frac{\text { dished }}{\text { dished }}$ & $\frac{0.3048}{0.3048}$ & $\frac{50.6413}{50.6413}$ & $\frac{173.6110}{173.6110}$ & $\frac{1.22171}{1.2171}$ & 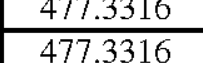 & $\frac{1.2192}{1.2192}$ & $\frac{6.0098}{6.098}$ \\
\hline S-109 & $\begin{array}{l}\text { SST } \\
\text { SST }\end{array}$ & $\frac{1,467}{1,412}$ & 1,903 & normal & 299 & 294 & $\mathrm{~s}$ & 3,975 & 7.14 & dished & 0.3048 & 50.6413 & \begin{tabular}{|l|}
173.6110 \\
\end{tabular} & $\begin{array}{l}1.2171 \\
.2171\end{array}$ & 477.3316 & $\frac{1.2122}{1.2192}$ & 6.098 \\
\hline S-110 & SST & 1,416 & 1,908 & normal & 315 & 299 & $\mathrm{~s}$ & 3,975 & 7.14 & dished & 0.3048 & 50. & \begin{tabular}{|l}
173. \\
\end{tabular} & 1.2171 & 477. & 1.2192 & 6.098 \\
\hline S-111 & SST & 1,315 & 1,772 & normal & 301 & 297 & $\mathrm{~s}$ & 3,975 & 7.14 & dished & 0.3048 & 50. & & 1.2171 & & 1.2192 & 6.098 \\
\hline S-112* & SST & 1,458 & 1,964 & norn & 302 & 294 & $\mathrm{~s}$ & 3,9 & 7.14 & dis & 0.3 & 50. & & 1.2 & 477 & 1.2192 & 6.098 \\
\hline SX-101 & $\begin{array}{l}\text { SST } \\
\end{array}$ & 1,431 & $\begin{array}{ll}1,92 \\
\end{array}$ & nor & 324 & 311 & $\mathrm{sx}$ & 4,5 & 9.3 & dis & 0.8 & & & 0.0000 & 0.4 & 0.0000 & 9.474 \\
\hline SX-102 & $\begin{array}{l}\text { SST } \\
\end{array}$ & 1,446 & 1,948 & normal & 325 & 307 & $8 x$ & 4,903 & 9. & dis & 0.3778 & 77.8 & & 0.0000 & 0.0000 & 0.0000 & 9.474 \\
\hline SX-103 & $\begin{array}{l}\text { SST } \\
\end{array}$ & 1,473 & $\begin{array}{l}1,985 \\
\end{array}$ & $\begin{array}{l}\text { normal } \\
\end{array}$ & 331 & 300 & sx & 4,903 & 9.35 & dish. & 0.3778 & 77.8 & 173.6 & 0.0000 & 0.0000 & 0.0000 & 9.474 \\
\hline SX-104 & $\begin{array}{l}\text { SST } \\
\end{array}$ & 1,444 & 1,946 & normal & 329 & 308 & $\mathrm{sx}$ & 4,903 & 9.35 & $\begin{array}{l}\text { dishe } \\
\end{array}$ & 0.3778 & 77.8 & 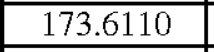 & 0.0000 & 0.0000 & 0.0000 & 9.474 \\
\hline SX-105 & SST & 1,389 & 1,872 & normal & 333 & 307 & $\mathrm{sx}$ & 4,5 & 9.2 & dished & 0.37 & 77.8 & \begin{tabular}{|l|l}
173.6 \\
\end{tabular} & 0.0000 & 0.0000 & 0.0000 & 9.474 \\
\hline$\frac{\text { SX-106 }}{\text { SX-107 }}$ & $\begin{array}{l}\text { SST } \\
\text { SST }\end{array}$ & $\frac{1,345}{1.508}$ & $\begin{array}{l}1,812 \\
2,032 \\
\end{array}$ & $\frac{n_{n} \text { normal }}{\text { normal }}$ & $\frac{306}{342}$ & $\frac{299}{326}$ & $\frac{s x}{5 x}$ & $\begin{array}{r}4,903 \\
4,903\end{array}$ & $\begin{array}{l}9.35 \\
9.35\end{array}$ & $\frac{\text { dished }}{\text { dished }}$ & 0.37778 & $\begin{array}{r}77.8029 \\
77.8229\end{array}$ & \begin{tabular}{|l|}
173.6110 \\
17.6110
\end{tabular} & $\frac{0.0000}{0.0000}$ & $\frac{0.0000}{0.0000}$ & 0.0000 & $\frac{9.474}{9.474}$ \\
\hline SX-108 & $\begin{array}{l}\text { SST } \\
\text { S }\end{array}$ & $\frac{1,50}{1,508}$ & $\frac{1,02}{2,032}$ & normal & 349 & 332 & $\frac{\mathrm{si}}{\mathrm{SX}}$ & 4,903 & 9.35 & dished & 0.3778 & 77.8029 & \begin{tabular}{|l|}
173.6110 \\
\end{tabular} & 0.0000 & 0.0000 & 0.0000 & 9.474 \\
\hline
\end{tabular}




\begin{tabular}{|c|c|c|c|c|c|c|c|c|c|c|c|c|c|c|c|c|c|}
\hline Data Source & & \begin{tabular}{|c|} 
Calculated value \\
see RPP-10006, \\
Appendix B), \\
RPP-10006 R7
\end{tabular} & 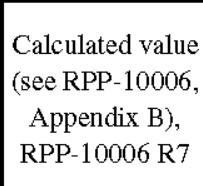 & $\begin{array}{l}\text { RPP-10006, } \\
\text { Appendix B }\end{array}$ & \begin{tabular}{|l} 
RPP.5926 R8, \\
RPP-10006 R7
\end{tabular} & \begin{tabular}{|l|} 
RPP.5926 R8, \\
RPP-10066 R7
\end{tabular} & $\begin{array}{l}\text { RPP- } 10006 \text { R7 } \\
\text { Data }\end{array}$ & $\begin{array}{c}\text { RPP-10006 R7 } \\
\text { Data }\end{array}$ & \begin{tabular}{|c|} 
RPP. $100006 \mathrm{RT}$, \\
OSD- T-1.1- \\
$00007, \mathrm{R1}$
\end{tabular} & $\begin{array}{l}\text { RPP-10006 R7 } \\
\text { Data }\end{array}$ & $\begin{array}{l}\text { RPP-10006 R7 } \\
\text { Data }\end{array}$ & $\begin{array}{c}\text { RPP-10006 R7 } \\
\text { Data }\end{array}$ & $\underset{\substack{\text { RPP-10006 R7 } \\
\text { Data }}}{\text { Res }}$ & $\begin{array}{l}\text { RPP-10006 R7 } \\
\text { Data }\end{array}$ & $\begin{array}{l}\text { RPP-10006 R7 } \\
\text { Data }\end{array}$ & $\begin{array}{c}\text { RPP-10006 R7 } \\
\text { Data }\end{array}$ & $\begin{array}{c}\text { RPP-10006 R7 } \\
\text { Data }\end{array}$ \\
\hline Tank \# & Tank Type & \begin{tabular}{|c|} 
Non- \\
Convective \\
Waste \\
Density \\
Min \\
$(\mathrm{kg} / \mathbf{m} 3)$ \\
\end{tabular} & $\begin{array}{c}\text { Non- } \\
\text { Convective } \\
\text { Waste } \\
\text { Density } \\
\text { Max } \\
\text { (kg/m3) } \\
\end{array}$ & $\begin{array}{c}\text { Non- } \\
\text { Convective } \\
\text { Waste } \\
\text { Density } \\
\text { Dist } \\
(\mathrm{kg} / \mathbf{m} 3) \\
\end{array}$ & \begin{tabular}{|c|} 
Non- \\
Convective \\
Waste \\
Average \\
Temperatur \\
$\mathbf{e}(\mathbf{K})$ \\
\end{tabular} & \begin{tabular}{|c|} 
Tank Vapor \\
Space \\
Average \\
Temperatur \\
$\mathbf{e}(\mathbf{K})$ \\
\end{tabular} & \begin{tabular}{|c} 
Tank type \\
group
\end{tabular} & \begin{tabular}{|c}
$\begin{array}{c}\text { Total tank } \\
\text { volume } \\
(\mathrm{m} 3)\end{array}$ \\
\end{tabular} & \begin{tabular}{|c} 
OSD \\
Maximum \\
Operating \\
Limit (m) \\
\end{tabular} & Dish type & $\begin{array}{c}\begin{array}{c}\text { Dish height } \\
(\mathbf{m})\end{array} \\
\end{array}$ & \begin{tabular}{|c}
$\begin{array}{c}\text { Dish volume } \\
(\mathbf{k L})\end{array}$ \\
\end{tabular} & \begin{tabular}{|c|c|}
$\begin{array}{c}\text { Dish Radius } \\
(\mathbf{m})\end{array}$ \\
\end{tabular} & $\begin{array}{c}\text { Knuckle } \\
\text { height } \\
(\mathbf{m})\end{array}$ & $\begin{array}{l}\text { Knuckle } \\
\text { volume } \\
\text { (M3) }\end{array}$ & $\begin{array}{l}\text { Knuckle } \\
\text { Radius } \\
\text { (m) }\end{array}$ & $\begin{array}{c}\text { Body height } \\
(\mathbf{m})\end{array}$ \\
\hline 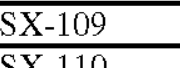 & $\begin{array}{l}\text { SST } \\
\text { SST }\end{array}$ & 1,477 & 1,990 & $\begin{array}{l}\text { normal } \\
\end{array}$ & 328 & 321 & $8 x$ & 4,903 & 9.35 & dished & \begin{tabular}{|l|l|}
0.3778 \\
\end{tabular} & 77.8029 & \begin{tabular}{|l|l|}
173.6110 \\
\end{tabular} & & $\begin{array}{l}0.0000 \\
\end{array}$ & 0.0000 & 9.474 \\
\hline$\frac{\text { SX-110 }}{\text { SX-111 }}$ & $\begin{array}{l}\text { SST } \\
\text { SST }\end{array}$ & $\begin{array}{l}1,502 \\
1502 \\
\end{array}$ & 2,024 & normal & 342 & 333 & $\mathrm{sx}$ & 4,903 & 9.35 & dished & $\begin{array}{l}0.3778 \\
0.270\end{array}$ & 77.8029 & \begin{tabular}{l|l|}
173.6110 \\
1.27 .610
\end{tabular} & 0.0000 & 0.0000 & 0.0000 & 9.474 \\
\hline$\frac{\mathrm{S}-111}{\mathrm{SX}-112}$ & $\frac{\text { SST }}{\text { SST }}$ & $\frac{1,502}{1,508}$ & $\frac{2,023}{2,032}$ & $\frac{n_{\text {normal }}}{\text { normal }}$ & $\frac{341}{334}$ & $\frac{334}{326}$ & $\frac{\mathrm{sx}}{\mathrm{sx}}$ & $\frac{4,903}{4,903}$ & $\frac{9.35}{9.35}$ & $\frac{\text { dished }}{\text { dished }}$ & 0.37778 & $\frac{77.8029}{77.829}$ & $\frac{173.6110}{1736110}$ & $\frac{0.0000}{0.0000}$ & $\frac{0.0000}{0.0000}$ & $\frac{0.0000}{0.0000}$ & $\frac{9.474}{9.444}$ \\
\hline$\frac{S X-113}{S}$ & $\mathrm{csT}$ & 1,491 & 2,009 & 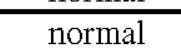 & $\infty$ & 201 & sx & 4, & 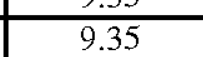 & $\begin{array}{l}\text { dished } \\
\end{array}$ & 0.3778 & 77.8029 & 173.6 & 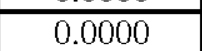 & 0.0000 & 0.0000 & 9.474 \\
\hline SX-114 & SST & 1,492 & 2,010 & normal & 345 & 331 & sx & 4,903 & 9.35 & dished & 0.3778 & 777.8029 & 173.6110 & 0.0000 & 0.0000 & 0.0000 & 9.474 \\
\hline SX-115 & SST & 1,508 & 2,032 & normal & 299 & 298 & sx & 4,903 & 9.35 & dished & 0.3778 & 77.8029 & 173.6110 & 0.0000 & 0.0000 & 0.0000 & 9.474 \\
\hline SY-101* & DST & 1326 & 1714 & normal & 301 & 298 & sy & 5,324 & 10.72 & flat & 0.0095 & 3.12 & 0.00 & 0.30 & 123.44 & 0.30 & 10.42 \\
\hline SY-102* & DST & 1347 & 1741 & normal & 303 & 300 & sy & 5,324 & 10.72 & flat & 0.0095 & 3.12 & 0.00 & 0.30 & 123.44 & 0.30 & 10.42 \\
\hline SY-103* & DST & 1405 & 1815 & normal & 305 & 303 & sy & 5,324 & 10.72 & flat & 0.0095 & 3.12 & 0.00 & 0.30 & 123.44 & 0.30 & 10.42 \\
\hline$T-101$ & $\begin{array}{ll}\text { SST } \\
\text { SST }\end{array}$ & 1,316 & 1,773 & normal & 296 & 296 & $\mathrm{t}$ & 3,215 & 4.80 & dished & 0.3048 & 50.6778 & $\begin{array}{l}173.7360 \\
1378\end{array}$ & 1.2171 & \begin{tabular}{|l|l|}
477.6507 \\
\end{tabular} & 1.2192 & 4.269 \\
\hline$\frac{T-102}{T-102}$ & SST & 1,531 & 2,063 & normal & 291 & 291 & $t$ & 3,215 & 4.80 & dished & 0.3048 & 78 & \begin{tabular}{l|l|}
173.7360 \\
\end{tabular} & $\begin{array}{l}1.2171 \\
\end{array}$ & \begin{tabular}{|l|}
477.6507 \\
\end{tabular} & 1.2192 & 4.269 \\
\hline$\frac{T-103}{T-104}$ & SST & 1,460 & 1,968 & normal & 292 & 294 & $t$ & 3,215 & 4.8 .51 & dished & 0.3048 & 50 & 1773.7360 & 1.2171 & \begin{tabular}{|l|}
477.6507 \\
\end{tabular} & 1.2192 & 4.269 \\
\hline $\begin{array}{l}\frac{T-104}{T-105} \\
T\end{array}$ & $\begin{array}{l}\text { SST } \\
\text { SCT }\end{array}$ & 1,099 & 1,481 & normal & 292 & $\frac{295}{280}$ & $t$ & 3,2 & 4.8 & dish & 0.3048 & $\frac{50.4}{5.0}$ & & 1.2171 & \begin{tabular}{|l|l|}
477.6507 \\
477.657
\end{tabular} & $\frac{1.2192}{10102}$ & 4.269 \\
\hline$\frac{1-105}{T-106}$ & $\frac{\text { SST }}{\text { SST }}$ & $\frac{1,244}{1,352}$ & $\frac{1,676}{1,822}$ & $\begin{array}{l}\text { normmal } \\
\text { normal }\end{array}$ & $\frac{290}{293}$ & $\frac{289}{295}$ & $\frac{t}{t}$ & $\frac{3,215}{3,215}$ & $\frac{4.80}{4.80}$ & dished & $\frac{0.3048}{0.3048}$ & $\frac{50.6778}{50.678}$ & $\begin{array}{l}\frac{173.7360}{173.7360} \\
\end{array}$ & $\frac{1.2171}{1.2171}$ & \begin{tabular}{|l|l}
477.6507 \\
\end{tabular} & $\frac{1.2192}{1.2192}$ & $\frac{4.269}{4.269}$ \\
\hline T-107 & $\begin{array}{l}\text { SST } \\
\end{array}$ & $\frac{1,329}{1,329}$ & $\frac{1,02}{1,791}$ & normal & 292 & 294 & $\mathrm{t}$ & & $\frac{4.80}{4.80}$ & & 0.0048 & $\frac{50.0718}{50.6778}$ & $\begin{array}{l}115.1300 \\
173.7360\end{array}$ & $\begin{array}{l}1.2111 \\
1.2171\end{array}$ & $\begin{array}{l}471.0501 \\
477.6507\end{array}$ & $\frac{1.2192}{1.2192}$ & $\begin{array}{l}4.209 \\
4.269\end{array}$ \\
\hline T-108 & SST & 1,318 & 1,776 & normal & 289 & 295 & $\mathrm{t}$ & 3,215 & 4.80 & dished & 0.3048 & 50.6778 & 173.7360 & 1.2171 & 477.6507 & 1.2192 & 4.269 \\
\hline T-109 & SST & 1,402 & 1,889 & normal & 296 & 295 & $\mathrm{t}$ & 3,215 & 4.80 & dished & 0.3048 & 50.6778 & 173.7360 & 1.2171 & 477.6507 & 1.2192 & 4.269 \\
\hline T-110 & SST & 1,065 & 1,435 & normal & 291 & 295 & $\mathrm{t}$ & 3,215 & 4.80 & dished & 0.3048 & 50.6778 & 173.7360 & 1.2171 & 477.6507 & 1.2192 & 4.269 \\
\hline T-111 & SST & 1,057 & 1,423 & normal & 296 & 296 & $\mathrm{t}$ & 3,215 & 4.80 & dished & 0.3048 & 50.6778 & 173 & 1.2171 & 477.6507 & 1.2192 & 4.269 \\
\hline$\frac{T-112}{-112}$ & $\begin{array}{l}\text { SST } \\
\end{array}$ & 1,091 & 1,4 & norl & 296 & 296 & $\mathrm{t}$ & 3,215 & 4.8 & dis & 0.3048 & 50. & 173 & 1.2171 & 477.6507 & 1.2192 & 4.269 \\
\hline T-201 & $\begin{array}{l}\text { SST } \\
\end{array}$ & 1,116 & $\begin{array}{l}1,504 \\
\end{array}$ & norl & 294 & 294 & $\mathrm{t} 2$ & 225 & 1.2 & & 0.1 & 1. & & & & 0.9144 & 6.866 \\
\hline T-202 & $\begin{array}{l}\text { SST } \\
\end{array}$ & 1,005 & 1,355 & $\begin{array}{l}\text { normal } \\
\end{array}$ & 294 & 294 & $\mathrm{t} 2$ & 225 & 7.24 & $\begin{array}{c}\text { diss } \\
\end{array}$ & 0.1524 & 1.2214 & 16. & 0.9065 & 23.3622 & 0.9144 & 6.866 \\
\hline$\frac{T-203}{T-201}$ & SST & 1,039 & \begin{tabular}{|l}
1,401 \\
\end{tabular} & normal & 294 & 294 & $\mathrm{t} 2$ & $\frac{25}{2-2}$ & 1.24 & disl & 0.1 & 1.2 & 16.7894 & 0.9065 & 23.3622 & 0.9144 & 6.866 \\
\hline $\begin{array}{l}\text { T-204 } \\
\text { TX-101 }\end{array}$ & $\begin{array}{l}\text { SST } \\
\text { SCT }\end{array}$ & 1,005 & \begin{tabular}{|l}
1,355 \\
\end{tabular} & normal & 294 & 294 & $\mathrm{t} 2$ & 225 & 7.24 & & & 1.22 & 16.7 & 0.9 & & 0.9144 & 6.866 \\
\hline$\frac{\text { TX-101 }}{\text { TXX102 }}$ & $\begin{array}{l}\text { SST } \\
\text { SST }\end{array}$ & $\frac{1,482}{1.375}$ & $\begin{array}{l}1,997 \\
1.853\end{array}$ & $\begin{array}{l}\text { normal } \\
\text { normal }\end{array}$ & $\frac{298}{299}$ & $\frac{297}{297}$ & $\frac{t x}{t x}$ & $\frac{3,967}{3,967}$ & $\frac{7.14}{7.14}$ & $\frac{\text { dished }}{\text { dished }}$ & $\frac{0.3048}{0.3048}$ & $\frac{50.6413}{50.643}$ & $\frac{173.6110}{173.110}$ & $\frac{1.2171}{1.2171}$ & \begin{tabular}{|l|}
477.3316 \\
477.31616
\end{tabular} & $\frac{1.2192}{1.2192}$ & $\frac{6.079}{6.079}$ \\
\hline TX-103 & SST & 1,372 & 1,849 & normal & 295 & 294 & $\frac{a}{t x}$ & $\frac{3,917}{3,967}$ & $\frac{1.14}{7.14}$ & $\frac{\text { osister }}{\text { dished }}$ & 0.3048 & $\frac{50.6413}{50.6413}$ & $\begin{array}{l}15.0110 \\
173.6110\end{array}$ & $\frac{1.211}{1.2171}$ & \begin{tabular}{|l|}
47.131010 \\
\end{tabular} & $\frac{1.2192}{1.2192}$ & $\frac{6.079}{6.079}$ \\
\hline TX-104 & SST & 1,480 & 1,994 & normal & 294 & 294 & $\mathrm{tx}$ & 3,967 & 7.14 & dished & 0.3048 & 50.6413 & 173.6110 & 1.2171 & 477.3316 & 1.2192 & 6.079 \\
\hline TX-105 & SST & 1,392 & 1,876 & normal & 306 & 297 & $\mathrm{tx}$ & 3,967 & 7.14 & dis & 0.3 & 50. & 173 & 1.2171 & 477.3316 & 1.2192 & 6.079 \\
\hline TX-106 & SST & 1,380 & 1,86 & norn & 299 & 298 & $\mathrm{tx}$ & 3,96 & 7.14 & dis & 0. & 50 & 173 & 1.217 & 477.3316 & 1.2192 & 6.079 \\
\hline TX-107 & $\begin{array}{l}\text { SST } \\
\end{array}$ & 1,518 & 2,04 & norl & 295 & 290 & tx & 3,9 & 7. & & 0. & & & 1.2171 & 477. & 1.2192 & 6.079 \\
\hline TX-108 & $\begin{array}{l}\text { SST } \\
\end{array}$ & 1,382 & 1,8 & & 294 & 294 & $\mathrm{tx}$ & 3, & 1.14 & & & & & $\begin{array}{l}1.2171 \\
\end{array}$ & 477.3316 & 1.2192 & 6.079 \\
\hline TX-109 & $\begin{array}{l}\text { SST } \\
\end{array}$ & 1,218 & 1,642 & nor & 309 & 314 & tx & 3, & 7.14 & dished & 0.3048 & 50. & 173 & .21 & 477.3316 & 1.2192 & 6.079 \\
\hline$\frac{T X-110}{T}$ & $\begin{array}{l}\text { SST } \\
\text { ScTr }\end{array}$ & $\begin{array}{l}1,379 \\
1,72\end{array}$ & $\begin{array}{l}1,858 \\
1,956\end{array}$ & $\begin{array}{l}\text { normal } \\
\end{array}$ & $\frac{301}{301}$ & 290 & $\mathrm{tx}$ & 3,961 & 7 & $\begin{array}{l}\text { dished } \\
\end{array}$ & $\begin{array}{l}0.3048 \\
0.020\end{array}$ & 569 & 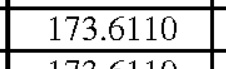 & 1.2171 & 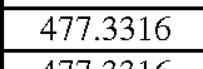 & 1.2192 & $\begin{array}{l}5.079 \\
.070\end{array}$ \\
\hline 111 & SST & 1,373 & 1,850 & normal & 302 & 299 & tx & 3,967 & 7.14 & dished & 0.3048 & 50.6413 & 173.6110 & 1.2171 & 477.3316 & 1.2192 & 6.079 \\
\hline
\end{tabular}




\begin{tabular}{|c|c|c|c|c|c|c|c|c|c|c|c|c|c|c|c|c|c|}
\hline Data Source & & $\begin{array}{c}\text { Calculated value } \\
\text { (see RPP-10006, } \\
\text { Appendix B, } \\
\text { RPP-10006 R7 }\end{array}$ & $\begin{array}{c}\text { Calculated value } \\
\text { (see RPP-10006, } \\
\text { Appendix B, } \\
\text { RPP-10006 R7 }\end{array}$ & $\begin{array}{l}\text { RPP-10006, } \\
\text { Appendix B }\end{array}$ & \begin{tabular}{|l|} 
RPP-5926 R8, \\
RPP-10006 R7
\end{tabular} & \begin{tabular}{|l|} 
RPP-5926 R8, \\
RPP-10006 R7
\end{tabular} & $\begin{array}{c}\text { RPP-10006 R7 } \\
\text { Data }\end{array}$ & $\begin{array}{c}\text { RPP-10006 R7 } \\
\text { Data }\end{array}$ & $\begin{array}{c}\text { RPP-10006 R7, } \\
\text { OSD-T-151- } \\
00007, \mathrm{R} 1\end{array}$ & $\begin{array}{c}\text { RPP-10006 R7 } \\
\text { Data }\end{array}$ & $\begin{array}{c}\text { RPP-10006 R7 } \\
\text { Data }\end{array}$ & $\begin{array}{c}\text { RPP-10006 R7 } \\
\text { Data }\end{array}$ & $\begin{array}{c}\text { RPP-10006 R7 } \\
\text { Data }\end{array}$ & $\begin{array}{c}\text { RPP-10006 R7 } \\
\text { Data }\end{array}$ & $\begin{array}{c}\text { RPP-10006 R7 } \\
\text { Data }\end{array}$ & $\begin{array}{c}\text { RPP-10006 R7 } \\
\text { Data }\end{array}$ & $\begin{array}{c}\text { RPP-10006 R7 } \\
\text { Data }\end{array}$ \\
\hline Tank \# & Tank Type & \begin{tabular}{|c|} 
Non- \\
Convective \\
Waste \\
Density \\
Min \\
$(\mathrm{kg} / \mathrm{m} 3)$ \\
\end{tabular} & $\begin{array}{c}\text { Non- } \\
\text { Convective } \\
\text { Waste } \\
\text { Density } \\
\text { Max } \\
(\mathrm{kg} / \mathrm{m} 3) \\
\end{array}$ & $\begin{array}{c}\text { Non- } \\
\text { Convective } \\
\text { Waste } \\
\text { Density } \\
\text { Dist } \\
(\mathrm{kg} / \mathrm{m} 3) \\
\end{array}$ & $\begin{array}{c}\text { Non- } \\
\text { Convective } \\
\text { Waste } \\
\text { Average } \\
\text { Temperatur } \\
\text { e (K) } \\
\end{array}$ & $\begin{array}{c}\text { Tank Vapor } \\
\text { Space } \\
\text { Average } \\
\text { Temperatur } \\
\text { e (K) } \\
\end{array}$ & $\begin{array}{c}\text { Tank type } \\
\text { group }\end{array}$ & $\begin{array}{c}\text { Total tank } \\
\text { volume } \\
(\mathbf{m 3})\end{array}$ & $\begin{array}{c}\text { OSD } \\
\text { Maximum } \\
\text { Operating } \\
\text { Limit (m) } \\
\end{array}$ & Dish type & \begin{tabular}{|c} 
Dish height \\
$(\mathbf{m})$
\end{tabular} & \begin{tabular}{|c} 
Dish volume \\
$(\mathrm{kL})$
\end{tabular} & $\begin{array}{c}\text { Dish Radius } \\
(\mathbf{m})\end{array}$ & $\begin{array}{c}\text { Knuckle } \\
\text { height } \\
(\mathbf{m})\end{array}$ & $\begin{array}{c}\text { Knuckle } \\
\text { volume } \\
\text { (M3) }\end{array}$ & $\begin{array}{c}\text { Knuckle } \\
\text { Radius } \\
\text { (m) }\end{array}$ & $\begin{array}{c}\text { Body height } \\
\text { (m) }\end{array}$ \\
\hline TX-112 & SST & 1,391 & 1,874 & normal & 301 & 298 & tx & 3,967 & 7.14 & dished & 0.3048 & 50.6413 & \begin{tabular}{|l|}
173.6110 \\
\end{tabular} & 1.2171 & 477.3316 & 1.2192 & 6.079 \\
\hline TX-113 & SST & 1,370 & 1,846 & normal & 296 & 295 & $\mathrm{tx}$ & 3,967 & 7.14 & dished & 0.3048 & 50.6413 & 173.6110 & 1.2171 & 477.3316 & 1.2192 & 6.079 \\
\hline TX-114 & SST & 1,392 & 1,876 & normal & 294 & 291 & tx & 3,967 & 7.14 & dished & 0.3048 & 50.6413 & 173.6110 & 1.2171 & 477.3316 & 1.2192 & 6.079 \\
\hline TX-115 & SST & 1,387 & 1,869 & normal & 295 & 294 & $\mathrm{tx}$ & 3,967 & 7.14 & dished & 0.3048 & 50.6413 & 173.6110 & 1.2171 & 477.3316 & 1.2192 & 6.079 \\
\hline TX-116 & SST & 1,412 & 1,903 & normal & 294 & 293 & $\mathrm{tx}$ & 3,967 & 7.14 & dished & 0.3048 & 50.6413 & 173.6110 & 1.2171 & 477.3316 & 1.2192 & 6.079 \\
\hline TX-117 & SST & 1,347 & 1,816 & normal & 294 & 293 & tx & 3,967 & 7.14 & dished & 0.3048 & 50.6413 & 173.6110 & 1.2171 & 477.3316 & 1.2192 & 6.079 \\
\hline TX-118 & SST & 1,441 & 1,942 & normal & 302 & 298 & $\mathrm{tx}$ & 3,967 & 7.14 & dished & 0.3048 & 50.6413 & 173.6110 & 1.2171 & 477.3316 & 1.2192 & 6.079 \\
\hline TY-101 & SST & 1,386 & 1,868 & normal & 292 & 293 & ty & 3,975 & 7.14 & dished & 0.3048 & 50.6413 & 173.6110 & 1.2171 & 477.3316 & 1.2192 & 6.098 \\
\hline TY-102 & SST & 1,496 & 2,015 & normal & 289 & 292 & ty & 3,975 & 7.14 & dished & 0.3048 & 50.6413 & 173.6110 & 1.2171 & 477.3316 & 1.2192 & 6.098 \\
\hline TY-103 & SST & 1,432 & 1,929 & normal & 298 & 295 & ty & 3,975 & 7.14 & dished & 0.3048 & 50.6413 & 173.6110 & 1.2171 & 477.3316 & 1.2192 & 6.098 \\
\hline TY-104 & SST & 1,406 & 1,894 & normal & 295 & 294 & ty & 3,975 & 7.14 & dished & 0.3048 & 50.6413 & 173.6110 & 1.2171 & 477.3316 & 1.2192 & 6.098 \\
\hline TY-105 & SST & 1,304 & 1,756 & normal & 298 & 297 & ty & 3,975 & 7.14 & dished & 0.3048 & 50.6413 & 173.6110 & 1.2171 & 477.3316 & 1.2192 & 6.098 \\
\hline TY-106 & $\begin{array}{l}\text { SST } \\
\end{array}$ & 1,193 & 1,607 & normal & 289 & 292 & ty & 3,975 & 7.14 & dished & 0.3048 & 50.6413 & 173.6110 & 1.2171 & 477.3316 & 1.2192 & 6.098 \\
\hline $\mathrm{U}-101$ & SST & 1,508 & 2,032 & normal & 294 & 294 & $\mathrm{u}$ & 3,215 & 4.80 & dished & 0.3048 & 50.6778 & 173.7360 & 1.2171 & 477.6507 & 1.2192 & 4.269 \\
\hline$\overline{\mathrm{U}-102}$ & $\begin{array}{l}\text { SST } \\
\end{array}$ & 1,425 & 1,920 & normal & 302 & 296 & $\mathrm{u}$ & 3,215 & 4.80 & dished & 0.3048 & 50.6778 & 173.7360 & 1.2171 & 477.6507 & 1.2192 & 4.269 \\
\hline U-103 & SST & 1,450 & 1,954 & normal & 303 & 300 & $\mathrm{u}$ & 3,215 & 4.80 & dished & 0.3048 & 50.6778 & 173.7360 & 1.2171 & 477.6507 & 1.2192 & 4.269 \\
\hline U-104 & $\begin{array}{l}\text { SST } \\
\end{array}$ & 1,216 & 1,638 & normal & 301 & 298 & $\mathrm{u}$ & 3,215 & 4.80 & dished & 0.3048 & 50.6778 & 173.7360 & 1.2171 & 477.6507 & 1.2192 & 4.269 \\
\hline U-105 & SST & 1,423 & 1,918 & normal & 304 & 302 & $\mathrm{u}$ & 3,215 & 4.80 & dished & 0.3048 & 50.6778 & 173.7360 & 1.2171 & 477.6507 & 1.2192 & 4.269 \\
\hline $\mathrm{U}-106$ & SST & 1,323 & 1,782 & normal & 303 & 301 & $\mathrm{u}$ & 3,215 & 4.80 & dished & 0.3048 & 50.6778 & 173.7360 & 1.2171 & 477.6507 & 1.2192 & 4.269 \\
\hline U-107 & $\begin{array}{l}\text { SST } \\
\end{array}$ & 1,481 & 1,995 & normal & 297 & 298 & $\mathrm{u}$ & 3,215 & 4.80 & dishhed & 0.3048 & 50.6778 & 173.7360 & 1.2171 & 477.6507 & 1.2192 & 4.269 \\
\hline U-108 & SST & 1,432 & 1,929 & normal & 300 & 295 & u & 3,215 & 4.80 & dished & 0.3048 & 50.6778 & 173.7360 & 1.2171 & 477.6507 & 1.2192 & 4.269 \\
\hline U-109 & SST & 1,408 & 1,897 & normal & 299 & 296 & $\mathrm{u}$ & 3,215 & 4.80 & dished & 0.3048 & 50.6778 & 173.7360 & 1.2171 & 477.6507 & 1.2192 & 4.269 \\
\hline $\mathrm{U}-110$ & SST & 1,462 & 1,969 & normal & 302 & 301 & $\mathrm{u}$ & 3,215 & 4.80 & dished & 0.3048 & 50.6778 & 173.7360 & 1.2171 & 477.6507 & 1.2192 & 4.269 \\
\hline U-111 & SST & 1,371 & 1,847 & normal & 296 & 297 & $\mathrm{u}$ & 3,215 & 4.80 & dished & 0.3048 & 50.6778 & $\begin{array}{l}173.7360 \\
\end{array}$ & 1.2171 & 477.6507 & 1.2192 & 4.269 \\
\hline U-112 & SST & 1,485 & 2,000 & normal & 294 & 294 & $\mathrm{u}$ & 3,215 & 4.80 & dished & 0.3048 & 50.6778 & 173.7360 & 1.2171 & 477.6507 & 1.2192 & 4.269 \\
\hline $\mathrm{U}-201$ & SST & 1,389 & 1,871 & normal & 296 & 296 & u2 & 225 & 7.24 & dished & 0.1524 & 1.2214 & 16.7894 & 0.9065 & 23.3622 & 0.9144 & 6.866 \\
\hline $\mathrm{U}-202$ & SST & 1,287 & 1,733 & normal & 293 & 293 & $\mathrm{u} 2$ & 225 & 7.24 & dished & 0.1524 & 1.2214 & 16.7894 & 0.9065 & 23.3622 & 0.9144 & 6.866 \\
\hline $\mathrm{U}-203$ & SST & 1,355 & 1,825 & normal & 292 & 293 & $\mathrm{u} 2$ & 225 & 7.24 & dished & 0.1524 & 1.2214 & 16.7894 & 0.9065 & 23.3622 & 0.9144 & 6.866 \\
\hline$\overline{\mathrm{U}-204}$ & $\begin{array}{l}\text { SST } \\
\end{array}$ & 1,252 & 1,688 & normal & 291 & 292 & $\mathrm{u} 2$ & 225 & 7.24 & dished & 0.1524 & 1.2214 & 16.7894 & 0.9065 & 23.3622 & 0.9144 & 6.866 \\
\hline
\end{tabular}




\begin{tabular}{|c|c|c|c|c|c|c|c|c|c|c|c|c|c|c|c|c|c|}
\hline Data Source & & $\begin{array}{c}\text { RPP-10006 R7 } \\
\text { Data }\end{array}$ & $\begin{array}{c}\text { RPP-10006 R7 } \\
\text { Data }\end{array}$ & $\begin{array}{c}\text { RPP-10006 R7 } \\
\text { Data }\end{array}$ & $\begin{array}{c}\text { RPP-10006 R7 } \\
\text { Data }\end{array}$ & $\begin{array}{c}\text { RPP-10006 R7 } \\
\text { Data }\end{array}$ & $\begin{array}{c}\text { RPP-10006 R7 } \\
\text { Data }\end{array}$ & $\begin{array}{c}\text { RPP-10006 R7 } \\
\text { Data }\end{array}$ & $\begin{array}{l}\text { RPP-10006 R7 } \\
\text { based on waste } \\
\text { type }\end{array}$ & $\begin{array}{c}\text { RPP-10006 R7 } \\
\text { based on waste } \\
\text { type }\end{array}$ & $\begin{array}{c}\text { RPP-10006 R7 } \\
\text { based on waste } \\
\text { type }\end{array}$ & $\begin{array}{l}\text { RPP-10006 R7 } \\
\text { based on waste } \\
\text { type }\end{array}$ & $\begin{array}{c}\text { RPP-10006 R7 } \\
\text { based on waste } \\
\text { type }\end{array}$ & $\begin{array}{c}\text { RPP-10006 R7 } \\
\text { based on waste } \\
\text { type }\end{array}$ & $\begin{array}{c}\text { RPP-10006 R7 } \\
\text { based on waste } \\
\text { type }\end{array}$ & $\begin{array}{c}\text { RPP-10006 R7 } \\
\text { based on waste } \\
\text { type }\end{array}$ & $\begin{array}{c}\text { RPP-10006 R7 } \\
\text { based on waste } \\
\text { type }\end{array}$ \\
\hline Tank \# & Tank Type & \begin{tabular}{|c|} 
Body volume \\
(M3)
\end{tabular} & $\begin{array}{c}\text { Body } \\
\text { Operating } \\
\text { Capacity } \\
(\mathbf{m} 3 / \mathbf{m}) \\
\end{array}$ & $\begin{array}{c}\text { Body Radius } \\
(\mathbf{m})\end{array}$ & $\begin{array}{c}\text { Dome Arc } \\
\text { height } \\
(\mathbf{m})\end{array}$ & $\begin{array}{c}\begin{array}{c}\text { Dome Arc } \\
\text { volume } \\
\text { (M3) }\end{array} \\
\end{array}$ & $\begin{array}{c}\text { Dome Arc } \\
\text { Radius } \\
\text { (m) }\end{array}$ & $\begin{array}{c}\text { Tank } \\
\text { capacity } \\
(\mathbf{k L} / \mathbf{m})\end{array}$ & $\begin{array}{c}\text { Void } \\
\text { Fraction or } \\
\text { Maximum } \\
\text { Wetted } \\
\text { Solids Void } \\
\text { Fraction } \\
\text { Mean } \\
\text { (Dimension- } \\
\text { less) } \\
\end{array}$ & \begin{tabular}{|c|} 
Void \\
Fraction or \\
Maximum \\
Wetted \\
Solids Void \\
Fraction \\
Uncertainty \\
(Dimension- \\
less) \\
\end{tabular} & \begin{tabular}{|c|} 
Void \\
Fraction or \\
Maximum \\
Wetted \\
Solids Void \\
Fraction \\
Minimum \\
(Dimension- \\
less) \\
\end{tabular} & $\begin{array}{c}\text { Void } \\
\text { Fraction or } \\
\text { Maximum } \\
\text { Wetted } \\
\text { Solids Void } \\
\text { Fraction } \\
\text { Maximum } \\
\text { (Dimension- } \\
\text { less) } \\
\end{array}$ & \begin{tabular}{|c|} 
Void \\
Fraction or \\
Maximum \\
Wetted \\
Solids Void \\
Fraction \\
Dist Type \\
(Dimension- \\
less) \\
\end{tabular} & \begin{tabular}{|c|} 
non- \\
convective \\
waste yield \\
stress mean \\
$(\mathrm{Pa})$ \\
\end{tabular} & $\begin{array}{c}\text { non- } \\
\text { convective } \\
\text { waste yield } \\
\text { stress std } \\
\text { dev }(P a) \\
\end{array}$ & \begin{tabular}{|c|} 
non- \\
convective \\
waste yield \\
stress min \\
$(\mathrm{Pa})$ \\
\end{tabular} & $\begin{array}{c}\text { non- } \\
\text { convective } \\
\text { waste yield } \\
\text { stress max } \\
(\mathrm{Pa}) \\
\end{array}$ \\
\hline $\mathrm{A}-101$ & SST & $4,053.92$ & 411.35 & 11.443 & 0.0000 & 0.000 & 0.0000 & 411.35 & 8.838 & 7.1328 & 0.01 & 40 & normal & 631.25 & 260.88 & 109.49 & 1674.77 \\
\hline A-102 & SST & $4,053.92$ & 411.35 & 11.443 & 0.0000 & 0.000 & 0.0000 & 411.35 & 8.838 & 7.1328 & 0.01 & 40 & normal & 631.25 & 260.88 & 109.49 & 1674.77 \\
\hline A-103 & SST & $4,053.92$ & 411.35 & 11.443 & 0.0000 & 0.000 & 0.0000 & 411.35 & 0.400 & 0.2 & 0.01 & 40 & normal & 631.25 & 260.88 & 109.49 & 1674.77 \\
\hline A-104 & SST & $4,053.92$ & 411.35 & 11.443 & 0.0000 & 0.000 & 0.0000 & 411.35 & 2.437 & 2.4869 & 0.01 & 26.5 & Lognorm & 1143.27 & 272.08 & 327.03 & 2231.59 \\
\hline A-105 & SST & $4,053.92$ & 411.35 & 11.443 & 0.0000 & 0.000 & 0.0000 & 411.35 & 2.437 & 2.4869 & 0.01 & 26.5 & Lognorm & 1143.27 & 272.08 & 327.03 & 2231.59 \\
\hline A-106 & SST & $4,053.92$ & 411.35 & 11.443 & 0.0000 & 0.000 & 0.0000 & 411.35 & 8.838 & 7.1328 & 0.01 & 40 & normal & 631.25 & 260.88 & 109.49 & 1674.77 \\
\hline AN-101* & $\overline{\mathrm{DST}}$ & 4263 & 409 & 11.42 & 0.97 & 379 & 1.22 & 409.04 & 6.37 & 2.73 & 0.01 & 15.11 & normal & 144.00 & 13.87 & 88.52 & 199.48 \\
\hline AN-102* & DST & 4263 & 409 & 11.42 & 0.97 & 379 & 1.22 & 409.04 & 6.37 & 2.73 & 0.01 & 15.11 & normal & 144.00 & 13.87 & 88.52 & 199.48 \\
\hline AN-103* & DST & 4263 & 409 & 11.42 & 0.97 & 379 & 1.22 & 409.04 & 10.70 & 5.35 & 0.01 & 15.11 & normal & 144.00 & 13.87 & 88.52 & 199.48 \\
\hline AN-104* & DST & 4263 & 409 & 11.42 & 0.97 & 379 & 1.22 & 409.04 & 6.20 & 3.10 & 0.01 & 15.11 & normal & 144.00 & 13.87 & 88.52 & 199.48 \\
\hline AN-105* & $\overline{\mathrm{DST}}$ & 4263 & 409 & 11.42 & 0.97 & 379 & 1.22 & 409.04 & 4.20 & 2.10 & 0.01 & 15.11 & normal & 144.00 & 13.87 & 88.52 & 199.48 \\
\hline AN-106* & DST & 4263 & 409 & 11.42 & 0.97 & 379 & 1.22 & 409.04 & 6.37 & 2.73 & 0.01 & 15.11 & normal & 829.55 & 218.64 & 173.63 & 1704.11 \\
\hline AN-107* & DST & 4263 & 409 & 11.42 & 0.97 & 379 & 1.22 & 409.04 & 1.10 & 0.55 & 0.01 & 15.11 & normal & 144.00 & 13.87 & 88.52 & 199.48 \\
\hline AP-101* & DST & 4263 & 409 & 11.42 & 0.97 & 379 & 1.22 & 409.07 & 0.02 & 0.00 & 0.01 & 0.02 & normal & 144.00 & 13.87 & 88.52 & 199.48 \\
\hline AP-102* & DST & 4263 & 409 & 11.42 & 0.97 & 379 & 1.22 & 409.07 & 6.37 & 2.73 & 0.01 & 15.11 & normal & 829.55 & 218.64 & 173.63 & 1704.11 \\
\hline AP-103* & DST & 4263 & 409 & 11.42 & 0.97 & 379 & 1.22 & 409.07 & 6.37 & 2.73 & 0.01 & 15.11 & normal & 829.55 & 218.64 & 173.63 & 1704.11 \\
\hline AP-104* & DST & 4263 & 409 & 11.42 & 0.97 & 379 & 1.22 & 409.07 & 6.37 & 2.73 & 0.01 & 15.11 & normal & 144.00 & 13.87 & 88.52 & 199.48 \\
\hline AP-105* & DST & 4263 & 409 & 11.42 & 0.97 & 379 & 1.22 & 409.07 & 6.37 & 2.73 & 0.01 & 15.11 & normal & 144.00 & 13.87 & 88.52 & 199.48 \\
\hline AP-106* & DST & 4263 & 409 & 11.42 & 0.97 & 379 & 1.22 & 409.07 & 6.37 & 2.73 & 0.01 & 15.11 & normal & 144.00 & 13.87 & 88.52 & 199.48 \\
\hline AP-107* & DST & 4263 & 409 & 11.42 & 0.97 & 379 & 1.22 & 409.07 & 6.37 & 2.73 & 0.01 & 15.11 & normal & 144.00 & 13.87 & 88.52 & 199.48 \\
\hline AP-108* & DST & 4263 & 409 & 11.42 & 0.97 & 379 & 1.22 & 409.07 & 6.37 & 2.73 & 0.01 & 15.11 & normal & 144.00 & 13.87 & 88.52 & 199.48 \\
\hline $\mathrm{AW}-101^{*}$ & DST & 4263 & 409 & 11.42 & 0.97 & 379 & 1.22 & 409.04 & 4.70 & 2.35 & 0.01 & 15.11 & normal & 144.00 & 13.87 & 88.52 & 199.48 \\
\hline AW-102* & DST & 4263 & 409 & 11.42 & 0.97 & 379 & 1.22 & 409.04 & 6.37 & 2.73 & 0.01 & 15.11 & normal & 829.55 & 218.64 & 173.63 & 1704.11 \\
\hline AW-103* & DST & 4263 & 409 & 11.42 & 0.97 & 379 & 1.22 & 409.04 & 0.90 & 0.45 & 0.01 & 15.11 & normal & 829.55 & 218.64 & 173.63 & 1704.11 \\
\hline AW-104* & DST & 4263 & 409 & 11.42 & 0.97 & 379 & 1.22 & 409.04 & 5.80 & 2.90 & 0.00 & 15.11 & normal & 144.00 & 13.87 & 88.52 & 199.48 \\
\hline AW-105* & DST & 4263 & 409 & 11.42 & 0.97 & 379 & 1.22 & 409.04 & 6.37 & 2.73 & 0.01 & 15.11 & normal & 829.55 & 218.64 & 173.63 & 1704.11 \\
\hline AW-106* & DST & 4263 & 409 & 11.42 & 0.97 & 379 & 1.22 & 409.04 & 3.20 & 1.60 & 0.01 & 15.11 & normal & 144.00 & 13.87 & 88.52 & 199.48 \\
\hline AX-101 & SST & $4,005.45$ & 410.66 & 11.433 & 0.0000 & 0.000 & 0.0000 & 410.66 & 8.838 & 7.1328 & 0.01 & 40 & normal & 631.25 & 260.88 & 109.49 & 1674.77 \\
\hline $\mathrm{AX}-102$ & SST & $4,005.45$ & 410.66 & 11.433 & 0.0000 & 0.000 & 0.0000 & 410.66 & 8.838 & 7.1328 & 0.01 & 40 & normal & 631.25 & 260.88 & 109.49 & 1674.77 \\
\hline \begin{tabular}{|l|l}
$\mathrm{AX}-103$ \\
\end{tabular} & $\begin{array}{l}\text { SST } \\
\end{array}$ & $4,005.45$ & 410.66 & 11.433 & 0.0000 & 0.000 & 0.0000 & 410.66 & 8.838 & 7.1328 & 0.01 & 40 & normal & 631.25 & 260.88 & 109.49 & 1674.77 \\
\hline AX-104 & SST & $4,005.45$ & 410.66 & 11.433 & 0.0000 & 0.000 & 0.0000 & 410.66 & 2.437 & 2.4869 & 0.01 & 26.5 & Lognorm & 1143.27 & 272.08 & 327.03 & 2231.59 \\
\hline AY-101* & DST & 4263 & 409 & 11.43 & 0.97 & 378 & 1.22 & 409.07 & 4.20 & 2.10 & 0.01 & 15.11 & normal & 829.55 & 218.64 & 173.63 & 1704.11 \\
\hline AY-102* & DST & 4263 & 409 & 11.43 & 0.97 & 378 & 1.22 & 409.07 & 6.37 & 2.73 & 0.01 & 15.11 & normal & 829.55 & 218.64 & 173.63 & 1704.11 \\
\hline \begin{tabular}{|l|l|} 
AZ-101* \\
\end{tabular} & DST & 4263 & 409 & 11.42 & 0.97 & 379 & 1.22 & 409.04 & 6.37 & 2.73 & 0.01 & 15.11 & normal & 829.55 & 218.64 & 173.63 & 1704.11 \\
\hline \begin{tabular}{|l|l} 
AZ-102* \\
\end{tabular} & $\begin{array}{l}\mathrm{DST} \\
\end{array}$ & 4263 & 409 & $\begin{array}{l}11.42 \\
\end{array}$ & 0.97 & 379 & 1.22 & 409.04 & 6.37 & 2.73 & 0.01 & 15.11 & normal & 829.55 & 218.64 & 173.63 & $\begin{array}{l}704.11 \\
\end{array}$ \\
\hline B-101 & SST & $1,752.29$ & 410.44 & 11.430 & 0.0000 & 0.000 & 0.0000 & 410.44 & 8.838 & 7.1328 & 0.01 & 40 & normal & 631.25 & 260.88 & 109.49 & 1674.77 \\
\hline B-102 & SST & $1,752.29$ & 410.44 & 11.430 & 0.0000 & 0.000 & 0.0000 & 410.44 & 2.700 & 1.35 & 0.01 & 40 & normal & 631.25 & 260.88 & 109.49 & 1674.77 \\
\hline
\end{tabular}




\begin{tabular}{|c|c|c|c|c|c|c|c|c|c|c|c|c|c|c|c|c|c|}
\hline Data Source & & $\begin{array}{c}\text { RPP-10006 R7 } \\
\text { Data }\end{array}$ & $\begin{array}{c}\text { RPP-10006 R7 } \\
\text { Data }\end{array}$ & $\begin{array}{c}\text { RPP-10006 R7 } \\
\text { Data }\end{array}$ & $\begin{array}{c}\text { RPP-10006 R7 } \\
\text { Data }\end{array}$ & $\begin{array}{c}\text { RPP-10006 R7 } \\
\text { Data }\end{array}$ & $\begin{array}{c}\text { RPP-10006 R7 } \\
\text { Data }\end{array}$ & $\begin{array}{c}\text { RPP-10006 R7 } \\
\text { Data }\end{array}$ & $\begin{array}{l}\text { RPP-10006 R7 } \\
\text { based on waste } \\
\text { type }\end{array}$ & $\begin{array}{c}\text { RPP-10006 R7 } \\
\text { based on waste } \\
\text { type }\end{array}$ & $\begin{array}{c}\text { RPP-10006 R7 } \\
\text { based on waste } \\
\text { type }\end{array}$ & $\begin{array}{l}\text { RPP-10006 R7 } \\
\text { based on waste } \\
\text { type }\end{array}$ & $\begin{array}{c}\text { RPP-10006 R7 } \\
\text { based on waste } \\
\text { type }\end{array}$ & $\begin{array}{c}\text { RPP-10006 R7 } \\
\text { based on waste } \\
\text { type }\end{array}$ & $\begin{array}{c}\text { RPP-10006 R7 } \\
\text { based on waste } \\
\text { type }\end{array}$ & $\begin{array}{c}\text { RPP-10006 R7 } \\
\text { based on waste } \\
\text { type }\end{array}$ & $\begin{array}{c}\text { RPP-10006 R7 } \\
\text { based on waste } \\
\text { type }\end{array}$ \\
\hline Tank \# & Tank Type & $\begin{array}{c}\text { Body volume } \\
\text { (M3) }\end{array}$ & $\begin{array}{l}\text { Body } \\
\text { Operating } \\
\text { Capacity } \\
\text { (m3/m) }\end{array}$ & \begin{tabular}{|c|} 
Body Radius \\
(m)
\end{tabular} & $\begin{array}{c}\text { Dome Arc } \\
\text { height } \\
(\mathbf{m})\end{array}$ & $\begin{array}{c}\text { Dome Arc } \\
\text { volume } \\
\text { (M3) }\end{array}$ & $\begin{array}{c}\text { Dome Arc } \\
\text { Radius } \\
\text { (m) }\end{array}$ & $\begin{array}{c}\text { Tank } \\
\text { capacity } \\
(\mathbf{k L} / \mathbf{m})\end{array}$ & $\begin{array}{c}\text { Void } \\
\text { Fraction or } \\
\text { Maximum } \\
\text { Wetted } \\
\text { Solids Void } \\
\text { Fraction } \\
\text { Mean } \\
\text { (Dimension- } \\
\text { less) }\end{array}$ & \begin{tabular}{|c|} 
Void \\
Fraction or \\
Maximum \\
Wetted \\
Solids Void \\
Fraction \\
Uncertainty \\
(Dimension- \\
less)
\end{tabular} & \begin{tabular}{|c|} 
Void \\
Fraction or \\
Maximum \\
Wetted \\
Solids Void \\
Fraction \\
Minimum \\
(Dimension- \\
less)
\end{tabular} & $\begin{array}{c}\text { Void } \\
\text { Fraction or } \\
\text { Maximum } \\
\text { Wetted } \\
\text { Solids Void } \\
\text { Fraction } \\
\text { Maximum } \\
\text { (Dimension- } \\
\text { less) }\end{array}$ & \begin{tabular}{|c|} 
Void \\
Fraction or \\
Maximum \\
Wetted \\
Solids Void \\
Fraction \\
Dist Type \\
(Dimension- \\
less)
\end{tabular} & \begin{tabular}{|c|} 
non- \\
convective \\
waste yield \\
stress mean \\
(Pa)
\end{tabular} & $\begin{array}{c}\text { non- } \\
\text { convective } \\
\text { waste yield } \\
\text { stress std } \\
\text { dev }(P a)\end{array}$ & \begin{tabular}{|c|} 
non- \\
convective \\
waste yield \\
stress min \\
$($ Pa)
\end{tabular} & $\begin{array}{c}\text { non- } \\
\text { convective } \\
\text { waste yield } \\
\text { stress max } \\
\text { (Pa) }\end{array}$ \\
\hline B-103 & SST & $1,752.29$ & 410.44 & 11.430 & 0.0000 & 0.000 & 0.0000 & 410.44 & 8.838 & 7.1328 & 0.01 & 40 & normal & 631.25 & 260.88 & 109.49 & 1674.77 \\
\hline B-104 & SST & $1,752.29$ & 410.44 & 11.430 & 0.0000 & 0.000 & 0.0000 & 410.44 & 2.437 & 2.4869 & 0.01 & 26.5 & Lognorm & 1143.27 & 272.08 & 327.03 & 2231.59 \\
\hline B-105 & SST & $1,752.29$ & 410.44 & 11.430 & 0.0000 & 0.000 & 0.0000 & 410.44 & 8.838 & 7.1328 & 0.01 & 40 & normal & 631.25 & 260.88 & 109.49 & 1674.77 \\
\hline B-106 & SST & $1,752.29$ & 410.44 & 11.430 & 0.0000 & 0.000 & 0.0000 & 410.44 & 2.437 & 2.4869 & 0.01 & 26.5 & Lognorm & 1143.27 & 272.08 & 327.03 & 2231.59 \\
\hline B-107 & SST & $1,752.29$ & 410.44 & 11.430 & 0.0000 & 0.000 & 0.0000 & 410.44 & 8.838 & 7.1328 & 0.01 & 40 & normal & 631.25 & 260.88 & 109.49 & 1674.77 \\
\hline B-108 & SST & $1,752.29$ & 410.44 & 11.430 & 0.0000 & 0.000 & 0.0000 & 410.44 & 8.838 & 7.1328 & 0.01 & 40 & normal & 631.25 & 260.88 & 109.49 & 1674.77 \\
\hline B-109 & SST & $1,752.29$ & 410.44 & 11.430 & 0.0000 & 0.000 & 0.0000 & 410.44 & 8.838 & 7.1328 & 0.01 & 40 & normal & 631.25 & 260.88 & 109.49 & 1674.77 \\
\hline B-110 & SST & $1,752.29$ & 410.44 & 11.430 & 0.0000 & 0.000 & 0.0000 & 410.44 & 2.437 & 2.4869 & 0.01 & 26.5 & Lognorm & 1143.27 & 272.08 & 327.03 & 2231.59 \\
\hline B-111 & SST & $1,752.29$ & 410.44 & 11.430 & 0.0000 & 0.000 & 0.0000 & 410.44 & 2.437 & 2.4869 & 0.01 & 26.5 & Lognorm & 1143.27 & 272.08 & 327.03 & 2231.59 \\
\hline B-112 & SST & $1,752.29$ & 410.44 & 11.430 & 0.0000 & 0.000 & 0.0000 & 410.44 & 2.500 & 1.25 & 0.01 & 40 & normal & 631.25 & 260.88 & 109.49 & 1674.77 \\
\hline B-201 & SST & 200.39 & 29.19 & 3.048 & 0.0000 & 0.000 & 0.0000 & 29.19 & 2.437 & 2.4869 & 0.01 & 26.5 & Lognorm & 1143.27 & 272.08 & 327.03 & 2231.59 \\
\hline B-202 & SST & 200.39 & 29.19 & 3.048 & 0.0000 & 0.000 & 0.0000 & 29.19 & 2.437 & 2.4869 & 0.01 & 26.5 & Lognorm & 1143.27 & 272.08 & 327.03 & 2231.59 \\
\hline B-203 & SST & 200.39 & 29.19 & 3.048 & 0.0000 & 0.000 & 0.0000 & 29.19 & 2.437 & 2.4869 & 0.01 & 26.5 & Lognorm & 1143.27 & 272.08 & 327.03 & 2231.59 \\
\hline B-204 & SST & 200.39 & 29.19 & 3.048 & 0.0000 & 0.000 & 0.0000 & 29.19 & 2.437 & 2.4869 & 0.01 & 26.5 & Lognorm & 1143.27 & 272.08 & 327.03 & 2231.59 \\
\hline BX-101 & SST & $1,754.89$ & 410.44 & 11.430 & 0.0000 & 0.000 & 0.0000 & 410.44 & 2.000 & 1 & 0.001 & 26.5 & normal & 1143.27 & 272.08 & 327.03 & 2231.59 \\
\hline BX-102 & SST & $1,754.89$ & 410.44 & 11.430 & 0.0000 & 0.000 & 0.0000 & 410.44 & 2.437 & 2.4869 & 0.01 & 26.5 & Lognorm & 1143.27 & 272.08 & 327.03 & 2231.59 \\
\hline$\overline{B X}-103$ & SST & $1,754.89$ & 410.44 & 11.430 & 0.0000 & 0.000 & 0.0000 & 410.44 & 1.200 & 0.6 & 0.001 & 26.5 & normal & 1143.27 & 272.08 & 327.03 & 2231.59 \\
\hline BX-104 & SST & $1,754.89$ & 410.44 & 11.430 & 0.0000 & 0.000 & 0.0000 & 410.44 & 7.500 & 3.75 & 0.001 & 26.5 & normal & 1143.27 & 272.08 & 327.03 & 2231.59 \\
\hline BX-105 & SST & $1,754.89$ & 410.44 & 11.430 & 0.0000 & 0.000 & 0.0000 & 410.44 & 1.600 & 0.8 & 0.01 & 40 & normal & 631.25 & 260.88 & 109.49 & 1674.77 \\
\hline BX-106 & SST & $1,754.89$ & 410.44 & 11.430 & 0.0000 & 0.000 & 0.0000 & 410.44 & 8.838 & 7.1328 & 0.01 & 40 & normal & 631.25 & 260.88 & 109.49 & 1674.77 \\
\hline BX-107 & SST & $1,754.89$ & 410.44 & 11.430 & 0.0000 & 0.000 & 0.0000 & 410.44 & 2.500 & 1.25 & 0.001 & 26.5 & normal & 1143.27 & 272.08 & 327.03 & 2231.59 \\
\hline BX-108 & SST & $1,754.89$ & 410.44 & 11.430 & 0.0000 & 0.000 & 0.0000 & 410.44 & 2.437 & 2.4869 & 0.01 & 26.5 & Lognorm & 1143.27 & 272.08 & 327.03 & 2231.59 \\
\hline BX-109 & SST & $1,754.89$ & 410.44 & 11.430 & 0.0000 & 0.000 & 0.0000 & 410.44 & 2.437 & 2.4869 & 0.01 & 26.5 & Lognorm & 1143.27 & 272.08 & 327.03 & 2231.59 \\
\hline BX-110 & SST & $1,754.89$ & 410.44 & 11.430 & 0.0000 & 0.000 & 0.0000 & 410.44 & 4.000 & 2 & 0.01 & 40 & normal & 631.25 & 260.88 & 109.49 & 1674.77 \\
\hline BX-111 & SST & $1,754.89$ & 410.44 & 11.430 & 0.0000 & 0.000 & 0.0000 & 410.44 & 0.500 & 0.25 & 0.01 & 40 & normal & 631.25 & 260.88 & 109.49 & 1674.77 \\
\hline BX-112 & SST & $1,754.89$ & 410.44 & 11.430 & 0.0000 & 0.000 & 0.0000 & 410.44 & 0.500 & 0.25 & 0.001 & 26.5 & normal & 1143.27 & 272.08 & 327.03 & 2231.59 \\
\hline BY-101 & SST & $2,495.07$ & 410.44 & 11.430 & 0.0000 & 0.000 & 0.0000 & 410.44 & 8.838 & 7.1328 & 0.01 & 40 & normal & 631.25 & 260.88 & 109.49 & 1674.77 \\
\hline BY-102 & SST & $2,495.07$ & 410.44 & 11.430 & 0.0000 & 0.000 & 0.0000 & 410.44 & 8.838 & 7.1328 & 0.01 & 40 & normal & 631.25 & 260.88 & 109.49 & 1674.77 \\
\hline BY-103 & SST & $2,495.07$ & 410.44 & 11.430 & 0.0000 & 0.000 & 0.0000 & 410.44 & 8.838 & 7.1328 & 0.01 & 40 & normal & 631.25 & 260.88 & 109.49 & 1674.77 \\
\hline BY-104 & SST & $2,495.07$ & 410.44 & 11.430 & 0.0000 & 0.000 & 0.0000 & 410.44 & 8.838 & 7.1328 & 0.01 & 40 & normal & 631.25 & 260.88 & 109.49 & 1674.77 \\
\hline BY-105 & SST & $2,495.07$ & 410.44 & 11.430 & 0.0000 & 0.000 & 0.0000 & 410.44 & 8.838 & 7.1328 & 0.01 & 40 & normal & 631.25 & 260.88 & 109.49 & 1674.77 \\
\hline \begin{tabular}{|l} 
BY-106 \\
\end{tabular} & SST & $2,495.07$ & 410.44 & 11.430 & 0.0000 & 0.000 & 0.0000 & 410.44 & 8.838 & 7.1328 & 0.01 & 40 & normal & 631.25 & 260.88 & 109.49 & 1674.77 \\
\hline BY-107 & SST & $2,495.07$ & 410.44 & 11.430 & 0.0000 & 0.000 & 0.0000 & 410.44 & 8.838 & 7.1328 & 0.01 & 40 & normal & 631.25 & 260.88 & 109.49 & 1674.77 \\
\hline BY-108 & SST & $2,495.07$ & 410.44 & 11.430 & 0.0000 & 0.000 & 0.0000 & 410.44 & 8.838 & 7.1328 & 0.01 & 40 & normal & 631.25 & 260.88 & 109.49 & 1674.77 \\
\hline BY-109 & SST & $2,495.07$ & 410.44 & 11.430 & 0.0000 & 0.000 & 0.0000 & 410.44 & 8.838 & 7.1328 & 0.01 & 40 & normal & 631.25 & 260.88 & 109.49 & 1674.77 \\
\hline BY-110 & SST & $2,495.07$ & 410.44 & 11.430 & 0.0000 & 0.000 & 0.0000 & 410.44 & 8.838 & 7.1328 & 0.01 & 40 & normal & 631.25 & 260.88 & 109.49 & 1674.77 \\
\hline BY-111 & SST & $2,495.07$ & 410.44 & 11.430 & 0.0000 & 0.000 & 0.0000 & 410.44 & 8.838 & 7.1328 & 0.01 & 40 & normal & 631.25 & 260.88 & 109.49 & 1674.77 \\
\hline
\end{tabular}




\begin{tabular}{|c|c|c|c|c|c|c|c|c|c|c|c|c|c|c|c|c|c|}
\hline Data Source & & $\begin{array}{c}\text { RPP-10006 R7 } \\
\text { Data }\end{array}$ & $\begin{array}{c}\text { RPP-10006 R7 } \\
\text { Data }\end{array}$ & $\begin{array}{c}\text { RPP-10006 R7 } \\
\text { Data }\end{array}$ & $\begin{array}{c}\text { RPP-10006 R7 } \\
\text { Data }\end{array}$ & $\begin{array}{c}\text { RPP-10006 R7 } \\
\text { Data }\end{array}$ & $\begin{array}{c}\text { RPP-10006 R7 } \\
\text { Data }\end{array}$ & $\begin{array}{c}\text { RPP-10006 R7 } \\
\text { Data }\end{array}$ & $\begin{array}{l}\text { RPP-10006 R7 } \\
\text { based on waste } \\
\text { type }\end{array}$ & $\begin{array}{c}\text { RPP-10006 R7 } \\
\text { based on waste } \\
\text { type }\end{array}$ & $\begin{array}{c}\text { RPP-10006 R7 } \\
\text { based on waste } \\
\text { type }\end{array}$ & $\begin{array}{l}\text { RPP-10006 R7 } \\
\text { based on waste } \\
\text { type }\end{array}$ & $\begin{array}{c}\text { RPP-10006 R7 } \\
\text { based on waste } \\
\text { type }\end{array}$ & $\begin{array}{c}\text { RPP-10006 R7 } \\
\text { based on waste } \\
\text { type }\end{array}$ & $\begin{array}{l}\text { RPP-10006 R7 } \\
\text { based on waste } \\
\text { type }\end{array}$ & $\begin{array}{c}\text { RPP-10006 R7 } \\
\text { based on waste } \\
\text { type }\end{array}$ & $\begin{array}{l}\text { RPP-10006 R7 } \\
\text { based on waste } \\
\text { type }\end{array}$ \\
\hline Tank \# & Tank Type & \begin{tabular}{|c|} 
Body volume \\
(M3)
\end{tabular} & $\begin{array}{c}\text { Body } \\
\text { Operating } \\
\text { Capacity } \\
(\mathbf{m} 3 / \mathbf{m}) \\
\end{array}$ & \begin{tabular}{|c|} 
Body Radius \\
$(\mathbf{m})$
\end{tabular} & $\begin{array}{c}\text { Dome Arc } \\
\text { height } \\
(\mathbf{m})\end{array}$ & $\begin{array}{c}\begin{array}{c}\text { Dome Arc } \\
\text { volume } \\
\text { (M3) }\end{array} \\
\end{array}$ & $\begin{array}{c}\text { Dome Arc } \\
\text { Radius } \\
\text { (m) }\end{array}$ & $\begin{array}{c}\text { Tank } \\
\text { capacity } \\
(\mathbf{k L} / \mathbf{m})\end{array}$ & $\begin{array}{c}\text { Void } \\
\text { Fraction or } \\
\text { Maximum } \\
\text { Wetted } \\
\text { Solids Void } \\
\text { Fraction } \\
\text { Mean } \\
\text { (Dimension- } \\
\text { less) } \\
\end{array}$ & \begin{tabular}{|c|} 
Void \\
Fraction or \\
Maximum \\
Wetted \\
Solids Void \\
Fraction \\
Uncertainty \\
(Dimension- \\
less) \\
\end{tabular} & \begin{tabular}{|c|} 
Void \\
Fraction or \\
Maximum \\
Wetted \\
Solids Void \\
Fraction \\
Minimum \\
(Dimension- \\
less) \\
\end{tabular} & $\begin{array}{c}\text { Void } \\
\text { Fraction or } \\
\text { Maximum } \\
\text { Wetted } \\
\text { Solids Void } \\
\text { Fraction } \\
\text { Maximum } \\
\text { (Dimension- } \\
\text { less) } \\
\end{array}$ & \begin{tabular}{|c|} 
Void \\
Fraction or \\
Maximum \\
Wetted \\
Solids Void \\
Fraction \\
Dist Type \\
(Dimension- \\
less) \\
\end{tabular} & \begin{tabular}{|c|} 
non- \\
convective \\
waste yield \\
stress mean \\
$(\mathrm{Pa})$ \\
\end{tabular} & $\begin{array}{c}\text { non- } \\
\text { convective } \\
\text { waste yield } \\
\text { stress std } \\
\text { dev }(P a) \\
\end{array}$ & \begin{tabular}{|c|} 
non- \\
convective \\
waste yield \\
stress min \\
$(\mathrm{Pa})$ \\
\end{tabular} & $\begin{array}{c}\text { non- } \\
\text { convective } \\
\text { waste yield } \\
\text { stress max } \\
(\mathrm{Pa}) \\
\end{array}$ \\
\hline$\overline{B Y-112}$ & SST & $2,495.07$ & 410.44 & 11.430 & 0.0000 & 0.000 & 0.0000 & 410.44 & 8.838 & 7.1328 & 0.01 & 40 & normal & 631.25 & 260.88 & 109.49 & 1674.77 \\
\hline C-101 & SST & $1,752.29$ & 410.44 & 11.430 & 0.0000 & 0.000 & 0.0000 & 410.44 & 2.437 & 2.4869 & 0.01 & 26.5 & Lognorm & 1143.27 & 272.08 & 327.03 & 2231.59 \\
\hline$\overline{C-102}$ & SST & $1,752.29$ & 410.44 & 11.430 & 0.0000 & 0.000 & 0.0000 & 410.44 & 2.437 & 2.4869 & 0.01 & 26.5 & Lognorm & 1143.27 & 272.08 & 327.03 & 2231.59 \\
\hline $\mathrm{C}-103$ & SST & $1,752.29$ & 410.44 & 11.430 & 0.0000 & 0.000 & 0.0000 & 410.44 & 0.600 & 0.3 & 0.001 & 26.5 & normal & 1143.27 & 272.08 & 327.03 & 2231.59 \\
\hline C-104 & SST & $1,752.29$ & 410.44 & 11.430 & 0.0000 & 0.000 & 0.0000 & 410.44 & 2.437 & 2.4869 & 0.01 & 26.5 & Lognorm & 1143.27 & 272.08 & 327.03 & 2231.59 \\
\hline $\mathrm{C}-105$ & SST & $1,752.29$ & 410.44 & 11.430 & 0.0000 & 0.000 & 0.0000 & 410.44 & 2.437 & 2.4869 & 0.01 & 26.5 & Lognorm & 1143.27 & 272.08 & 327.03 & 2231.59 \\
\hline $\mathrm{C}-106$ & SST & $1,752.29$ & 410.44 & 11.430 & 0.0000 & 0.000 & 0.0000 & 410.44 & 2.437 & 2.4869 & 0.01 & 26.5 & Lognorm & 1143.27 & 272.08 & 327.03 & 2231.59 \\
\hline $\mathrm{C}-107$ & SST & $1,752.29$ & 410.44 & 11.430 & 0.0000 & 0.000 & 0.0000 & 410.44 & 2.437 & 2.4869 & 0.01 & 26.5 & Lognorm & 1143.27 & 272.08 & 327.03 & 2231.59 \\
\hline C-108* & SST & $1,752.29$ & 410.44 & 11.430 & 0.0000 & 0.000 & 0.0000 & 410.44 & 2.437 & 2.4869 & 0.01 & 26.5 & Lognorm & 1143.27 & 272.08 & 327.03 & 2231.59 \\
\hline C-109* & SST & $1,752.29$ & 410.44 & 11.430 & 0.0000 & 0.000 & 0.0000 & 410.44 & 2.437 & 2.4869 & 0.01 & 26.5 & Lognorm & 1143.27 & 272.08 & 327.03 & 2231.59 \\
\hline $\mathrm{C}-110$ & SST & $1,752.29$ & 410.44 & 11.430 & 0.0000 & 0.000 & 0.0000 & 410.44 & 2.437 & 2.4869 & 0.01 & 26.5 & Lognorm & 1143.27 & 272.08 & 327.03 & 2231.59 \\
\hline $\mathrm{C}-111$ & SST & $1,752.29$ & 410.44 & 11.430 & 0.0000 & 0.000 & 0.0000 & 410.44 & 2.437 & 2.4869 & 0.01 & 26.5 & Lognorm & 1143.27 & 272.08 & 327.03 & 2231.59 \\
\hline$\overline{\mathrm{C}-112}$ & SST & $1,752.29$ & 410.44 & 11.430 & 0.0000 & 0.000 & 0.0000 & 410.44 & 2.437 & 2.4869 & 0.01 & 26.5 & Lognorm & 1143.27 & 272.08 & 327.03 & 2231.59 \\
\hline $\mathrm{C}-201$ & $\begin{array}{l}\text { SST } \\
\end{array}$ & 200.39 & 29.19 & 3.048 & 0.0000 & 0.000 & 0.0000 & 29.19 & 2.437 & 2.4869 & 0.01 & 26.5 & Lognorm & 1143.27 & 272.08 & 327.03 & 2231.59 \\
\hline $\mathrm{C}-202$ & SST & 200.39 & 29.19 & 3.048 & 0.0000 & 0.000 & 0.0000 & 29.19 & 2.437 & 2.4869 & 0.01 & 26.5 & Lognorm & 1143.27 & 272.08 & 327.03 & 2231.59 \\
\hline $\mathrm{C}-203$ & SST & 200.39 & 29.19 & 3.048 & 0.0000 & 0.000 & 0.0000 & 29.19 & 2.437 & 2.4869 & 0.01 & 26.5 & Lognorm & 1143.27 & 272.08 & 327.03 & 2231.59 \\
\hline $\mathrm{C}-204$ & SST & 200.39 & 29.19 & 3.048 & 0.0000 & 0.000 & 0.0000 & 29.19 & 2.437 & 2.4869 & 0.01 & 26.5 & Lognorm & 1143.27 & 272.08 & 327.03 & 2231.59 \\
\hline S-101 & SST & $2,502.89$ & 410.44 & 11.430 & 0.0000 & 0.000 & 0.0000 & 410.44 & 4.300 & 2.15 & 0.01 & 40 & normal & 631.25 & 260.88 & 109.49 & 1674.77 \\
\hline S-102* & SST & $2,502.89$ & 410.44 & 11.430 & 0.0000 & 0.000 & 0.0000 & 410.44 & 8.838 & 7.1328 & 0.01 & 40 & normal & 631.25 & 260.88 & 109.49 & 1674.77 \\
\hline S-103 & SST & $2,502.89$ & 410.44 & 11.430 & 0.0000 & 0.000 & 0.0000 & 410.44 & 14.700 & 7.35 & 0.01 & 40 & normal & 631.25 & 260.88 & 109.49 & 1674.77 \\
\hline S-104 & SST & $2,502.89$ & 410.44 & 11.430 & 0.0000 & 0.000 & 0.0000 & 410.44 & 8.838 & 7.1328 & 0.01 & 40 & normal & 631.25 & 260.88 & 109.49 & 1674.77 \\
\hline S-105 & $\begin{array}{l}\text { SST } \\
\end{array}$ & $2,502.89$ & 410.44 & 11.430 & 0.0000 & 0.000 & 0.0000 & 410.44 & 8.838 & 7.1328 & 0.01 & 40 & normal & 631.25 & 260.88 & 109.49 & 1674.77 \\
\hline S-106 & SST & $2,502.89$ & 410.44 & 11.430 & 0.0000 & 0.000 & 0.0000 & 410.44 & 8.200 & 4.1 & 0.01 & 40 & normal & 631.25 & 260.88 & 109.49 & 1674.77 \\
\hline S-107 & SST & $2,502.89$ & 410.44 & 11.430 & 0.0000 & 0.000 & 0.0000 & 410.44 & 2.400 & 1.2 & 0.01 & 26.5 & normal & 1143.27 & 272.08 & 327.03 & 2231.59 \\
\hline S-108 & SST & $2,502.89$ & 44 & 11.430 & 0.0000 & 0.000 & 0.0000 & 410.44 & 8.838 & 7.1328 & 0.01 & 40 & normal & 631.25 & 260.88 & 109.49 & 1674.77 \\
\hline $\begin{array}{l}\text { S-109 } \\
\end{array}$ & $\begin{array}{l}\text { SST } \\
\end{array}$ & $2,502.89$ & 410.44 & 11.430 & 0.0000 & 0.000 & 0.0000 & 410.44 & 8.838 & 7.1328 & 0.01 & 40 & normal & 631.25 & 260.88 & 109.49 & 1674.77 \\
\hline S-110 & SST & $2,502.89$ & 410.44 & 11.430 & 0.0000 & 0.000 & 0.0000 & 410.44 & 8.838 & 7.1328 & 0.01 & 40 & normal & 631.25 & 260.88 & 109.49 & 1674.77 \\
\hline S-111 & SST & $2,502.89$ & 410.44 & 11.430 & 0.0000 & 0.000 & 0.0000 & 410.44 & 11.900 & 5.95 & 0.01 & 40 & normal & 631.25 & 260.88 & 109.49 & 1674.77 \\
\hline S-112* & SST & $2,502.89$ & 410.44 & 11.430 & 0.0000 & 0.000 & 0.0000 & 410.44 & 8.838 & 7.1328 & 0.01 & 40 & normal & 631.25 & 260.88 & 109.49 & 1674.77 \\
\hline SX-101 & SST & $3,890.71$ & 410.66 & 11.433 & 0.0000 & 0.000 & 0.0000 & 410.66 & 8.838 & 7.1328 & 0.01 & 40 & normal & 631.25 & 260.88 & 109.49 & 1674.77 \\
\hline SX-102 & SST & $3,890.71$ & 410.66 & 11.433 & 0.0000 & 0.000 & 0.0000 & 410.66 & 8.838 & 7.1328 & 0.01 & 40 & normal & 631.25 & 260.88 & 109.49 & 1674.77 \\
\hline SX-103 & SST & $3,890.71$ & 410.66 & 11.433 & 0.0000 & 0.000 & 0.0000 & 410.66 & 8.838 & 7.1328 & 0.01 & 40 & normal & 631.25 & 260.88 & 109.49 & 1674.77 \\
\hline SX-104 & SST & $3,890.71$ & 410.66 & 11.433 & 0.0000 & 0.000 & 0.0000 & 410.66 & 8.838 & 7.1328 & 0.01 & 40 & normal & 631.25 & 260.88 & 109.49 & 1674.77 \\
\hline SX-105 & SST & $3,890.71$ & 410.66 & 11.433 & 0.0000 & 0.000 & 0.0000 & 410.66 & 8.838 & 7.1328 & 0.01 & 40 & normal & 631.25 & 260.88 & 109.49 & 1674.77 \\
\hline SX-106 & SST & $3,890.71$ & 410.66 & 11.433 & 0.0000 & 0.000 & 0.0000 & 410.66 & 14.000 & 7 & 0.01 & 40 & normal & 631.25 & 260.88 & 109.49 & 1674.77 \\
\hline SX-107 & SST & $3,890.71$ & 410.66 & 11.433 & 0.0000 & 0.000 & 0.0000 & 410.66 & 2.437 & 2.4869 & 0.01 & 26.5 & Lognorm & 1143.27 & 272.08 & 327.03 & 2231.59 \\
\hline SX-108 & SST & $3,890.71$ & 410.66 & 11.433 & 0.0000 & 0.000 & 0.0000 & 410.66 & 2.437 & 2.4869 & 0.01 & 26.5 & Lognorm & 1143.27 & 272.08 & 327.03 & 2231.59 \\
\hline
\end{tabular}




\begin{tabular}{|c|c|c|c|c|c|c|c|c|c|c|c|c|c|c|c|c|c|}
\hline Data Source & & $\begin{array}{c}\text { RPP-10006 R7 } \\
\text { Data }\end{array}$ & $\begin{array}{c}\text { RPP-10006 R7 } \\
\text { Data }\end{array}$ & $\begin{array}{c}\text { RPP-10006 R7 } \\
\text { Data }\end{array}$ & $\begin{array}{c}\text { RPP-10006 R7 } \\
\text { Data }\end{array}$ & $\begin{array}{c}\text { RPP-10006 R7 } \\
\text { Data }\end{array}$ & $\begin{array}{c}\text { RPP-10006 R7 } \\
\text { Data }\end{array}$ & $\begin{array}{c}\text { RPP-10006 R7 } \\
\text { Data }\end{array}$ & $\begin{array}{l}\text { RPP-10006 R7 } \\
\text { based on waste } \\
\text { type }\end{array}$ & $\begin{array}{c}\text { RPP-10006 R7 } \\
\text { based on waste } \\
\text { type }\end{array}$ & $\begin{array}{c}\text { RPP-10006 R7 } \\
\text { based on waste } \\
\text { type }\end{array}$ & $\begin{array}{l}\text { RPP-10006 R7 } \\
\text { based on waste } \\
\text { type }\end{array}$ & $\begin{array}{c}\text { RPP-10006 R7 } \\
\text { based on waste } \\
\text { type }\end{array}$ & $\begin{array}{c}\text { RPP-10006 R7 } \\
\text { based on waste } \\
\text { type }\end{array}$ & $\begin{array}{c}\text { RPP-10006 R7 } \\
\text { based on waste } \\
\text { type }\end{array}$ & $\begin{array}{c}\text { RPP-10006 R7 } \\
\text { based on waste } \\
\text { type }\end{array}$ & $\begin{array}{c}\text { RPP-10006 R7 } \\
\text { based on waste } \\
\text { type }\end{array}$ \\
\hline Tank \# & Tank Type & \begin{tabular}{|c|} 
Body volume \\
(M3)
\end{tabular} & $\begin{array}{c}\text { Body } \\
\text { Operating } \\
\text { Capacity } \\
(\mathbf{m} 3 / \mathbf{m}) \\
\end{array}$ & $\begin{array}{c}\text { Body Radius } \\
(\mathbf{m})\end{array}$ & $\begin{array}{c}\text { Dome Arc } \\
\text { height } \\
(\mathbf{m})\end{array}$ & $\begin{array}{c}\begin{array}{c}\text { Dome Arc } \\
\text { volume } \\
\text { (M3) }\end{array} \\
\end{array}$ & $\begin{array}{c}\text { Dome Arc } \\
\text { Radius } \\
\text { (m) }\end{array}$ & $\begin{array}{c}\text { Tank } \\
\text { capacity } \\
(\mathbf{k L} / \mathbf{m})\end{array}$ & $\begin{array}{c}\text { Void } \\
\text { Fraction or } \\
\text { Maximum } \\
\text { Wetted } \\
\text { Solids Void } \\
\text { Fraction } \\
\text { Mean } \\
\text { (Dimension- } \\
\text { less) } \\
\end{array}$ & \begin{tabular}{|c|} 
Void \\
Fraction or \\
Maximum \\
Wetted \\
Solids Void \\
Fraction \\
Uncertainty \\
(Dimension- \\
less) \\
\end{tabular} & \begin{tabular}{|c|} 
Void \\
Fraction or \\
Maximum \\
Wetted \\
Solids Void \\
Fraction \\
Minimum \\
(Dimension- \\
less) \\
\end{tabular} & $\begin{array}{c}\text { Void } \\
\text { Fraction or } \\
\text { Maximum } \\
\text { Wetted } \\
\text { Solids Void } \\
\text { Fraction } \\
\text { Maximum } \\
\text { (Dimension- } \\
\text { less) } \\
\end{array}$ & \begin{tabular}{|c|} 
Void \\
Fraction or \\
Maximum \\
Wetted \\
Solids Void \\
Fraction \\
Dist Type \\
(Dimension- \\
less) \\
\end{tabular} & \begin{tabular}{|c|} 
non- \\
convective \\
waste yield \\
stress mean \\
$(\mathrm{Pa})$ \\
\end{tabular} & $\begin{array}{c}\text { non- } \\
\text { convective } \\
\text { waste yield } \\
\text { stress std } \\
\text { dev }(P a) \\
\end{array}$ & \begin{tabular}{|c|} 
non- \\
convective \\
waste yield \\
stress min \\
$(\mathrm{Pa})$ \\
\end{tabular} & $\begin{array}{c}\text { non- } \\
\text { convective } \\
\text { waste yield } \\
\text { stress max } \\
(\mathrm{Pa}) \\
\end{array}$ \\
\hline SX-109 & SST & $3,890.71$ & 410.66 & 11.433 & 0.0000 & 0.000 & 0.0000 & 410.66 & 8.838 & 7.1328 & 0.01 & 40 & normal & 631.25 & 260.88 & 109.49 & 1674.77 \\
\hline SX-110 & SST & $3,890.71$ & 410.66 & 11.433 & 0.0000 & 0.000 & 0.0000 & 410.66 & 2.437 & 2.4869 & 0.01 & 26.5 & Lognorm & 1143.27 & 272.08 & 327.03 & 2231.59 \\
\hline SX-111 & SST & $3,890.71$ & 410.66 & 11.433 & 0.0000 & 0.000 & 0.0000 & 410.66 & 2.437 & 2.4869 & 0.01 & 26.5 & Lognorm & 1143.27 & 272.08 & 327.03 & 2231.59 \\
\hline SX-112 & SST & $3,890.71$ & 410.66 & 11.433 & 0.0000 & 0.000 & 0.0000 & 410.66 & 2.437 & 2.4869 & 0.01 & 26.5 & Lognorm & 1143.27 & 272.08 & 327.03 & 2231.59 \\
\hline SX-113 & SST & $3,890.71$ & 410.66 & 11.433 & 0.0000 & 0.000 & 0.0000 & 410.66 & 2.437 & 2.4869 & 0.01 & 26.5 & Lognorm & 1143.27 & 272.08 & 327.03 & 2231.59 \\
\hline SX-114 & SST & $3,890.71$ & 410.66 & 11.433 & 0.0000 & 0.000 & 0.0000 & 410.66 & 2.437 & 2.4869 & 0.01 & 26.5 & Lognorm & 1143.27 & 272.08 & 327.03 & 2231.59 \\
\hline SX-115 & SST & $3,890.71$ & 410.66 & 11.433 & 0.0000 & 0.000 & 0.0000 & 410.66 & 2.437 & 2.4869 & 0.01 & 26.5 & Lognorm & 1143.27 & 272.08 & 327.03 & 2231.59 \\
\hline SY-101* & DST & 4263 & 409 & 11.42 & 0.97 & 379 & 1.22 & 409.04 & 8.50 & 4.25 & 0.00 & 15.11 & normal & 144.00 & 13.87 & 88.52 & 199.48 \\
\hline SY-102* & DST & 4263 & 409 & 11.42 & 0.97 & 379 & 1.22 & 409.04 & 0.90 & 0.45 & 0.01 & 15.11 & normal & 829.55 & 218.64 & 173.63 & 1704.11 \\
\hline SY-103* & DST & 4263 & 409 & 11.42 & 0.97 & 379 & 1.22 & 409.04 & 6.00 & 3.00 & 0.00 & 15.11 & normal & 144.00 & 13.87 & 88.52 & 199.48 \\
\hline T-101 & SST & $1,752.29$ & 410.44 & 11.430 & 0.0000 & 0.000 & 0.0000 & 410.44 & 0.700 & 0.35 & 0.01 & 40 & normal & 631.25 & 260.88 & 109.49 & 1674.77 \\
\hline T-102 & SST & $1,752.29$ & 410.44 & 11.430 & 0.0000 & 0.000 & 0.0000 & 410.44 & 2.437 & 2.4869 & 0.01 & 26.5 & Lognorm & 1143.27 & 272.08 & 327.03 & 2231.59 \\
\hline T-103 & SST & $1,752.29$ & 410.44 & 11.430 & 0.0000 & 0.000 & 0.0000 & 410.44 & 2.437 & 2.4869 & 0.01 & 26.5 & Lognorm & 1143.27 & 272.08 & 327.03 & 2231.59 \\
\hline T-104 & $\begin{array}{l}\text { SST } \\
\end{array}$ & $1,752.29$ & 410.44 & 11.430 & 0.0000 & 0.000 & 0.0000 & 410.44 & 2.437 & 2.4869 & 0.01 & 26.5 & Lognorm & 1143.27 & 272.08 & 327.03 & 2231.59 \\
\hline T-105 & SST & $1,752.29$ & 410.44 & 11.430 & 0.0000 & 0.000 & 0.0000 & 410.44 & 2.437 & 2.4869 & 0.01 & 26.5 & Lognorm & 1143.27 & 272.08 & 327.03 & 2231.59 \\
\hline T-106 & SST & $1,752.29$ & 410.44 & 11.430 & 0.0000 & 0.000 & 0.0000 & 410.44 & 2.437 & 2.4869 & 0.01 & 26.5 & Lognorm & 1143.27 & 272.08 & 327.03 & 2231.59 \\
\hline T-107 & SST & $1,752.29$ & 410.44 & 11.430 & 0.0000 & 0.000 & 0.0000 & 410.44 & 2.437 & 2.4869 & 0.01 & 26.5 & Lognorm & 1143.27 & 272.08 & 327.03 & 2231.59 \\
\hline T-108 & SST & $1,752.29$ & 410.44 & 11.430 & 0.0000 & 0.000 & 0.0000 & 410.44 & 8.838 & 7.1328 & 0.01 & 40 & normal & 631.25 & 260.88 & 109.49 & 1674.77 \\
\hline T-109 & SST & $1,752.29$ & 410.44 & 11.430 & 0.0000 & 0.000 & 0.0000 & 410.44 & 8.838 & 7.1328 & 0.01 & 40 & normal & 631.25 & 260.88 & 109.49 & 1674.77 \\
\hline T-110 & SST & $1,752.29$ & 410.44 & 11.430 & 0.0000 & 0.000 & 0.0000 & 410.44 & 2.437 & 2.4869 & 0.01 & 26.5 & Lognorm & 1143.27 & 272.08 & 327.03 & 2231.59 \\
\hline T-111 & SST & $1,752.29$ & 410.44 & 11.430 & 0.0000 & 0.000 & 0.0000 & 410.44 & 2.437 & 2.4869 & 0.01 & 26.5 & Lognorm & 1143.27 & 272.08 & 327.03 & 2231.59 \\
\hline$T-112$ & $\begin{array}{l}\text { SST } \\
\end{array}$ & $1,752.29$ & 410.44 & 11.430 & 0.0000 & 0.000 & 0.0000 & 410.44 & 2.437 & 2.4869 & 0.01 & 26.5 & Lognorm & 1143.27 & 272.08 & 327.03 & 2231.59 \\
\hline T-201 & SST & 200.39 & 29.19 & 3.048 & 0.0000 & 0.000 & 0.0000 & 29.19 & 2.437 & 2.4869 & 0.01 & 26.5 & Lognorm & 1143.27 & 272.08 & 327.03 & 2231.59 \\
\hline T-202 & SST & 200.39 & 29.19 & 3.048 & 0.0000 & 0.000 & 0.0000 & 29.19 & 2.437 & 2.4869 & 0.01 & 26.5 & Lognorm & 1143.27 & 272.08 & 327.03 & 2231.59 \\
\hline $\mathrm{T}-203$ & SST & 200.39 & 29.19 & 3.048 & 0.0000 & 0.000 & 0.0000 & 29.19 & 2.437 & 2.4869 & 0.01 & 26.5 & Lognorm & 1143.27 & 272.08 & 327.03 & 2231.59 \\
\hline T-204 & $\begin{array}{l}\text { SST } \\
\end{array}$ & 200.39 & 29.19 & 3.048 & 0.0000 & 0.000 & 0.0000 & 29.19 & 2.437 & 2.4869 & 0.01 & 26.5 & Lognorm & 1143.27 & 272.08 & 327.03 & 2231.59 \\
\hline TX-101 & SST & $2,495.07$ & 410.44 & 11.430 & 0.0000 & 0.000 & 0.0000 & 410.44 & 0.900 & 0.45 & 0.01 & 26.5 & normal & 1143.27 & 272.08 & 327.03 & 2231.59 \\
\hline TX-102 & SST & $2,495.07$ & 410.44 & 11.430 & 0.0000 & 0.000 & 0.0000 & 410.44 & 8.838 & 7.1328 & 0.01 & 40 & normal & 631.25 & 260.88 & 109.49 & 1674.77 \\
\hline TX-103 & SST & $2,495.07$ & 410.44 & 11.430 & 0.0000 & 0.000 & 0.0000 & 410.44 & 8.838 & 7.1328 & 0.01 & 40 & normal & 631.25 & 260.88 & 109.49 & 1674.77 \\
\hline TX-104 & SST & $2,495.07$ & 410.44 & 11.430 & 0.0000 & 0.000 & 0.0000 & 410.44 & 1.200 & 0.6 & 0.01 & 40 & normal & 631.25 & 260.88 & 109.49 & 1674.77 \\
\hline TX-105 & SST & $2,495.07$ & 410.44 & 11.430 & 0.0000 & 0.000 & 0.0000 & 410.44 & 8.838 & 7.1328 & 0.01 & 40 & normal & 631.25 & 260.88 & 109.49 & 1674.77 \\
\hline TX-106 & SST & $2,495.07$ & 410.44 & 11.430 & 0.0000 & 0.000 & 0.0000 & 410.44 & 8.838 & 7.1328 & 0.01 & 40 & normal & 631.25 & 260.88 & 109.49 & 1674.77 \\
\hline TX-107 & SST & $2,495.07$ & 410.44 & 11.430 & 0.0000 & 0.000 & 0.0000 & 410.44 & 2.100 & 1.05 & 0.01 & 40 & normal & 631.25 & 260.88 & 109.49 & 1674.77 \\
\hline TX-108 & SST & $2,495.07$ & 410.44 & 11.430 & 0.0000 & 0.000 & 0.0000 & 410.44 & 8.838 & 7.1328 & 0.01 & 40 & normal & 631.25 & 260.88 & 109.49 & 1674.77 \\
\hline TX-109 & SST & $2,495.07$ & 410.44 & 11.430 & 0.0000 & 0.000 & 0.0000 & 410.44 & 2.437 & 2.4869 & 0.01 & 26.5 & Lognorm & 1143.27 & 272.08 & 327.03 & 2231.59 \\
\hline TX-110 & SST & $2,495.07$ & 410.44 & 11.430 & 0.0000 & 0.000 & 0.0000 & 410.44 & 8.838 & 7.1328 & 0.01 & 40 & normal & 631.25 & 260.88 & 109.49 & 1674.77 \\
\hline TX-111 & SST & $2,495.07$ & 410.44 & 11.430 & 0.0000 & 0.000 & 0.0000 & 410.44 & 8.838 & 7.1328 & 0.01 & 40 & normal & 631.25 & 260.88 & 109.49 & 1674.77 \\
\hline
\end{tabular}




\begin{tabular}{|c|c|c|c|c|c|c|c|c|c|c|c|c|c|c|c|c|c|}
\hline Data Source & & $\begin{array}{c}\text { RPP-10006 R7 } \\
\text { Data }\end{array}$ & $\begin{array}{c}\text { RPP-10006 R7 } \\
\text { Data }\end{array}$ & $\begin{array}{c}\text { RPP-10006 R7 } \\
\text { Data }\end{array}$ & $\begin{array}{c}\text { RPP-10006 R7 } \\
\text { Data }\end{array}$ & $\begin{array}{c}\text { RPP-10006 R7 } \\
\text { Data }\end{array}$ & $\begin{array}{c}\text { RPP-10006 R7 } \\
\text { Data }\end{array}$ & $\begin{array}{c}\text { RPP-10006 R7 } \\
\text { Data }\end{array}$ & $\begin{array}{c}\text { RPP-10006 R7 } \\
\text { based on waste } \\
\text { type }\end{array}$ & $\begin{array}{l}\text { RPP-10006 R7 } \\
\text { based on waste } \\
\text { type }\end{array}$ & $\begin{array}{c}\text { RPP-10006 R7 } \\
\text { based on waste } \\
\text { type }\end{array}$ & $\begin{array}{c}\text { RPP-10006 R7 } \\
\text { based on waste } \\
\text { type }\end{array}$ & $\begin{array}{c}\text { RPP-10006 R7 } \\
\text { based on waste } \\
\text { type }\end{array}$ & $\begin{array}{c}\text { RPP-10006 R7 } \\
\text { based on waste } \\
\text { type }\end{array}$ & $\begin{array}{c}\text { RPP-10006 R7 } \\
\text { based on waste } \\
\text { type }\end{array}$ & $\begin{array}{l}\text { RPP-10006 R7 } \\
\text { based on waste } \\
\text { type }\end{array}$ & $\begin{array}{l}\text { RPP-10006 R7 } \\
\text { based on waste } \\
\text { type }\end{array}$ \\
\hline Tank \# & Tank Type & $\begin{array}{c}\text { Body volume } \\
\text { (M3) }\end{array}$ & $\begin{array}{l}\text { Body } \\
\text { Operating } \\
\text { Capacity } \\
\text { (m3/m) }\end{array}$ & $\begin{array}{c}\text { Body Radius } \\
(\mathbf{m})\end{array}$ & $\begin{array}{c}\text { Dome Arc } \\
\text { height } \\
\text { (m) }\end{array}$ & $\begin{array}{l}\text { Dome Arc } \\
\text { volume } \\
\text { (M3) }\end{array}$ & $\begin{array}{c}\text { Dome Arc } \\
\text { Radius } \\
\text { (m) }\end{array}$ & $\begin{array}{c}\text { Tank } \\
\text { capacity } \\
(\mathbf{k L} / \mathbf{m})\end{array}$ & $\begin{array}{c}\text { Void } \\
\text { Fraction or } \\
\text { Maximum } \\
\text { Wetted } \\
\text { Solids Void } \\
\text { Fraction } \\
\text { Mean } \\
\text { (Dimension- } \\
\text { less) }\end{array}$ & $\begin{array}{c}\text { Void } \\
\text { Fraction or } \\
\text { Maximum } \\
\text { Wetted } \\
\text { Solids Void } \\
\text { Fraction } \\
\text { Uncertainty } \\
\text { (Dimension- } \\
\text { less) }\end{array}$ & \begin{tabular}{|c|} 
Void \\
Fraction or \\
Maximum \\
Wetted \\
Solids Void \\
Fraction \\
Minimum \\
(Dimension- \\
less)
\end{tabular} & $\begin{array}{c}\text { Void } \\
\text { Fraction or } \\
\text { Maximum } \\
\text { Wetted } \\
\text { Solids Void } \\
\text { Fraction } \\
\text { Maximum } \\
\text { (Dimension- } \\
\text { less) }\end{array}$ & $\begin{array}{c}\text { Void } \\
\text { Fraction or } \\
\text { Maximum } \\
\text { Wetted } \\
\text { Solids Void } \\
\text { Fraction } \\
\text { Dist Type } \\
\text { (Dimension- } \\
\text { less) }\end{array}$ & \begin{tabular}{|c|} 
non- \\
convective \\
waste yield \\
stress mean \\
$(\mathrm{Pa})$
\end{tabular} & $\begin{array}{c}\text { non- } \\
\text { convective } \\
\text { waste yield } \\
\text { stress std } \\
\text { dev }(P a)\end{array}$ & $\begin{array}{c}\text { non- } \\
\text { convective } \\
\text { waste yield } \\
\text { stress min } \\
\text { (Pa) }\end{array}$ & \begin{tabular}{|c} 
non- \\
convective \\
waste yield \\
stress max \\
$(\mathrm{Pa})$
\end{tabular} \\
\hline TX-112 & SST & $2,495.07$ & 410.44 & 11.430 & 0.0000 & 0.000 & 0.0000 & 410.44 & 8.838 & 7.1328 & 0.01 & 40 & normal & 631.25 & 260.88 & 109.49 & 1674.77 \\
\hline TX-113 & SST & $2,495.07$ & 410.44 & 11.430 & 0.0000 & 0.000 & 0.0000 & 410.44 & 8.838 & 7.1328 & 0.01 & 40 & normal & 631.25 & 260.88 & 109.49 & 1674.77 \\
\hline TX-114 & SST & $2,495.07$ & 410.44 & 11.430 & 0.0000 & 0.000 & 0.0000 & 410.44 & 8.838 & 7.1328 & 0.01 & 40 & normal & 631.25 & 260.88 & 109.49 & 1674.77 \\
\hline TX-115 & SST & $2,495.07$ & 410.44 & 11.430 & 0.0000 & 0.000 & 0.0000 & 410.44 & 8.838 & 7.1328 & 0.01 & 40 & normal & 631.25 & 260.88 & 109.49 & 1674.77 \\
\hline TX-116 & SST & $2,495.07$ & 410.44 & 11.430 & 0.0000 & 0.000 & 0.0000 & 410.44 & 8.838 & 7.1328 & 0.01 & 40 & normal & 631.25 & 260.88 & 109.49 & 1674.77 \\
\hline TX-117 & SST & $2,495.07$ & 410.44 & 11.430 & 0.0000 & 0.000 & 0.0000 & 410.44 & 8.838 & 7.1328 & 0.01 & 40 & normal & 631.25 & 260.88 & 109.49 & 1674.77 \\
\hline TX-118 & SST & $2,495.07$ & 410.44 & 11.430 & 0.0000 & 0.000 & 0.0000 & 410.44 & 8.838 & 7.1328 & 0.01 & 40 & normal & 631.25 & 260.88 & 109.49 & 1674.77 \\
\hline TY-101 & SST & $2,502.89$ & 410.44 & 11.430 & 0.0000 & 0.000 & 0.0000 & 410.44 & 8.838 & 7.1328 & 0.01 & 40 & normal & 631.25 & 260.88 & 109.49 & 1674.77 \\
\hline TY-102 & SST & $2,502.89$ & 410.44 & 11.430 & 0.0000 & 0.000 & 0.0000 & 410.44 & 8.838 & 7.1328 & 0.01 & 40 & normal & 631.25 & 260.88 & 109.49 & 1674.77 \\
\hline TY-103 & SST & $2,502.89$ & 410.44 & 11.430 & 0.0000 & 0.000 & 0.0000 & 410.44 & 8.838 & 7.1328 & 0.01 & 40 & normal & 631.25 & 260.88 & 109.49 & 1674.77 \\
\hline TY-104 & SST & $2,502.89$ & 410.44 & 11.430 & 0.0000 & 0.000 & 0.0000 & 410.44 & 1.700 & 0.85 & 0.01 & 26. & normal & 1143.27 & 272.08 & 327.03 & 2231.59 \\
\hline TY-105 & SST & $2,502.89$ & 410.44 & 11.430 & 0.0000 & 0.000 & 0.0000 & 410.44 & 2.437 & 2.4869 & 0.01 & 26.5 & Lognorm & 1143.27 & 272.08 & 327.03 & 2231.59 \\
\hline TY-106 & SST & $2,502.89$ & 410.44 & 11.430 & 0.0000 & 0.000 & 0.0000 & 410.44 & 2.437 & 2.4869 & 0.01 & 26.5 & Lognorm & 1143.27 & 272.08 & 327.03 & 2231.59 \\
\hline U-101 & SST & $1,752.29$ & 410.44 & 11.430 & 0.0000 & 0.000 & 0.0000 & 410.44 & 2.437 & 2.4869 & 0.01 & 26.5 & Lognorm & 1143.27 & 272.08 & 327.03 & 2231.59 \\
\hline \begin{tabular}{|l}
$\mathrm{U}-102$ \\
\end{tabular} & SST & $1,752.29$ & 10.44 & 11.430 & 0.0000 & 0.000 & 0.0000 & 410.44 & 8.838 & 7.1328 & 0.01 & 40 & normal & 631.25 & 260.88 & 109.49 & 1674.77 \\
\hline \begin{tabular}{|l|} 
U-103 \\
\end{tabular} & SST & $1,752.29$ & 410.44 & 11.430 & 0.0000 & 0.000 & 0.0000 & 410.44 & 8.000 & 4 & 0.01 & 40 & normal & 631.25 & 260.88 & 109.49 & 1674.77 \\
\hline \begin{tabular}{|l} 
U-104 \\
\end{tabular} & SST & $1,752.29$ & 410.44 & 11.430 & 0.0000 & 0.000 & 0.0000 & 410.44 & 2.437 & 2.4869 & 0.01 & 26.5 & Lognorm & 1143.27 & 272.08 & 327.03 & 2231.59 \\
\hline U-105 & SST & $1,752.29$ & 410.44 & 11.430 & 0.0000 & 0.000 & 0.0000 & 410.44 & 7.300 & 3.65 & 0.01 & 40 & normal & 631.25 & 260.88 & 109.49 & 1674.77 \\
\hline U-106 & SST & $1,752.29$ & 410.44 & 11.430 & 0.0000 & 0.000 & 0.0000 & 410.44 & 1.500 & 0.75 & 0.01 & 40 & normal & 631.25 & 260.88 & 109.49 & 1674.77 \\
\hline U-107 & SST & $1,752.29$ & 0.44 & 11.430 & 0.0000 & 0.000 & 0.0000 & 410.44 & 7.600 & 3.8 & 0.01 & 40 & normal & 631.25 & 260.88 & 109.49 & 1674.77 \\
\hline \begin{tabular}{|l|} 
U-108 \\
\end{tabular} & SST & $1,752.29$ & 410.44 & 11.430 & 0.0000 & 0.000 & 0.0000 & 410.44 & 8.838 & 7.1328 & 0.01 & 40 & normal & 631.25 & 260.88 & 109.49 & 1674.77 \\
\hline U-109 & SST & $1,752.29$ & 410.44 & 11.430 & 0.0000 & 0.000 & 0.0000 & 410.44 & 4.100 & 2.05 & 0.01 & 40 & normal & 631.25 & 260.88 & 109.49 & 1674.77 \\
\hline U-110 & SST & $1,752.29$ & 410.44 & 11.430 & 0.00000 & 0.000 & 0.0000 & 410.44 & 2.437 & 2.4869 & 0.01 & 26.5 & Lognorm & 1143.27 & 272.08 & 327.03 & 2231.59 \\
\hline \begin{tabular}{|l} 
U-111 \\
\end{tabular} & SST & $1,752.29$ & 410.44 & 11.430 & 0.0000 & 0.000 & 0.0000 & 410.44 & 8.838 & 7.1328 & 0.01 & 40 & normal & 631.25 & 260.88 & 109.49 & 1674.77 \\
\hline U-112 & SST & $1,752.29$ & 410.44 & 11.430 & 0.0000 & 0.000 & 0.0000 & 410.44 & 2.437 & 2.4869 & 0.01 & 26.5 & Lognorm & 1143.27 & 272.08 & 327.03 & 2231.59 \\
\hline U-201 & SST & 200.39 & 29.19 & 3.048 & 0.0000 & 0.000 & 0.0000 & 29.19 & 2.437 & 2.4869 & 0.01 & 26.5 & Lognorm & 1143.27 & 272.08 & 327.03 & 2231.59 \\
\hline $\mathrm{U}-202$ & SST & 200.39 & 29.19 & 3.048 & 0.0000 & 0.000 & 0.0000 & 29.19 & 2.437 & 2.4869 & 0.01 & 26.5 & Lognorm & 1143.27 & 272.08 & 327.03 & 2231.59 \\
\hline U-203 & SST & 200.39 & 29.19 & 3.048 & 0.0000 & 0.000 & 0.0000 & 29.19 & 2.437 & 2.4869 & 0.01 & 26.5 & Lognorm & 1143.27 & 272.08 & 327.03 & 2231.59 \\
\hline U-204 & $\begin{array}{l}\text { SST } \\
\end{array}$ & 200.39 & 29.19 & 3.048 & 0.0000 & 0.000 & 0.0000 & 29.19 & 2.437 & 2.4869 & 0.01 & 26.5 & Lognorm & 1143.27 & 272.08 & 327.03 & 2231.59 \\
\hline
\end{tabular}




\begin{tabular}{|c|c|c|c|c|c|c|c|c|c|c|c|c|c|c|c|c|c|}
\hline Data Source & & $\begin{array}{c}\text { RPP-10006 } \\
\text { R7,or based on } \\
\text { waste type }\end{array}$ & $\begin{array}{l}\text { RPP-10006 R7 } \\
\text { NonCon }\end{array}$ & $\begin{array}{l}\text { RPP-10006 R7 } \\
\text { NonCon }\end{array}$ & $\begin{array}{l}\text { RPP-10006 R7 } \\
\text { NonCon }\end{array}$ & $\begin{array}{l}\text { RPP-10006 R7 } \\
\text { NonCon }\end{array}$ & $\begin{array}{l}\text { RPP-10006 R7 } \\
\text { NonCon }\end{array}$ & $\begin{array}{l}\text { RPP-10006 R7 } \\
\text { NonCon }\end{array}$ & $\begin{array}{l}\text { RPP-10006 R7 } \\
\text { NonCon }\end{array}$ & $\begin{array}{l}\text { RPP-10006 R7 } \\
\text { NonCon }\end{array}$ & $\begin{array}{l}\text { RPP-10006 R7 } \\
\text { NonCon }\end{array}$ & $\begin{array}{l}\text { RPP-10006 R7 } \\
\text { NonCon }\end{array}$ & $\begin{array}{l}\text { RPP-10006 R7 } \\
\text { NonCon }\end{array}$ & $\begin{array}{l}\text { RPP-10006 R7 } \\
\text { NonCon }\end{array}$ & $\begin{array}{l}\text { RPP-10006 R7 } \\
\text { NonCon }\end{array}$ & $\begin{array}{l}\text { RPP-10006 R7 } \\
\text { NonCon }\end{array}$ & $\begin{array}{l}\text { RPP-10006 R7 } \\
\text { NonCon }\end{array}$ \\
\hline Tank \# & Tank Type & $\begin{array}{c}\text { non- } \\
\text { convective } \\
\text { waste yield } \\
\text { stress dist } \\
\text { type }(\mathbf{P a})\end{array}$ & $\begin{array}{l}\text { Headspace } \\
\text { gas ratio } \\
\mathrm{CH} 4 \\
\text { mean }\end{array}$ & $\begin{array}{c}\text { Headspace } \\
\text { gas ratio } \\
\mathrm{CH} 4 \\
\text { mean }\end{array}$ & $\begin{array}{c}\text { Headspace } \\
\text { gas ratio } \\
\text { CH4 } \\
\text { std dev }\end{array}$ & $\begin{array}{l}\text { Headspace } \\
\text { gas ratio } \\
\text { CH4 } \\
\text { min }\end{array}$ & $\begin{array}{c}\text { Headspace } \\
\text { gas ratio } \\
\text { CH4 } \\
\max \end{array}$ & $\begin{array}{c}\text { Headspace } \\
\text { gas ratio } \\
\text { CH4 } \\
\text { type }\end{array}$ & $\begin{array}{l}\text { Headspace } \\
\text { gas ratio } \\
\text { N2O } \\
\text { mean }\end{array}$ & $\begin{array}{c}\text { Headspace } \\
\text { gas ratio } \\
\mathrm{N} 2 \mathrm{O} \\
\text { mean }\end{array}$ & $\begin{array}{c}\text { Headspace } \\
\text { gas ratio } \\
\text { N2O } \\
\text { std dev }\end{array}$ & $\begin{array}{l}\text { Headspace } \\
\text { gas ratio } \\
\text { N2O } \\
\text { min }\end{array}$ & $\begin{array}{c}\text { Headspace } \\
\text { gas ratio } \\
\mathrm{N} 2 \mathrm{O} \\
\max \end{array}$ & $\begin{array}{l}\text { Headspace } \\
\text { gas ratio } \\
\mathrm{N} 2 \mathrm{O} \\
\text { tvpe }\end{array}$ & $\begin{array}{l}\text { Retained gas } \\
\text { composition } \\
\text { N2 mean }\end{array}$ & $\begin{array}{c}\text { Retained gas } \\
\text { composition } \\
\mathrm{N} 2 \\
\text { mean }\end{array}$ & $\begin{array}{c}\text { Retained gas } \\
\text { composition } \\
\text { N2 } \\
\text { std dev }\end{array}$ \\
\hline A-101 & SST & Normal & 0.021 & 0.021 & 0.001 & 0.018 & 0.024 & Normal & 0.071 & 0.071 & 0.005 & 0.058 & 0.084 & Normal & 19.001 & 19.001 & 2.326 \\
\hline A-102 & SST & Normal & 0.053 & 0.053 & 0.056 & 0.001 & 0.318 & LogNorm & 0.253 & 0.253 & 0.176 & 0.001 & 0.619 & LogNorm & 29.840 & 29.840 & 12.010 \\
\hline A-103 & SST & Normal & 0.053 & 0.053 & 0.056 & 0.001 & 0.318 & LogNorm & 0.253 & 0.253 & 0.176 & 0.001 & 0.619 & LogNorm & 29.840 & 29.840 & 12.010 \\
\hline A-104 & SST & LogNorm & 0.053 & 0.053 & 0.056 & 0.001 & 0.318 & LogNorm & 0.253 & 0.253 & 0.176 & 0.001 & 0.619 & LogNorm & 29.840 & 29.840 & 12.010 \\
\hline A-105 & SST & LogNorm & 0.053 & 0.053 & 0.056 & 0.001 & 0.318 & LogNorm & 0.253 & 0.253 & 0.176 & 0.001 & 0.619 & LogNorm & 29.840 & 29.840 & 12.010 \\
\hline A-106 & SST & Normal & 0.053 & 0.053 & 0.056 & 0.001 & 0.318 & LogNorm & 0.253 & 0.253 & 0.176 & 0.001 & 0.619 & LogNorm & 29.840 & 29.840 & 12.010 \\
\hline AN-101* & DST & Normal & 0.05 & 0.05 & 0.06 & 0.00 & 0.32 & $\begin{array}{l}\text { LogNorm } \\
\end{array}$ & 0.25 & 0.25 & 0.18 & 0.00 & 0.62 & LogNorm & 29.84 & 29.84 & 12.01 \\
\hline AN-102* & DST & Normal & 0.05 & 0.05 & 0.06 & 0.00 & 0.32 & LogNorm & 0.25 & 0.25 & 0.18 & 0.00 & 0.62 & LogNorm & 29.84 & 29.84 & 12.01 \\
\hline AN-103* & DST & Normal & 0.09 & 0.09 & 0.04 & 0.02 & 0.16 & Normal & 0.05 & 0.05 & 0.01 & 0.04 & 0.08 & Normal & 28.66 & 28.66 & 5.15 \\
\hline AN-104* & DST & Normal & 0.06 & 0.06 & 0.01 & 0.03 & 0.10 & Normal & 0.31 & 0.31 & 0.03 & 0.22 & 0.40 & Normal & 29.17 & 29.17 & 4.92 \\
\hline AN-105* & DST & Normal & 0.02 & 0.02 & 0.01 & 0.01 & 0.04 & Normal & 0.17 & 0.17 & 0.02 & 0.12 & 0.22 & Normal & 24.57 & 24.57 & 3.63 \\
\hline AN-106* & DST & LogNorm & 0.05 & 0.05 & 0.06 & 0.00 & 0.32 & LogNorm & 0.25 & 0.25 & 0.18 & 0.00 & 0.62 & LogNorm & 29.84 & 29.84 & 12.01 \\
\hline AN-107* & DST & Normal & 0.05 & 0.05 & 0.06 & 0.00 & 0.32 & LogNorm & 0.25 & 0.25 & 0.18 & 0.00 & 0.62 & LogNorm & 29.84 & 29.84 & 12.01 \\
\hline AP-101* & DST & Normal & 0.05 & 0.05 & 0.06 & 0.00 & 0.32 & LogNorm & 0.25 & 0.25 & 0.18 & 0.00 & 0.62 & LogNorm & 29.84 & 29.84 & 12.01 \\
\hline AP-102* & DST & LogNorm & 0.05 & 0.05 & 0.06 & 0.00 & 0.32 & LogNorm & 0.25 & 0.25 & 0.18 & 0.00 & 0.62 & LogNorm & 29.84 & 29.84 & 12.01 \\
\hline AP-103* & DST & LogNorm & 0.05 & 0.05 & 0.06 & 0.00 & 0.32 & LogNorm & 0.25 & 0.25 & 0.18 & 0.00 & 0.62 & LogNorm & 29.84 & 29.84 & 12.01 \\
\hline AP-104* & DST & Normal & 0.05 & 0.05 & 0.06 & 0.00 & 0.32 & LogNorm & 0.25 & 0.25 & 0.18 & 0.00 & 0.62 & LogNorm & 29.84 & 29.84 & 12.01 \\
\hline AP-105* & DST & Normal & 0.05 & 0.05 & 0.06 & 0.00 & 0.32 & LogNorm & 0.25 & 0.25 & 0.18 & 0.00 & 0.62 & LogNorm & 29.84 & 29.84 & 12.01 \\
\hline AP-106* & DST & Normal & 0.05 & 0.05 & 0.06 & 0.00 & 0.32 & $\begin{array}{l}\text { LogNorm } \\
\end{array}$ & 0.25 & 0.25 & 0.18 & 0.00 & 0.62 & LogNorm & 29.84 & 29.84 & 12.01 \\
\hline AP-107* & DST & Normal & 0.05 & 0.05 & 0.06 & 0.00 & 0.32 & LogNorm & 0.25 & 0.25 & 0.18 & 0.00 & 0.62 & LogNorm & 29.84 & 29.84 & 12.01 \\
\hline AP-108* & DST & Normal & 0.05 & 0.05 & 0.06 & 0.00 & 0.32 & LogNorm & 0.25 & 0.25 & 0.18 & 0.00 & 0.62 & LogNorm & 29.84 & 29.84 & 12.01 \\
\hline AW-101* & DST & Normal & 0.21 & 0.21 & 0.02 & 0.16 & 0.28 & Normal & 0.13 & 0.13 & 0.02 & 0.08 & 0.17 & Normal & 53.55 & 53.55 & 2.71 \\
\hline AW-102* & DST & LogNorm & 0.05 & 0.05 & 0.06 & 0.00 & 0.32 & LogNorm & 0.25 & 0.25 & 0.18 & 0.00 & 0.62 & LogNorm & 29.84 & 29.84 & 12.01 \\
\hline AW-103* & DST & LogNorm & 0.05 & 0.05 & 0.06 & 0.00 & 0.32 & LogNorm & 0.25 & 0.25 & 0.18 & 0.00 & 0.62 & LogNorm & 29.84 & 29.84 & 12.01 \\
\hline AW-104* & DST & Normal & 0.05 & 0.05 & 0.06 & 0.00 & 0.32 & LogNorm & 0.25 & 0.25 & 0.18 & 0.00 & 0.62 & LogNorm & 29.84 & 29.84 & 12.01 \\
\hline AW-105* & DST & LogNorm & 0.05 & 0.05 & 0.06 & 0.00 & 0.32 & LogNorm & 0.25 & 0.25 & 0.18 & 0.00 & 0.62 & LogNorm & 29.84 & 29.84 & 12.01 \\
\hline AW-106* & DST & Normal & 0.05 & 0.05 & 0.06 & 0.00 & 0.32 & LogNorm & 0.25 & 0.25 & 0.18 & 0.00 & 0.62 & LogNorm & 29.84 & 29.84 & 12.01 \\
\hline AX-101 & SST & Normal & 0.057 & 0.057 & 0.007 & 0.040 & 0.076 & Normal & 0.142 & 0.142 & 0.008 & 0.122 & 0.163 & Normal & 16.683 & 16.683 & 4.284 \\
\hline AX-102 & SST & Normal & 0.053 & 0.053 & 0.056 & 0.001 & 0.318 & LogNorm & 0.253 & 0.253 & 0.176 & 0.001 & 0.619 & LogNorm & 29.840 & 29.840 & 12.010 \\
\hline AX-103 & SST & Normal & 0.053 & 0.053 & 0.056 & 0.001 & 0.318 & LogNorm & 0.253 & 0.253 & 0.176 & 0.001 & 0.619 & LogNorm & 29.840 & 29.840 & 12.010 \\
\hline AX-104 & SST & LogNorm & 0.053 & 0.053 & 0.056 & 0.001 & 0.318 & LogNorm & 0.253 & 0.253 & 0.176 & 0.001 & $\begin{array}{ll}0.619 \\
\end{array}$ & LogNorm & 29.840 & 29.840 & 12.010 \\
\hline AY-101* & DST & LogNorm & 0.05 & 0.05 & 0.06 & 0.00 & 0.32 & LogNorm & 0.25 & 0.25 & \begin{tabular}{l|l|}
0.18 \\
\end{tabular} & 0.00 & 0.62 & LogNorm & 29.84 & 29.84 & 12.01 \\
\hline AY-102* & DST & LogNorm & 0.05 & 0.05 & 0.06 & 0.00 & 0.32 & LogNorm & 0.25 & 0.25 & 0.18 & 0.00 & 0.62 & LogNorm & 29.84 & 29.84 & 12.01 \\
\hline AZ-101* & DST & LogNorm & 0.05 & 0.05 & 0.06 & 0.00 & 0.32 & LogNorm & 0.25 & 0.25 & 0.18 & 0.00 & 0.62 & LogNorm & 29.84 & 29.84 & 12.01 \\
\hline AZ-102* & DST & LogNorm & 0.05 & 0.05 & 0.06 & 0.00 & 0.32 & LogNorm & 0.25 & 0.25 & 0.18 & 0.00 & 0.62 & LogNorm & 29.84 & 29.84 & 12.01 \\
\hline B-101 & SST & Normal & 0.053 & 0.053 & 0.056 & 0.001 & 0.318 & LogNorm & 0.253 & 0.253 & 0.176 & 0.001 & 0.619 & LogNorm & 29.840 & 29.840 & 12.010 \\
\hline B-102 & SST & Normal & 0.053 & 0.053 & 0.056 & 0.001 & $\begin{array}{ll}0.318 \\
\end{array}$ & LogNorm & 0.253 & 0.253 & \begin{tabular}{l|l|}
0.176 \\
\end{tabular} & 0.001 & 0.619 & LogNorm & 29.840 & 29.840 & 12.010 \\
\hline
\end{tabular}




\begin{tabular}{|c|c|c|c|c|c|c|c|c|c|c|c|c|c|c|c|c|c|}
\hline Data Source & & $\begin{array}{c}\mathrm{RPP}-10006 \\
\mathrm{R} 7 \text {,or based on } \\
\text { waste type }\end{array}$ & $\begin{array}{l}\text { RPP-10006 R7 } \\
\text { NonCon }\end{array}$ & $\begin{array}{l}\text { RPP-10006 R7 } \\
\text { NonCon }\end{array}$ & $\begin{array}{l}\text { RPP-10006 R7 } \\
\text { NonCon }\end{array}$ & $\begin{array}{l}\text { RPP-10006 R7 } \\
\text { NonCon }\end{array}$ & $\begin{array}{l}\text { RPP-10006 R7 } \\
\text { NonCon }\end{array}$ & $\begin{array}{c}\text { RPP-10006 R7 } \\
\text { NonCon }\end{array}$ & $\begin{array}{l}\text { RPP-10006 R7 } \\
\text { NonCon }\end{array}$ & $\begin{array}{l}\text { RPP-10006 R7 } \\
\text { NonCon }\end{array}$ & $\begin{array}{c}\text { RPP-10006 R7 } \\
\text { NonCon }\end{array}$ & $\begin{array}{l}\text { RPP-10006 R7 } \\
\text { NonCon }\end{array}$ & $\begin{array}{l}\text { RPP-10006 R7 } \\
\text { NonCon }\end{array}$ & $\begin{array}{l}\text { RPP-10006 R7 } \\
\text { NonCon }\end{array}$ & $\begin{array}{l}\text { RPP-10006 R7 } \\
\text { NonCon }\end{array}$ & $\begin{array}{c}\text { RPP-10006 R7 } \\
\text { NonCon }\end{array}$ & $\begin{array}{l}\text { RPP-10006 R7 } \\
\text { NonCon }\end{array}$ \\
\hline Tank \# & Tank Type & $\begin{array}{c}\text { non- } \\
\text { convective } \\
\text { waste yield } \\
\text { stress dist } \\
\text { type }(\mathbf{P a}) \\
\end{array}$ & $\begin{array}{c}\text { Headspace } \\
\text { gas ratio } \\
\text { CH4 } \\
\text { mean } \\
\end{array}$ & $\begin{array}{c}\text { Headspace } \\
\text { gas ratio } \\
\text { CH4 } \\
\text { mean } \\
\end{array}$ & $\begin{array}{c}\text { Headspace } \\
\text { gas ratio } \\
\text { CH4 } \\
\text { std dev }\end{array}$ & $\begin{array}{c}\text { Headspace } \\
\text { gas ratio } \\
\mathrm{CH} 4 \\
\text { min }\end{array}$ & $\begin{array}{c}\text { Headspace } \\
\text { gas ratio } \\
\mathrm{CH} 4 \\
\max \end{array}$ & $\begin{array}{l}\text { Headspace } \\
\text { gas ratio } \\
\text { CH4 } \\
\text { type } \\
\end{array}$ & $\begin{array}{l}\text { Headspace } \\
\text { gas ratio } \\
\text { N2O } \\
\text { mean }\end{array}$ & $\begin{array}{c}\text { Headspace } \\
\text { gas ratio } \\
\text { N2O } \\
\text { mean }\end{array}$ & $\begin{array}{c}\text { Headspace } \\
\text { gas ratio } \\
\mathbf{N} 2 \mathrm{O} \\
\text { std dev }\end{array}$ & $\begin{array}{l}\text { Headspace } \\
\text { gas ratio } \\
\text { N2O } \\
\text { min }\end{array}$ & $\begin{array}{c}\text { Headspace } \\
\text { gas ratio } \\
\text { N2O } \\
\max \end{array}$ & $\begin{array}{l}\text { Headspace } \\
\text { gas ratio } \\
\text { N2O } \\
\text { type }\end{array}$ & $\begin{array}{c}\text { Retained gas } \\
\text { composition } \\
\text { N2 mean }\end{array}$ & $\begin{array}{c}\text { Retained gas } \\
\text { composition } \\
\text { N2 } \\
\text { mean }\end{array}$ & $\begin{array}{l}\text { Retained gas } \\
\text { composition } \\
\text { N2 } \\
\text { std dev }\end{array}$ \\
\hline B-103 & SST & Normal & 0.053 & 0.053 & 0.056 & 0.001 & 0.318 & LogNorm & 0.253 & 0.253 & 0.176 & 0.001 & 0.619 & LogNorm & 29.840 & 29.840 & 12.010 \\
\hline B-104 & SST & LogNorm & 0.053 & 0.053 & 0.056 & 0.001 & 0.318 & LogNorm & 0.253 & 0.253 & 0.176 & 0.001 & 0.619 & LogNorm & 29.840 & 29.840 & 12.010 \\
\hline B-105 & SST & Normal & 0.053 & 0.053 & 0.056 & 0.001 & 0.318 & LogNorm & 0.253 & 0.253 & 0.176 & 0.001 & 0.619 & LogNorm & 29.840 & 29.840 & 12.010 \\
\hline B-106 & SST & LogNorm & 0.053 & 0.053 & 0.056 & 0.001 & 0.318 & LogNorm & 0.253 & 0.253 & 0.176 & 0.001 & 0.619 & LogNorm & 29.840 & 29.840 & 12.010 \\
\hline B-107 & SST & Normal & 0.053 & 0.053 & 0.056 & 0.001 & 0.318 & LogNorm & 0.253 & 0.253 & \begin{tabular}{l|l|l|}
0.176 \\
\end{tabular} & 0.001 & 0.619 & LogNorm & 29.840 & 29.840 & 12.010 \\
\hline B-108 & $\begin{array}{l}\text { SST } \\
\end{array}$ & Normal & 0.053 & 0.053 & 0.056 & 0.001 & 0.318 & LogNorm & 0.253 & 0.253 & 0.176 & 0.001 & 0.619 & LogNorm & 29.840 & 29.840 & 12.010 \\
\hline B-109 & SST & Normal & 0.053 & 0.053 & 0.056 & 0.001 & 0.318 & LogNorm & 0.253 & 0.253 & 0.176 & 0.001 & 0.619 & LogNorm & 29.840 & 29.840 & 12.010 \\
\hline B-110 & $\begin{array}{l}\text { SST } \\
\end{array}$ & LogNorm & 0.053 & 0.053 & 0.056 & 0.001 & 0.318 & LogNorm & 0.253 & 0.253 & 0.176 & 0.001 & 0.619 & LogNorm & 29.840 & 29.840 & 12.010 \\
\hline B-111 & SST & LogNorm & 0.053 & 0.053 & 0.056 & 0.001 & 0.318 & LogNorm & 0.253 & 0.253 & 0.176 & 0.001 & 0.619 & LogNorm & 29.840 & 29.840 & 12.010 \\
\hline B-112 & SST & Normal & 0.053 & 0.053 & 0.056 & 0.001 & 0.318 & LogNorm & 0.253 & 0.253 & 0.176 & 0.001 & 0.619 & LogNorm & 29.840 & 29.840 & 12.010 \\
\hline B-201 & SST & LogNorm & 0.053 & 0.053 & 0.056 & 0.001 & 0.318 & LogNorm & 0.253 & 0.253 & 0.176 & 0.001 & 0.619 & LogNorm & 29.840 & 29.840 & 12.010 \\
\hline B-202 & SST & LogNorm & 0.053 & 0.053 & 0.056 & 0.001 & 0.318 & LogNorm & 0.253 & 0.253 & 0.176 & 0.001 & 0.619 & LogNorm & 29.840 & 29.840 & 12.010 \\
\hline B-203 & SST & LogNorm & 0.053 & 0.053 & 0.056 & 0.001 & 0.318 & LogNorm & 0.253 & 0.253 & \begin{tabular}{l|l|}
0.176 \\
\end{tabular} & 0.001 & 0.619 & LogNorm & 29.840 & 29.840 & 12.010 \\
\hline B-204 & SST & LogNorm & 0.053 & 0.053 & 0.056 & 0.001 & 0.318 & LogNorm & 0.253 & 0.253 & 0.176 & 0.001 & 0.619 & LogNorm & 29.840 & 29.840 & 12.010 \\
\hline BX-101 & SST & LogNorm & 0.053 & 0.053 & 0.056 & 0.001 & 0.318 & LogNorm & 0.253 & 0.253 & 0.176 & 0.001 & 0.619 & LogNorm & 29.840 & 29.840 & 12.010 \\
\hline BX-102 & SST & LogNorm & 0.053 & 0.053 & 0.056 & 0.001 & 0.318 & LogNorm & 0.253 & 0.253 & \begin{tabular}{l|l|}
0.176 \\
\end{tabular} & 0.001 & 0.619 & LogNorm & 29.840 & 29.840 & 12.010 \\
\hline BX-103 & SST & LogNorm & 0.053 & 0.053 & 0.056 & 0.001 & 0.318 & LogNorm & 0.253 & 0.253 & 0.176 & 0.001 & 0.619 & LogNorm & 29.840 & 29.840 & 12.010 \\
\hline BX-104 & SST & LogNorm & 0.053 & 0.053 & 0.056 & 0.001 & 0.318 & LogNorm & 0.253 & 0.253 & 0.176 & 0.001 & 0.619 & LogNorm & 29.840 & 29.840 & 12.010 \\
\hline BX-105 & SST & Normal & 0.053 & 0.053 & 0.056 & 0.001 & 0.318 & LogNorm & 0.253 & 0.253 & \begin{tabular}{l|l|}
0.176 \\
\end{tabular} & 0.001 & 0.619 & LogNorm & 29.840 & 29.840 & 12.010 \\
\hline BX-106 & SST & Normal & 0.053 & 0.053 & 0.056 & 0.001 & 0.318 & LogNorm & 0.253 & 0.253 & 0.176 & 0.001 & 0.619 & LogNorm & 29.840 & 29.840 & 12.010 \\
\hline BX-107 & SST & LogNorm & 0.053 & 0.053 & 0.056 & 0.001 & 0.318 & LogNorm & 0.253 & 0.253 & 0.176 & 0.001 & 0.619 & LogNorm & 29.840 & 29.840 & 12.010 \\
\hline BX-108 & SST & LogNorm & 0.053 & 0.053 & 0.056 & 0.001 & 0.318 & LogNorm & 0.253 & 0.253 & 0.176 & 0.001 & 0.619 & LogNorm & 29.840 & 29.840 & 12.010 \\
\hline BX-109 & SST & LogNorm & 0.053 & 0.053 & 0.056 & 0.001 & 0.318 & LogNorm & 0.253 & 0.253 & 0.176 & 0.001 & 0.619 & LogNorm & 29.840 & 29.840 & 12.010 \\
\hline BX-110 & SST & Normal & 0.053 & 0.053 & 0.056 & 0.001 & 0.318 & LogNorm & 0.253 & 0.253 & 0.176 & 0.001 & 0.619 & LogNorm & 29.840 & 29.840 & 12.010 \\
\hline BX-111 & SST & Normal & 0.053 & 0.053 & 0.056 & 0.001 & 0.318 & LogNorm & 0.253 & 0.253 & \begin{tabular}{l|l|}
0.176 &
\end{tabular} & 0.001 & 0.619 & LogNorm & 29.840 & 29.840 & 12.010 \\
\hline BX-112 & SST & LogNorm & 0.053 & 0.053 & 0.056 & 0.001 & 0.318 & LogNorm & 0.253 & 0.253 & \begin{tabular}{l|l|}
0.176 \\
\end{tabular} & 0.001 & 0.619 & LogNorm & 29.840 & 29.840 & 12.010 \\
\hline \begin{tabular}{|l|} 
BY-101 \\
\end{tabular} & SST & Normal & 0.053 & 0.053 & 0.056 & 0.001 & 0.318 & LogNorm & 0.253 & 0.253 & \begin{tabular}{|l|}
0.176 \\
\end{tabular} & 0.001 & 0.619 & LogNorm & 29.840 & 29.840 & 12.010 \\
\hline BY-102 & SST & Normal & 0.053 & 0.053 & 0.056 & 0.001 & 0.318 & LogNorm & 0.253 & 0.253 & \begin{tabular}{l|l|}
0.176 \\
\end{tabular} & 0.001 & 0.619 & LogNorm & 29.840 & 29.840 & 12.010 \\
\hline BY-103 & SST & Normal & 0.053 & 0.053 & 0.056 & 0.001 & 0.318 & LogNorm & 0.253 & 0.253 & \begin{tabular}{|l|}
0.176 \\
\end{tabular} & 0.001 & 0.619 & LogNorm & 29.840 & 29.840 & 12.010 \\
\hline BY-104 & SST & Normal & 0.053 & 0.053 & 0.056 & 0.001 & 0.318 & LogNorm & 0.253 & 0.253 & \begin{tabular}{l|l|}
0.176 \\
\end{tabular} & 0.001 & 0.619 & LogNorm & 29.840 & 29.840 & 12.010 \\
\hline BY-105 & SST & Normal & 0.053 & 0.053 & 0.056 & 0.001 & 0.318 & LogNorm & 0.253 & 0.253 & \begin{tabular}{|l|}
0.176 \\
\end{tabular} & 0.001 & 0.619 & LogNorm & 29.840 & 29.840 & 12.010 \\
\hline \begin{tabular}{|l} 
BY-106 \\
\end{tabular} & SST & Normal & 0.053 & 0.053 & 0.056 & 0.001 & 0.318 & LogNorm & 0.253 & 0.253 & \begin{tabular}{|l|l|}
0.176 \\
\end{tabular} & 0.001 & 0.619 & LogNorm & 29.840 & 29.840 & 12.010 \\
\hline BY-107 & SST & Normal & 0.053 & 0.053 & 0.056 & 0.001 & 0.318 & LogNorm & 0.253 & 0.253 & \begin{tabular}{|l|}
0.176 \\
\end{tabular} & 0.001 & 0.619 & LogNorm & 29.840 & 29.840 & 12.010 \\
\hline BY-108 & SST & Normal & 0.053 & 0.053 & 0.056 & 0.001 & 0.318 & LogNorm & 0.253 & 0.253 & \begin{tabular}{l|l|}
0.176 \\
\end{tabular} & 0.001 & 0.619 & LogNorm & 29.840 & 29.840 & 12.010 \\
\hline BY-109 & SST & Normal & 0.086 & 0.086 & 0.031 & 0.028 & 0.161 & Normal & 0.236 & 0.236 & 0.021 & 0.178 & 0.305 & Normal & 29.045 & 29.045 & 4.437 \\
\hline BY-110 & SST & Normal & 0.053 & 0.053 & 0.056 & 0.001 & 0.318 & LogNorm & 0.253 & 0.253 & 0.176 & 0.001 & 0.619 & LogNorm & 29.840 & 29.840 & 12.010 \\
\hline BY-111 & SST & Normal & 0.053 & 0.053 & 0.056 & 0.001 & $\begin{array}{l}0.318 \\
\end{array}$ & LogNorm & 0.253 & 0.253 & \begin{tabular}{l|l|}
0.176 \\
\end{tabular} & 0.001 & 0.619 & LogNorm & 29.840 & 29.840 & 12.010 \\
\hline
\end{tabular}




\begin{tabular}{|c|c|c|c|c|c|c|c|c|c|c|c|c|c|c|c|c|c|}
\hline Data Source & & $\begin{array}{c}\mathrm{RPP}-10006 \\
\mathrm{R} 7 \text {,or based on } \\
\text { waste type }\end{array}$ & $\begin{array}{l}\text { RPP-10006 R7 } \\
\text { NonCon }\end{array}$ & $\begin{array}{l}\text { RPP-10006 R7 } \\
\text { NonCon }\end{array}$ & $\begin{array}{l}\text { RPP-10006 R7 } \\
\text { NonCon }\end{array}$ & $\begin{array}{l}\text { RPP-10006 R7 } \\
\text { NonCon }\end{array}$ & $\begin{array}{l}\text { RPP-10006 R7 } \\
\text { NonCon }\end{array}$ & $\begin{array}{c}\text { RPP-10006 R7 } \\
\text { NonCon }\end{array}$ & $\begin{array}{l}\text { RPP-10006 R7 } \\
\text { NonCon }\end{array}$ & $\begin{array}{l}\text { RPP-10006 R7 } \\
\text { NonCon }\end{array}$ & $\begin{array}{c}\text { RPP-10006 R7 } \\
\text { NonCon }\end{array}$ & $\begin{array}{l}\text { RPP-10006 R7 } \\
\text { NonCon }\end{array}$ & $\begin{array}{l}\text { RPP-10006 R7 } \\
\text { NonCon }\end{array}$ & $\begin{array}{l}\text { RPP-10006 R7 } \\
\text { NonCon }\end{array}$ & $\begin{array}{l}\text { RPP-10006 R7 } \\
\text { NonCon }\end{array}$ & $\begin{array}{c}\text { RPP-10006 R7 } \\
\text { NonCon }\end{array}$ & $\begin{array}{l}\text { RPP-10006 R7 } \\
\text { NonCon }\end{array}$ \\
\hline Tank \# & Tank Type & $\begin{array}{c}\text { non- } \\
\text { convective } \\
\text { waste yield } \\
\text { stress dist } \\
\text { type }(\mathbf{P a})\end{array}$ & $\begin{array}{l}\text { Headspace } \\
\text { gas ratio } \\
\mathrm{CH} 4 \\
\text { mean }\end{array}$ & $\begin{array}{c}\text { Headspace } \\
\text { gas ratio } \\
\text { CH4 } \\
\text { mean }\end{array}$ & $\begin{array}{c}\text { Headspace } \\
\text { gas ratio } \\
\text { CH4 } \\
\text { std dev }\end{array}$ & $\begin{array}{l}\text { Headspace } \\
\text { gas ratio } \\
\text { CH4 } \\
\text { min }\end{array}$ & $\begin{array}{c}\text { Headspace } \\
\text { gas ratio } \\
\text { CH4 } \\
\max \end{array}$ & $\begin{array}{l}\text { Headspace } \\
\text { gas ratio } \\
\mathrm{CH} 4 \\
\text { type }\end{array}$ & $\begin{array}{l}\text { Headspace } \\
\text { gas ratio } \\
\text { N2O } \\
\text { mean }\end{array}$ & $\begin{array}{c}\text { Headspace } \\
\text { gas ratio } \\
\mathrm{N} 2 \mathrm{O} \\
\text { mean }\end{array}$ & $\begin{array}{c}\text { Headspace } \\
\text { gas ratio } \\
\text { N2O } \\
\text { std dev }\end{array}$ & $\begin{array}{l}\text { Headspace } \\
\text { gas ratio } \\
\text { N2O } \\
\text { min }\end{array}$ & $\begin{array}{c}\text { Headspace } \\
\text { gas ratio } \\
\mathrm{N} 2 \mathrm{O} \\
\max \end{array}$ & $\begin{array}{c}\text { Headspace } \\
\text { gas ratio } \\
\text { N2O } \\
\text { type }\end{array}$ & $\begin{array}{c}\text { Retained gas } \\
\text { composition } \\
\mathrm{N} 2 \text { mean }\end{array}$ & $\begin{array}{c}\text { Retained gas } \\
\text { composition } \\
\text { N2 } \\
\text { mean }\end{array}$ & $\begin{array}{c}\text { Retained gas } \\
\text { composition } \\
\text { N2 } \\
\text { std dev }\end{array}$ \\
\hline BY-112 & SST & Normal & 0.053 & 0.053 & 0.056 & 0.001 & 0.318 & LogNorm & 0.253 & 0.253 & 0.176 & 0.001 & 0.619 & LogNorm & 29.840 & \begin{tabular}{l|}
29.840 \\
\end{tabular} & 12.010 \\
\hline C-101 & SST & LogNorm & 0.053 & 0.053 & 0.056 & 0.001 & 0.318 & LogNorm & 0.253 & 0.253 & 0.176 & 0.001 & 0.619 & LogNorm & 29.840 & 29.840 & 12.010 \\
\hline C-102 & SST & LogNorm & 0.053 & 0.053 & 0.056 & 0.001 & 0.318 & LogNorm & 0.253 & 0.253 & 0.176 & 0.001 & 0.619 & LogNorm & 29.840 & 29.840 & 12.010 \\
\hline C-103 & SST & LogNorm & 0.053 & 0.053 & 0.056 & 0.001 & 0.318 & LogNorm & 0.253 & 0.253 & 0.176 & 0.001 & 0.619 & LogNorm & 29.840 & 29.840 & 12.010 \\
\hline C-104 & SST & LogNorm & 0.053 & 0.053 & 0.056 & 0.001 & 0.318 & LogNorm & 0.253 & 0.253 & \begin{tabular}{l|l|l|}
0.176 \\
\end{tabular} & 0.001 & 0.619 & LogNorm & 29.840 & 29.840 & 12.010 \\
\hline C-105 & SST & LogNorm & 0.053 & 0.053 & 0.056 & 0.001 & 0.318 & LogNorm & 0.253 & 0.253 & 0.176 & 0.001 & 0.619 & LogNorm & 29.840 & 29.840 & 12.010 \\
\hline C-106 & SST & $\begin{array}{l}\text { LogNorm } \\
\end{array}$ & 0.053 & 0.053 & 0.056 & 0.001 & 0.318 & LogNorm & 0.253 & 0.253 & 0.176 & 0.001 & 0.619 & LogNorm & 29.840 & 29.840 & 12.010 \\
\hline C-107 & $\begin{array}{l}\text { SST } \\
\end{array}$ & LogNorm & 0.053 & 0.053 & 0.056 & 0.001 & 0.318 & LogNorm & 0.253 & 0.253 & 0.176 & 0.001 & 0.619 & LogNorm & 29.840 & 29.840 & 12.010 \\
\hline C-108* & SST & LogNorm & 0.053 & 0.053 & 0.056 & 0.001 & 0.318 & LogNorm & 0.253 & 0.253 & 0.176 & 0.001 & 0.619 & LogNorm & 29.840 & 29.840 & 12.010 \\
\hline C-109* & SST & LogNorm & 0.053 & 0.053 & 0.056 & 0.001 & 0.318 & LogNorm & 0.253 & 0.253 & 0.176 & 0.001 & 0.619 & LogNorm & 29.840 & 29.840 & 12.010 \\
\hline C-110 & SST & LogNorm & 0.053 & 0.053 & 0.056 & 0.001 & 0.318 & LogNorm & 0.253 & 0.253 & 0.176 & 0.001 & 0.619 & LogNorm & 29.840 & 29.840 & 12.010 \\
\hline C-111 & SST & LogNorm & 0.053 & 0.053 & 0.056 & 0.001 & 0.318 & LogNorm & 0.253 & 0.253 & 0.176 & 0.001 & 0.619 & LogNorm & 29.840 & 29.840 & 12.010 \\
\hline C-112 & SST & LogNorm & 0.053 & 0.053 & 0.056 & 0.001 & 0.318 & LogNorm & 0.253 & 0.253 & \begin{tabular}{l|l|}
0.176 \\
\end{tabular} & 0.001 & 0.619 & LogNorm & 29.840 & 29.840 & 12.010 \\
\hline C-201 & SST & LogNorm & 0.053 & 0.053 & 0.056 & 0.001 & 0.318 & LogNorm & 0.253 & 0.253 & 0.176 & 0.001 & 0.619 & LogNorm & 29.840 & 29.840 & 12.010 \\
\hline $\mathrm{C}-202$ & SST & LogNorm & 0.053 & 0.053 & 0.056 & 0.001 & 0.318 & LogNorm & 0.253 & 0.253 & 0.176 & 0.001 & 0.619 & LogNorm & 29.840 & 29.840 & 12.010 \\
\hline C-203 & SST & LogNorm & 0.053 & 0.053 & 0.056 & 0.001 & 0.318 & LogNorm & 0.253 & 0.253 & \begin{tabular}{l|l|}
0.176 \\
\end{tabular} & 0.001 & 0.619 & LogNorm & 29.840 & 29.840 & 12.010 \\
\hline C-204 & SST & LogNorm & 0.053 & 0.053 & 0.056 & 0.001 & 0.318 & LogNorm & 0.253 & 0.253 & 0.176 & 0.001 & 0.619 & LogNorm & 29.840 & 29.840 & 12.010 \\
\hline S-101 & SST & Normal & 0.053 & 0.053 & 0.056 & 0.001 & 0.318 & LogNorm & 0.253 & 0.253 & 0.176 & 0.001 & 0.619 & LogNorm & 29.840 & 29.840 & 12.010 \\
\hline S-102* & SST & Normal & 0.020 & 0.020 & 0.004 & 0.012 & 0.031 & Normal & 0.481 & 0.481 & 0.022 & 0.414 & 0.549 & Normal & 32.246 & 32.246 & 3.074 \\
\hline S-103 & SST & Normal & 0.053 & 0.053 & 0.056 & 0.001 & 0.318 & LogNorm & 0.253 & 0.253 & 0.176 & 0.001 & 0.619 & LogNorm & 29.840 & 29.840 & 12.010 \\
\hline S-104 & SST & Normal & 0.053 & 0.053 & 0.056 & 0.001 & 0.318 & LogNorm & 0.253 & 0.253 & 0.176 & 0.001 & 0.619 & LogNorm & 29.840 & 29.840 & 12.010 \\
\hline S-105 & SST & Normal & 0.053 & 0.053 & 0.056 & 0.001 & 0.318 & LogNorm & 0.253 & 0.253 & 0.176 & 0.001 & 0.619 & LogNorm & 29.840 & 29.840 & 12.010 \\
\hline S-106 & SST & Normal & 0.013 & 0.013 & 0.006 & 0.000 & 0.030 & Normal & 0.131 & 0.131 & 0.015 & 0.098 & 0.169 & Normal & 25.217 & 25.217 & 3.789 \\
\hline S-107 & SST & LogNorm & 0.053 & 0.053 & 0.056 & 0.001 & 0.318 & LogNorm & 0.253 & 0.253 & 0.176 & 0.001 & 0.619 & LogNorm & 29.840 & 29.840 & 12.010 \\
\hline S-108 & SST & Normal & 0.053 & 0.053 & 0.056 & 0.001 & 0.318 & LogNorm & 0.253 & 0.253 & \begin{tabular}{|l|}
0.176 \\
\end{tabular} & 0.001 & 0.619 & LogNorm & 29.840 & 29.840 & 12.010 \\
\hline S-109 & SST & Normal & 0.053 & 0.053 & 0.056 & 0.001 & 0.318 & LogNorm & 0.253 & 0.253 & \begin{tabular}{l|l|}
0.176 \\
\end{tabular} & 0.001 & 0.619 & LogNorm & 29.840 & 29.840 & 12.010 \\
\hline S-110 & SST & Normal & 0.053 & 0.053 & 0.056 & 0.001 & 0.318 & LogNorm & 0.253 & 0.253 & \begin{tabular}{|l|}
0.176 \\
\end{tabular} & 0.001 & 0.619 & LogNorm & 29.840 & 29.840 & 12.010 \\
\hline S-111 & SST & Normal & 0.014 & 0.014 & 0.002 & 0.010 & 0.019 & Normal & 0.135 & 0.135 & \begin{tabular}{l|l|}
0.017 \\
\end{tabular} & 0.092 & 0.190 & Normal & 20.990 & 20.990 & 5.953 \\
\hline S-112* & SST & Normal & 0.053 & 0.053 & 0.056 & 0.001 & 0.318 & LogNorm & 0.253 & 0.253 & \begin{tabular}{|l|l|}
0.176 \\
\end{tabular} & 0.001 & 0.619 & LogNorm & 29.840 & 29.840 & 12.010 \\
\hline SX-101 & SST & Normal & 0.053 & 0.053 & 0.056 & 0.001 & 0.318 & LogNorm & 0.253 & 0.253 & \begin{tabular}{l|l|}
0.176 \\
\end{tabular} & 0.001 & 0.619 & LogNorm & 29.840 & 29.840 & 12.010 \\
\hline SX-102 & SST & Normal & 0.053 & 0.053 & 0.056 & 0.001 & 0.318 & LogNorm & 0.253 & 0.253 & \begin{tabular}{|c|}
0.176 \\
\end{tabular} & 0.001 & 0.619 & LogNorm & 29.840 & 29.840 & 12.010 \\
\hline SX-103 & SST & Normal & 0.053 & 0.053 & 0.056 & 0.001 & 0.318 & LogNorm & 0.253 & 0.253 & \begin{tabular}{|l|l|}
0.176 \\
\end{tabular} & 0.001 & 0.619 & LogNorm & 29.840 & 29.840 & 12.010 \\
\hline SX-104 & SST & Normal & 0.053 & 0.053 & 0.056 & 0.001 & 0.318 & LogNorm & 0.253 & 0.253 & \begin{tabular}{|l|}
0.176 \\
\end{tabular} & 0.001 & 0.619 & LogNorm & 29.840 & 29.840 & 12.010 \\
\hline SX-105 & SST & Normal & 0.053 & 0.053 & 0.056 & 0.001 & 0.318 & LogNorm & 0.253 & 0.253 & \begin{tabular}{l|l|}
0.176 \\
\end{tabular} & 0.001 & 0.619 & LogNorm & 29.840 & 29.840 & 12.010 \\
\hline SX-106 & SST & Normal & 0.017 & 0.017 & 0.007 & 0.005 & 0.034 & Normal & 0.315 & 0.315 & 0.015 & 0.275 & 0.360 & Normal & 20.203 & 20.203 & 3.446 \\
\hline SX-107 & SST & LogNorm & 0.053 & 0.053 & 0.056 & 0.001 & 0.318 & LogNorm & 0.253 & 0.253 & 0.176 & 0.001 & 0.619 & LogNorm & 29.840 & 29.840 & 12.010 \\
\hline SX-108 & SST & LogNorm & 0.053 & 0.053 & 0.056 & 0.001 & $\begin{array}{l}0.318 \\
\end{array}$ & LogNorm & 0.253 & 0.253 & \begin{tabular}{l|l|}
0.176 \\
\end{tabular} & 0.001 & 0.619 & LogNorm & 29.840 & 29.840 & 12.010 \\
\hline
\end{tabular}




\begin{tabular}{|c|c|c|c|c|c|c|c|c|c|c|c|c|c|c|c|c|c|}
\hline Data Source & & $\begin{array}{c}\text { RPP-10006 } \\
\text { R7,or based on } \\
\text { waste type }\end{array}$ & $\begin{array}{l}\text { RPP-10006 R7 } \\
\text { NonCon }\end{array}$ & $\begin{array}{l}\text { RPP-10006 R7 } \\
\text { NonCon }\end{array}$ & $\begin{array}{l}\text { RPP-10006 R7 } \\
\text { NonCon }\end{array}$ & $\begin{array}{l}\text { RPP-10006 R7 } \\
\text { NonCon }\end{array}$ & $\begin{array}{l}\text { RPP-10006 R7 } \\
\text { NonCon }\end{array}$ & $\begin{array}{c}\text { RPP-10006 R7 } \\
\text { NonCon }\end{array}$ & $\begin{array}{l}\text { RPP-10006 R7 } \\
\text { NonCon }\end{array}$ & $\begin{array}{l}\text { RPP-10006 R7 } \\
\text { NonCon }\end{array}$ & $\begin{array}{c}\text { RPP-10006 R7 } \\
\text { NonCon }\end{array}$ & $\begin{array}{l}\text { RPP-10006 R7 } \\
\text { NonCon }\end{array}$ & $\begin{array}{l}\text { RPP-10006 R7 } \\
\text { NonCon }\end{array}$ & $\begin{array}{l}\text { RPP-10006 R7 } \\
\text { NonCon }\end{array}$ & $\begin{array}{l}\text { RPP-10006 R7 } \\
\text { NonCon }\end{array}$ & $\begin{array}{c}\text { RPP-10006 R7 } \\
\text { NonCon }\end{array}$ & $\begin{array}{l}\text { RPP-10006 R7 } \\
\text { NonCon }\end{array}$ \\
\hline Tank \# & Tank Type & $\begin{array}{c}\text { non- } \\
\text { convective } \\
\text { waste yield } \\
\text { stress dist } \\
\text { type }(\mathbf{P a})\end{array}$ & $\begin{array}{l}\text { Headspace } \\
\text { gas ratio } \\
\mathrm{CH} 4 \\
\text { mean }\end{array}$ & $\begin{array}{c}\text { Headspace } \\
\text { gas ratio } \\
\text { CH4 } \\
\text { mean }\end{array}$ & $\begin{array}{c}\text { Headspace } \\
\text { gas ratio } \\
\text { CH4 } \\
\text { std dev }\end{array}$ & $\begin{array}{l}\text { Headspace } \\
\text { gas ratio } \\
\text { CH4 } \\
\text { min }\end{array}$ & $\begin{array}{c}\text { Headspace } \\
\text { gas ratio } \\
\text { CH4 } \\
\max \end{array}$ & $\begin{array}{l}\text { Headspace } \\
\text { gas ratio } \\
\mathrm{CH} 4 \\
\text { type }\end{array}$ & $\begin{array}{l}\text { Headspace } \\
\text { gas ratio } \\
\text { N2O } \\
\text { mean }\end{array}$ & $\begin{array}{c}\text { Headspace } \\
\text { gas ratio } \\
\mathrm{N} 2 \mathrm{O} \\
\text { mean }\end{array}$ & $\begin{array}{c}\text { Headspace } \\
\text { gas ratio } \\
\text { N2O } \\
\text { std dev }\end{array}$ & $\begin{array}{l}\text { Headspace } \\
\text { gas ratio } \\
\text { N2O } \\
\text { min }\end{array}$ & $\begin{array}{c}\text { Headspace } \\
\text { gas ratio } \\
\mathrm{N} 2 \mathrm{O} \\
\max \end{array}$ & $\begin{array}{c}\text { Headspace } \\
\text { gas ratio } \\
\text { N2O } \\
\text { type }\end{array}$ & $\begin{array}{c}\text { Retained gas } \\
\text { composition } \\
\mathrm{N} 2 \text { mean }\end{array}$ & $\begin{array}{c}\text { Retained gas } \\
\text { composition } \\
\text { N2 } \\
\text { mean }\end{array}$ & $\begin{array}{c}\text { Retained gas } \\
\text { composition } \\
\text { N2 } \\
\text { std dev }\end{array}$ \\
\hline SX-109 & SST & Normal & 0.053 & 0.053 & 0.056 & 0.001 & 0.318 & LogNorm & 0.253 & 0.253 & 0.176 & 0.001 & 0.619 & LogNorm & 29.840 & \begin{tabular}{l|}
29.840 \\
\end{tabular} & 12.010 \\
\hline SX-110 & SST & LogNorm & 0.053 & 0.053 & 0.056 & 0.001 & 0.318 & LogNorm & 0.253 & 0.253 & 0.176 & 0.001 & 0.619 & LogNorm & 29.840 & 29.840 & 12.010 \\
\hline SX-111 & SST & LogNorm & 0.053 & 0.053 & 0.056 & 0.001 & 0.318 & LogNorm & 0.253 & 0.253 & 0.176 & 0.001 & 0.619 & LogNorm & 29.840 & 29.840 & 12.010 \\
\hline SX-112 & SST & LogNorm & 0.053 & 0.053 & 0.056 & 0.001 & 0.318 & LogNorm & 0.253 & 0.253 & 0.176 & 0.001 & 0.619 & LogNorm & 29.840 & 29.840 & 12.010 \\
\hline SX-113 & SST & LogNorm & 0.053 & 0.053 & 0.056 & 0.001 & 0.318 & LogNorm & 0.253 & 0.253 & 0.176 & 0.001 & 0.619 & LogNorm & 29.840 & 29.840 & 12.010 \\
\hline SX-114 & $\begin{array}{l}\text { SST } \\
\end{array}$ & LogNorm & 0.053 & 0.053 & 0.056 & 0.001 & 0.318 & LogNorm & 0.253 & 0.253 & 0.176 & 0.001 & 0.619 & LogNorm & 29.840 & 29.840 & 12.010 \\
\hline SX-115 & $\begin{array}{l}\text { SST } \\
\end{array}$ & LogNorm & 0.053 & 0.053 & 0.056 & 0.001 & 0.318 & LogNorm & 0.253 & 0.253 & \begin{tabular}{ll|}
0.176 \\
\end{tabular} & 0.001 & 0.619 & LogNorm & \begin{tabular}{l|l|}
29.840 \\
\end{tabular} & 29.840 & 12.010 \\
\hline SY-101* & $\overline{\mathrm{DST}}$ & Normal & 0.07 & 0.07 & 0.03 & 0.01 & 0.15 & Normal & 0.36 & 0.36 & 0.05 & 0.23 & 0.50 & Normal & 33.87 & 33.87 & 6.78 \\
\hline SY-102* & DST & LogNorm & 0.05 & 0.05 & 0.06 & 0.00 & 0.32 & LogNorm & 0.25 & 0.25 & 0.18 & 0.00 & 0.62 & LogNorm & 29.84 & 29.84 & 12.01 \\
\hline SY-103* & DST & Normal & 0.05 & 0.05 & 0.06 & 0.00 & 0.32 & LogNorm & 0.25 & 0.25 & 0.18 & 0.00 & 0.62 & LogNorm & 29.84 & 29.84 & 12.01 \\
\hline T-101 & SST & Normal & 0.053 & 0.053 & 0.056 & 0.001 & 0.318 & LogNorm & 0.253 & 0.253 & \begin{tabular}{r|}
0.176 \\
\end{tabular} & 0.001 & 0.619 & LogNorm & 29.840 & 29.840 & 12.010 \\
\hline T-102 & SST & LogNorm & 0.053 & 0.053 & 0.056 & 0.001 & 0.318 & LogNorm & 0.253 & 0.253 & \begin{tabular}{l|l|}
0.176 \\
\end{tabular} & 0.001 & 0.619 & LogNorm & 29.840 & 29.840 & 12.010 \\
\hline T-103 & SST & LogNorm & 0.053 & 0.053 & 0.056 & 0.001 & 0.318 & LogNorm & 0.253 & 0.253 & \begin{tabular}{l|l|}
0.176 \\
\end{tabular} & 0.001 & 0.619 & LogNorm & 29.840 & 29.840 & 12.010 \\
\hline T-104 & SST & LogNorm & 0.053 & 0.053 & 0.056 & 0.001 & 0.318 & LogNorm & 0.253 & 0.253 & 0.176 & 0.001 & 0.619 & LogNorm & 29.840 & 29.840 & 12.010 \\
\hline T-105 & SST & LogNorm & 0.053 & 0.053 & 0.056 & 0.001 & 0.318 & LogNorm & 0.253 & 0.253 & 0.176 & 0.001 & 0.619 & LogNorm & 29.840 & 29.840 & 12.010 \\
\hline T-106 & SST & LogNorm & 0.053 & 0.053 & 0.056 & 0.001 & 0.318 & LogNorm & 0.253 & 0.253 & \begin{tabular}{l|l|}
0.176 \\
\end{tabular} & 0.001 & 0.619 & LogNorm & 29.840 & 29.840 & 12.010 \\
\hline T-107 & SST & LogNorm & 0.053 & 0.053 & 0.056 & 0.001 & 0.318 & LogNorm & 0.253 & 0.253 & 0.176 & 0.001 & 0.619 & LogNorm & 29.840 & 29.840 & 12.010 \\
\hline T-108 & SST & Normal & 0.053 & 0.053 & 0.056 & 0.001 & 0.318 & LogNorm & 0.253 & 0.253 & 0.176 & 0.001 & 0.619 & LogNorm & 29.840 & 29.840 & 12.010 \\
\hline T-109 & SST & Normal & 0.053 & 0.053 & 0.056 & 0.001 & 0.318 & LogNorm & 0.253 & 0.253 & \begin{tabular}{l|l|}
0.176 \\
\end{tabular} & 0.001 & 0.619 & LogNorm & 29.840 & 29.840 & 12.010 \\
\hline T-110 & SST & LogNorm & 0.053 & 0.053 & 0.056 & 0.001 & 0.318 & LogNorm & 0.253 & 0.253 & 0.176 & 0.001 & 0.619 & LogNorm & 29.840 & 29.840 & 12.010 \\
\hline T-111 & SST & LogNorm & 0.053 & 0.053 & 0.056 & 0.001 & 0.318 & LogNorm & 0.253 & 0.253 & 0.176 & 0.001 & 0.619 & LogNorm & 29.840 & 29.840 & 12.010 \\
\hline T-112 & SST & LogNorm & 0.053 & 0.053 & 0.056 & 0.001 & 0.318 & LogNorm & 0.253 & 0.253 & 0.176 & 0.001 & 0.619 & LogNorm & 29.840 & 29.840 & 12.010 \\
\hline $\mathrm{T}-201$ & SST & LogNorm & 0.053 & 0.053 & 0.056 & 0.001 & 0.318 & LogNorm & 0.253 & 0.253 & 0.176 & 0.001 & 0.619 & LogNorm & 29.840 & 29.840 & 12.010 \\
\hline T-202 & SST & LogNorm & 0.053 & 0.053 & 0.056 & 0.001 & 0.318 & LogNorm & 0.253 & 0.253 & 0.176 & 0.001 & 0.619 & LogNorm & 29.840 & 29.840 & 12.010 \\
\hline T-203 & SST & LogNorm & 0.053 & 0.053 & 0.056 & 0.001 & 0.318 & LogNorm & 0.253 & 0.253 & \begin{tabular}{l|l|}
0.176 \\
\end{tabular} & 0.001 & 0.619 & LogNorm & 29.840 & 29.840 & 12.010 \\
\hline T-204 & SST & LogNorm & 0.053 & 0.053 & 0.056 & 0.001 & 0.318 & LogNorm & 0.253 & 0.253 & 0.176 & 0.001 & 0.619 & LogNorm & 29.840 & 29.840 & 12.010 \\
\hline TX-101 & SST & LogNorm & 0.053 & 0.053 & 0.056 & 0.001 & 0.318 & LogNorm & 0.253 & 0.253 & \begin{tabular}{l|l|}
0.176 \\
\end{tabular} & 0.001 & 0.619 & LogNorm & 29.840 & 29.840 & 12.010 \\
\hline TX-102 & SST & Normal & 0.053 & 0.053 & 0.056 & 0.001 & 0.318 & LogNorm & 0.253 & 0.253 & \begin{tabular}{l|l|}
0.176 \\
\end{tabular} & 0.001 & 0.619 & LogNorm & 29.840 & 29.840 & 12.010 \\
\hline TX-103 & SST & Normal & 0.053 & 0.053 & 0.056 & 0.001 & 0.318 & LogNorm & 0.253 & 0.253 & \begin{tabular}{l|l|}
0.176 \\
\end{tabular} & 0.001 & 0.619 & LogNorm & 29.840 & 29.840 & 12.010 \\
\hline TX-104 & SST & Normal & 0.053 & 0.053 & 0.056 & 0.001 & 0.318 & LogNorm & 0.253 & 0.253 & 0.176 & 0.001 & 0.619 & LogNorm & 29.840 & 29.840 & 12.010 \\
\hline TX-105 & SST & Normal & 0.053 & 0.053 & 0.056 & 0.001 & 0.318 & LogNorm & 0.253 & 0.253 & \begin{tabular}{l|l|}
0.176 \\
\end{tabular} & 0.001 & 0.619 & LogNorm & 29.840 & 29.840 & 12.010 \\
\hline TX-106 & SST & Normal & 0.053 & 0.053 & 0.056 & 0.001 & 0.318 & LogNorm & 0.253 & 0.253 & 0.176 & 0.001 & 0.619 & LogNorm & 29.840 & 29.840 & 12.010 \\
\hline TX-107 & SST & Normal & 0.053 & 0.053 & 0.056 & 0.001 & 0.318 & LogNorm & 0.253 & 0.253 & 0.176 & 0.001 & 0.619 & LogNorm & 29.840 & 29.840 & 12.010 \\
\hline TX-108 & SST & Normal & 0.053 & 0.053 & 0.056 & 0.001 & 0.318 & LogNorm & 0.253 & 0.253 & 0.176 & 0.001 & 0.619 & LogNorm & 29.840 & 29.840 & 12.010 \\
\hline TX-109 & SST & LogNorm & 0.053 & 0.053 & 0.056 & 0.001 & 0.318 & LogNorm & 0.253 & 0.253 & 0.176 & 0.001 & 0.619 & LogNorm & 29.840 & 29.840 & 12.010 \\
\hline TX-110 & SST & Normal & 0.053 & 0.053 & 0.056 & 0.001 & 0.318 & LogNorm & 0.253 & 0.253 & 0.176 & 0.001 & 0.619 & LogNorm & 29.840 & 29.840 & 12.010 \\
\hline TX-111 & SST & Normal & 0.053 & 0.053 & 0.056 & 0.001 & $\begin{array}{l}0.318 \\
\end{array}$ & LogNorm & 0.253 & 0.253 & \begin{tabular}{l|l|}
0.176 \\
\end{tabular} & 0.001 & 0.619 & LogNorm & 29.840 & 29.840 & 12.010 \\
\hline
\end{tabular}




\begin{tabular}{|c|c|c|c|c|c|c|c|c|c|c|c|c|c|c|c|c|c|}
\hline Data Source & & $\begin{array}{c}\text { RPP-10006 } \\
\text { R7,or based on } \\
\text { waste type }\end{array}$ & $\begin{array}{l}\text { RPP-10006 R7 } \\
\text { NonCon }\end{array}$ & $\begin{array}{l}\text { RPP-10006 R7 } \\
\text { NonCon }\end{array}$ & $\begin{array}{l}\text { RPP-10006 R7 } \\
\text { NonCon }\end{array}$ & $\begin{array}{l}\text { RPP-10006 R7 } \\
\text { NonCon }\end{array}$ & $\begin{array}{l}\text { RPP-10006 R7 } \\
\text { NonCon }\end{array}$ & $\begin{array}{l}\text { RPP-10006 R7 } \\
\text { NonCon }\end{array}$ & $\begin{array}{l}\text { RPP-10006 R7 } \\
\text { NonCon }\end{array}$ & $\begin{array}{l}\text { RPP-10006 R7 } \\
\text { NonCon }\end{array}$ & $\begin{array}{l}\text { RPP-10006 R7 } \\
\text { NonCon }\end{array}$ & $\begin{array}{l}\text { RPP-10006 R7 } \\
\text { NonCon }\end{array}$ & $\begin{array}{l}\text { RPP-10006 R7 } \\
\text { NonCon }\end{array}$ & $\begin{array}{c}\text { RPP-10006 R7 } \\
\text { NonCon }\end{array}$ & $\begin{array}{l}\text { RPP-10006 R7 } \\
\text { NonCon }\end{array}$ & $\begin{array}{l}\text { RPP-10006 R7 } \\
\text { NonCon }\end{array}$ & $\begin{array}{l}\text { RPP-10006 R7 } \\
\text { NonCon }\end{array}$ \\
\hline Tank \# & Tank Type & $\begin{array}{c}\text { non- } \\
\text { convective } \\
\text { waste yield } \\
\text { stress dist } \\
\text { type }(\mathbf{P a})\end{array}$ & $\begin{array}{l}\text { Headspace } \\
\text { gas ratio } \\
\mathrm{CH} 4 \\
\text { mean }\end{array}$ & $\begin{array}{c}\text { Headspace } \\
\text { gas ratio } \\
\mathrm{CH} 4 \\
\text { mean }\end{array}$ & $\begin{array}{c}\text { Headspace } \\
\text { gas ratio } \\
\text { CH4 } \\
\text { std dev }\end{array}$ & $\begin{array}{l}\text { Headspace } \\
\text { gas ratio } \\
\text { CH4 } \\
\text { min }\end{array}$ & $\begin{array}{c}\text { Headspace } \\
\text { gas ratio } \\
\text { CH4 } \\
\max \end{array}$ & $\begin{array}{c}\text { Headspace } \\
\text { gas ratio } \\
\text { CH4 } \\
\text { type }\end{array}$ & $\begin{array}{l}\text { Headspace } \\
\text { gas ratio } \\
\text { N2O } \\
\text { mean }\end{array}$ & $\begin{array}{c}\text { Headspace } \\
\text { gas ratio } \\
\mathrm{N} 2 \mathrm{O} \\
\text { mean }\end{array}$ & $\begin{array}{c}\text { Headspace } \\
\text { gas ratio } \\
\text { N2O } \\
\text { std dev }\end{array}$ & $\begin{array}{l}\text { Headspace } \\
\text { gas ratio } \\
\text { N2O } \\
\text { min }\end{array}$ & $\begin{array}{c}\text { Headspace } \\
\text { gas ratio } \\
\mathrm{N} 2 \mathrm{O} \\
\max \end{array}$ & $\begin{array}{c}\text { Headspace } \\
\text { gas ratio } \\
\text { N2O } \\
\text { type }\end{array}$ & $\begin{array}{l}\text { Retained gas } \\
\text { composition } \\
\text { N2 mean }\end{array}$ & $\begin{array}{c}\text { Retained gas } \\
\text { composition } \\
\mathbf{N} 2 \\
\text { mean }\end{array}$ & $\begin{array}{c}\text { Retained gas } \\
\text { composition } \\
\mathrm{N} 2 \\
\text { std dev }\end{array}$ \\
\hline TX-112 & SST & Normal & 0.053 & 0.053 & 0.056 & 0.001 & 0.318 & LogNorm & 0.253 & 0.253 & 0.176 & 0.001 & 0.619 & LogNorm & 29.840 & 29.840 & 12.010 \\
\hline TX-113 & SST & Normal & 0.053 & 0.053 & 0.056 & 0.001 & 0.318 & LogNorm & 0.253 & 0.253 & 0.176 & 0.001 & 0.619 & LogNorm & 29.840 & 29.840 & 12.010 \\
\hline TX-114 & SST & Normal & 0.053 & 0.053 & 0.056 & 0.001 & 0.318 & LogNorm & 0.253 & 0.253 & 0.176 & 0.001 & 0.619 & LogNorm & 29.840 & 29.840 & 12.010 \\
\hline TX-115 & SST & Normal & 0.053 & 0.053 & 0.056 & 0.001 & 0.318 & LogNorm & 0.253 & 0.253 & 0.176 & 0.001 & 0.619 & LogNorm & 29.840 & 29.840 & 12.010 \\
\hline TX-116 & SST & Normal & 0.053 & 0.053 & 0.056 & 0.001 & 0.318 & LogNorm & 0.253 & 0.253 & 0.176 & 0.001 & 0.619 & LogNorm & 29.840 & 29.840 & 12.010 \\
\hline TX-117 & SST & Normal & 0.053 & 0.053 & 0.056 & 0.001 & 0.318 & LogNorm & 0.253 & 0.253 & 0.176 & 0.001 & 0.619 & LogNorm & 29.840 & 29.840 & 12.010 \\
\hline TX-118 & $\begin{array}{l}\text { SST } \\
\end{array}$ & Normal & 0.053 & 0.053 & 0.056 & 0.001 & 0.318 & LogNorm & 0.253 & 0.253 & 0.176 & 0.001 & 0.619 & LogNorm & 29.840 & 29.840 & 12.010 \\
\hline TY-101 & SST & Normal & 0.053 & 0.053 & 0.056 & 0.001 & 0.318 & LogNorm & 0.253 & 0.253 & 0.176 & 0.001 & 0.619 & LogNorm & 29.840 & 29.840 & 12.010 \\
\hline TY-102 & SST & Normal & 0.053 & 0.053 & 0.056 & 0.001 & 0.318 & LogNorm & 0.253 & 0.253 & $\begin{array}{ll}0.176 \\
\end{array}$ & 0.001 & 0.619 & LogNorm & 29.840 & 29.840 & 12.010 \\
\hline TY-103 & SST & Normal & 0.053 & 0.053 & 0.056 & 0.001 & 0.318 & LogNorm & 0.253 & 0.253 & 0.176 & 0.001 & 0.619 & LogNorm & 29.840 & 29.840 & 12.010 \\
\hline TY-104 & SST & LogNorm & 0.053 & 0.053 & 0.056 & 0.001 & 0.318 & LogNorm & 0.253 & 0.253 & 0.176 & 0.001 & 0.619 & LogNorm & 29.840 & 29.840 & 12.010 \\
\hline TY-105 & SST & LogNorm & 0.053 & 0.053 & 0.056 & 0.001 & 0.318 & LogNorm & 0.253 & 0.253 & 0.176 & 0.001 & 0.619 & LogNorm & 29.840 & 29.840 & 12.010 \\
\hline TY-106 & SST & LogNorm & 0.053 & 0.053 & 0.056 & 0.001 & 0.318 & LogNorm & 0.253 & 0.253 & 0.176 & 0.001 & 0.619 & LogNorm & 29.840 & 29.840 & 12.010 \\
\hline U-101 & SST & LogNorm & 0.053 & 0.053 & 0.056 & 0.001 & 0.318 & LogNorm & 0.253 & 0.253 & 0.176 & 0.001 & 0.619 & LogNorm & 29.840 & 29.840 & 12.010 \\
\hline U-102 & SST & Normal & 0.053 & 0.053 & 0.056 & 0.001 & 0.318 & LogNorm & 0.253 & 0.253 & 0.176 & 0.001 & 0.619 & LogNorm & 29.840 & 29.840 & 12.010 \\
\hline U-103 & SST & Normal & 0.057 & 0.057 & 0.011 & 0.034 & 0.082 & Normal & 0.603 & 0.603 & 0.015 & 0.561 & 0.645 & Normal & 36.711 & 36.711 & 2.018 \\
\hline U-104 & SST & LogNorm & 0.053 & 0.053 & 0.056 & 0.001 & $\begin{array}{ll}0.318 \\
\end{array}$ & LogNorm & 0.253 & 0.253 & 0.176 & 0.001 & 0.619 & LogNorm & 29.840 & 29.840 & 12.010 \\
\hline U-105 & SST & Normal & 0.053 & 0.053 & 0.056 & 0.001 & 0.318 & LogNorm & 0.253 & 0.253 & 0.176 & 0.001 & 0.619 & LogNorm & 29.840 & 29.840 & 12.010 \\
\hline U-106 & $\overline{\mathrm{SST}}$ & Normal & 0.053 & 0.053 & 0.056 & 0.001 & 0.318 & LogNorm & 0.253 & 0.253 & 0.176 & 0.001 & 0.619 & LogNorm & 29.840 & 29.840 & 12.010 \\
\hline U-107 & SST & Normal & 0.053 & 0.053 & 0.056 & 0.001 & 0.318 & LogNorm & 0.253 & 0.253 & 0.176 & 0.001 & 0.619 & LogNorm & 29.840 & 29.840 & 12.010 \\
\hline U-108 & SST & Normal & 0.053 & 0.053 & 0.056 & 0.001 & 0.318 & LogNorm & 0.253 & 0.253 & 0.176 & 0.001 & 0.619 & LogNorm & 29.840 & 29.840 & 12.010 \\
\hline \begin{tabular}{|l|} 
U-109 \\
\end{tabular} & SST & Normal & 0.049 & 0.049 & 0.013 & 0.024 & 0.087 & Normal & 0.489 & 0.489 & 0.031 & 0.402 & 0.577 & Normal & 46.777 & 46.777 & 3.188 \\
\hline U-110 & SST & LogNorm & 0.053 & 0.053 & 0.056 & 0.001 & 0.318 & LogNorm & 0.253 & 0.253 & 0.176 & 0.001 & 0.619 & LogNorm & 29.840 & 29.840 & 12.010 \\
\hline U-111 & SST & Normal & 0.053 & 0.053 & 0.056 & 0.001 & 0.318 & LogNorm & 0.253 & 0.253 & 0.176 & 0.001 & 0.619 & LogNorm & 29.840 & 29.840 & 12.010 \\
\hline U-112 & SST & LogNorm & 0.053 & 0.053 & 0.056 & 0.001 & 0.318 & LogNorm & 0.253 & 0.253 & 0.176 & 0.001 & 0.619 & LogNorm & 29.840 & 29.840 & 12.010 \\
\hline U-201 & SST & LogNorm & 0.053 & 0.053 & 0.056 & 0.001 & 0.318 & LogNorm & 0.253 & 0.253 & 0.176 & 0.001 & 0.619 & LogNorm & 29.840 & 29.840 & 12.010 \\
\hline U-202 & SST & LogNorm & 0.053 & 0.053 & 0.056 & 0.001 & 0.318 & LogNorm & 0.253 & 0.253 & 0.176 & 0.001 & 0.619 & LogNorm & 29.840 & 29.840 & 12.010 \\
\hline U-203 & SST & LogNorm & 0.053 & 0.053 & 0.056 & 0.001 & 0.318 & LogNorm & 0.253 & 0.253 & 0.176 & 0.001 & 0.619 & LogNorm & 29.840 & 29.840 & 12.010 \\
\hline $\mathrm{U}-204$ & SST & LogNorm & 0.053 & 0.053 & 0.056 & 0.001 & $\begin{array}{ll}0.318 \\
\end{array}$ & LogNorm & 0.253 & 0.253 & \begin{tabular}{l|l|}
0.176 \\
\end{tabular} & 0.001 & 0.619 & LogNorm & 29.840 & 29.840 & 12.010 \\
\hline
\end{tabular}




\begin{tabular}{|c|c|c|c|c|c|c|c|c|c|c|c|c|c|c|c|c|}
\hline Data Source & & $\begin{array}{c}\text { RPP-10006 R7 } \\
\text { NonCon }\end{array}$ & $\begin{array}{c}\text { RPP-10006 R7 } \\
\text { NonCon }\end{array}$ & $\begin{array}{l}\text { RPP-10006 R7 } \\
\text { NonCon }\end{array}$ & $\begin{array}{c}\text { RPP-10006 R7 } \\
\text { NonCon }\end{array}$ & $\begin{array}{c}\text { RPP-10006 R7 } \\
\text { NonCon }\end{array}$ & $\begin{array}{l}\text { RPP-10006 R7 } \\
\text { NonCon }\end{array}$ & $\begin{array}{c}\text { RPP-10006 R7 } \\
\text { NonCon }\end{array}$ & $\begin{array}{c}\text { RPP-10006 R7 } \\
\text { NonCon }\end{array}$ & $\begin{array}{l}\text { RPP-10006 R7 } \\
\text { NonCon }\end{array}$ & \begin{tabular}{|c|} 
RPP-5926 R8 \\
(Table B-3) \& \\
RPP-10006 R7
\end{tabular} & \begin{tabular}{|c|} 
Calculated \\
Value \\
RPP-10006 \\
See Appendix \\
E \\
\end{tabular} & \begin{tabular}{|c|} 
Calculated \\
Value \\
RPP-10006 \\
See Appendix \\
E \\
\end{tabular} & \begin{tabular}{|c|} 
Calculated \\
Value \\
RPP-10006 \\
See Appendix \\
E \\
\end{tabular} & $\begin{array}{l}\text { RPP-10006 R7 } \\
\text { NonCon }\end{array}$ & \begin{tabular}{|c|} 
Based on waste \\
phase volumes in \\
RPP-5926 R8 \& \\
RPP-10006 R7 \\
See Appendix A \\
\end{tabular} \\
\hline Tank \# & Tank Type & $\begin{array}{c}\text { Retained gas } \\
\text { composition } \\
\mathrm{N} 2 \\
\mathrm{~min}\end{array}$ & $\begin{array}{c}\text { Retained gas } \\
\text { composition } \\
\mathrm{N} 2 \\
\max \end{array}$ & $\begin{array}{c}\text { Retained gas } \\
\text { composition } \\
\text { N2 } \\
\text { type }\end{array}$ & $\begin{array}{c}\text { Retained gas } \\
\text { composition } \\
\text { NH3 } \\
\text { mean }\end{array}$ & $\begin{array}{c}\text { Retained gas } \\
\text { composition } \\
\text { NH3 mean }\end{array}$ & $\begin{array}{c}\text { Retained gas } \\
\text { composition } \\
\text { NH3 } \\
\text { std dev }\end{array}$ & $\begin{array}{c}\text { Retained gas } \\
\text { composition } \\
\text { NH3 } \\
\text { min }\end{array}$ & $\begin{array}{c}\text { Retained gas } \\
\text { composition } \\
\mathrm{NH3} \\
\max \end{array}$ & $\begin{array}{c}\text { Retained gas } \\
\text { composition } \\
\mathrm{NH3} \\
\text { type }\end{array}$ & \begin{tabular}{|c|} 
Hydrogen \\
Generation \\
Rate in Non- \\
Convective \\
Waste \\
$($ moles $/ \mathbf{m} 3 / \mathbf{d}$ \\
ay)
\end{tabular} & $\begin{array}{c}\text { Hydrogen } \\
\text { Generation } \\
\text { Rate in Non- } \\
\text { Convective } \\
\text { Waste Min } \\
(\text { moles } / \mathrm{m} 3 / \mathrm{d} \\
\text { ay) }\end{array}$ & $\begin{array}{c}\text { Hydrogen } \\
\text { Generation } \\
\text { Rate in Non- } \\
\text { Convective } \\
\text { Waste Max } \\
(\text { moles } / \mathbf{m} 3 / \mathrm{d} \\
\text { ay) }\end{array}$ & \begin{tabular}{|c|} 
Hydrogen \\
Generation \\
Rate in Non- \\
Convective \\
Waste \\
Dist Type \\
$\left(\begin{array}{c}\text { (moles/m3/d } \\
\text { ay) }\end{array}\right.$
\end{tabular} & $\begin{array}{c}\text { Cross } \\
\text { sectional } \\
\text { area of tank } \\
(\mathbf{m} 2)\end{array}$ & Waste Type \\
\hline $\mathrm{A}-101$ & SST & \begin{tabular}{l|l}
11.352 \\
\end{tabular} & 26.594 & Normal & 2.457 & 2.457 & 0.295 & 1.242 & \begin{tabular}{r|}
3.347 \\
\end{tabular} & Normal & \begin{tabular}{|l}
$1.11 \mathrm{E}-03$ \\
\end{tabular} & $\begin{array}{r}5.57 \mathrm{E}-04 \\
\end{array}$ & \begin{tabular}{|l|l|} 
\\
\end{tabular} $.12 \mathrm{E}-03$ & \begin{tabular}{|l} 
triangular \\
\end{tabular} & 411.35 & \begin{tabular}{|l|} 
SC/SS-NL \\
\end{tabular} \\
\hline A-102 & SST & 4.500 & 80.000 & LogNorm & 0.250 & 0.250 & & 0.010 & 18.318 & ContLin & $1.60 \mathrm{E}-03$ & $8.01 \mathrm{E}-04$ & $3.04 \mathrm{E}-03$ & triangular & 411.35 & $\begin{array}{l}\text { SC/SS-NL } \\
\end{array}$ \\
\hline A-103 & SST & 4.500 & 80.000 & LogNorm & 0.250 & 0.250 & & 0.010 & 18.318 & ContLin & $1.57 \mathrm{E}-03$ & $7.84 \mathrm{E}-04$ & $2.35 \mathrm{E}-03$ & triangular & 411.35 & $\begin{array}{l}\text { SC/SS-NL } \\
\end{array}$ \\
\hline A-104 & SST & 4.500 & 80.000 & LogNorm & 0.250 & 0.250 & & 0.010 & 18.318 & ContLin & $3.50 \mathrm{E}-03$ & $1.75 \mathrm{E}-03$ & $6.64 \mathrm{E}-03$ & triangular & 411.35 & SL-NL \\
\hline A-105 & SST & 4.500 & 80.000 & LogNorm & 0.250 & 0.250 & & 0.010 & 18.318 & ContLin & $2.70 \mathrm{E}-03$ & $1.35 \mathrm{E}-03$ & $5.13 \mathrm{E}-03$ & triangular & 411.35 & SL-NL \\
\hline A-106 & SST & 4.500 & 80.000 & LogNorm & 0.250 & 0.250 & & 0.010 & \begin{tabular}{|l|l|}
18.318 \\
\end{tabular} & ContLin & $6.79 \mathrm{E}-03$ & $3.39 \mathrm{E}-03$ & $1.02 \mathrm{E}-02$ & triangular & 411.35 & MIX-NL \\
\hline AN-101* & DST & 4.50 & 80.00 & LogNorm & 0.25 & 0.25 & & 0.01 & 18.32 & ContLin & $5.18 \mathrm{E}-04$ & $2.59 \mathrm{E}-04$ & $9.84 \mathrm{E}-04$ & triangular & 409.9 & $\begin{array}{l}\text { SC/SS-LIQ } \\
\end{array}$ \\
\hline AN-102* & $\overline{\mathrm{DST}}$ & 4.50 & 80.00 & LogNorm & 0.25 & 0.25 & & 0.01 & 18.32 & ContLin & $4.71 \mathrm{E}-03$ & $1.57 \mathrm{E}-03$ & $5.18 \mathrm{E}-03$ & triangular & 409.9 & $\begin{array}{l}\text { SC/SS-LIQ } \\
\end{array}$ \\
\hline AN-103* & DST & 14.91 & 42.80 & Normal & 0.60 & 0.60 & 0.07 & 0.40 & 0.78 & Normal & $1.08 \mathrm{E}-03$ & $5.39 \mathrm{E}-04$ & $1.62 \mathrm{E}-03$ & triangular & 409.9 & $\begin{array}{l}\text { SC/SS-LIQ } \\
\end{array}$ \\
\hline AN-104* & DST & 14.33 & 41.44 & Normal & 0.88 & 0.88 & 0.13 & 0.38 & 1.29 & Normal & $1.88 \mathrm{E}-03$ & $6.27 \mathrm{E}-04$ & $2.07 \mathrm{E}-03$ & triangular & 409.9 & $\begin{array}{l}\text { SC/SS-LIQ } \\
\end{array}$ \\
\hline AN-105* & DST & 14.17 & & Normal & 0.50 & 0.50 & 0.06 & 0.30 & 0.76 & Normal & $1.13 \mathrm{E}-03$ & $5.67 \mathrm{E}-04$ & $1.70 \mathrm{E}-03$ & triangular & 409.9 & SC/SS-LIQ \\
\hline AN-106* & DST & 4.50 & 80.00 & LogNorm & 0.25 & 0.25 & & 0.01 & 18.32 & ContLin & $6.82 \mathrm{E}-03$ & $2.27 \mathrm{E}-03$ & $7.50 \mathrm{E}-03$ & triangular & 409.9 & SL-LIQ \\
\hline AN-107* & DST & 4.50 & 80.00 & LogNorm & 0.25 & 0.25 & & 0.01 & 18.32 & ContLin & $4.54 \mathrm{E}-03$ & $1.51 \mathrm{E}-03$ & $4.99 \mathrm{E}-03$ & triangular & 409.9 & $\begin{array}{l}\text { SC/SS-LIQ } \\
\end{array}$ \\
\hline AP-101* & DST & 4.50 & 80.00 & LogNorm & 0.25 & 0.25 & & 0.01 & 18.32 & ContLin & $3.34 \mathrm{E}-04$ & $1.67 \mathrm{E}-04$ & $6.35 \mathrm{E}-04$ & triangular & 409.9 & LIQ \\
\hline AP-102* & DST & 4.50 & 80.00 & LogNorm & 0.25 & 0.25 & & 0.01 & 18.32 & ContLin & $2.71 \mathrm{E}-04$ & $1.35 \mathrm{E}-04$ & $5.15 \mathrm{E}-04$ & triangular & 409.9 & $\begin{array}{l}\text { SL-LIQ } \\
\end{array}$ \\
\hline AP-103* & DST & 4.50 & 80.00 & LogNorm & 0.25 & 0.25 & & 0.01 & 18.32 & ContLin & $9.67 \mathrm{E}-04$ & $4.84 \mathrm{E}-04$ & $1.84 \mathrm{E}-03$ & triangular & 409.9 & 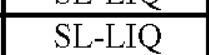 \\
\hline AP-104* & DST & 4.50 & 80.00 & LogNorm & 0.25 & 0.25 & & 0.01 & 18.32 & ContLin & $2.14 \mathrm{E}-03$ & $1.07 \mathrm{E}-03$ & $4.07 \mathrm{E}-03$ & triangular & 409.9 & $\begin{array}{l}\text { SC/SS-LIQ } \\
\end{array}$ \\
\hline AP-105* & DST & 4.50 & 80.00 & LogNorm & 0.25 & 0.25 & & 0.01 & 18.32 & ContLin & $4.33 \mathrm{E}-04$ & $2.16 \mathrm{E}-04$ & $8.22 \mathrm{E}-04$ & triangular & 409.9 & SC/SS-LIQ \\
\hline AP-106* & DST & 4.50 & 80.00 & LogNorm & 0.25 & 0.25 & & 0.01 & 18.32 & ContLin & $1.13 \mathrm{E}-03$ & $5.66 \mathrm{E}-04$ & $2.15 \mathrm{E}-03$ & triangular & 409.9 & SC/SS-LIQ \\
\hline AP-107* & DST & 4.50 & 80.00 & LogNorm & 0.25 & 0.25 & & 0.01 & 18.32 & ContLin & $9.76 \mathrm{E}-04$ & $4.88 \mathrm{E}-04$ & $1.85 \mathrm{E}-03$ & triangular & 409.9 & \begin{tabular}{|l|} 
SC/SS-LIQ \\
\end{tabular} \\
\hline AP-108* & DST & & 80.00 & LogNorm & 0.25 & 0.25 & & 0.01 & 18.32 & ContLin & $3.49 \mathrm{E}-04$ & $1.75 \mathrm{E}-04$ & $6.63 \mathrm{E}-04$ & triangular & 409.9 & SC/SS-LIQ \\
\hline AW-101* & DST & 45.45 & 62.01 & Normal & 0.57 & 0.57 & 0.10 & 0.27 & 0.96 & Normal & $1.37 \mathrm{E}-03$ & $6.83 \mathrm{E}-04$ & $2.05 \mathrm{E}-03$ & triangular & 409.9 & $\begin{array}{l}\text { SC/SS-LIQ } \\
\end{array}$ \\
\hline AW-102* & & & 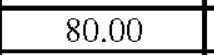 & LogNorm & 0.25 & 0.25 & & $\overline{0.1}$ & 18.2 & ContLin & $9.42 \mathrm{E}-04$ & $4.71 \mathrm{E}-04$ & $1.79 \mathrm{E}-03$ & triangular & 409.9 & $\begin{array}{l}\text { SL-LIQ } \\
\end{array}$ \\
\hline AW-103* & DST & 4.50 & 80.00 & LogNorm & 0.25 & 0.25 & & 0.01 & 18.32 & ContLin & $3.37 \mathrm{E}-04$ & $1.68 \mathrm{E}-04$ & $6.40 \mathrm{E}-04$ & triangular & 409.9 & $\frac{\text { SL-LIQ }}{\text { SLI }}$ \\
\hline AW-104* & DST & 4.50 & 80.00 & LogNorm & 0.25 & 0.25 & & 0.01 & 18.32 & ContLin & $6.45 \mathrm{E}-04$ & $3.23 \mathrm{E}-04$ & $1.23 \mathrm{E}-03$ & triangular & 409.9 & $\begin{array}{l}\text { SC/SS-LIQ } \\
\end{array}$ \\
\hline AW-105* & DST & 4.50 & 80.00 & LogNorm & 0.25 & 0.25 & & 0.01 & 18.32 & ContLin & $8.18 \mathrm{E}-04$ & $4.09 \mathrm{E}-04$ & $1.55 \mathrm{E}-03$ & triangular & 409.9 & SL-LIQ \\
\hline AW-106* & DST & 4.50 & 80.00 & LogNorm & 0.25 & 0.25 & & 0.01 & 18.32 & ContLin & $7.36 \mathrm{E}-04$ & $3.68 \mathrm{E}-04$ & $1.40 \mathrm{E}-03$ & triangular & 409.9 & $\begin{array}{l}\text { SC/SS-LIQ } \\
\end{array}$ \\
\hline AX-101 & SST & 4.6. & 27.39 & Normal & 6.5 & 6.58 & 1.769 & 3.0 & \begin{tabular}{l|}
10.784 \\
\end{tabular} & Normal & $7.37 \mathrm{E}-04$ & $3.68 \mathrm{E}-04$ & $1.40 \mathrm{E}-03$ & triangular & 410.66 & $\begin{array}{l}\text { SC/SS-NL } \\
\end{array}$ \\
\hline AX-102 & SST & 4.500 & 80.000 & LogNorm & 0.250 & 0.250 & & 0.010 & 18.318 & ContLin & $4.26 \mathrm{E}-03$ & $2.13 \mathrm{E}-03$ & $8.10 \mathrm{E}-03$ & triangular & 410.66 & SC/SS-NL \\
\hline AX-103 & SST & 4.500 & 80.000 & LogNorm & 0.250 & 0.250 & & 0.01 & 18.318 & ContLin & $2.35 \mathrm{E}-03$ & $1.18 \mathrm{E}-03$ & $4.47 \mathrm{E}-03$ & triangular & 410.66 & SC/SS-NL \\
\hline AX-104 & SST & 4.500 & 80.000 & LogNorm & 0.250 & 0.250 & & 0.010 & 18.318 & ContLin & $2.92 \mathrm{E}-02$ & $1.46 \mathrm{E}-02$ & $5.55 \mathrm{E}-02$ & triangular & 410.66 & SL-NL \\
\hline AY-101* & DST & 4.50 & 80.00 & LogNorm & 0.25 & 0.25 & & 0.01 & 18.32 & ContLin & $8.27 \mathrm{E}-03$ & $2.76 \mathrm{E}-03$ & $9.10 \mathrm{E}-03$ & triangular & 410.4 & SL-LIQ \\
\hline AY-102* & DST & 4.50 & 80.00 & LogNorm & 0.25 & 0.25 & & 0.01 & 18.32 & ContLin & $2.77 \mathrm{E}-02$ & $9.24 \mathrm{E}-03$ & $3.05 \mathrm{E}-02$ & triangular & 410.4 & SL-LIQ \\
\hline AZ-101* & DST & 4.50 & 80.00 & LogNorm & 0.25 & 0.25 & & 0.01 & 18.32 & ContLin & $4.78 \mathrm{E}-02$ & $1.59 \mathrm{E}-02$ & $5.26 \mathrm{E}-02$ & triangular & 409.9 & SL-LIQ \\
\hline AZ-102* & DST & 4.50 & 80.00 & LogNorm & 0.25 & 0.25 & & 0.01 & 18.32 & ContLin & $6.27 \mathrm{E}-02$ & $2.09 \mathrm{E}-02$ & $6.90 \mathrm{E}-02$ & triangular & 409.9 & $\begin{array}{l}\text { SL-LIQ } \\
\end{array}$ \\
\hline B-101 & SST & 4.500 & 80.000 & LogNorm & 0.250 & 0.2 & & 0.010 & 18.318 & ContLin & $4.84 \mathrm{E}-04$ & $2.42 \mathrm{E}-04$ & $9.19 \mathrm{E}-04$ & triangular & 410.43 & SC/SS-NL \\
\hline B-102 & SST & 4.500 & 80.000 & LogNorm & 0.250 & 0.250 & & 0.010 & \begin{tabular}{l|l|}
18.318 \\
\end{tabular} & ContLin & $5.67 \mathrm{E}-06$ & $2.84 \mathrm{E}-06$ & $1.08 \mathrm{E}-05$ & triangular & 410.43 & SC/SS-NL \\
\hline
\end{tabular}




\begin{tabular}{|c|c|c|c|c|c|c|c|c|c|c|c|c|c|c|c|c|}
\hline Data Source & & $\begin{array}{c}\text { RPP-10006 R7 } \\
\text { NonCon }\end{array}$ & $\begin{array}{c}\text { RPP-10006 R7 } \\
\text { NonCon }\end{array}$ & $\begin{array}{c}\text { RPP-10006 R7 } \\
\text { NonCon }\end{array}$ & $\begin{array}{c}\text { RPP-10006 R7 } \\
\text { NonCon }\end{array}$ & $\begin{array}{l}\text { RPP-10006 R7 } \\
\text { NonCon }\end{array}$ & $\begin{array}{c}\text { RPP-10006 R7 } \\
\text { NonCon }\end{array}$ & $\begin{array}{c}\text { RPP-10006 R7 } \\
\text { NonCon }\end{array}$ & \begin{tabular}{|c|} 
RPP-10006 R7 \\
NonCon
\end{tabular} & $\begin{array}{c}\text { RPP-10006 R7 } \\
\text { NonCon }\end{array}$ & $\begin{array}{l}\text { RPP-5926 R8 } \\
\text { (Table B-3) \& } \\
\text { RPP-10006 R7 }\end{array}$ & \begin{tabular}{|c} 
Calculated \\
Value \\
RPP-10006 \\
See Appendix \\
E \\
\end{tabular} & \begin{tabular}{|c|} 
Calculated \\
Value \\
RPP-10006 \\
See Appendix \\
E \\
\end{tabular} & \begin{tabular}{|c} 
Calculated \\
Value \\
RPP-10006 \\
See Appendix \\
E \\
\end{tabular} & $\begin{array}{c}\text { RPP-10006 R7 } \\
\text { NonCon }\end{array}$ & \begin{tabular}{|c|} 
Based on waste \\
phase volumes in \\
RPP-5926 R8 \& \\
RPP-10006 R7 \\
See Appendix A \\
\end{tabular} \\
\hline Tank \# & Tank Type & $\begin{array}{c}\text { Retained gas } \\
\text { composition } \\
\mathrm{N} 2 \\
\mathrm{~min}\end{array}$ & $\begin{array}{l}\text { Retained gas } \\
\text { composition } \\
\mathrm{N} 2 \\
\mathrm{max}\end{array}$ & \begin{tabular}{|c} 
Retained gas \\
composition \\
$\mathrm{N} 2$ \\
type
\end{tabular} & $\begin{array}{c}\text { Retained gas } \\
\text { composition } \\
\text { NH3 } \\
\text { mean }\end{array}$ & $\begin{array}{l}\text { Retained gas } \\
\text { composition } \\
\text { NH3 mean }\end{array}$ & \begin{tabular}{|c} 
Retained gas \\
composition \\
NH3 \\
std dev
\end{tabular} & $\begin{array}{c}\text { Retained gas } \\
\text { composition } \\
\mathrm{NH3} \\
\mathrm{min}\end{array}$ & $\begin{array}{c}\text { Retained gas } \\
\text { composition } \\
\text { NH3 } \\
\max \end{array}$ & $\begin{array}{c}\text { Retained gas } \\
\text { composition } \\
\text { NH3 } \\
\text { type }\end{array}$ & \begin{tabular}{|c} 
Hydrogen \\
Generation \\
Rate in Non- \\
Convective \\
Waste \\
$($ moles $/ \mathbf{m} 3 / \mathrm{d}$ \\
ay)
\end{tabular} & $\begin{array}{c}\text { Hydrogen } \\
\text { Generation } \\
\text { Rate in Non- } \\
\text { Convective } \\
\text { Waste Min } \\
(\text { moles } / \text { m3/d } \\
\text { ay) }\end{array}$ & $\begin{array}{c}\text { Hydrogen } \\
\text { Generation } \\
\text { Rate in Non- } \\
\text { Convective } \\
\text { Waste Max } \\
(\text { moles } / \mathrm{m} 3 / \mathrm{d} \\
\text { ay) }\end{array}$ & $\begin{array}{c}\text { Hydrogen } \\
\text { Generation } \\
\text { Rate in Non- } \\
\text { Convective } \\
\text { Waste } \\
\text { Dist Type } \\
\text { (moles/m3/d } \\
\text { ay) }\end{array}$ & $\begin{array}{c}\text { Cross } \\
\text { sectional } \\
\text { area of tank } \\
\text { (m2) }\end{array}$ & Waste Type \\
\hline B-103 & SST & 4.500 & 80.000 & LogNorm & 0.250 & 0.250 & & 0.010 & 18.318 & ContLin & $1.26 \mathrm{E}-05$ & $6.32 \mathrm{E}-06$ & $2.40 \mathrm{E}-05$ & \begin{tabular}{|c|} 
triangular \\
\end{tabular} & 410.43 & SC/SS-NL \\
\hline B-104 & SST & 4.500 & 80.000 & LogNorm & 0.250 & 0.250 & & 0.010 & 18.318 & ContLin & $1.28 \mathrm{E}-05$ & $6.38 \mathrm{E}-06$ & $2.42 \mathrm{E}-05$ & triangular & 410.43 & SL-NL \\
\hline B-105 & SST & 4.500 & 80.000 & LogNorm & 0.250 & 0.250 & & 0.010 & 18.318 & ContLin & $5.33 \mathrm{E}-06$ & $2.66 \mathrm{E}-06$ & $1.01 \mathrm{E}-05$ & triangular & 410.43 & SC/SS-NL \\
\hline$B-106$ & SST & 4.500 & 80.000 & LogNorm & 0.250 & 0.250 & & 0.010 & $\begin{array}{ll}18.318 \\
\end{array}$ & ContLin & $1.32 \mathrm{E}-04$ & $6.61 \mathrm{E}-05$ & $2.51 \mathrm{E}-04$ & triangular & 410.43 & $\begin{array}{l}\text { SL-NL } \\
\end{array}$ \\
\hline B-107 & SST & 4.500 & 80.000 & LogNorm & 0.250 & 0.250 & & 0.010 & \begin{tabular}{l|}
18.318 \\
\end{tabular} & ContLin & $1.69 \mathrm{E}-05$ & $8.45 \mathrm{E}-06$ & $3.21 \mathrm{E}-05$ & triangular & 410.43 & MIX-NL \\
\hline B-108 & SST & 4.500 & 80.000 & LogNorm & 0.250 & 0.250 & & 0.010 & \begin{tabular}{l|l|}
18.318 \\
\end{tabular} & ContLin & $9.79 \mathrm{E}-06$ & $4.89 \mathrm{E}-06$ & $1.86 \mathrm{E}-05$ & triangular & 410.43 & 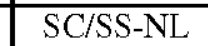 \\
\hline B-109 & SST & 4.500 & 80.000 & LogNorm & 0.250 & 0.250 & & 0.010 & $\begin{array}{ll}18.318 \\
\end{array}$ & ContLin & $3.67 \mathrm{E}-06$ & $1.84 \mathrm{E}-06$ & $6.98 \mathrm{E}-06$ & triangular & 410.43 & MIX-NL \\
\hline B-110 & SST & 4.500 & 80.000 & LogNorm & 0.250 & 0.250 & & 0.010 & 18.318 & ContLin & $3.69 \mathrm{E}-04$ & $1.84 \mathrm{E}-04$ & $7.01 \mathrm{E}-04$ & triangular & 410.43 & SL-NL \\
\hline B-111 & SST & 4.500 & 80.000 & LogNorm & 0.250 & 0.250 & & 0.010 & \begin{tabular}{l|}
18.318 \\
\end{tabular} & ContLin & $1.07 \mathrm{E}-03$ & $5.34 \mathrm{E}-04$ & $2.03 \mathrm{E}-03$ & triangular & 410.43 & SL-NL \\
\hline B-112 & SST & 4.500 & 80.000 & LogNorm & 0.250 & 0.250 & & 0.010 & 18.318 & ContLin & $6.21 \mathrm{E}-04$ & $3.10 \mathrm{E}-04$ & $1.18 \mathrm{E}-03$ & triangular & 410.43 & MIX-NL \\
\hline B-201 & SST & 4.500 & 80.000 & LogNorm & 0.250 & 0.250 & & 0.010 & 18.318 & ContLin & $8.24 \mathrm{E}-05$ & $4.12 \mathrm{E}-05$ & $1.57 \mathrm{E}-04$ & triangular & 29.19 & SL-NL \\
\hline$B-202$ & SST & 4.500 & 80.000 & LogNorm & 0.250 & 0.250 & & 0.010 & 18.318 & ContLin & $4.34 \mathrm{E}-05$ & $2.17 \mathrm{E}-05$ & $8.25 \mathrm{E}-05$ & triangular & 29.19 & SL-NL \\
\hline B-203 & SST & 4.500 & 80.000 & LogNorm & 0.250 & 0.250 & & 0.010 & \begin{tabular}{l|}
18.318 \\
\end{tabular} & ContLin & $2.82 \mathrm{E}-05$ & $1.41 \mathrm{E}-05$ & $5.35 \mathrm{E}-05$ & triangular & 29.19 & SL-NL \\
\hline B-204 & SST & 4.500 & 80.000 & LogNorm & 0.250 & 0.250 & & 0.010 & 18.318 & ContLin & $3.35 \mathrm{E}-05$ & $1.68 \mathrm{E}-05$ & $6.37 \mathrm{E}-05$ & triangular & 29.19 & SL-NL \\
\hline BX-101 & SST & 4.500 & 80.000 & LogNorm & 0.250 & 0.250 & & \begin{tabular}{l|l|}
0.010 \\
\end{tabular} & 18.318 & ContLin & $2.65 \mathrm{E}-04$ & $1.33 \mathrm{E}-04$ & $5.04 \mathrm{E}-04$ & triangular & 410.43 & SL-NL \\
\hline BX-102 & SST & 4.500 & 80.000 & LogNorm & 0.250 & 0.250 & & 0.010 & $\begin{array}{l}18.318 \\
\end{array}$ & ContLin & $5.67 \mathrm{E}-04$ & $2.84 \mathrm{E}-04$ & $1.08 \mathrm{E}-03$ & triangular & 410.43 & SL-NL \\
\hline BX-103 & SST & 4.500 & 80.000 & LogNorm & 0.250 & 0.250 & & \begin{tabular}{l|l|}
0.010 \\
\end{tabular} & 18.318 & ContLin & $3.54 \mathrm{E}-03$ & $1.77 \mathrm{E}-03$ & $6.73 \mathrm{E}-03$ & triangular & 410.43 & SL-NL \\
\hline BX-104 & SST & 4.500 & 80.000 & LogNorm & \begin{tabular}{l|}
0.250 \\
\end{tabular} & 0.250 & & \begin{tabular}{l|l|}
0.010 \\
\end{tabular} & 18.318 & ContLin & $4.58 \mathrm{E}-04$ & $2.29 \mathrm{E}-04$ & $8.71 \mathrm{E}-04$ & triangular & 410.43 & SL-NL \\
\hline BX-105 & SST & 4.500 & 80.000 & LogNorm & 0.250 & 0.250 & & \begin{tabular}{l|}
0.010 \\
\end{tabular} & 18.318 & ContLin & $2.19 \mathrm{E}-04$ & $1.10 \mathrm{E}-04$ & $4.16 \mathrm{E}-04$ & triangular & 410.43 & MIX-NL \\
\hline BX-106 & SST & 4.500 & 80.000 & LogNorm & 0.250 & 0.250 & & 0.010 & 18.318 & ContLin & $1.10 \mathrm{E}-03$ & $5.48 \mathrm{E}-04$ & $2.08 \mathrm{E}-03$ & triangular & 410.43 & SC/SS-NL \\
\hline BX-107 & SST & 4.500 & 80.000 & LogNorm & 0.250 & 0.250 & & 0.010 & \begin{tabular}{|c|}
18.318 \\
\end{tabular} & ContLin & $8.99 \mathrm{E}-05$ & 4.49E-05 & $1.71 \mathrm{E}-04$ & triangular & 410.43 & SL-NL \\
\hline BX-108 & SST & 4.500 & 80.000 & LogNorm & 0.250 & 0.250 & & 0.010 & 18.318 & ContLin & $1.75 \mathrm{E}-04$ & $8.73 \mathrm{E}-05$ & $3.32 \mathrm{E}-04$ & triangular & 410.43 & SL-NL \\
\hline BX-109 & SST & 4.500 & 80.000 & LogNorm & \begin{tabular}{l|l|}
0.250 \\
\end{tabular} & 0.250 & & 0.010 & \begin{tabular}{l|}
18.318 \\
\end{tabular} & ContLin & $4.48 \mathrm{E}-04$ & $2.24 \mathrm{E}-04$ & $8.52 \mathrm{E}-04$ & triangular & 410.43 & SL-NL \\
\hline BX-110 & SST & 4.500 & 80.000 & LogNorm & 0.250 & 0.250 & & 0.010 & \begin{tabular}{|l|}
18.318 \\
\end{tabular} & ContLin & $2.60 \mathrm{E}-04$ & $1.30 \mathrm{E}-04$ & $4.94 \mathrm{E}-04$ & triangular & 410.43 & MIX-NL \\
\hline BX-111 & SST & 4.500 & 80.000 & LogNorm & 0.250 & 0.250 & & 0.010 & 18.318 & ContLin & $6.38 \mathrm{E}-05$ & $3.19 \mathrm{E}-05$ & $1.21 \mathrm{E}-04$ & triangular & 410.43 & SC/SS-NL \\
\hline BX-112 & SST & & 80.000 & LogNorm & 0.250 & 0.250 & & 0.010 & 18.318 & ContLin & $1.47 \mathrm{E}-04$ & $7.37 \mathrm{E}-05$ & $2.80 \mathrm{E}-04$ & triangular & 410.43 & SL-NL \\
\hline BY-101 & SST & 4.500 & 80.000 & LogNorm & 0.250 & 0.250 & & \begin{tabular}{l|l}
0.010 \\
\end{tabular} & \begin{tabular}{|l|}
18.318 \\
\end{tabular} & ContLin & $7.05 \mathrm{E}-04$ & $3.53 \mathrm{E}-04$ & $1.34 \mathrm{E}-03$ & triangular & 410.43 & SC/SS-NL \\
\hline BY-102 & SST & 4.500 & 80.000 & LogNorm & 0.250 & 0.250 & & 0.010 & \begin{tabular}{l|}
18.318 \\
\end{tabular} & ContLin & $8.63 \mathrm{E}-05$ & $4.32 \mathrm{E}-05$ & $1.64 \mathrm{E}-04$ & triangular & 410.43 & $\begin{array}{l}\mathrm{SC} / \mathrm{SS}-\mathrm{NL} \\
\end{array}$ \\
\hline BY-103 & SST & 4.500 & 80.000 & LogNorm & 0.250 & 0.250 & & 0.010 & \begin{tabular}{l|}
18.318 \\
\end{tabular} & ContLin & $9.32 \mathrm{E}-05$ & $4.66 \mathrm{E}-05$ & $1.77 \mathrm{E}-04$ & triangular & 410.43 & SC/SS-NL \\
\hline BY-104 & SST & 4.500 & 80.000 & LogNorm & 0.250 & 0.250 & & 0.010 & 18.318 & ContLin & $5.14 \mathrm{E}-04$ & $2.57 \mathrm{E}-04$ & $9.77 \mathrm{E}-04$ & triangular & 410.43 & SC/SS-NL \\
\hline BY-105 & SST & 4.500 & 80.000 & LogNorm & 0.250 & 0.250 & & 0.010 & \begin{tabular}{|l|}
18.318 \\
\end{tabular} & ContLin & $1.78 \mathrm{E}-04$ & $8.91 \mathrm{E}-05$ & $3.38 \mathrm{E}-04$ & triangular & 410.43 & SC/SS-NL \\
\hline BY-106 & SST & 4.500 & 80.000 & LogNorm & 0.250 & 0.250 & & 0.010 & \begin{tabular}{l|}
18.318 \\
\end{tabular} & ContLin & $3.15 \mathrm{E}-04$ & $1.58 \mathrm{E}-04$ & $5.99 \mathrm{E}-04$ & triangular & 410.43 & SC/SS-NL \\
\hline BY-107 & SST & 4.500 & 80.000 & LogNorm & 0.250 & 0.250 & & 0.010 & \begin{tabular}{l|l|}
18.318 \\
\end{tabular} & ContLin & $3.23 \mathrm{E}-04$ & $1.61 \mathrm{E}-04$ & $6.14 \mathrm{E}-04$ & triangular & 410.43 & SC/SS-NL \\
\hline BY-108 & SST & 4.500 & 80.000 & LogNorm & 0.250 & 0.250 & & 0.010 & 18.318 & ContLin & $4.01 \mathrm{E}-04$ & $2.00 \mathrm{E}-04$ & $7.62 \mathrm{E}-04$ & triangular & 410.43 & SC/SS-NL \\
\hline BY-109 & SST & 16.678 & 42.377 & Normal & 0.191 & 0.191 & 0.034 & 0.081 & 0.321 & Normal & $1.00 \mathrm{E}-04$ & $5.02 \mathrm{E}-05$ & $1.91 \mathrm{E}-04$ & triangular & 410.43 & SC/SS-NL \\
\hline BY-110 & SST & 4.500 & 80.000 & LogNorm & 0.250 & 0.250 & & 0.010 & 18.318 & ContLin & $1.95 \mathrm{E}-03$ & $6.50 \mathrm{E}-04$ & $2.15 \mathrm{E}-03$ & triangular & 410.43 & SC/SS-NL \\
\hline BY-111 & SST & 4.500 & 80.000 & LogNorm & 0.250 & 0.250 & & 0.010 & \begin{tabular}{l|l|}
18.318 \\
\end{tabular} & ContLin & $1.01 \mathrm{E}-04$ & $5.07 \mathrm{E}-05$ & $1.93 \mathrm{E}-04$ & triangular & 410.43 & SC/SS-NL \\
\hline
\end{tabular}




\begin{tabular}{|c|c|c|c|c|c|c|c|c|c|c|c|c|c|c|c|c|}
\hline Data Source & & $\begin{array}{c}\text { RPP-10006 R7 } \\
\text { NonCon }\end{array}$ & $\begin{array}{c}\text { RPP-10006 R7 } \\
\text { NonCon }\end{array}$ & $\begin{array}{l}\text { RPP-10006 R7 } \\
\text { NonCon }\end{array}$ & $\begin{array}{c}\text { RPP-10006 R7 } \\
\text { NonCon }\end{array}$ & $\begin{array}{c}\text { RPP-10006 R7 } \\
\text { NonCon }\end{array}$ & $\begin{array}{l}\text { RPP-10006 R7 } \\
\text { NonCon }\end{array}$ & $\begin{array}{c}\text { RPP-10006 R7 } \\
\text { NonCon }\end{array}$ & $\begin{array}{c}\text { RPP-10006 R7 } \\
\text { NonCon }\end{array}$ & $\begin{array}{c}\text { RPP-10006 R7 } \\
\text { NonCon }\end{array}$ & \begin{tabular}{|l} 
RPP-5926 R8 \\
(Table B-3) \& \\
RPP-10006 R7
\end{tabular} & \begin{tabular}{|c|} 
Calculated \\
Value \\
RPP-10006 \\
See Appendix \\
E \\
\end{tabular} & \begin{tabular}{|c|} 
Calculated \\
Value \\
RPP-10006 \\
See Appendix \\
E \\
\end{tabular} & \begin{tabular}{|c|} 
Calculated \\
Value \\
RPP-10006 \\
See Appendix \\
E \\
\end{tabular} & $\begin{array}{c}\text { RPP-10006 R7 } \\
\text { NonCon }\end{array}$ & \begin{tabular}{|c|} 
Based on waste \\
phase volumes in \\
RPP-5926 R8 \& \\
RPP-10006 R7 \\
See Appendix A \\
\end{tabular} \\
\hline Tank \# & Tank Type & \begin{tabular}{|c} 
Retained gas \\
composition \\
$\mathbf{N} 2$ \\
min
\end{tabular} & $\begin{array}{c}\text { Retained gas } \\
\text { composition } \\
\mathrm{N} 2 \\
\max \end{array}$ & $\begin{array}{l}\text { Retained gas } \\
\text { composition } \\
\mathrm{N} 2 \\
\text { type }\end{array}$ & $\begin{array}{c}\text { Retained gas } \\
\text { composition } \\
\text { NH3 } \\
\text { mean }\end{array}$ & $\begin{array}{c}\text { Retained gas } \\
\text { composition } \\
\text { NH3 mean }\end{array}$ & $\begin{array}{l}\text { Retained gas } \\
\text { composition } \\
\text { NH3 } \\
\text { std dev }\end{array}$ & $\begin{array}{c}\text { Retained gas } \\
\text { composition } \\
\text { NH3 } \\
\text { min }\end{array}$ & $\begin{array}{c}\text { Retained gas } \\
\text { composition } \\
\text { NH3 } \\
\text { max }\end{array}$ & $\begin{array}{c}\text { Retained gas } \\
\text { composition } \\
\text { NH3 } \\
\text { type }\end{array}$ & $\begin{array}{c}\text { Hydrogen } \\
\text { Generation } \\
\text { Rate in Non- } \\
\text { Convective } \\
\text { Waste } \\
(\text { moles } / \mathbf{m} 3 / \mathrm{d} \\
\text { ay) }\end{array}$ & $\begin{array}{c}\text { Hydrogen } \\
\text { Generation } \\
\text { Rate in Non- } \\
\text { Convective } \\
\text { Waste Min } \\
\text { (moles/m3/d } \\
\text { ay) }\end{array}$ & \begin{tabular}{|c|} 
Hydrogen \\
Generation \\
Rate in Non- \\
Convective \\
Waste Max \\
$($ moles $/ \mathbf{m} 3 / \mathrm{d}$ \\
ay)
\end{tabular} & \begin{tabular}{|c|} 
Hydrogen \\
Generation \\
Rate in Non- \\
Convective \\
Waste \\
Dist Type \\
(moles/m3/d \\
ay)
\end{tabular} & $\begin{array}{c}\text { Cross } \\
\text { sectional } \\
\text { area of tank } \\
(\mathbf{m} 2)\end{array}$ & Waste Type \\
\hline BY-112 & SST & 4.500 & 80.000 & LogNorm & 0.250 & 0.250 & & 0.010 & \begin{tabular}{ll|}
18.318 \\
\end{tabular} & ContLin & $1.41 \mathrm{E}-04$ & $7.06 \mathrm{E}-05$ & $2.68 \mathrm{E}-04$ & \begin{tabular}{|l|} 
triangular \\
\end{tabular} & 410.43 & SC/SS-NL \\
\hline C-101 & SST & 4.500 & 80.000 & LogNorm & 0.250 & 0.250 & & 0.010 & \begin{tabular}{l|l|}
18.318 \\
\end{tabular} & ContLin & $2.98 \mathrm{E}-04$ & $1.49 \mathrm{E}-04$ & $5.65 \mathrm{E}-04$ & triangular & 410.43 & SL-NL \\
\hline C-102 & SST & 4.500 & 80.000 & LogNorm & 0.250 & 0.250 & & 0.010 & \begin{tabular}{|l|l|}
18.318 \\
\end{tabular} & ContLin & $3.01 \mathrm{E}-04$ & $1.51 \mathrm{E}-04$ & $5.72 \mathrm{E}-04$ & triangular & 410.43 & SL-NL \\
\hline $\mathrm{C}-103$ & SST & 4.500 & 80.000 & LogNorm & 0.250 & 0.250 & & 0.010 & \begin{tabular}{l|l|}
18.318 \\
\end{tabular} & ContLin & $4.32 \mathrm{E}-03$ & $2.16 \mathrm{E}-03$ & $8.21 \mathrm{E}-03$ & triangular & 410.43 & SL-NL \\
\hline C-104 & SST & 4.500 & 80.000 & LogNorm & 0.250 & 0.250 & & 0.010 & \begin{tabular}{l|l|}
18.318 \\
\end{tabular} & ContLin & $1.90 \mathrm{E}-03$ & $9.52 \mathrm{E}-04$ & $2.86 \mathrm{E}-03$ & triangular & 410.43 & SL-NL \\
\hline C-105 & SST & 4.500 & 80.000 & $\begin{array}{l}\text { LogNorm } \\
\end{array}$ & 0.250 & 0.250 & & 0.010 & 18.318 & ContLin & $1.65 \mathrm{E}-03$ & $8.26 \mathrm{E}-04$ & $3.14 \mathrm{E}-03$ & triangular & 410.43 & SL-NL \\
\hline C-106 & SST & 4.500 & 80.000 & $\begin{array}{l}\text { LogNorm } \\
\end{array}$ & 0.250 & 0.250 & & 0.010 & \begin{tabular}{l|l|}
18.318 \\
\end{tabular} & ContLin & $6.46 \mathrm{E}-02$ & $3.23 \mathrm{E}-02$ & $1.23 \mathrm{E}-01$ & triangular & 410.43 & SL-NL \\
\hline C-107 & SST & 4.500 & 80.000 & LogNorm & 0.250 & 0.250 & & 0.010 & 18.318 & ContLin & $5.79 \mathrm{E}-03$ & $1.93 \mathrm{E}-03$ & $6.37 \mathrm{E}-03$ & triangular & 410.43 & SL-NL \\
\hline C-108* & SST & 4.500 & 80.000 & LogNorm & 0.250 & 0.250 & & 0.010 & \begin{tabular}{l|}
18.318 \\
\end{tabular} & ContLin & $9.69 \mathrm{E}-04$ & $4.84 \mathrm{E}-04$ & $1.84 \mathrm{E}-03$ & triangular & 410.43 & SL-NL \\
\hline C-109* & SST & 4.500 & 80.000 & LogNorm & 0.250 & 0.250 & & 0.010 & 18.318 & ContLin & $1.10 \mathrm{E}-04$ & $5.52 \mathrm{E}-05$ & $2.10 \mathrm{E}-04$ & triangular & 410.43 & SL-NL \\
\hline C-110 & SST & 4.500 & 80.000 & LogNorm & 0.250 & 0.250 & & 0.010 & \begin{tabular}{|l|}
18.318 \\
\end{tabular} & ContLin & $9.32 \mathrm{E}-05$ & $4.66 \mathrm{E}-05$ & $1.77 \mathrm{E}-04$ & triangular & 410.43 & SL-NL \\
\hline C-111 & SST & 4.500 & 80.000 & LogNorm & 0.250 & 0.250 & & 0.010 & \begin{tabular}{|l|}
18.318 \\
\end{tabular} & ContLin & $6.87 \mathrm{E}-03$ & $3.43 \mathrm{E}-03$ & $1.30 \mathrm{E}-02$ & triangular & 410.43 & SL-NL \\
\hline C-112 & SST & 4.500 & 80.000 & LogNorm & 0.250 & 0.250 & & 0.010 & \begin{tabular}{l|}
18.318 \\
\end{tabular} & ContLin & $4.15 \mathrm{E}-03$ & $2.08 \mathrm{E}-03$ & $7.89 \mathrm{E}-03$ & triangular & 410.43 & SL-NL \\
\hline $\mathrm{C}-201$ & SST & 4.500 & 80.000 & LogNorm & 0.250 & 0.250 & & 0.010 & \begin{tabular}{l|l|}
18.318 \\
\end{tabular} & ContLin & $6.85 \mathrm{E}-03$ & $3.43 \mathrm{E}-03$ & $1.30 \mathrm{E}-02$ & triangular & 29.19 & SL-NL \\
\hline $\mathrm{C}-202$ & SST & 4.500 & 80.000 & LogNorm & 0.250 & 0.250 & & 0.010 & \begin{tabular}{|l|}
18.318 \\
\end{tabular} & ContLin & $8.71 \mathrm{E}-03$ & $4.36 \mathrm{E}-03$ & $1.66 \mathrm{E}-02$ & triangular & 29.19 & SL-NL \\
\hline C-203 & SST & 4.500 & 80.000 & LogNorm & 0.250 & 0.250 & & 0.010 & \begin{tabular}{l|l|}
18.318 \\
\end{tabular} & ContLin & $4.55 \mathrm{E}-03$ & $2.27 \mathrm{E}-03$ & $8.64 \mathrm{E}-03$ & triangular & 29.19 & SL-NL \\
\hline C-204 & SST & 4.500 & 80.000 & LogNorm & 0.250 & 0.250 & & 0.010 & \begin{tabular}{l|}
18.318 \\
\end{tabular} & ContLin & $2.89 \mathrm{E}-03$ & $1.45 \mathrm{E}-03$ & $5.49 \mathrm{E}-03$ & triangular & 29.19 & SL-NL \\
\hline S-101 & SST & 4.500 & 80.000 & $\begin{array}{l}\text { LogNorm } \\
\end{array}$ & 0.250 & 0.250 & & 0.010 & 18.318 & ContLin & $7.12 \mathrm{E}-04$ & $3.56 \mathrm{E}-04$ & $1.35 \mathrm{E}-03$ & triangular & 410.43 & MIX-NL \\
\hline S-102* & SST & 23.974 & 40.719 & Normal & 0.932 & \begin{tabular}{l|l|}
0.932 \\
\end{tabular} & 0.288 & 0.347 & 1.624 & Normal & $4.81 \mathrm{E}-04$ & $2.41 \mathrm{E}-04$ & $9.14 \mathrm{E}-04$ & triangular & 410.43 & MIX-NL \\
\hline S-103 & SST & 4.500 & 80.000 & LogNorm & 0.250 & 0.250 & & 0.010 & \begin{tabular}{l|l|}
18.318 \\
\end{tabular} & ContLin & $3.97 \mathrm{E}-04$ & $1.99 \mathrm{E}-04$ & $7.55 \mathrm{E}-04$ & triangular & 410.43 & SC/SS-NL \\
\hline S-104 & SST & 4.500 & 80.000 & LogNorm & 0.250 & 0.250 & & 0.010 & \begin{tabular}{l|}
18.318 \\
\end{tabular} & ContLin & $3.81 \mathrm{E}-04$ & $1.90 \mathrm{E}-04$ & $7.23 \mathrm{E}-04$ & triangular & 410.43 & MIX-NL \\
\hline S-105 & SST & 4.500 & 80.000 & LogNorm & 0.250 & 0.250 & & 0.010 & \begin{tabular}{l|l}
18.318 \\
\end{tabular} & ContLin & $3.79 \mathrm{E}-05$ & $1.89 \mathrm{E}-05$ & $7.20 \mathrm{E}-05$ & triangular & 410.43 & SC/SS-NL \\
\hline S-106 & SST & 15.249 & 34.922 & Normal & 0.299 & 0.299 & 0.067 & 0.094 & 0.520 & Normal & $1.45 \mathrm{E}-04$ & $7.26 \mathrm{E}-05$ & $2.76 \mathrm{E}-04$ & triangular & 410.43 & $\begin{array}{l}\text { SC/SS-NL } \\
\text { n }\end{array}$ \\
\hline S-107 & SST & 4.500 & 80.000 & LogNorm & 0.250 & 0.250 & & 0.010 & \begin{tabular}{|l|}
18.318 \\
\end{tabular} & ContLin & $3.98 \mathrm{E}-04$ & $1.99 \mathrm{E}-04$ & $7.57 \mathrm{E}-04$ & triangular & 410.43 & SL-NL \\
\hline S-108 & SST & 4.500 & 80.000 & LogNorm & 0.250 & 0.250 & & 0.010 & \begin{tabular}{l|}
18.318 \\
\end{tabular} & ContLin & $1.30 \mathrm{E}-05$ & $6.51 \mathrm{E}-06$ & $2.47 \mathrm{E}-05$ & triangular & 410.43 & SC/SS-NL \\
\hline S-109 & SST & 4.500 & 80.000 & LogNorm & 0.250 & 0.250 & & 0.010 & \begin{tabular}{l|l|}
18.318 \\
\end{tabular} & ContLin & $1.96 \mathrm{E}-05$ & $9.80 \mathrm{E}-06$ & $3.73 \mathrm{E}-05$ & triangular & 410.43 & SC/SS-NL \\
\hline S-110 & SST & 4.500 & 80.000 & LogNorm & 0.250 & 0.250 & & 0.010 & \begin{tabular}{l|}
18.318 \\
\end{tabular} & ContLin & $3.88 \mathrm{E}-04$ & $1.94 \mathrm{E}-04$ & $7.38 \mathrm{E}-04$ & triangular & 410.43 & SC/SS-NL \\
\hline S-111 & SST & 4.556 & 34.751 & Normal & 0.929 & \begin{tabular}{l|l|}
0.929 \\
\end{tabular} & 0.285 & 0.355 & 1.603 & Normal & $2.73 \mathrm{E}-04$ & $1.37 \mathrm{E}-04$ & $5.19 \mathrm{E}-04$ & triangular & 410.43 & SC/SS-NL \\
\hline S-112* & SST & 4.500 & 80.000 & LogNorm & 0.250 & 0.250 & & 0.010 & \begin{tabular}{l|}
18.318 \\
\end{tabular} & ContLin & $1.66 \mathrm{E}-05$ & $8.28 \mathrm{E}-06$ & $3.14 \mathrm{E}-05$ & triangular & 410.43 & SC/SS-NL \\
\hline SX-101 & SST & 4.500 & 80.000 & LogNorm & 0.250 & 0.250 & & 0.010 & \begin{tabular}{l|l|}
18.318 \\
\end{tabular} & ContLin & $3.29 \mathrm{E}-04$ & $1.64 \mathrm{E}-04$ & $6.25 \mathrm{E}-04$ & triangular & 410.66 & MIX-NL \\
\hline SX-102 & SST & 4.500 & 80.000 & LogNorm & 0.250 & 0.250 & & 0.010 & \begin{tabular}{l|l}
18.318 \\
\end{tabular} & ContLin & $1.43 \mathrm{E}-03$ & $7.14 \mathrm{E}-04$ & $2.14 \mathrm{E}-03$ & triangular & 410.66 & SC/SS-NL \\
\hline SX-103 & SST & 4.500 & 80.000 & LogNorm & 0.250 & 0.250 & & 0.010 & \begin{tabular}{l|}
18.318 \\
\end{tabular} & ContLin & $3.91 \mathrm{E}-03$ & $1.30 \mathrm{E}-03$ & $4.31 \mathrm{E}-03$ & triangular & 410.66 & SC/SS-NL \\
\hline SX-104 & SST & 4.500 & 80.000 & LogNorm & 0.250 & 0.250 & & 0.010 & \begin{tabular}{l|l}
18.318 \\
\end{tabular} & ContLin & $1.90 \mathrm{E}-03$ & $6.33 \mathrm{E}-04$ & $2.09 \mathrm{E}-03$ & triangular & 410.66 & MIX-NL \\
\hline SX-105 & SST & 4.500 & 80.000 & LogNorm & 0.250 & 0.250 & & 0.010 & \begin{tabular}{l|l}
18.318 \\
\end{tabular} & ContLin & $5.69 \mathrm{E}-03$ & $1.90 \mathrm{E}-03$ & $6.26 \mathrm{E}-03$ & triangular & 410.66 & SC/SS-NL \\
\hline SX-106 & SST & 10.198 & 29.551 & Normal & 4.202 & 4.202 & 1.255 & 1.790 & 6.805 & Normal & $4.49 \mathrm{E}-04$ & $2.25 \mathrm{E}-04$ & $8.54 \mathrm{E}-04$ & triangular & 410.66 & SC/SS-NL \\
\hline SX-107 & SST & 4.500 & 80.000 & LogNorm & 0.250 & 0.250 & & 0.010 & \begin{tabular}{|l|}
18.318 \\
\end{tabular} & ContLin & $4.10 \mathrm{E}-03$ & $2.05 \mathrm{E}-03$ & $6.15 \mathrm{E}-03$ & triangular & 410.66 & SL-NL \\
\hline SX-108 & SST & 4.500 & 80.000 & LogNorm & 0.250 & 0.250 & & 0.010 & \begin{tabular}{l|l}
18.318 \\
\end{tabular} & ContLin & $1.14 \mathrm{E}-03$ & $5.71 \mathrm{E}-04$ & $2.17 \mathrm{E}-03$ & triangular & 410.66 & $\begin{array}{l}\text { SL-NL } \\
\end{array}$ \\
\hline
\end{tabular}




\begin{tabular}{|c|c|c|c|c|c|c|c|c|c|c|c|c|c|c|c|c|}
\hline Data Source & & $\begin{array}{l}\text { RPP-10006 R7 } \\
\text { NonCon }\end{array}$ & $\mid \begin{array}{c}\text { RPP-10006 R7 } \\
\text { NonCon }\end{array}$ & $\begin{array}{l}\text { RPP-10006 R7 } \\
\text { NonCon }\end{array}$ & $\begin{array}{c}\text { RPP-10006 R7 } \\
\text { NonCon }\end{array}$ & $\begin{array}{c}\text { RPP-10006 R7 } \\
\text { NonCon }\end{array}$ & $\begin{array}{l}\text { RPP-10006 R7 } \\
\text { NonCon }\end{array}$ & $\begin{array}{c}\text { RPP-10006 R7 } \\
\text { NonCon }\end{array}$ & $\left|\begin{array}{c}\text { RPP-10006 R7 } \\
\text { NonCon }\end{array}\right|$ & $\begin{array}{c}\text { RPP-10006 R7 } \\
\text { NonCon }\end{array}$ & \begin{tabular}{|l} 
RPP-5926 R8 \\
(Table B-3) \& \\
RPP-10006 R7
\end{tabular} & \begin{tabular}{|c|} 
Calculated \\
Value \\
RPP-10006 \\
See Appendix \\
E \\
\end{tabular} & \begin{tabular}{|c|} 
Calculated \\
Value \\
RPP-10006 \\
See Appendix \\
E \\
\end{tabular} & \begin{tabular}{|c|} 
Calculated \\
Value \\
RPP-10006 \\
See Appendix \\
E \\
\end{tabular} & $\begin{array}{c}\text { RPP-10006 R7 } \\
\text { NonCon }\end{array}$ & \begin{tabular}{|c|c} 
Based on waste \\
phase volumes in \\
RPP-5926 R8 \& \\
RPP-10006 R7 \\
See Appendix A \\
\end{tabular} \\
\hline Tank \# & Tank Type & $\begin{array}{c}\text { Retained gas } \\
\text { composition } \\
\mathrm{N} 2 \\
\mathrm{~min}\end{array}$ & $\begin{array}{c}\text { Retained gas } \\
\text { composition } \\
\mathrm{N} 2 \\
\max \end{array}$ & $\begin{array}{l}\text { Retained gas } \\
\text { composition } \\
\mathrm{N} 2 \\
\text { type }\end{array}$ & $\begin{array}{c}\text { Retained gas } \\
\text { composition } \\
\text { NH3 } \\
\text { mean }\end{array}$ & $\begin{array}{c}\text { Retained gas } \\
\text { composition } \\
\text { NH3 mean }\end{array}$ & $\begin{array}{l}\text { Retained gas } \\
\text { composition } \\
\text { NH3 } \\
\text { std dev }\end{array}$ & $\begin{array}{c}\text { Retained gas } \\
\text { composition } \\
\mathrm{NH} 3 \\
\mathrm{~min}\end{array}$ & $\begin{array}{c}\text { Retained gas } \\
\text { composition } \\
\text { NH3 } \\
\text { max }\end{array}$ & $\begin{array}{c}\text { Retained gas } \\
\text { composition } \\
\text { NH3 } \\
\text { type }\end{array}$ & $\begin{array}{c}\text { Hydrogen } \\
\text { Generation } \\
\text { Rate in Non- } \\
\text { Convective } \\
\text { Waste } \\
(\text { moles } / \mathbf{m} 3 / \mathrm{d} \\
\text { ay) }\end{array}$ & \begin{tabular}{|c} 
Hydrogen \\
Generation \\
Rate in Non- \\
Convective \\
Waste Min \\
$($ moles $/$ m3/d \\
ay)
\end{tabular} & \begin{tabular}{|c} 
Hydrogen \\
Generation \\
Rate in Non- \\
Convective \\
Waste Max \\
$($ moles/m3/d \\
ay)
\end{tabular} & $\begin{array}{c}\text { Hydrogen } \\
\text { Generation } \\
\text { Rate in Non- } \\
\text { Convective } \\
\text { Waste } \\
\text { Dist Type } \\
(\text { moles } / \mathbf{m 3} 3 / \mathbf{d} \\
\text { ay) }\end{array}$ & $\begin{array}{c}\text { Cross } \\
\text { sectional } \\
\text { area of tank } \\
(\mathbf{m} 2)\end{array}$ & Waste Type \\
\hline SX-109 & SST & 4.500 & 80.000 & LogNorm & 0.250 & 0.250 & & 0.010 & \begin{tabular}{l|l|}
18.318 & \\
\end{tabular} & ContLin & $5.91 \mathrm{E}-03$ & $1.97 \mathrm{E}-03$ & $6.50 \mathrm{E}-03$ & triangular & 410.66 & $\begin{array}{l}\text { SC/SS-NL } \\
\end{array}$ \\
\hline SX-110 & SST & 4.500 & 80.000 & LogNorm & 0.250 & 0.250 & & 0.010 & \begin{tabular}{l|l|}
18.318 \\
\end{tabular} & ContLin & $1.46 \mathrm{E}-02$ & $4.87 \mathrm{E}-03$ & $1.61 \mathrm{E}-02$ & triangular & 410.66 & SL-NL \\
\hline SX-111 & SST & 4.500 & 80.000 & LogNorm & 0.250 & 0.250 & & 0.010 & \begin{tabular}{|l|l|}
18.318 \\
\end{tabular} & ContLin & $4.52 \mathrm{E}-03$ & $2.26 \mathrm{E}-03$ & $6.78 \mathrm{E}-03$ & triangular & 410.66 & SL-NL \\
\hline SX-112 & SST & 4.500 & 80.000 & LogNorm & 0.250 & 0.250 & & 0.010 & \begin{tabular}{|l|l|}
18.318 \\
\end{tabular} & ContLin & $3.62 \mathrm{E}-03$ & $1.81 \mathrm{E}-03$ & $6.87 \mathrm{E}-03$ & triangular & 410.66 & SL-NL \\
\hline SX-113 & SST & 4.500 & 80.000 & LogNorm & 0.250 & 0.250 & & 0.010 & $\begin{array}{l}18.318 \\
\end{array}$ & ContLin & $1.91 \mathrm{E}-04$ & $9.56 \mathrm{E}-05$ & $3.63 \mathrm{E}-04$ & triangular & 410.66 & SL-NL \\
\hline SX-114 & SST & 4.500 & 80.000 & LogNorm & 0.250 & 0.250 & & 0.010 & \begin{tabular}{l|l|}
18.318 \\
\end{tabular} & ContLin & $5.09 \mathrm{E}-03$ & $1.70 \mathrm{E}-03$ & $5.60 \mathrm{E}-03$ & triangular & 410.66 & SL-NL \\
\hline SX-115 & SST & 4.500 & 80.000 & $\begin{array}{l}\text { LogNorm } \\
\end{array}$ & 0.250 & 0.250 & & 0.010 & \begin{tabular}{l|l|}
18.318 \\
\end{tabular} & ContLin & $1.17 \mathrm{E}-02$ & $5.85 \mathrm{E}-03$ & $2.22 \mathrm{E}-02$ & triangular & 410.66 & SL-NL \\
\hline SY-101* & DST & 13.36 & 53.31 & Normal & 9.17 & 9.17 & 2.99 & 3.27 & 15.77 & Normal & $6.45 \mathrm{E}-04$ & $3.22 \mathrm{E}-04$ & $1.23 \mathrm{E}-03$ & triangular & 409.9 & SC/SS-LIQ \\
\hline SY-102* & DST & 4.50 & 80.00 & $\begin{array}{l}\text { LogNorm } \\
\end{array}$ & 0.25 & 0.25 & & 0.01 & 18.32 & ContLin & $2.07 \mathrm{E}-03$ & $1.03 \mathrm{E}-03$ & $3.93 \mathrm{E}-03$ & triangular & 409.9 & $\begin{array}{l}\text { SL-LIQ } \\
\end{array}$ \\
\hline SY-103* & DST & 4.50 & 80.00 & LogNorm & 0.25 & 0.25 & & 0.01 & 18.32 & ContLin & $1.29 \mathrm{E}-03$ & $6.44 \mathrm{E}-04$ & $1.93 \mathrm{E}-03$ & triangular & 409.9 & SC/SS-LIQ \\
\hline T-101 & SST & 4.500 & 80.000 & LogNorm & 0.250 & 0.250 & & 0.010 & 18.318 & ContLin & $1.90 \mathrm{E}-04$ & $9.48 \mathrm{E}-05$ & $3.60 \mathrm{E}-04$ & triangular & 410.43 & MIX-NL \\
\hline T-102 & SST & 4.500 & 80.000 & $\begin{array}{l}\text { LogNorm } \\
\end{array}$ & 0.250 & 0.250 & & 0.010 & \begin{tabular}{l|l|}
18.318 \\
\end{tabular} & ContLin & $3.02 \mathrm{E}-04$ & $1.51 \mathrm{E}-04$ & $5.74 \mathrm{E}-04$ & triangular & 410.43 & SL-NL \\
\hline T-103 & SST & 4.500 & 80.000 & LogNorm & 0.250 & 0.250 & & 0.010 & \begin{tabular}{|l|}
18.318 \\
\end{tabular} & ContLin & $6.15 \mathrm{E}-05$ & $3.07 \mathrm{E}-05$ & $1.17 \mathrm{E}-04$ & triangular & 410.43 & SL-NL \\
\hline T-104 & $\begin{array}{l}\text { SST } \\
\end{array}$ & 4.500 & 80.000 & LogNorm & 0.250 & 0.250 & & 0.010 & \begin{tabular}{|l|l|}
18.318 \\
\end{tabular} & ContLin & $4.11 \mathrm{E}-05$ & $2.06 \mathrm{E}-05$ & $7.82 \mathrm{E}-05$ & triangular & 410.43 & SL-NL \\
\hline T-105 & SST & 4.500 & 80.000 & LogNorm & 0.250 & 0.250 & & 0.010 & \begin{tabular}{|l|}
18.318 \\
\end{tabular} & ContLin & $2.65 \mathrm{E}-04$ & $1.33 \mathrm{E}-04$ & $5.04 \mathrm{E}-04$ & triangular & 410.43 & SL-NL \\
\hline T-106 & SST & 4.500 & 80.000 & $\begin{array}{l}\text { LogNorm } \\
\end{array}$ & 0.250 & 0.250 & & 0.010 & 18.318 & ContLin & $3.17 \mathrm{E}-05$ & $1.58 \mathrm{E}-05$ & $6.02 \mathrm{E}-05$ & triangular & 410.43 & SL-NL \\
\hline T-107 & SST & 4.500 & 80.000 & \begin{tabular}{|l} 
LogNorm \\
\end{tabular} & 0.250 & 0.250 & & 0.010 & \begin{tabular}{|l|}
18.318 \\
\end{tabular} & ContLin & $3.60 \mathrm{E}-04$ & $1.80 \mathrm{E}-04$ & $6.84 \mathrm{E}-04$ & triangular & 410.43 & SL-NL \\
\hline T-108 & SST & 4.500 & 80.000 & $\begin{array}{l}\text { LogNorm } \\
\end{array}$ & 0.250 & 0.250 & & 0.010 & 18.318 & ContLin & $1.07 \mathrm{E}-05$ & $5.35 \mathrm{E}-06$ & $2.03 \mathrm{E}-05$ & triangular & 410.43 & MIX-NL \\
\hline T-109 & SST & 4.500 & 80.000 & LogNorm & 0.250 & 0.250 & & 0.010 & \begin{tabular}{l|l}
18.318 \\
\end{tabular} & ContLin & $4.03 \mathrm{E}-06$ & $2.02 \mathrm{E}-06$ & $7.66 \mathrm{E}-06$ & triangular & 410.43 & SC/SS-NL \\
\hline T-110 & $\begin{array}{l}\text { SST } \\
\end{array}$ & 4.500 & 80.000 & LogNorm & 0.250 & 0.250 & & 0.010 & \begin{tabular}{l|l|}
18.318 \\
\end{tabular} & ContLin & $1.29 \mathrm{E}-05$ & $6.47 \mathrm{E}-06$ & $2.46 \mathrm{E}-05$ & triangular & 410.43 & SL-NL \\
\hline T-111 & SST & 4.500 & 80.000 & $\begin{array}{l}\text { LogNorm } \\
\end{array}$ & 0.250 & 0.250 & & 0.010 & \begin{tabular}{l|l|}
18.318 \\
\end{tabular} & ContLin & $7.13 \mathrm{E}-05$ & $3.56 \mathrm{E}-05$ & $1.35 \mathrm{E}-04$ & triangular & 410.43 & SL-NL \\
\hline$T-112$ & SST & 4.500 & 80.000 & $\begin{array}{l}\text { LogNorm } \\
\end{array}$ & 0.250 & 0.250 & & 0.010 & \begin{tabular}{l|l|}
18.318 \\
\end{tabular} & ContLin & $3.58 \mathrm{E}-05$ & $1.79 \mathrm{E}-05$ & $6.80 \mathrm{E}-05$ & triangular & 410.43 & SL-NL \\
\hline T-201 & SST & 4.500 & 80.000 & LogNorm & 0.250 & 0.250 & & 0.010 & \begin{tabular}{|l|}
18.318 \\
\end{tabular} & ContLin & $7.79 \mathrm{E}-05$ & $3.89 \mathrm{E}-05$ & $1.48 \mathrm{E}-04$ & triangular & 29.19 & SL-NL \\
\hline$T-202$ & SST & 4.500 & 80.000 & LogNorm & 0.250 & 0.250 & & 0.010 & \begin{tabular}{|l|}
18.318 \\
\end{tabular} & ContLin & $4.62 \mathrm{E}-05$ & $2.31 \mathrm{E}-05$ & $8.79 \mathrm{E}-05$ & triangular & 29.19 & SL-NL \\
\hline$T-203$ & SST & 4.500 & 80.000 & LogNorm & 0.250 & 0.250 & & 0.010 & \begin{tabular}{|l|}
18.318 \\
\end{tabular} & ContLin & $4.93 \mathrm{E}-05$ & $2.46 \mathrm{E}-05$ & $9.37 \mathrm{E}-05$ & triangular & 29.19 & SL-NL \\
\hline T-204 & SST & 4.500 & 80.000 & LogNorm & 0.250 & 0.250 & & 0.010 & \begin{tabular}{l|l|}
18.318 \\
\end{tabular} & ContLin & $4.74 \mathrm{E}-05$ & $2.37 \mathrm{E}-05$ & $9.00 \mathrm{E}-05$ & triangular & 29.19 & SL-NL \\
\hline TX-101 & SST & 4.500 & 80.000 & LogNorm & 0.250 & 0.250 & & 0.010 & \begin{tabular}{|l|l|}
18.318 \\
\end{tabular} & ContLin & $5.23 \mathrm{E}-04$ & $2.61 \mathrm{E}-04$ & $9.93 \mathrm{E}-04$ & triangular & 410.43 & SL-NL \\
\hline TX-102 & $\begin{array}{l}\text { SST } \\
\end{array}$ & 4.5 & 80.000 & LogNorm & 0.250 & 0.250 & & 0.010 & \begin{tabular}{l|l|}
18.318 \\
\end{tabular} & ContLin & $2.01 \mathrm{E}-04$ & $1.01 \mathrm{E}-04$ & $3.83 \mathrm{E}-04$ & triangular & 410.43 & $\begin{array}{l}\text { SC/SS-NL } \\
\end{array}$ \\
\hline TX-103 & SST & 4.500 & 80.000 & LogNorm & 0.250 & 0.250 & & 0.010 & \begin{tabular}{l|}
18.318 \\
\end{tabular} & ContLin & $1.49 \mathrm{E}-04$ & $7.45 \mathrm{E}-05$ & $2.83 \mathrm{E}-04$ & triangular & 410.43 & SC/SS-NL \\
\hline TX-104 & SST & 4.500 & 80.000 & LogNorm & 0.250 & 0.250 & & 0.010 & \begin{tabular}{l|l|}
18.318 \\
\end{tabular} & ContLin & $3.75 \mathrm{E}-04$ & $1.88 \mathrm{E}-04$ & $7.13 \mathrm{E}-04$ & triangular & 410.43 & MIX-NL \\
\hline TX-105 & SST & 4.500 & 80.000 & $\begin{array}{l}\text { LogNorm } \\
\end{array}$ & 0.250 & 0.250 & & 0.010 & \begin{tabular}{|l|}
18.318 \\
\end{tabular} & ContLin & $3.28 \mathrm{E}-04$ & $1.64 \mathrm{E}-04$ & $6.23 \mathrm{E}-04$ & triangular & 410.43 & SC/SS-NL \\
\hline TX-106 & SST & 4.500 & 80.000 & LogNorm & 0.250 & 0.250 & & 0.010 & 18.318 & ContLin & $1.90 \mathrm{E}-04$ & $9.52 \mathrm{E}-05$ & $3.62 \mathrm{E}-04$ & triangular & 410.43 & SC/SS-NL \\
\hline TX-107 & SST & 4.500 & 80.000 & $\begin{array}{l}\text { LogNorm } \\
\end{array}$ & 0.250 & 0.250 & & 0.010 & \begin{tabular}{|l|l|}
18.318 \\
\end{tabular} & ContLin & $2.25 \mathrm{E}-04$ & $1.13 \mathrm{E}-04$ & $4.28 \mathrm{E}-04$ & triangular & 410.43 & SC/SS-NL \\
\hline TX-108 & SST & 4.500 & 80.000 & LogNorm & 0.250 & 0.250 & & 0.010 & 18.318 & ContLin & $1.38 \mathrm{E}-04$ & $6.88 \mathrm{E}-05$ & $2.61 \mathrm{E}-04$ & triangular & 410.43 & SC/SS-NL \\
\hline TX-109 & SST & 4.500 & 80.000 & LogNorm & 0.250 & 0.250 & & 0.010 & \begin{tabular}{l|l}
18.318 \\
\end{tabular} & ContLin & $2.16 \mathrm{E}-04$ & $1.08 \mathrm{E}-04$ & $4.10 \mathrm{E}-04$ & triangular & 410.43 & SL-NL \\
\hline TX-110 & SST & 4.500 & 80.000 & $\begin{array}{l}\text { LogNorm } \\
\end{array}$ & 0.250 & 0.250 & & 0.010 & 18.318 & ContLin & $2.00 \mathrm{E}-04$ & $9.99 \mathrm{E}-05$ & $3.79 \mathrm{E}-04$ & triangular & 410.43 & $\begin{array}{l}\text { SC/SS-NL } \\
\end{array}$ \\
\hline TX-111 & SST & 4.500 & 80.000 & LogNorm & 0.250 & 0.250 & & 0.010 & 18.318 & ContLin & $2.19 \mathrm{E}-04$ & $1.10 \mathrm{E}-04$ & $4.16 \mathrm{E}-04$ & triangular & 410.43 & SC/SS-NL \\
\hline
\end{tabular}




\begin{tabular}{|c|c|c|c|c|c|c|c|c|c|c|c|c|c|c|c|c|}
\hline Data Source & & $\begin{array}{c}\text { RPP-10006 R7 } \\
\text { NonCon }\end{array}$ & $\begin{array}{c}\text { RPP-10006 R7 } \\
\text { NonCon }\end{array}$ & $\begin{array}{c}\text { RPP-10006 R7 } \\
\text { NonCon }\end{array}$ & $\begin{array}{c}\text { RPP-10006 R7 } \\
\text { NonCon }\end{array}$ & $\mid \begin{array}{c}\text { RPP-10006 R7 } \\
\text { NonCon }\end{array}$ & $\begin{array}{c}\text { RPP-10006 R7 } \\
\text { NonCon }\end{array}$ & $\begin{array}{c}\text { RPP-10006 R7 } \\
\text { NonCon }\end{array}$ & $\mid \begin{array}{c}\text { RPP-10006 R7 } \\
\text { NonCon }\end{array}$ & $\begin{array}{c}\text { RPP-10006 R7 } \\
\text { NonCon }\end{array}$ & \begin{tabular}{|l} 
RPP-5926 R8 \\
(Table B-3) \& \\
RPP-10006 R7
\end{tabular} & \begin{tabular}{|c|} 
Calculated \\
Value \\
RPP-10006 \\
See Appendix \\
E \\
\end{tabular} & \begin{tabular}{|c|} 
Calculated \\
Value \\
RPP-10006 \\
See Appendix \\
E
\end{tabular} & \begin{tabular}{|c} 
Calculated \\
Value \\
RPP-10006 \\
See Appendix \\
E
\end{tabular} & $\begin{array}{c}\text { RPP-10006 R7 } \\
\text { NonCon }\end{array}$ & $\begin{array}{c}\text { Based on waste } \\
\text { phase volumes in } \\
\text { RPP-5926 R8 \& } \\
\text { RPP-10006 R7 } \\
\text { See Appendix A }\end{array}$ \\
\hline Tank \# & Tank Type & $\begin{array}{c}\text { Retained gas } \\
\text { composition } \\
\text { N2 } \\
\text { min }\end{array}$ & $\mid \begin{array}{c}\text { Retained gas } \\
\text { composition } \\
\mathrm{N} 2 \\
\max \end{array}$ & $\begin{array}{l}\text { Retained gas } \\
\text { composition } \\
\mathrm{N} 2 \\
\text { type }\end{array}$ & $\begin{array}{c}\text { Retained gas } \\
\text { composition } \\
\text { NH3 } \\
\text { mean }\end{array}$ & $\begin{array}{c}\text { Retained gas } \\
\text { composition } \\
\text { NH3 mean }\end{array}$ & $\begin{array}{l}\text { Retained gas } \\
\text { composition } \\
\text { NH3 } \\
\text { std dev }\end{array}$ & $\begin{array}{c}\text { Retained gas } \\
\text { composition } \\
\text { NH3 } \\
\text { min }\end{array}$ & $\begin{array}{c}\text { Retained gas } \\
\text { composition } \\
\text { NH3 } \\
\text { max }\end{array}$ & $\begin{array}{c}\text { Retained gas } \\
\text { composition } \\
\text { NH3 } \\
\text { type }\end{array}$ & $\begin{array}{c}\text { Hydrogen } \\
\text { Generation } \\
\text { Rate in Non- } \\
\text { Convective } \\
\text { Waste } \\
(\text { moles } / \mathbf{m} 3 / \mathrm{d} \\
\text { ay) }\end{array}$ & $\begin{array}{c}\text { Hydrogen } \\
\text { Generation } \\
\text { Rate in Non- } \\
\text { Convective } \\
\text { Waste Min } \\
\text { (moles/m3/d } \\
\text { ay) }\end{array}$ & \begin{tabular}{|c|} 
Hydrogen \\
Generation \\
Rate in Non- \\
Convective \\
Waste Max \\
$($ moles $/ \mathbf{m} 3 / \mathrm{d}$ \\
ay)
\end{tabular} & $\begin{array}{c}\text { Hydrogen } \\
\text { Generation } \\
\text { Rate in Non- } \\
\text { Convective } \\
\text { Waste } \\
\text { Dist Type } \\
\text { (moles/m3/d } \\
\text { ay) }\end{array}$ & $\begin{array}{c}\text { Cross } \\
\text { sectional } \\
\text { area of tank } \\
(\mathbf{m} 2)\end{array}$ & Waste Type \\
\hline TX-112 & SST & 4.500 & \begin{tabular}{l|l}
80.000 \\
\end{tabular} & LogNorm & 0.250 & 0.250 & & 0.010 & \begin{tabular}{l|}
18.318 \\
\end{tabular} & ContLin & $1.70 \mathrm{E}-04$ & $8.48 \mathrm{E}-05$ & $3.22 \mathrm{E}-04$ & \begin{tabular}{|l|} 
triangular \\
\end{tabular} & 410.43 & SC/SS-NL \\
\hline TX-113 & SST & 4.500 & \begin{tabular}{l|l}
80.000 \\
\end{tabular} & LogNorm & 0.250 & 0.250 & & 0.010 & \begin{tabular}{l|l|}
18.318 \\
\end{tabular} & ContLin & $4.11 \mathrm{E}-05$ & $2.05 \mathrm{E}-05$ & $7.80 \mathrm{E}-05$ & triangular & 410.43 & SC/SS-NL \\
\hline TX-114 & SST & 4.500 & \begin{tabular}{l|}
80.000 \\
\end{tabular} & LogNorm & 0.250 & 0.250 & & 0.010 & \begin{tabular}{l|l}
18.318 \\
\end{tabular} & ContLin & $7.20 \mathrm{E}-05$ & $3.60 \mathrm{E}-05$ & $1.37 \mathrm{E}-04$ & triangular & 410.43 & SC/SS-NL \\
\hline TX-115 & SST & 4.500 & \begin{tabular}{l|l}
80.000 \\
\end{tabular} & $\begin{array}{l}\text { LogNorm } \\
\end{array}$ & 0.250 & 0.250 & & 0.010 & 18.318 & ContLin & $1.34 \mathrm{E}-04$ & $6.70 \mathrm{E}-05$ & $2.55 \mathrm{E}-04$ & triangular & 410.43 & SC/SS-NL \\
\hline TX-116 & SST & 4.500 & \begin{tabular}{l|}
80.000 \\
\end{tabular} & LogNorm & 0.250 & 0.250 & & 0.010 & \begin{tabular}{l|}
18.318 \\
\end{tabular} & ContLin & $2.09 \mathrm{E}-05$ & $1.05 \mathrm{E}-05$ & $3.97 \mathrm{E}-05$ & triangular & 410.43 & SC/SS-NL \\
\hline TX-117 & SST & 4.500 & \begin{tabular}{l|l}
80.000 \\
\end{tabular} & $\begin{array}{l}\text { LogNorm } \\
\end{array}$ & 0.250 & 0.250 & & 0.010 & 18.318 & ContLin & $2.50 \mathrm{E}-05$ & $1.25 \mathrm{E}-05$ & $4.75 \mathrm{E}-05$ & triangular & 410.43 & SC/SS-NL \\
\hline TX-118 & SST & 4.500 & 80.000 & \begin{tabular}{|l} 
LogNorm \\
\end{tabular} & 0.250 & 0.250 & & 0.010 & \begin{tabular}{l|l|}
18.318 \\
\end{tabular} & ContLin & $8.60 \mathrm{E}-04$ & $4.30 \mathrm{E}-04$ & $1.63 \mathrm{E}-03$ & triangular & 410.43 & SC/SS-NL \\
\hline TY-101 & SST & 4.500 & \begin{tabular}{l|}
80.000 \\
\end{tabular} & LogNorm & 0.250 & 0.250 & & 0.010 & \begin{tabular}{l|}
18.318 \\
\end{tabular} & ContLin & $2.43 \mathrm{E}-05$ & $1.21 \mathrm{E}-05$ & $4.61 \mathrm{E}-05$ & triangular & 410.43 & MIX-NL \\
\hline TY-102 & SST & 4.500 & \begin{tabular}{l|}
80.000 \\
\end{tabular} & LogNorm & 0.250 & 0.250 & & 0.010 & \begin{tabular}{l|}
18.318 \\
\end{tabular} & ContLin & $4.67 \mathrm{E}-05$ & $2.34 \mathrm{E}-05$ & $8.88 \mathrm{E}-05$ & triangular & 410.43 & SC/SS-NL \\
\hline TY-103 & SST & 4.500 & 80.000 & LogNorm & 0.250 & 0.250 & & 0.010 & 18.318 & ContLin & $3.60 \mathrm{E}-04$ & $1.80 \mathrm{E}-04$ & $6.83 \mathrm{E}-04$ & triangular & 410.43 & MIX-NL \\
\hline TY-104 & SST & 4.500 & \begin{tabular}{l|}
80.000 \\
\end{tabular} & LogNorm & 0.250 & 0.250 & & 0.010 & \begin{tabular}{l|}
18.318 \\
\end{tabular} & ContLin & $4.02 \mathrm{E}-04$ & $2.01 \mathrm{E}-04$ & $7.64 \mathrm{E}-04$ & triangular & 410.43 & SL-NL \\
\hline TY-105 & SST & 4.500 & \begin{tabular}{l|l}
80.000 \\
\end{tabular} & \begin{tabular}{|l} 
LogNorm \\
\end{tabular} & 0.250 & 0.250 & & 0.010 & \begin{tabular}{|l|}
18.318 \\
\end{tabular} & ContLin & $4.55 \mathrm{E}-04$ & $2.27 \mathrm{E}-04$ & $8.64 \mathrm{E}-04$ & triangular & 410.43 & SL-NL \\
\hline TY-106 & SST & 4.500 & \begin{tabular}{l|}
80.000 \\
\end{tabular} & LogNorm & 0.250 & 0.250 & & 0.010 & \begin{tabular}{l|}
18.318 \\
\end{tabular} & ContLin & $4.01 \mathrm{E}-04$ & $2.01 \mathrm{E}-04$ & $7.62 \mathrm{E}-04$ & triangular & 410.43 & SL-NL \\
\hline U-101 & SST & 4.500 & \begin{tabular}{l|}
80.000 \\
\end{tabular} & LogNorm & 0.250 & 0.250 & & 0.010 & \begin{tabular}{l|}
18.318 \\
\end{tabular} & ContLin & $9.98 \mathrm{E}-04$ & $4.99 \mathrm{E}-04$ & $1.90 \mathrm{E}-03$ & triangular & 410.43 & SL-NL \\
\hline U-102 & SST & 4.500 & \begin{tabular}{l|}
80.000 \\
\end{tabular} & \begin{tabular}{|l} 
LogNorm \\
\end{tabular} & 0.250 & 0.250 & & 0.010 & \begin{tabular}{l|}
18.318 \\
\end{tabular} & ContLin & $8.63 \mathrm{E}-04$ & $4.32 \mathrm{E}-04$ & $1.64 \mathrm{E}-03$ & triangular & 410.43 & SC/SS-NL \\
\hline \begin{tabular}{|l}
$\mathrm{U}-103$ \\
\end{tabular} & SST & 30.945 & 2.561 & Normal & 0.596 & 0.596 & 0.156 & 0.246 & \begin{tabular}{r|}
0.963 \\
\end{tabular} & Normal & $8.54 \mathrm{E}-04$ & $4.27 \mathrm{E}-04$ & $1.62 \mathrm{E}-03$ & triangular & 410.43 & SC/SS-NL \\
\hline$\overline{\mathrm{U}-104}$ & SST & 4.500 & \begin{tabular}{l|}
80.000 \\
\end{tabular} & LogNorm & 0.250 & 0.250 & & 0.010 & \begin{tabular}{l|}
18.318 \\
\end{tabular} & ContLin & $3.68 \mathrm{E}-04$ & $1.84 \mathrm{E}-04$ & $6.99 \mathrm{E}-04$ & triangular & 410.43 & SL-NL \\
\hline U-105 & SST & & 0.000 & $\begin{array}{l}\text { LogNorm } \\
\end{array}$ & 0.250 & 0250 & & 0.010 & 18.318 & ContLin & $1.58 \mathrm{E}-03$ & $7.88 \mathrm{E}-04$ & $2.36 \mathrm{E}-03$ & triangular & 410.43 & SC/SS-NL \\
\hline U-106 & SST & 4.500 & \begin{tabular}{l|l}
80.000 \\
\end{tabular} & LogNorm & 0.250 & 0.250 & & 0.010 & \begin{tabular}{l|}
18.318 \\
\end{tabular} & ContLin & $1.99 \mathrm{E}-03$ & $9.93 \mathrm{E}-04$ & $3.77 \mathrm{E}-03$ & triangular & 410.43 & SC/SS-NL \\
\hline \begin{tabular}{|l|}
$\mathrm{U}-107$ \\
\end{tabular} & SST & 4.500 & \begin{tabular}{l|}
80.000 \\
\end{tabular} & LogNorm & 0.250 & 0.250 & & 0.010 & \begin{tabular}{l|}
18.318 \\
\end{tabular} & ContLin & $2.86 \mathrm{E}-04$ & $1.43 \mathrm{E}-04$ & $5.44 \mathrm{E}-04$ & triangular & 410.43 & SC/SS-NL \\
\hline U-108 & SST & 4.500 & \begin{tabular}{l|}
80.000 \\
\end{tabular} & LogNorm & 0.250 & 0.250 & & 0.010 & \begin{tabular}{l|l}
18.318 \\
\end{tabular} & ContLin & $4.44 \mathrm{E}-04$ & $2.22 \mathrm{E}-04$ & $8.44 \mathrm{E}-04$ & triangular & 410.43 & SC/SS-NL \\
\hline \begin{tabular}{|l} 
U-109 \\
\end{tabular} & SST & 36.854 & \begin{tabular}{l|}
56.618 \\
\end{tabular} & Normal & 1.007 & 1.007 & 0.328 & 0.354 & \begin{tabular}{|l|}
1.812 \\
\end{tabular} & Normal & $2.36 \mathrm{E}-04$ & $1.18 \mathrm{E}-04$ & $4.48 \mathrm{E}-04$ & triangular & 410.43 & SC/SS-NL \\
\hline U-110 & SST & 4.500 & \begin{tabular}{l|l}
80.000 \\
\end{tabular} & LogNorm & 0.250 & 0.250 & & 0.010 & \begin{tabular}{l|}
18.318 \\
\end{tabular} & ContLin & $4.85 \mathrm{E}-04$ & $2.43 \mathrm{E}-04$ & $9.22 \mathrm{E}-04$ & triangular & 410.43 & SL-NL \\
\hline \begin{tabular}{|l}
$\mathrm{U}-111$ \\
\end{tabular} & SST & 4.500 & \begin{tabular}{l|}
80.000 \\
\end{tabular} & LogNorm & 0.250 & 0.250 & & 0.010 & \begin{tabular}{|l|}
18.318 \\
\end{tabular} & ContLin & $2.96 \mathrm{E}-04$ & $1.48 \mathrm{E}-04$ & $5.63 \mathrm{E}-04$ & triangular & 410.43 & SC/SS-NL \\
\hline$\overline{\mathrm{U}-112}$ & SST & 4.500 & \begin{tabular}{l|}
80.000 \\
\end{tabular} & LogNorm & 0.250 & 0.250 & & 0.010 & \begin{tabular}{l|l}
18.318 \\
\end{tabular} & ContLin & $4.98 \mathrm{E}-04$ & $2.49 \mathrm{E}-04$ & $9.46 \mathrm{E}-04$ & triangular & 410.43 & SL-NL \\
\hline U-201 & SST & 4.500 & \begin{tabular}{l|}
80.000 \\
\end{tabular} & LogNorm & 0.250 & 0.250 & & 0.010 & \begin{tabular}{l|l|}
18.318 \\
\end{tabular} & ContLin & $4.84 \mathrm{E}-06$ & $2.42 \mathrm{E}-06$ & $9.20 \mathrm{E}-06$ & triangular & 29.19 & SL-NL \\
\hline U-202 & SST & 4.500 & \begin{tabular}{l|l}
80.000 \\
\end{tabular} & LogNorm & 0.250 & 0.250 & & 0.010 & \begin{tabular}{|l|}
18.318 \\
\end{tabular} & ContLin & $4.03 \mathrm{E}-06$ & $2.01 \mathrm{E}-06$ & $7.65 \mathrm{E}-06$ & triangular & 29.19 & SL-NL \\
\hline \begin{tabular}{|l|}
$\mathrm{U}-203$ \\
\end{tabular} & SST & 4.500 & \begin{tabular}{l|}
80.000 \\
\end{tabular} & LogNorm & 0.250 & 0.250 & & 0.010 & \begin{tabular}{|l|}
18.318 \\
\end{tabular} & ContLin & $6.43 \mathrm{E}-06$ & $3.21 \mathrm{E}-06$ & $1.22 \mathrm{E}-05$ & triangular & 29.19 & SL-NL \\
\hline$\overline{\mathrm{U}-204}$ & SST & 4.500 & 80.000 & LogNorm & 0.250 & 0.250 & & 0.010 & \begin{tabular}{|l|}
18.318 \\
\end{tabular} & ContLin & $2.12 \mathrm{E}-05$ & $1.06 \mathrm{E}-05$ & $4.02 \mathrm{E}-05$ & triangular & 29.19 & SL-NL \\
\hline
\end{tabular}


RPP-10006 REV 8

\section{H3.0 REFERENCES}

OSD-T-151-00007, 2007, Operating Specifications for the Double-Shell Storage Tanks, Rev. 1, CH2M HILL Hanford Group, Inc., Richland, Washington.

Personal Computer Surveillance Analysis Computer System (PCSACS) 2005, Surveillance Analysis Computer System, queried 11/22/2005, [Interstitial Liquid Level Reading], HISI ID No. 242, CH2M HILL Hanford Group, Inc., Richland, Washington.

RPP-5926, 2005, Steady-State Flammable Gas Release Rate Calculation and Lower Flammability Level Evaluation for Hanford Tank Waste, Rev. 5, CH2M HILL Hanford Group, Inc., Richland, Washington.

RPP-5926, 2007, Steady-State Flammable Gas Release Rate Calculation and Lower Flammability Level Evaluation for Hanford Tank Waste, Rev. 7, CH2M HILL Hanford Group, Inc., Richland, Washington.

RPP-6655, 2000, Data Observations on Double-Shell Flammable Gas Watch List Tank Behavior, Rev. 0, CH2M HILL Hanford Group, Inc., Richland, Washington.

RPP-7625, 2006, Best-Basis Inventory Process Requirements, Rev. 6, CH2M HILL Hanford Group, Inc., Richland, Washington.

RPP-10006, 2006, Methodology and Calculations for the Waste Groups for Large Underground Waste Storage Tanks at the Hanford Site, Rev. 5, CH2M HILL Hanford Group, Inc., Richland, Washington.

RPP-13019, 2003, Determination of Hanford Waste Tank Volumes, Rev. 0, CH2M HILL Hanford Group, Inc., Richland, Washington.

RPP-29167, 2006, Spreadsheet Description Document for RPP-10006 Rev 5 Data Rebuild 060306.xls, Rev. 0, CH2M HILL Hanford Group, Inc., Richland, Washington.

SVF-1118, 2006, Spreadsheet Verification \& Release Form for Spreadsheet RPP-10006 Rev 5 Data Rebuild 060306.xls, Rev. 0, CH2M HILL Hanford Group, Inc., Richland, Washington.

SVF-1536, 2008, Spreadsheet Verification \& Release Form for Spreadsheet DST_and_SST_TTLFL_v1.xls, Rev. 0, Washington River Protection Solutions LLC, Richland, Washington 
RPP-10006 REV 8

This page intentionally left blank. 
RPP-10006 REV 8

APPENDIX I

PEER REVIEW CHECKLIST 
RPP-10006 REV 8

This page intentionally left blank. 


\section{Peer Review Checklist}

Calculation Reviewed: RPP-10006 Rev. 8

Scope of Review: Entire document except Appendices F and G which remained unchanged from previous revision.

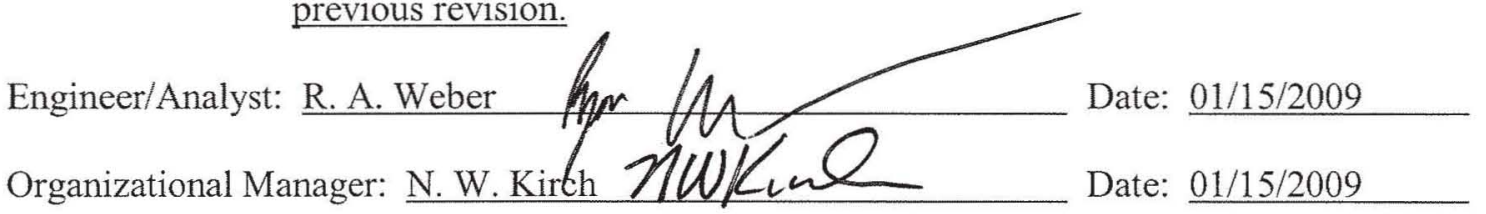

This document consists of 251 pages and the following attachments (if applicable):

Yes No NA*

[X] [ ] [] 1. Analytical and technical approaches and results are reasonable and appropriate.

[X] [] [ ] 2. Necessary assumptions are reasonable, explicitly stated, and supported.

[X] [ ] [ ] 3. Ensure calculations that use software include a paper printout, microfiche, CD ROM, or other electronic file of the input data and identification to the computer codes and versions used, or provide alternate documentation to uniquely and clearly identify the exact coding and execution process.

[X] [ ] [ ] 4. Input data were checked for consistency with original source information.

[X] [ ] [ ] 5. Key input data (e.g., dimensions, performance characteristics) that may affect equipment design is identified.

[X] [ ] [ ] 6. For both qualitative and quantitative data, uncertainties are recognized and discussed and the data is presented in a manner to minimize design interpretations.

[X] [ ] [ ] 7. Mathematical derivations were checked, including dimensional consistency of results.

[X] [ ] [ ] 8. Calculations are sufficiently detailed such that a technically qualified person can understand the analysis without requiring outside information.

[X] [ ] [ ] 9. Software verification and validation are addressed adequately.

[X] [ ] [ ] 10. Limits/criteria/guidelines applied to the analysis results are appropriate and referenced. Limits/criteria/guidelines were checked against references.

[X] [ ] [ ] 11. Conclusions are consistent with analytical results and applicable limits.

[X] [ ] [ ] 12. Results and conclusions address all points in the purpose.

[X] [ ] [] 13. Referenced documents are retrievable or otherwise available.

[X] [] [] 14. The version or revision of each reference is cited.

[X] [ ] [ ] 15. The document was prepared in accordance with Attachment A, "Calculation Format and Preparation Instructions."

[ ] [ ] [X] 16. Impacts on requirements have been assessed and change documentation initiated to incorporate revisions to affected documents, as appropriate.

[X] [ ] [ ] 17. All checker comments have been dispositioned and the design media matches the calculations.

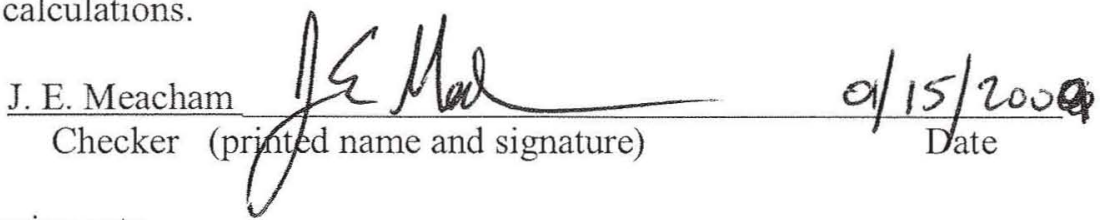

16. No impact on requirments. 